Fall 2008

\title{
2008 Miracle Yearbook
}

Cedarville University

Follow this and additional works at: https://digitalcommons.cedarville.edu/yearbooks

Part of the Higher Education Commons, Organizational Communication Commons, and the Public Relations and Advertising Commons

\section{Recommended Citation}

Cedarville University, "2008 Miracle Yearbook" (2008). Yearbooks. 16.

https://digitalcommons.cedarville.edu/yearbooks/16

This Book is brought to you for free and open access by DigitalCommons@Cedarville, a service of the Centennial Library. It has been accepted for inclusion in Yearbooks by an authorized administrator of DigitalCommons@Cedarville. For more information, please contact digitalcommons@cedarville.edu. 


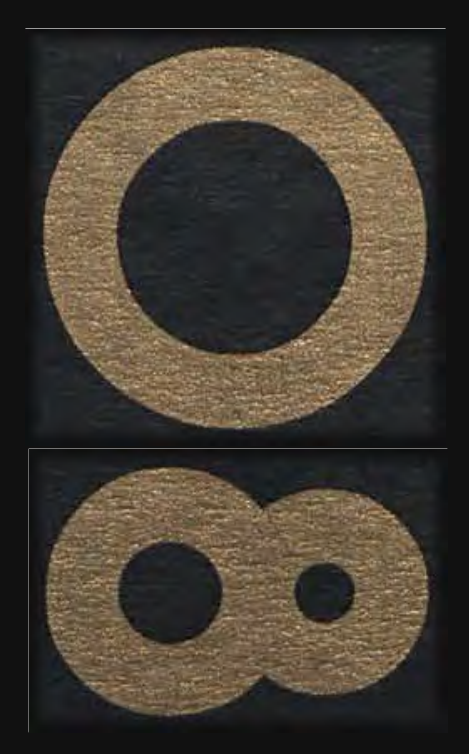


OPENING

DEDICATION

FALL

FACULTY - STAFF 28

ORGANIZATIONS 56

FRESHMEN

ACTIVITIES

SOPHOMORES

MINISTRIES

JUNIORS

ATHLETICS

SENIORS

For Reference

Not to be taken

from this library

92

152

SPRING

MEMORY

MIRACLE STAFF
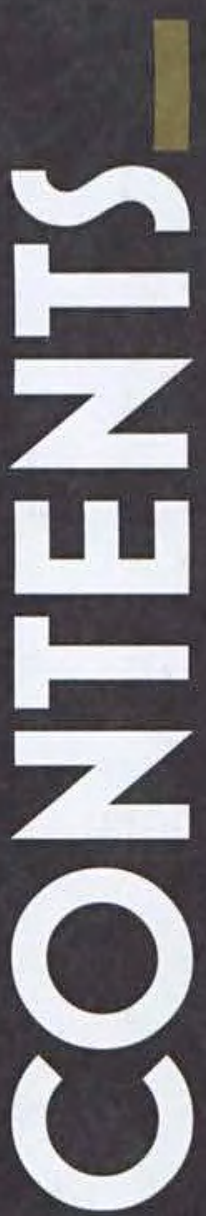

116

134

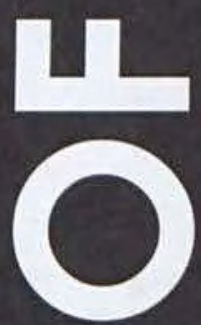

170

206

240

272

274

CLOSING - INDEX 280
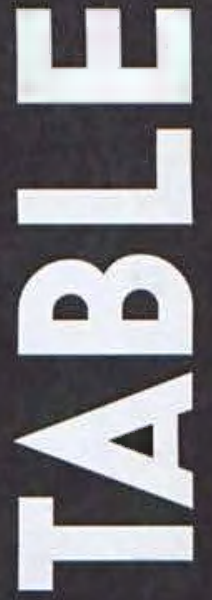


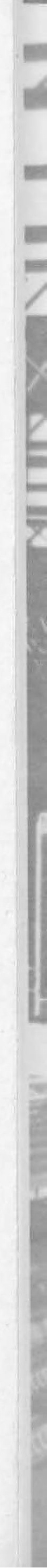




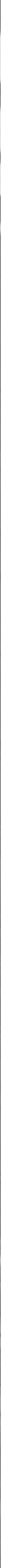




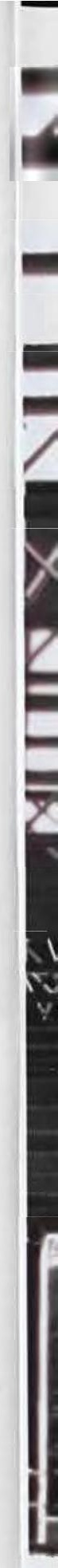




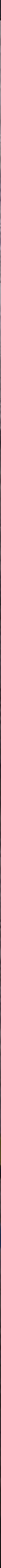




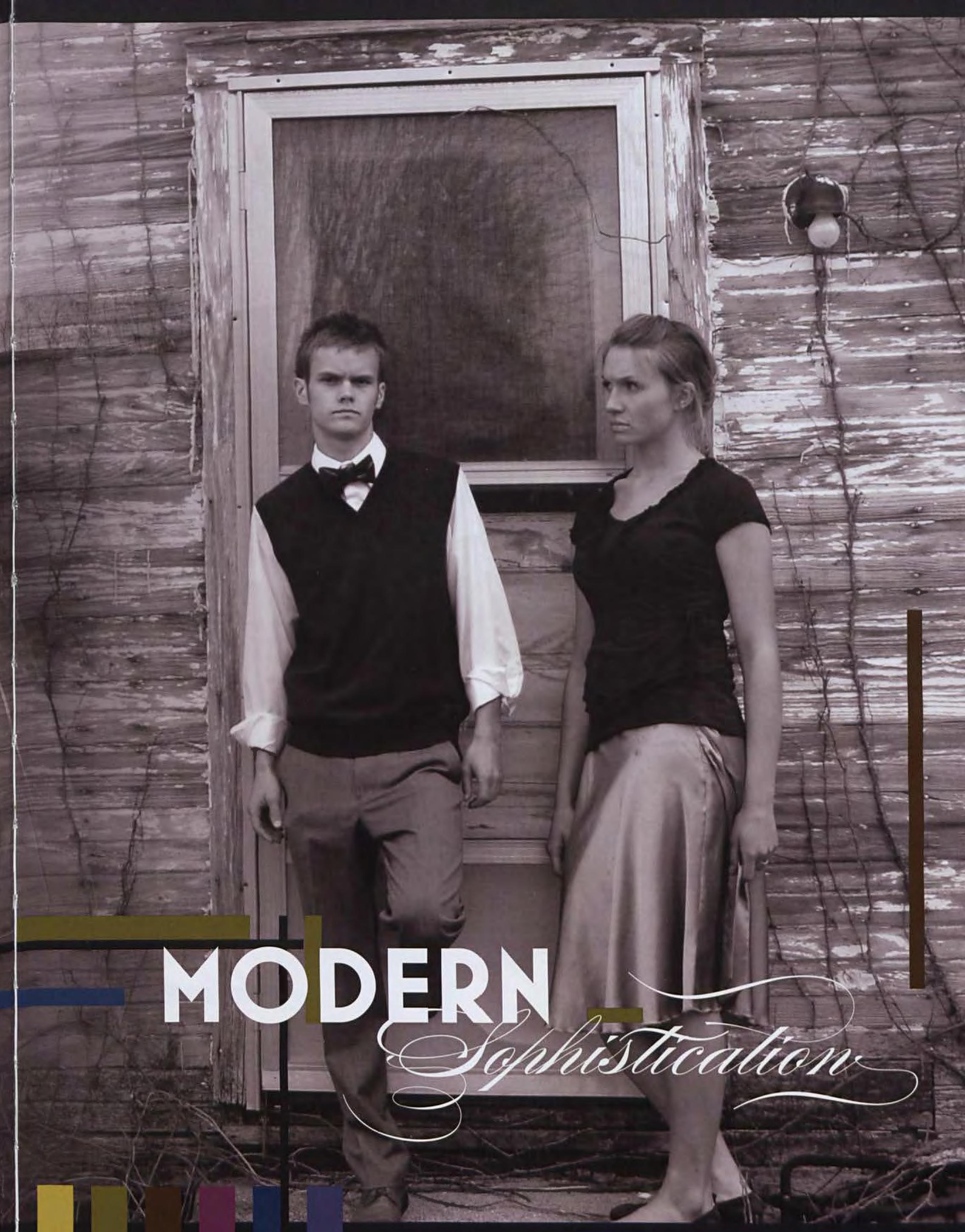




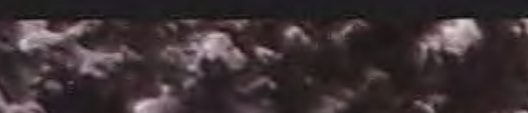

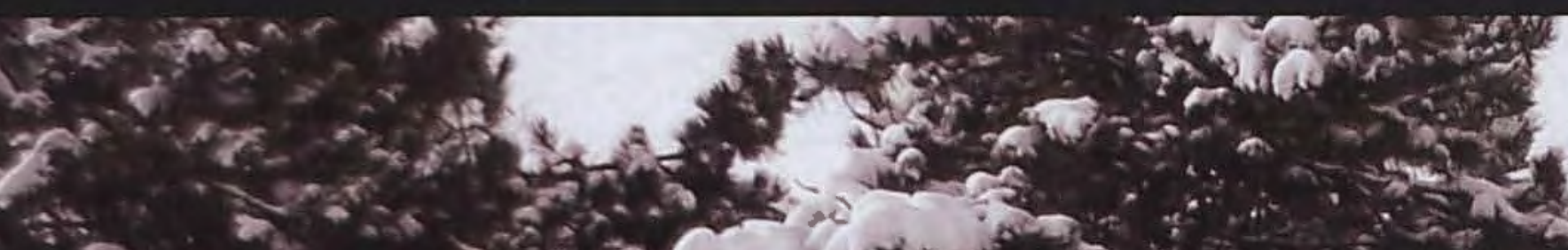

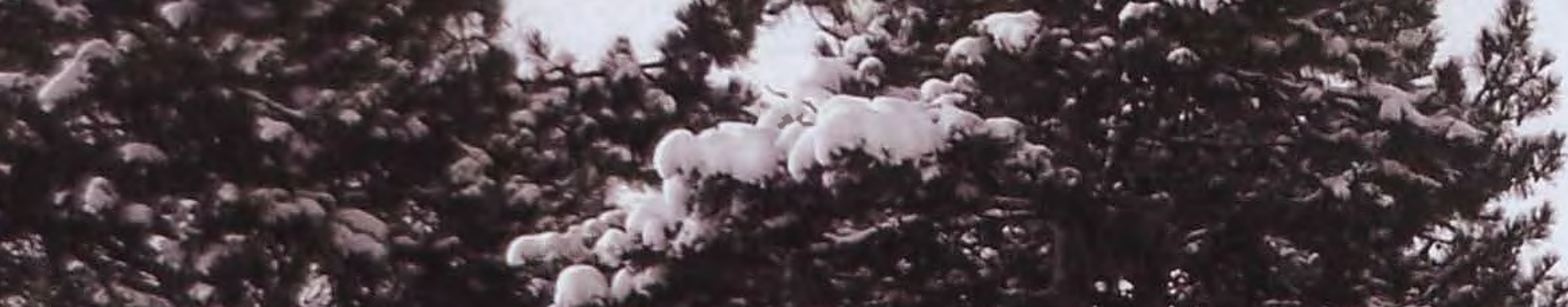

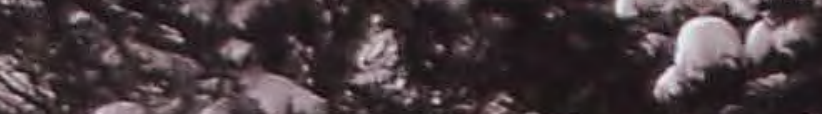

2.

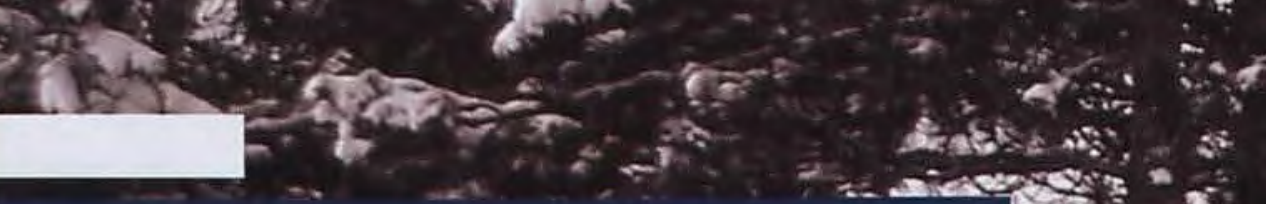

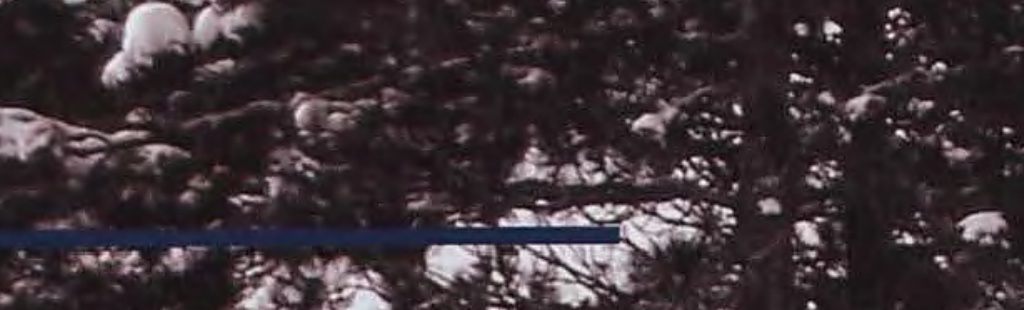

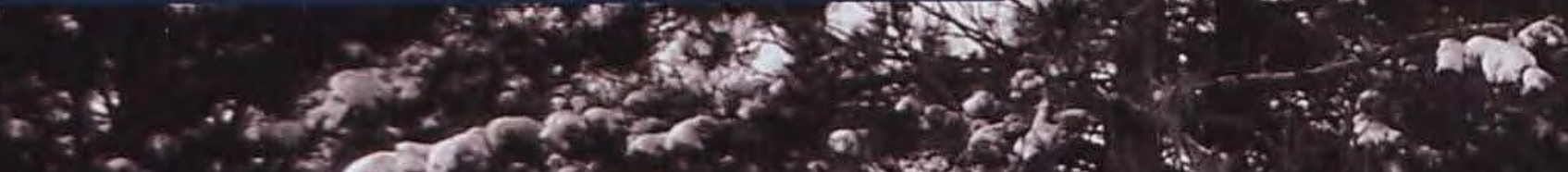

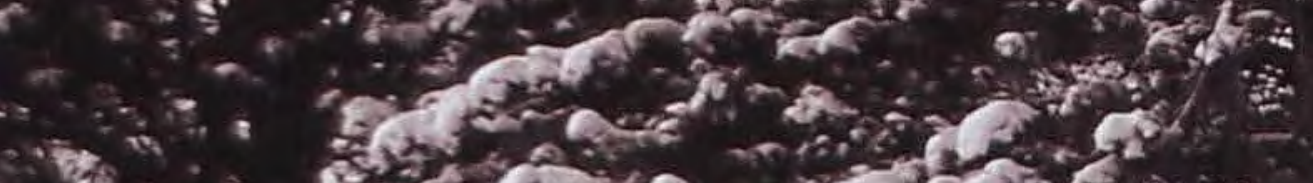

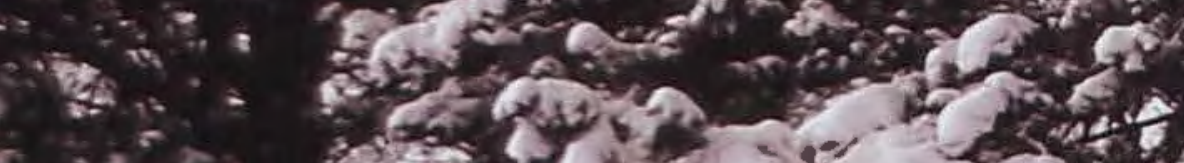

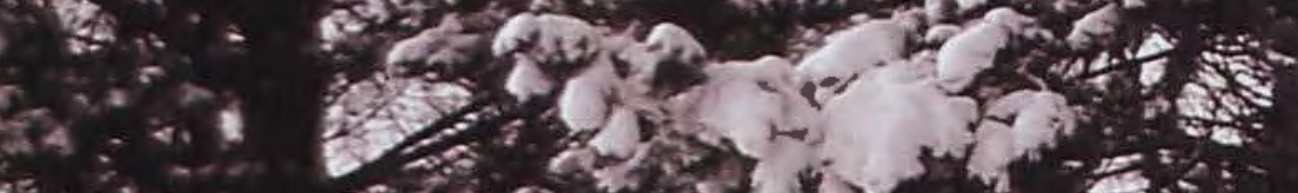

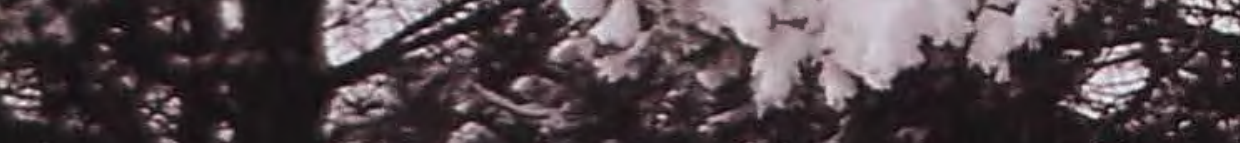

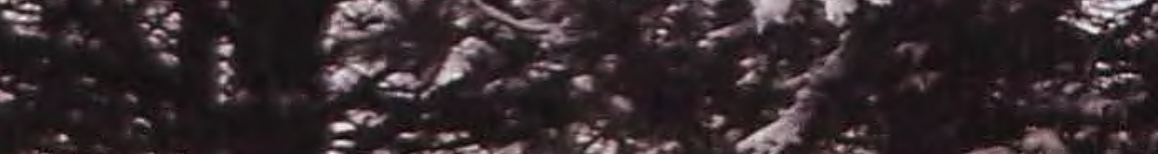

Sh

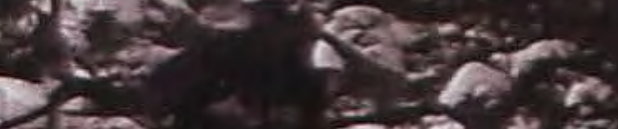

afe? 


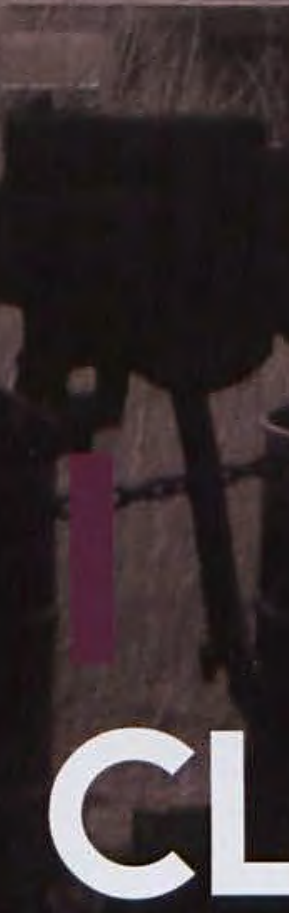

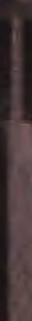




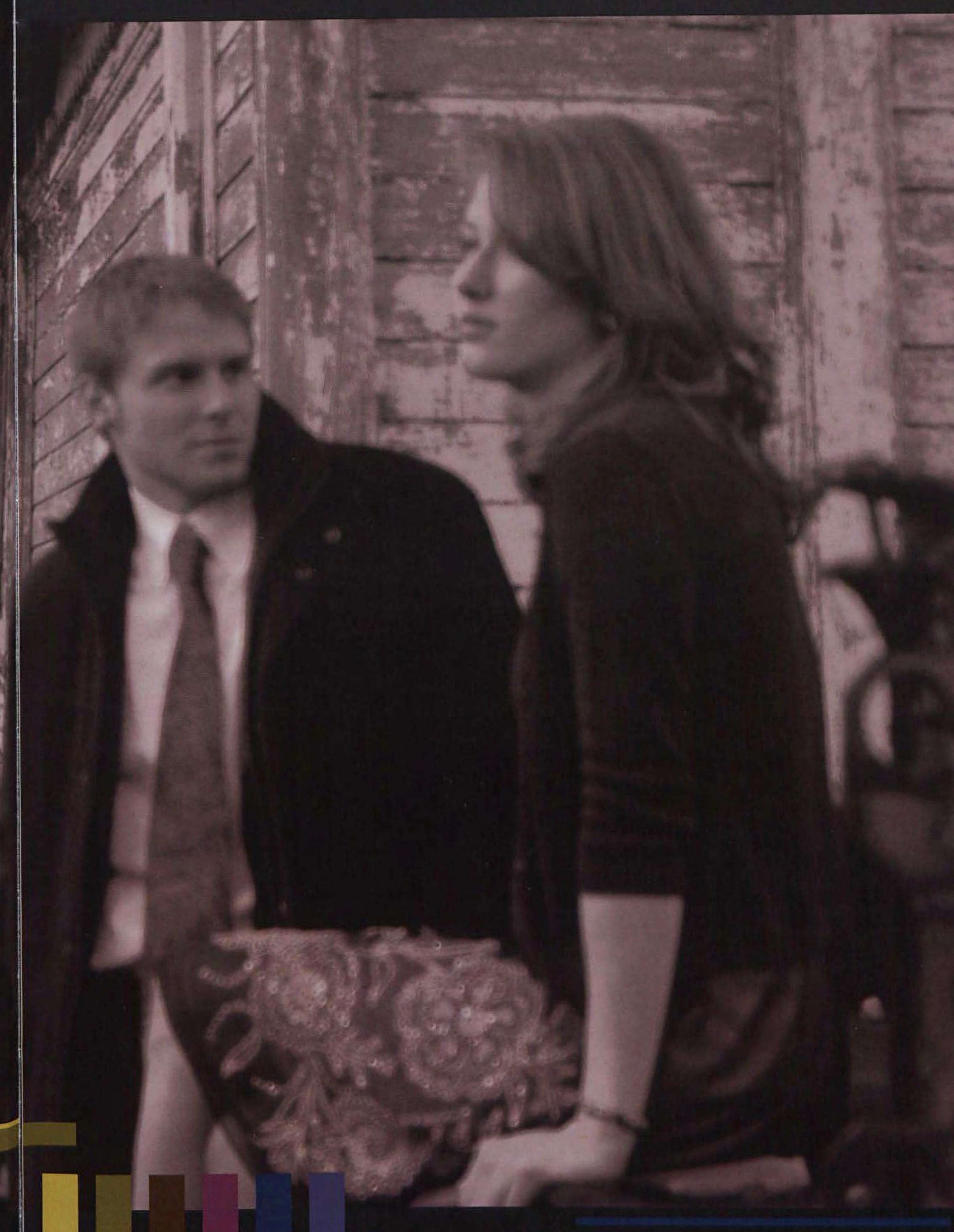


At every university there are professors who stand out for making a difference. At Cedarville we are very blessed to have many people who do make a big difference in the lives of those around them. These are the people who genuinely care about the students they work with and desire to see everyone succeed in what they are doing. Someone who exemplifies these characteristics is Mrs. Margaret Stowell Wheeler whose energetic laugh, radiant smile and unique accessories have the ability of turning everyone's head here on campus.

Mrs. Wheeler, a New Jersey native, attended Cedarville for her college years, graduating in 1964. While a student here, Mrs. Wheeler involved herself in a myriad of activities; in addition to involvement in student council and theatre, she was a member of the radio staff as well as serving as editor-in-chief for the Miracle yearbook.

Married forty-four years to whom she refers as "the good man," Margaret is a mother of six beautiful daughters who are all now married, giving her seven grandchildren to brag about. Anyone who has ever sat in one of Mrs. Wheeler's classes can attest to the way her family is very important to her. Mrs. Wheeler is always sharing stories and photographs of weddings and grandkids, creating a special relationship with students where all can feel comfortable sharing memories.

Staying home to raise her children while they were small, Mrs. Wheeler made her triumphant return to Cedarville University in 1995, serving as Assistant Professor of Communication Arts. Seeing the way God gives worth and talent to every student makes teaching so special for Mrs. Wheeler, as she finds joy in encouraging each student to develop that talent to its greatest potential for God's glory.

Aside from teaching students how to organize their speeches and write attention grabbingintroductions, Mrs. Wheeler finds several other avenues to exhaust her abundance of zest and energy. She is a member of the over 100 year old "Tuesday Literary Club" where she enjoys researching, writing about, and presenting on various subjects. Beyond that, Mrs. Wheeler also invests time into the Nobel Circle Sisters. Being a breast cancer survivor herself, she enjoys being a part of this group of cancer survivors who are committed to physical, emotional, and spiritual support though their seminars and retreats.

To "the good man," she is a creative, visionary, wise, loving, insightful, bright, beautiful and, above all, feisty woman; he claims his forty-four years with her has been an exciting journey. Through all of her blessings and personal struggles, she is to be commended for not only her accomplishments, but strength and her amazing optimism through it all. With everything in her past, present, and future, Mrs. Wheeler says that she "could not have a better life."
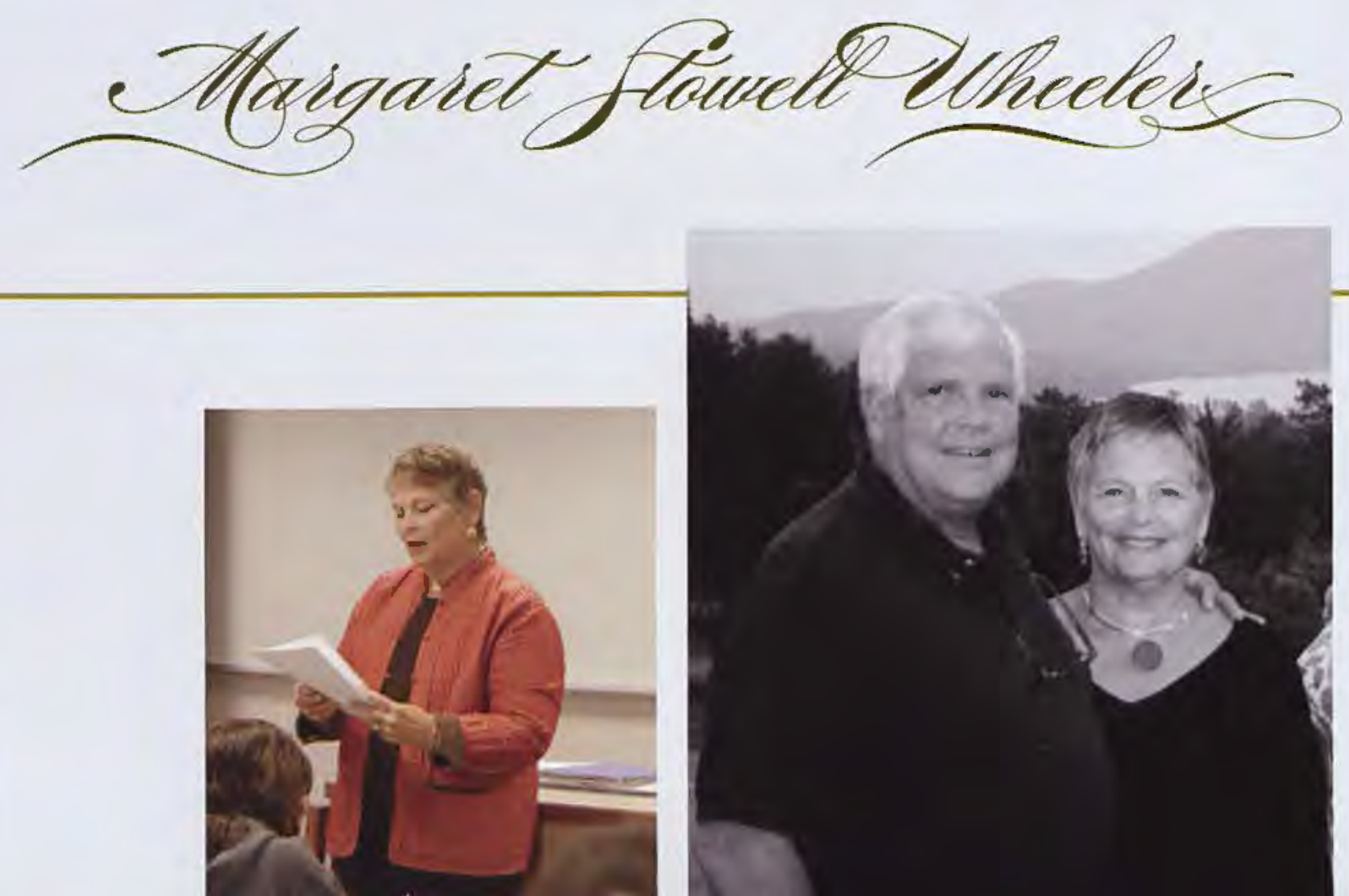

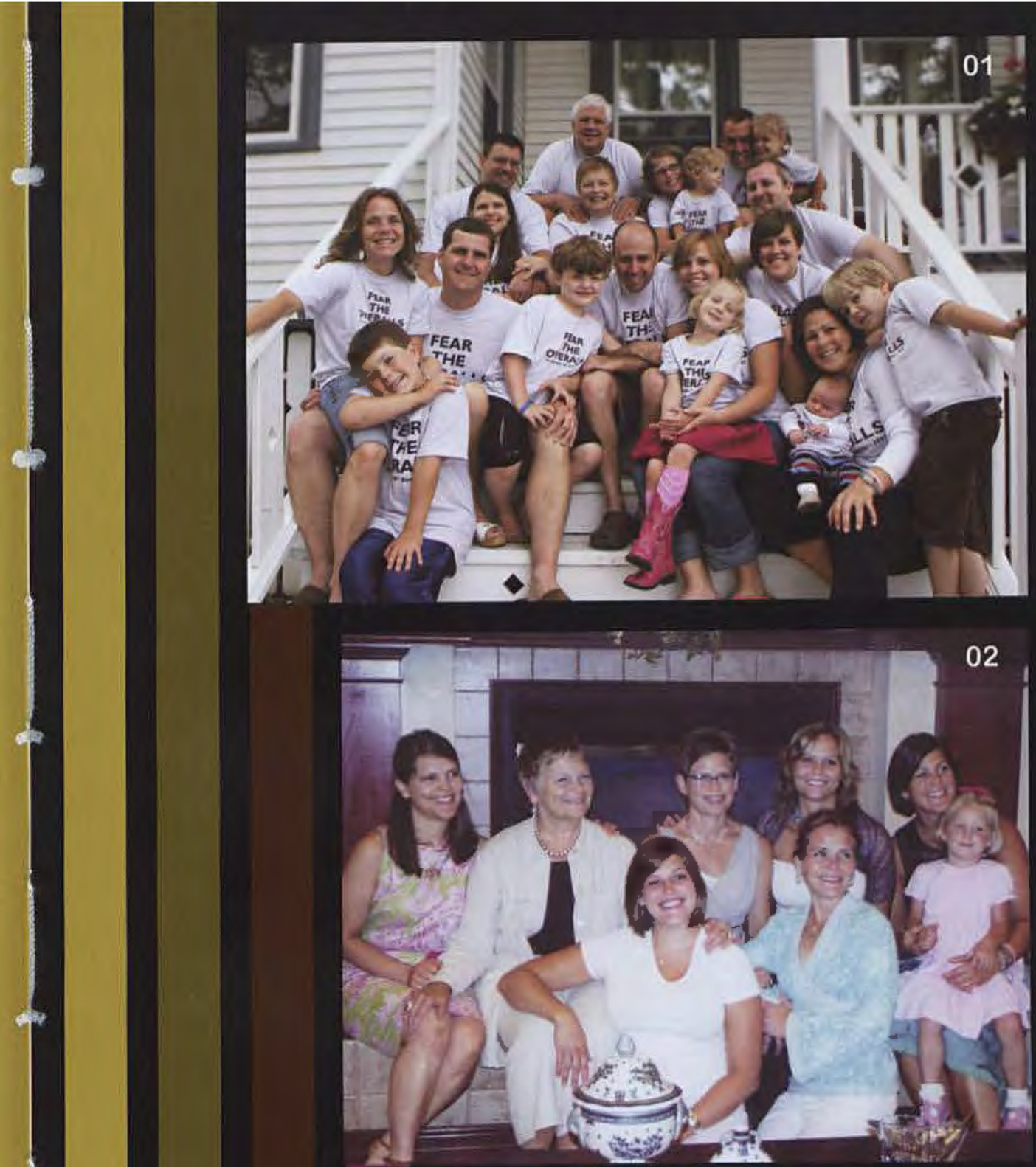

01 The whole extended Wheeler clan gather in the Bronx for a very special birthday party and reunion.

02 Mrs. Wheeler's six daughters live all over, from Seattle to Israel, so she cherishes time to reunite with them all.

03 Seen here with one of her seven grandchildren, Halsey, Mrs. Wheeler makes sure she finds time to invest in their lives.

04 Being the adventurous couple they are, the Wheelers let loose and have a little fun at a friend's wedding.
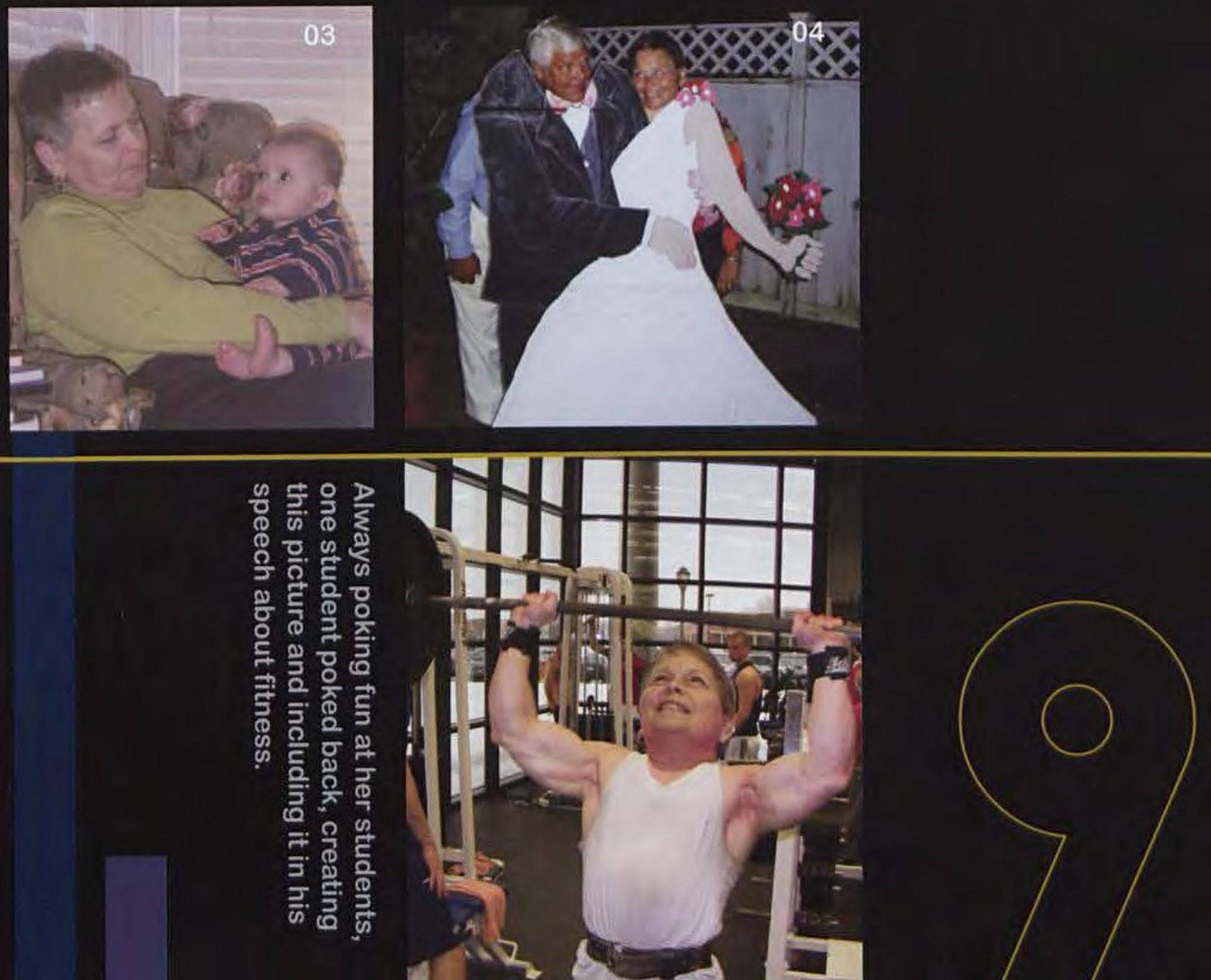
"DELCIOUS

MY VERY SOUL IS

WEDDED TO IT, AND

IF | WERE A BRD |

WOULD FLY ABOUT THE

EARTH SEEKING THE

SUCCESSIVE AUTUMNS"

GEORGE ELIOT 


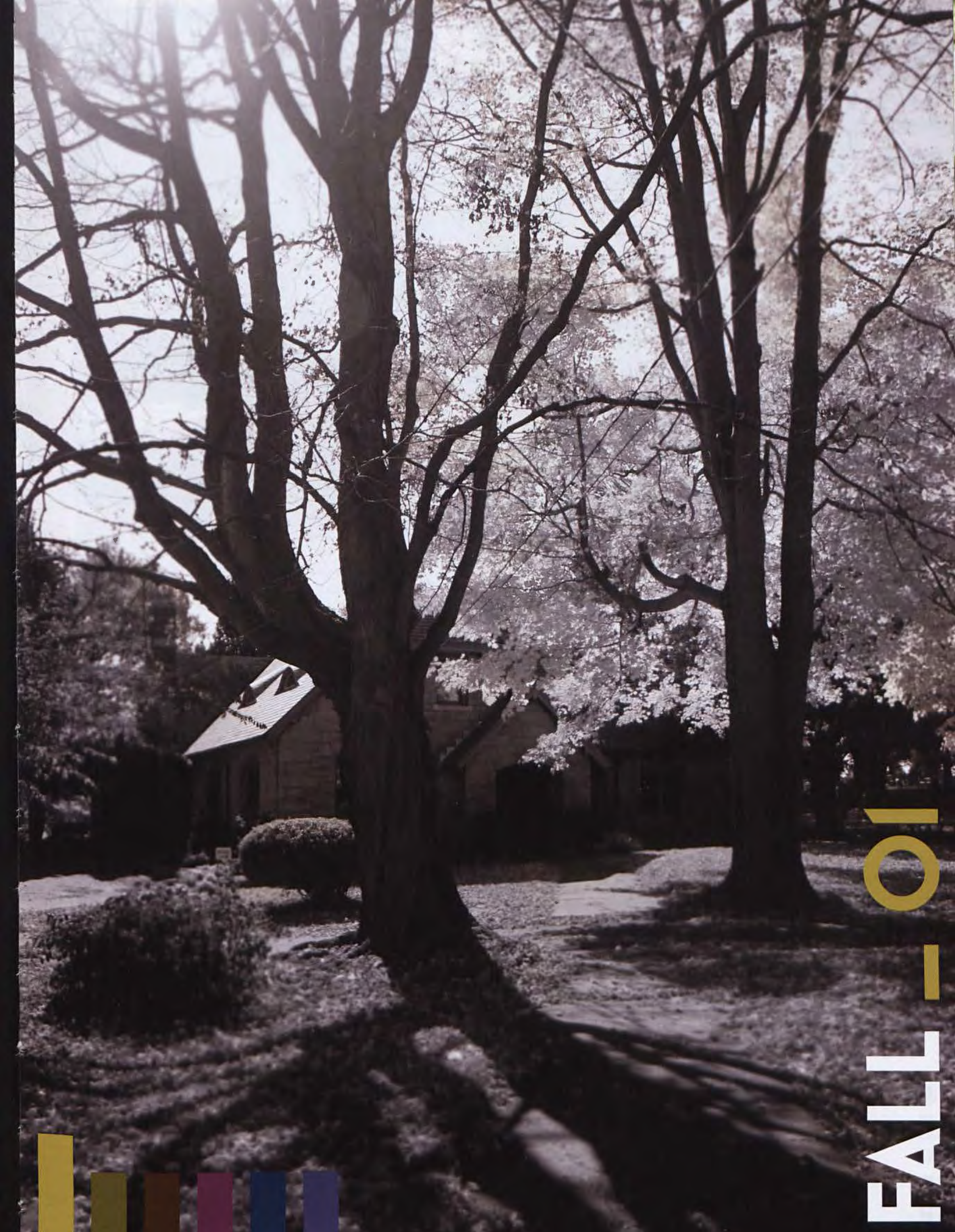


Picture this. Your palms are sweating. You fidget with your clothes one more time. Gulping, you step out of the car and make your way to the door. Going to see that special someone? Nope, you've arrived for Getting Started Weekend! Instead of a wary father, you were greeted by a giant bee. This was the premise of Getting Started Weekend: "Amazing; everyone made me feel like I was back at home." (Jesse Jones, freshman)

Following the exploits of all the new students, this tale took you on a journey of intrigue and mystery. And though it was "kinda awkward not knowing anyone, people were very welcoming!" (Stacie Beres, freshman)

The new students aren't the only stars of this show. Serving as supporting characters, plenty of returning students come back early to help out. "It was great to be able to help freshmen move in so we could make their transition to college go well. It was a really fun time to get to know them and meet their families." (Evan Wicker, senior). But this story wasn't all fun and games. "I don't think I could have carried all of those clothes and accessories up by myself! My muscles couldn't take that astonishing weight of all those hangers!" (Lauren McIntosh, freshman)

But the action didn't stop there! As the new students continued on in their epic arrival at college, "There were a ton of meetings...l believe it helped in making everyone feel at home." (Reese Stevenson, freshman) From conferences with Dr. Brown to breakfast with the academic departments, Getting Started Weekend had it all.
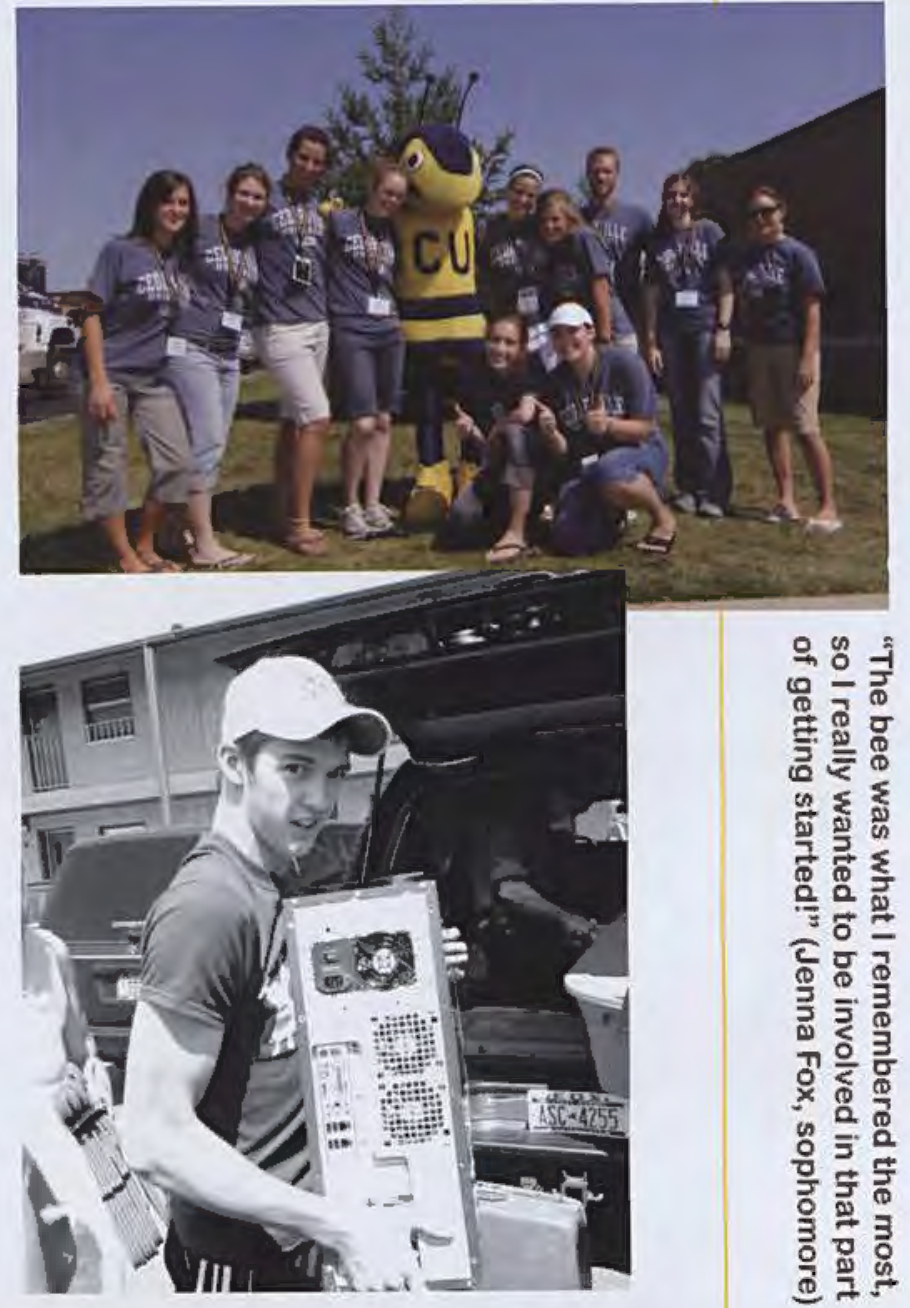

There are no signs of stopping for freshman Dan Ormsby, as he enthusiastically carts his hard drive to his new Lawlor room.

With long lines and piles of paperwork, CU's Getting Started program attempts to ease the strain of a student's first day.

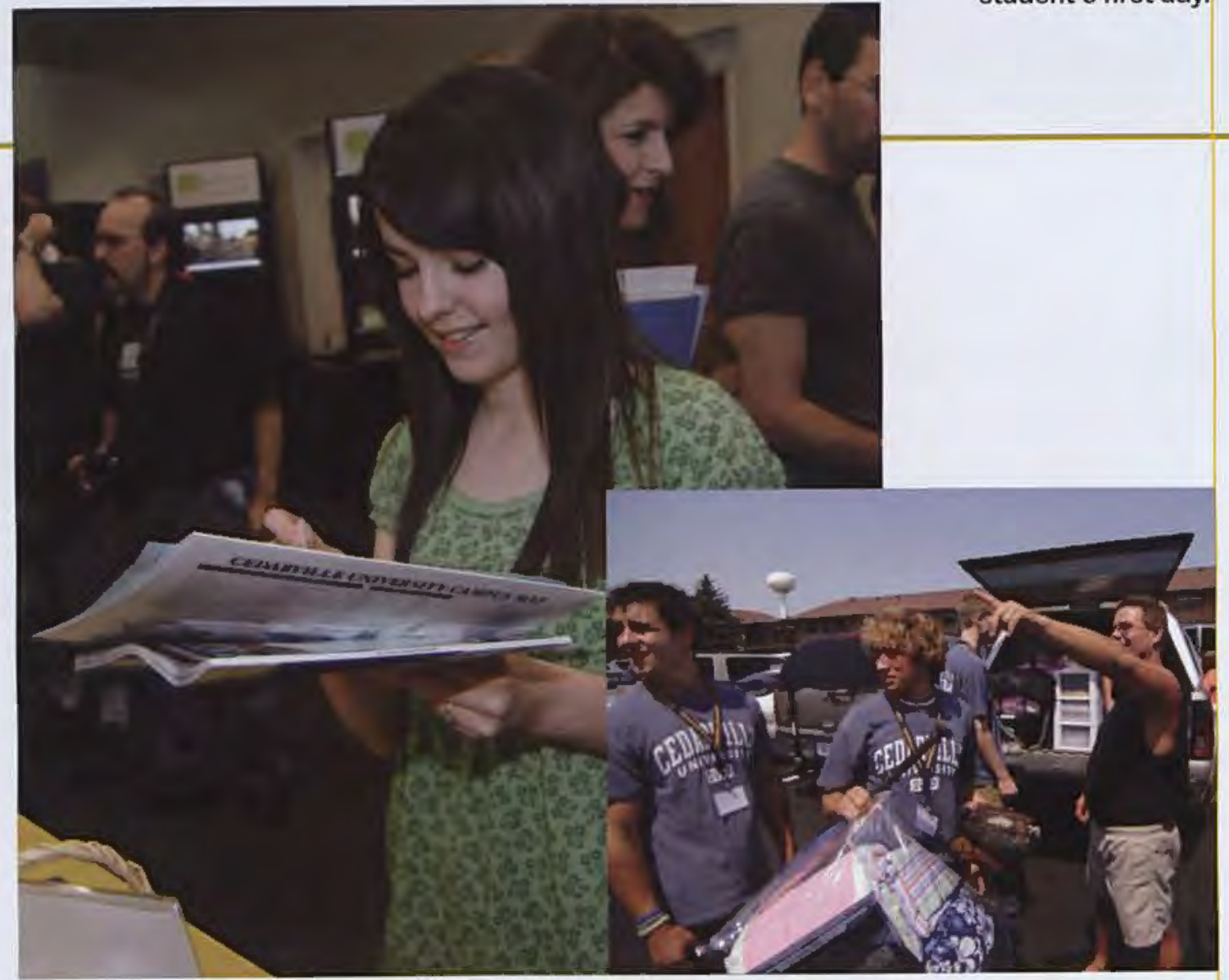



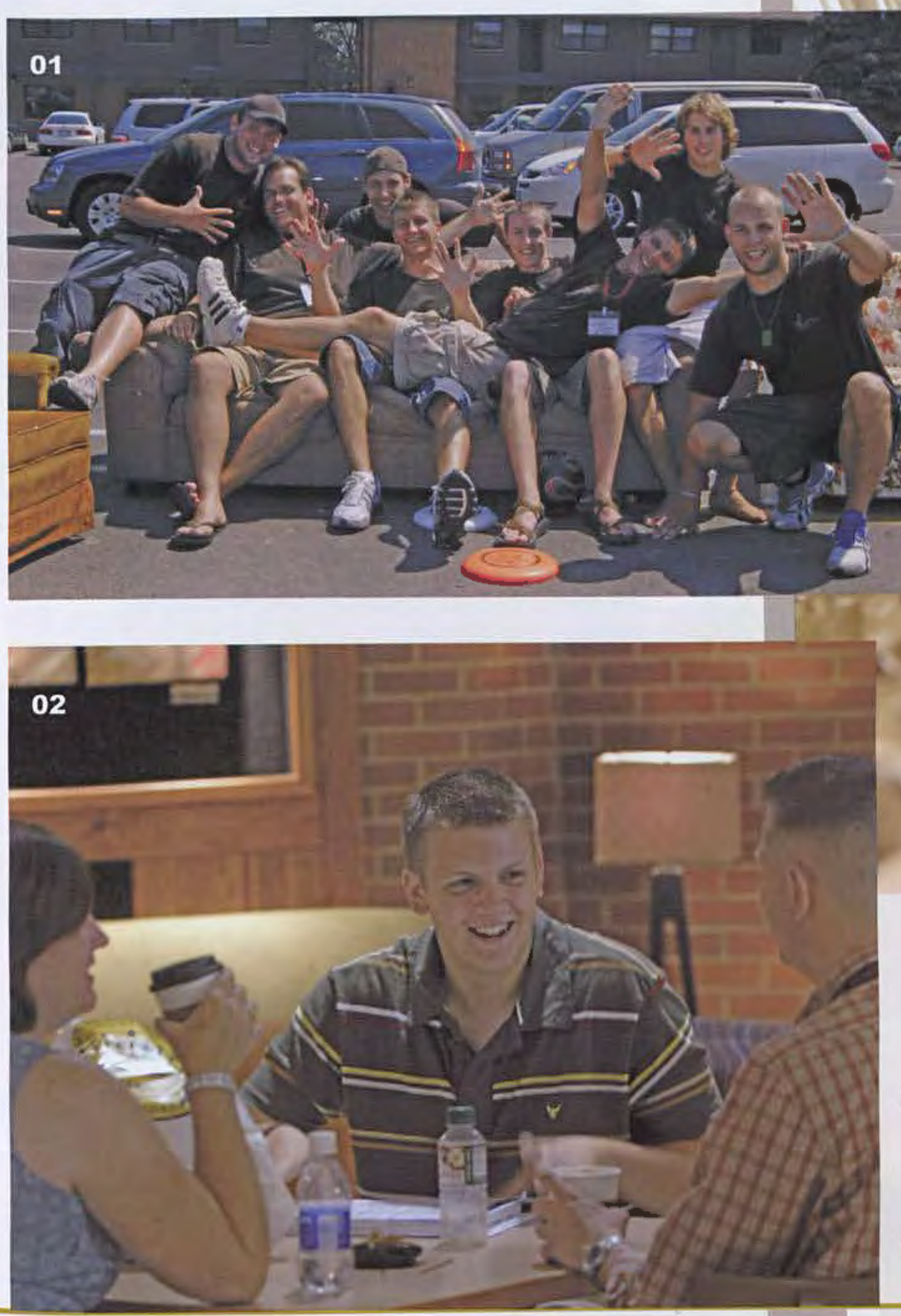

As these keys are slowly removed from their receptacles one-by-one, the future Hillians of Cedarville begin to take shape.

01 "I thought the RAs did a great job helping all the freshmen move in." (Lauren Mclntosh, freshman)

Parents spend time with their freshman by taking a break in the Hive. A Vecino's-induced energy burst should help complete the moving-in process.

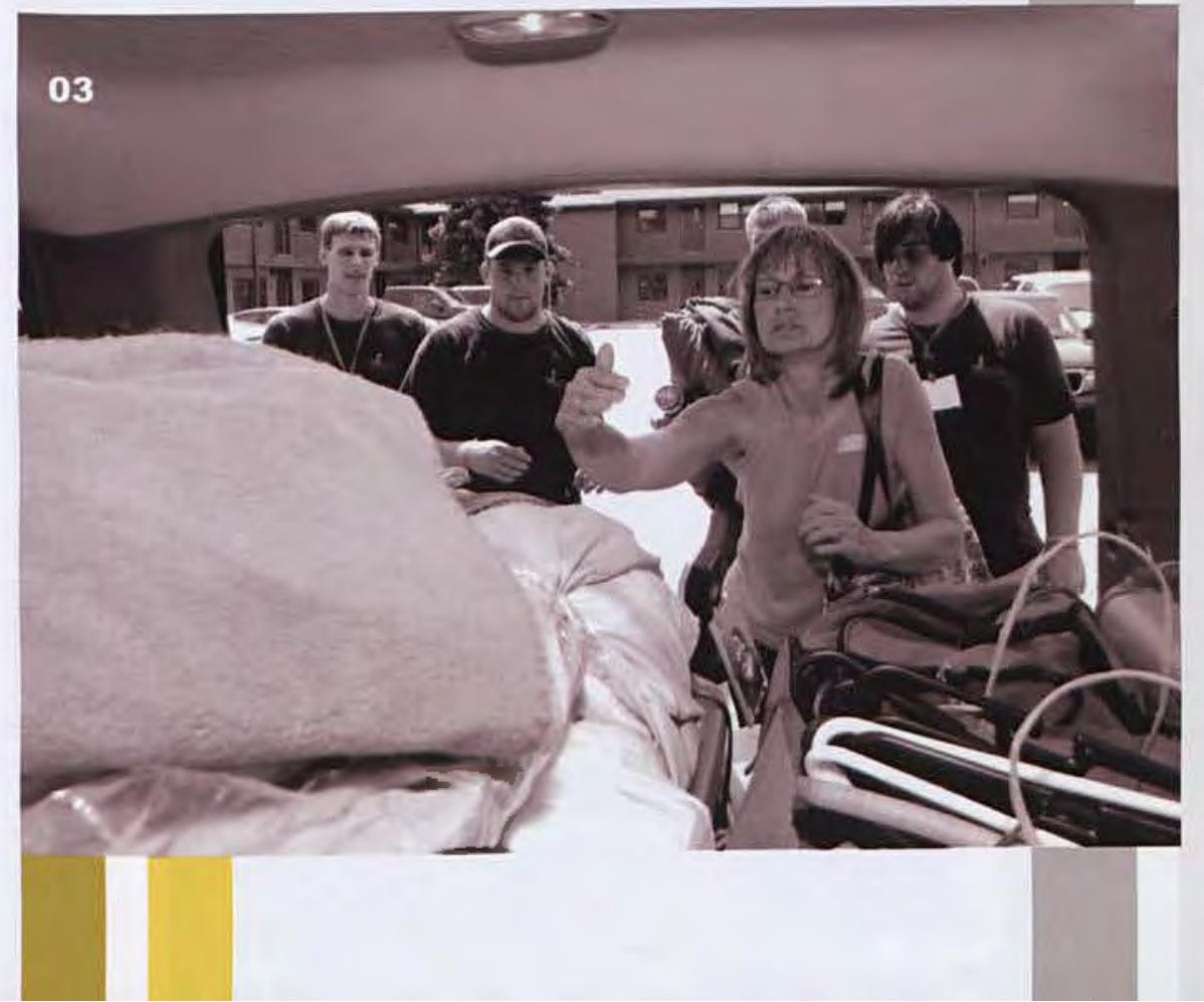

03 Lawlor RD (from left) Anthony Mandela and RAs Eric Carroll and J.B. Waggoner make sure to be as helpful as possible, especially as the parents try to unpack their vehicles. 


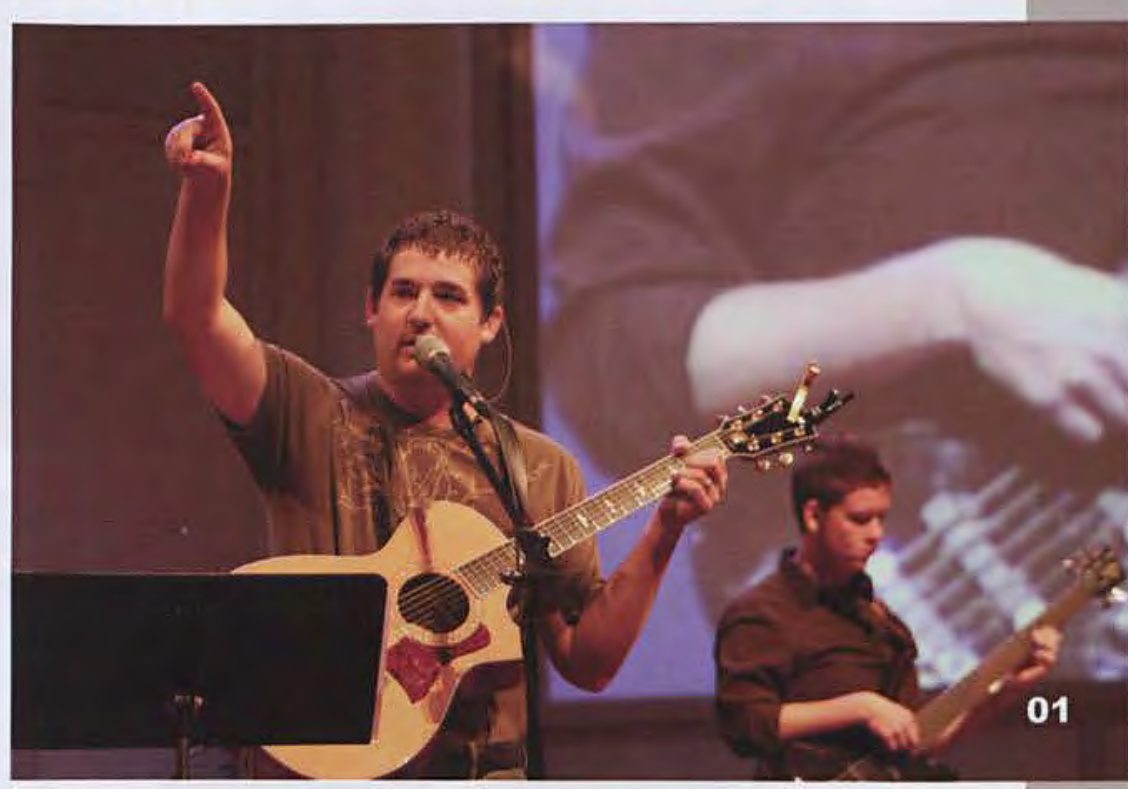

02
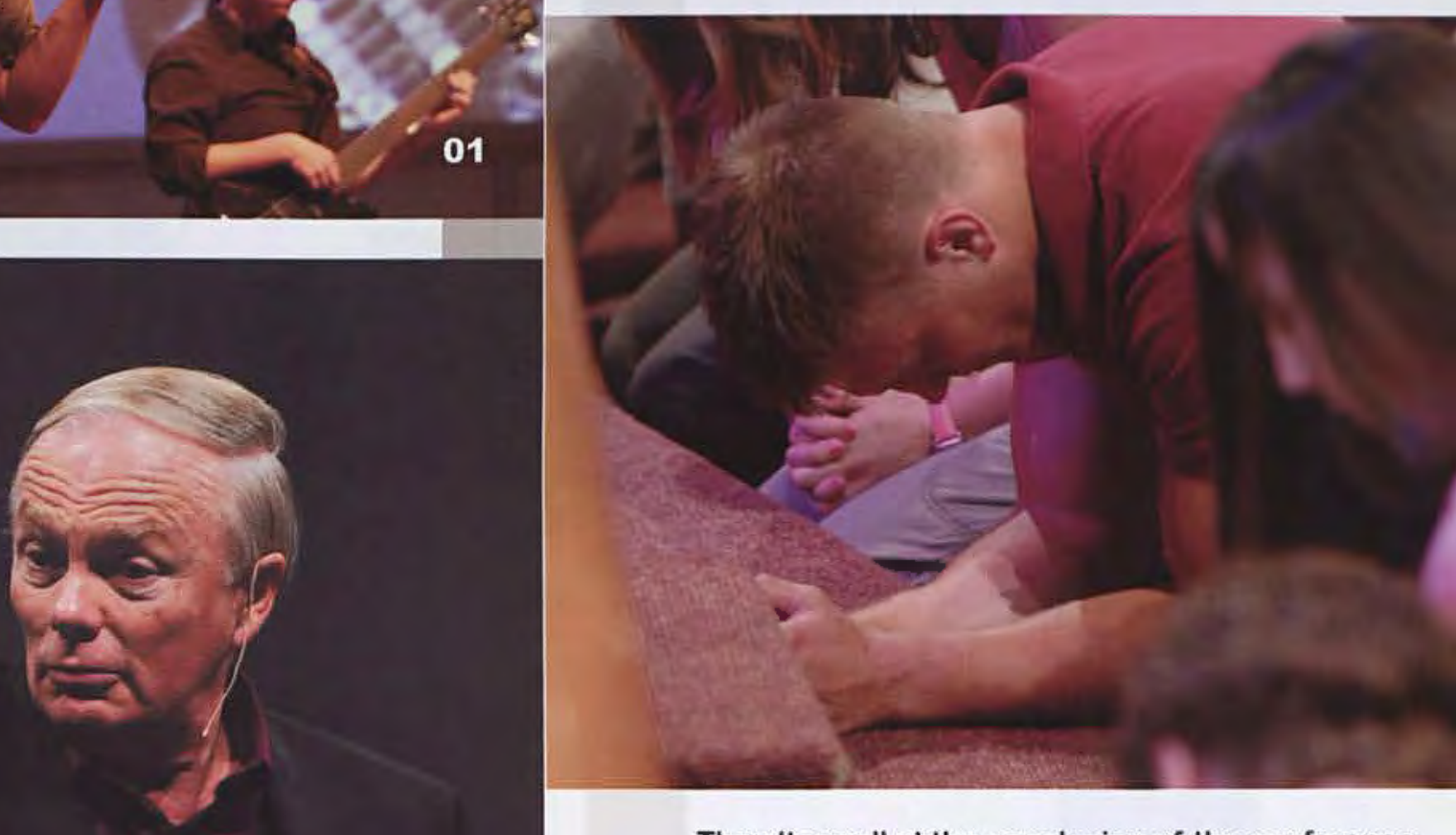

The altar call at the conclusion of the conference allows students to start the year with spiritual strength and clarity.

e

01 "Fall Bible Conference is a wonderful immersion back into school and life at Cedarville." (Garrett Williams, senior)

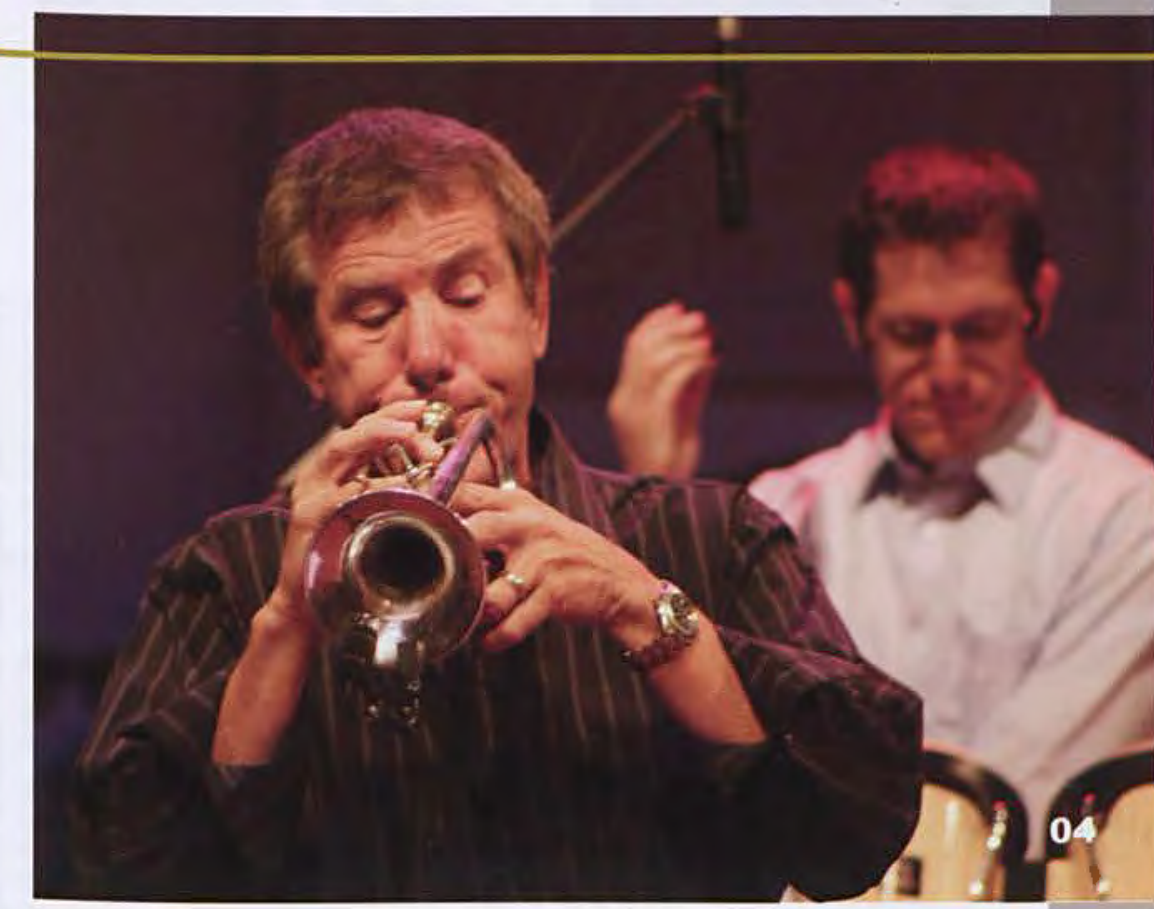

Adjunct Instructor of Music Mary Davis Fetherston plays a deeply moving piece for the students to reflect upon.

Dr. Ron Hutchcraft, renowned evangelist and radio host, emphasizes focus and patience during his series of messages.

Professor Charles Pagnard demonstrates his brass prowess during a special music segment. 
For the first time at Cedarville University, the Student Org Fair did not coincide with Alumni Weekend. Student orgs put together booths to woo more members of the student body into their ranks, and a good time was had by all. Students enjoyed the use of the entire Stevens Student Center and Dixon Ministry Center parking lots, which they filled with booths of all varieties. Returning favorites were the marshmallow blowers from Alpha Delta Gamma and the tattoos applied by the ladies of Phi Epsilon Beta. The Delta Phi Sigma girls put goldfish in bowls and made people throw ping pong balls into the water. Collective praise for the booth comes from two of its members: "The atmosphere was pretty thrilling, and a lot of people walked away with their own fish." (Nicole Rose and Robin Provo, seniors)

An organization brand new to the fair, the Icarus Collective, Cedarville's poetry organization, put out coffee and crackers, played music and read poetry aloud. "Students generally didn't stop in, and generally gave us weird looks, but we did entice a few prospective members." (Scott Kordic, junior) Splitting off from Alumni Weekend provided a less crowded atmosphere for students to mingle with their own and gave organizations more room to distinguish themselves. There was so much room, in fact, that art students were able to paint a mural on the side of a van: an Abercrombie and Fitch model, bleeding from his side, with caption "I want a Jesus who will take me shopping," provoking viewers to reevaluate their consumerist priorities. This year's success will certainly bring the Fall Fling back for 2008.
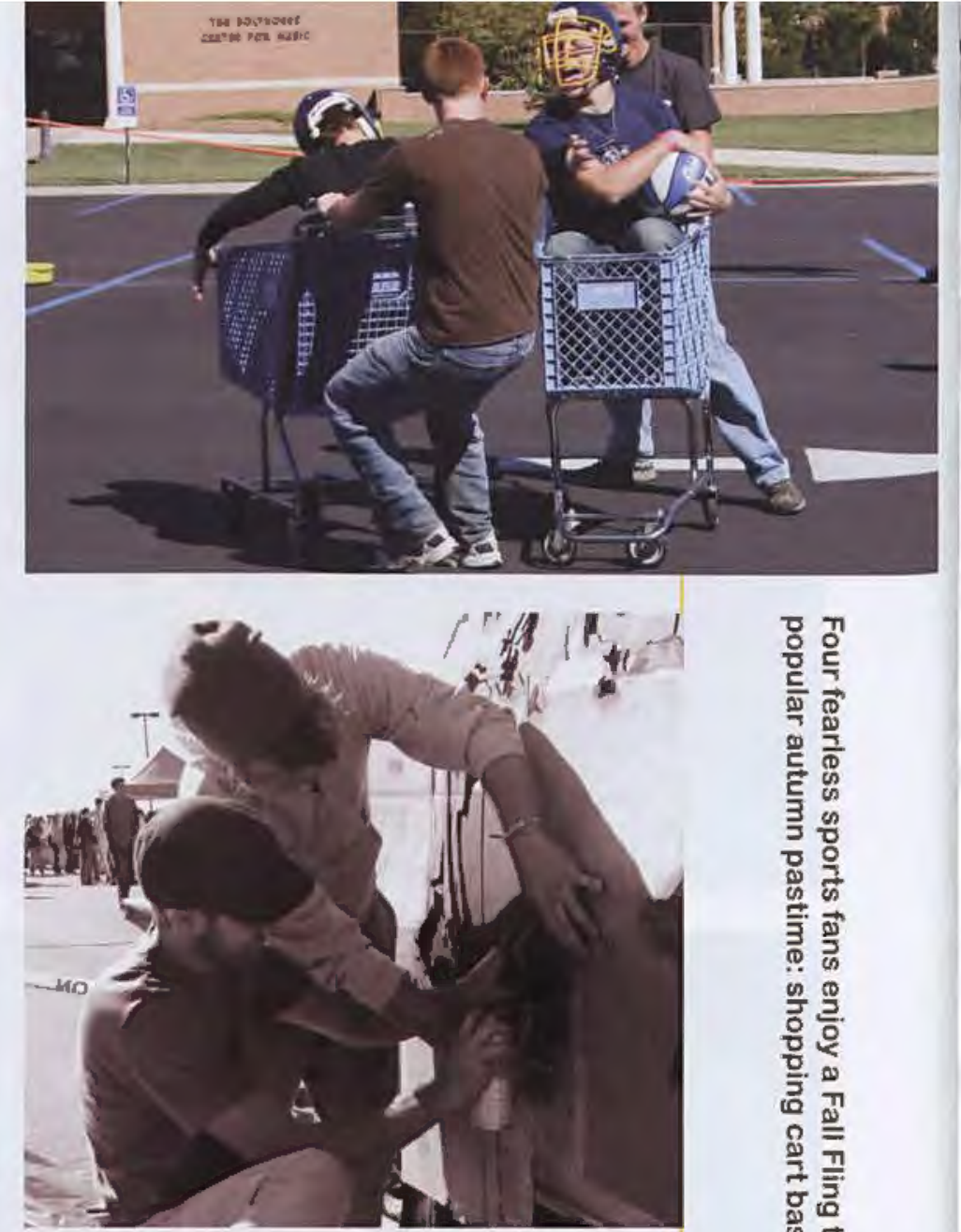

Seniors Dave Sizemore and John Rice paint a van for purpose. "We were trying to make a statement about consumerism and Christianity," Sizemore explained.

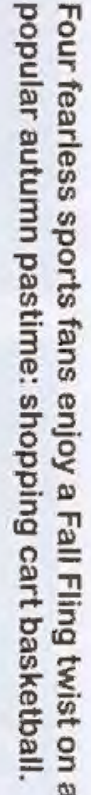

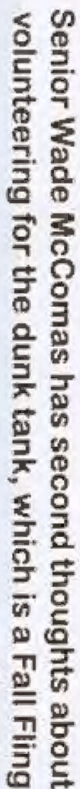

CU Transformed, the premier paintball org on campus, encourages students at the Fling to don a helmet and

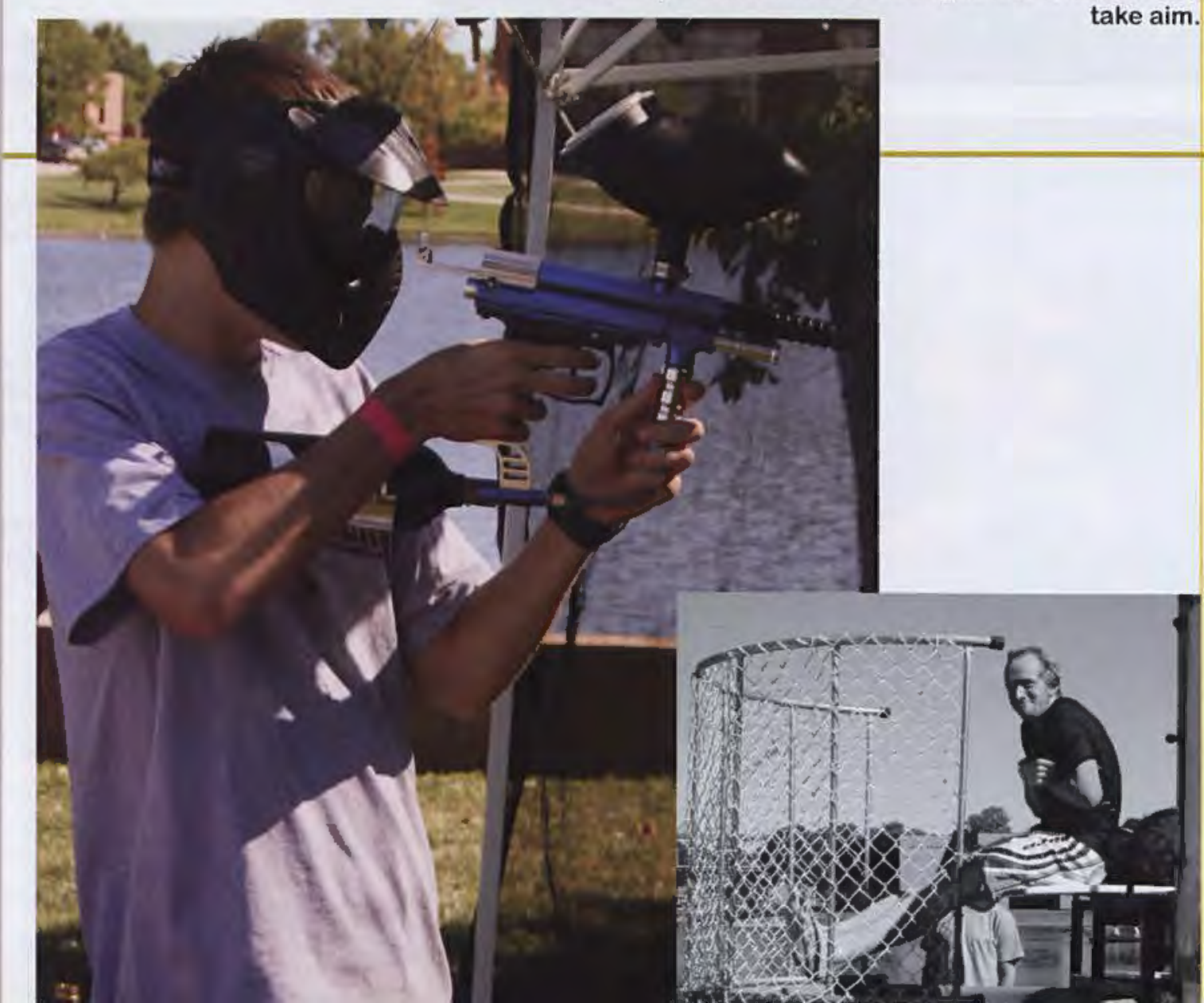



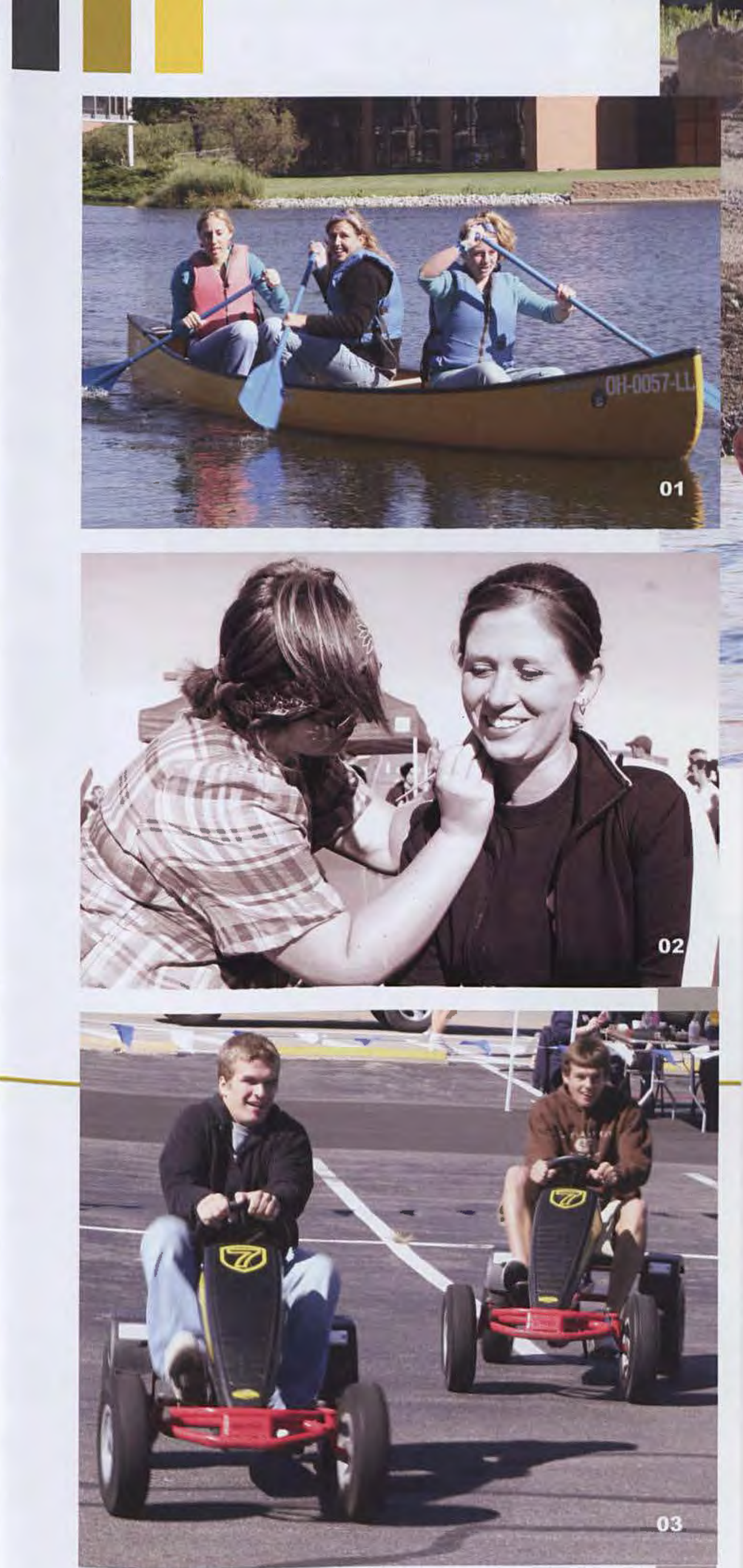

The lake isn't just for freshman engineers! Sophomore Bri Mottashed (front) and friends tackle the treacherous waters of Cedar Lake.

Senior Evan Chiu (far right) enjoys the mud between his toes during Mud Volleyball. Says Chiu, "The dirt never fully came out of my shirt."

02 Senior Teresa Keller, representing her org ADG, paints the hesitant face of junior Erin Olsen. According to Keller, the ADG booth included "everything that you could think of at a fall festival."

Freshman Grant Bacon closely trails fellow freshman Richard Leman in the four-wheeled cycle race. 
CU "Under the Big Top" made its debut at Alumni Homecoming on October 5-6 this year, featuring a three-ring circus of fun, excitement, and the ability to reunite with old friends. All the classic elements of homecoming combined with over 600 alumni families made for a weekend full of "great opportunities for alumni to come back to campus and reconnect with their friends and what is going on around campus." (Alise Merrin, Sophomore, Alumni Relations Office)

Homecoming served as an opportunity for alumni to catch up with each other, attend reunions, and maybe even "take you back to a time when you were someone else - someone you almost forgot about." (Jill McClain, Class of 1987) Homecoming brings back people whose only connection to each other may be Cedarville. For some it's a time to see "those certain ones that you can be away from for years and, when you get back together, it is like no time at all has passed (McClain)."

It was an action-packed weekend filled with canoe races, soccer and volleyball games, reunions, a parade, and play performances that created "fun for the whole family," (McClain) and more than just a trip down memory lane. A time for reconnecting with your college days became so much more with the excitement and atmosphere of Homecoming 2007. Alumni gave "CU Under the Big Top" two thumbs up!
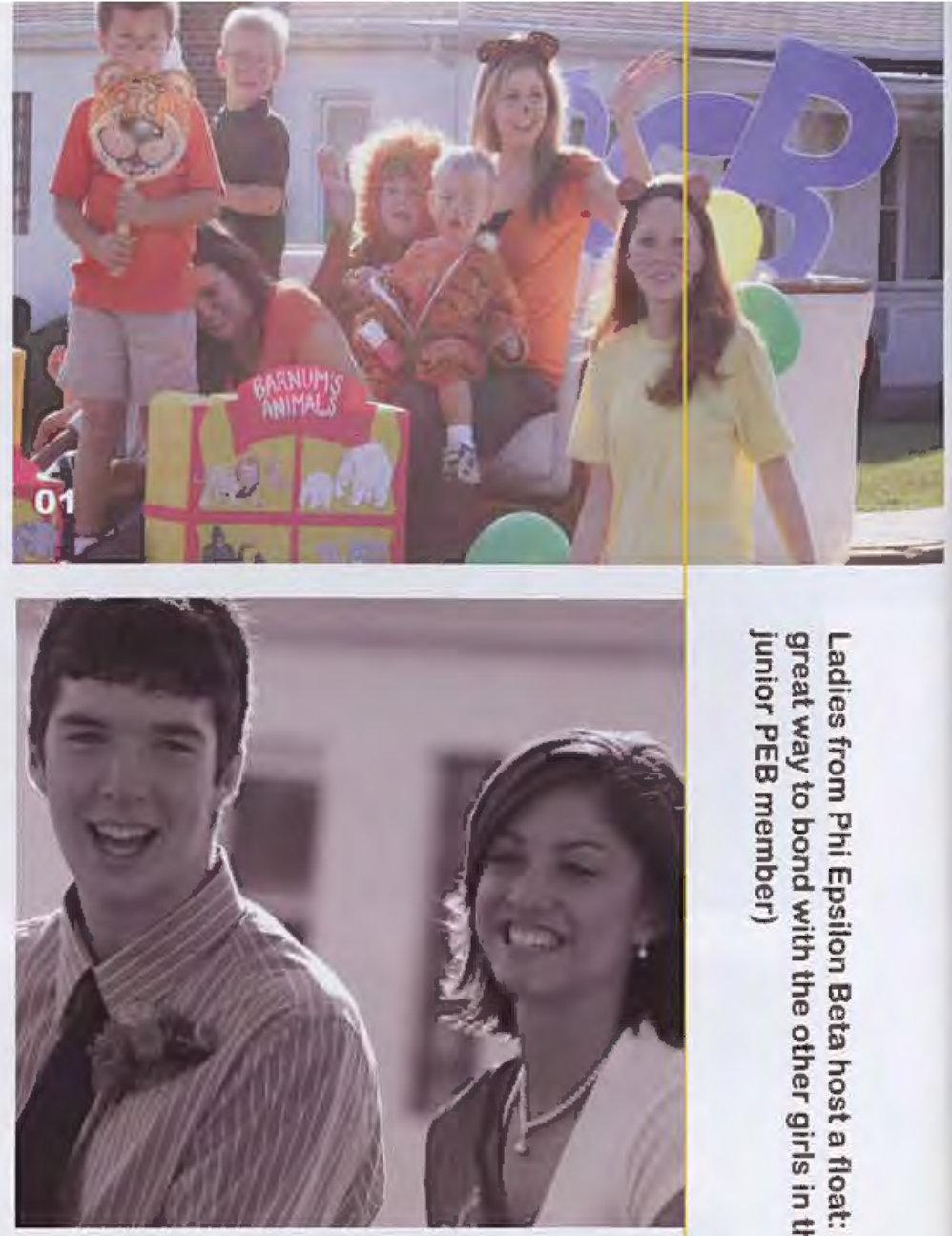

"Holly Israel and I definitely did not mind riding in a convertible on such a beautiful fall morning!" (Baxter Stapleton, freshman attendant)

"I offered pieces of cotton candy to spectators, but they were disappointed when they saw it wasn't real!"

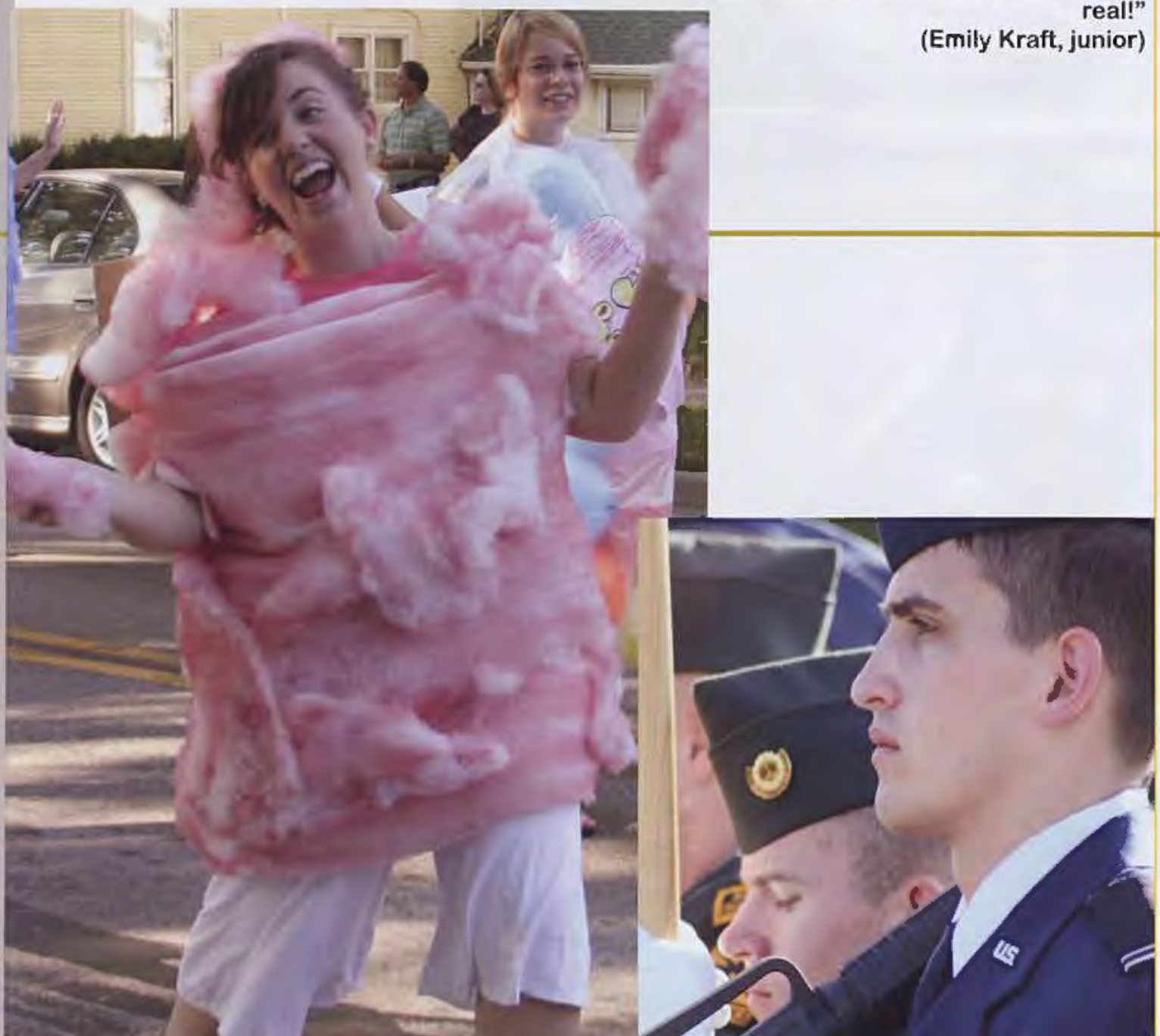




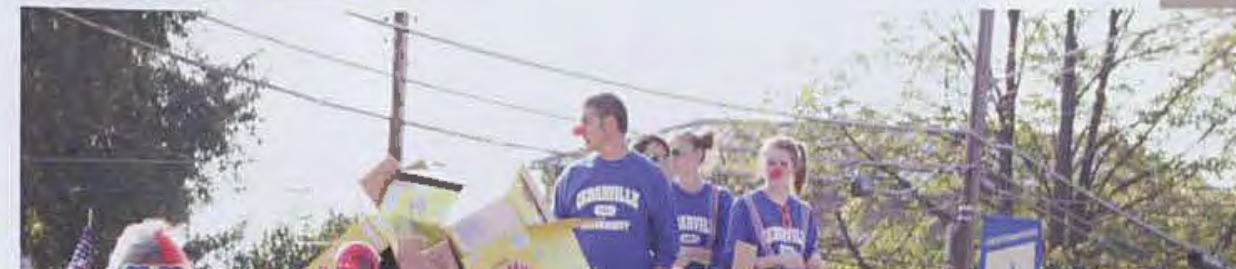

Eri
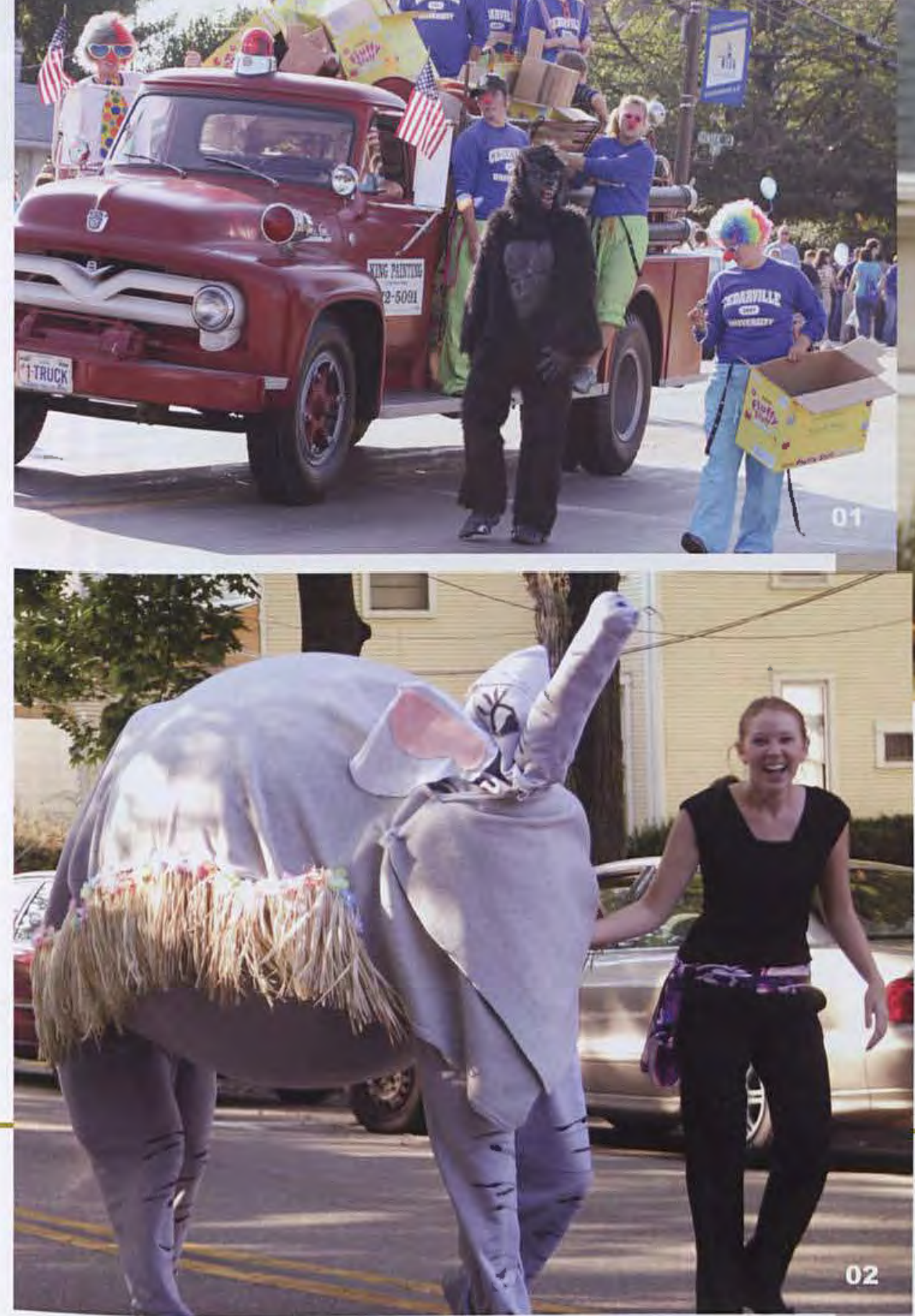

corts a gorilla down Main Street. "Homecoming was a good opportunity to say thanks to the community." (Dan Johnson, senior)

"How many can say they dressed up four guys as elephants and paraded them down the street?

can!"

(tiz Sudlow, senior)

03

"It was so much fun to hand out balloons and see the faces of the kids light right up!" (Shannon Young, junior
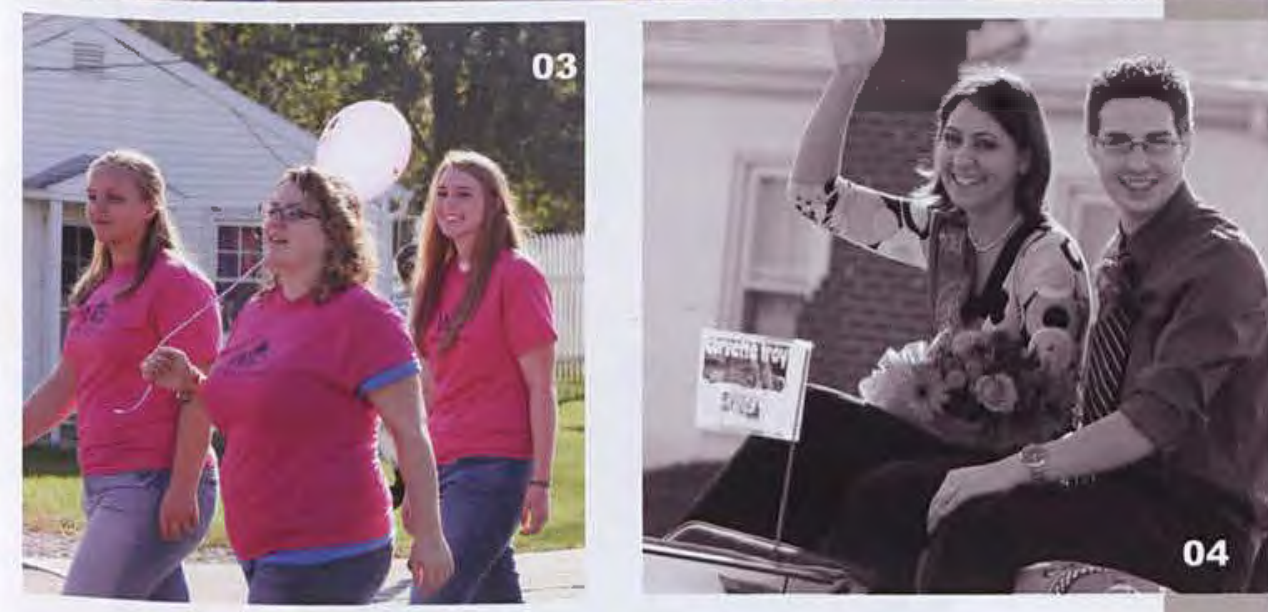

04

Joe and Susan Moss, senior homecoming attendants, sit on top of a Corvette as a married couple: "We loved being part of the activities!"

(Joe Moss) 
Under a sunny September sky, hundreds of alumni and students gathered on the shores of Cedar Lake to watch the annual Freshman Cardboard Canoe Race. However, this year's rite of passage for freshman engineering students came with a few extra twists. While in the past canoes had to hold an additional passenger, the race organizers decided for the 2007 contest to give students fewer materials and require only the two paddlers in the vessel. On top of this, Dr. Gerry Brown implemented a new challenge of adding cargo along the way by picking up gallon milk jugs filled with seven pounds of water. Dr. Robert Chasnov, Assistant to the Chair of the Engineering Department, explained that their reason for the change of rules was "to keep the competition from getting stale."

In spite of the new challenges, freshmen Colten Mounce, Paul Ikeda, Greg Donaldson, and Joshua Tucker beat a strong field of contenders by navigating their paper vessel across Cedar Lake in just under two minutes.

Ikeda, the chief designer of the canoe, claimed that the size of the team's boat contributed to their boat's speed and agility in the water, enabling it to "withstand a good amount of torque and stress."

Tucker, one of the paddlers, explained the confidence they had in their design when "about half-way across the lake, Greg and I started digging our paddles deep [and found] we could maneuver the cardboard boat like an actual canoe." It was this strength and maneuverability that enabled the team to win the 2007 Cardboard Canoe Race and collect the prize of a TI-89 Titanium Calculator.
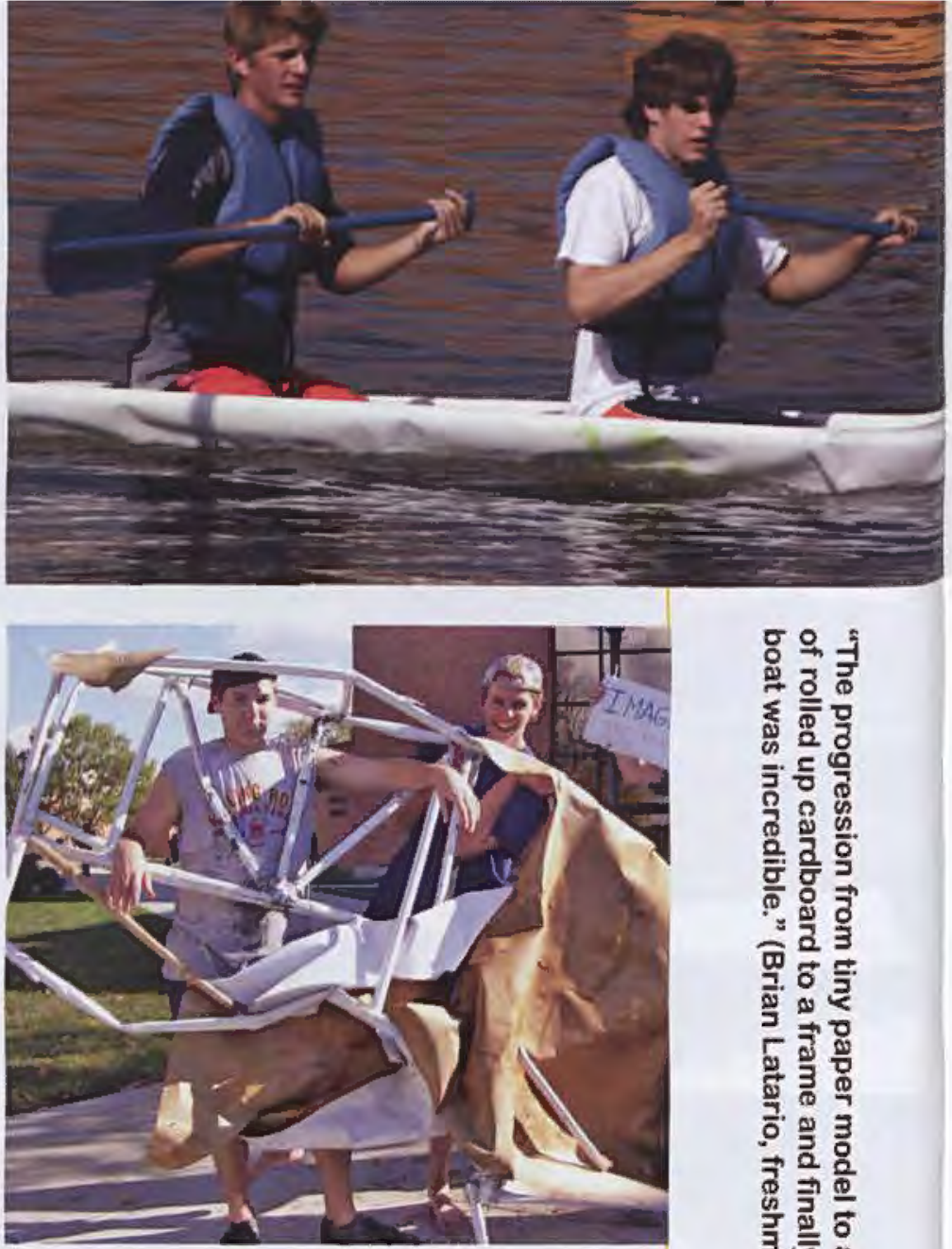

The Comm. Arts competitors proudly display their creative wreckage... minus the fancy sail that once adorned their "canoe."

Canoe Race Day 2007 sports summer temperatures, drawing many spectators and students hawking free ice cream and water.

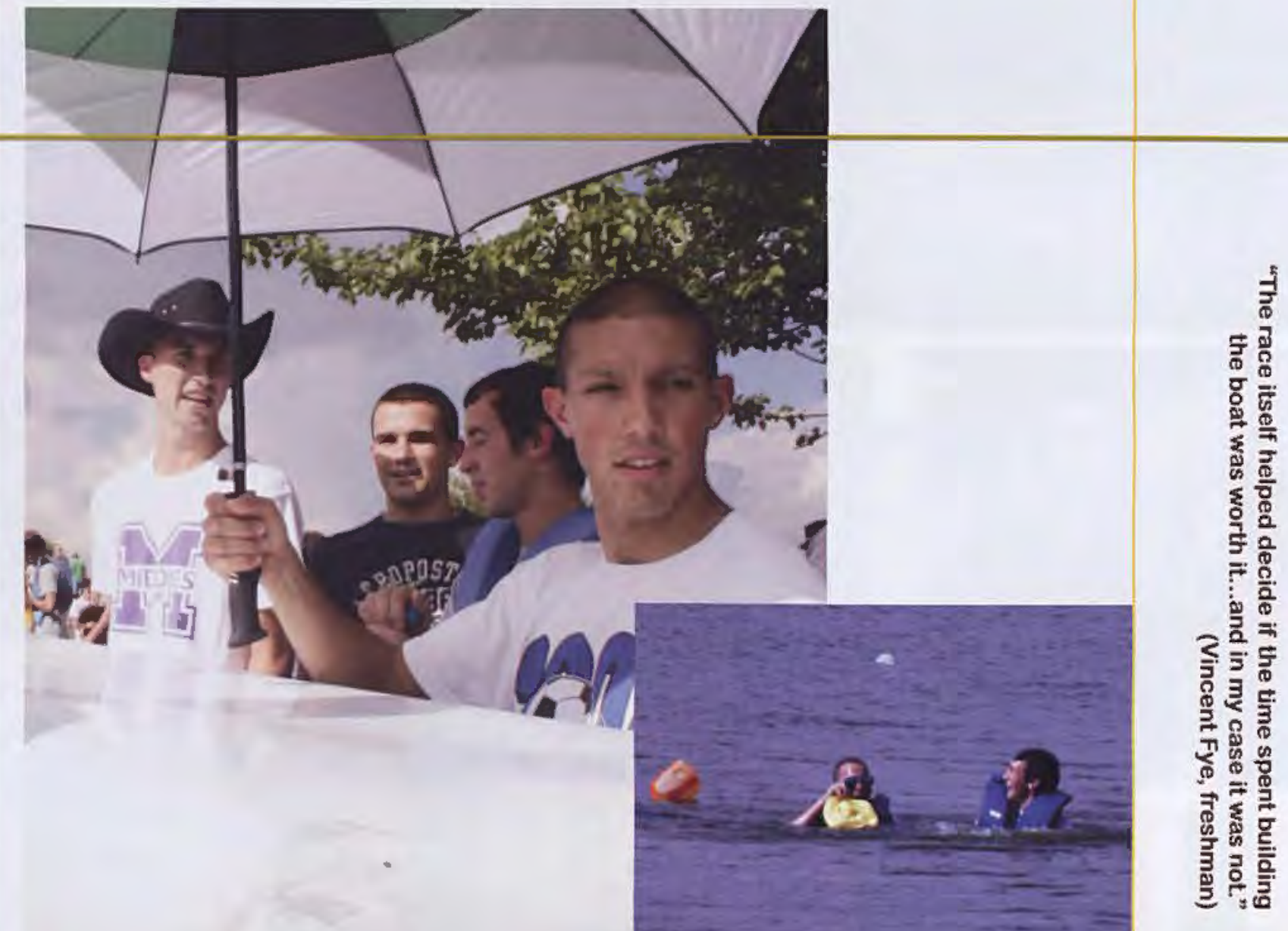



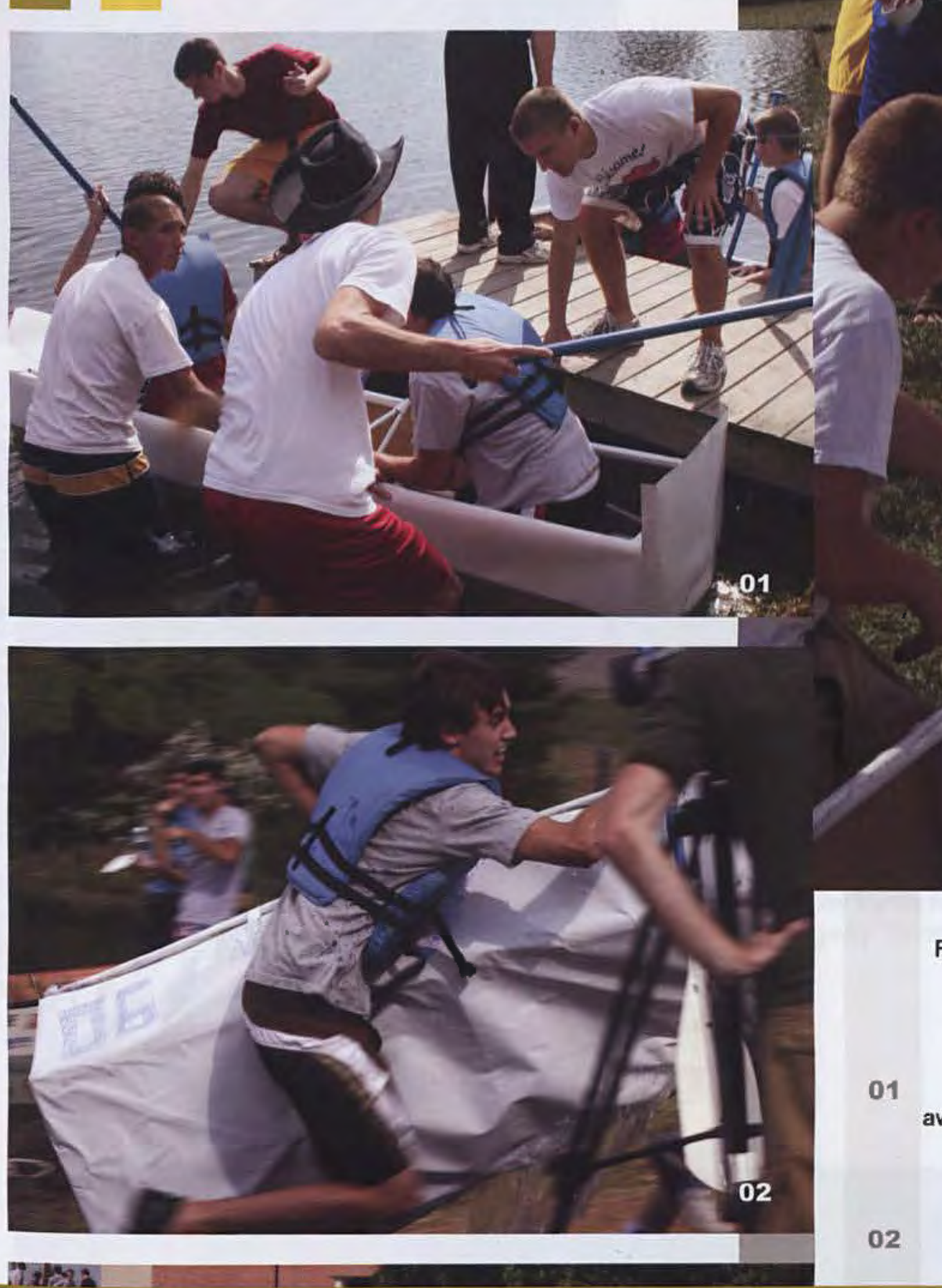

Freshman Joel Lightner and his partner do some
last-minute tape reinforcement.

01

"The race was a great experience. It was awesome to see our canoe make it across!" (Mark Hiteshew, freshman)

Intense competition doesn't end in the water. Freshman Drew Knesnik races out of the water

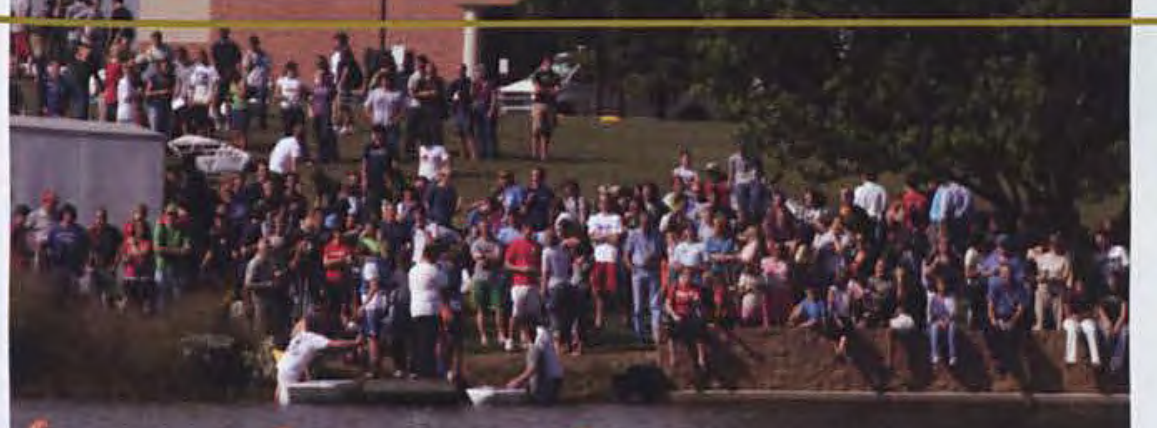
and into the green zone.

"It was awesome to see our canoe make it, and pretty funny watching some of my friends sink!" (Patrick Brady, freshman)

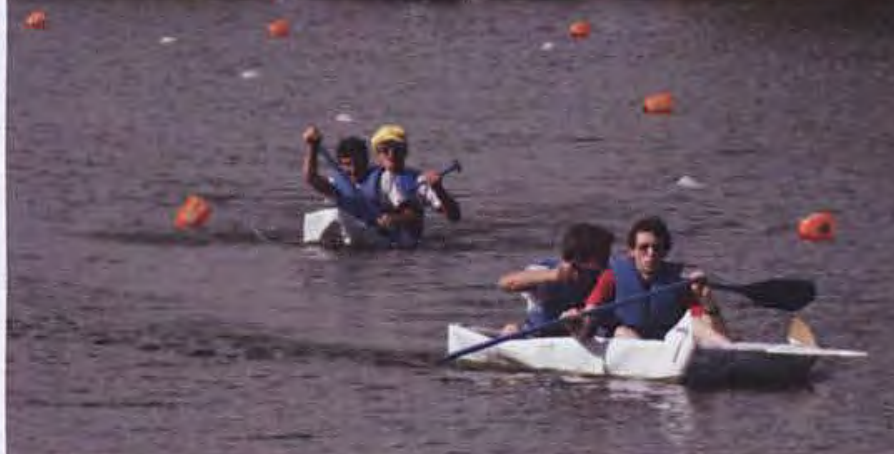




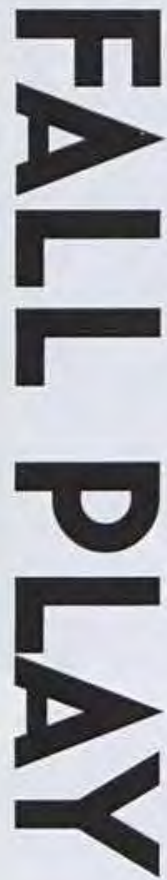

Picture a world full of vibrant color and outrageous costumes, quack doctors, and rap music, and there you have Cedarville University's performance of Moliere's The Imaginary Invalid.

From an electric wheelchair to over-sized needles and spring-shoes, the show drew quite the crowd and filled up almost every seat in the house. The /maginary Invalid was an energetic, in-your-face satire of the ineffective "cures" of the "learned" doctors who were distracted more by money than healthcare.

Several audience members thought CU's rendition was very effective: "The set was remarkable - no straight edges anywhere, like something out of Dr. Seuss. I think it helped the cast attain a level of weirdness that helped translate Moliere's jokes for a modern audience." (Anna Cummings, senior) Freshman Jessica Buchanan exclaimed, "There were points where I didn't think I would ever stop laughing!" Buchanan also remarked, "The actors were all over-the-top, adding to the comedy."

From the hypochondriac lead and his smart-aleck maid to the money-hungry stepmother and her equally greedy notary, each character added their own touch of humor to the show. Meagan Ray's favorite character was the maid: "Toinette had sass and attitude... she was definitely the funniest character."

"My favorite character was Thomas Diafoirus," Cummings claimed. "It is amazing to me that anyone could behave that weirdly for so long and make me laugh for so long." Attendees ranged from sixth graders from Cedar Cliff Middle School to prospective students' families in for CU Friday, and the show left all attendees in stitches. "I think it was the best play l've seen in the three and a half years I've been here!" (Angela Bacon, senior)

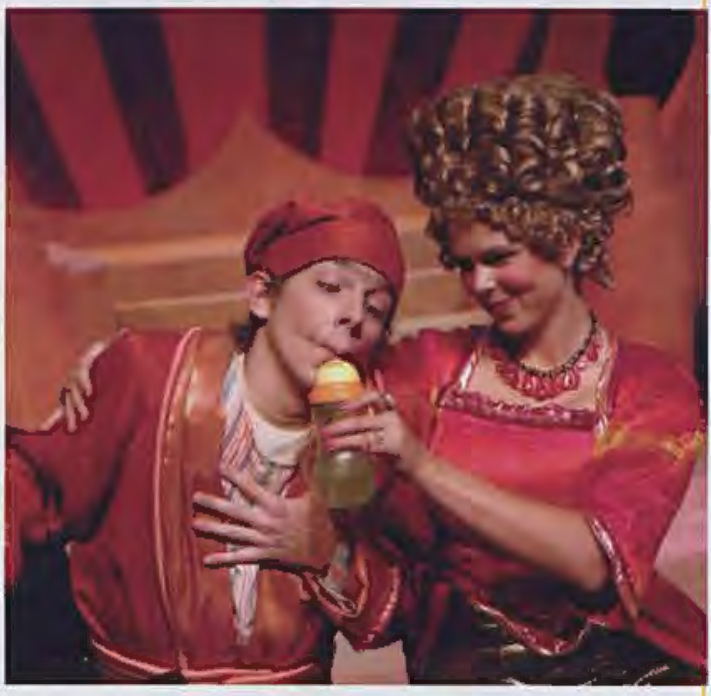

Argan (Michael Domeny, junior) naively finds relief in the arms of his scheming wife, Beline (Kelsey Nelson, senior).

"My character, Mr. Purgon, has just found out that Argan is refusing to make the remedies I have told him to make." (Justin Hobbs, sophomore)

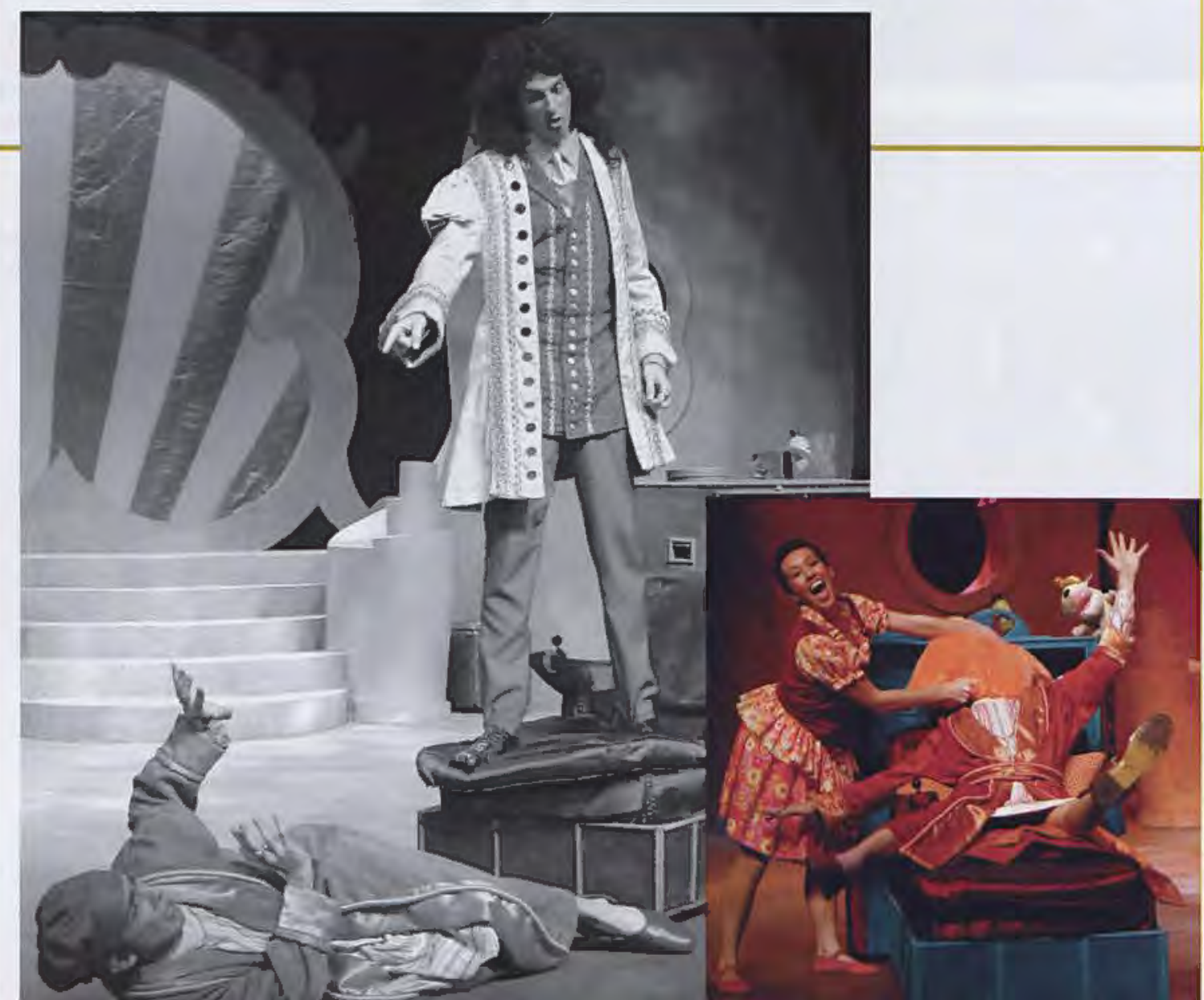



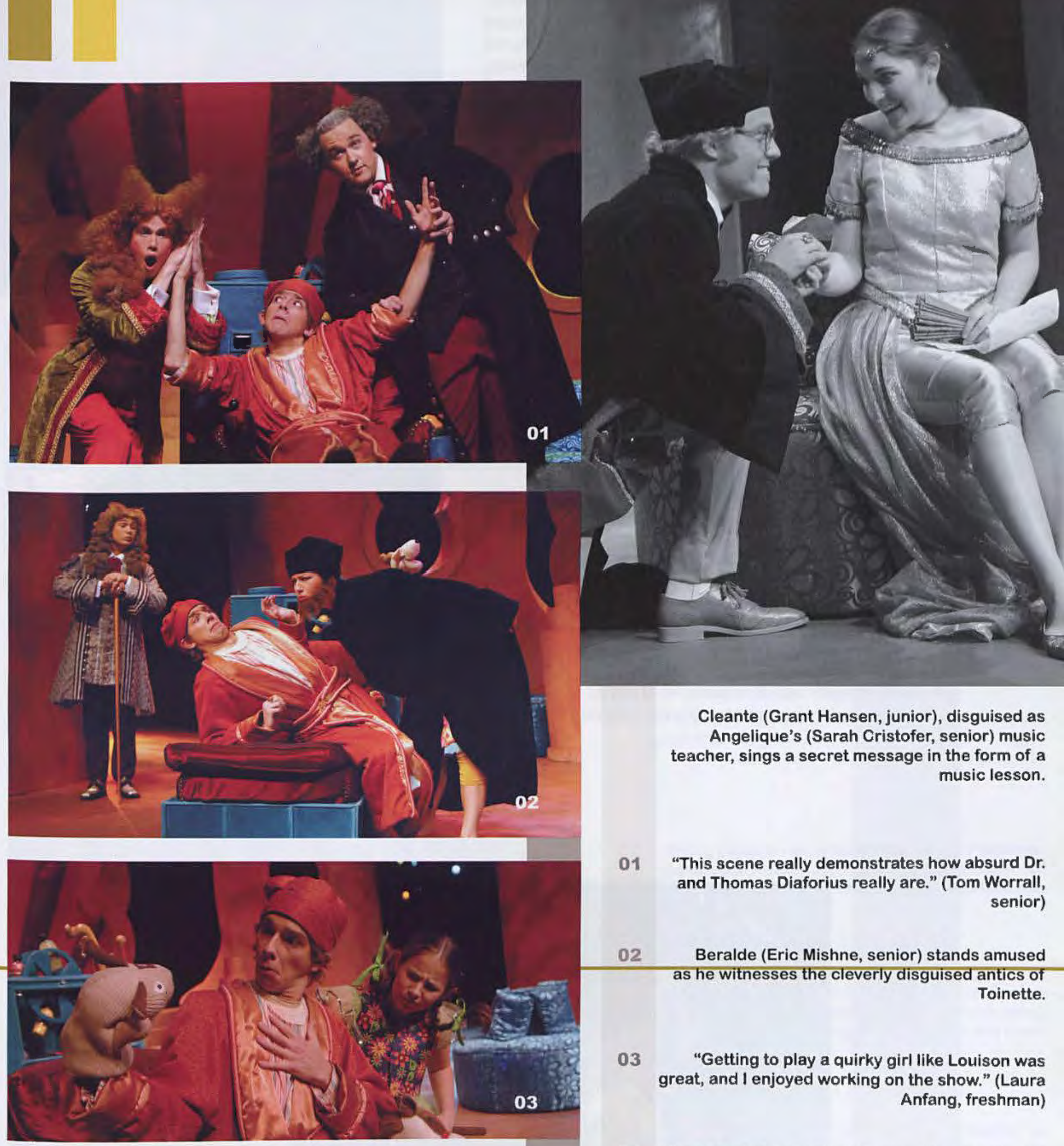

Cleante (Grant Hansen, junior), disguised as

Angelique's (Sarah Cristofer, senior) music teacher, sings a secret message in the form of a music lesson.

\section{and Thomas Diaforius really are." (Tom Worrall, and Thomas Diaforius really are." (Tom Worrall,
senior) \\ Beralde (Eric Mishne, senior) stands amused as he witnesses the cleverly disguised antics of Toinette.}

"Getting to play a quirky girl like Louison was great, and I enjoyed working on the show." (Laura Anfang, freshman)

04 When asked to describe the play, Director Donald N.C. Jones says, "Vive Moliere!" Here he is with the cast and crew of The Imaginary Invalid.

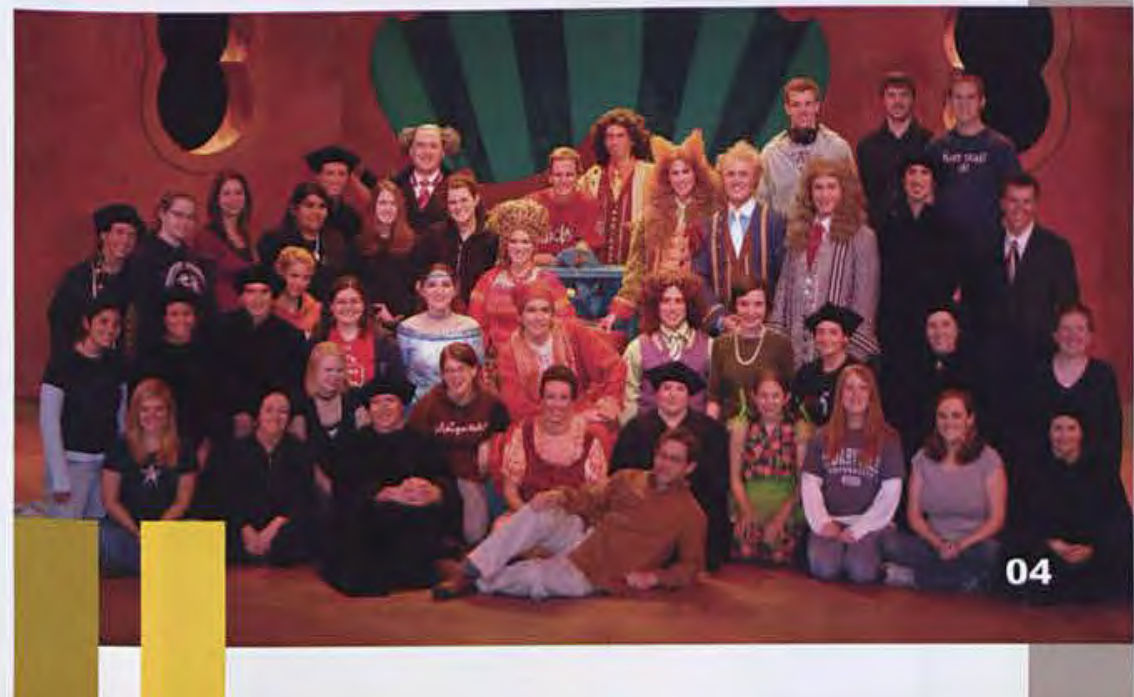


Several CU events this Fall were traditional favorites: Moonlight Madness, Dorm Wars, New Student Talent Show, and the Day of Prayer all returned in full force this year, but not without a few improvements to keep it fresh. Moonlight Madness, in addition to the always popular Slam Dunk Contest and scrimmages, included an option for fans to purchase pink "Cedarville Basketball" T-Shirts to raise money to find a cure for breast cancer.

Dorm Wars, in its second consecutive year, grew in popularity. By the end of a war-waged week, Maddox upset Lawlor's confidence even though it was thought "Lawlor has the best chance of winning... since we have sooo much dorm pride..." according to junior RA Mike Angle. Bold and confident in the forthcoming Maddox victory, senior RA Elyse Fye and her girls said, "We had no idea Lawlor was even in the running..."

Also sticking with a strong formula, the New Student Talent Show delighted audiences once again with impressive singing, acrobatics, comedy, and drama. Freshman Zach Sanderson enjoyed winner Negative 1 's powerful drama because "it did a good job of having a realistic redemption theme."

The Day of Prayer observed the cultural movements of the school year and integrated it into the day's activities. The unique motif allowed students to "experience the power that prayer can have, and...encourage students to build prayer into a part of their daily life." (Allison Jones, junior) This sparked such social outreach activites as the Jena 6 prayer vigil and the Fast for Food event. The biggest surprise, however, came at the conclusion of the season with the arrival of the Oscar Mayer weinermobile, in front of which numerous students posed for photos and met with friends.
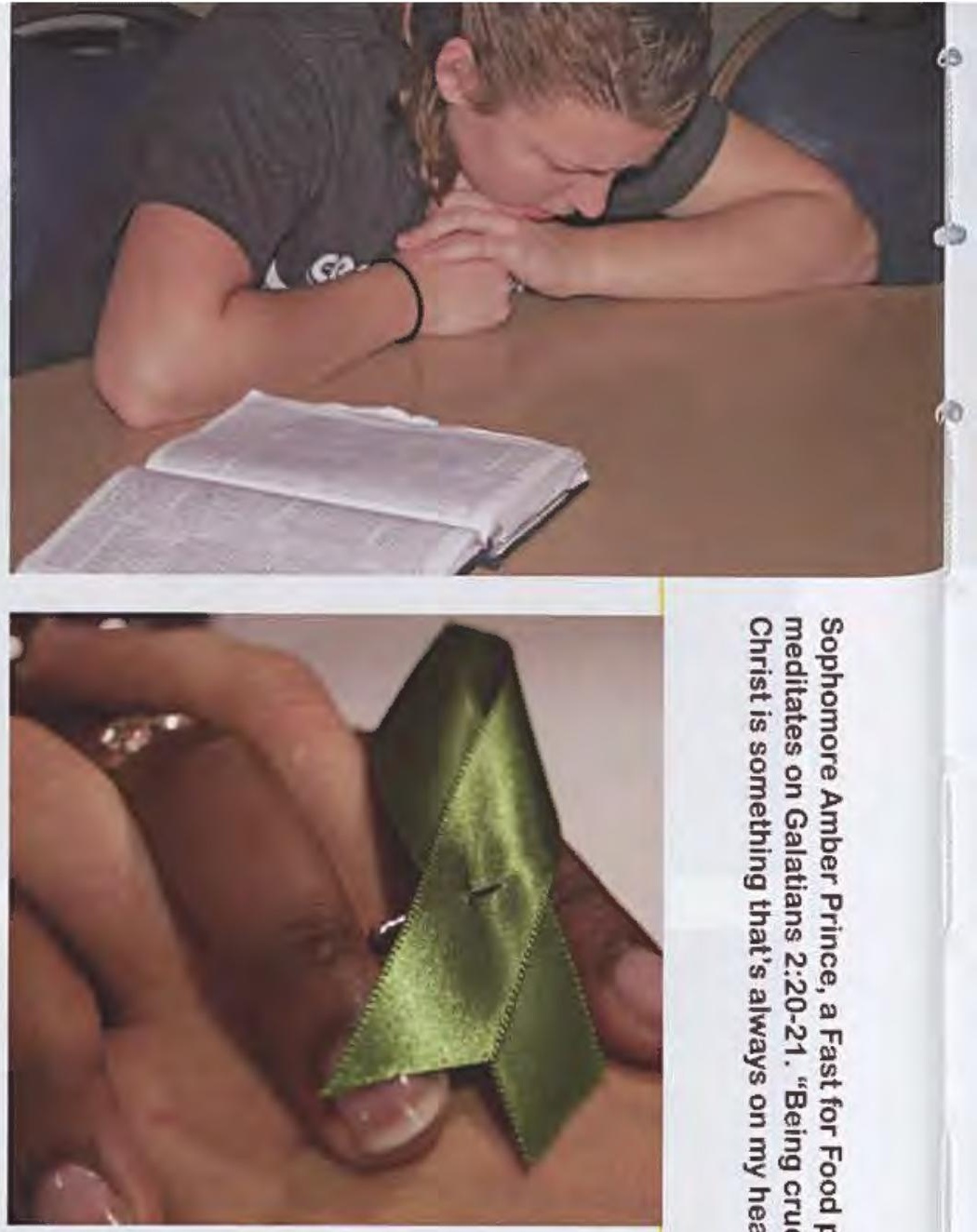

The P.E.A.C.E. project distributed green ribbons "because they represented growth and overcoming hate." (Jen Mukes, sophomore member)

Moonlight Madness consistently draws crowds and serves as an excellent springboard for the season. Freshman Jackets Forward Adam Riehle launches over freshman Chris Heading in the Slam Dunk Contest.

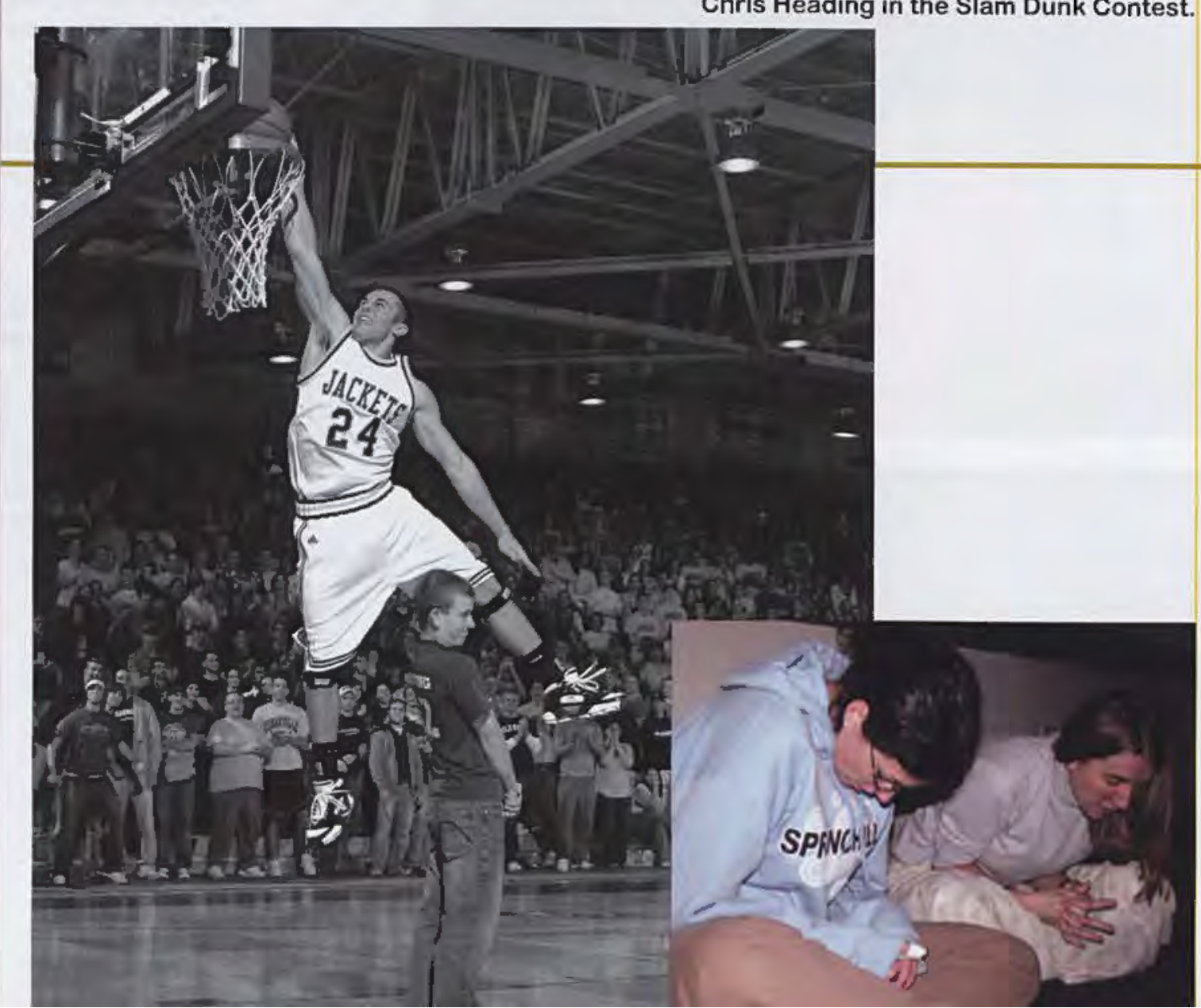



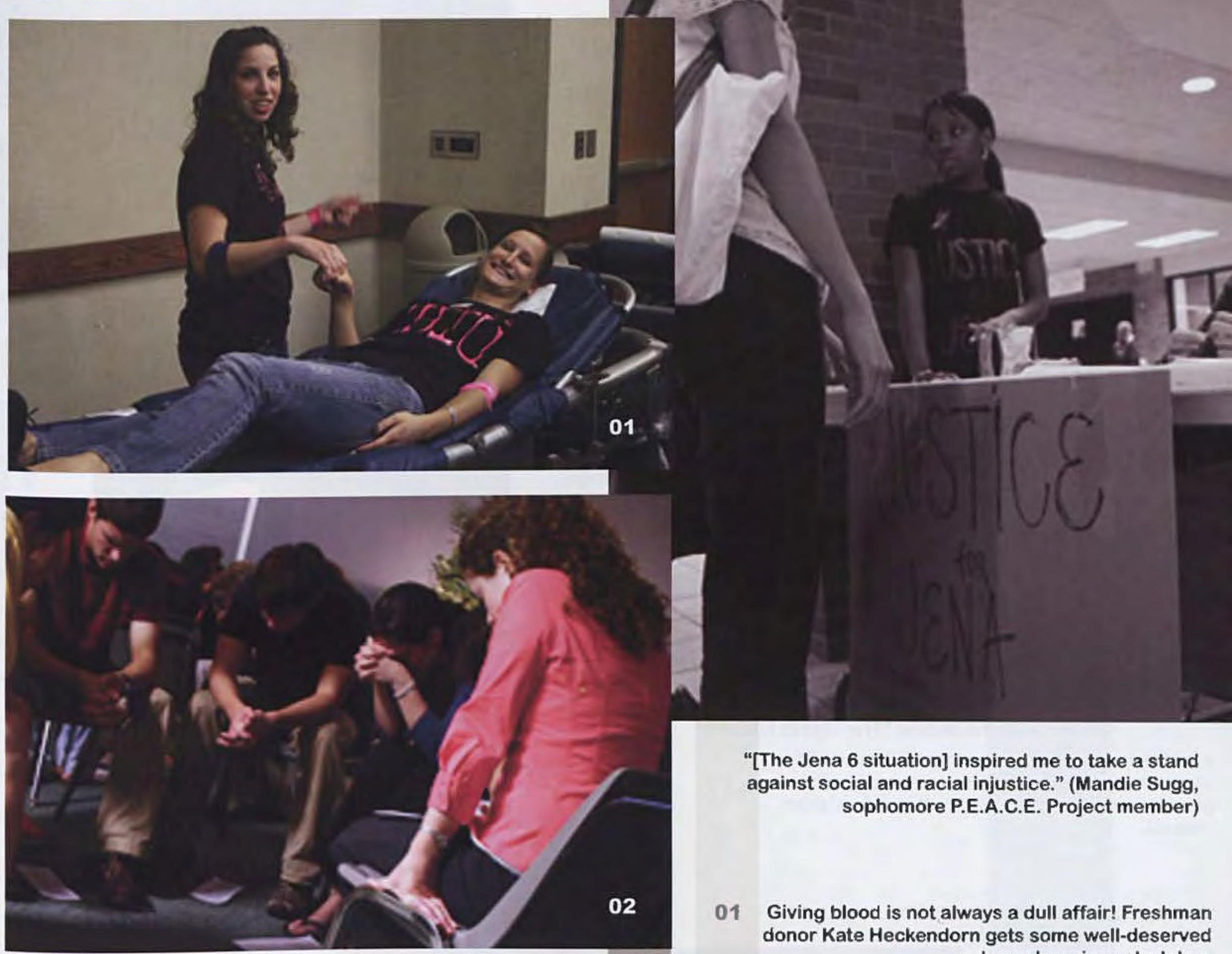

"[The Jena 6 situation] inspired me to take a stand against social and racial injustice." (Mandie Sugg, sophomore P.E.A.C.E. Project member)

01 Giving blood is not always a dull affair! Freshman donor Kate Heckendorn gets some well-deserved rest on a luxurious stretcher.
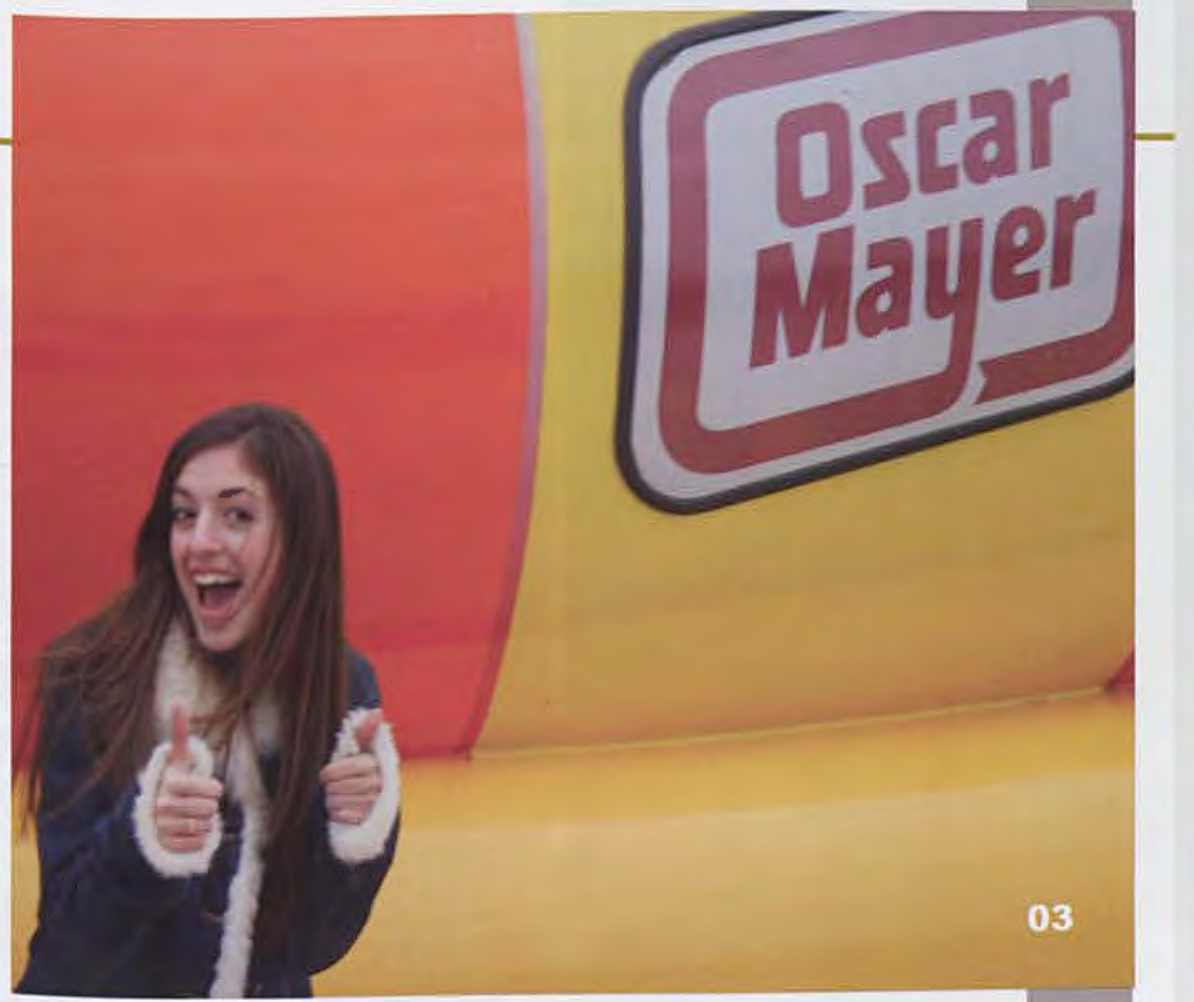

02

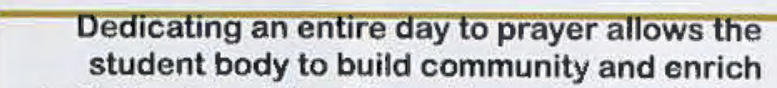
individuals' spiritual lives. Here, students bring anonymous needs to the Lord.

The Oscar Mayer weinermobile attracted so much attention that even siblings of students wanted their picture in front of the famed bus. Here, freshman Kate Roberts' little sister gets a shot with the hot dog. 
When Thanksgiving dinner came to Chuck's, students, faculty/staff members and families from the community lined up for "home-cookin" that launched the campus into the holiday spirit.

The weekend after Thanksgiving break, Cedarville's resident halls opened their doors for the annual Christmas Open Dorms, an event which showed the creativity and spirit of Cedarville students. In Willetts, a hall jokingly declared their hall "All I want for Christmas is my MRS. degree." In Lawlor and in Maddox, visitors could walk through Santa's workshop. The winning halls were announced the following weekend at Campus Christmas. Faith's "Christmas dinner goes through the digestive system" hall won overall for the women's dorms. McChesney Upper Middle's "Aborigine Christmas" won the grand prize for the men on campus.

SCAB (The Students Center Activities Board) pulled off a bigger, brighter, bolder Campus Christmas than in years past. "We decided to try something new for Campus Christmas this year with a student-led Christmas concert and movie in the DMC." (Jennifer Flynn, senior SCAB member) "[Planning] was kind of a challenge, because we were trying to make something attractive and new...I think it came out to be a success... it also left a lot more options open for the next years, because we did something different..." (Micah Chamber, senior SCAB member)

The event began with a time of pictures with Santa, also known as Larry Reid, and refreshments. After student bands played our favorite Christmas tunes, Dr. Brown read Christmas stories to the students, and the night ended with the movie "The Santa Clause."

\section{relocated}
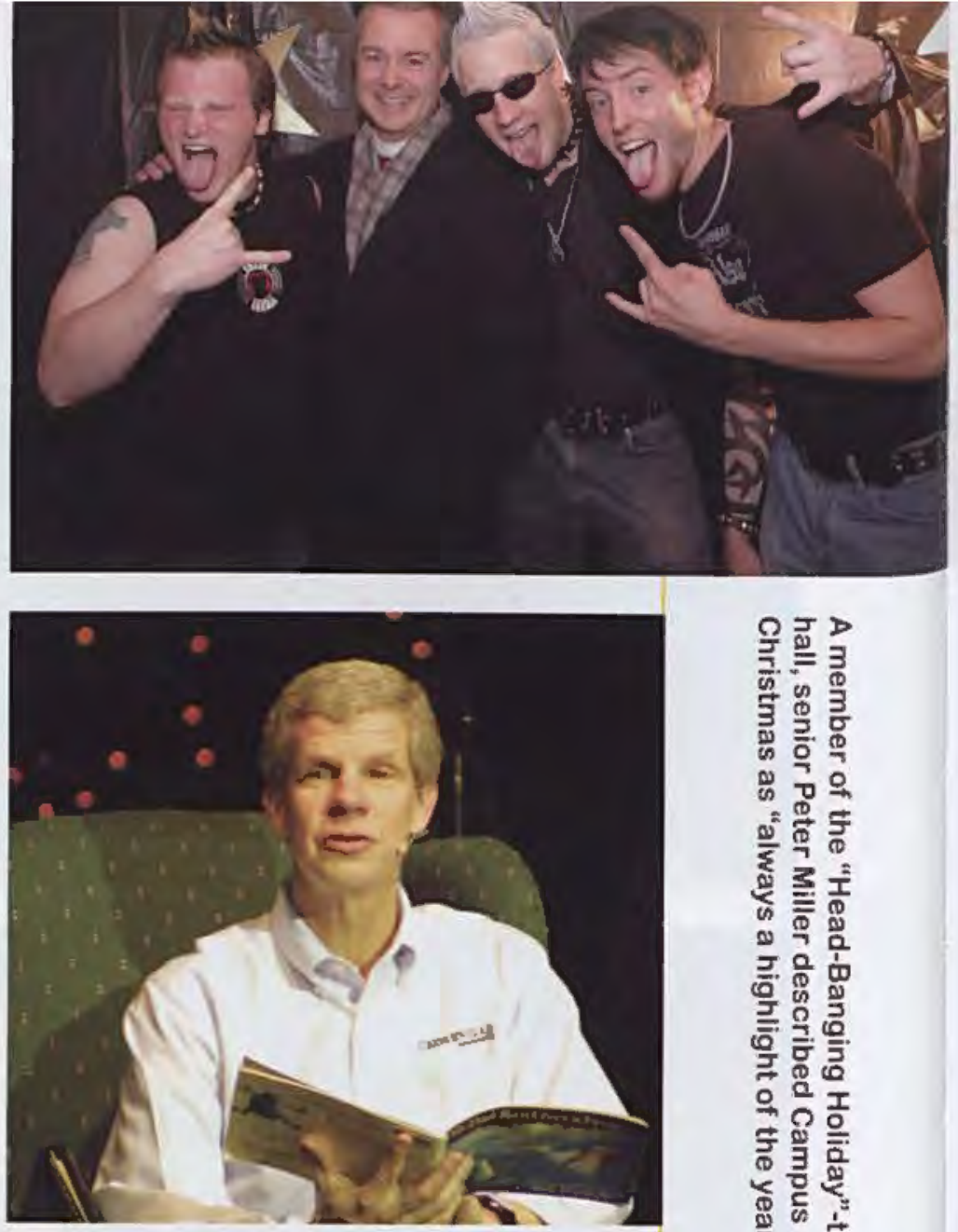

New this Christmas, Dr. Brown's story time was do the Jeremiah Chapel. Here, Dr. Brown reads "My Dad Ran Over a Frog."

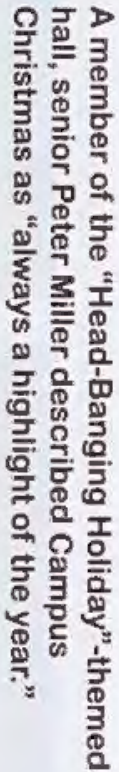

"Our theme was 'Christmas at the North Pole.' I was standing in our unit lounge, next to a polar bear and the North Pole. I was an eskimo." (Stefan Martello, sophomore)

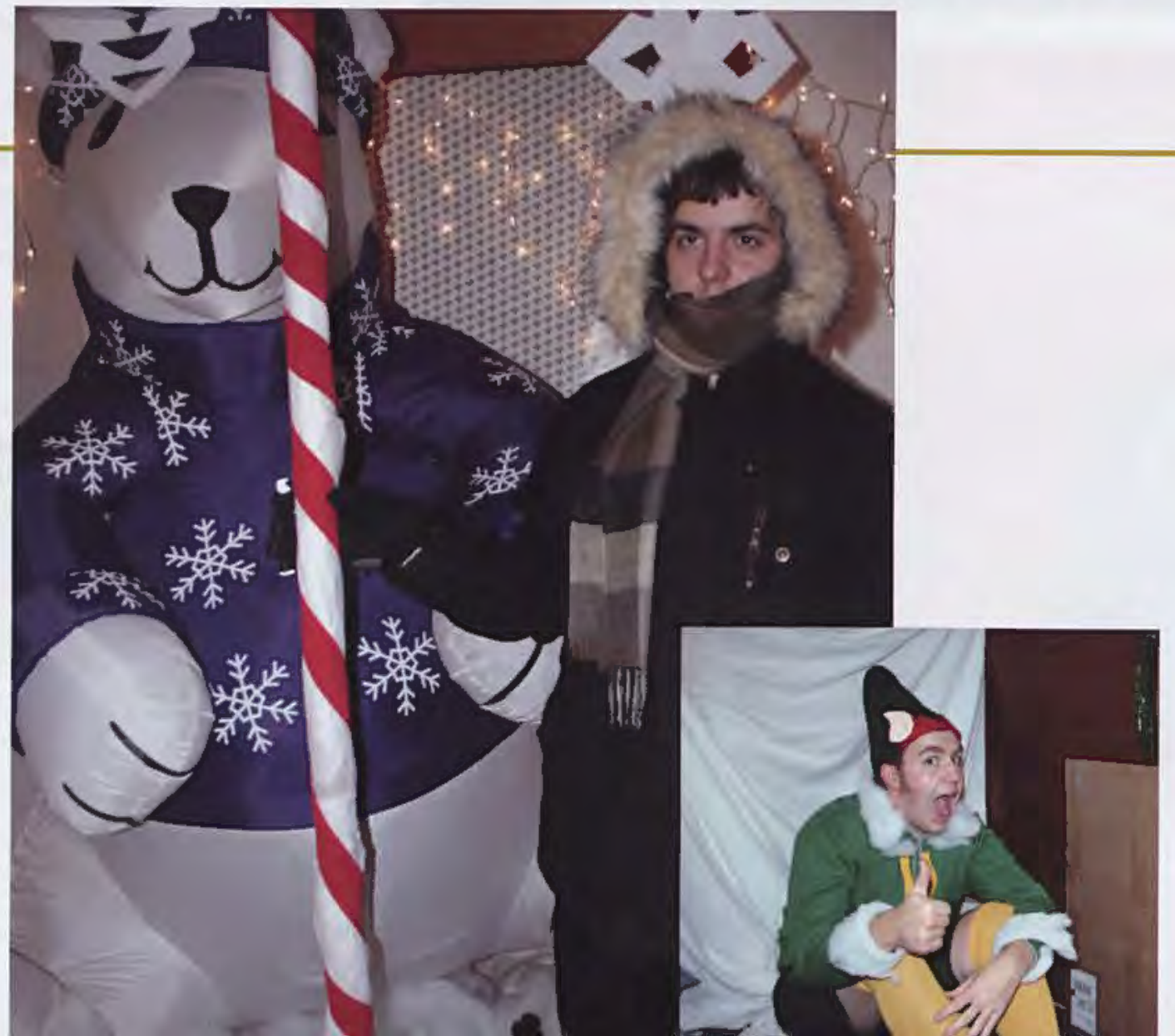




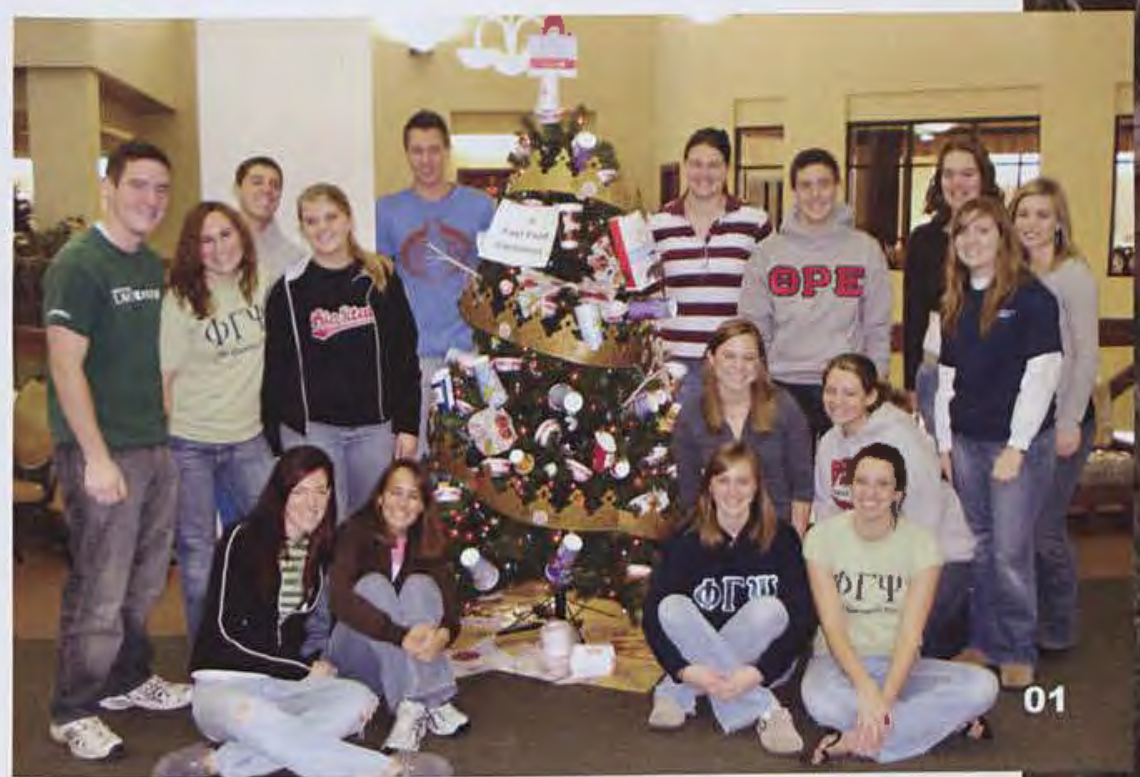

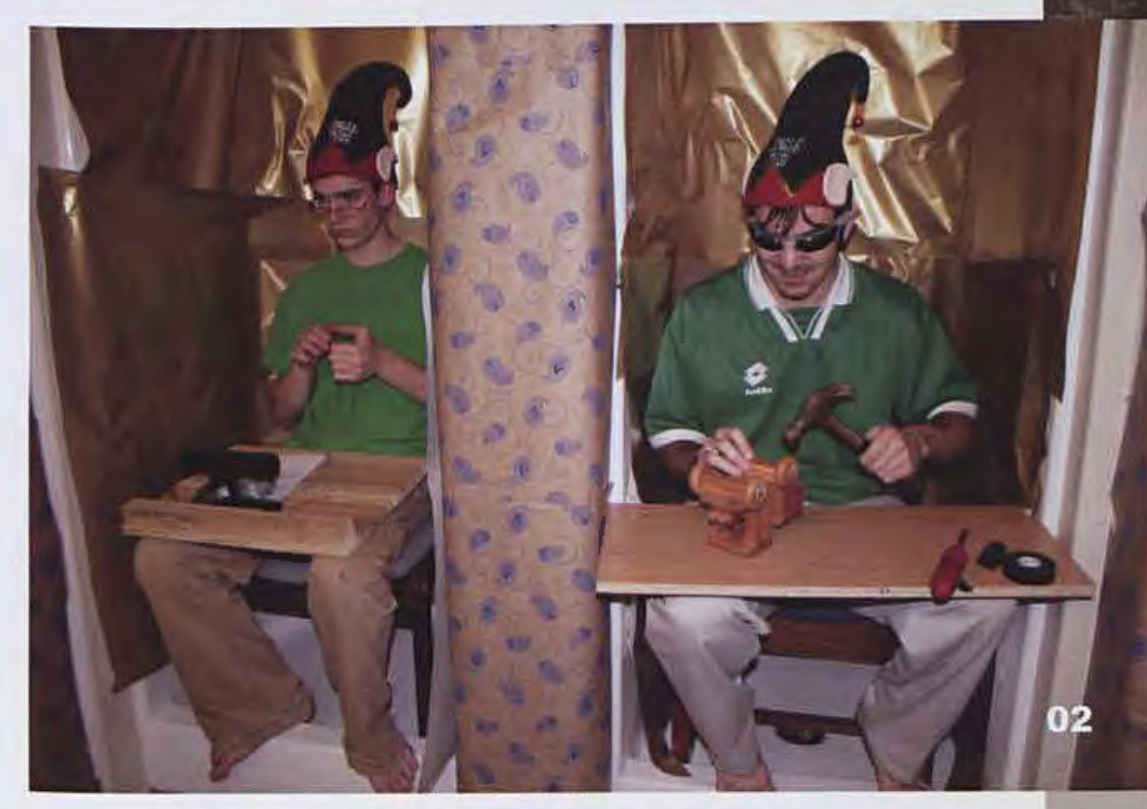
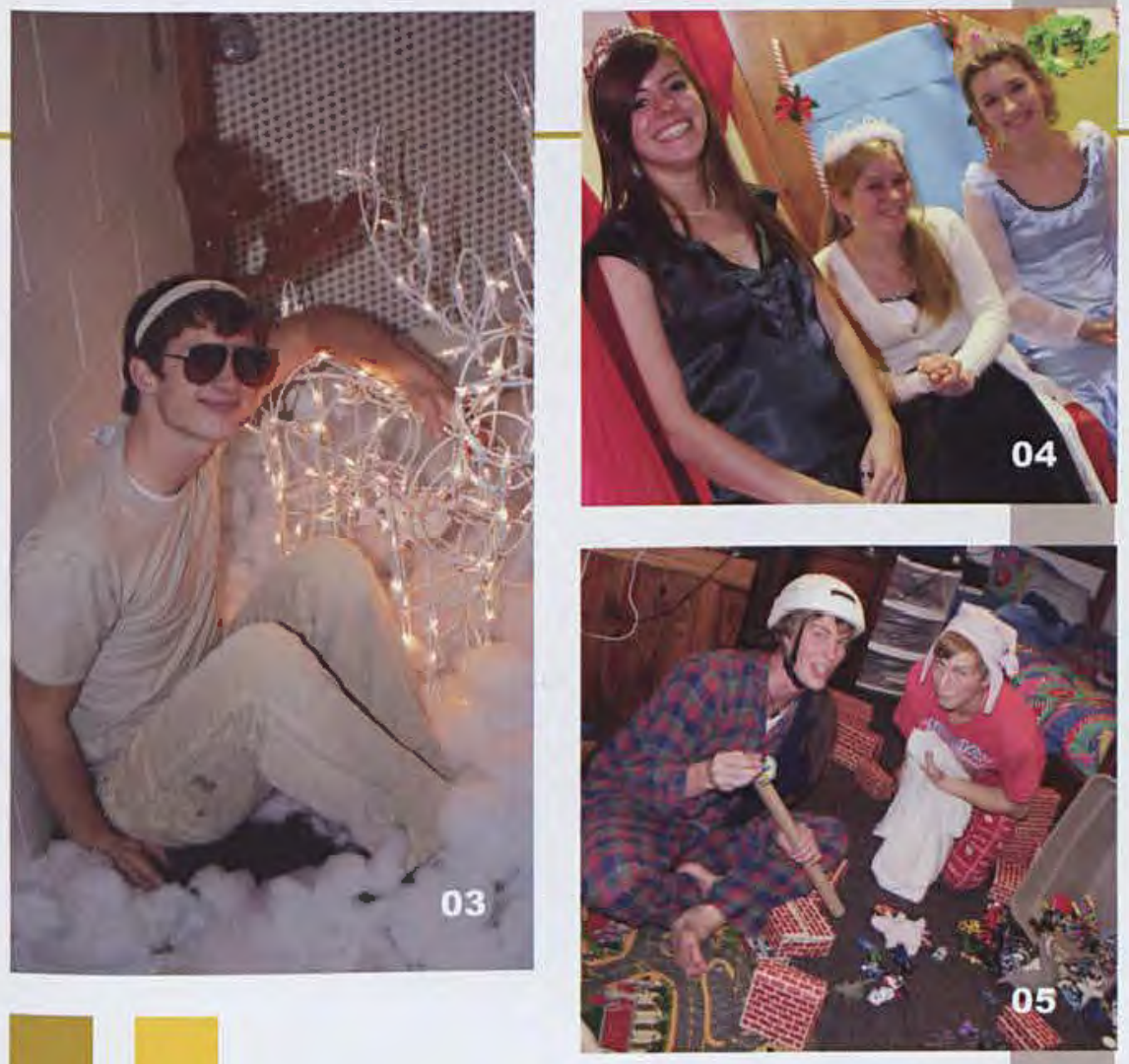

02

01

Members of OPE and PGP pose in front of their contest-winning tree, entitled "A Fast Food Christmas."

"Campus Christmas is one of the festive times of the year because all the campus community mingles. I love that." (Senior Kate Klein, playing Joseph)

\section{(1)}

03

Campus Christmas is a pair of reindeer antlers.

04 Three Printy princesses, freshmen Erin Crawford, Alicia McMaster, and Emily Klimek welcome students to their unit.

05 "Being a part of our unit's work was fun and a growing experience for the relationships between us." (Mikey Mazzola, sophomore) 


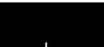

!

$\sqrt{4}$
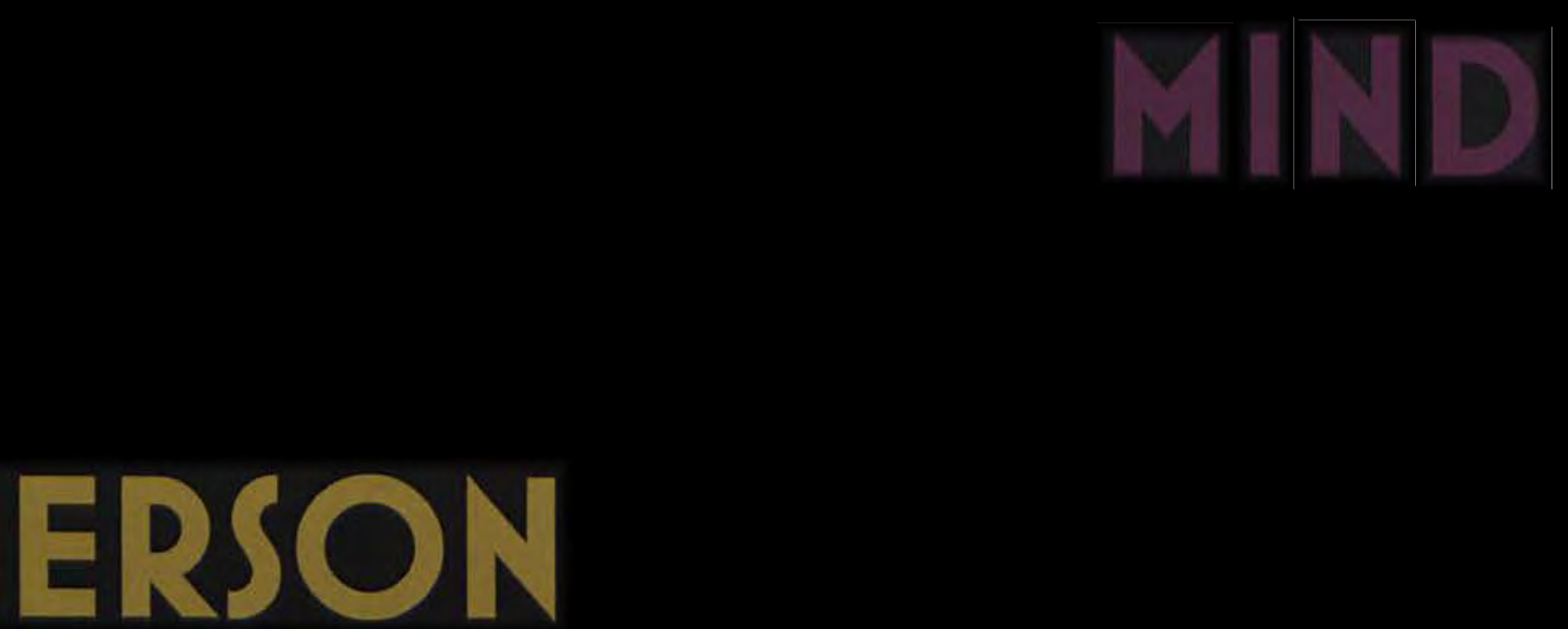

- EMERSON 


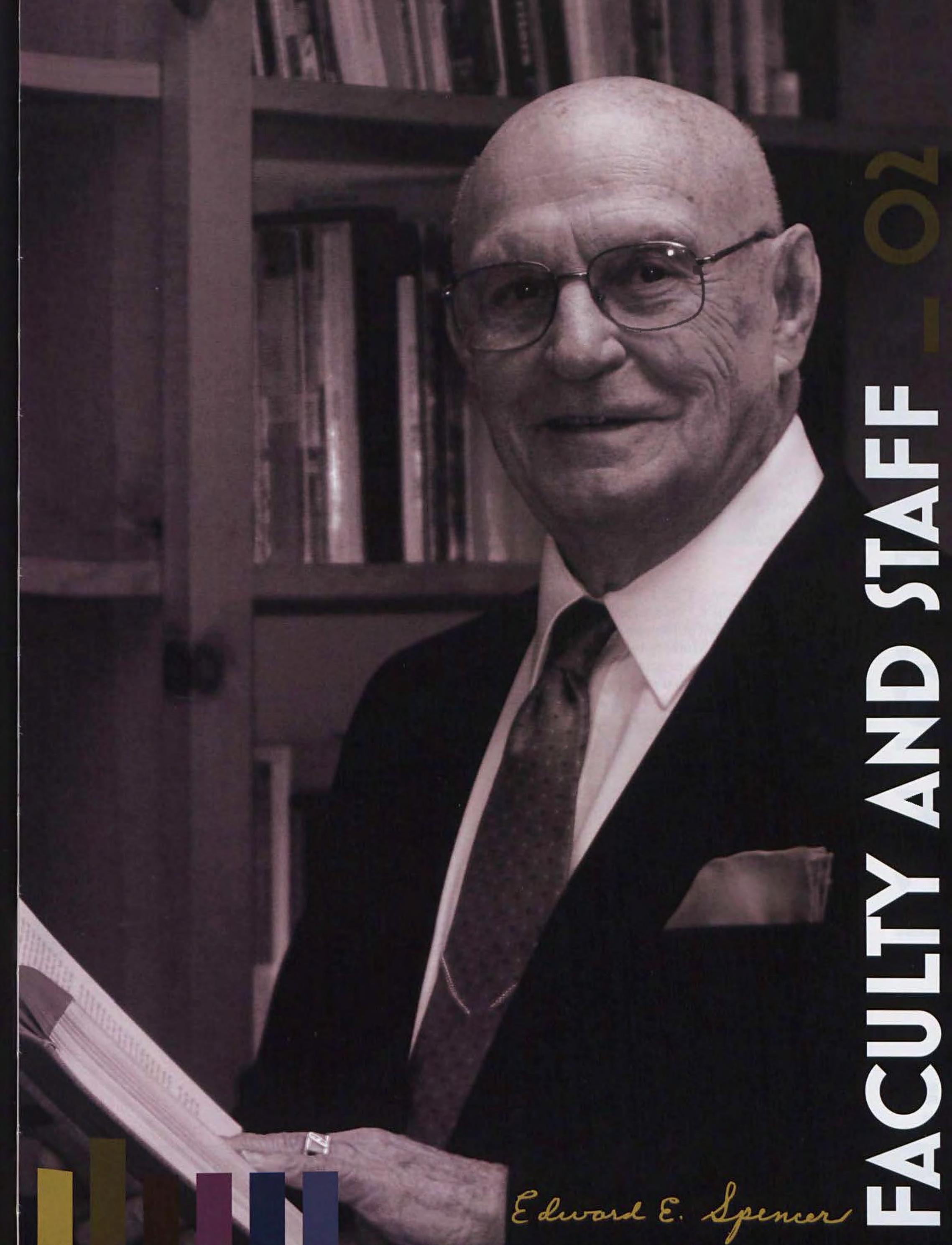


The 2007-2008 year at Cedarville University has been incredible. I will remember with fondness the enthusiastic and positive spirit of the student body. I do not think I have ever experienced such an upbeat year. Many thanks to all of you who chose to keep your eyes on our Lord and lift up those around you.

It has been exciting to see the construction of the Center for Biblical \& Theological Studies. Those of you who are of the class of 2008, of course, I know are disappointed that the CBTS will not be a part of your college experience (except you had to walk around the fence everyday!). God's faithfulness to Cedarville University in providing such an outstanding facility is a reminder of His intention to use us for His glory in this world.

Our theme this year, "God's Word: Timeless Truth for a Changing Culture," has provided us with great opportunity to recommit ourselves to what is important. I hope that Cedarville University 2007-2008 will be a reminder to all of us how crucial God's Word is in our lives wherever He may lead us.

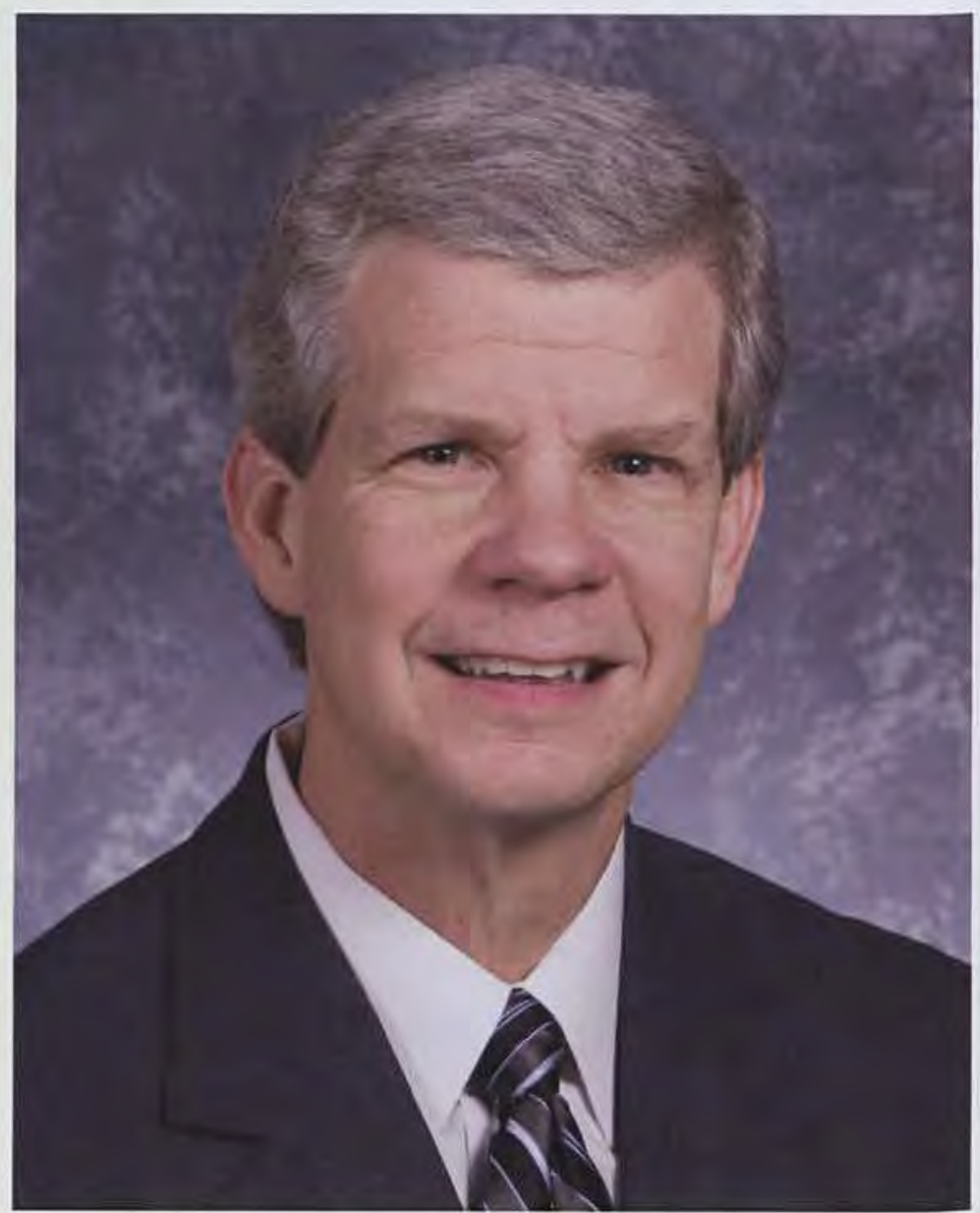

Dr. William Brown

President 
Mr. John Anglea

Vice President of Business
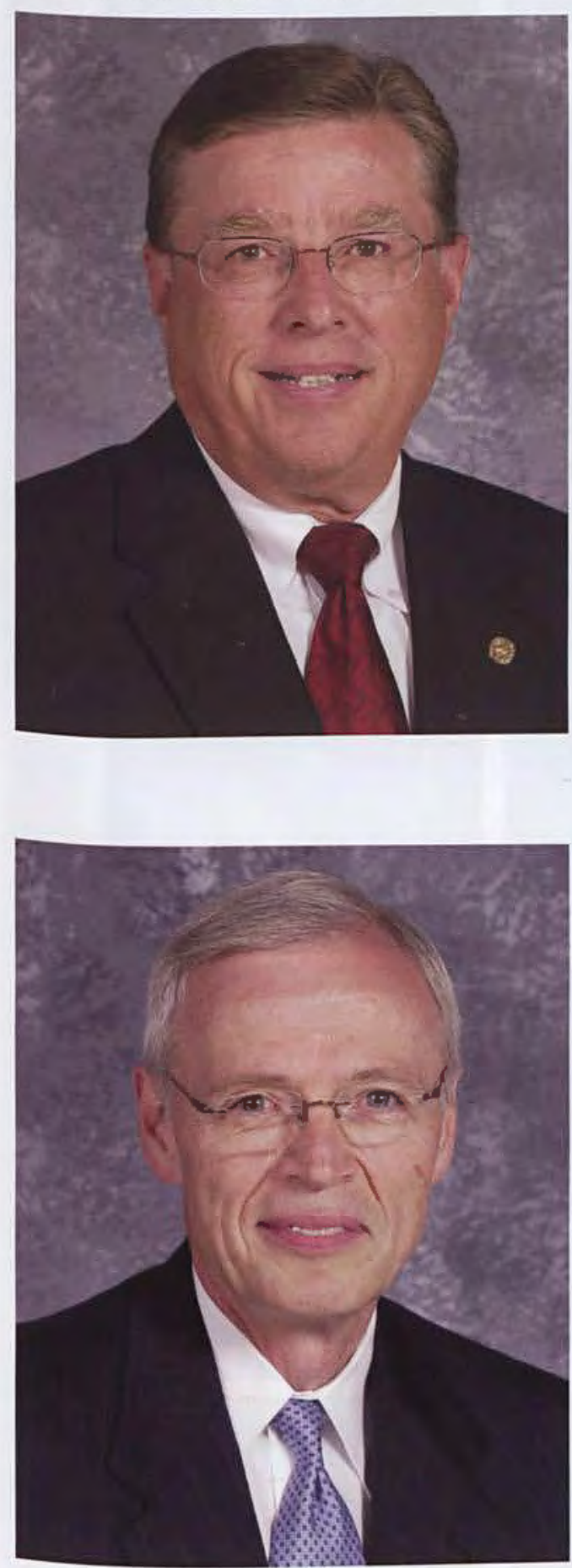

Mr. Robert Rohm

Vice President of Christian Ministries
Mr. John Gredy

Vice President of Enrollment Management
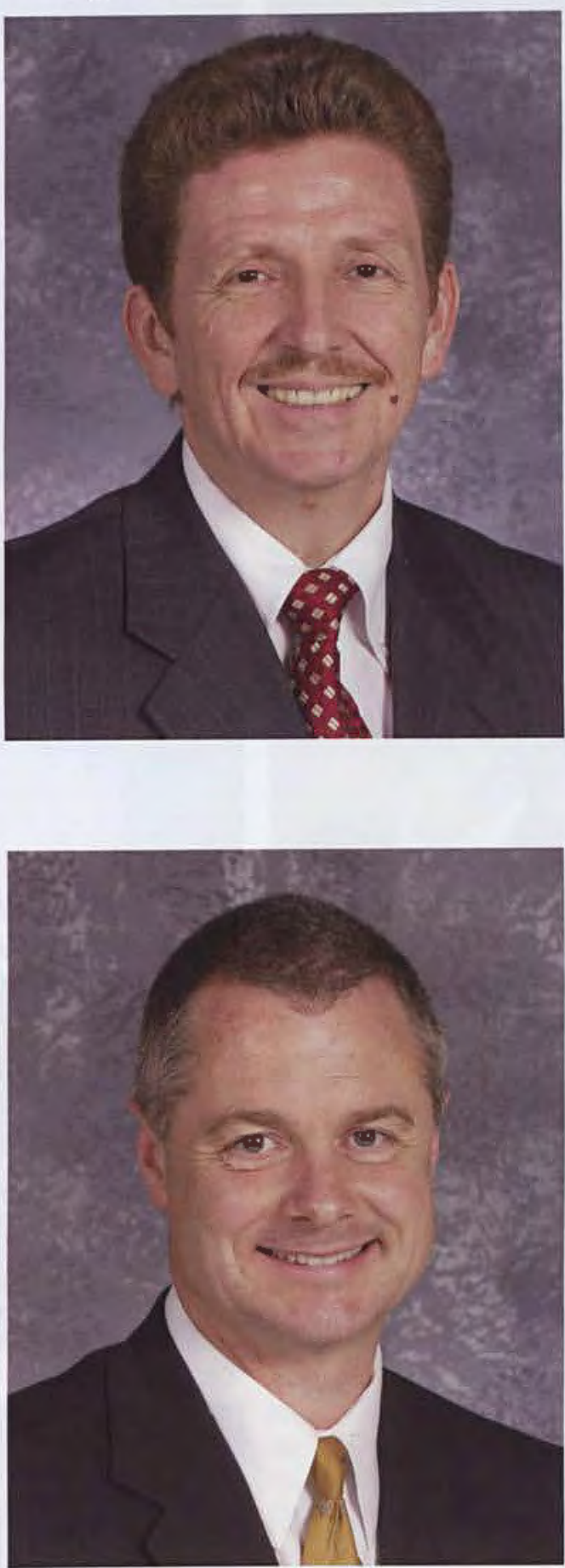

Dr. Carl Ruby

Vice President of Student Life
Dr. Robert Milliman

Academic Vice President

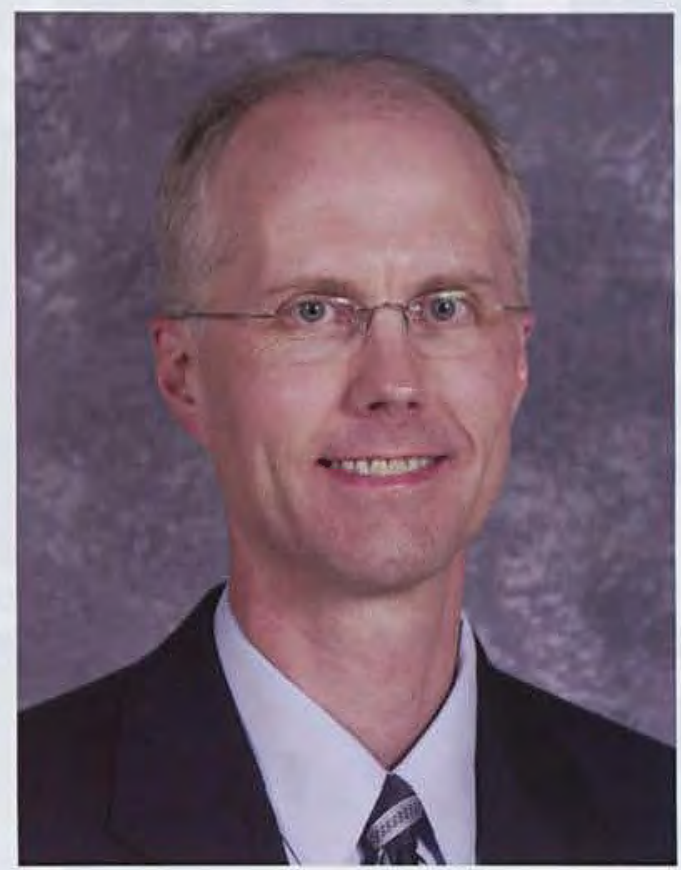

NOT PICTURED:

Mr. Ron Harris

Interim Vice President of Advancement 


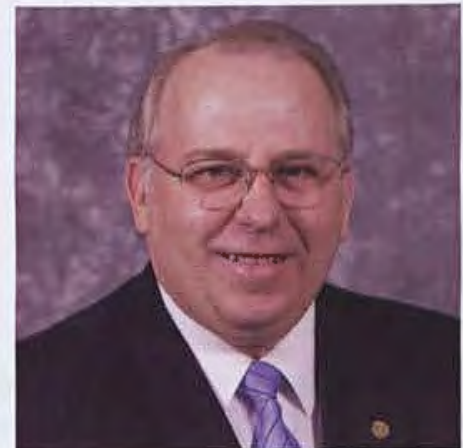

Rev. Randy Patten

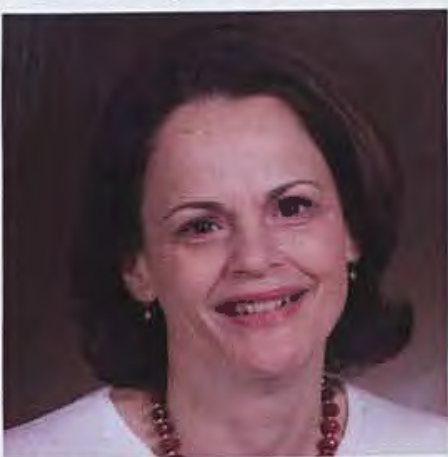

Mrs. Debby Stephens

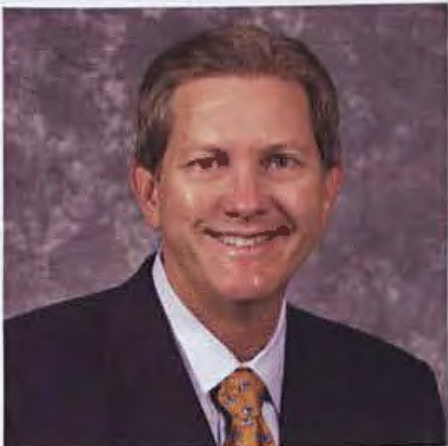

Dr. Hayes Wicker

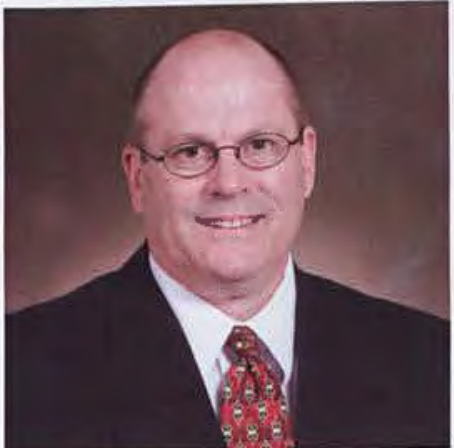

Mr. William Williams

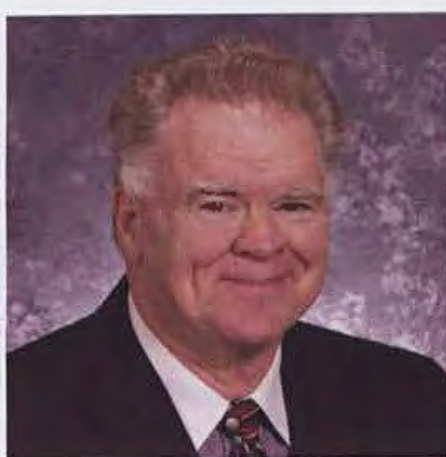

Dr. Paige Patterson

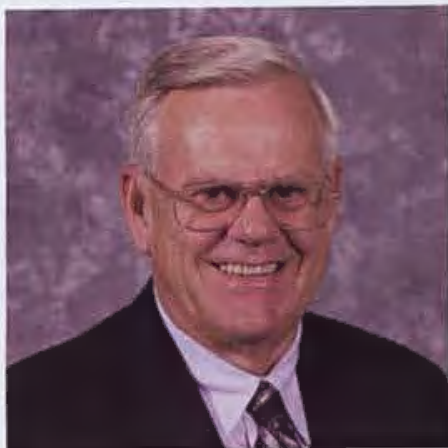

Mr. Albert Stevens

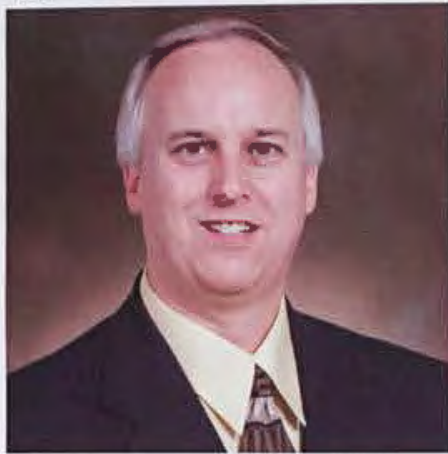

Rev. Jeffory Willetts

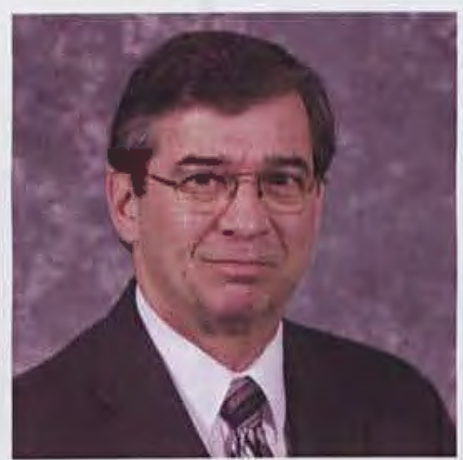

Dr. William Rudd

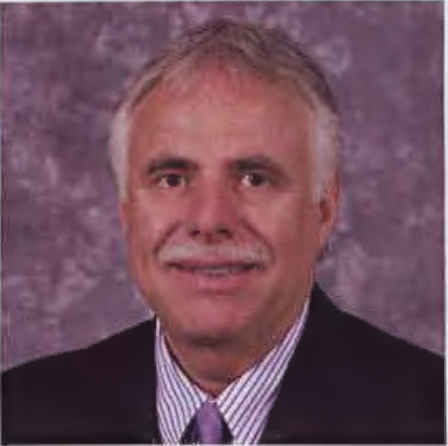

Hon. Robert R. Thomas

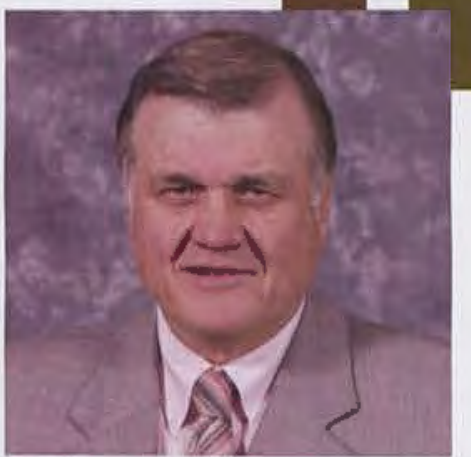

Mr. Lorne Scharnberg

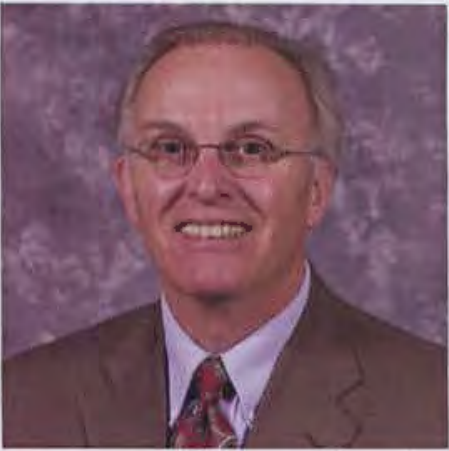

Dr. W. David Warren

NOT PICTURED:

Dr. Eugene Apple

Mr. Francis Bresson

Mr. Gil Brueckner

Mr. James Carraher

Dr. Jack Cline

Mr. John Draxler

Rev. Joseph Godwin

Mr. Roy Guenin

Dr. E.L. Hawkins

Mr. C.E. Gene Miller

Rev. Irwin Olson

Rev. Lynn Rogers

Mr. Bill Smith

Dr. Robert Sumner

Dr. Paul Vernier

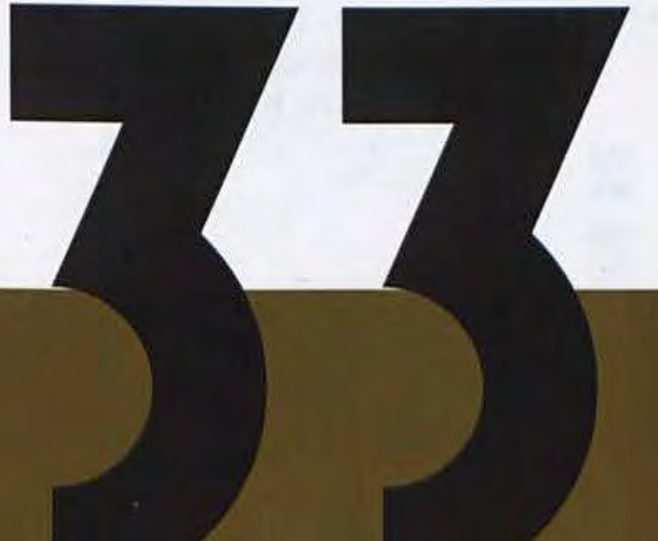




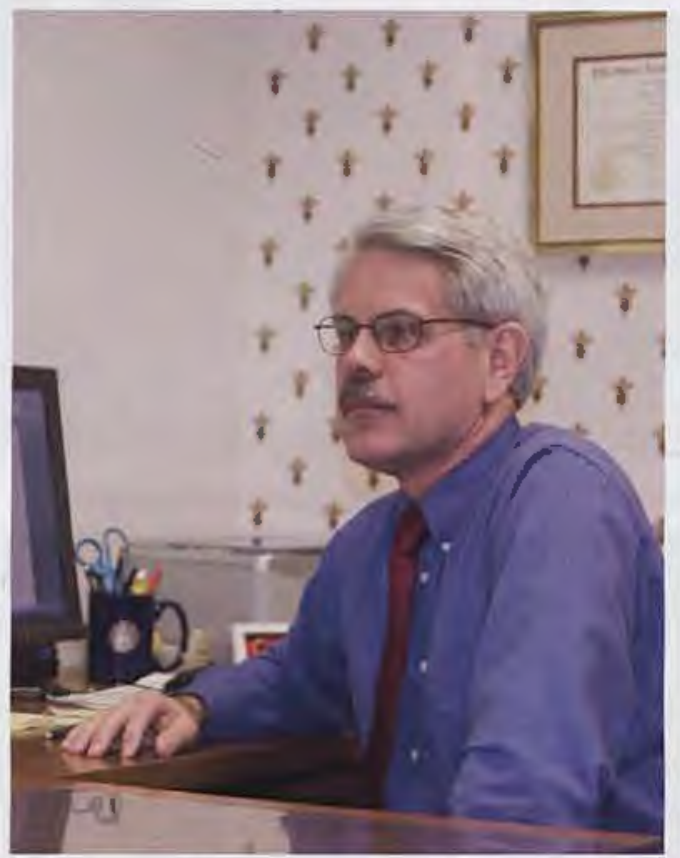

Dr. Steven Winteregg Dean

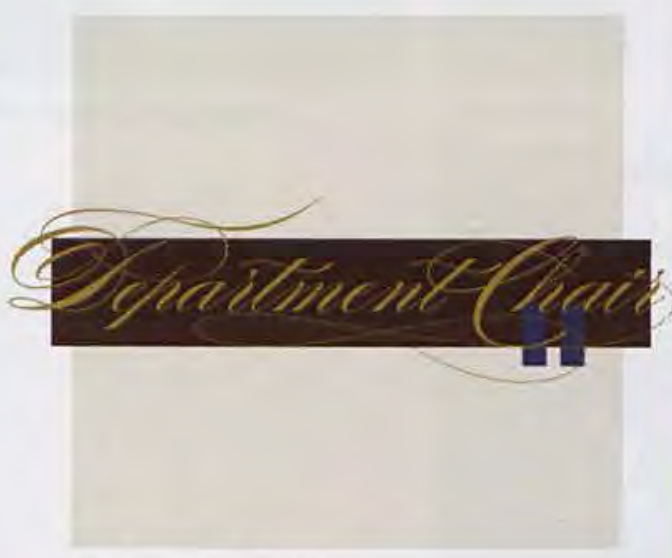

Dr. Charles Elliot

\section{NOT PICTURED:}

Mrs. Rebecca Baker

Dr. Wes Baker

Mr. Robert Clements

Mr. Derrick Green

Dr. Deborah Haffey

Mr. James Kragel

Mr. James Leightenheimer

Dr. Michael Lopez

Dr. Diane Merchant

Mr. Matthew Moore

Mrs. Margaret Wheeler

In July of 2007, the department of History \& Government joined with the departments of Communication Arts, Language \& Literature, and Music \& Art to form the School of Humanities. The school has seen a fine record of student achievement during the 2007-08 academic year. Besides the continued success of our Debate and Forensics teams, students taking the LSAT exams for law school scored in the top $6 \%$ in the country; two of our students took three first place awards in the 2008 Intercollegiate National Religious Broadcasters competition; five members of CU's chapter of Sigma Tau Delta, the International English Honor Society, had papers selected by peer review for presentation at this year's annual national conference; the Women's Choir performed at the Ohio Music Education Conference; and the Intercollegiate Model UN team returned home with many awards. The School of Humanities presented numerous plays, concerts, recitals, art shows and guest lecturers as well as sponsored significant campus events such as the Language Arts Educator's Conference and a performance of the Easter portion of Handel's Messiah.

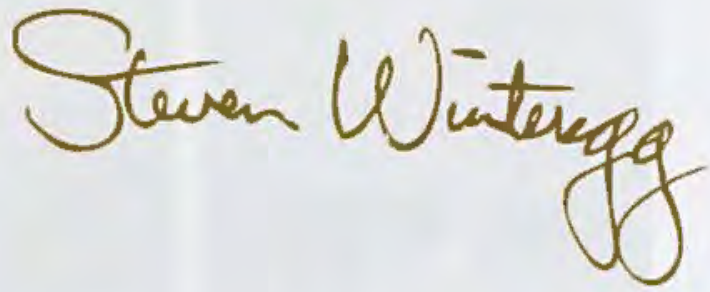

\section{DEPARTMENT OF COMMUNICATION ARTS}

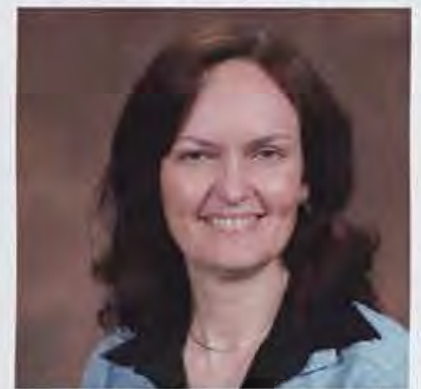

Mrs. Mischelle Mclntosh Assistant Professor

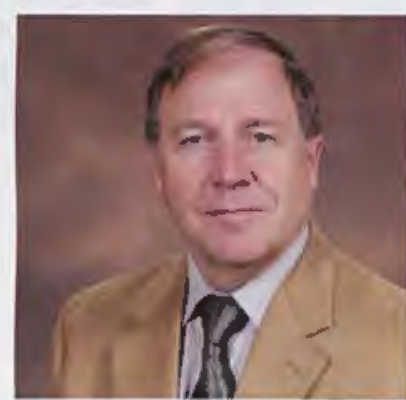

Dr. James Phipps Professor

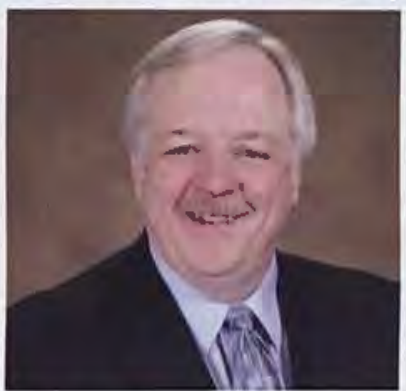

Mr. Kurt D. Moreland Associate Professor

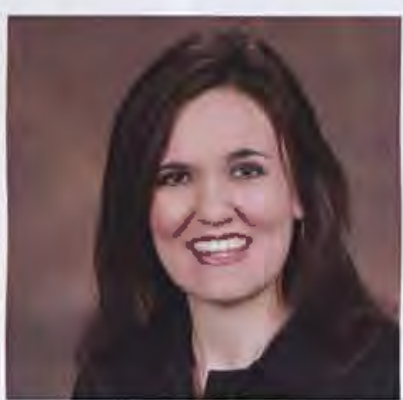

Dr. Rebecca Sietman Assistant Professor 


\section{DEPARTMENT OF HISTORY \& GOVERNMENT}

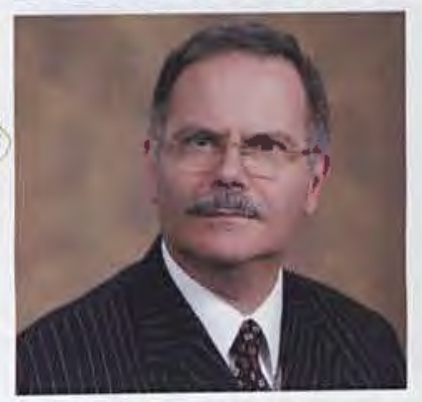

Dr. Kevin Sims

Professor

NOT PICTURED:

Dr. Marc Clauson

Dr. Frank Jenista

Dr. Thomas Mach

Dr. David Meyer

Dr. Murray Murdoch

Dr. Mark Smith

Dr. David Rich

Interim Chair

\section{DEPARTMENT OF LANGUAGE \& LITERATURE}

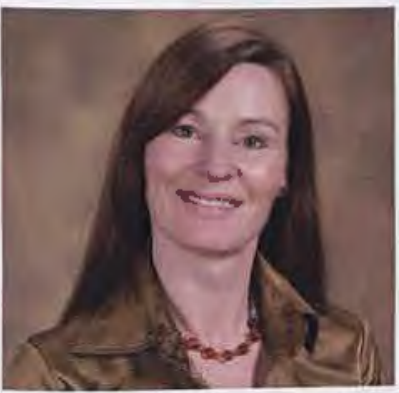

Ms. Melissa Faulkner Assistant Professor

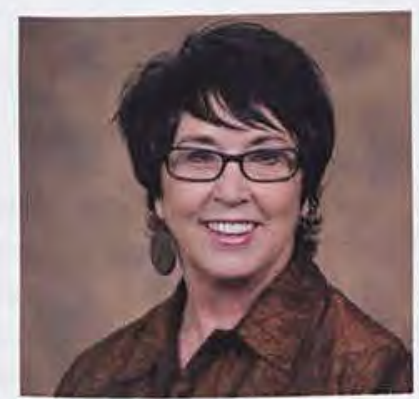

Mrs. Sandra Harner Professor

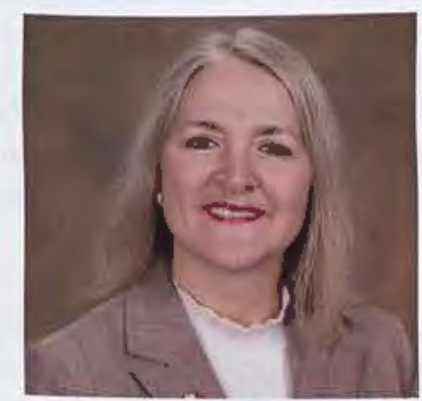

Dr. Annis N. Shaver Assistant Professor

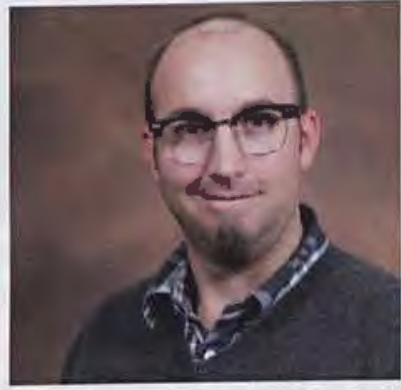

Mr. Ryan Futrell Assistant Professor

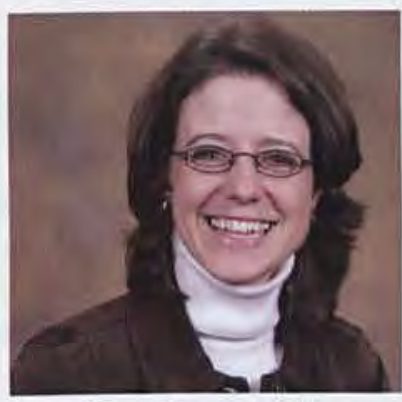

Mrs. Shannah Hogue Associate Professor

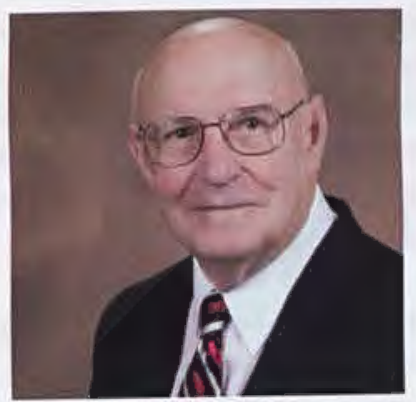

Mr. Edward Spencer Professor

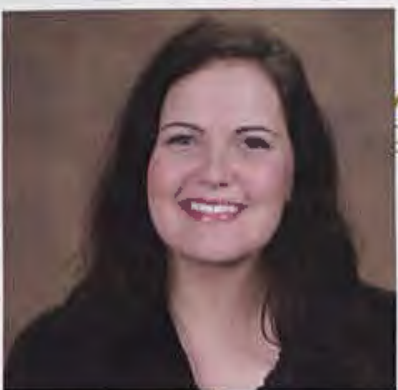

Ms. Helena "Nellie" Haack Assistant Professor

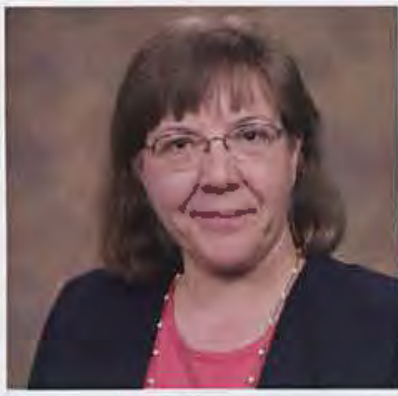

Dr. Barbara Loach Professor

NOT PICTURED:

Mr. Greg Belliveau Dr. Scott Calhoun Mr. Daniel Clark Mrs. Donald Deardoff

Mrs. Julie Moore

Mrs. Karen Power Dr. Peggy Wilfong Dr. Andrew Wiseman Mrs. Michelle Wood

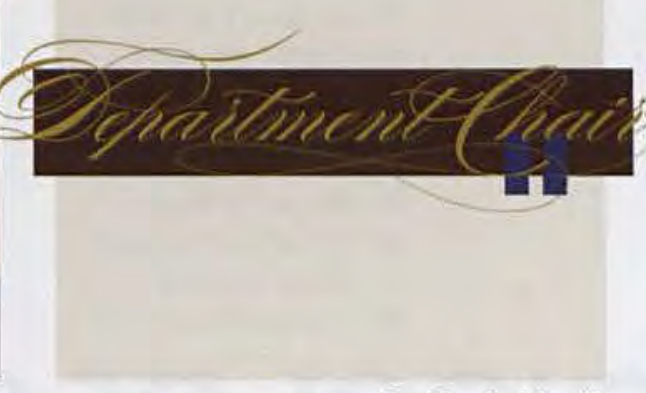

Dr. Kevin Heath

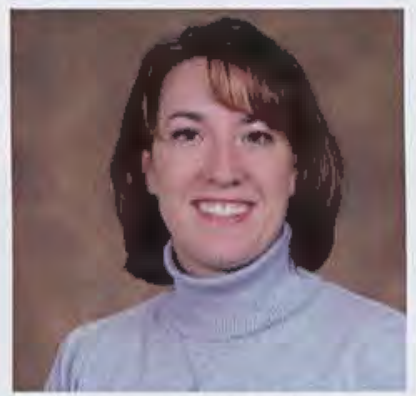

Mrs. Cynthia Messer Assistant Professor

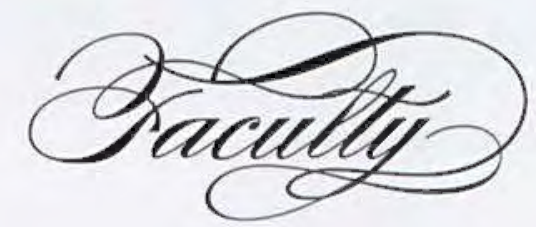




\section{DEPARTMENT OF MUSIC \& ART}

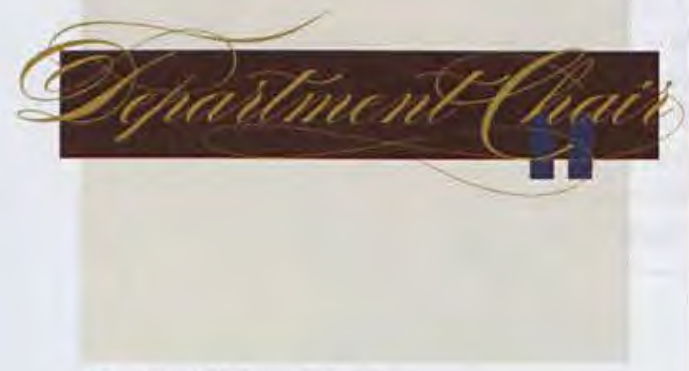

Ms. Beth Cram Porter Interim Chair

NOT PICTURED:

Mrs. Connie Anderson

Dr. Lyle Anderson

Mr. Terry Chamberlain

Dr. Bruce Curlette

Mrs. Laura Ferranti

Dr. Taylor Ferranti

Mr. Timothy Frame

Mr. Jun Kim

Dr. John Mortensen

Dr. Roger O'Neel

Mr. Charles Pagnard

Dr. Mark Spencer

Mr. Daniel Sternsher

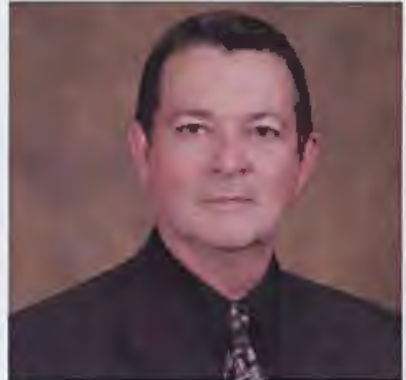

Dr. Charles Clevenger Professor

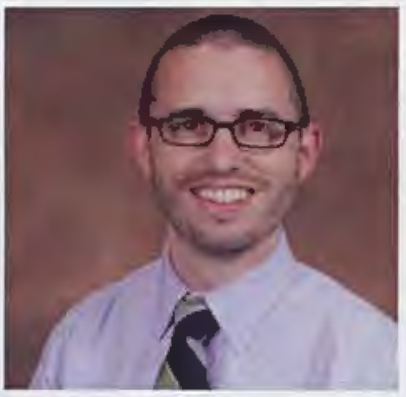

Mr. Aaron Gosser Instructor

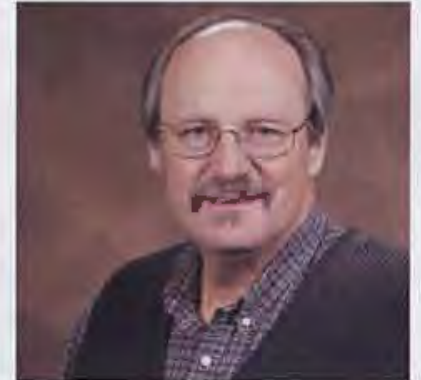

Mr. Michael DiCuirci Professor

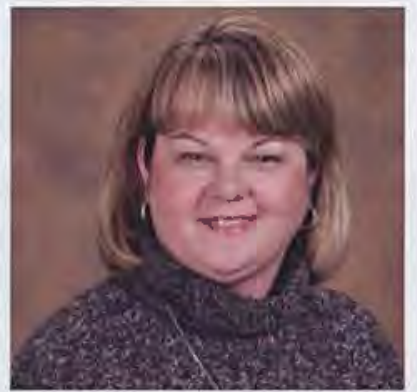

Mrs. Pam Milier

Administrative Assistant

\section{SCHOOL OF SOCIAL SCIENCES \& HUMAN}

\section{PERFORMANCE}

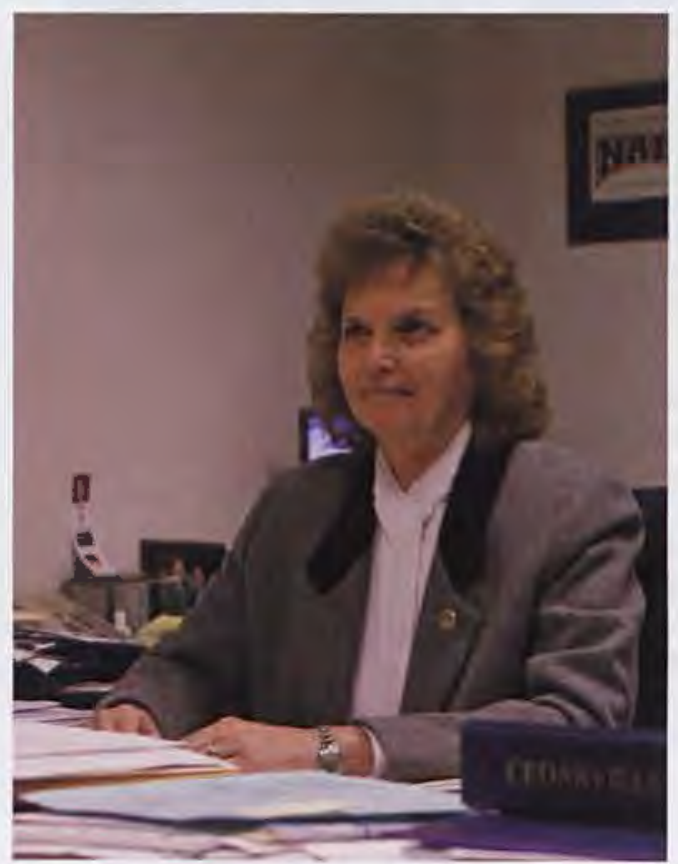

Dr. Pam Johnson

Dean
The 2007-08 academic year has been an exciting time for the new School of Social Sciences and Human Performance as we have sought to become a cohesive unit serving the students more effectively. As the most unique School at Cedarville, with five academic departments and two co-curricular program departments in our make-up, we have been involved with almost every student in the University, seeking to help them become a better prepared, more mature Christ-follower. To that end we provided more than 25 major and minor programs, an array of core curriculum courses like PACL, General Psychology and Cultural Anthropology, and various program offerings through our Campus Recreation Department. Our 14-team Yellow Jacket Athletic Department provided over 300 student-athletes intense competitive experiences where valuable lessons in living the Christian life were practiced and tested.

The Athletic Training Department faculty and staff provided both essential athletic training services for the athletic program, and also used it for key clinical education opportunities for athletic training students. Through various majors offered in our departments of Education, Exercise and Sport Science, Psychology, and Social Work, Criminal Justice and Sociology we have prepared a cadre of students ready to influence their world for Christ. We have prepared them to do that as licensed social workers, certified teachers in more than 20 licensure areas, certified athletic trainers, or through entry level positions in criminal justice, psychology, sociology, exercise science and sport management, or to enter graduate school in any of these areas. We look forward to hearing what He does through them! 


\section{NOT PICTURED:}

Mr. Christopher Cross

Mr. Robert Duchardt

Dr. Evan Hellwig

\section{DEPARTMENT OF ALTHETICS}

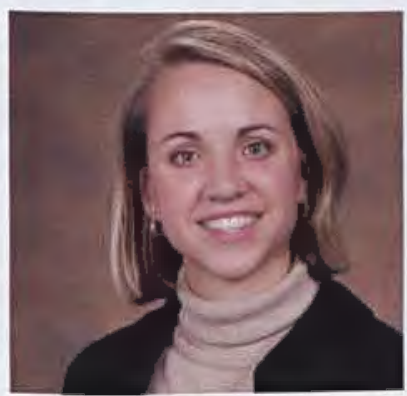

Dr. Melissa Hartman Head Women's Volleyball Coach

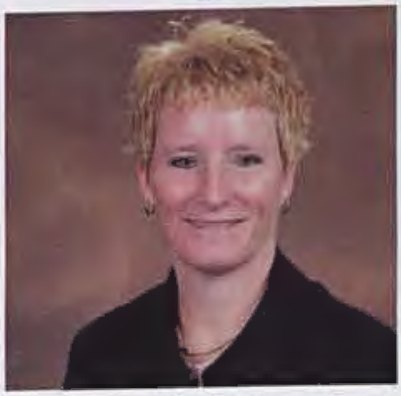

Miss Lori J. Huckaby Assistant Women's Basketball Coach

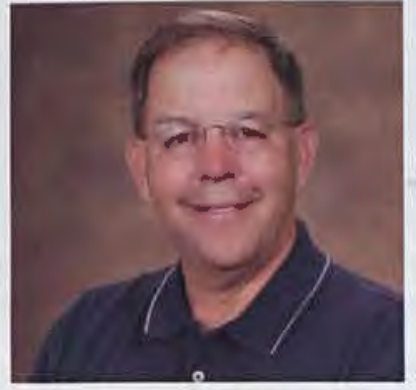

Dr. W. Ray Slagle Men's Basketball Coach

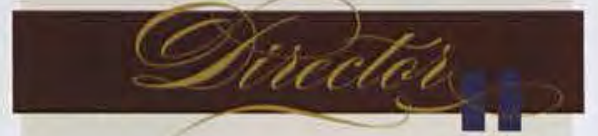

Mr. Pete Reese

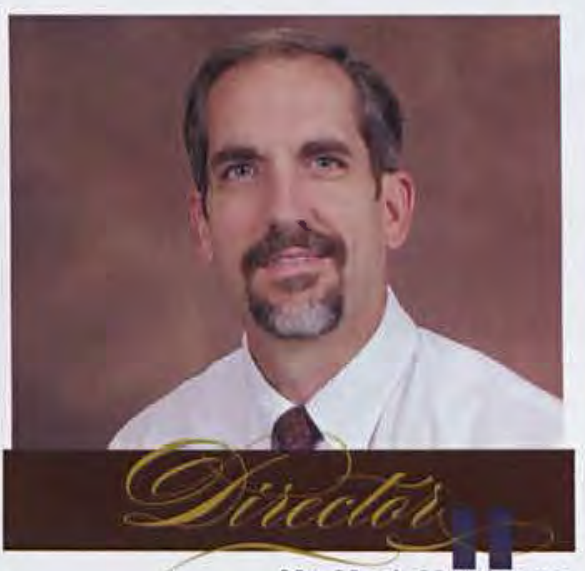

Mr. Mark Matthews

\section{DEPARTMENT OF RECREATION \& FACILITIES}

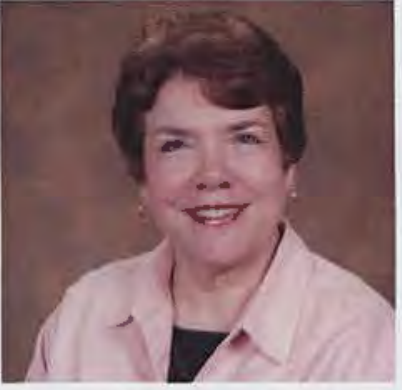

Mrs. Sherrie Wood Administrative Assistant

DEPARTMENT OF EDUCATION

NOT PICTURED:

Dr. Sue Baker

Dr. Eddie Baumann

Mr. Omer Bonenberger

Dr. Sally Castle

Mrs. Terry Comers

Mrs. Shelley Dugle

Mrs. Peggy Grigorenko

Dr. Timothy Heaton

Mr. John Hess

Mrs. Cheryl Irish

Dr. Brenda MacKay

Dr. Bryan Moore

Dr. Thomas Sweigard

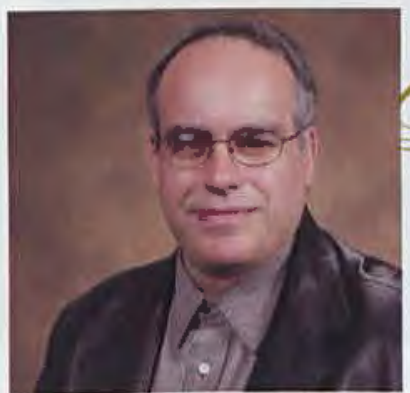

Dr. Kevin Winslow

Dr. Merlin Ager Professor

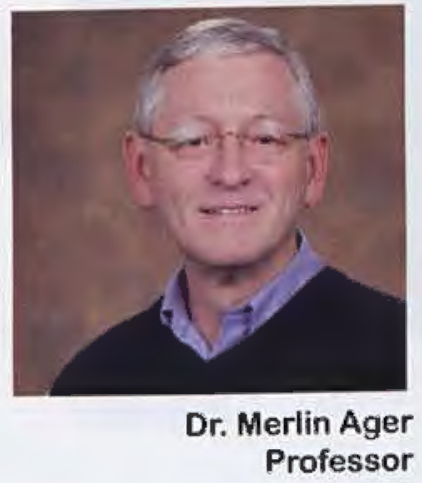

Associate Professor

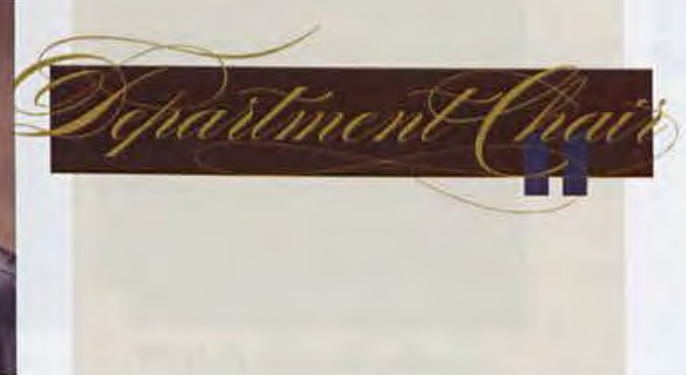

Dr. Stephen Gruber 


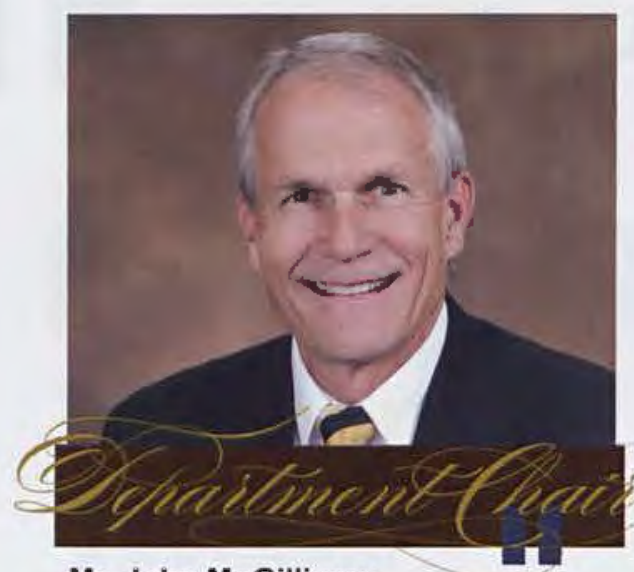

Mr. John McGillivray

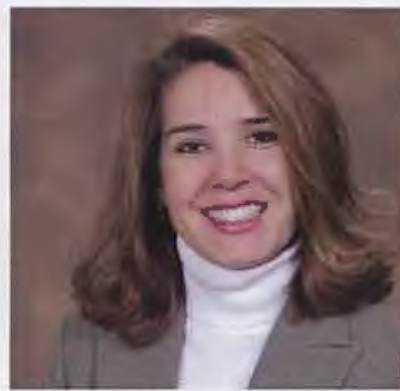

Dr. April Crommett Assistant Professor

DEPARTMENT OF EXERCISE \& SPORT SCIENCE

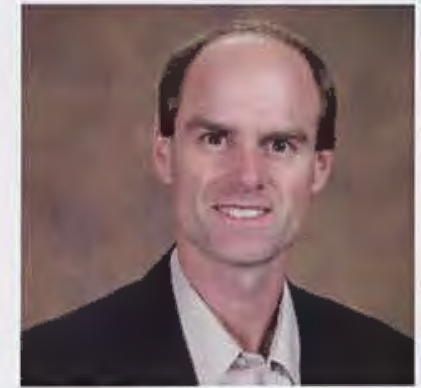

Mr. Jeffrey D. Bolender Assistant Professor

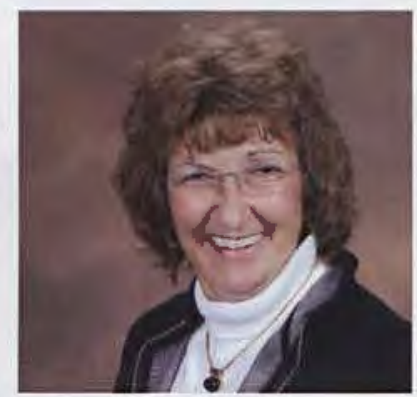

Miss Kathy Freese

Professor

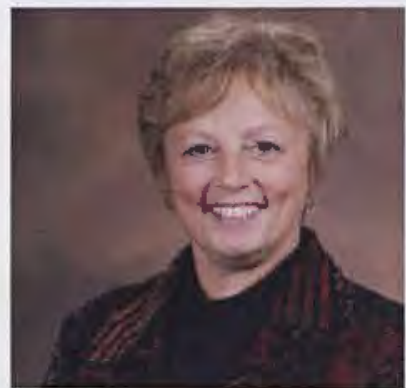

Mrs. Teresa Clark

Associate Professor

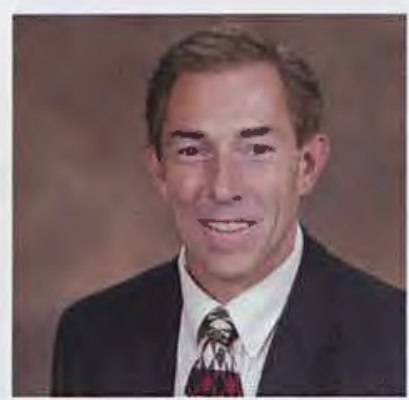

Mr. Paul Orchard

Assistant Professor
NOT PICTURED:

Mr. Ben Belleman

Dr. Alan Geist

Mr. Elvin King

\section{DEPARTMENT OF PSYCHOLOGY}

NOT PICTURED:

Dr. Milton Becknell

Dr. Charles Dolph

Dr. Cosette Fox

Dr. Chi-en Hwang

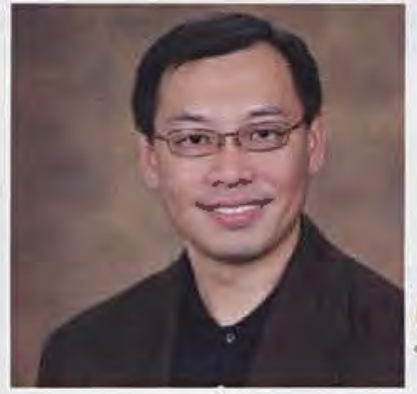

Dr. Luke Tse Associate Professor

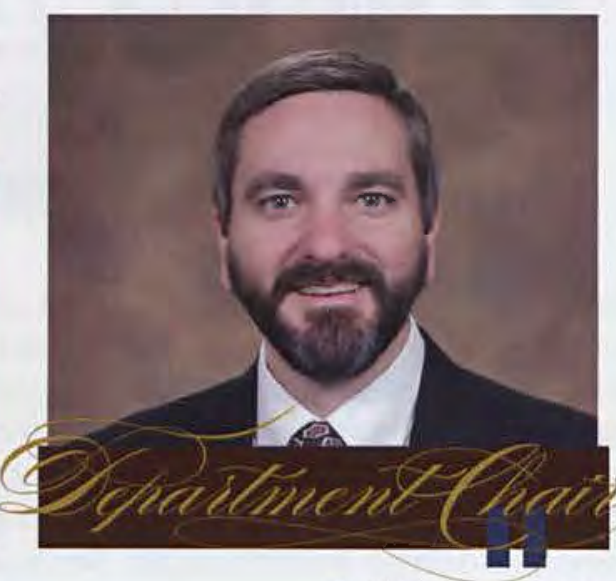

Dr. Michael Firmin

\section{DEPARTMENT OF SOCIAL WORK, CRIMINAL JUSTICE, \& SOCIOLOGY}

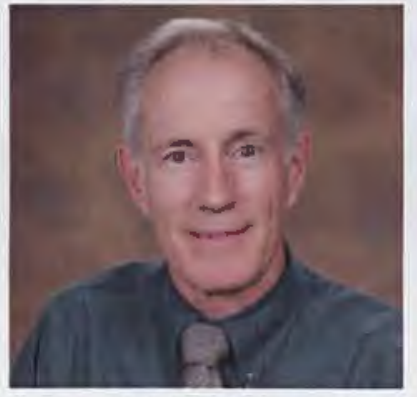

Mr. George E. Huff Associate Professor

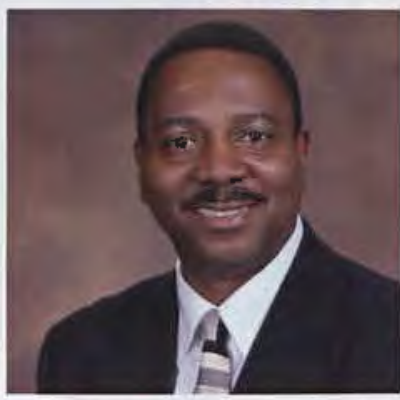

Mr. Patrick Oliver Assistant Professor

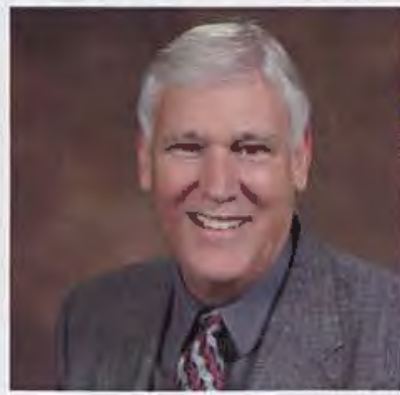

Dr. Robert Parr Professor

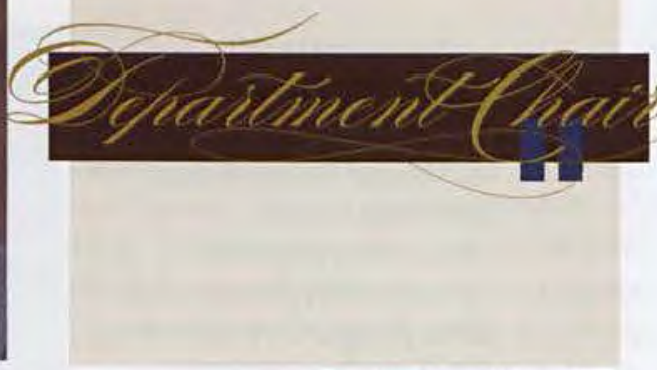

Dr. Nelson Henning

\section{NOT PICTURED:}

Mrs. Christine Fulmer Mr. Donald Hanna 
I count it an honor to serve as Dean of the School of Natural and Applied Sciences at Cedarville University. I am truly blessed to be leading an outstanding faculty and staff of four diverse departments that comprise the school. The quality of each of these people is without question, excellent. Each has responded to the call of our Lord Jesus on their lives to teach the students that $\mathrm{He}$ brought across their paths. The departments of Nursing, Science and Math, Engineering and Computer Science, and Business Administration each desire to impart vocational knowledge, godly wisdom, and character at a minimum so that graduating students can be contributing Christians in life and to the fields into which they are called.

Even before I was a believer in Christ, I charted out my life to conclude with a "deanship" at a small college somewhere. After becoming a believer, I spent almost two more decades in industrial research, almost forgetting my earlier desires of being a dean. Then the Lord shifted me from industry to the academy. After nine years of teaching in Pennsylvania, He called me to be dean at Cedarville. I've been thanking and praising him ever since.

While I minister to students, most directly through my five, yes five dean's lists, I see my primary role as ministering to my faculty to meet their needs so that they can, in turn, minister to students. I pray the Lord will continue to bring blessing to our students for many years to come.

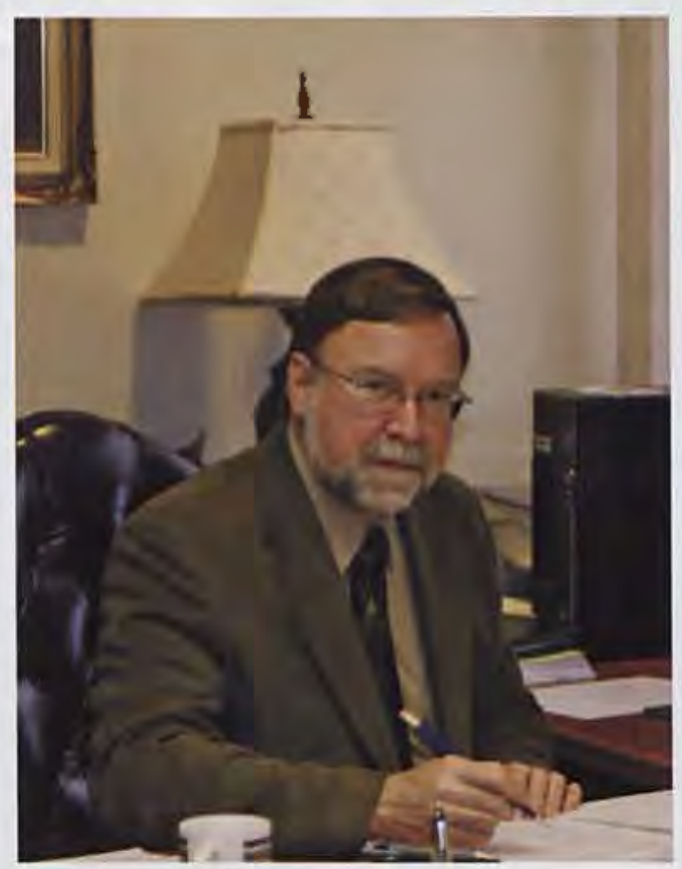

Dr. Stan Baczek

Dean

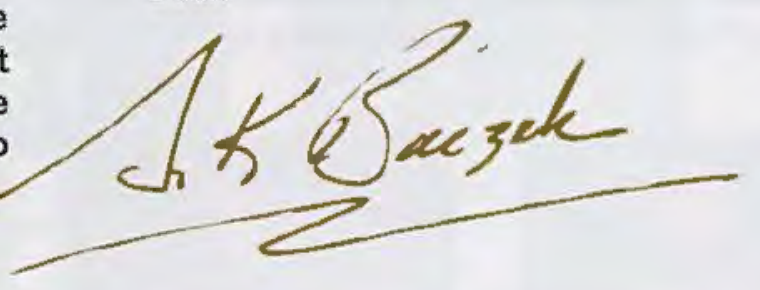

\section{DEPARTMENT OF BUSINESS ADMINISTRATION}

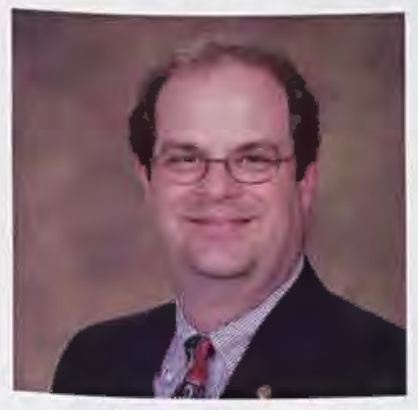

Dr. Jeffrey Fawcett Professor

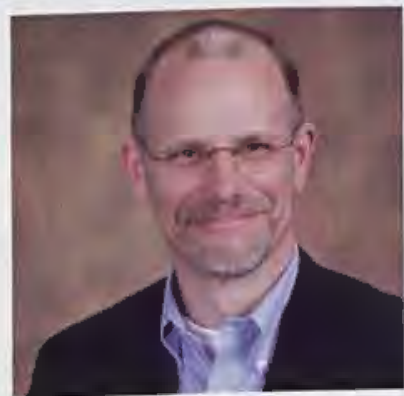

Mr. Jeffrey S. Guernsey Assistant Professor

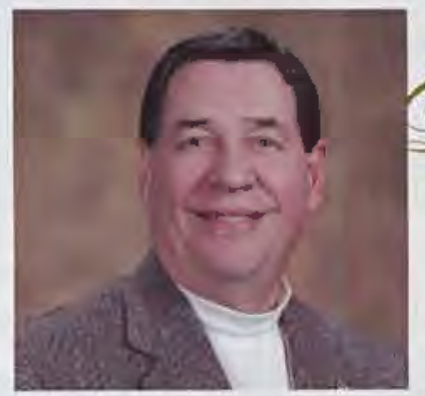

Mr. John LeBlanc Associate Professor

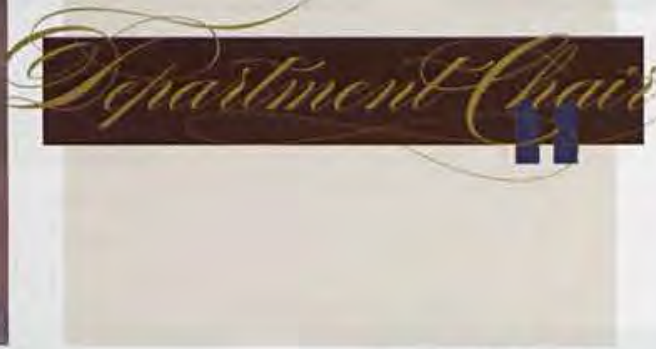

Dr. Bert Wheeler Interim Chair

\begin{abstract}
NOT PICTURED:
Mr. Harry Anderson Dr. Jon Austin

Mr. Charles Hartman

Dr. Sharon Johnson

Dr. David Schmidt

Dr. Galen Smith

Dr. Sarah Smith

Miss Susan Terkelsen

Dr. Ronald Walker
\end{abstract}

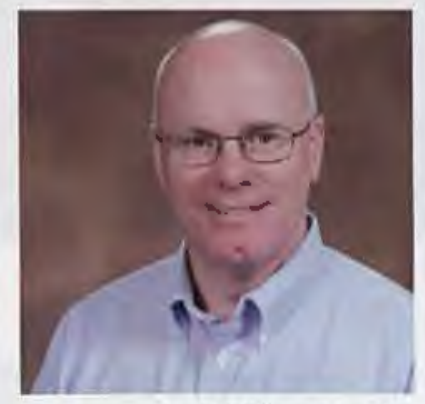

Dr. William Ragle Associate Professor

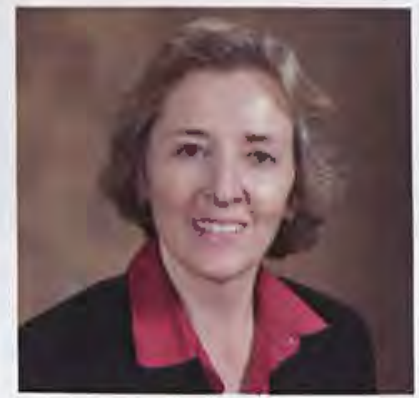

Mrs. Anne Rich Associate Professor 
DEPARTMENT OF ENGINEERING \& COMPUTER SCIENCE

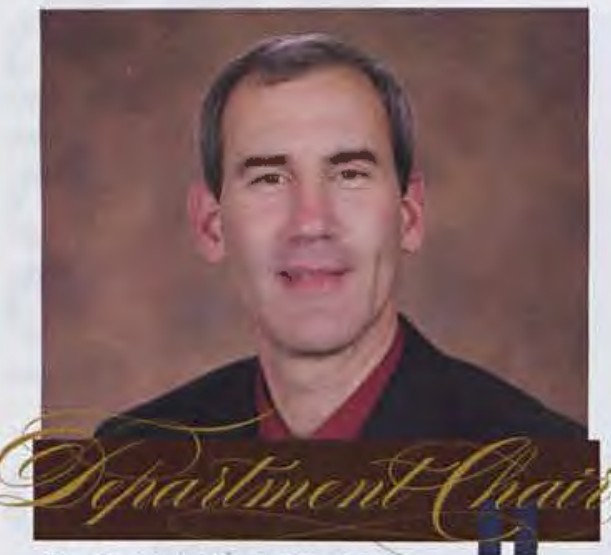

Dr. Samuel SanGregory

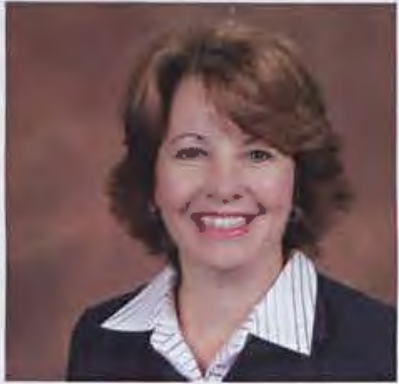

Mrs. Cheryl Hadra Secretary

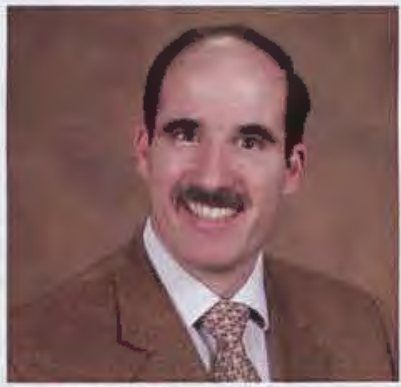
Associate Professor
Dr. Keith Shomper

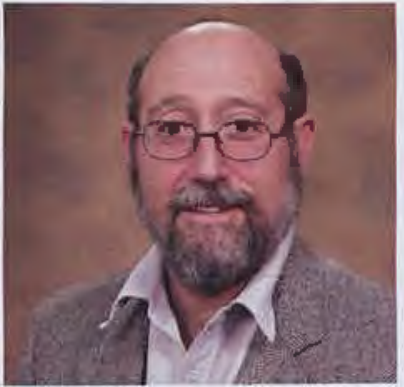

Dr. Robert Chasnov Assistant to the Chair Professor

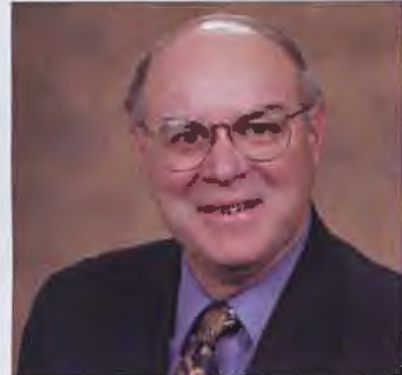

Dr. Harwood A. Hegna Professor

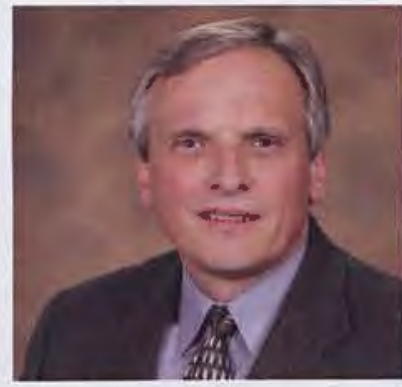

Dr. D. Jeffrey Shortt Professor

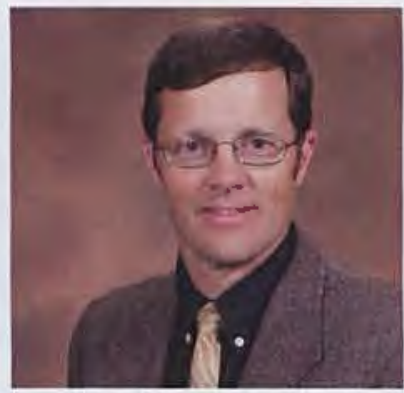

Dr. Gerald Brown Assistant Professor

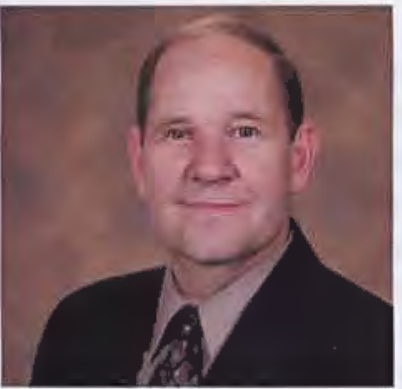

Dr. David M. Gallagher Professor

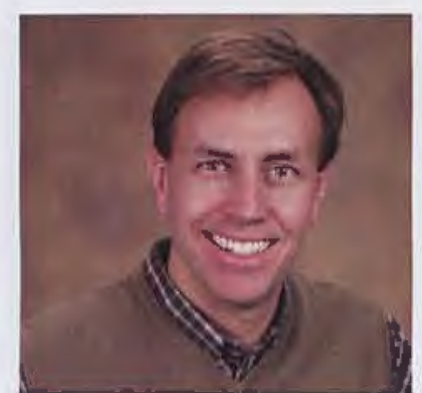

Mr. Jay Kinsinger Assistant Professor

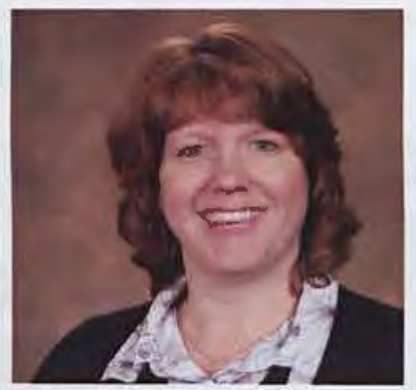

Mrs. Jean Weyandt Administrative Assistant

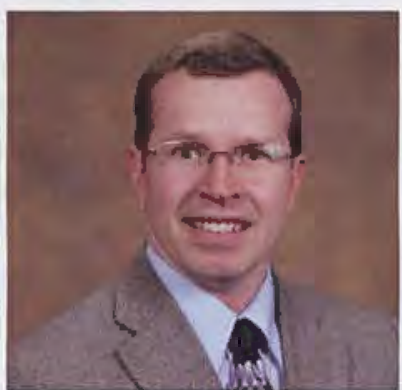

Dr. Clint Kohl

Professor

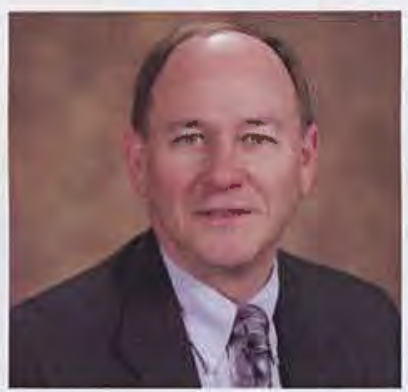
Professor
Dr. Lawrence D. Zavodney

\section{NOT PICTURED:}

Dr. Peter Burban

Dr. Timothy Dewhurst Dr. Vicky Fang Dr. Timothy Norman Dr. Thomas Thompson Mr. Timothy Tuinstra

\section{DEPARTMENT OF NURSING}

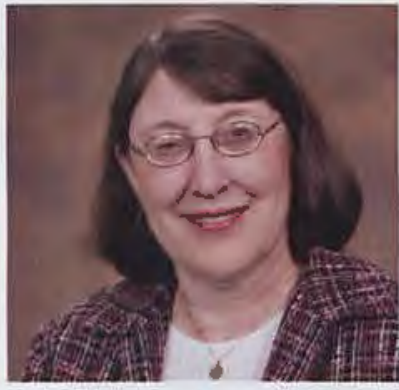

Dr. Lois Baker Professor

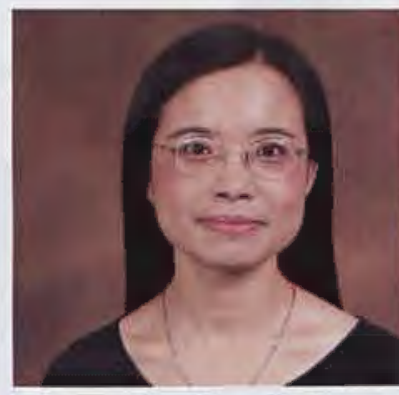

Dr. Chu-Yu Huang Associate Professor

NOT PICTURED: Mrs. Carolyn Barnett Miss Linda Cave

Dr. Sharon Christman Mrs. Connie Ford Miss Kimberly Higginbotham Mrs. Carrie Keib

Mrs. Suzanne Lefever Mrs. Yvonne Lusk Mrs. Rachel Parrill Dr. Susan Salladay Mrs. Amy Voris Mrs. Karen Callan

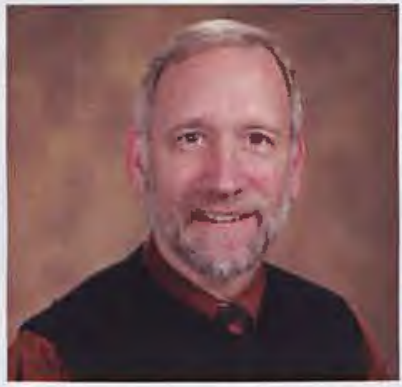

Mr. Mark Klimek Associate Professor

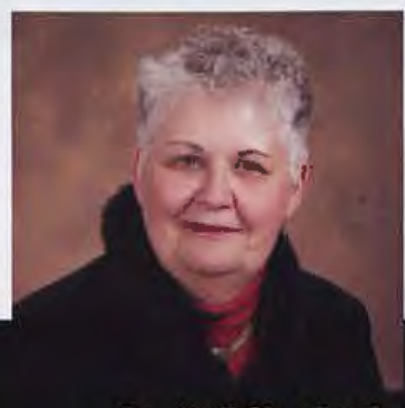

Dr. Judi Shrubsole Associate Professor

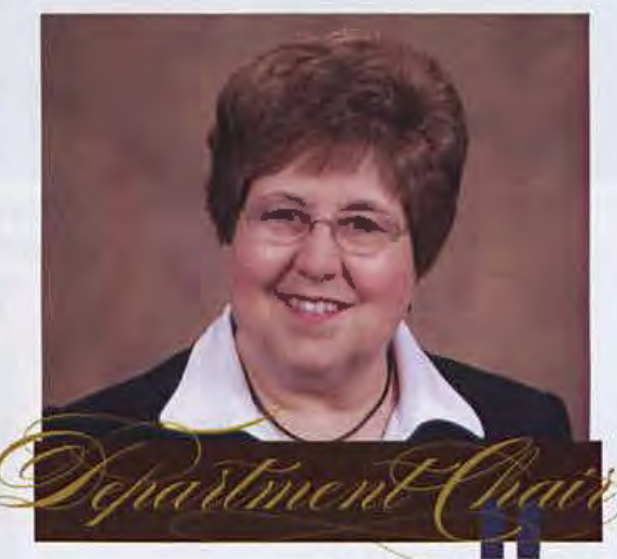

Dr. Janet Conway 


\section{DEPARTMENT OF SCIENCE \& MATH}

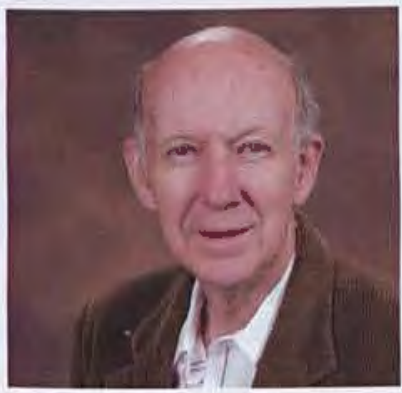

Dr. Donald Baumann Professor

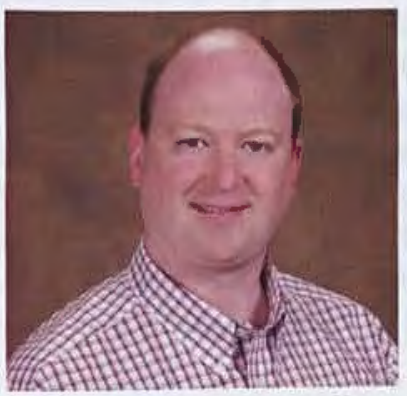

Dr. Darrin Frey Associate Professor

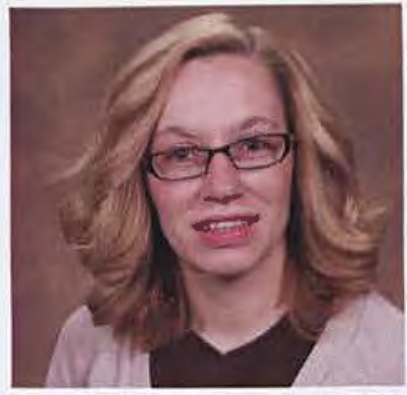

Mrs. Christina Penrose Administrative Assistant

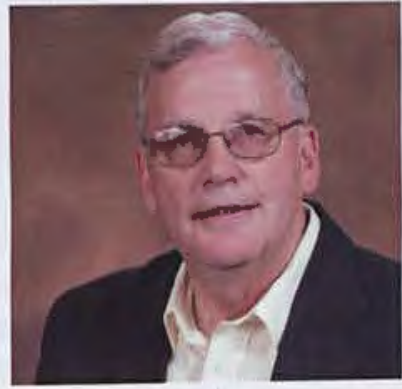

Dr. Edwin S. Braithwaite Professor

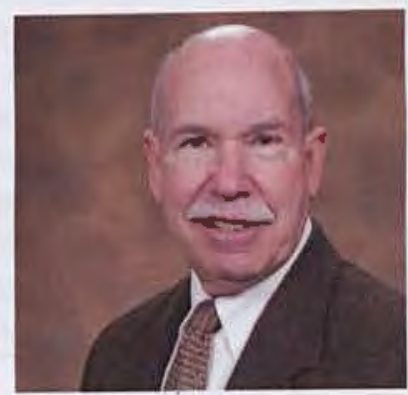

Dr. Larry Helmick Senior Professor

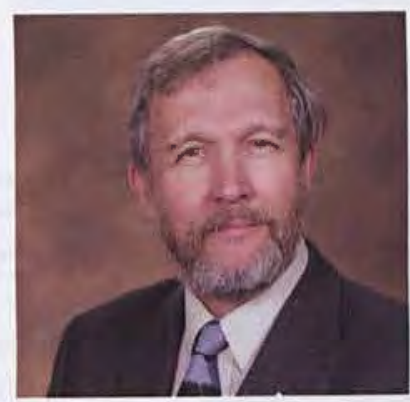

Mr. Robert M. Schumacher Assistant Professor

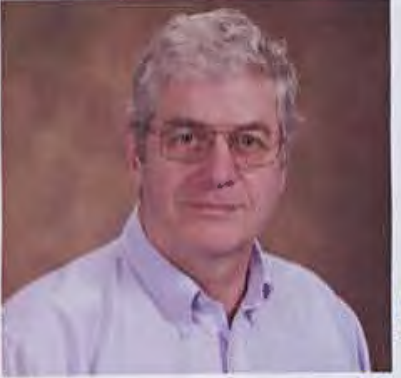

Dr. Lee Eimers

Professor

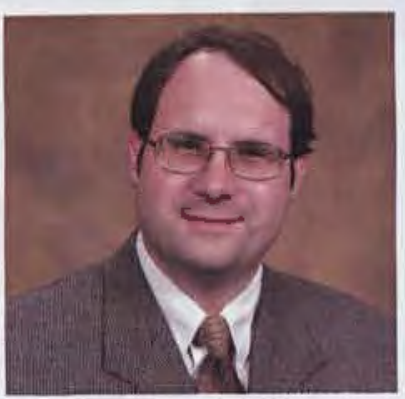

Mr. Aaron Hutchison Assistant Professor

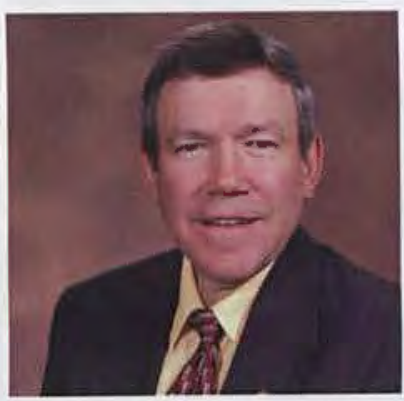

Dr. John Silvius Senior Professor

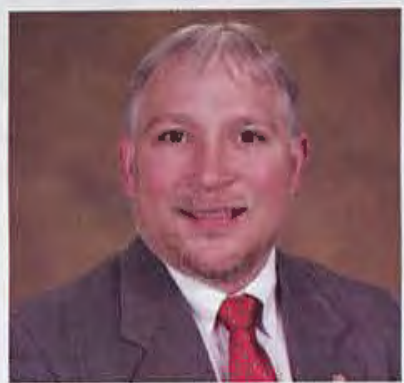

Dr. John H. Whitmore Associate Professor

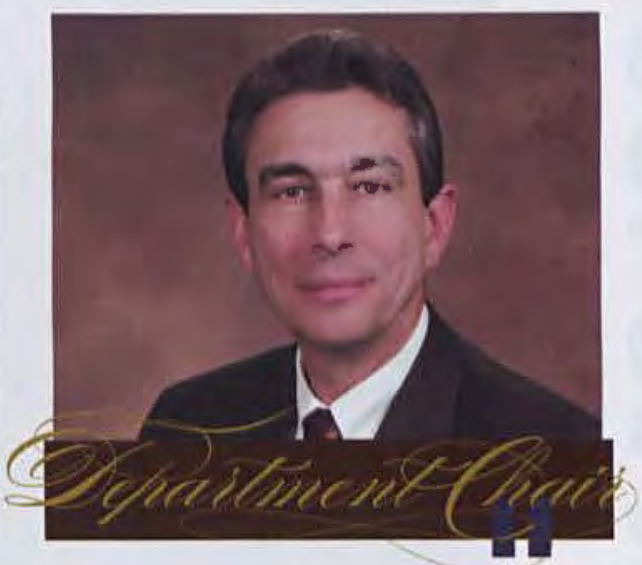

Dr. Dennis R. Flentge

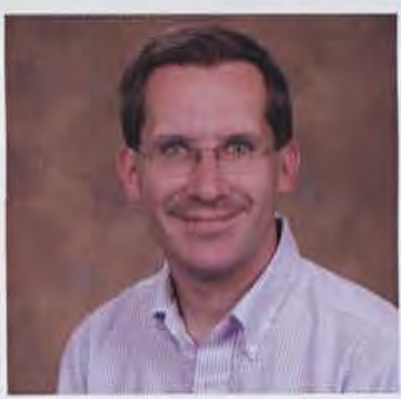

Mr. Eric L. Johnson Lab Technician

NOT PICTURED:

Dr. Xidong Chen

Mr. Mark Gathany

Miss Sarah Gilchrist

Dr. Steven Gollmer

Mr. William Jones

Dr. Heather Kuruvilla

Dr. Dali Luo

Dr. Mark McClain

Dr. Douglas Miller

Dr. Terry Phipps

Dr. Kevin Roper

Dr. Alicia Schaffner

Miss Jennifer Secor

Dr. Dennis Sullivan

Mrs. Cynthia Wingert

Dr. Otis Wright III 


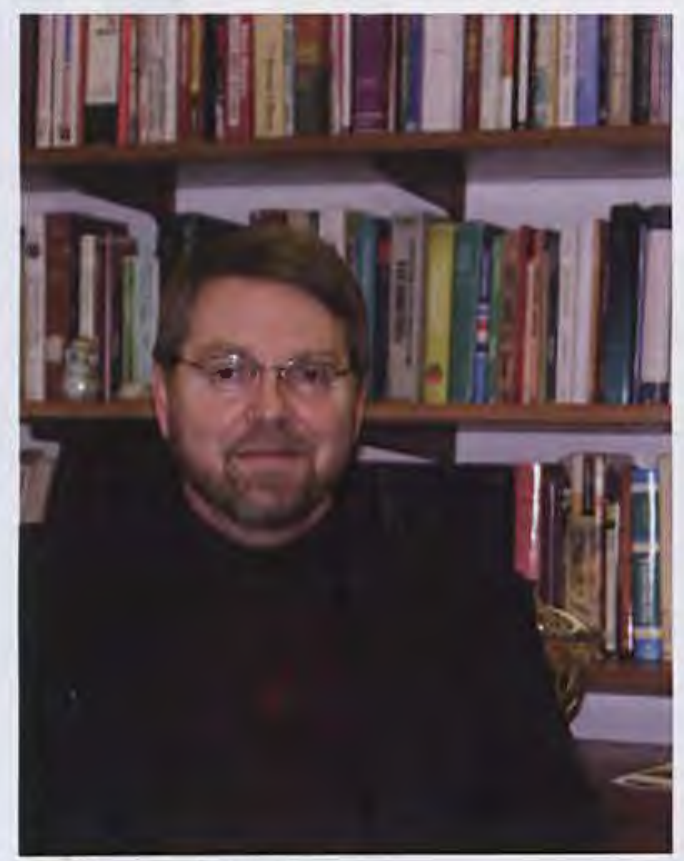

Dr. Thomas Hutchison Interim Dean

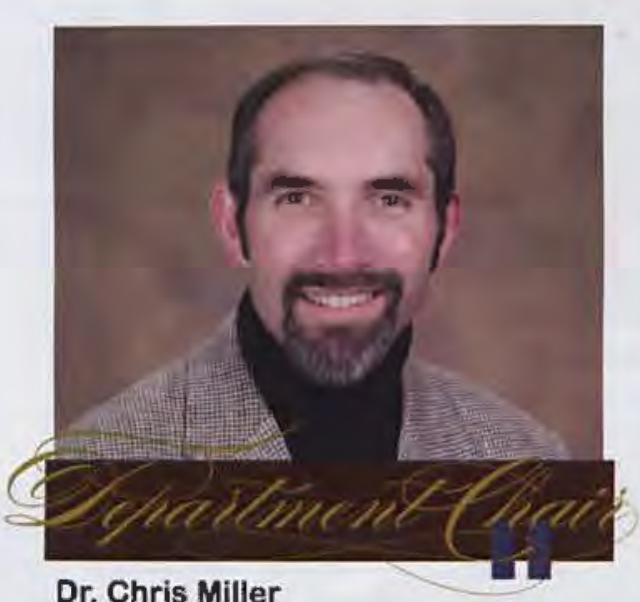
Interim Chair

Just before the start of the 2008-2009 school year the Department of Biblical Education was reorganized and became the School of Biblical and Theological Studies. I was appointed as interim dean. Three new departments were formed and interim chairs were appointed. Dr. Chris Miller served as Interim Chair for the Department of Biblical Studies, Dr. Don Grigorenko for the Department of Ministry and Mission, and Dr. Greg Couser for the Department of Theology and Philosophy. Dr. Scott Dixon was appointed Director of the Bible minor, giving oversight to this important part of the University curriculum. These changes provide greater resources for faculty so that students can be served more effectively.

Part of the excitement this year was watching construction of the new Center for Biblical and Theological Studies. A significant part of the Cedarville experience is the Bible minor as every student completes one full semester of Bible classes. The building represents our commitment to equip every student with knowledge of the Bible, skills for a lifetime of study, an intentional process for sustaining spiritual growth, and tools to engage the world for Christ. Our majors are being prepared to be leaders in this great work for the kingdom of Jesus Christ in a broad range of vocational ministries.

We ask for God's continued blessings on each of our students, and encourage all of us to take seriously Paul's instruction in 1 Timothy 4:15-16: "Be diligent in these matters; give yourself wholly to them, so that everyone may see your progress. Watch your life and doctrine closely. Persevere in them, because if you do, you will save both yourself and your hearers." (NIV)
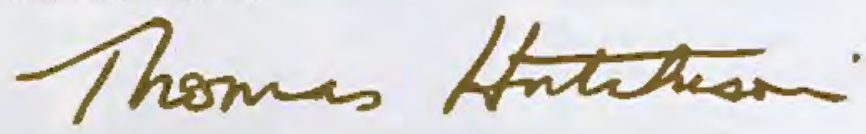

\section{DEPARTMENT OF BIBLICAL STUDIES}

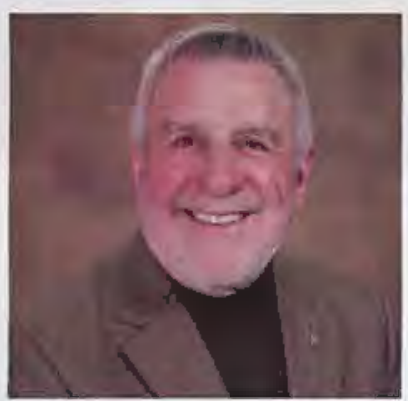

Dr. David W. Drullinger Professor

\section{NOT PICTURED:}

Dr. Daniel Estes

Dr. Timothy Gombis

Mr. Steven Janssen

Dr. Preston Sprinkle 


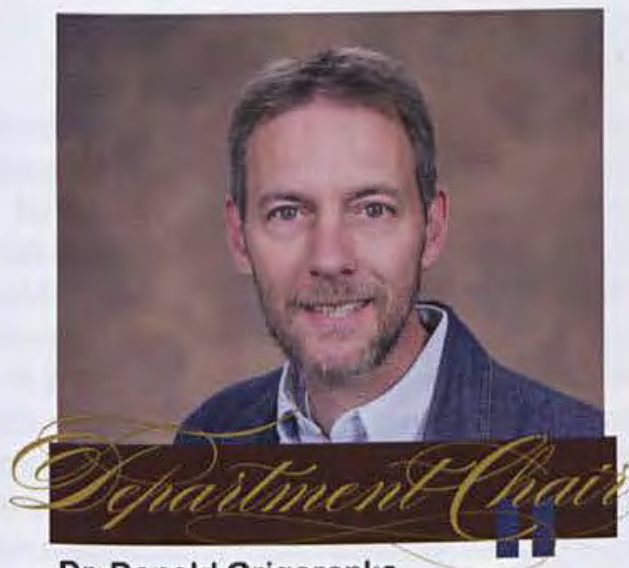

Dr. Donald Grigorenko Interim Chair

\section{DEPARTMENT OF MINISTRY \& MISSION}

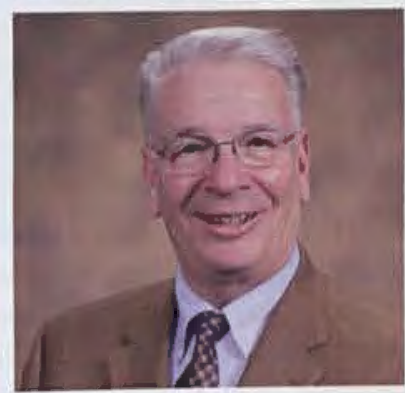

Dr. Richard Blumenstock Associate Professor

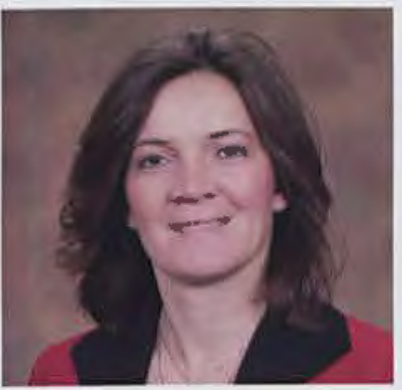

Dr. Joy Fagan

Assistant Professor

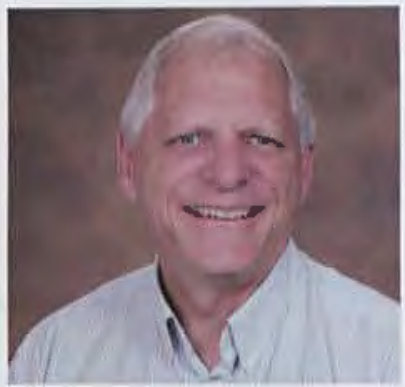

Mr. Mike Parrott Assistant Professor

NOT PICTURED:

Dr. Jeffrey Cook

Dr. Scott Dixon

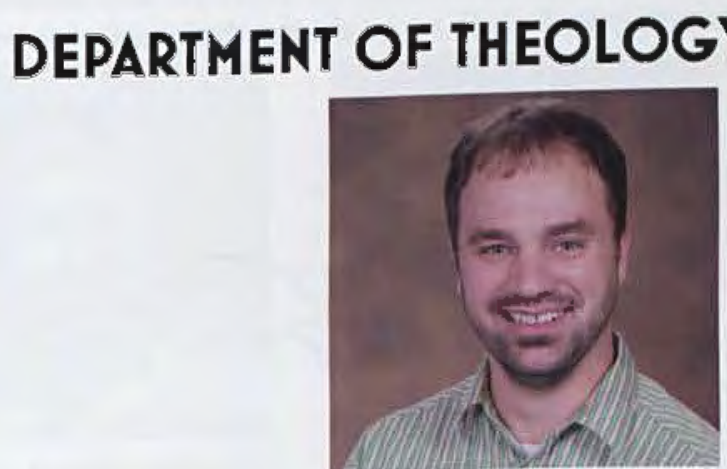

Mr. Shawn Graves Assistant Professor

NOT PICTURED:

Dr. James Bjornstad

Mr. Aaron James

Dr. Carl Smith

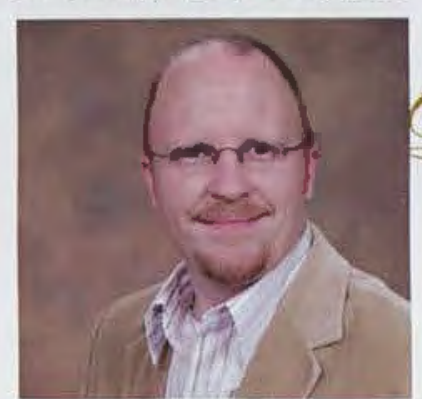

Dr. David Mills Associate Professor

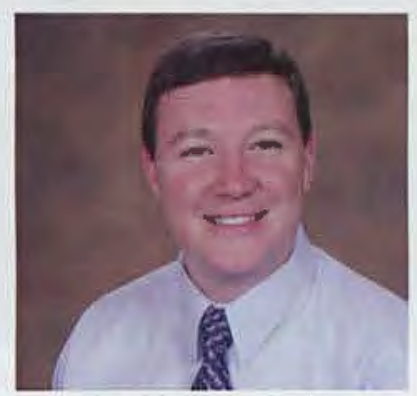

Mr. Ryan Peterson Assistant Professor

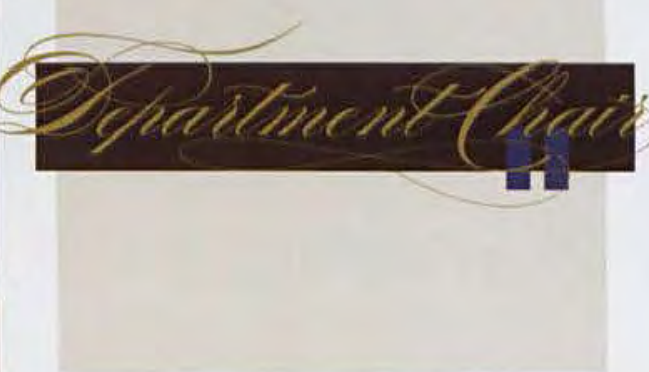

Dr. Greg Couser Interim Chair

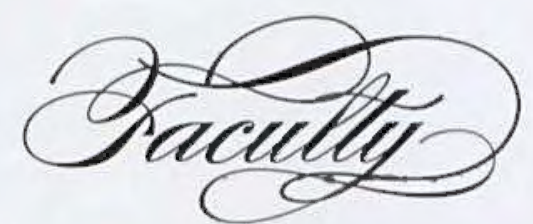




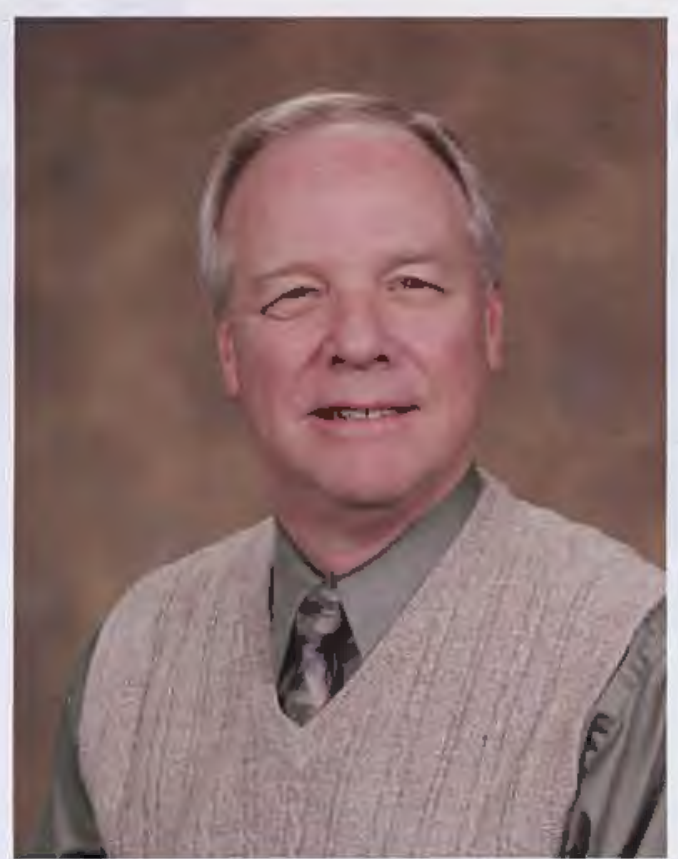

Lynn Brock

Dean of Library Services

The 2007/2008 academic year for the Library included a milestone and a several new beginnings. A milestone was recognized as the campus community celebrated the 40th anniversary of the Curriculum Materials Center, which has been in four buildings during that span of time and in its current location since the Centennial Library was opened in 1987. Then there were several new beginnings. The staff of the Media Resource Center, which had its start in the 1970 's, launched a re-designed and re-named service center called MediaPLEX, focusing specifically on serving students with imaging, graphics, multi-media, video integration, craft, and collaboration services. In the Fall, faculty and students returned to discover a newly designed, more user-friendly Library web site, and for Freshmen, the implementation of the "Amazing Race," a different approach to assisting freshmen in orientation to Library resources and services. The Library staff enhanced their ability to service faculty and students more effectively, and to expand the Library's instructional services program, with the addition of two new Library faculty members filling the Information Services Librarian and Instructional Services Librarian positions. The end of the academic year found the Library participating for the third time in the national library satisfaction survey called LibQUAL. This on-line survey allowed University students, faculty, and staff to evaluate their satisfaction with Library staff, resources, and services.

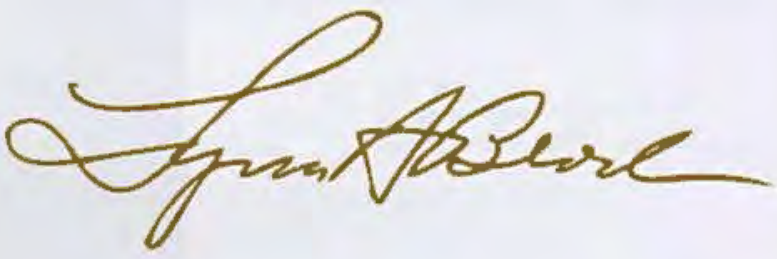

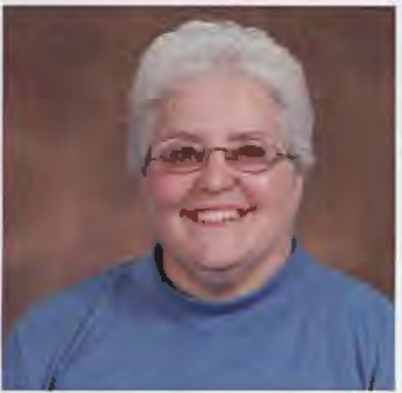

Michal Ann Bader

Staff Cataloger

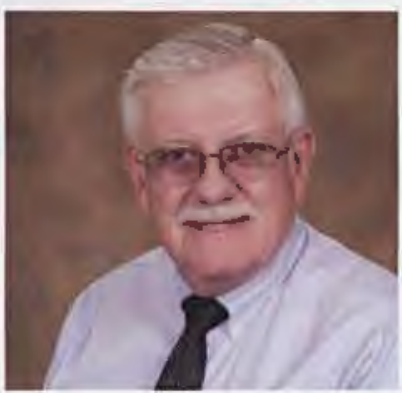

Carl Brandon

Assistant Library Director for Media Services

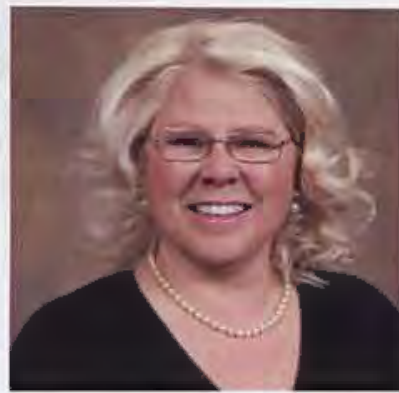

Janice Bosma

Associate Dean

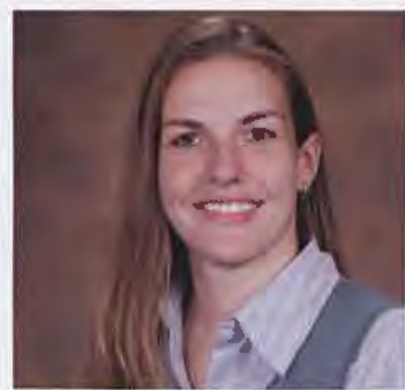

Tricia Clark

Technical Coordinator 


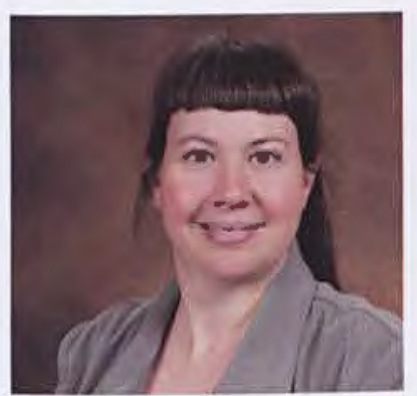

Julie Deardorff

Assistant Director for Collection Services

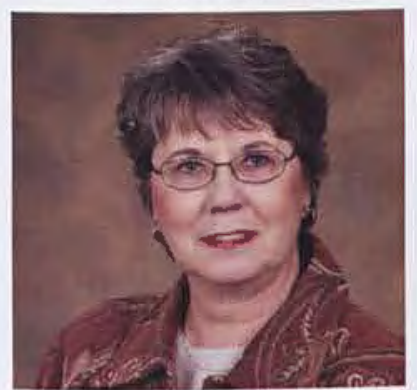

Lynne Funtik

Senior Reference

Librarian

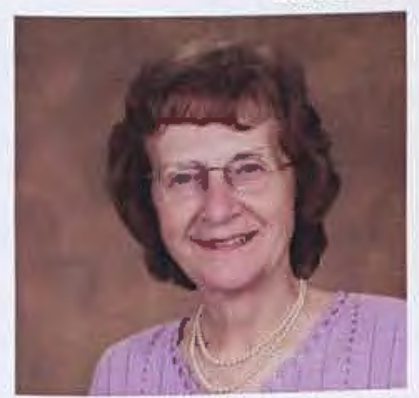

Rachel Johnson Collection Services Technical Assistant

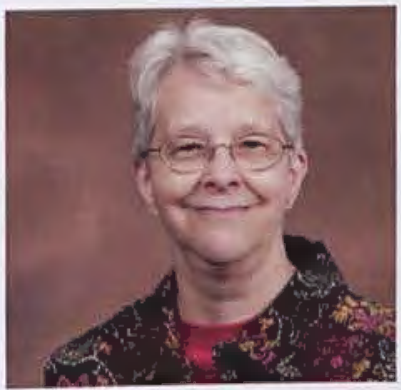

Linda Divan Library Systems Coordinator

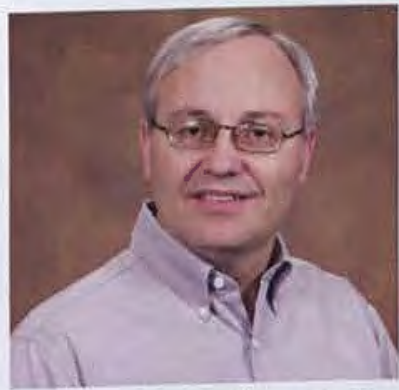

Jeffery Gates Information Services

Librarian

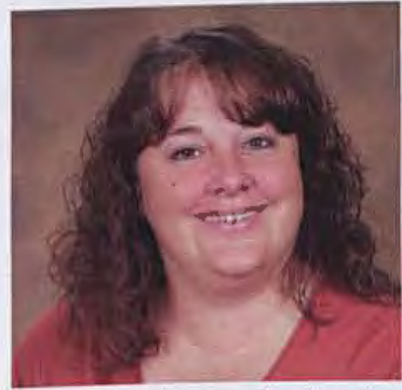

Laura LeMaster Serials Technical Assistant

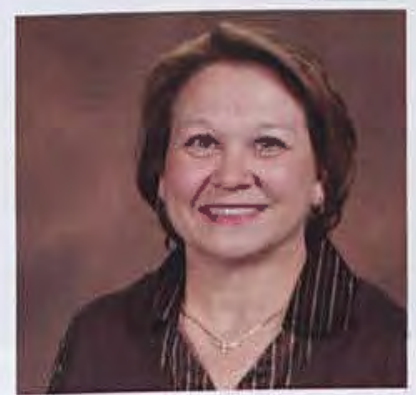

Andi Mounts Assistant Circulation Manager

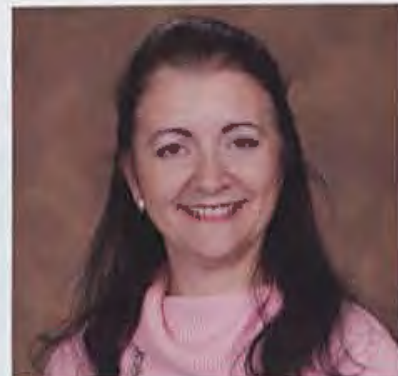

Tonya Fawcett Assistant Library Diretor for Reader Services

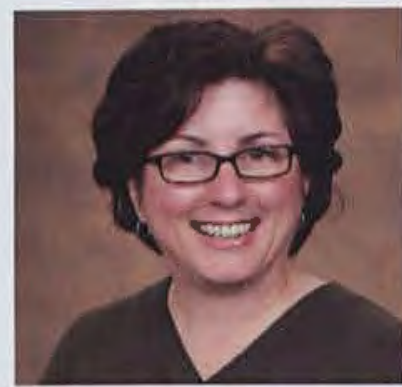

Becky Hayes

Circulation Services Manager

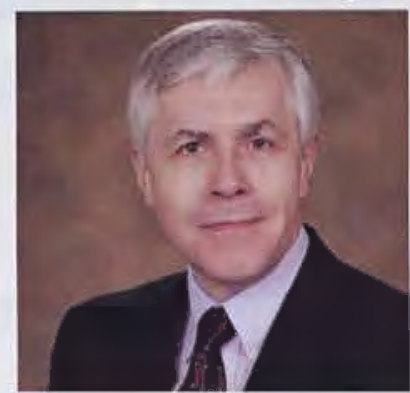

Greg Martin

Cirriculum Materials Center Librarian

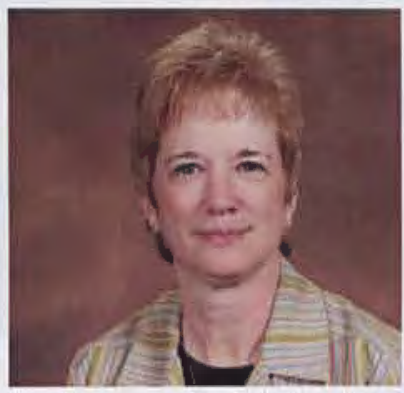

Luann Nicholas Interlibrary Services Coordinator

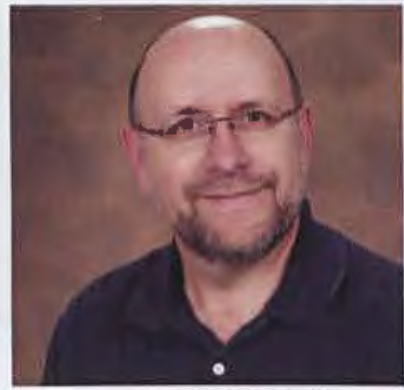

Rich Williams Lead AV Service Technician

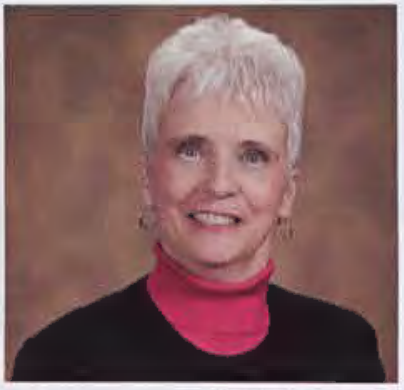

Patty Stutes Desktop Publishing Consultant 


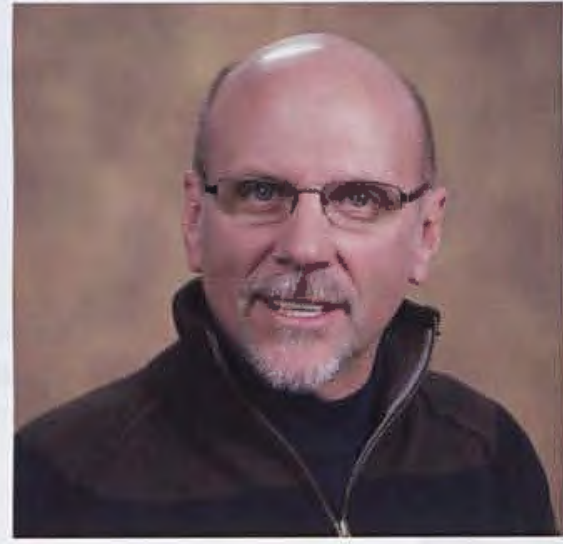

Jon Purple

Dean for Student Life

Programs

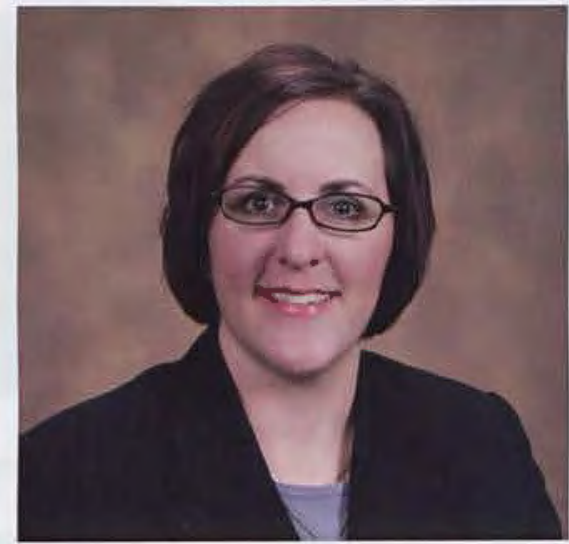

Kirsten Gibbs

Dean of Students

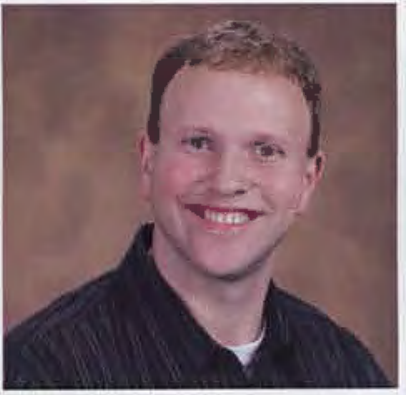

Brian Burns

Associate Dean

for Student Center

Operations and Programs

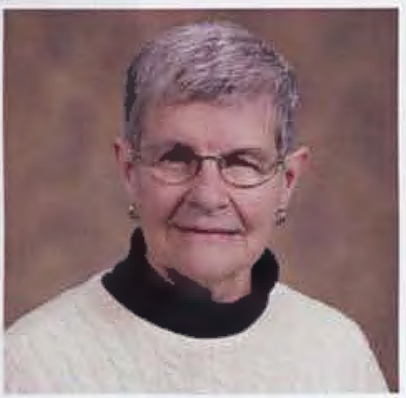

Nancy A. Knauff

Secretary to the Student Life Deans

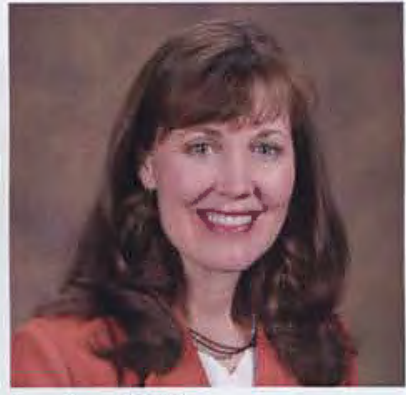

LeAnn Hill

Administrative Assistant

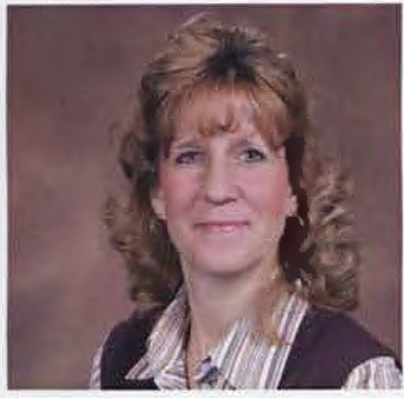

Dawn Scott

Information Center

Coordinator
Administrative Assistant to the Vice President 


\section{RESIDENCE LIFE}

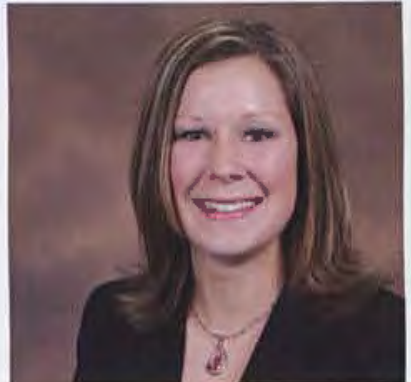

Lynsey Fabian Resident Director of Maddox Hall

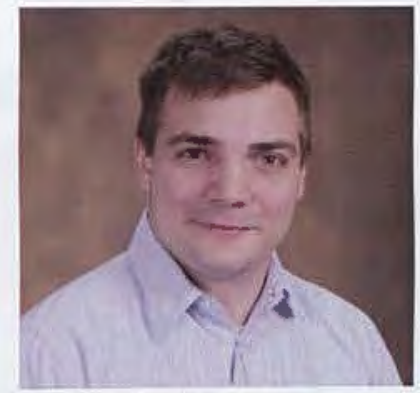

Matthew Minier Resident Director of Brock Hall

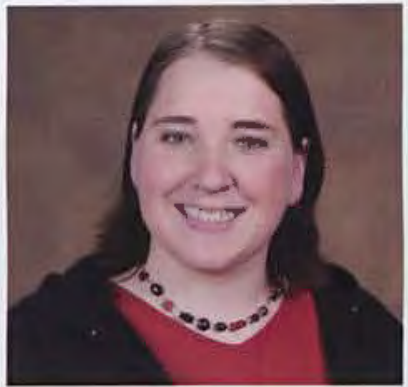

Ruth Poling

Resident Director of Printy Hall

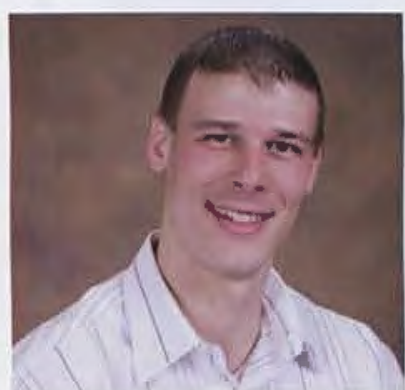

Anthony Mandela Resident Director of Lawlor Hall

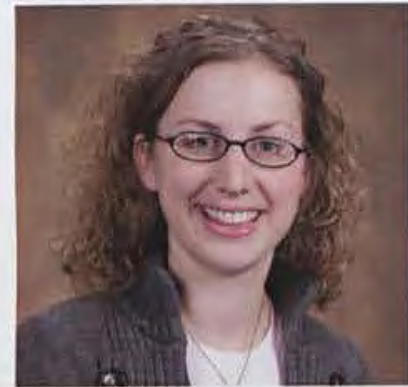

Becky Stowers

Resident Director of Faith Hall

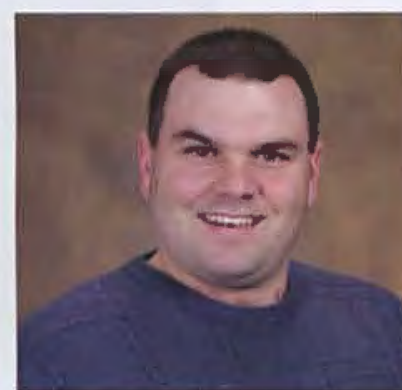

Adam T. McCune Hill

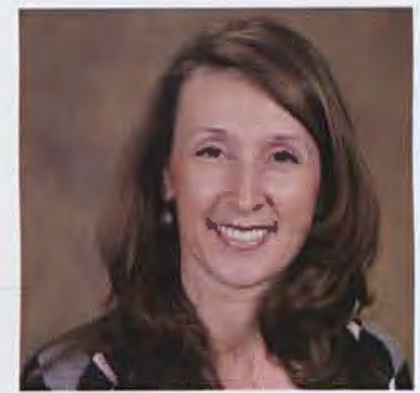

Susan West

Resident Director of

McKinney-Johnson Halls
Resident Director of The

COUNSELING SERVICES

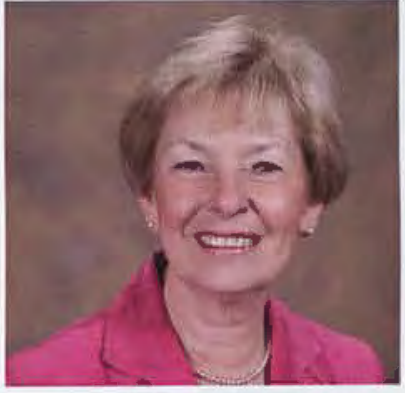

Helen Blumenstock Secretary

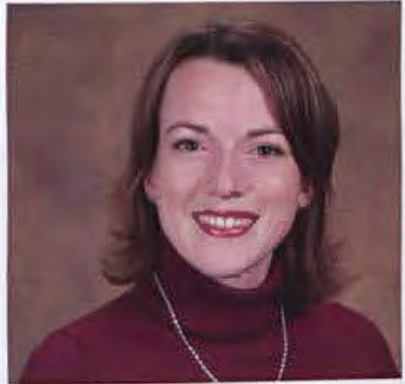

Rachel Heffield Counselor

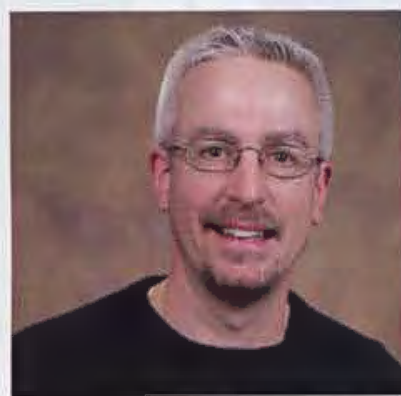

Jeffrey Fulmer Counselor

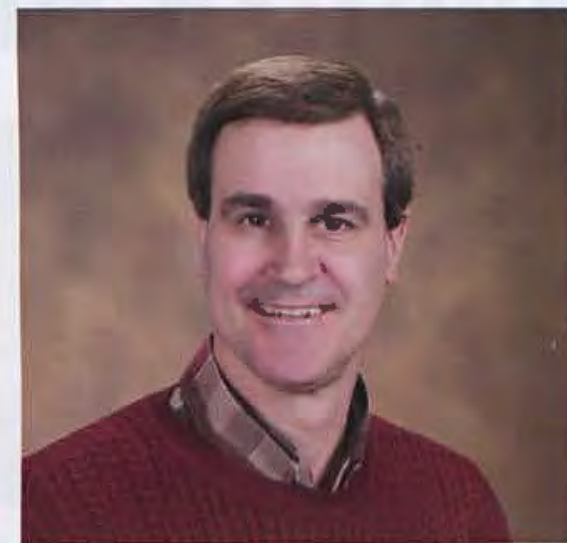

John Potter Director

\section{UMs}

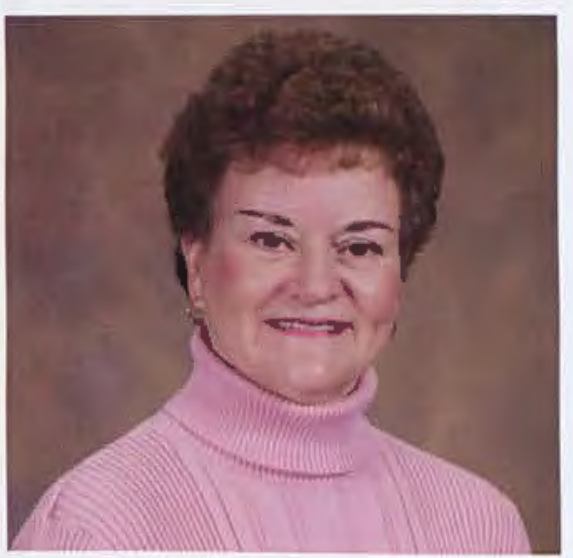

Beverly Robey 


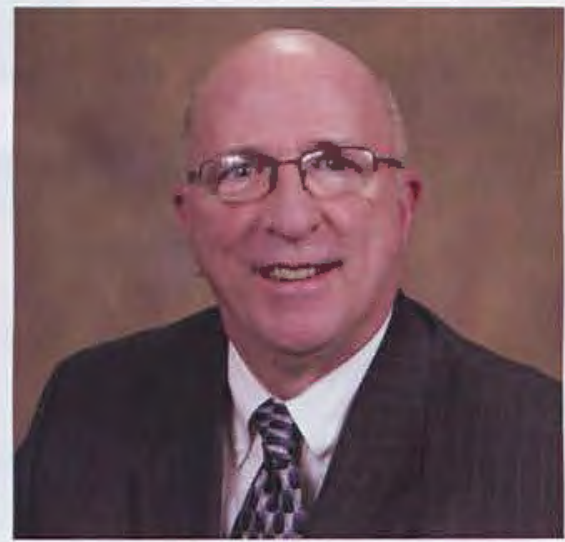

Lew Gibbs

Director

\section{CAREER SERVICES}

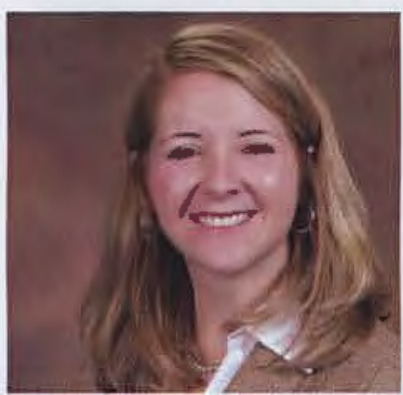

Mandy Hutchinson

Events Coordinator

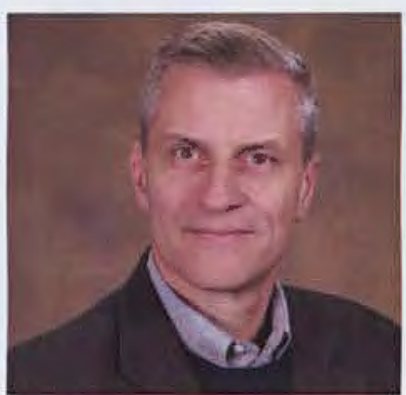

Jeff Reep

Associate Director

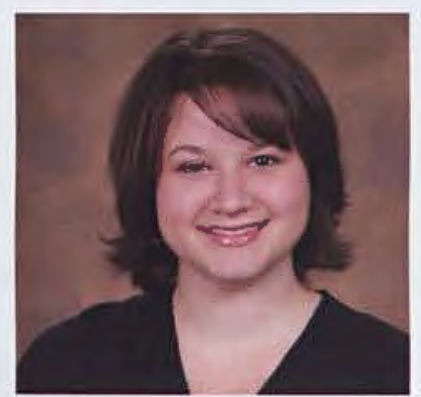

Laura Jolly

Office Manager

\section{CHRISTIAN MINISTRIES $\downarrow$}

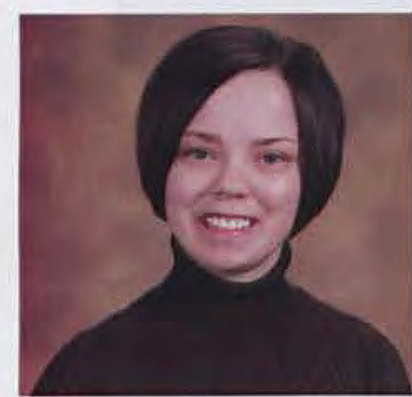

Brooke Colon

Chapel Scheduling ERAP Program

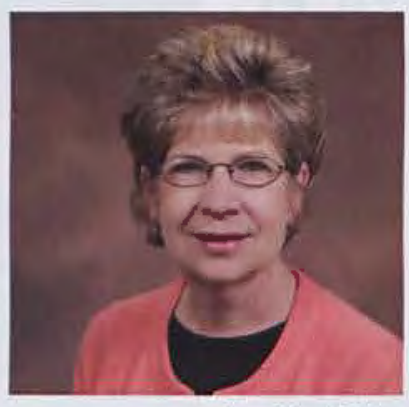

Jackie Pyles Front Desk Receptionist

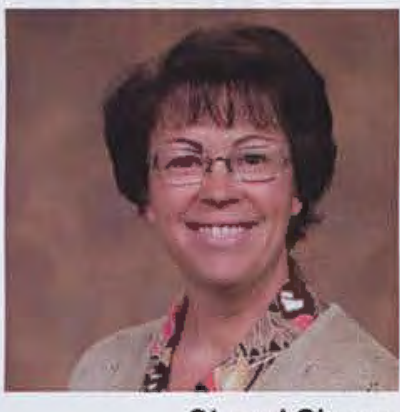

Cheryl Shupe

Executive Secretary

\section{COMMUNITY MINISTRIES}

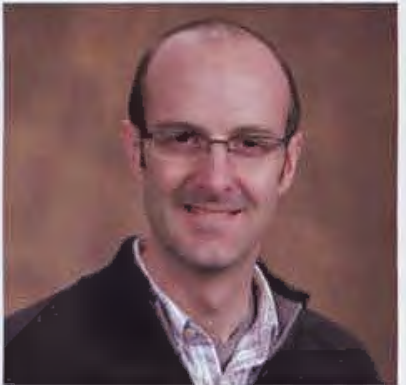

John Wambold Director

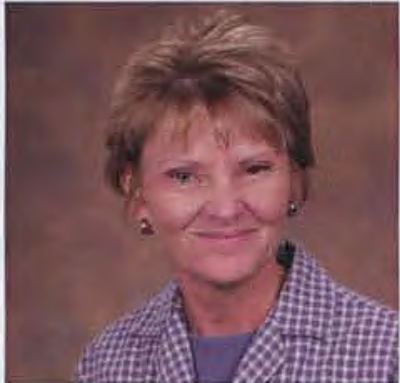

Vicky L. Hines Administrative Assistant 


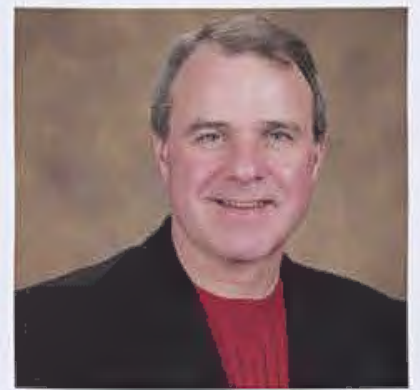

Brian Nester Director

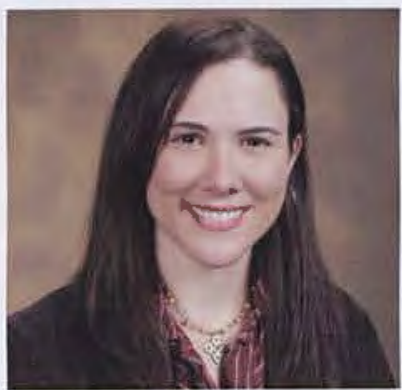

Danette Phillips Secretarial Assistant

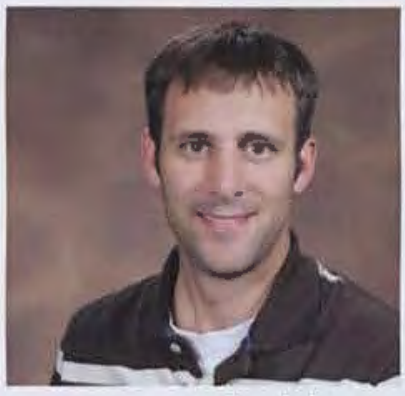

Mark Irving Director

\section{HEARTSONG TOURING TEAMS}

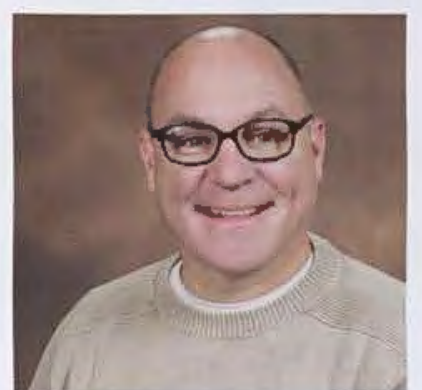

Jim Cato

Director

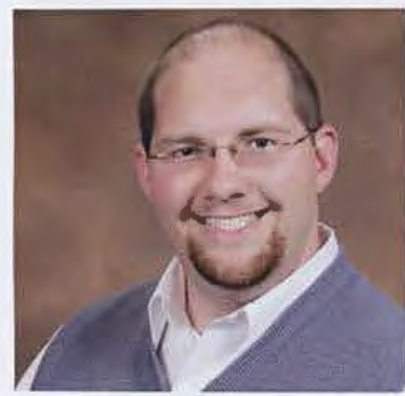

\section{Joel Tomkinson}

Assistant Director for Marketing and Events

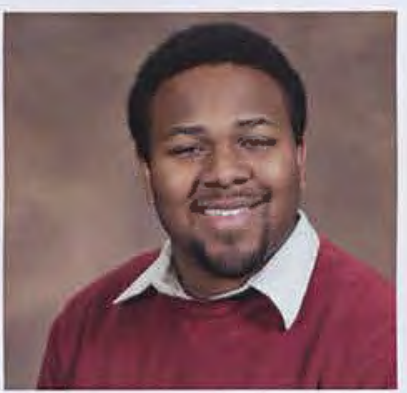

Justin Spann

Director of OneVoice

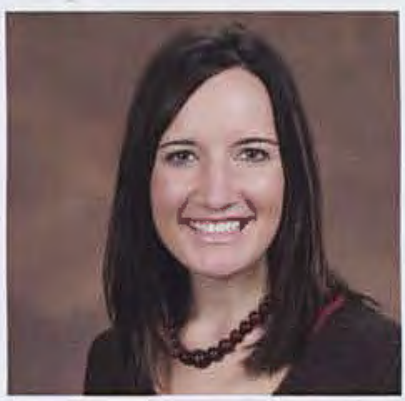

Jessica Waggoner

Administrative Assistant

\section{DRAMA TOURING TEAMS}

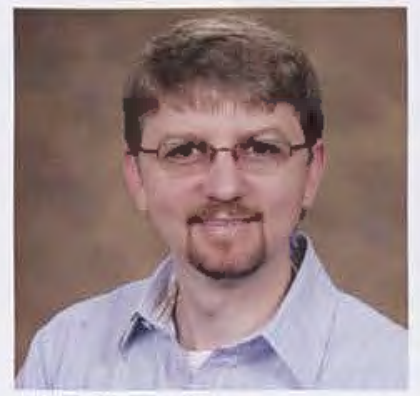

Brandon Waltz Director

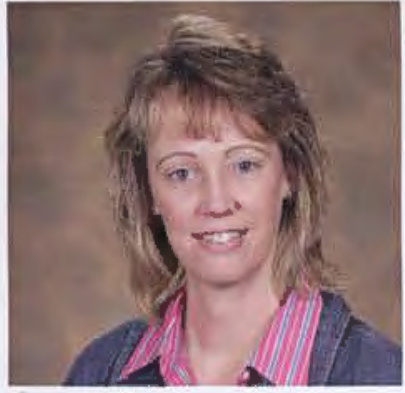

Carol Bliss

Administrative Assistant 


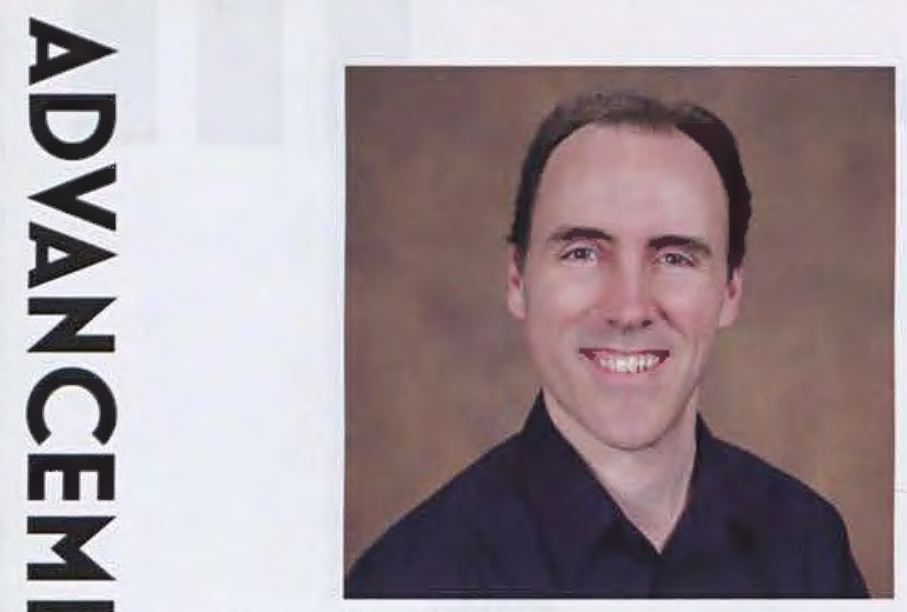

Tim Entner Director

\section{ADVANCEMENT SERVICES}

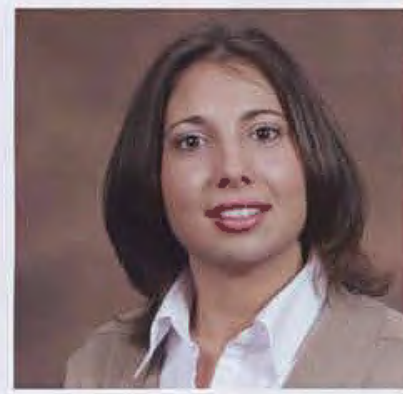

Jen Castellani

Advancement Coordinator

\section{ALUMNI OFFICE}

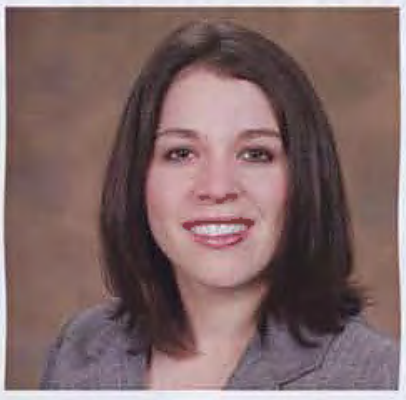

Michelle McCune Assistant Director for Regional Events and Services

\section{CONTROLLER OFFICE}

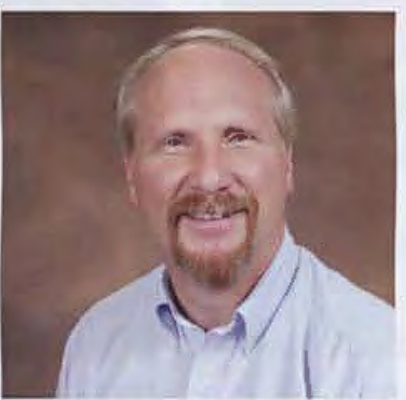

Steve Miller Gift Processor
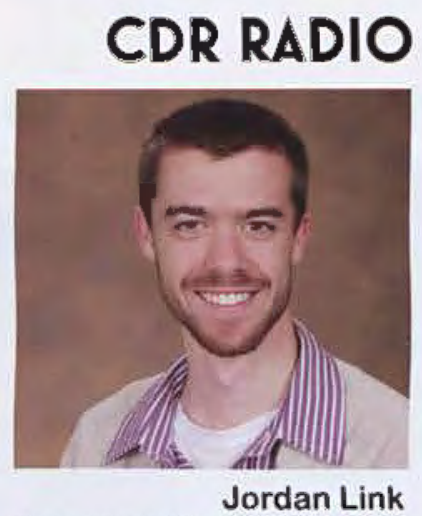

Overnight News Producer 


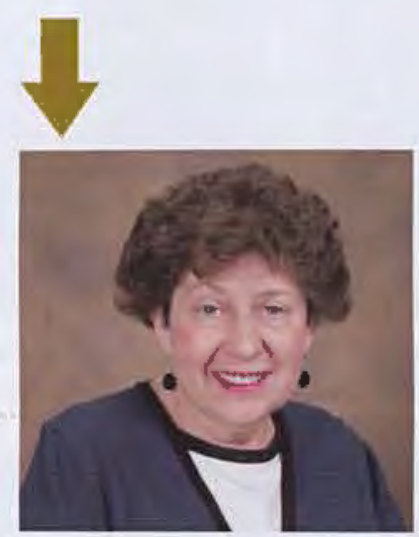

Judy Awabdy Associate Director

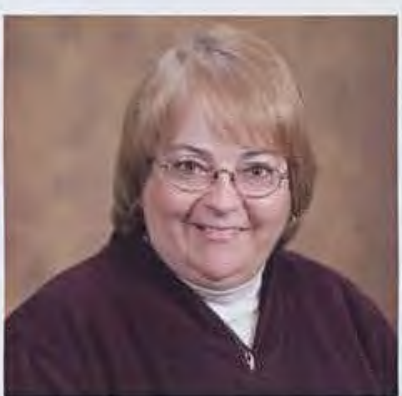

Amy Bielek

Senior Communications

Assistant

\section{MARKETING SERVICES}

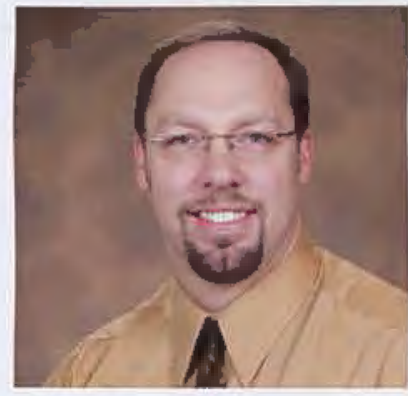

Mike Bienek

Senior Graphic Designer

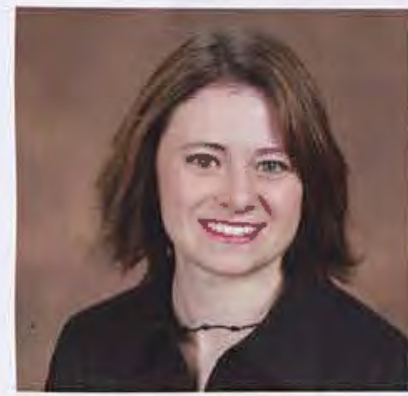

Chrissy Faulkner Assistant Director

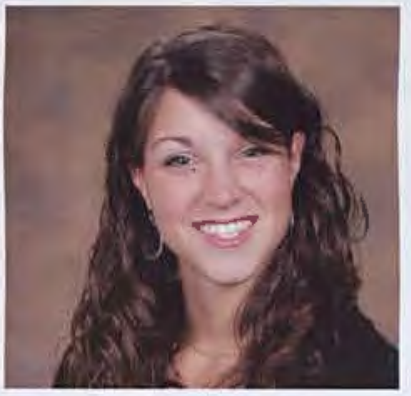

Sarah Brown

Junior Graphic Designer

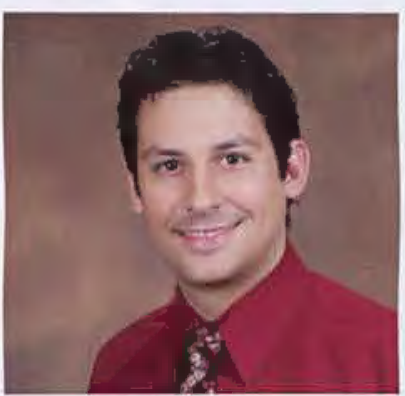

Chad Jackson

Associate Director for Creative Services

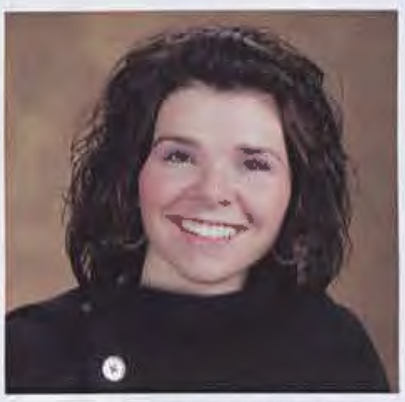

Kate McKallagat

Admissions Counselor

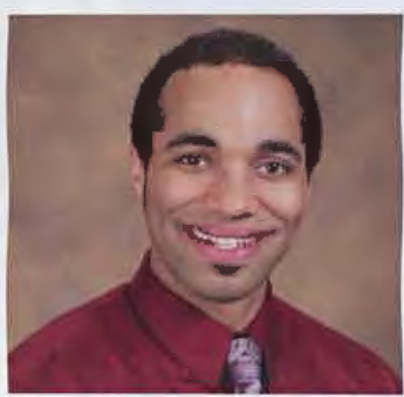

Robert Reid

Coordinator for Intercultural Recruitment

\section{ADMISSIONS}

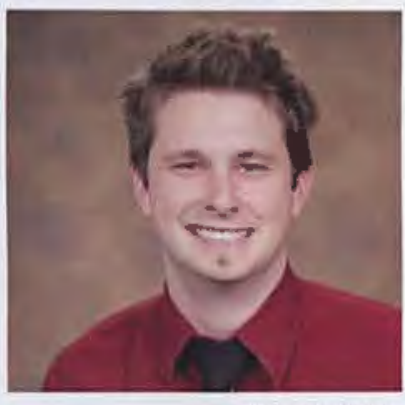

Jason Ney

Admissions Counselor

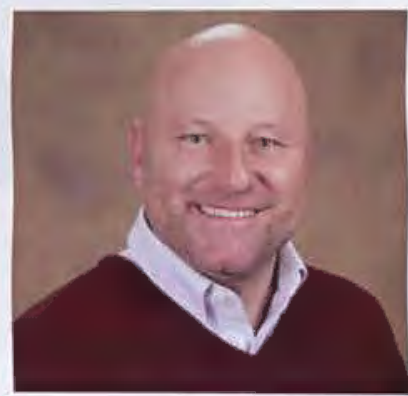

Michael Stream Admissions Counselor

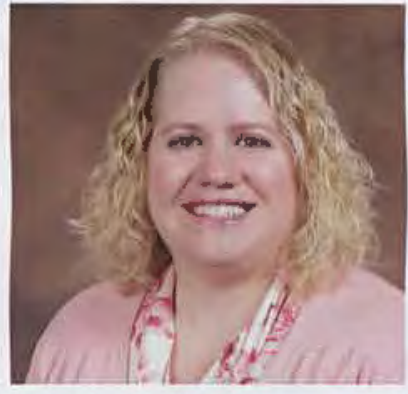

Sharyn Kopf

Assistant Director of

Public Relations

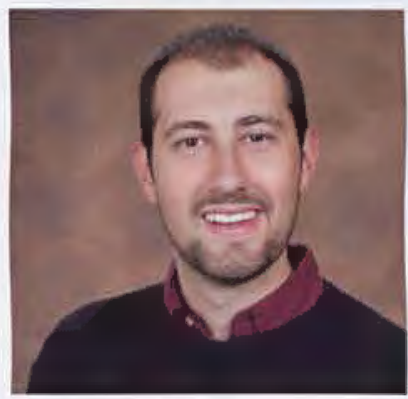

Andrew McKenzie Marketing Copywriter

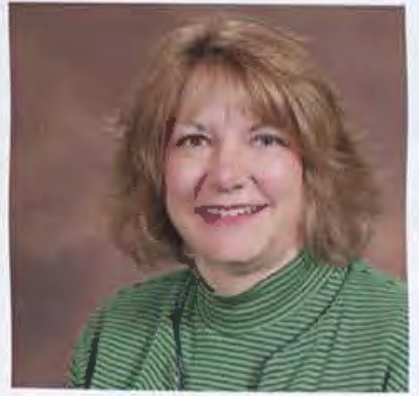

Sandy Yoder

Church and School

Relations

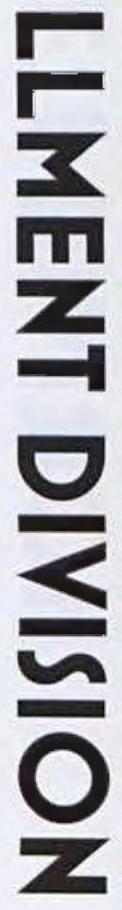

I 


\section{FINANCIAL AID}

\section{$\downarrow$}

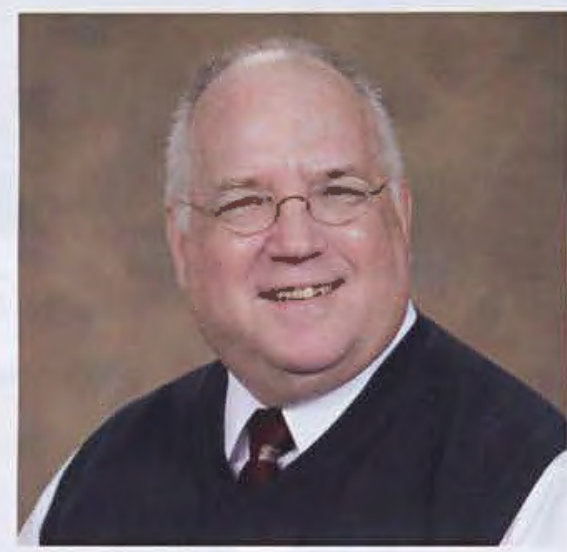

Fred Merrit

Director

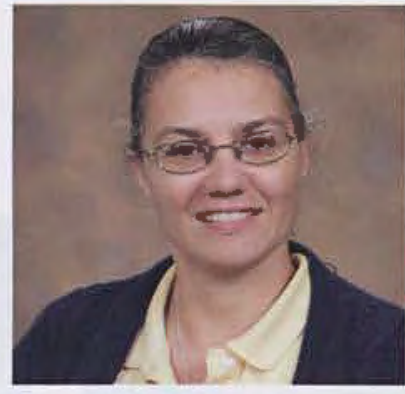

Tonya J. Bailey

Compliance Manager

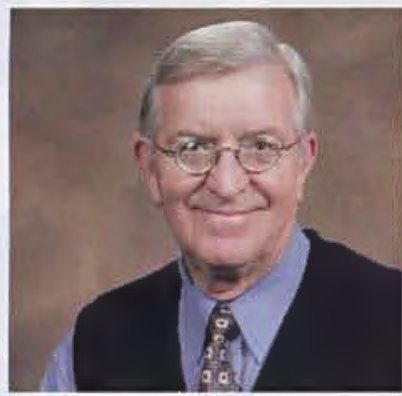

Ken Rotroff

Assistant Director

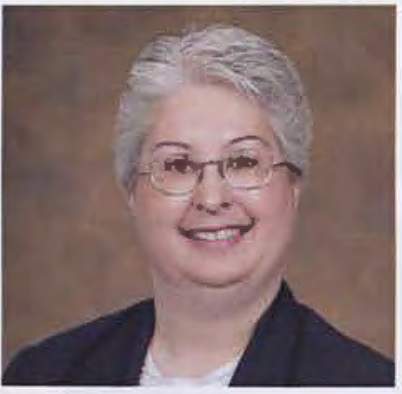

Pamela Flippin

Student Loan Processing Manager

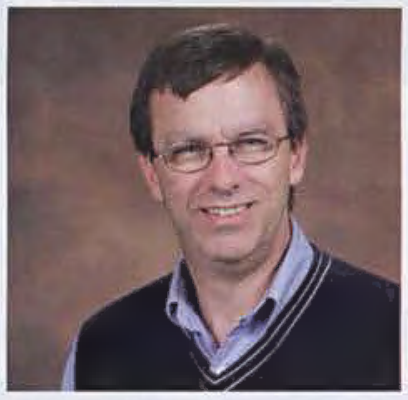

Steve Winey

Assistant Director 


\section{POST OFFICE}

Connie Bradds

Supervisor of Postal Services

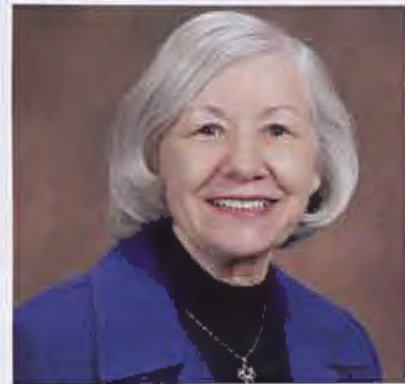

Phyllis Morris Postal Clerk

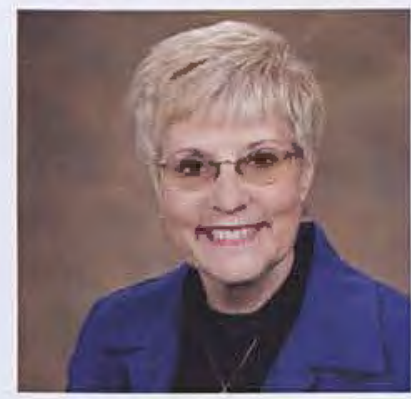

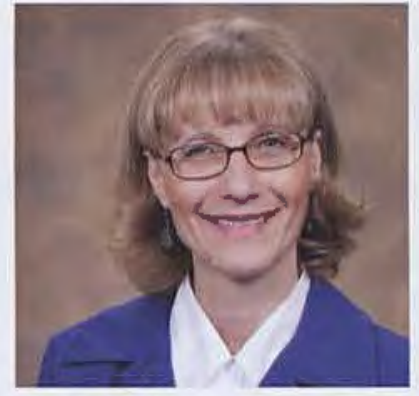

Melody Cato Postal Clerk

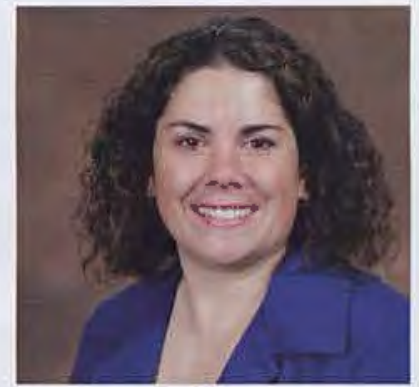

Dawn Wambold

Postal Clerk

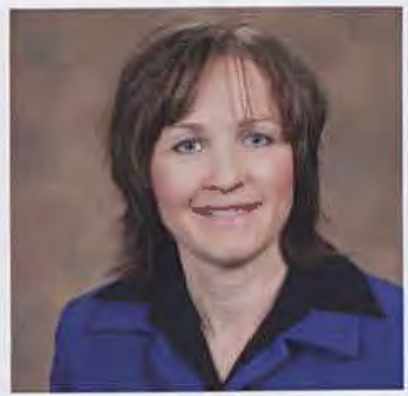

Postal Clerk
Mary Martindale

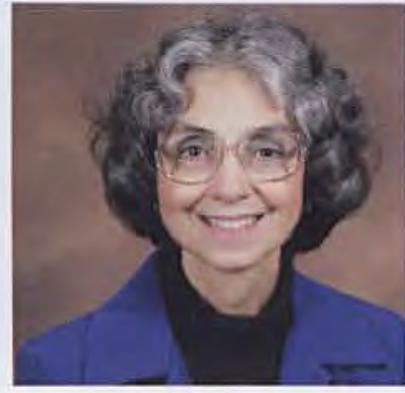

Bonnie McGillivray Postal Clerk

\section{BOOKSTORE}

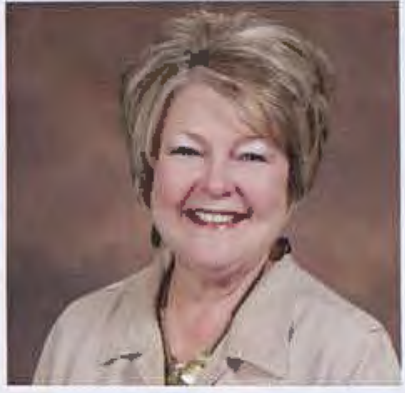

Jean M. LeBlanc Gift and Card Buyer

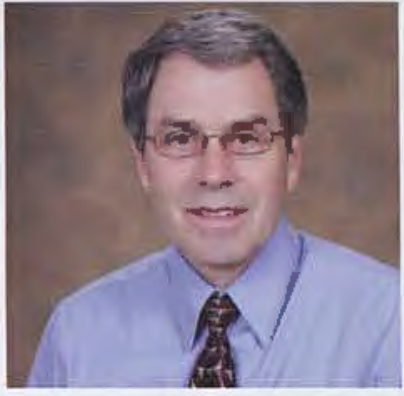

Lee Mattson Supervisor of Bookstore Operations

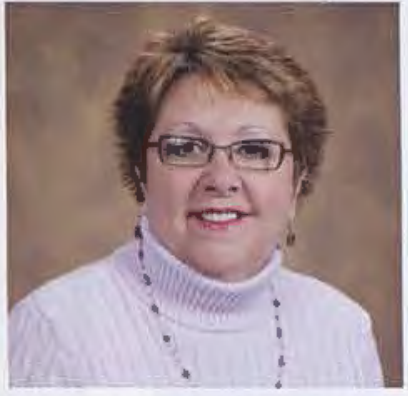

Nellie Tourney Assistant to the Manager

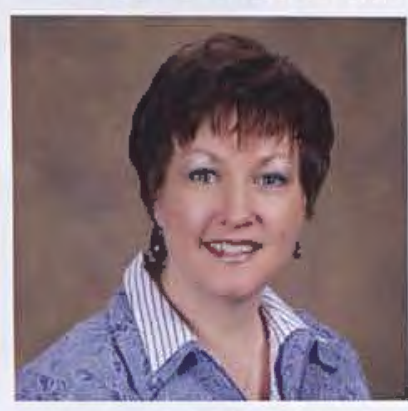

Sarah Young Tradebook Buyer

\section{CAMPUS SAFETY}

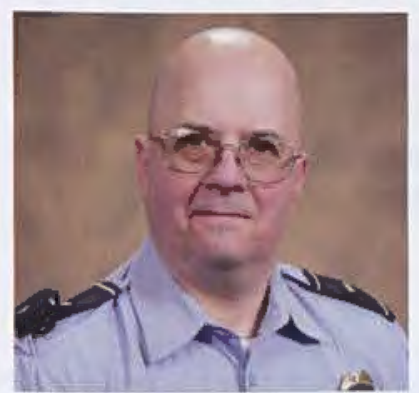

James Bowersox Lt./ Operations Manager

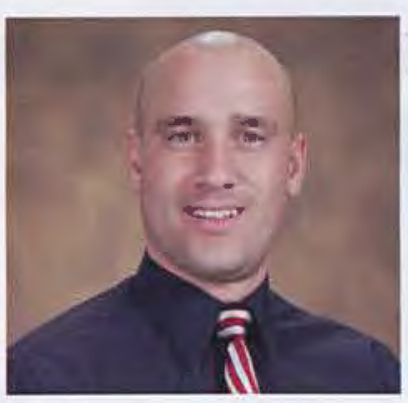

Robert Stiles Officer

\section{MAINTENANCE}

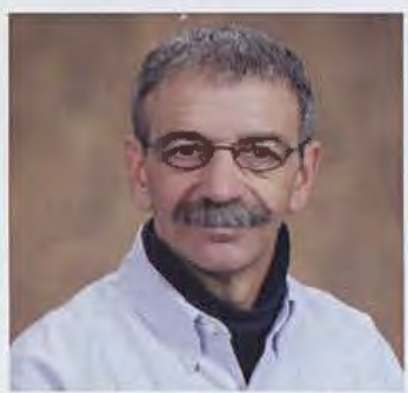

Robert Bielek CAD Technician

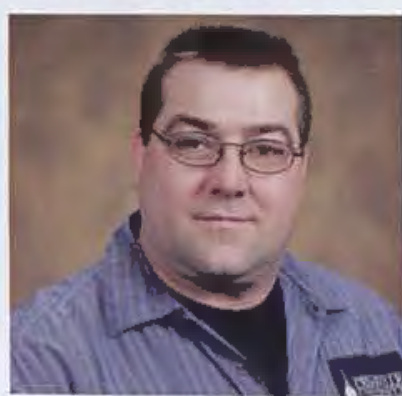

Steve Prether Groundskeeper 


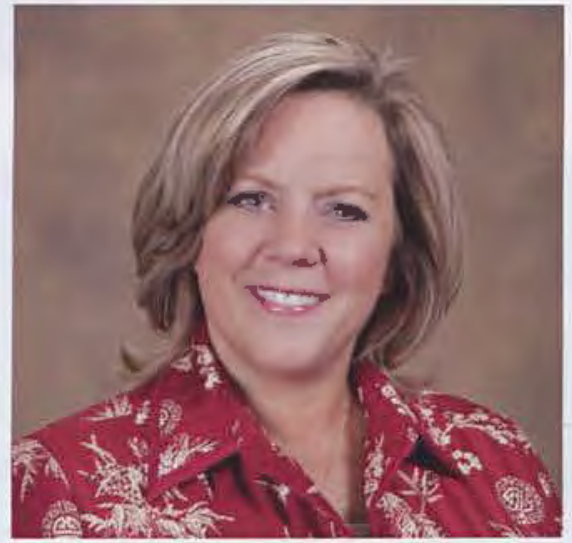

Kim Ahigrim

Director

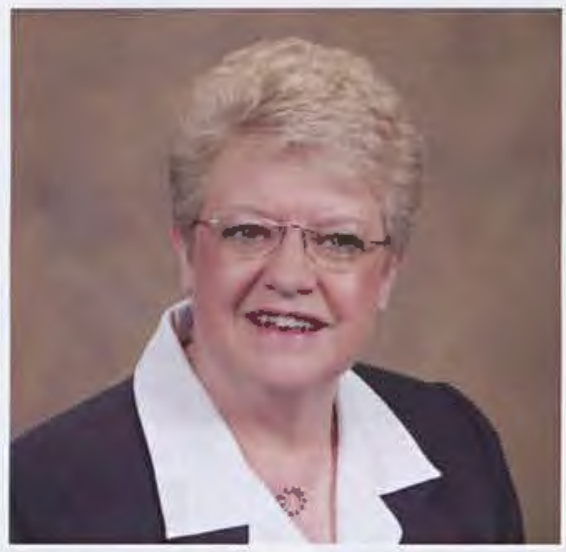

Fran Campbell

Registrar

\section{ACADEMIC ENRICHMENT CENTER}

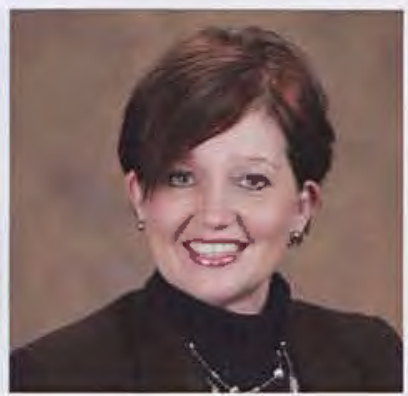

Kerry Stream

Testing and Tutoring

Coordinator

\section{REGISTAR'S OFFICE}

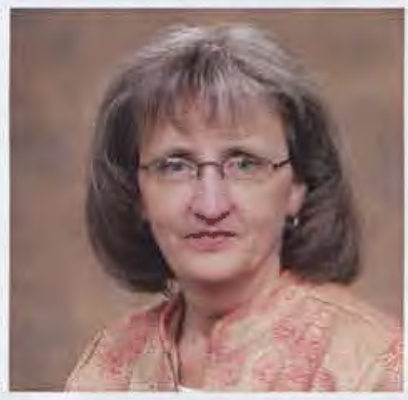

Cynthia F. Davis

Assistant to the Registrar

COMPUTER SERVICES
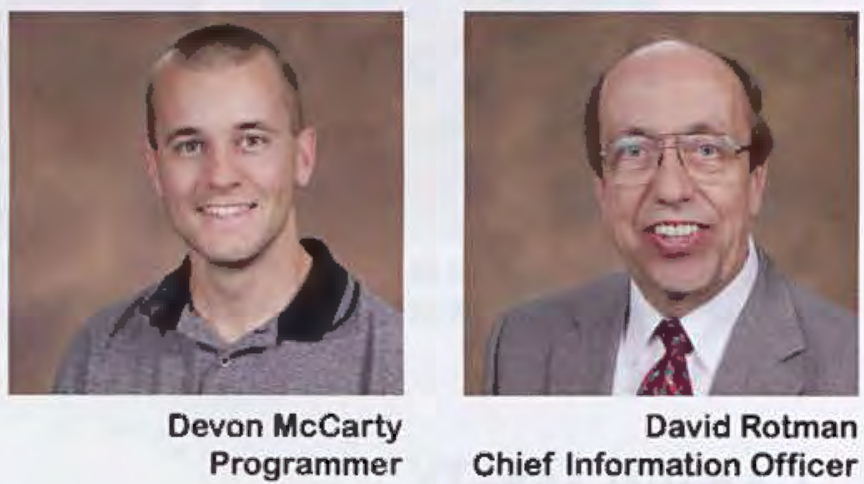

David Rotman Chief Information Officer

\section{DISTANCE LEARNING}

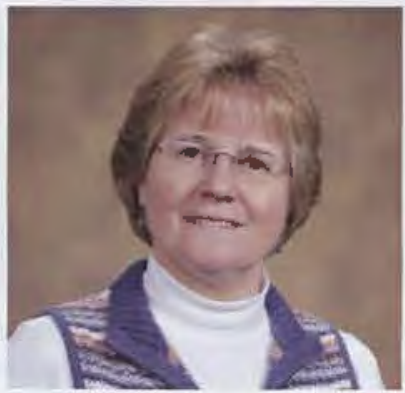

Joy A. Williams

Administrative Assistant

\section{CHANCELLOR'S OFFICE}

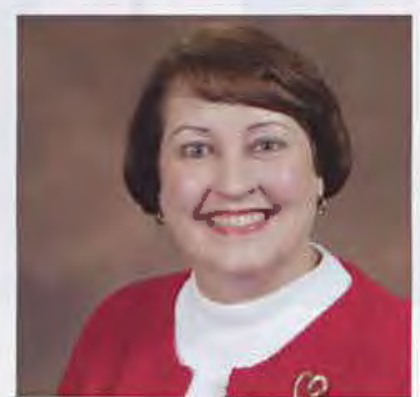

Lynn Rohm

Administrative Assistant

\section{PRESIDENT'S OFFICE}

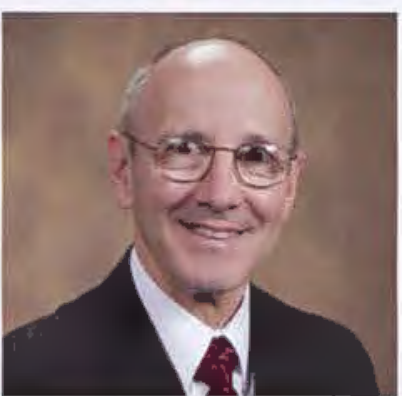

Duane R. Wood Executive Director for Program Development 


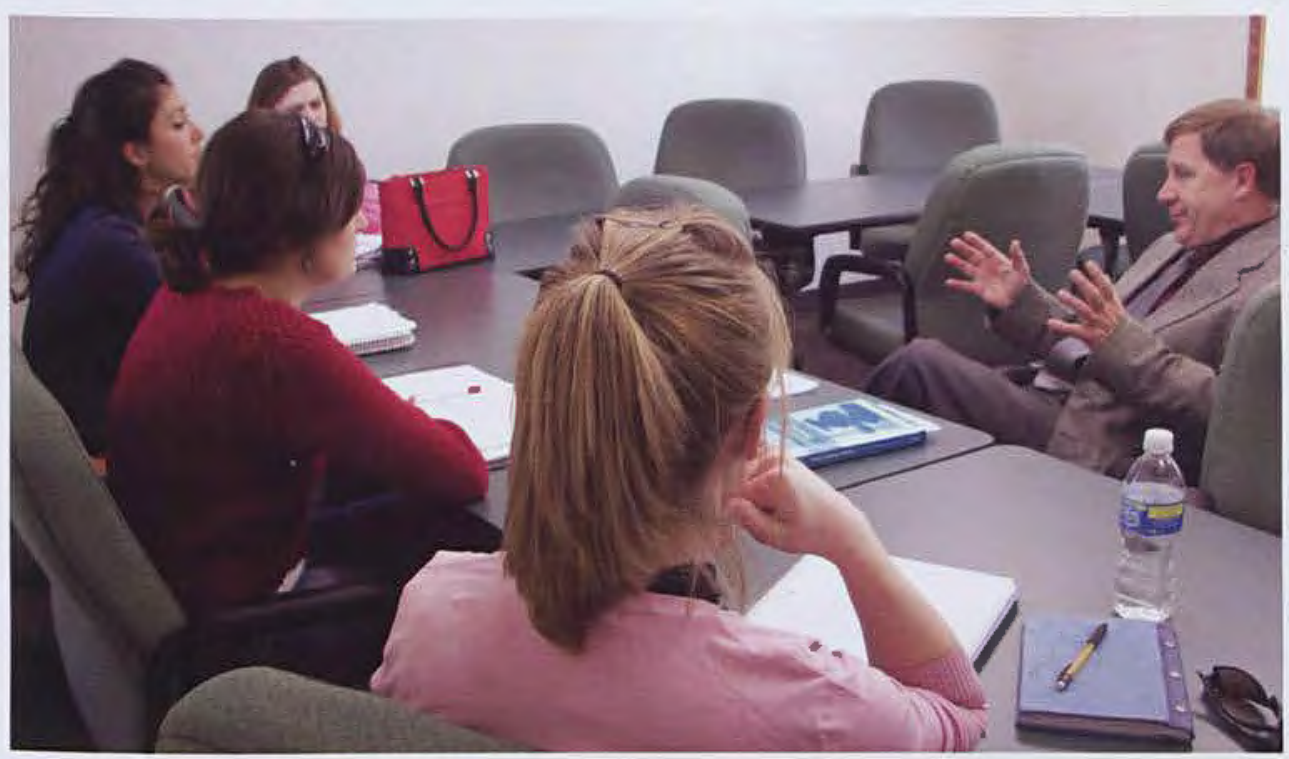

Dr. James Phipps instructs one of his many practical communication courses by working with a small group of students.
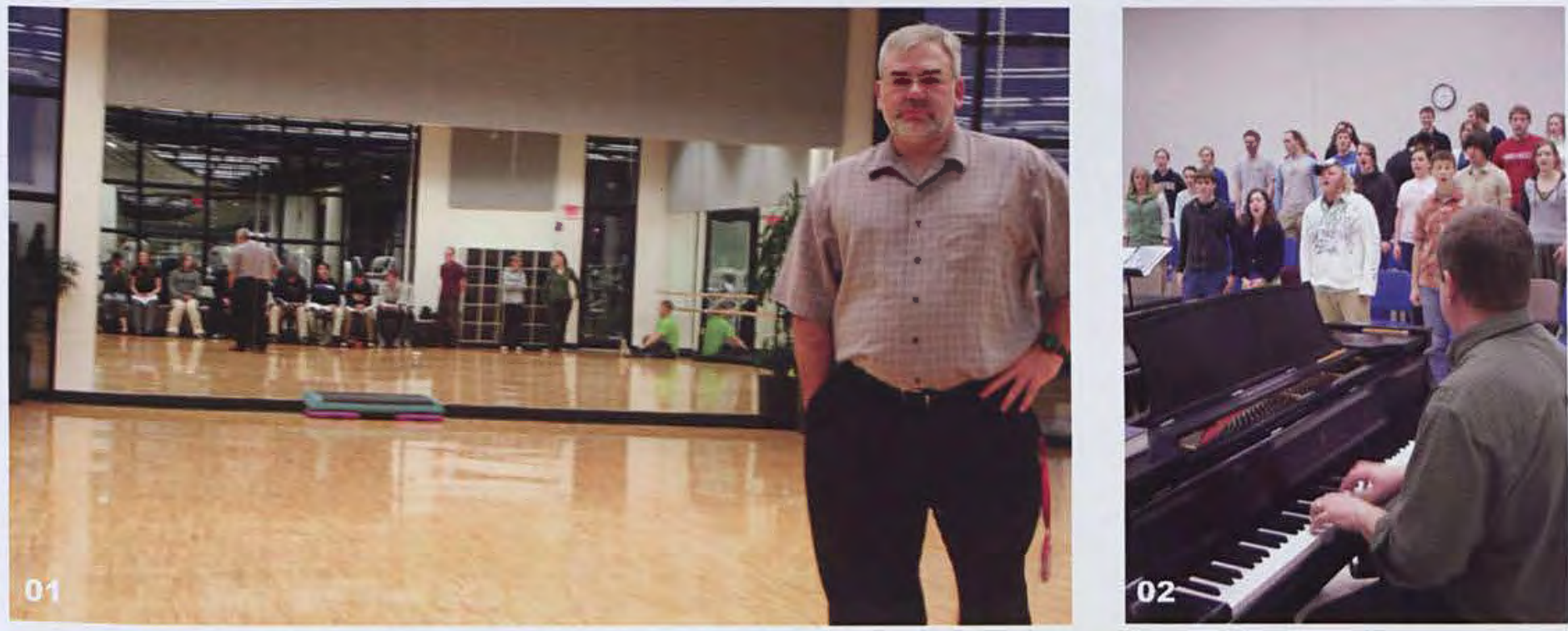

Mr. Ben Belleman takes a moment before beginning his PACL instruction.

Leading Jubilate through their warm-ups, Dr. Roger $\mathrm{O}^{\prime}$ Neel never hesitates to infuse a little comedy.

Dr. Jeff Cook is known as a professor around campus that goes out of his way to stay involved with his students.

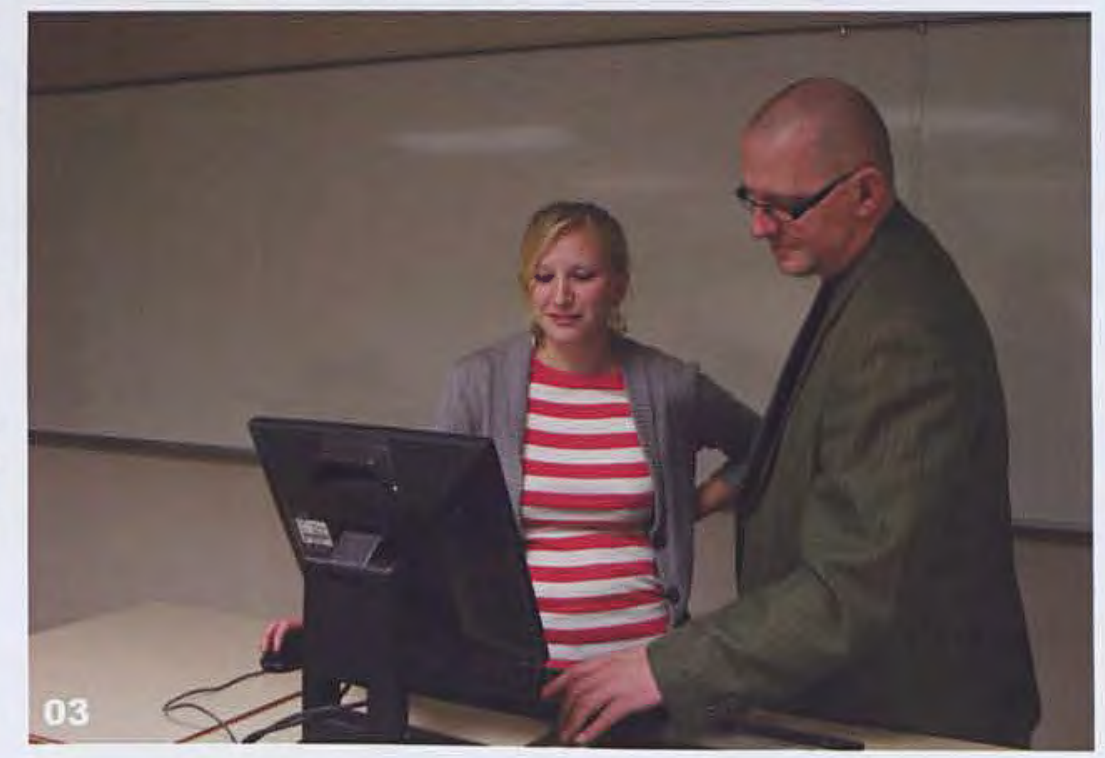




\section{W $\Delta M$}


MuKappa is a warm and friendly , MKs, International Students, or anyone who has an interest in missions or just wants to hear about our experiences."

(Carol Kreeger, president)

"Cedarville's chapter of the Society of Women Engineers exists to support female students majoring in engineering and computer science and to minister to the community. " (Catherine Shanks, president)

"Women in Business is an association of over 65 women of diverse majors at Cedarville involved in professional, social, and service activities." (Liz Taylor, chair)

"STC is a professional org that's great for connecting students with professional technical communicators in the area and over the nation, but we also have a lot of fun and eat some amazing desserts homemade by our faculty advisor." (April Cooper, president)
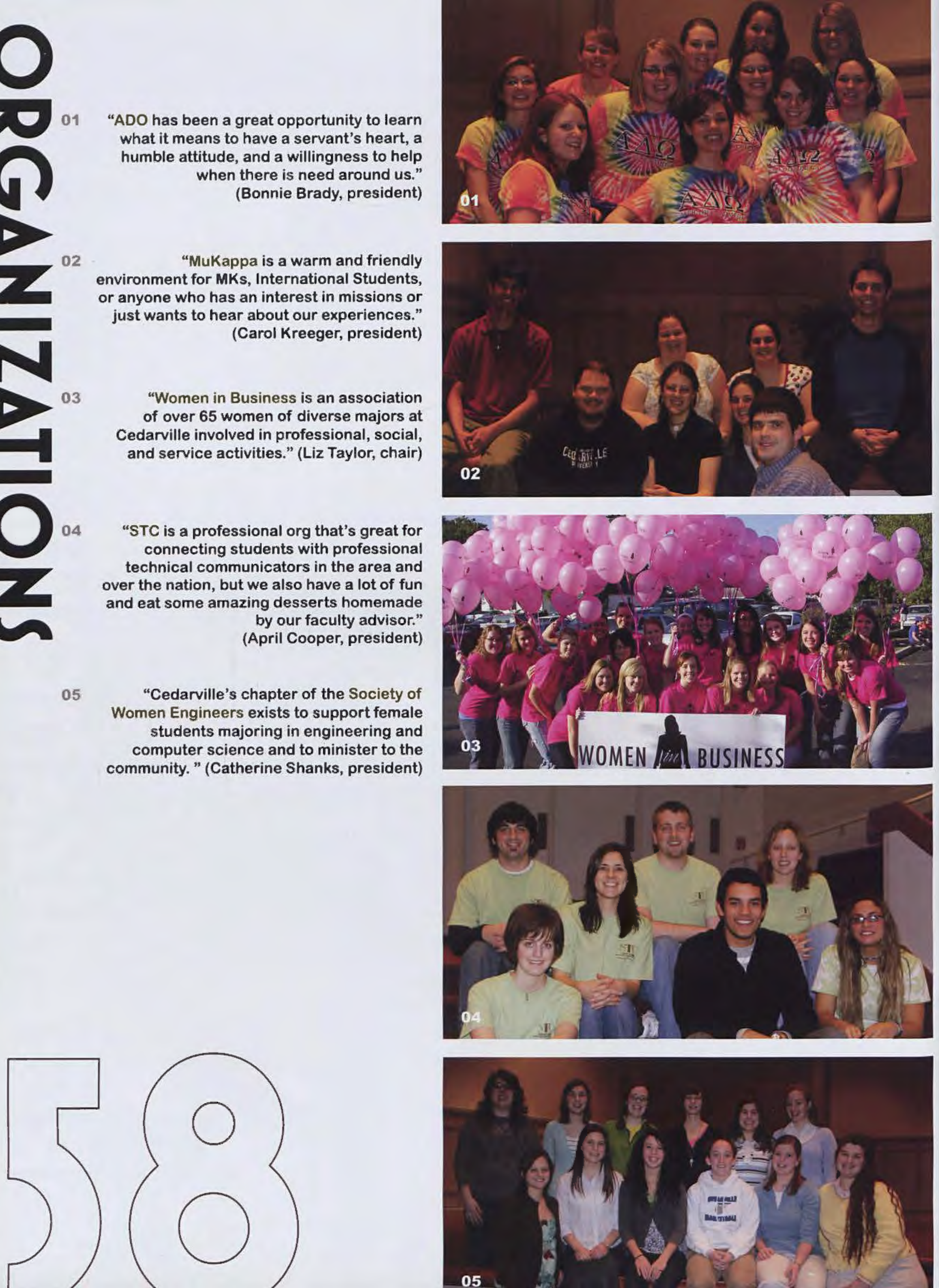

or fortune. In fact, dealing with HIVIAIDS is quite the opposite. It's a clisease of the poor, the infamous, and the unfortunate." (Joshua Saunders, volunteer coordinator)

02 "Being a member of Gamma Chi throughout my time at Cedarville has been an awesome chance to connect with girls from all different majors with a common goal: to serve women on our campus and around the community." (Lachelle Richter, president)

03 Amplified's purpose is to be a place where people can come and encourage each other in a common passion for inner-city ministry and to bring an awareness to Cedarville's campus. "Hearing the cries of the city."

(Sarah Miller, president)

04

"The first year of Basilean can only be described as a success. Should the quality of men be anywhere near this standard in the future, the organization can only go from strength to strength." (Jason Heuer, president)

"The DBA Student CEO is a group whose purpose is to enhance the relationship between students and faculty, provide a student's perspective on DBA issues, help organize events for business students, and

help promote the department by meeting with prospective business students." (Susan Terkelsen, advisor)
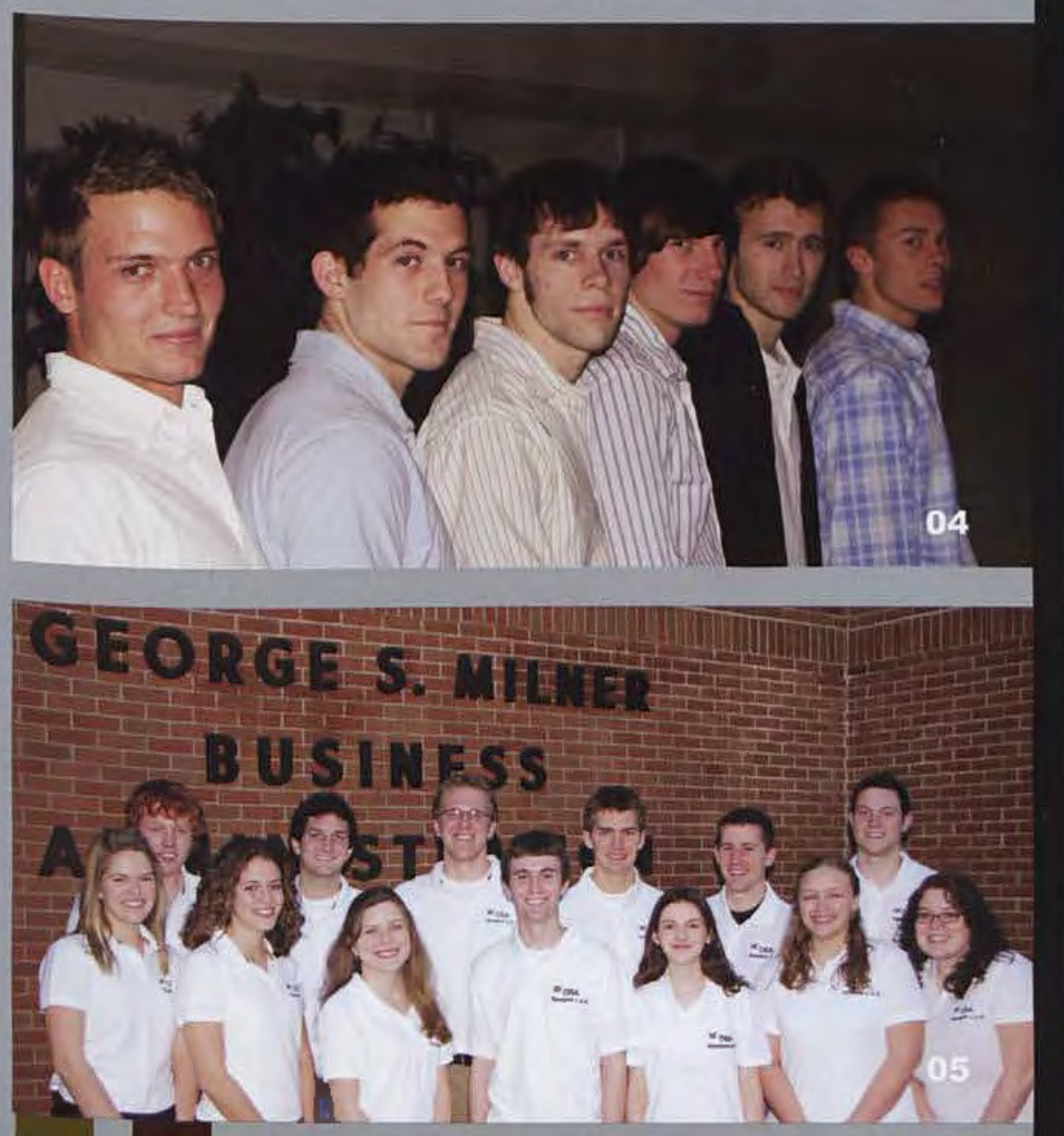

02

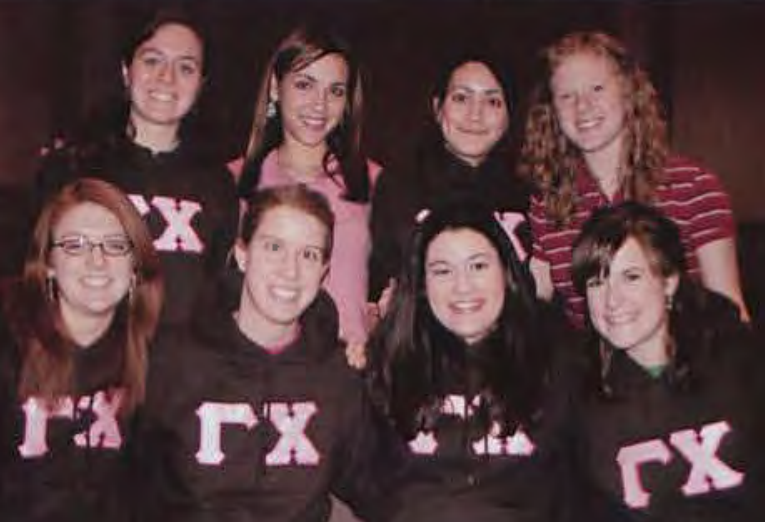

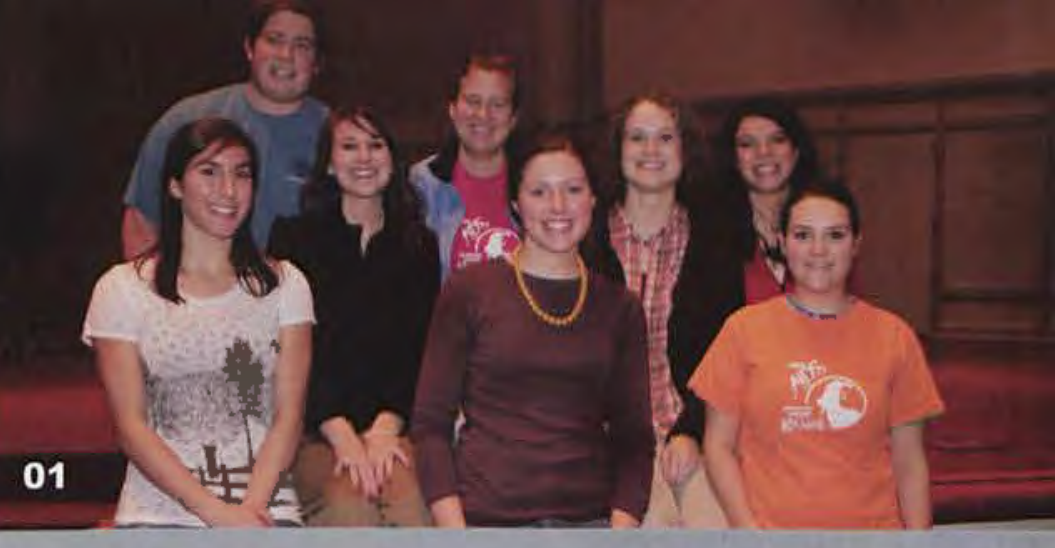
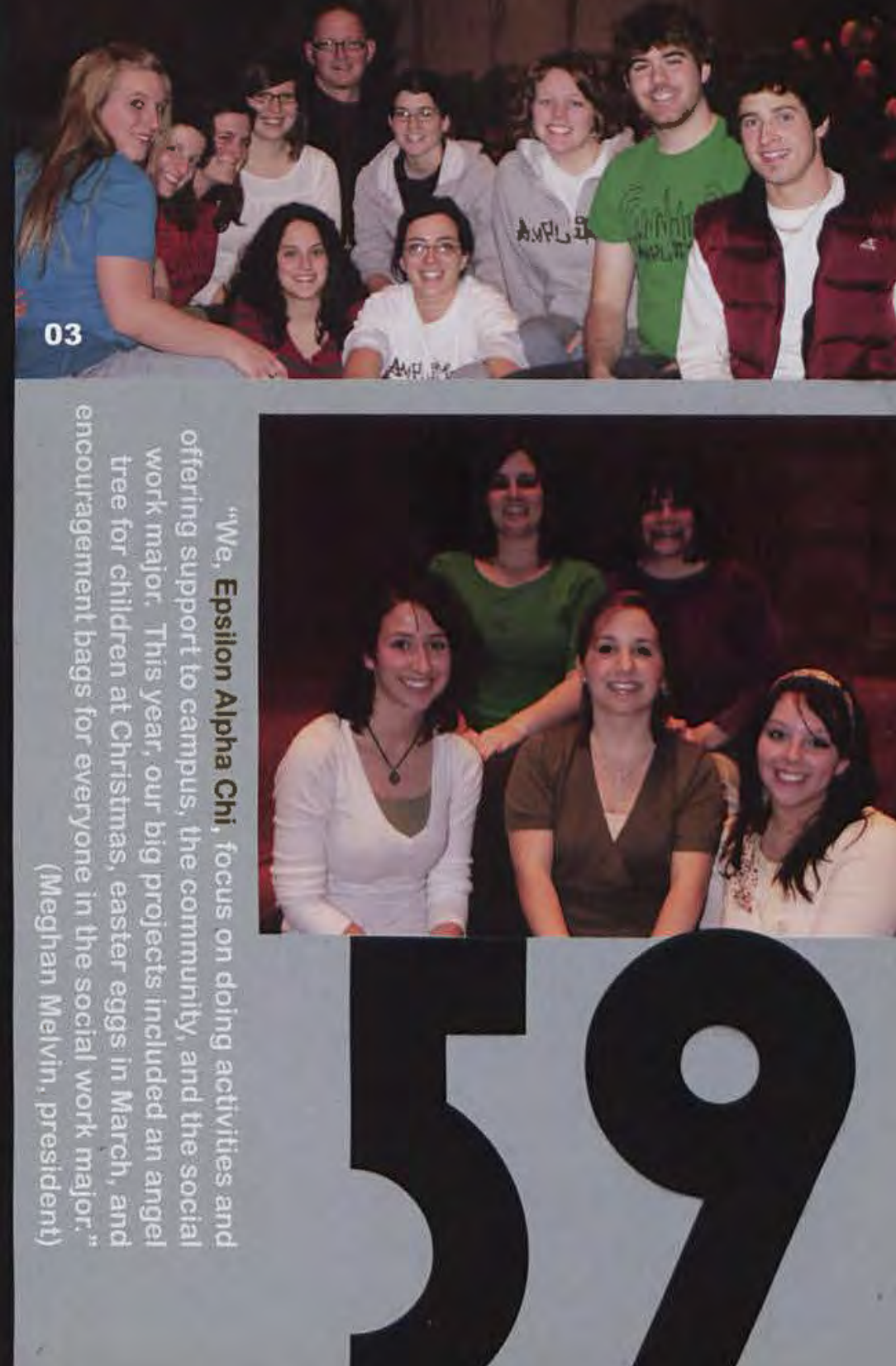


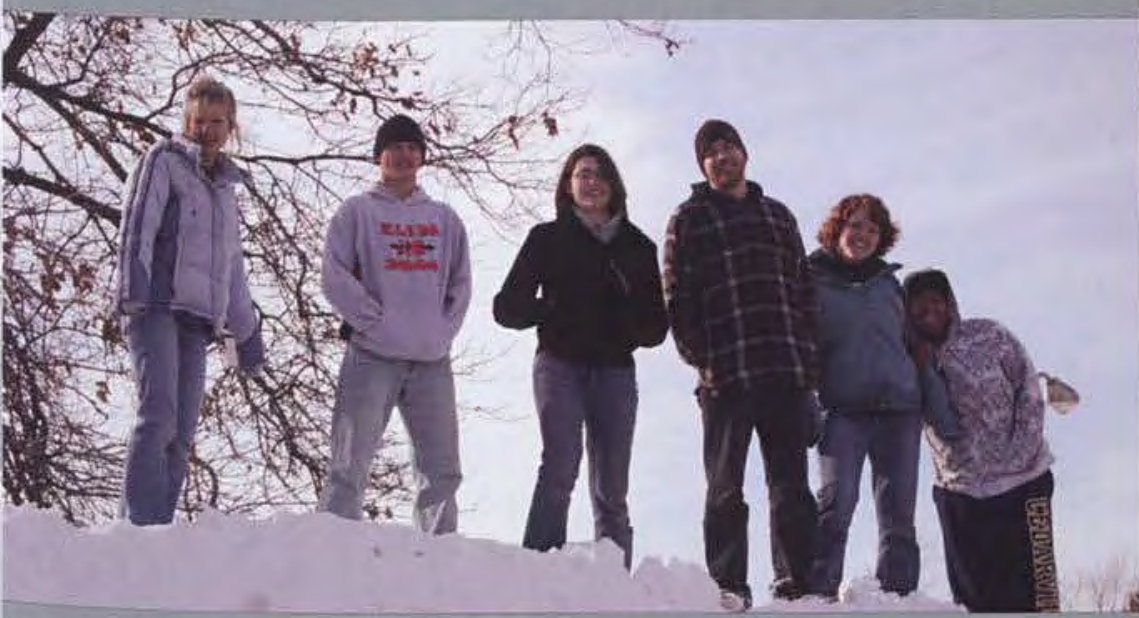

"Don't let the crazy people standing on snow banks fool you - people at Amplified have an authentic love for their brothers and sisters on campus, and they want them all to be aware of important issues relating to urban ministry." (Christy Cunliffe, sophomore)

"I really enjoyed the opportunity to connect with everyone in TDK this year, starting with the retreat over Labor Day weekend. It was a great time to build relationships with the freshmen and strengthen the ones with the upperclassmen."

(Jessica Korthais, sophomore)

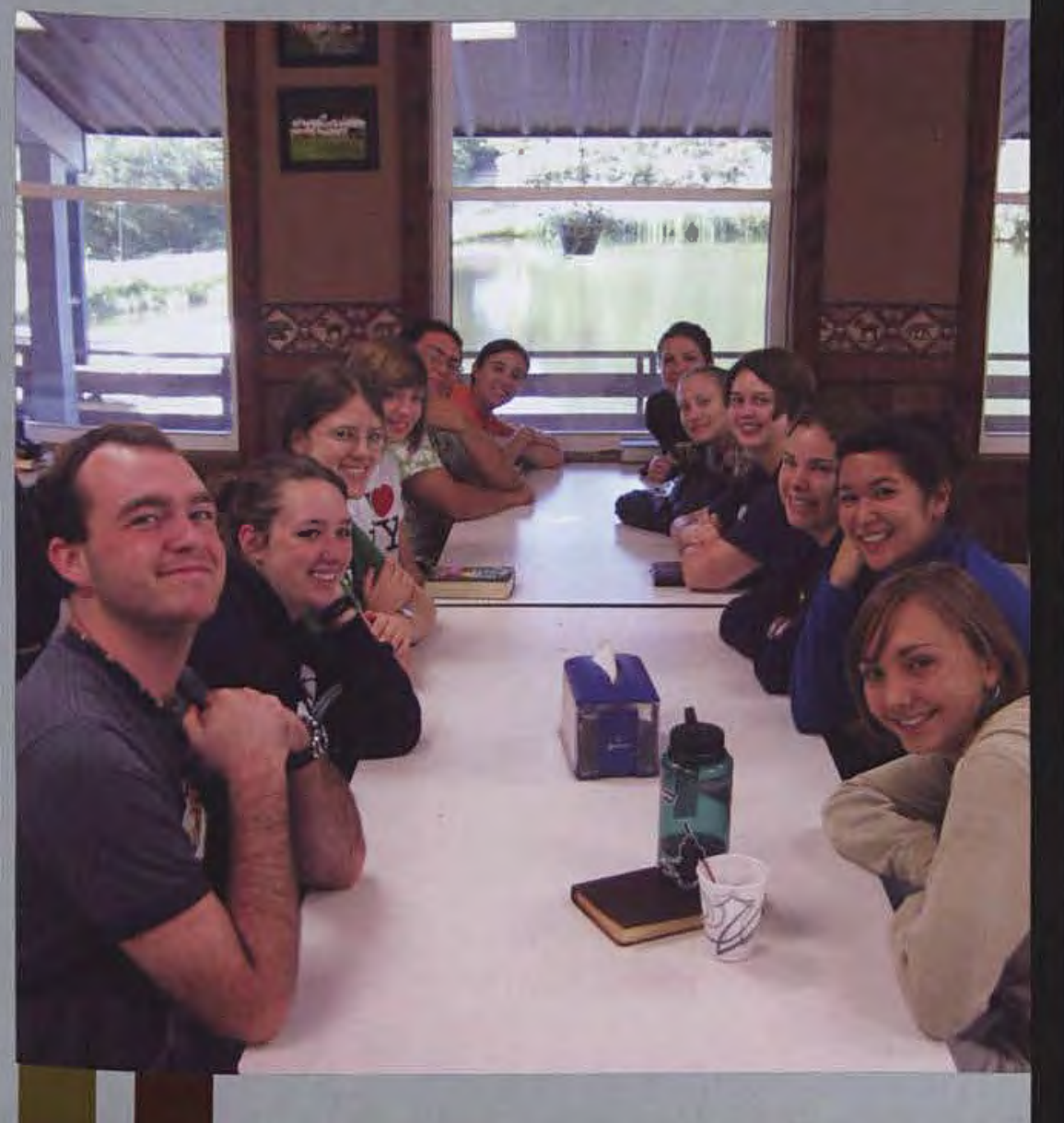

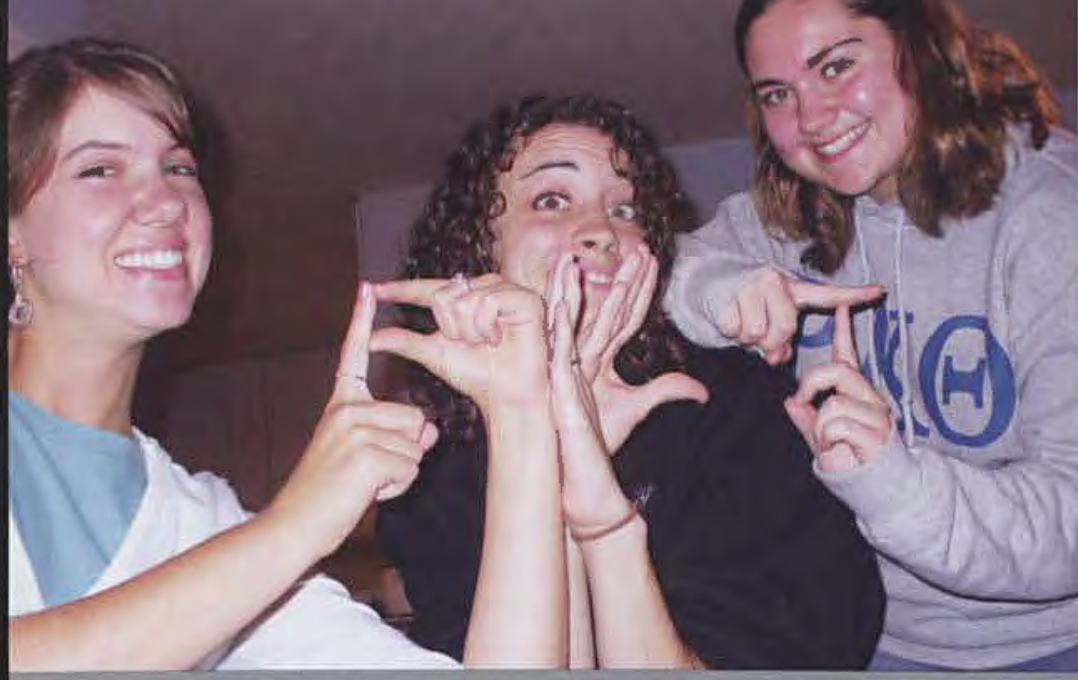

Members of Psi Kappa Theta, Cedarville's psychology organization, show off their org pride.

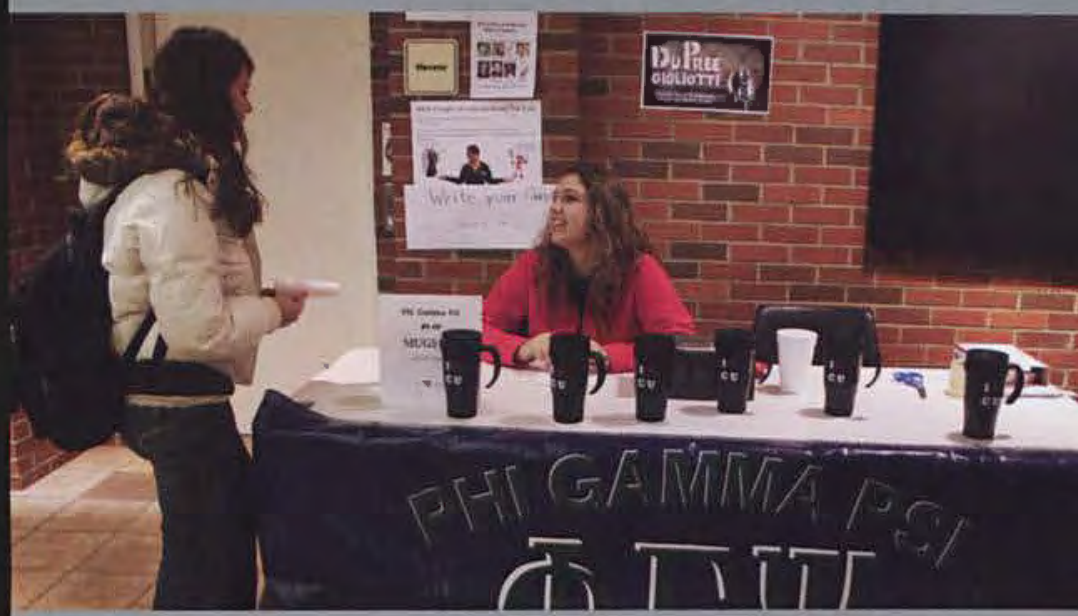

The girls of Phi Gamma Psi sell their customdesigned CU travel mugs. 
01 "Our mission in SPL is two fold: Love God. Love people. Brotherhood serves as the catalyst for the former:" (Pete Ledger, president)
02 "The purpose of the German club is to
promote the use of the German language
and to increase the knowledge and
appreciation of German culture."
(Katharina Stevens, vice president)

03 "Sharing our [HAFA] passion for healthy lifestyles with those around us has become even more important in a world of high obesity rates and skyrocketing health care cost." (April Crommett, advisor)

04 "In TDK, we try to foster friendships among honors students so we can challenge and encourage each other to grow intellectually and spiritually." (Mark Miller, president)

05

"DAE is a student-alumni service org
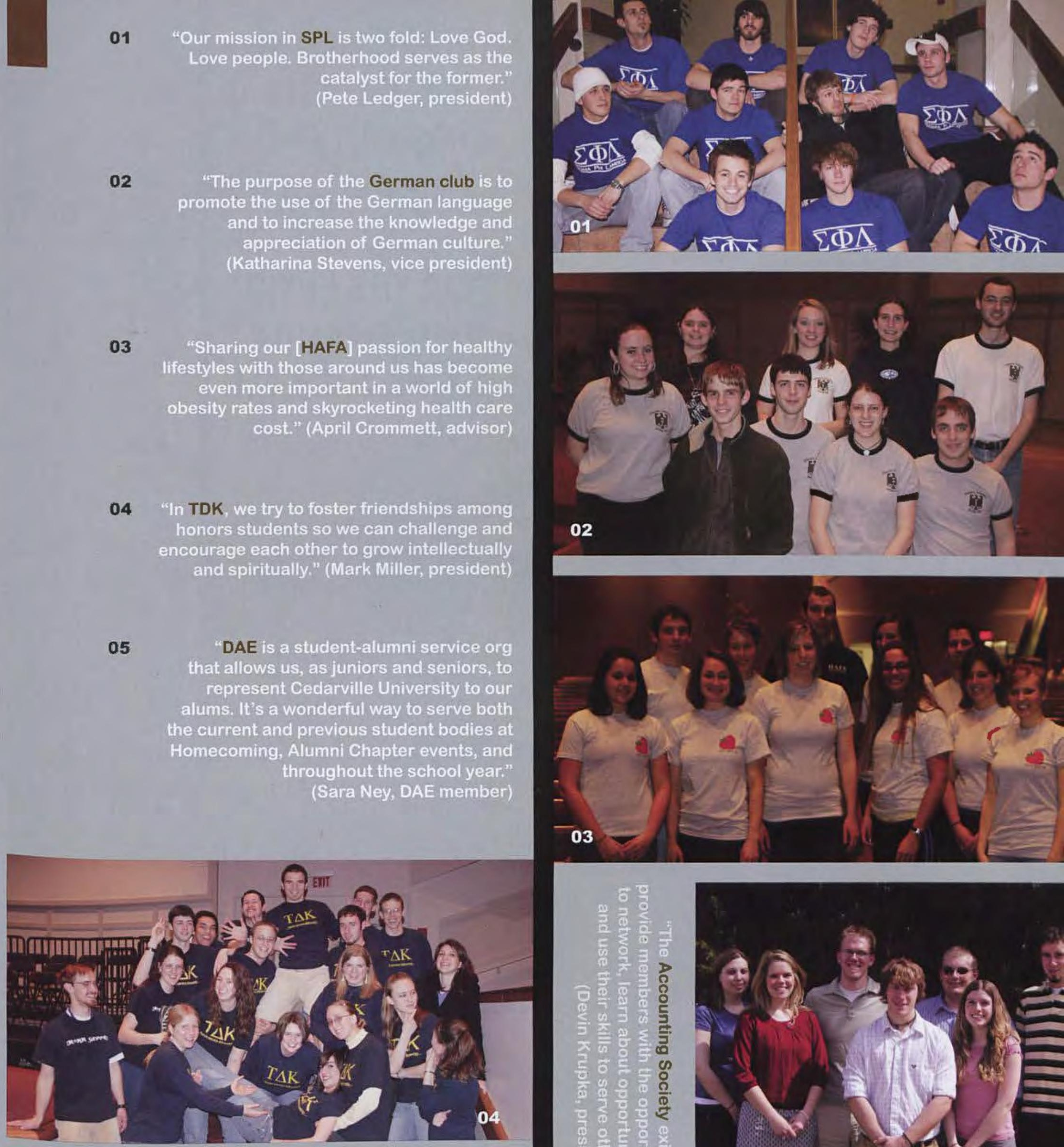
that allows us, as juniors and seniors, to represent Oedarville University to our alums. It's a wonderful way to serve both the current and previous student bodies at Homecoming, Alumni Chapter events, and throughout the school year. (Sara Ney, DAE member)

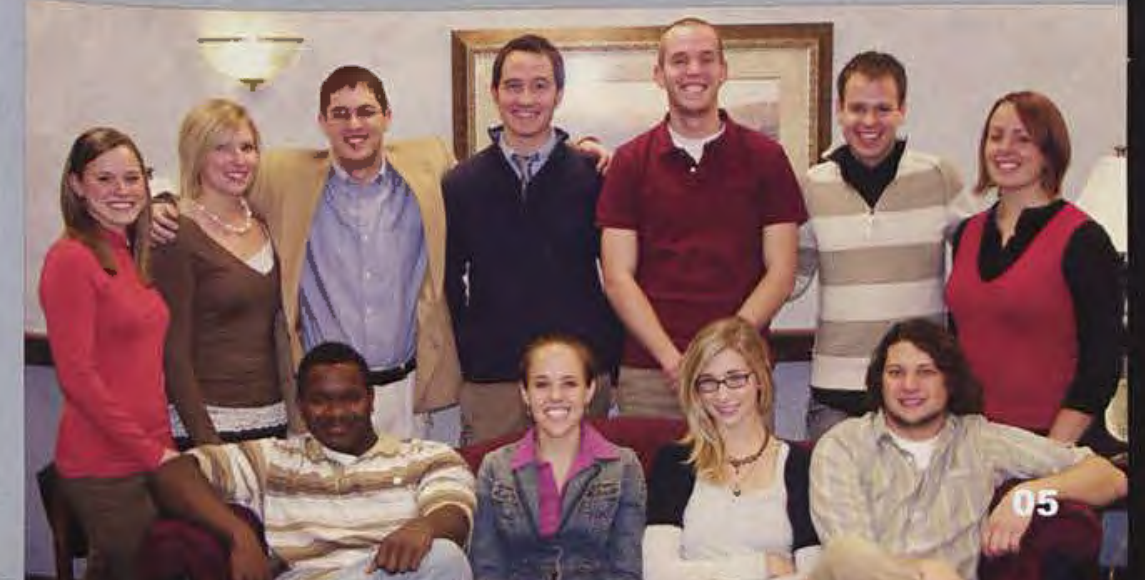

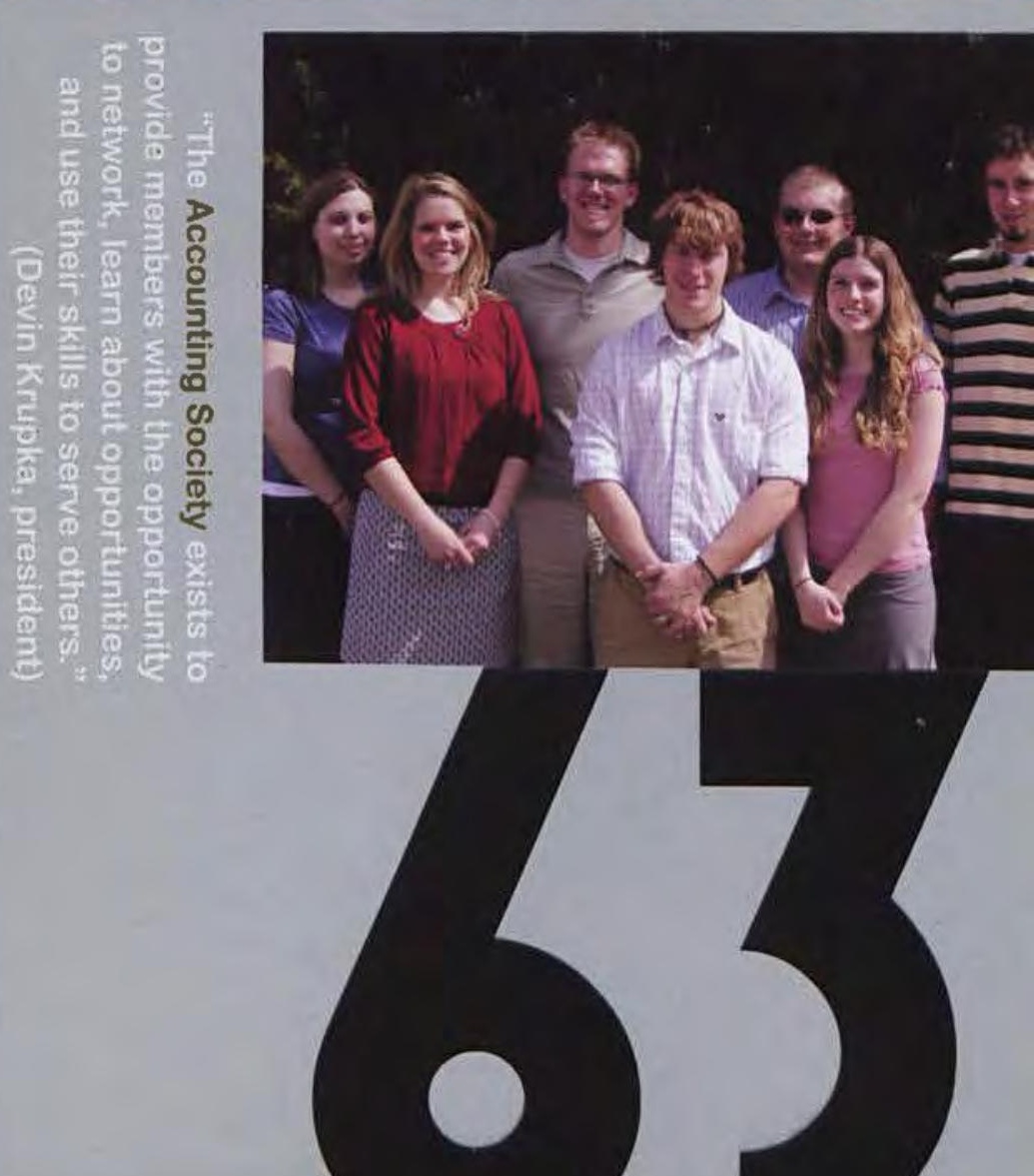




\section{"P.E.A.C.E. PROJECT (PROMOTING ETHNIC AND CULTURAL EDUCATION) IS $\triangle$ SERVICE AND SOCIAL ORGANIZATION THAT SEEKS TO FOSTER AND PROMOTE $\triangle$ GOD- CENTERED ATTITUDE OF MULTICULTURALISM FOR THE ENTIRE CEDARVILLE FAMILY." _BRIANA DUPREE, PRESIDENT, P.E.A.C.E}

Some of the members of The Society of Women
Engineers (SWE) pose with their picnic table,
built as a service project in Fall 2007, now located on the lawn by the ENS.

Basilean members sort through the generous donations for their Zimbabwe clothing drive. "We collected almost 1,000 pounds of clothing from Cedarville students, faculty and alumni. The drive occurred right before Christmas break, which I used to go home to Zimbabwe. I took all the children's clothes that we had, and brought them to an orphanage close to my house." (Jason Heuer, senior)
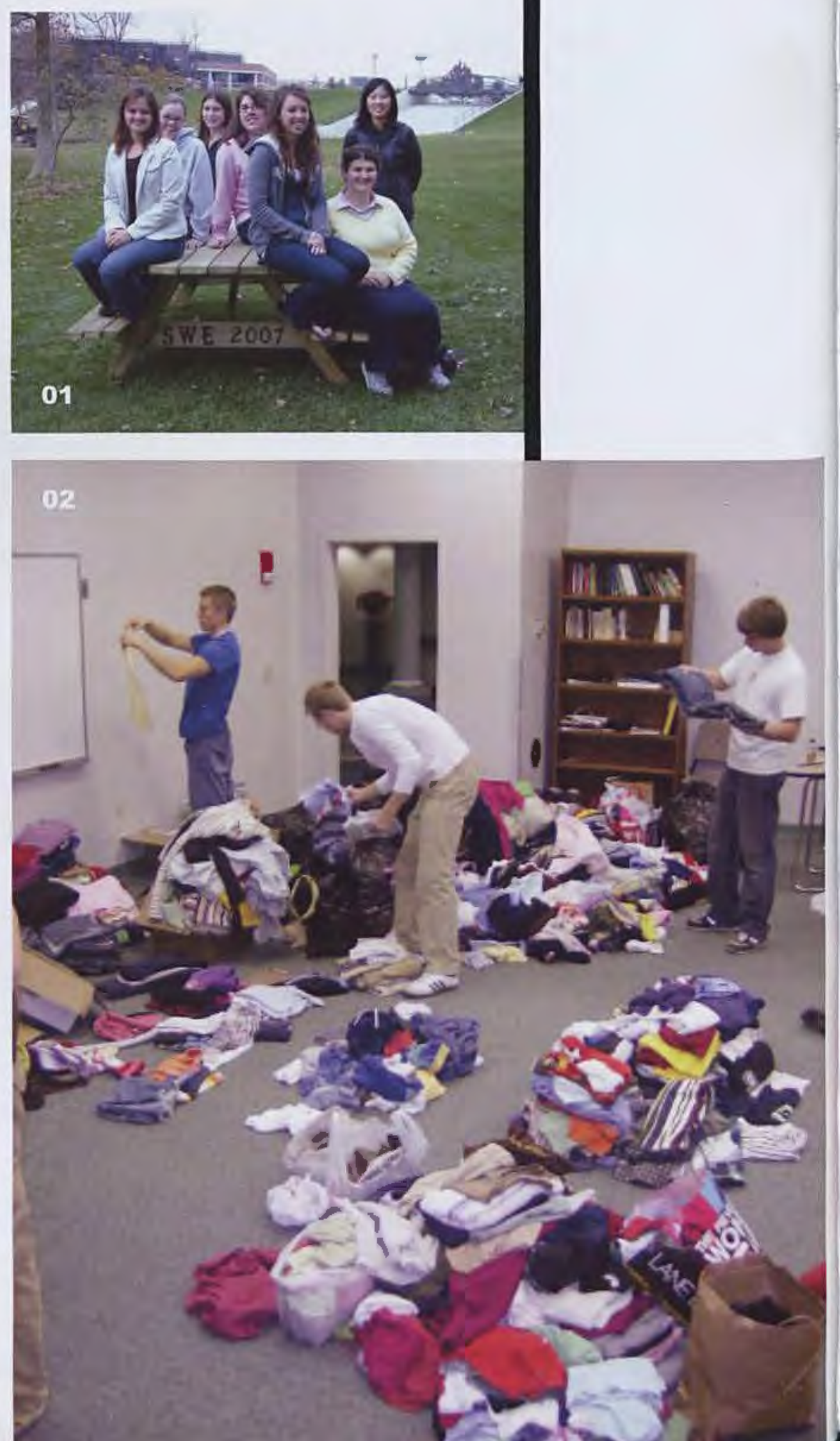


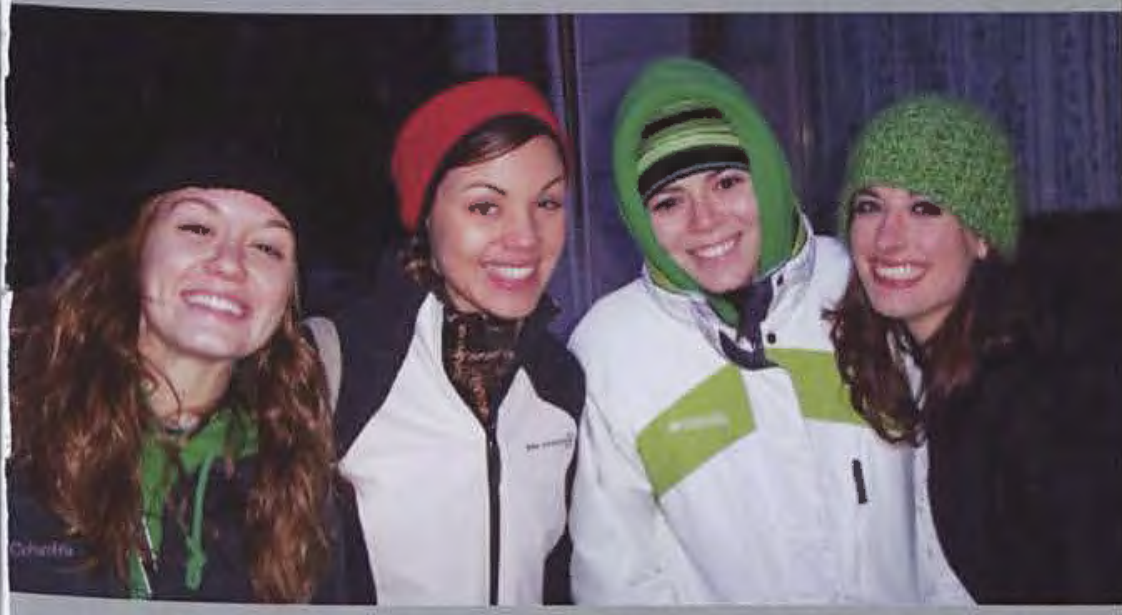

ADO members Jenny Stern, Bonnie Brady, and Amy Jacobs help out with "Little Town of Lights" in Cedarville.

"I enjoyed spending time with girls who have hearts for service... \{and have\} inspired me to serve willingly, humbly, and genuinely. I'm so excited to see how much closer we can grow together next year!" (Heather Flippin, sophomore)

"At our PGP induction, we had to transfer hidden gummy bears in chocolate filled plates into cups. I'm pretty sure we all were smelling chocolate pudding for days!" (Emily Ruffner, sophomore)

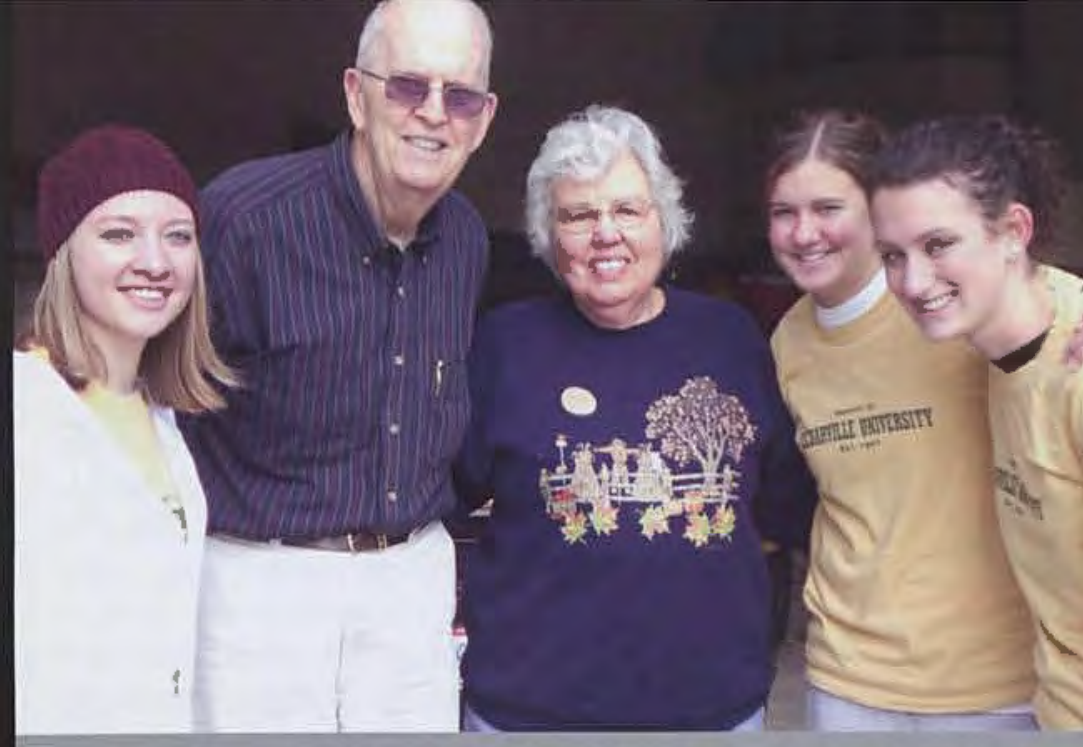

Big Bird, a service organization, and its members give back to the community. "I really enjoyed our day serving the some of our neighbors in Cedarville. It was fun to serve together in a tangible way! (Angela SanGregory, sophomore)

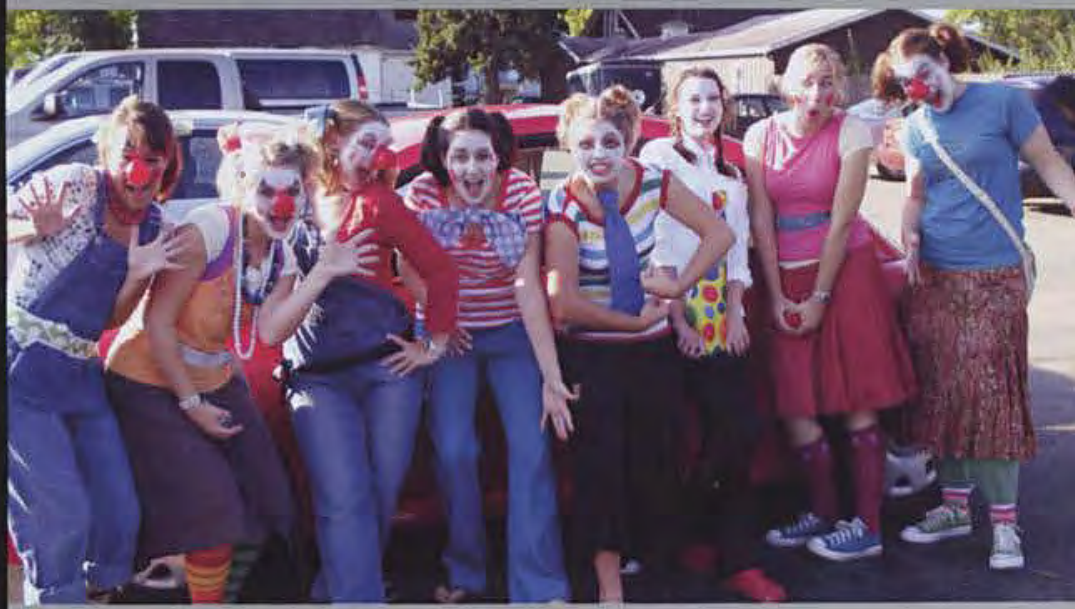

Women's social service org Phi Gamma Psi "clowns around at the Homecoming Parade," according to sophomore member Kaitlyn Cook.

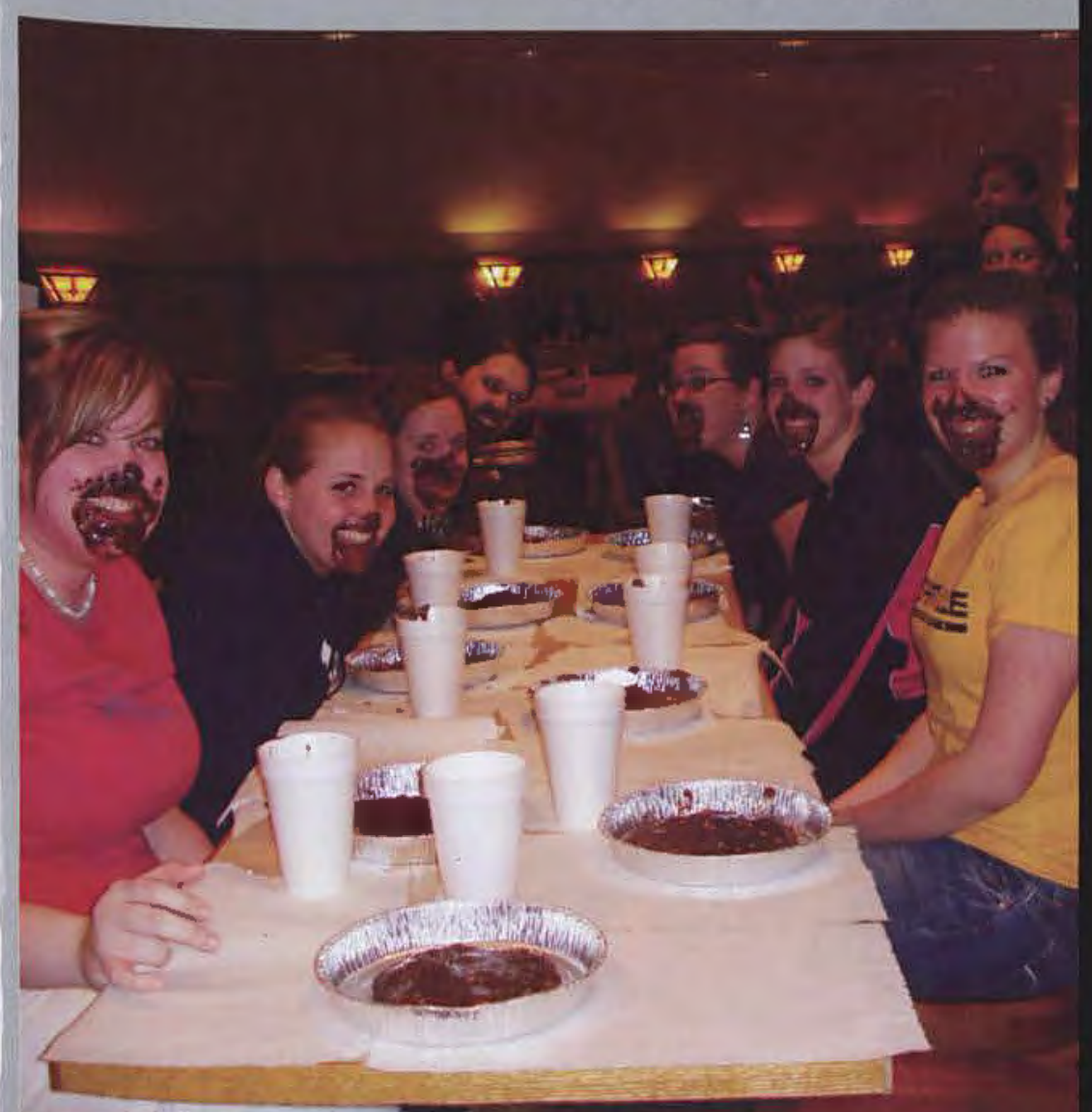




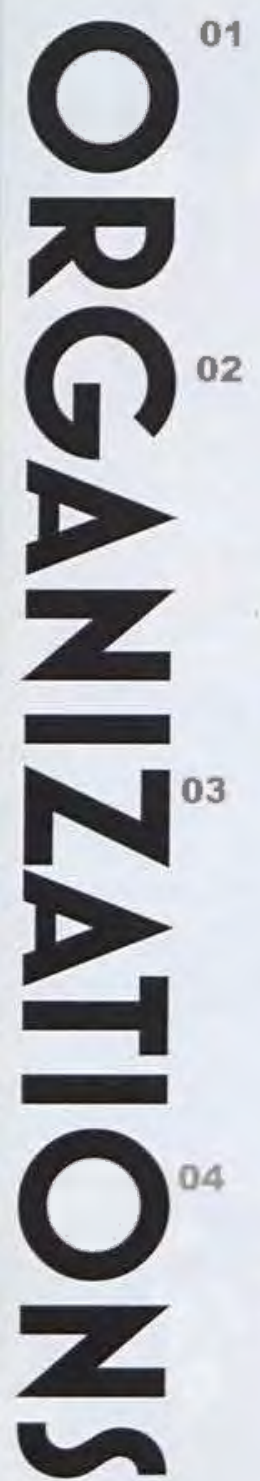

"Nothing is better than a group of guys

(OPE) working together to be better leaders and more Christ-like. I really enjoy seeing twenty-five different guys with different passions learn to support each other."

(Bobby Childs, president)

"The greatest thing that was encouraging to me this year was the enthusiasim of the members of Alpha Sigma Lambda.

Everyone was eager, willing, and quick to participate in the things we did. We had a small fundraiser for a ministry to the deaf in

Dayton. I am excited to see where the club goes next year." (Jennifer Lester, president)

"Psi Kappa Theta has helped its members broaden their appreciation for the field of psychology and each other's interests. This org has been great to be a part of, and I am thankful to have had the opportunity to get to know its enthusiastic members!" (Lauren Laake, president)

"PEB, Cedarville's women's service organization, exists to reach out and serve women at $\mathrm{CU}$, in surrounding communities, and around the world through. As an all-girls organization, we rejoice in being Friends for Life but, most importantly, Sisters for Eternity!" (Holly Foreman, president)

"Zeta Pi Sigma grew much closer this year through being shot with paintball guns and moving jet-skis. We are continually striving

to cultivate male leaders on this campus and encouraging men to grow in Christ. ZPS is a group of guys with a passion for Christ and a passion for Cedarville. Plus, I think we can say that we can make the largest group pyramids on campus. Well, other than the cheerleaders." (Kurt Groman, member)
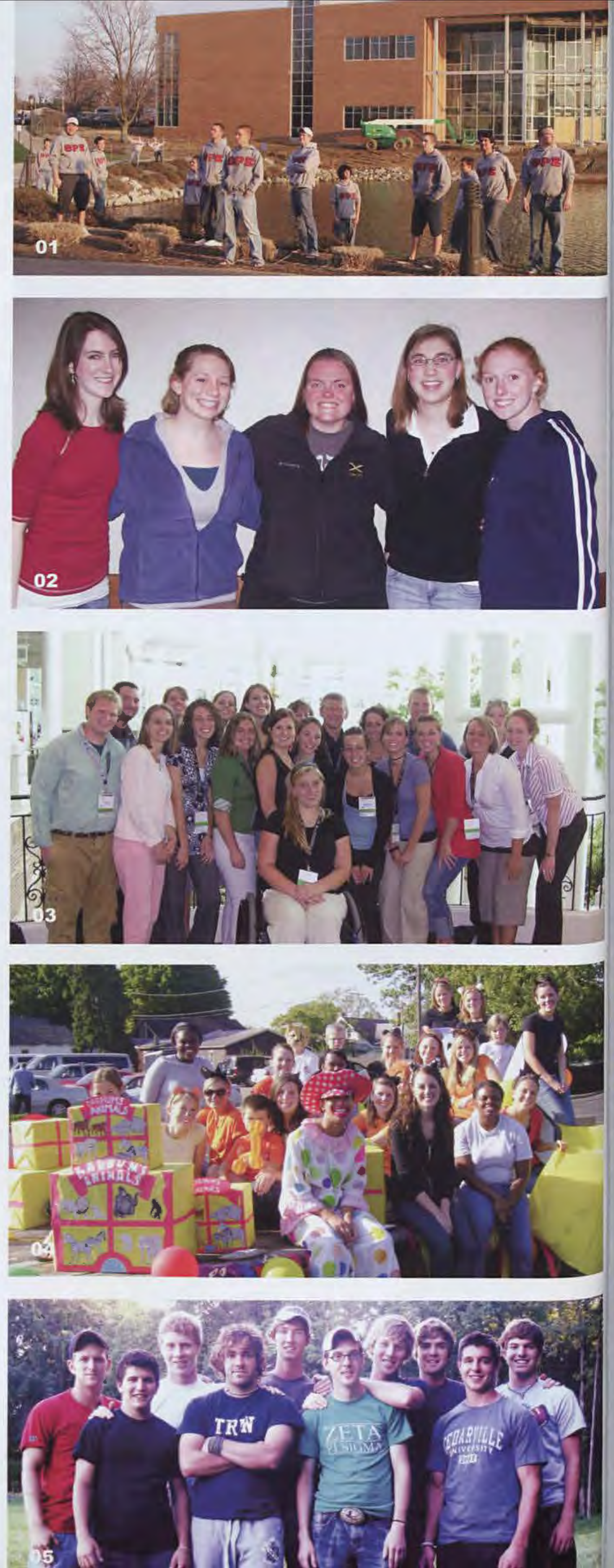
Women of Vision is a group who serve in the community while learning about global poverty and human rights issues. We're passionate about serving people both here in Ohio and our brothers and sisters overseas." (Sterling Meyers, president)

\section{2}

"Alpha Psi Omega exists to serve and glorify Christ through the medium of theatre.

There are only a handful of mediums that can show humanity's fallen nature, need of a savior, and God's amazing grace so purely... and theatre just happens to be one of them."

(Alex Vaughan, president)

03

"DPS is a women's organization on campus Who's focus is to serve the faculty and staff of Cedarville while building one another up in the Lord. We love to laugh, have fun, yet serving all at the same time."

(Tiffany Inskeep, president)

04

"l love how Big Bird reaches out not only to meet a need, but to minister to a different generation with the love of Christ. The people we serve have truly blessed me more than I have been able to give in return."

(Sarah Crichlow, co-officer)

05

"We want to inspire our [Cedars] readers to think, to laugh, and to maybe even do something that will change our community for the better." (Nathan Washatka, managing editor)

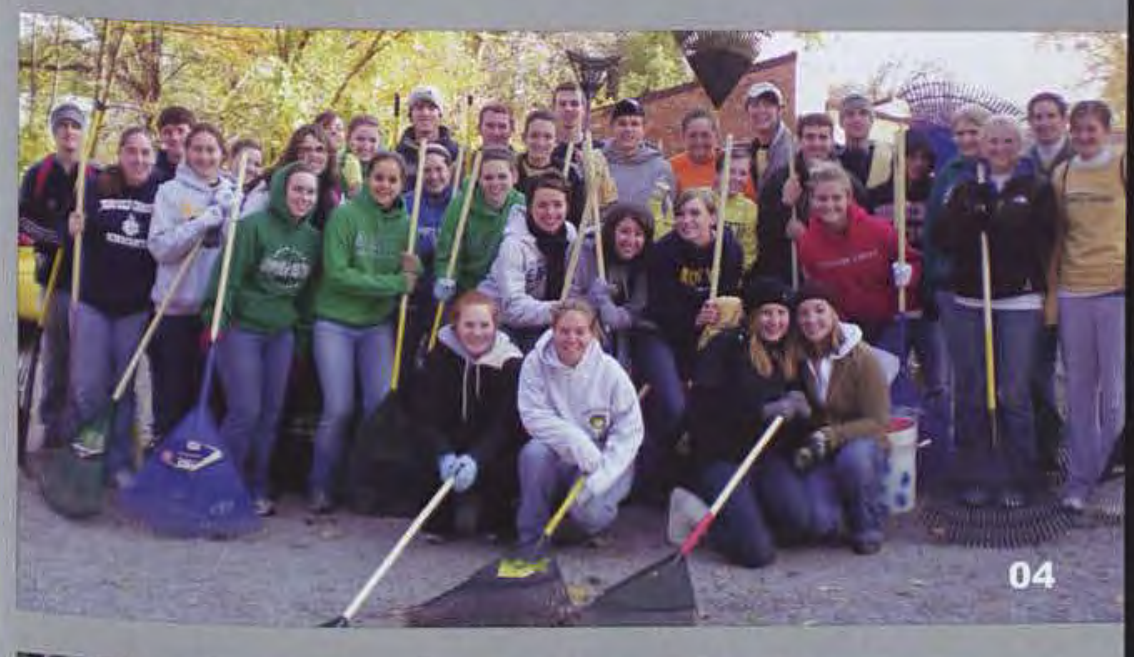

51

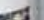




\section{"I WAS SO HAPPY TO BE A PART OF THIS YEAR'S SGA! IT WAS AMAZING TO WORK WITH SO MANY OTHER PEOPLE WHO SAW THEIR JOB AS AN OPPORTUNITY TO GIVE GLORY TO GOD." _SHANNON EVERSWICK, SECRETARY, SGA}

Leanna Baumer and Alicia McCullough enjoy trying new things and getting to know their fellow TDK members at the annual retreat.

"Big Bird was so much fun! You have fun with friends and make new ones as well. Helping the elderly folks in Cedarville in the seemingly simple way of raking the leaves out of their lawns helps them in such a huge way; seeing how much they appreciate it is an awesome blessing!" (Rachael Schnepp, senior)
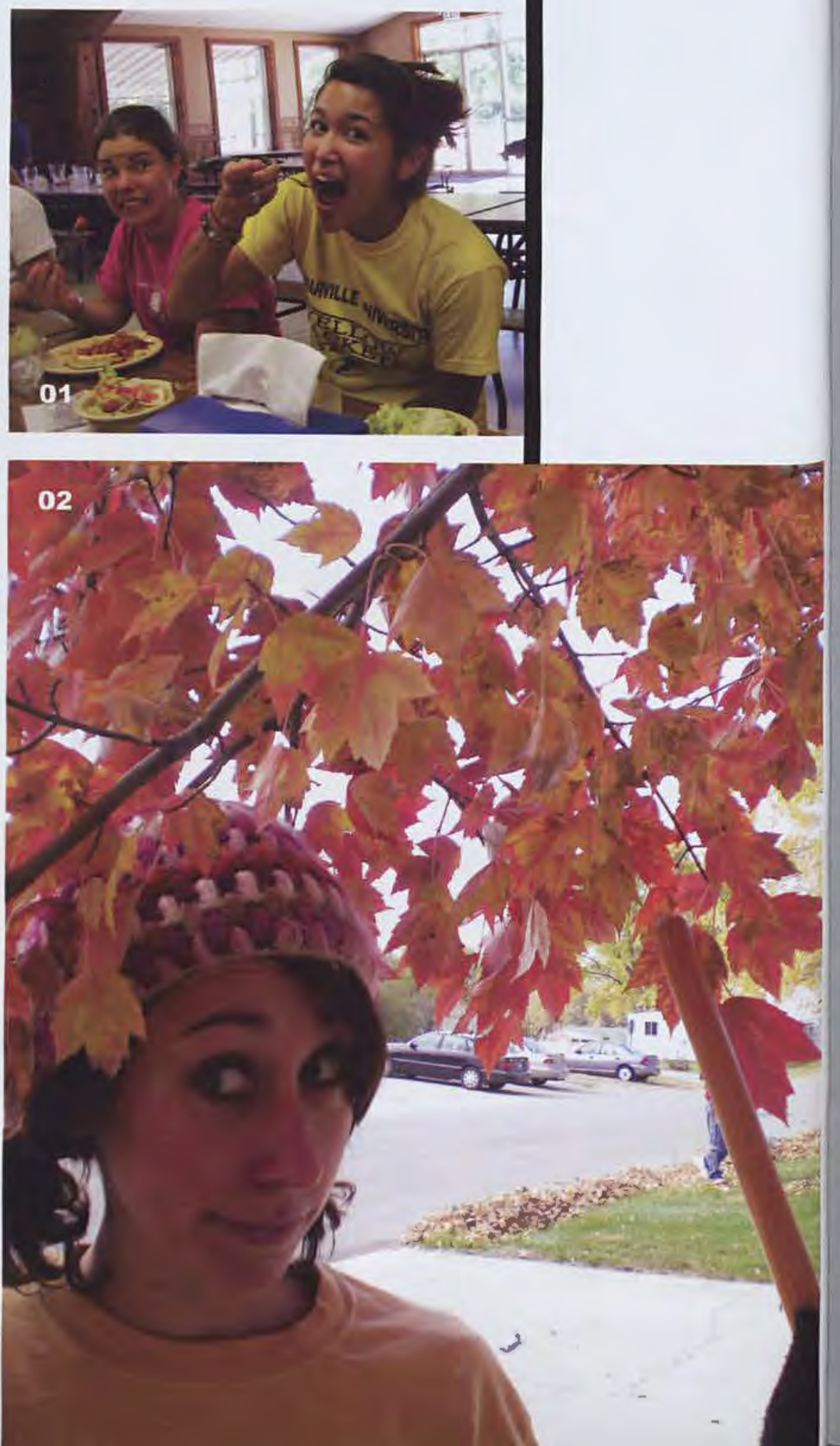


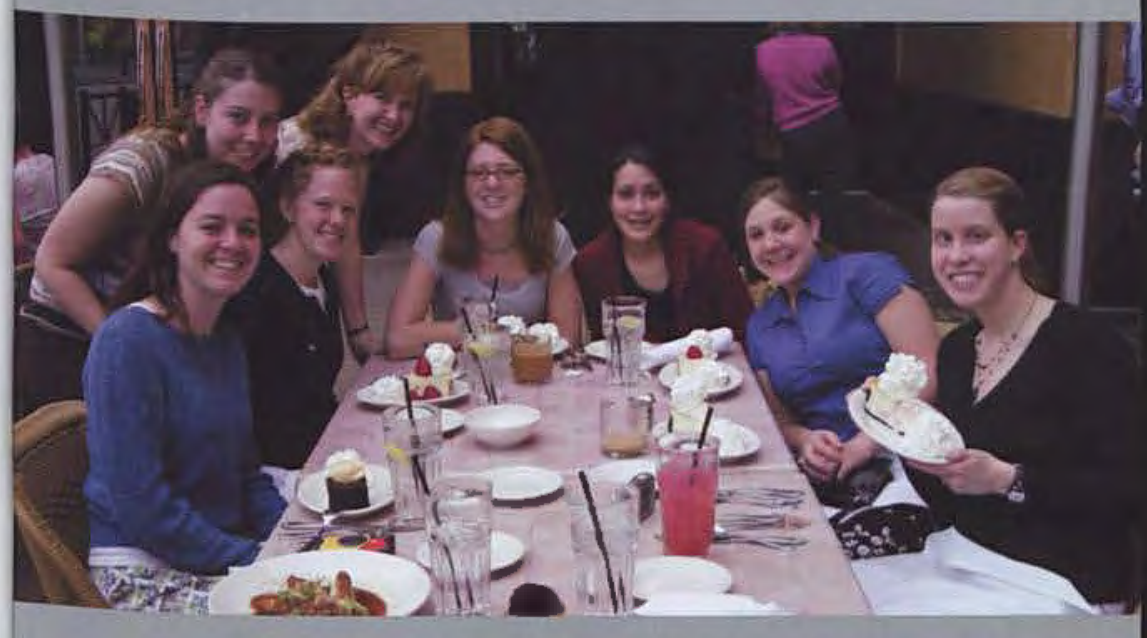

The ladies of Gamma Chi gather for a treat at the Cheesecake Factory.

Participating in one of their favorite events, these students lead one of Spanish Club's worship nights.

$$
\text { A Jehovó aloborí Alabaré }
$$$$
\text { seguire }(x 2) \text { mi Droz be }
$$

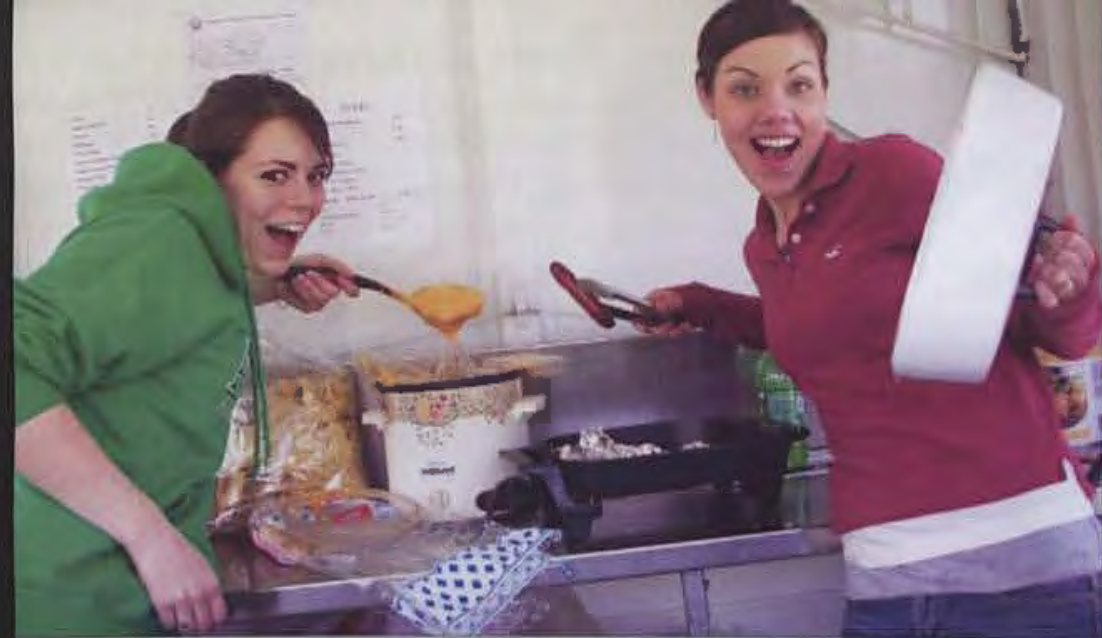

ADO members Amy Jacobs and Bonnie Brady help with concessions at a local soccer tournament.

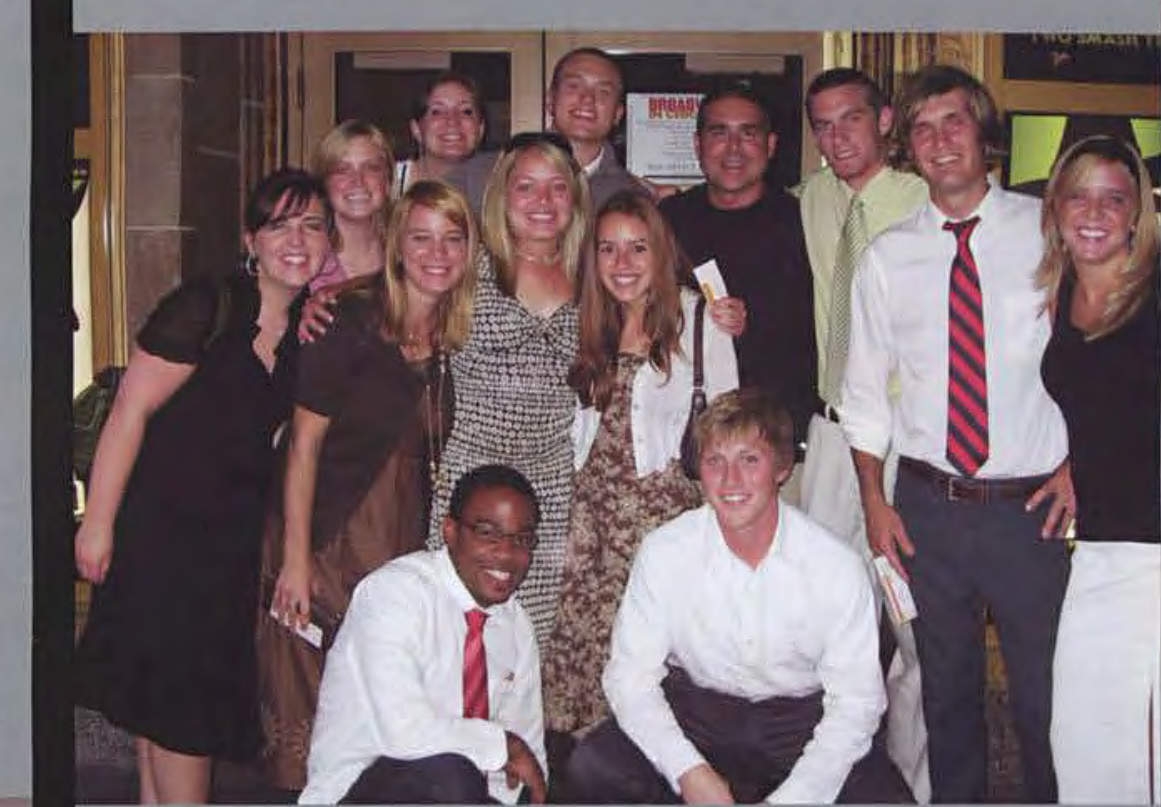

This year's SGA officers went to Chicago for their beginning of the year retreat, participating in some team building activities as well as service projects. "As President, I couldn't have asked for a better group to serve with. It was truly an incredible year." (Nick Arch, junior)
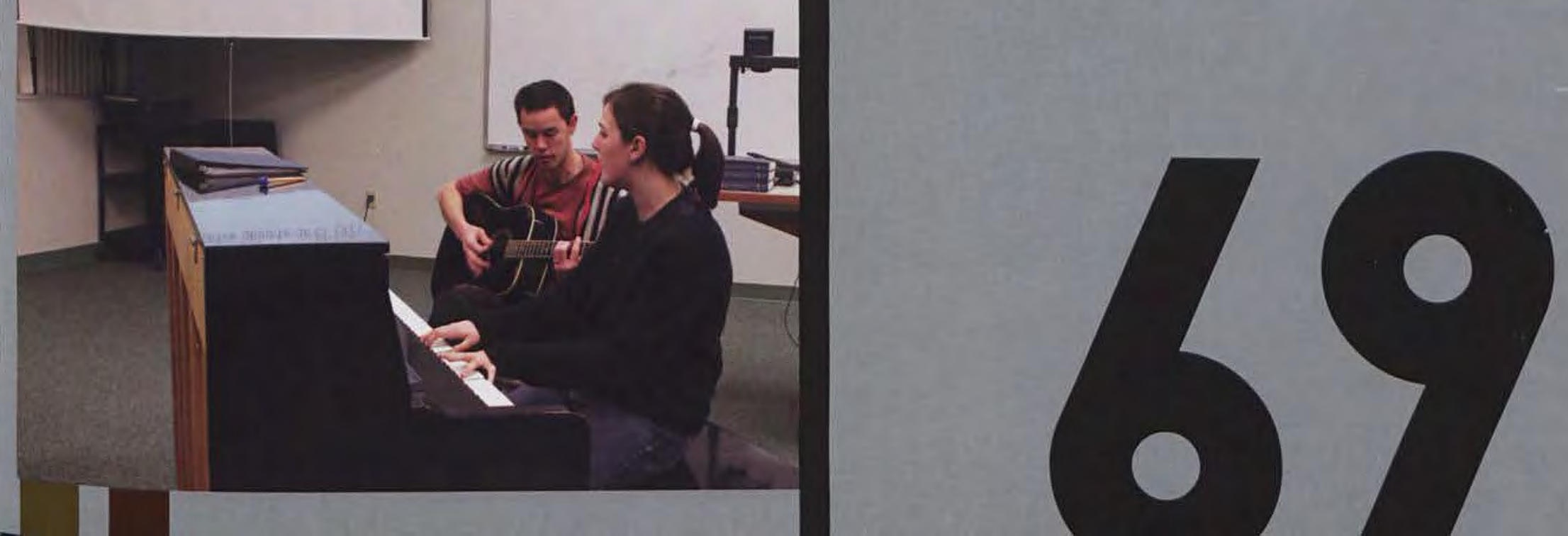
The Cedarville debate and forensics team had a young team this year, with a few seasoned veterans and a whole batch of rookie faces, their eyes bright with anticipation and their hearts fast and furious at first because they didn't know what to expect. However, the team shattered all previous records and stopped all hearts with a stunning sweep of awards and culminating championships during spring break's NCCFI National Christian Tournament in Nashville. Besides overall debate sweepstakes, overall forensics sweepstakes, and overall school sweepstakes, the teams brought home a number of individual awards and quality awards at that tournament and throughout the year, praising character and performance. Laced with a bit of sarcasm, Shirzadian commented, "We are the best debaters in all of Christendom!" (Michael Shirzadian, sophomore debate team member) A little school pride always helps performance.

Members of the Forensics Team, Brad Augustine, Katlyn Hiteshew, Elizabeth Gingell, Michael Domeny, Denise Serna, and Kyle Haring compete at The 'Holiday Frolic' at OSU in December.

The Debate Team continues to grow in success and reputation at Cedarville, having placed 8 th at the National Debate Tournament sponsored by the National Parliamentary Debate Association, which is the largest intercollegiate debate association in the U.S.
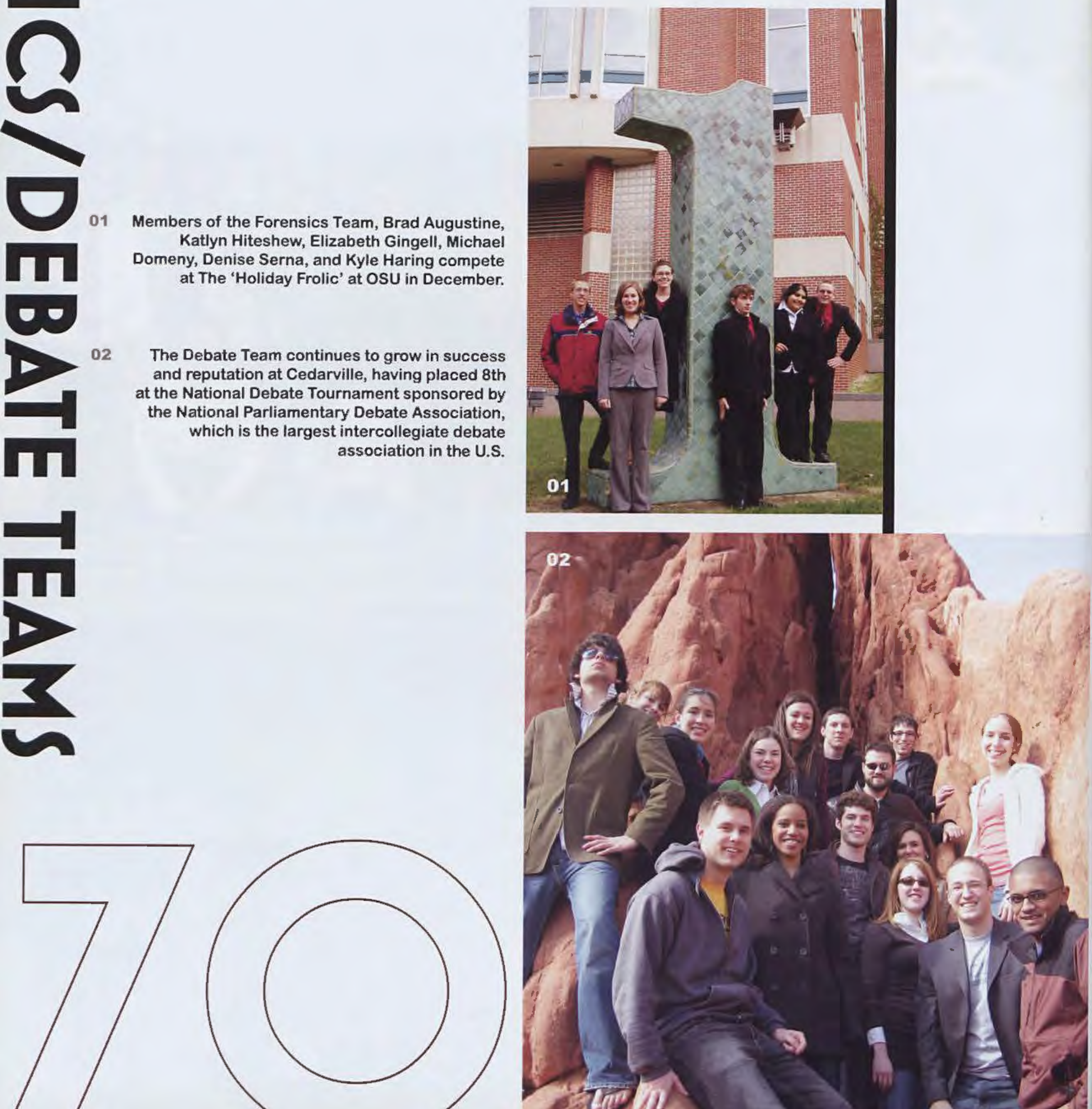
The idea of a radio station began in 1979. The station has gone through many changes, but the most recent occurred this year with the birth of Resound Radio. "Resound provides a Christ-centered radio station in a format that students know and love. Switching to an all online broadcast was a well-researched and thoughtfully-completed process. It's a slight change-in-medium that has had a huge difference with the way we look at broadcasting, and it has proven to be very beneficial in understanding more about the student body's listening habits." (Kevin Martelli, Station Manager) The research has certainly paid off-with the promotional activities at the beginning of the year including free, expensive prizes, and the endless music "resounding" around campus computers, Resound Radio is "more attractive than ever!"

Despite its attractiveness, Resound had other incentives for greatness. "In a culture inundated with negative ideals and images of humanity, Resound wants to be a place where Scriptural truths are present in all that goes on the air." (Jarrod Steinmetz, Resound Music Director) Steinmetz also commented that Resound has strived to provide more variety for its listeners, including the new hard rock show, Lithos, and the classic Christian rock show, Throwback. With ongoing research and a drive to cater to students' interests, Resound will continue to amaze listeners in the years to come.

01 Dillon Black, Barry Westefeld, and Dustin Norman capture Marilyn Ware during Cedarville's Most Wanted, sponsored by Resound. For their valiant efforts, the three each won speakers.

"My favorite event of the year had to be the swap to Resound. The best part of that whole swap was that the day of revealing the swap I got to throw frisbees in chapel, and seriously not many people can say they have done that." (Jesse Jones, freshman)
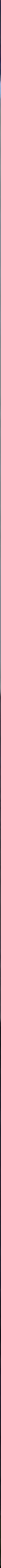


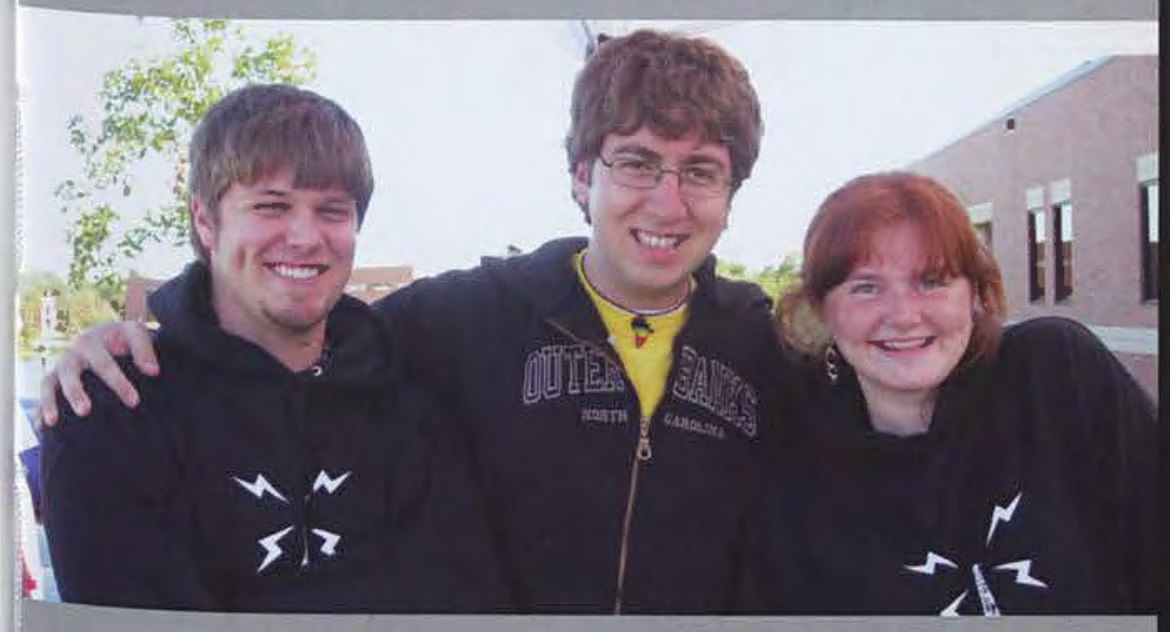

Jarrod Steinmetz, David Peterson, and Abby Wight proudly serve on the Resound Radio staff.

Danielle Randolph found Dr. Brown during Cedarville's Most Wanted and walked away with a MacBook as her reward.

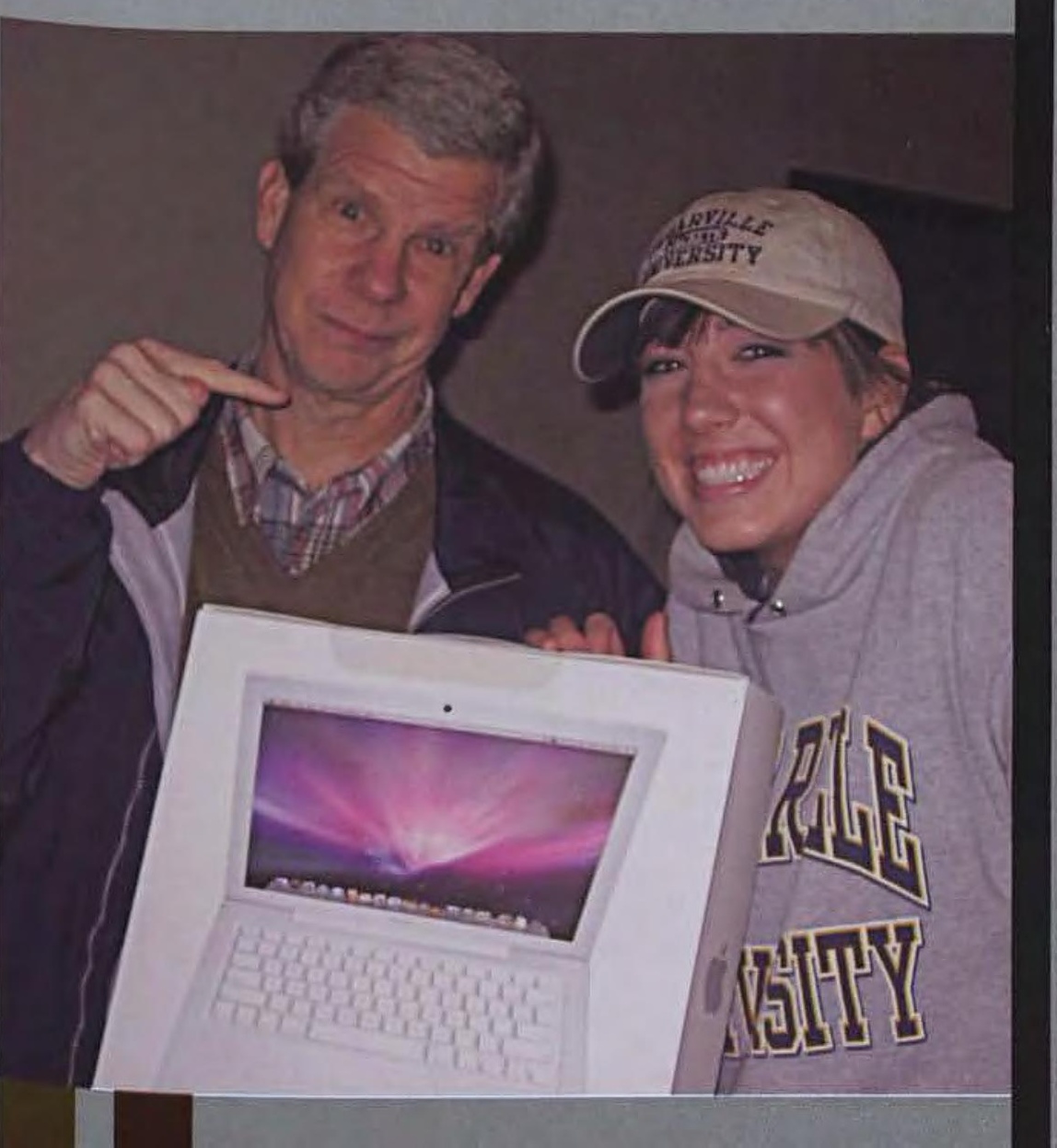

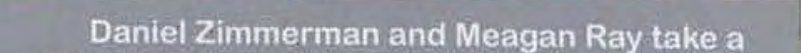
look inside the Weinermobile during its visit to campus, sponsored by Resound Radio.

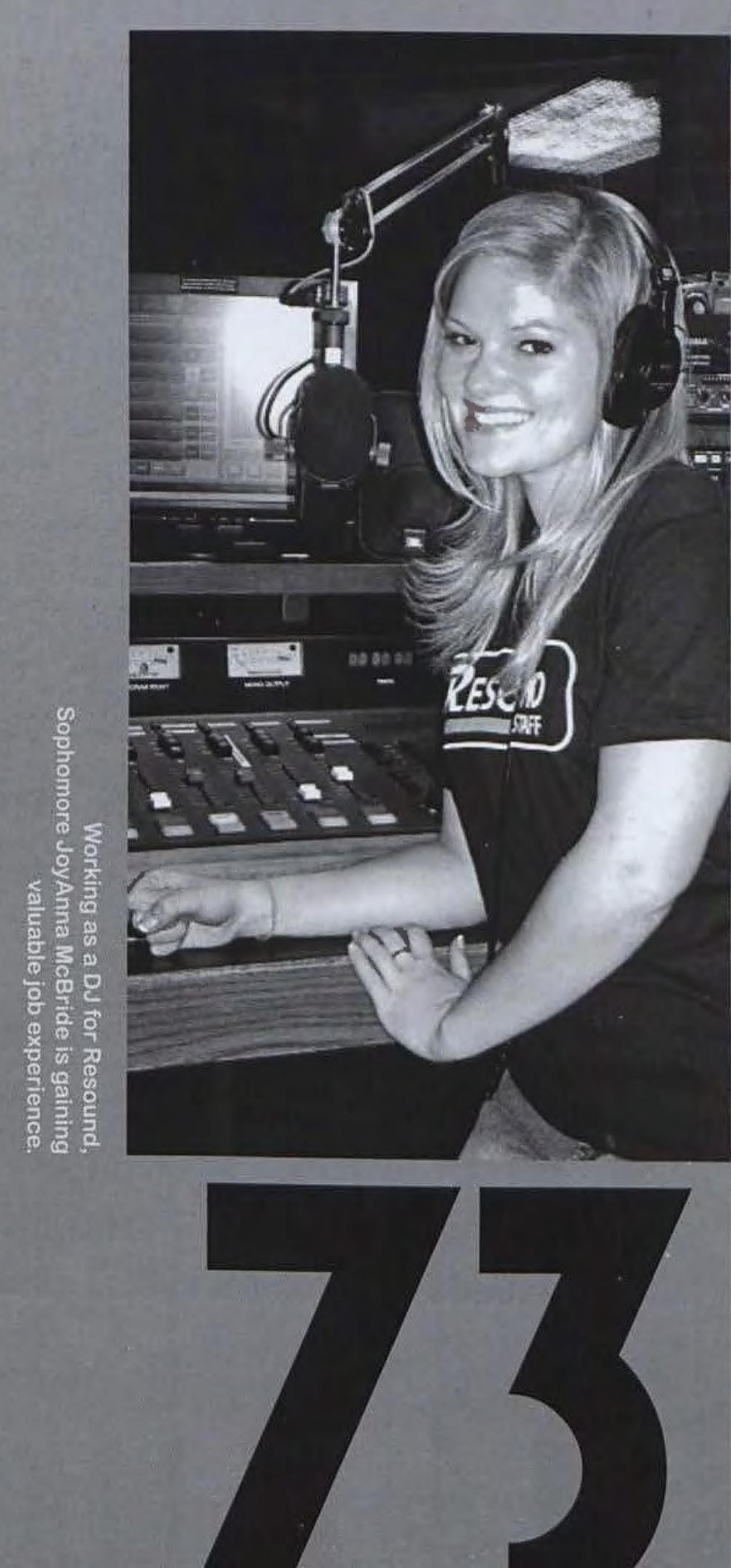


"TO BE A FRESHMAN IS

TO BE IN POSSESSION

OF A

THING", TIME".

— MALIK WILSON 


$$
=:=:=0
$$



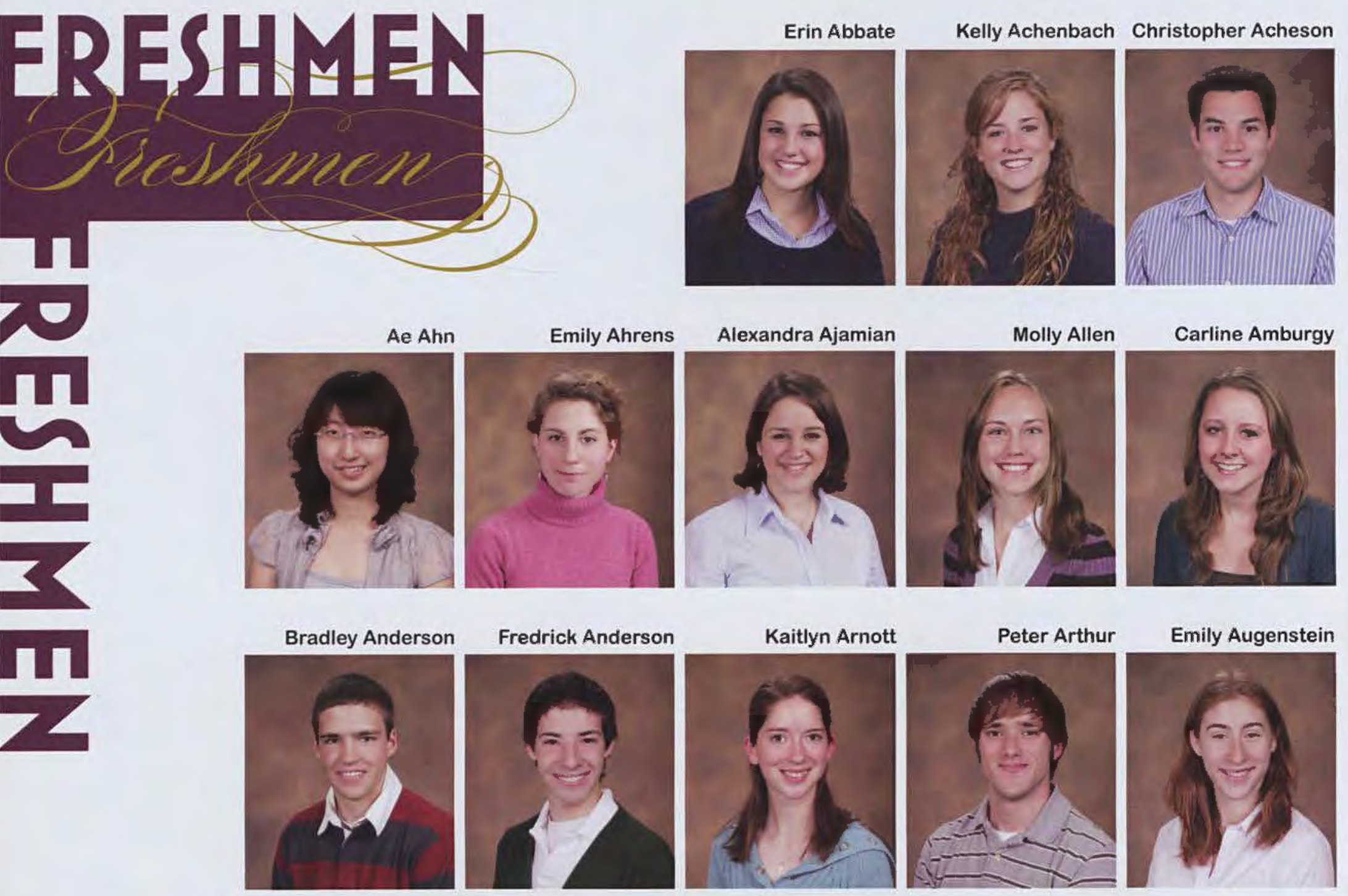

Emily Augenstein
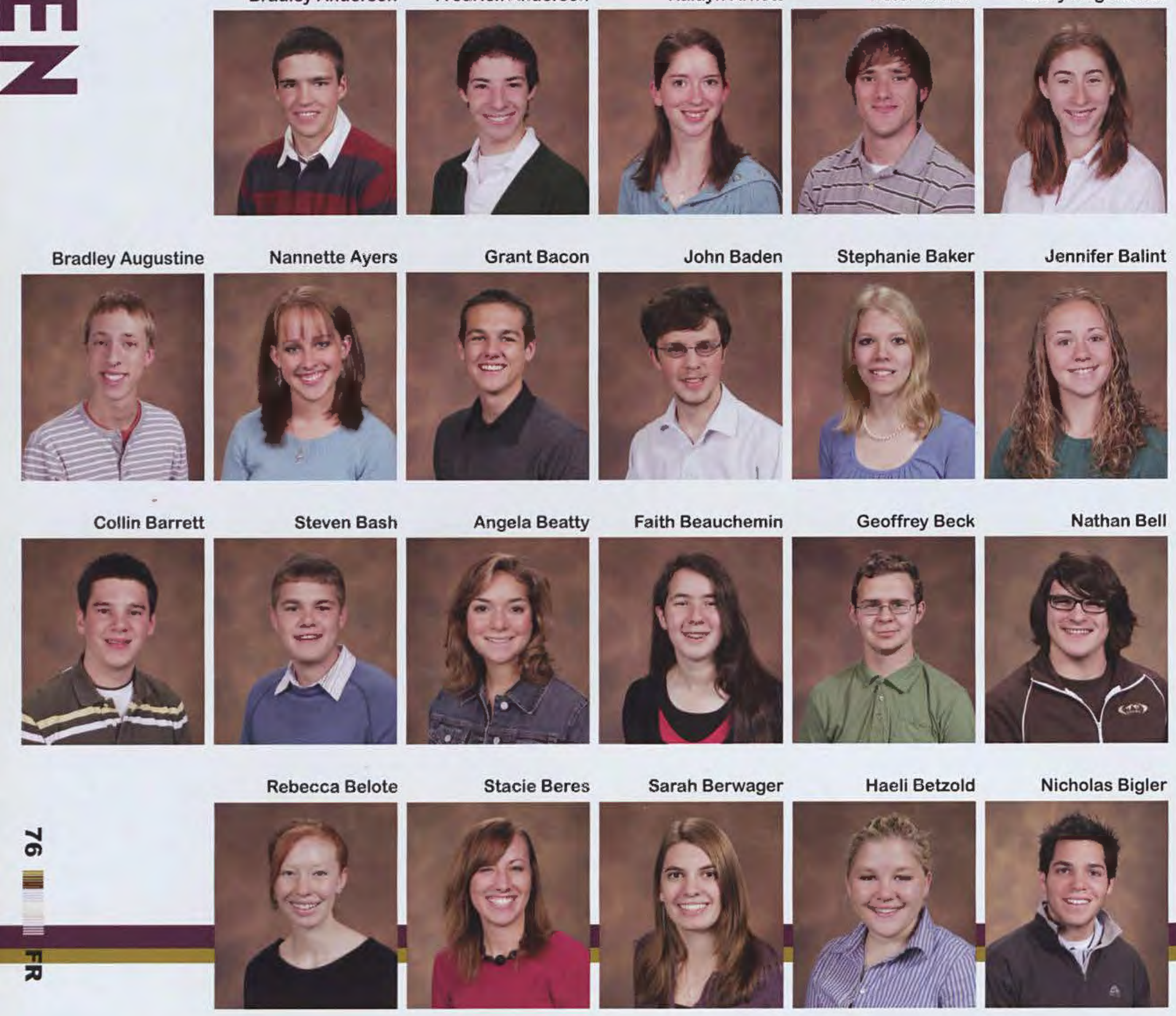

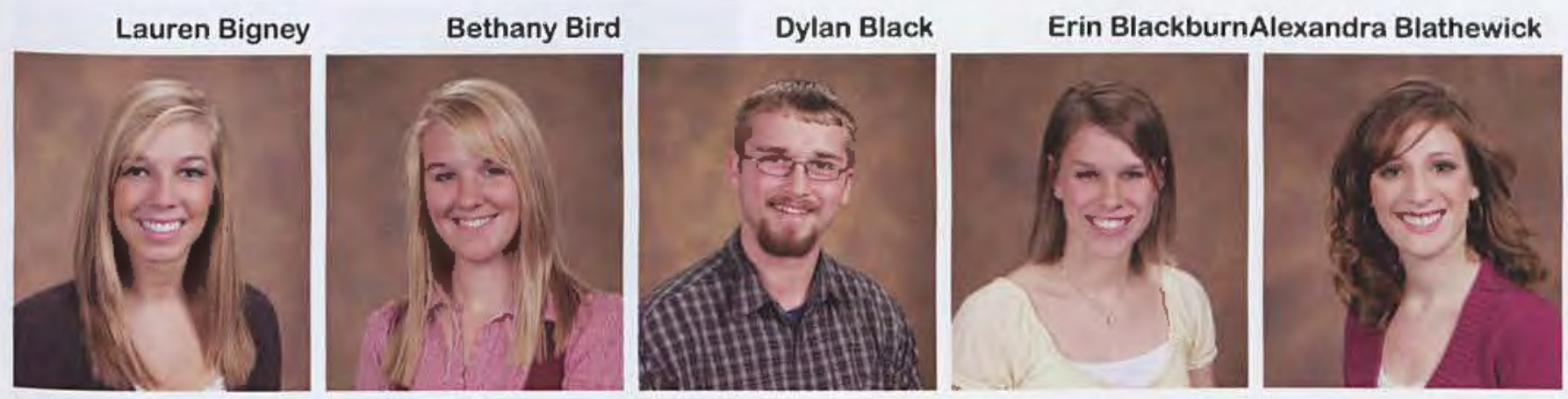

Kendra Bone
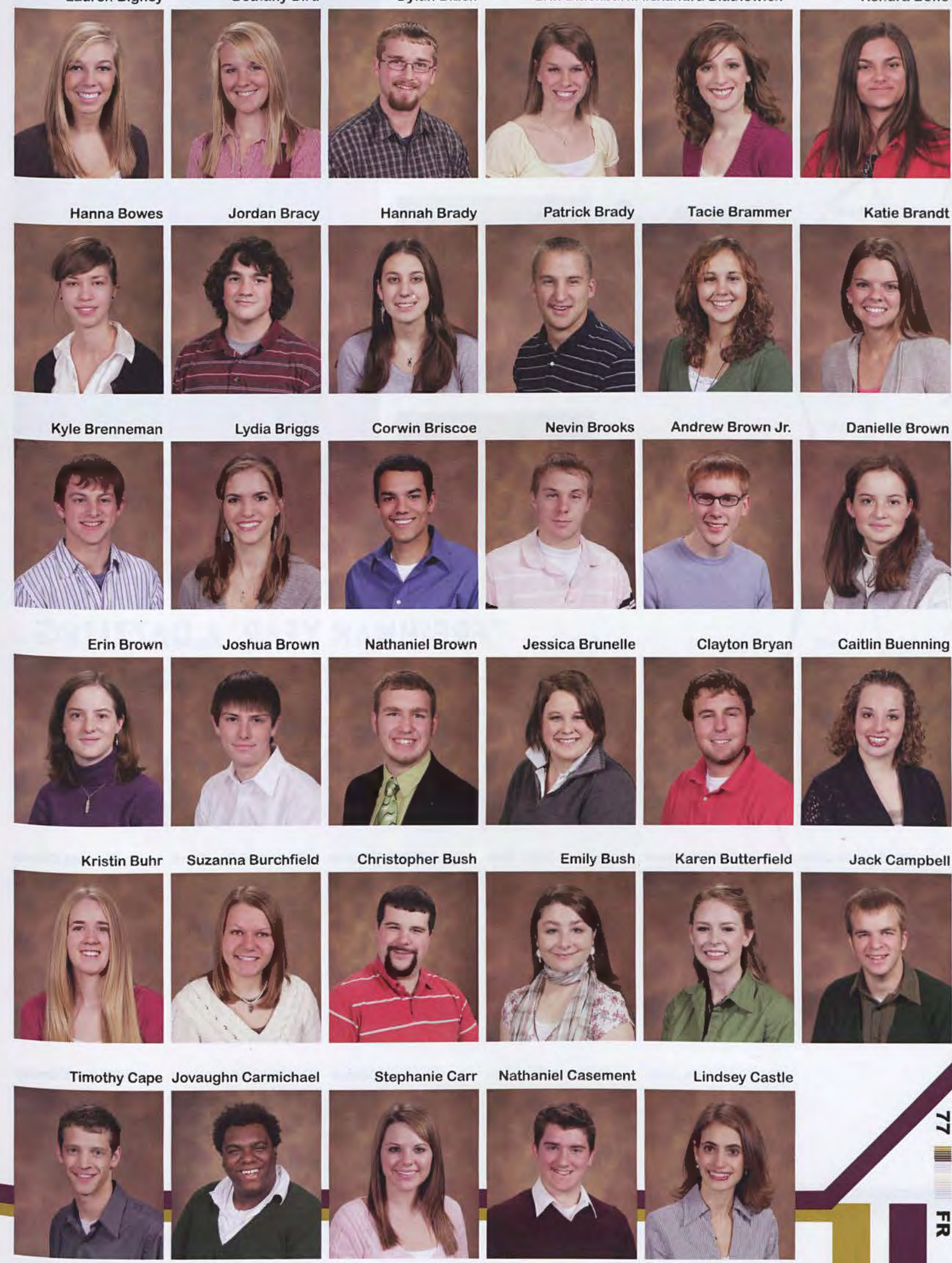

Lindsey Castle

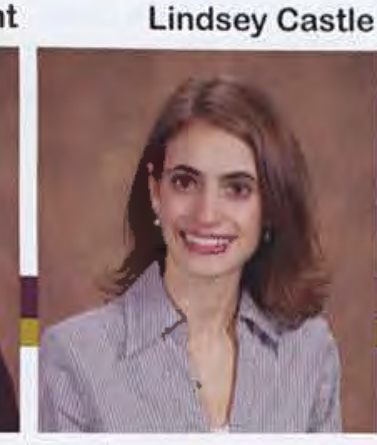




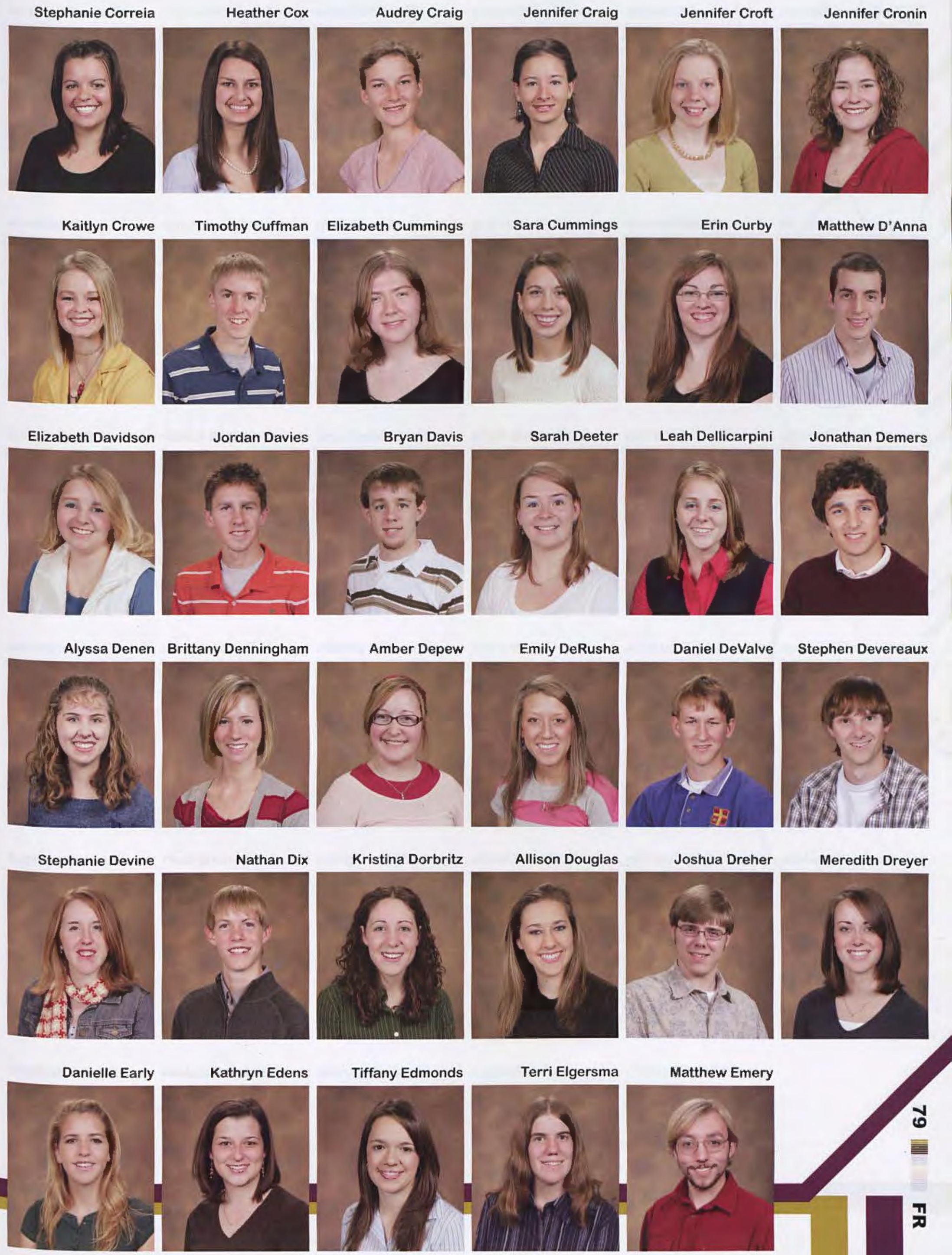


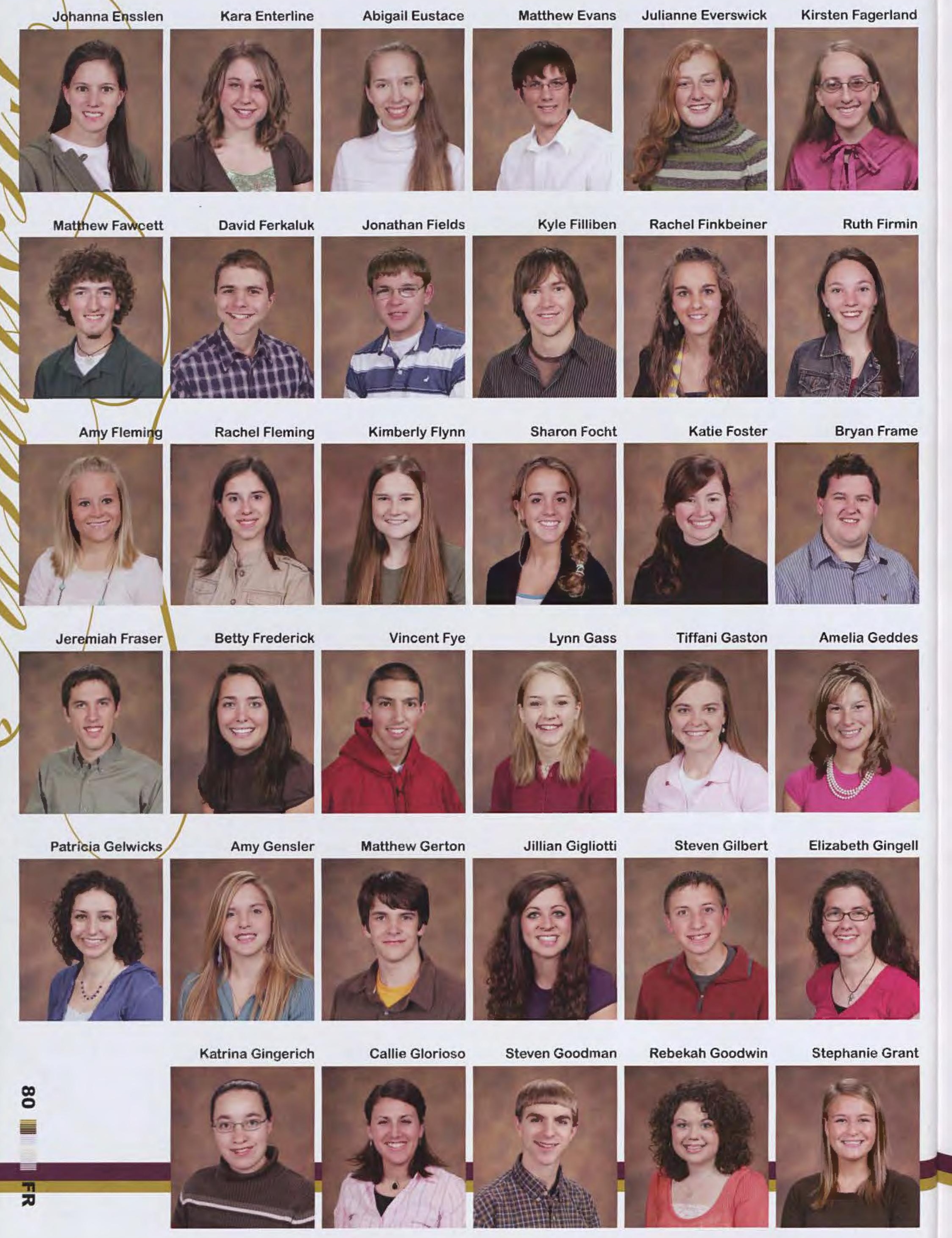



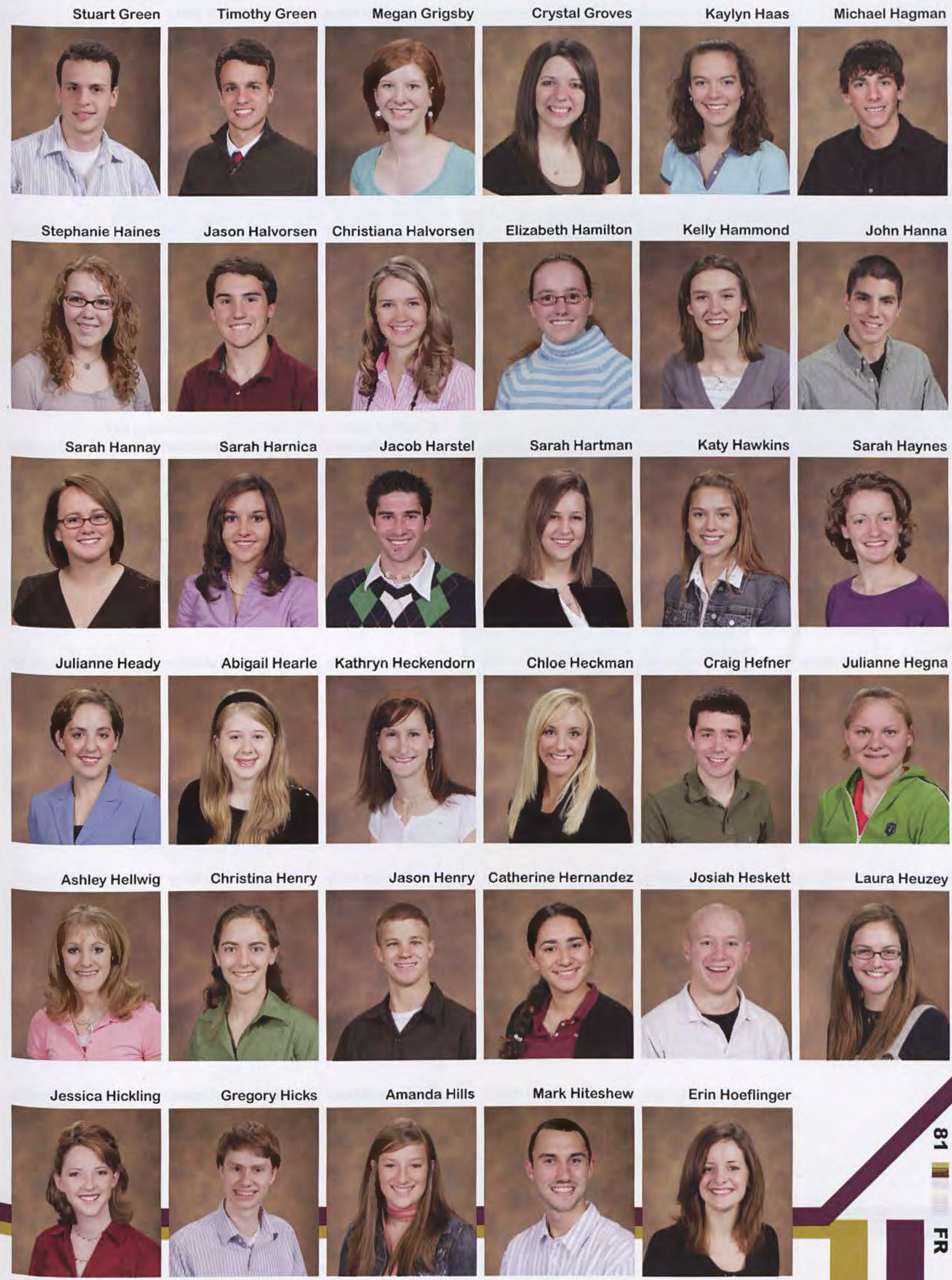



\section{"FRESHMAN YEAR WAS LIKE A DAY AT THE CARNIVAL, WITHOUT ALL OF THE

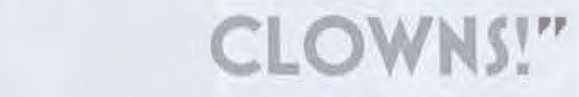

-MICAH KILMER

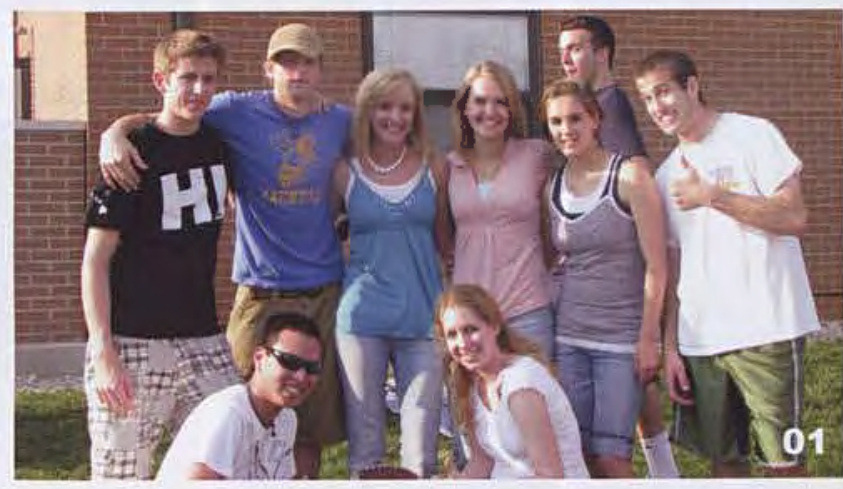

Tim Lukasiewicz, Christopher Newman, Chloe 01 Heckman, Christiana Halvorson, Rachel Finkbeinker, Rob Anfang, John Hegarty,

Bryan McFarland and Jessica Kolody have all discovered the importance of freshman traveling in groups.

Loving the sun and the sand is Emily Chiu. 02

Catherine Hernandez and her friends plop down 03 in the ever-popular Printy parking lot.
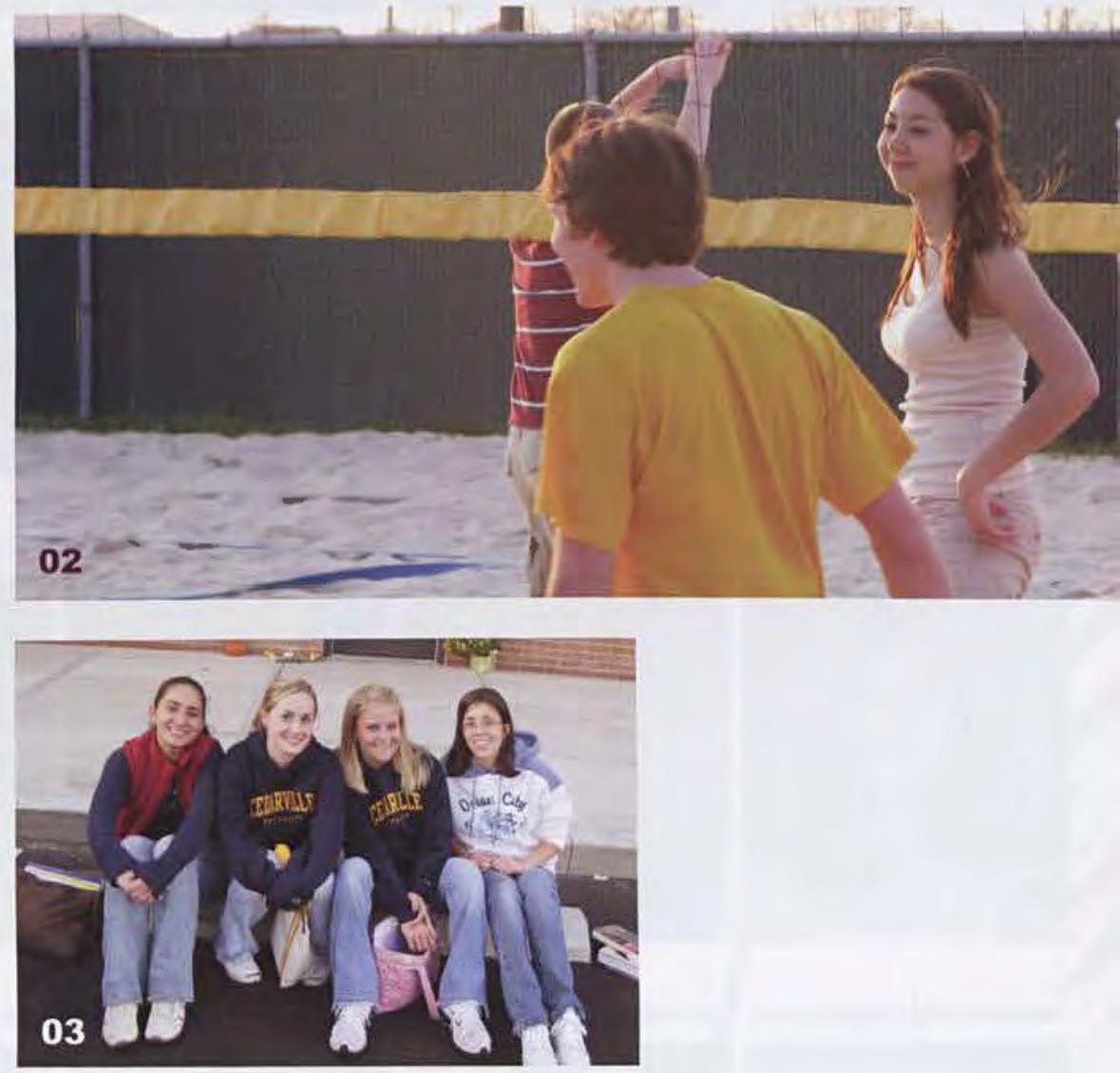
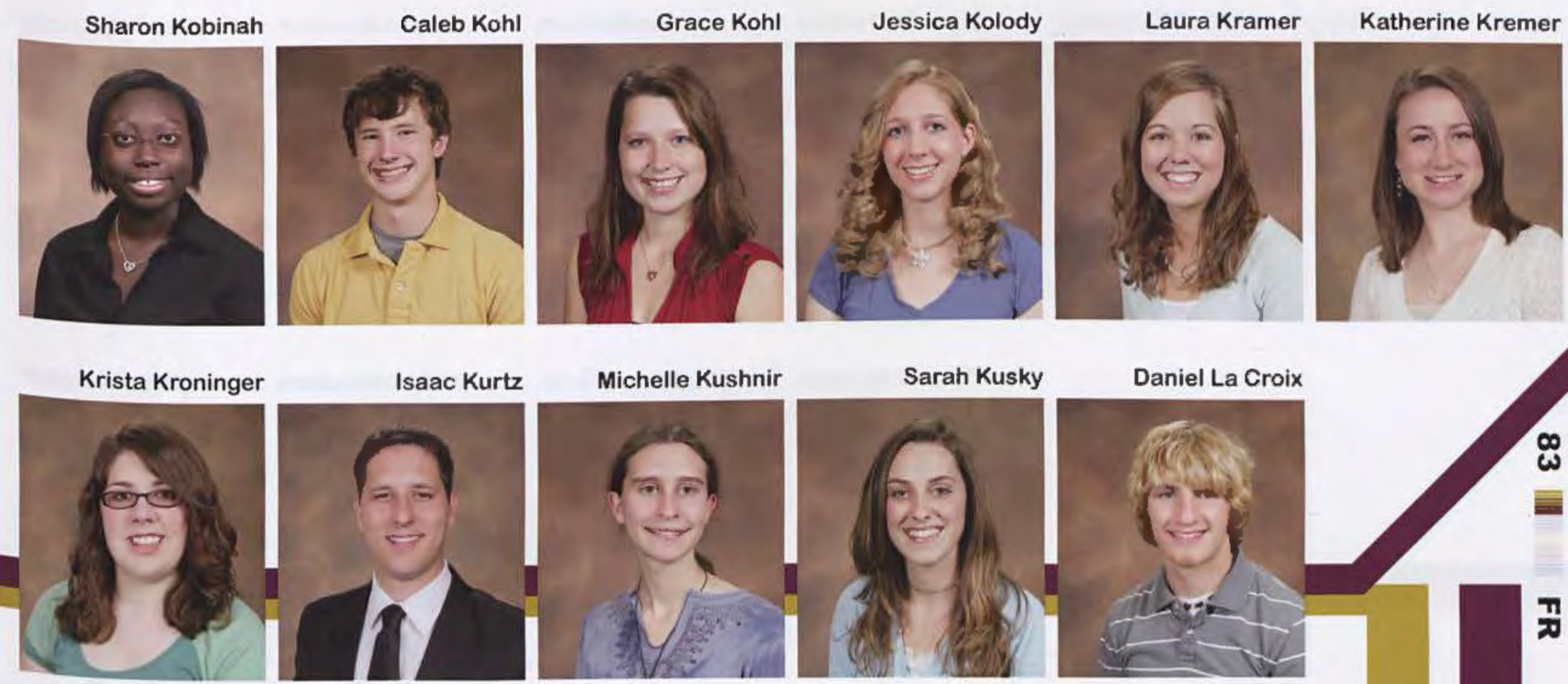

Daniel La Croix

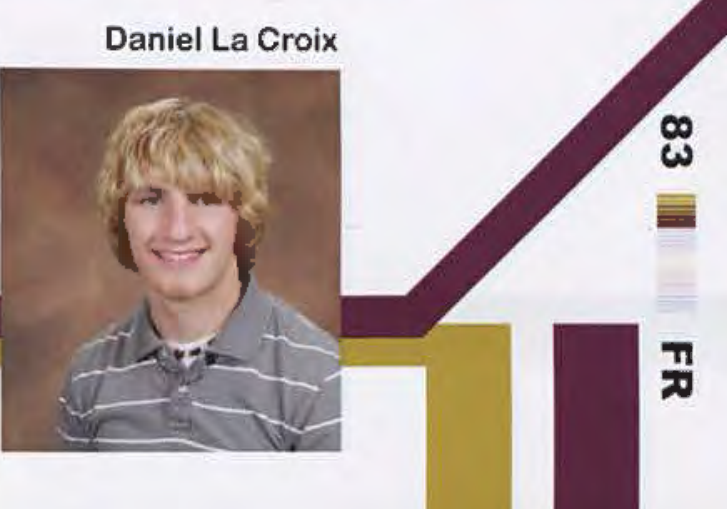




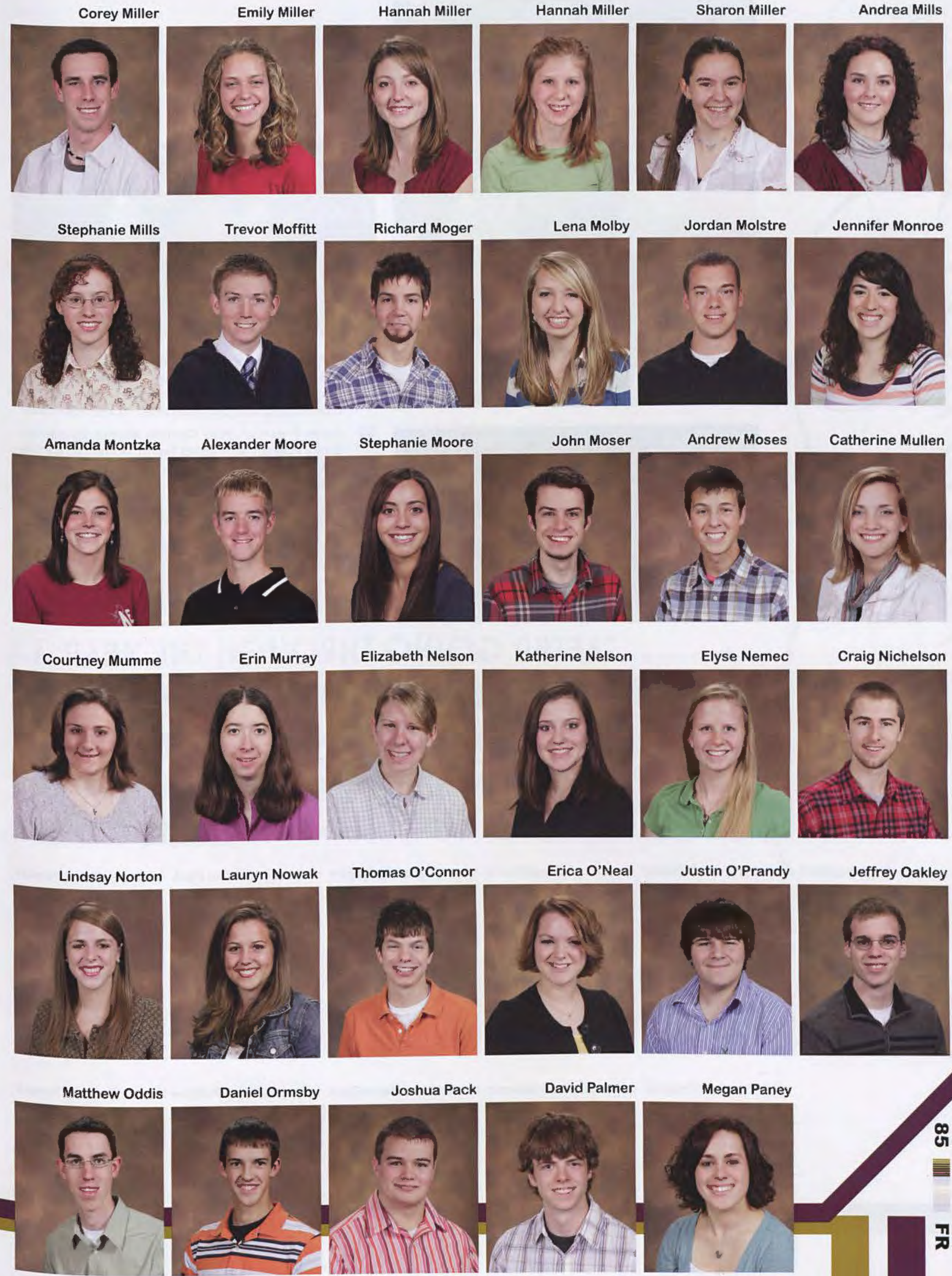


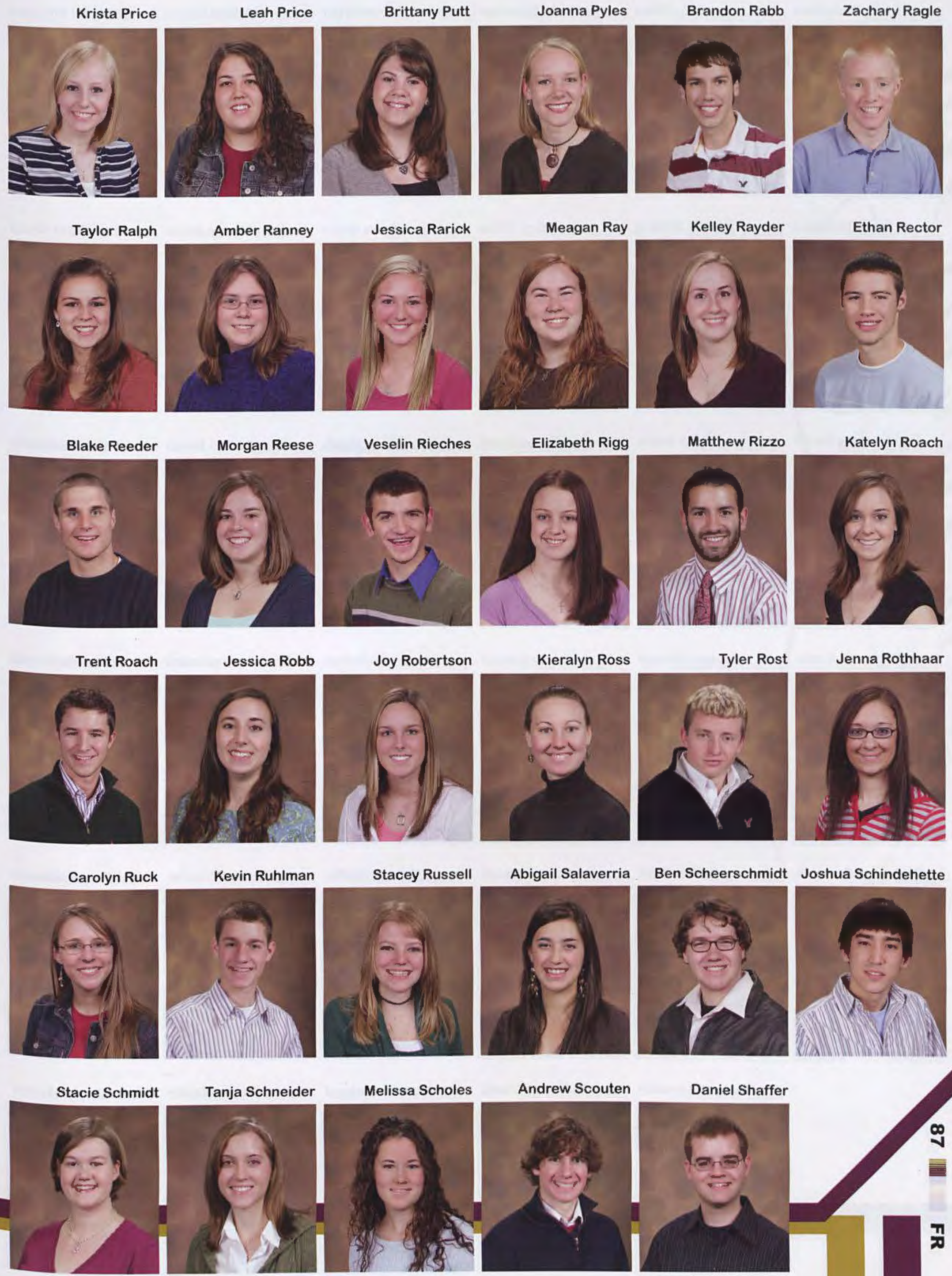

Tanja Schneider

Melissa Scholes

Andrew Scouten

Daniel Shaffer
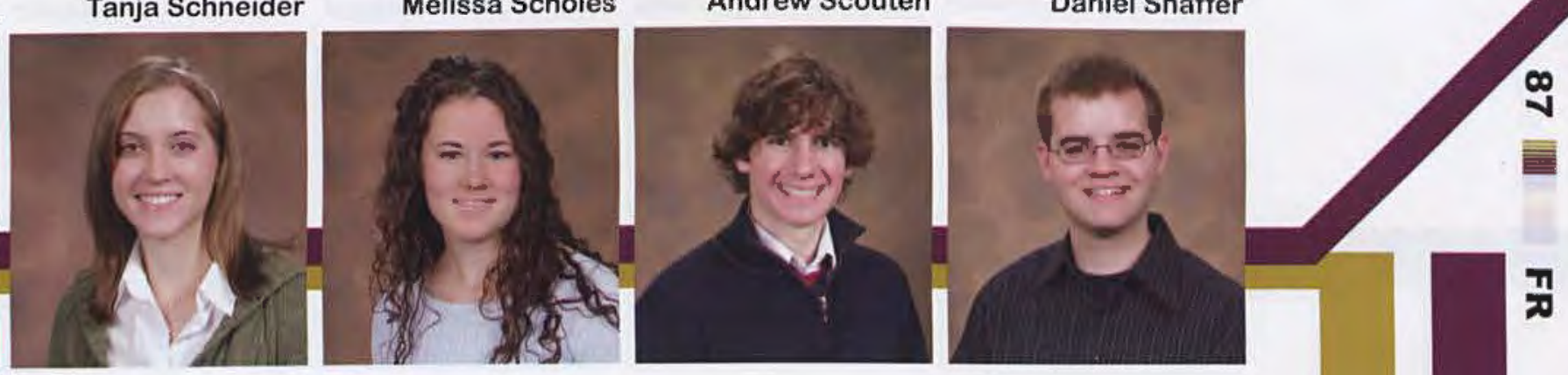

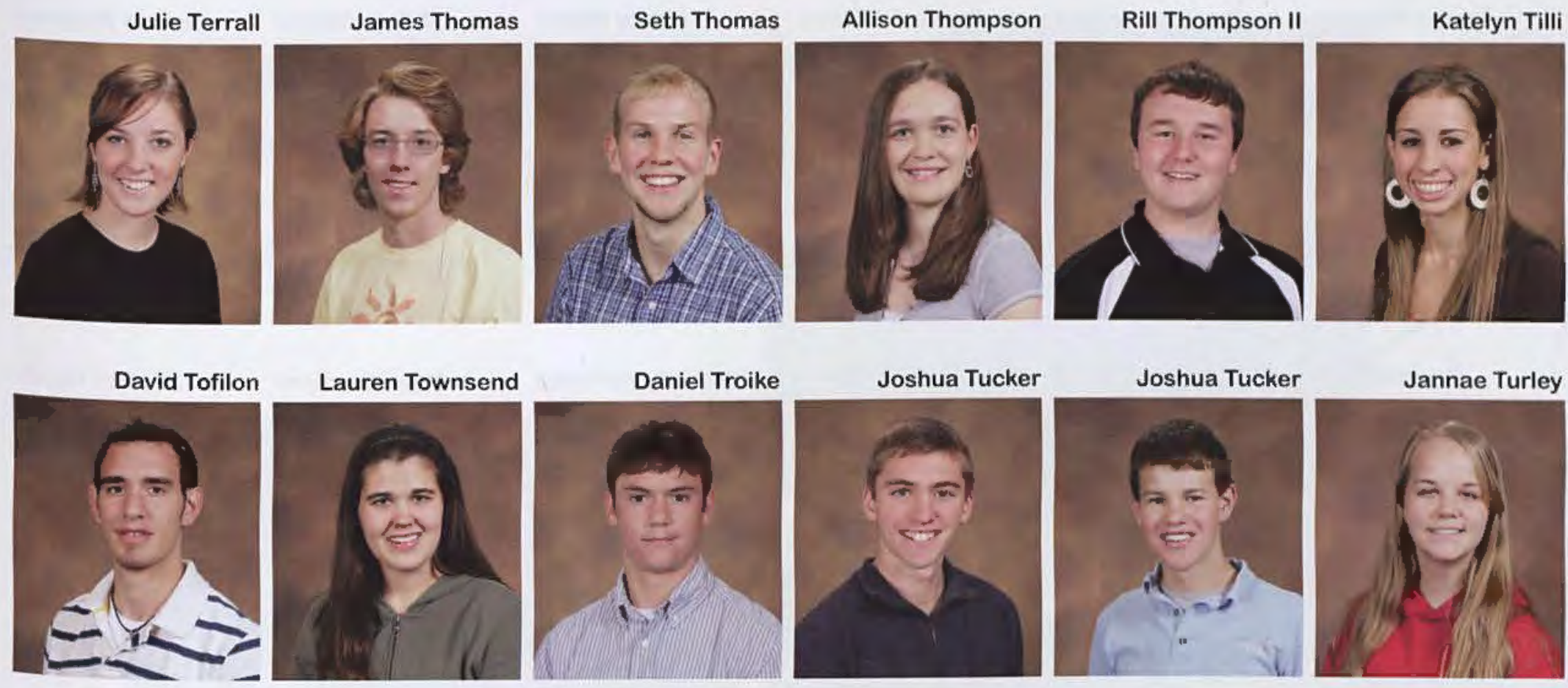

Jannae Turley
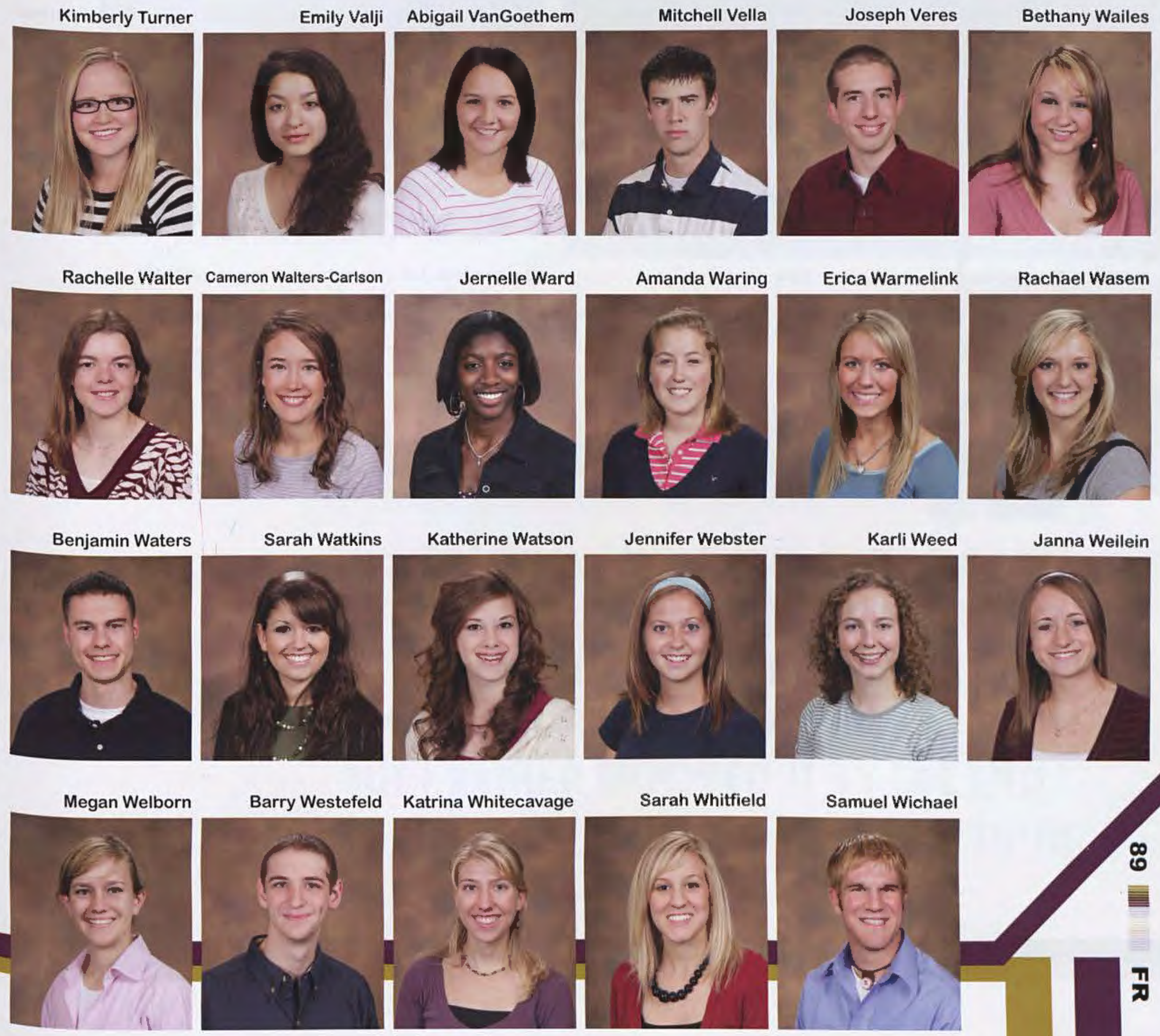

Sarah Whitfield

Samuel Wichael
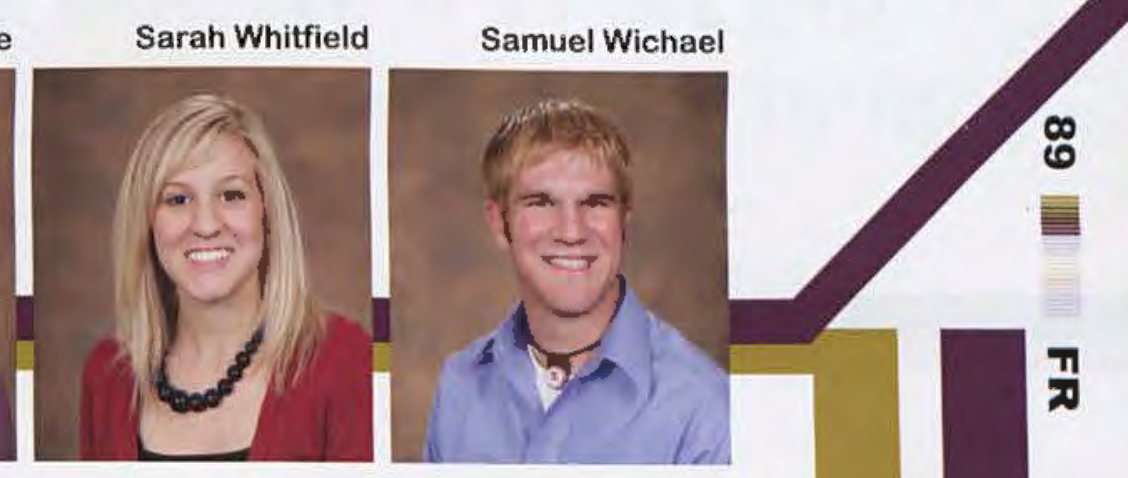


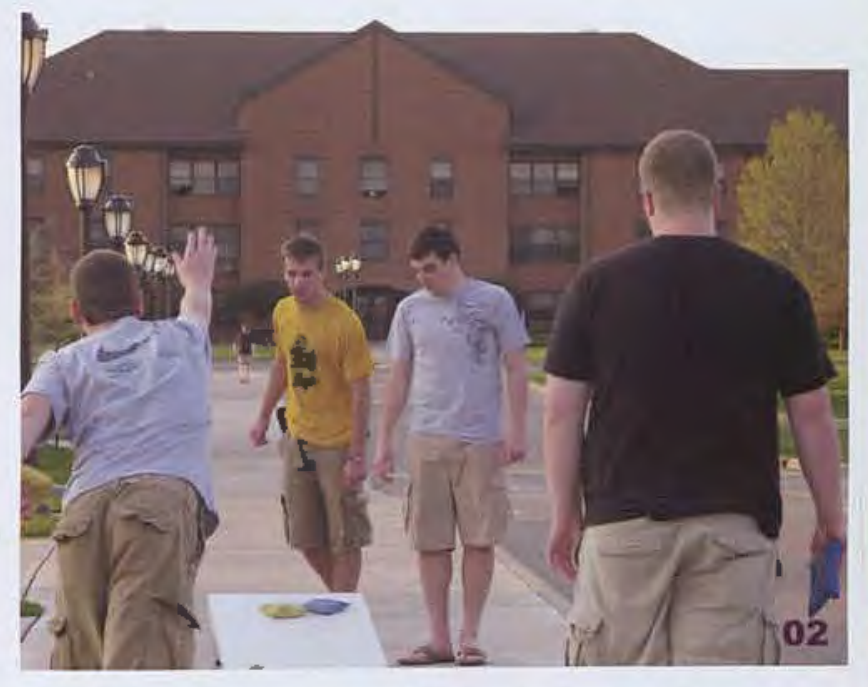

Alicia McMaster, Katie Brandt, Amber Depew, Josh Steckel, and Brad Augustine love living the "Meat Market" life.

Nathan Zion and friends enjoy a little cornhole as their first year at Cedarville winds down.

"My friends and I were hanging out, enjoying the sunny day and talking about the year" at the freshman/sophomore picnic. (Bethanne Linden)

Julie Terrall, Erin Hoeflinger, and Emily Powell enjoy the warm weather as the year comes to a close.

03

04
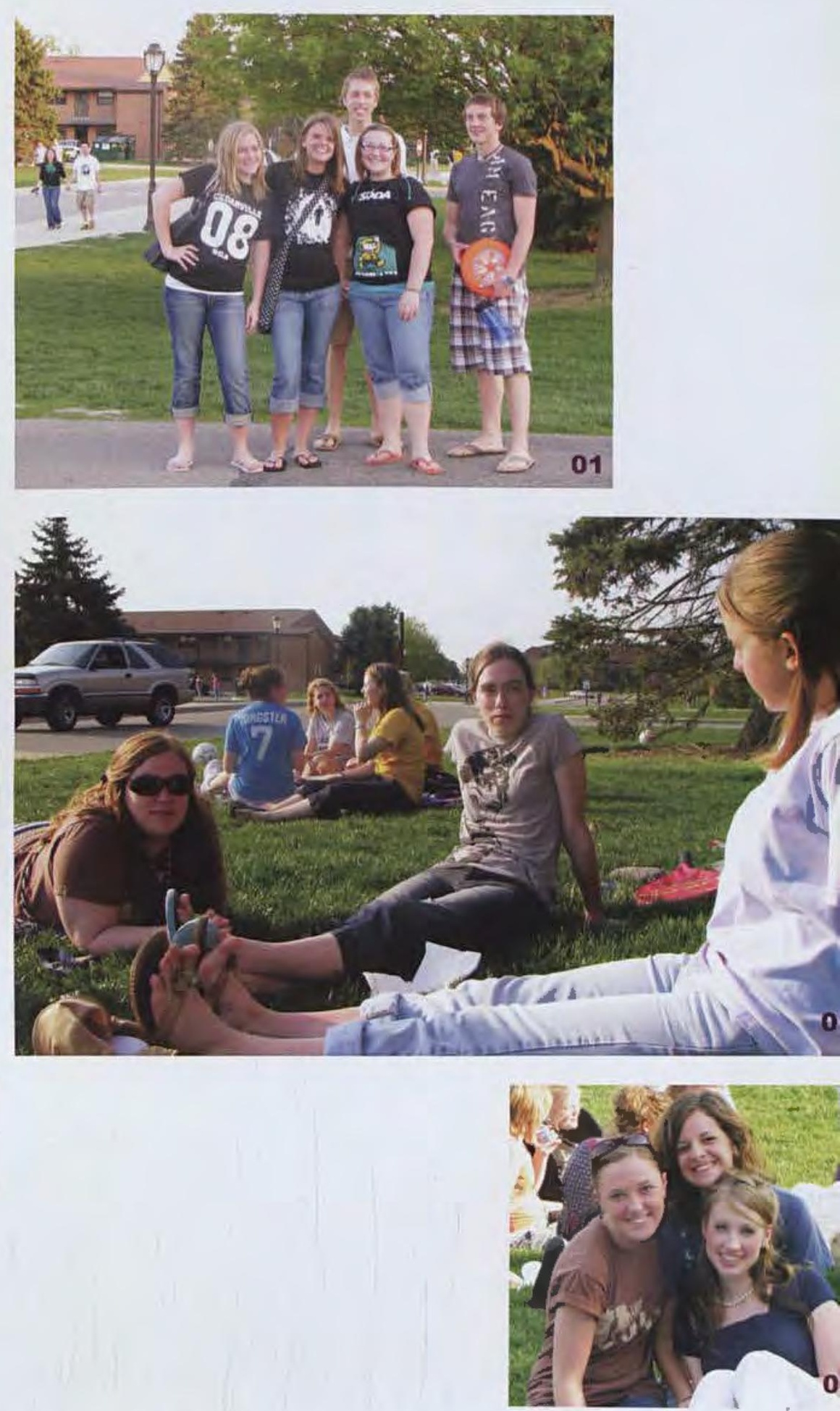

"MY FRESHMAN YEAR WAS KIND OF LIKE SITTING BESIDE SOME HOT GIRL YOU'VE NEVER MET BEFORE: IT WAS REALLY AWKWARD AND UNCOMFORTABLE AT FIRST, BUT I RATHER ENJOYED IT BY THE END." _ANDREW SMITH 


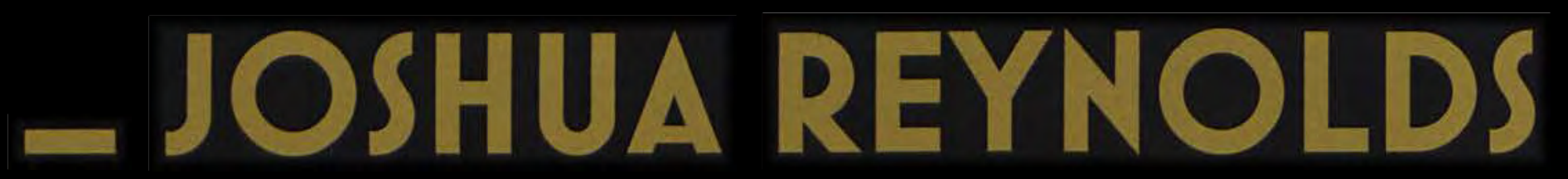




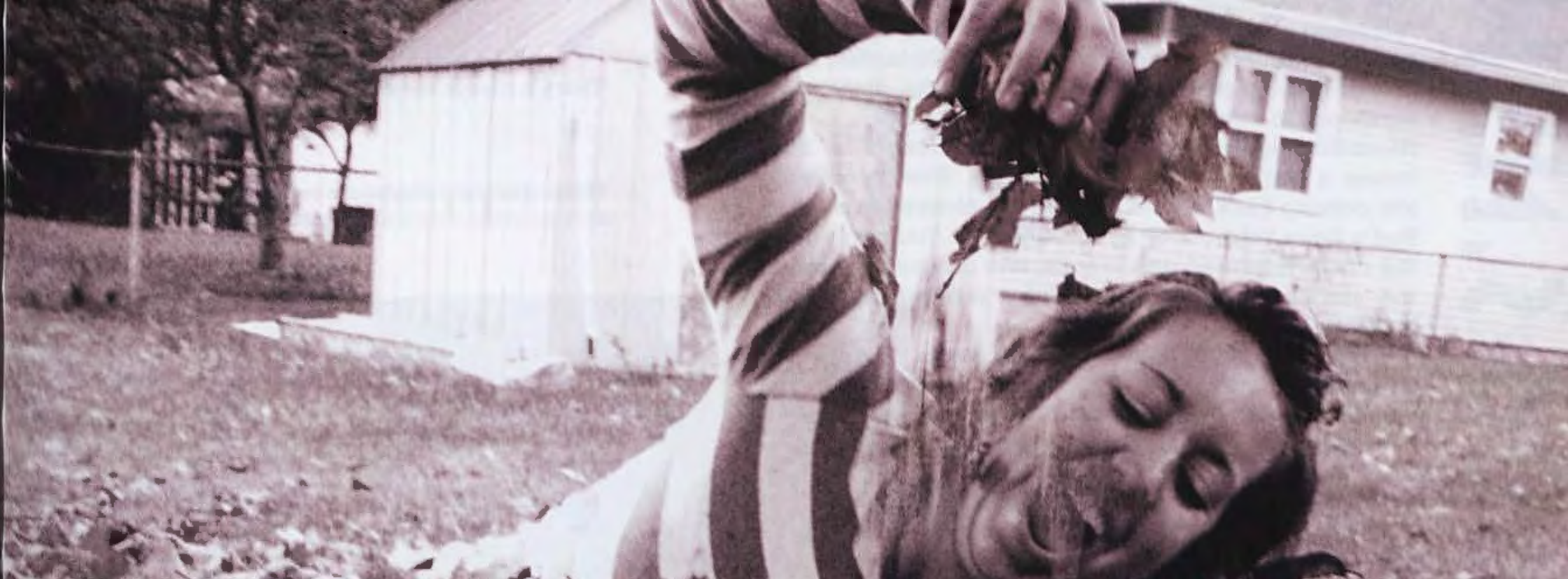

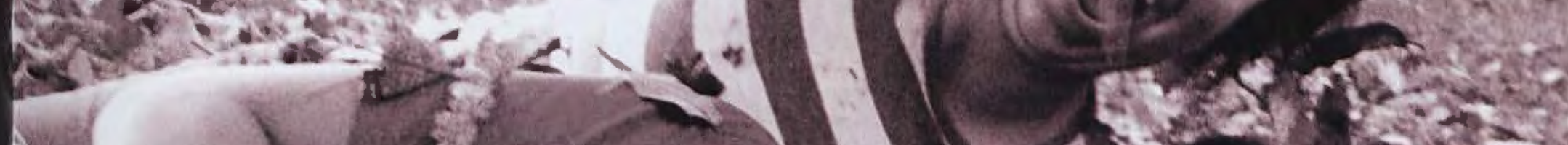

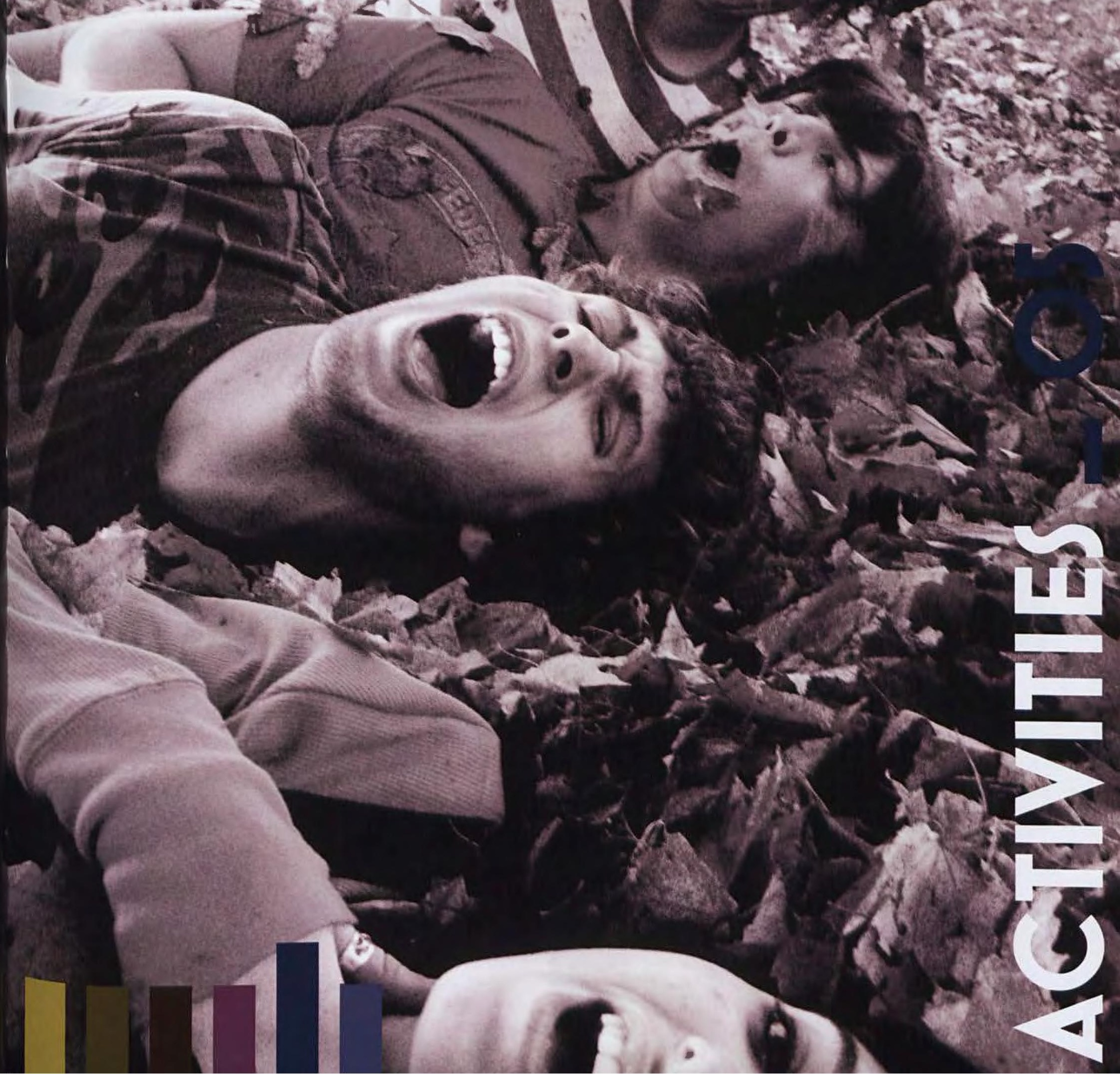


"Living off campus was never an option for me," (Ben Anderson, junior) "I've always loved the dorm. It's home." A seemingly larger number of Cedarville men are acquiring this attitude as Cedarville University continues to improve dorm quality and living.

Residents agree, the one aspect of Cedarville that leaves a lasting memory is dorm life. There's nothing like coming back after a long day of classes to a room that's been taken over by a roommate. You can't beat the camaraderie of unit pranks, and one never forgets the stench of neglected laundry wafting down the hallway.

"Having lived in St. Clair for three years now, it has established itself as a place where I can go and be myself. It's a dorm with a huge variety of people. I'm glad I've been able to live here for my career at Cedarville, and I've enjoyed the good times." (Brett Bigler, junior) In St. Clair you can always find guys playing NBA Live 2006 on Xbox, freshmen watching countless hours of Lost, guys in the lounge studying, or some friends with whom you can have a serious conversation.

Similar to the Hill and St. Clair, Brock remains a popular dwelling place as well. "Living in Brock has really enabled me to build close relationships with quality guys that love Jesus." (Travis Smith, junior) "I can discuss spiritual things, catch a game of Halo, and pig out on someone else's snacks all in one place. When you live in Brock, you quickly learn all snacks are 'community' snacks."

So whether you're looking for a good time of late-night pranks and video game marathons or you just want a relaxing day catching up on old TV shows, you can find it in the men's dorms of Cedarville University. "Since day one, the dorm has been the source of my closest friends and closest memories and I don't see that changing anytime soon." (Anderson)
"Dorm life is my favorite part of Cedarville. There's always something crazy going on." (Andy Winget, sophomore)

These guys all congregate in their gold to prepare for a big basketball game.
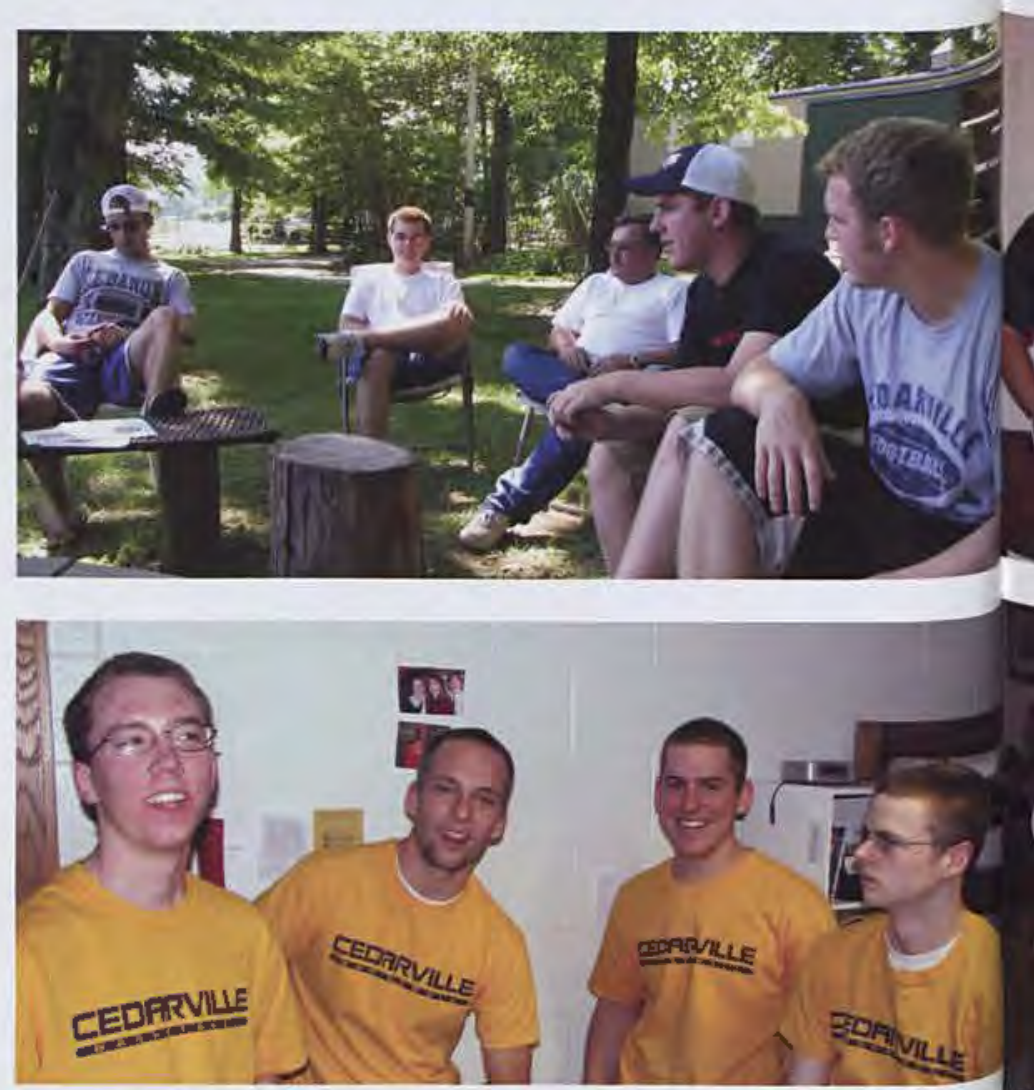

Sometimes the best part of life in the dorm isn't the chaos or the games, it's the ability to just kick back. 
Friends, fellowship, and food...for girls in residence halls and units, this combination makes college memorable. While the halls and units can be a place to retreat and do homework- "I've learned that all the bonding is great, but you need your personal space too." (Katie Houk, senior) The dorms most often provide an environment for friendships to thrive and memories to begin. Memories can involve anything from movie nights and surprise birthday parties to "practicing our 'Soulja Boy' movements while brushing our teeth" (Kim Elliot, junior). Living in the residence halls and units allows girls to be challenged and encouraged by "other girls who call on the Lord out of a pure heart." (Rebekah Goodwin, freshman) "I love living in the residence hall because it has allowed me to build deep friendships with incredible Godly young women that challenge me to grow." (Ann Marie Houg, junior) Resident Assistants play an important role in the halls and units by providing girls with "a person in whom I can trust and confide" (Rachel York, freshman) and planning activities to help an often-diverse group of girls bond together. Ultimately, halls and units are the places where friends for life becomes a reality. "Living in a hall has taught me what it means to live in community. Such close community with other girls has fostered very authentic and transparent relationships, which have come to resemble something close to sisterhood." (Bethany Young, junior)

\begin{abstract}
"Only a crazy RA would have her girls dress up as nerds, then parade them around campus, but that's what makes unit meetings fun. You never know what

to expect."

(Yekaterina Didik, sophomore)
\end{abstract}

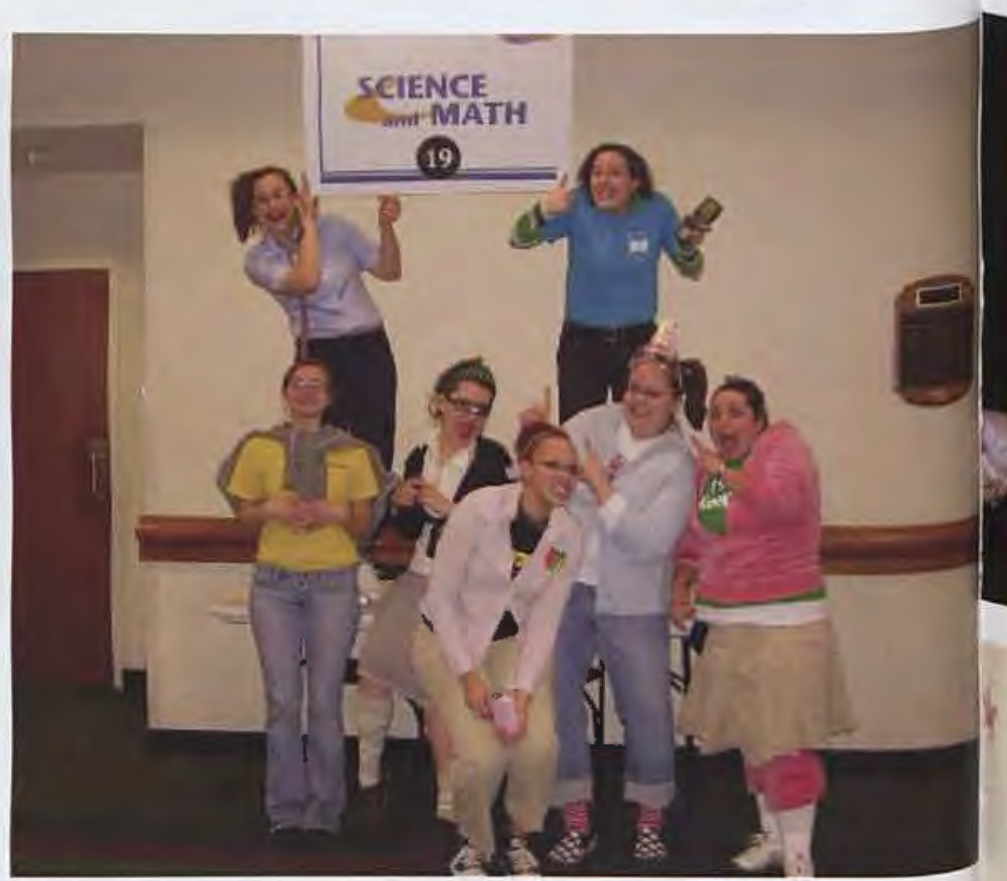

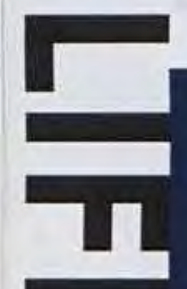

\section{列}


Freshmen Jessica Robb and Lauren Bigney

"get grossed" during dorm wars. According to

Jessica, "Printy Wars [was] a night of insanity

and the most disgusting foods I have ever eaten."

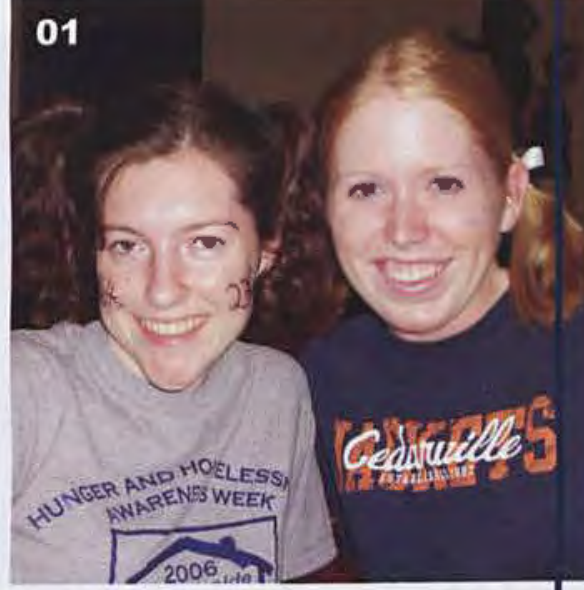

02

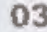

03
"Hallmates are the best because they French braid your hair, share their dark chocolate, and make sure you never have to eat alone," (Kim Elliot, junior)

"Printy Wars was such a blast! I really enjoyed having so much fun with all the girls in the units... and our mascots, Bobo and Dorothy!"

(Rachel Gilin, sophomore)

Freshman Meagan Ray remembers the night she and some friends bought an unusual ice-cream maker-"a ball that reminded us of a hamster toy," she says. "It worked pretty well, too, it just took a long time."

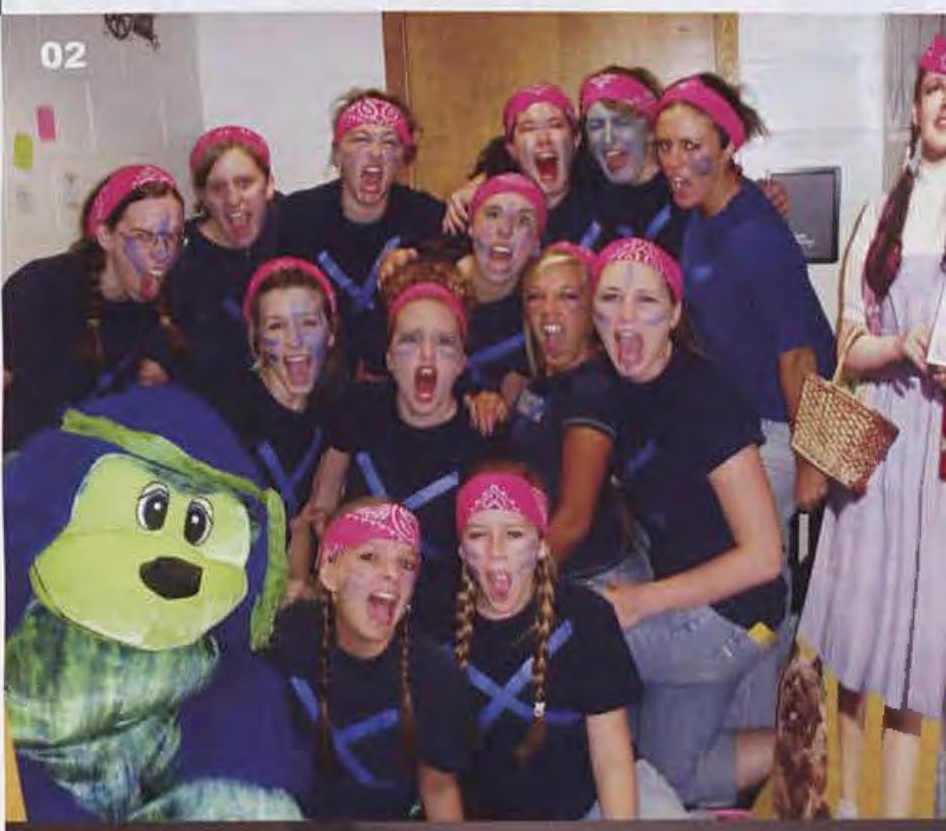

"Girls in Johnson Hall dress up in smiles for this birthday celebration. "Being able to build relationships and consequently grow because of them has been such a blessing!" (Chelsey Hauser, sophomore) 
RAs had to deal with broken mirrors, all-in checks, and "chapel-sleeping" duty. RAs built into other students' lives through a variety of ways. From party planner to curfew enforcer, counselor to roommate, RAs took on many different roles throughout the course of a school year. In fact, McChesney RA Justin Dodson said one his favorite memories of being an RA was "winning Campus Christmas in McChesney two years in a row." Yet most RAs would tell you that they see their position on campus as that of a servant; they became RAs to serve any of their hall-mates or unit-mates at any time, for any reason. RAs were in the exciting position to have an impact on every student under them. When asked to sum up what his RA is to him, sophomore John Weston unflinchingly replied with one word, "Father."

\section{"BEING AN RA IS THE HARDEST BUT GREATEST MINISTRY ON CAMPUS." -BETHANY DUNCAN, JUNIOR PRINTY RA}

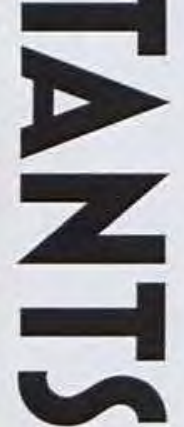

"Being an RA was a great experience because I had an opportunity to build some life long relationships with some amazing men." (Ben Thacker, sophomore Lawlor RA)

The job of RA starts before most students even arrive. Jacinda Gillete (left) and Laura Ziegenfus (right) "are anxiously awaiting the arrival of the girls that will be in our units." (Laura Ziegenfus, senior Printy RA)
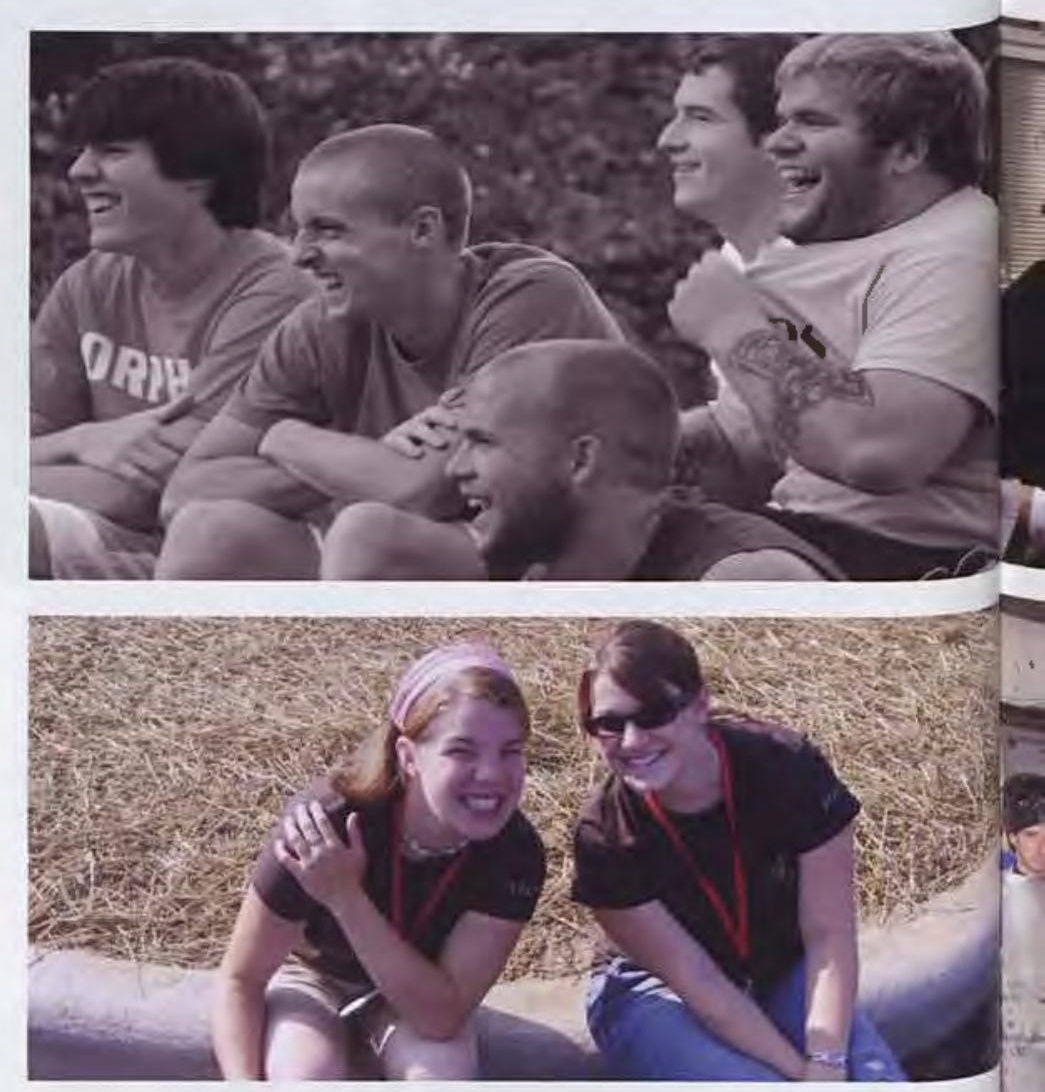

"Being an RA is one of the most formative things someone can do at Cedarville because it challenges you to grow in maturity while allowing you many opportunities to have fun." (Mark Smith, senior St. Clair RA) "This is one of the sweetest groups of people on campus." (Matt Fox, senior McChesney RA) "Thursday night randomness with my fellow RA's was a highlight of every week!" (Evan Wicker, senior, St. Clair RA) 
A group of Lawlor men take some time to get to know one another. Spending all year in a Lawlor unit tends to bring the guys pretty close together - literally.

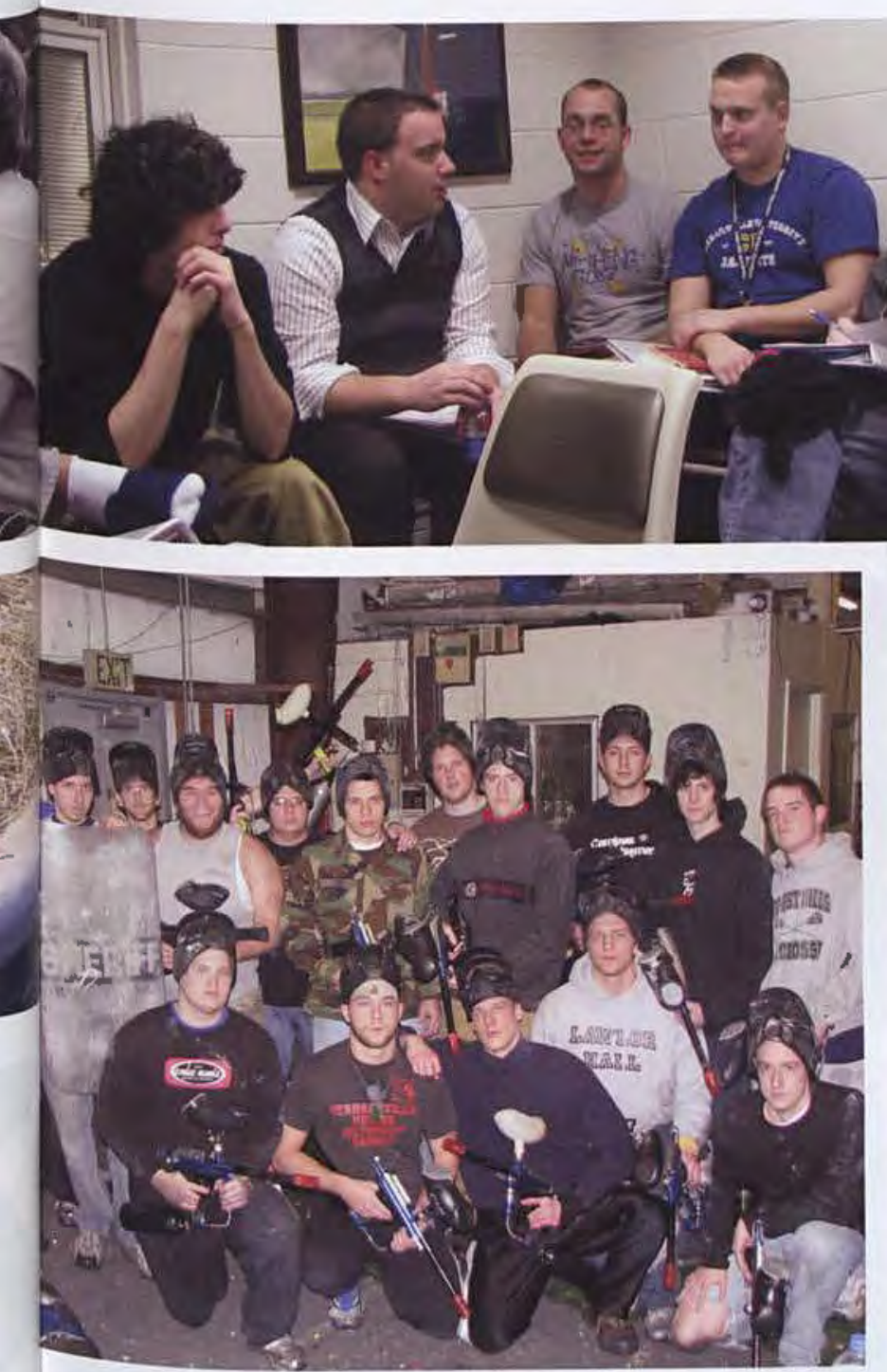

"Being part of a community of RAs as well as working to build community in your unit is such a stretching and growing experience. I love it!" (Michelle Kropf, junior, Printy RA)

02 The Lawlor cookout is always a highlight of the year, and this year's cooks were really on fire! And so were the hamburgers.

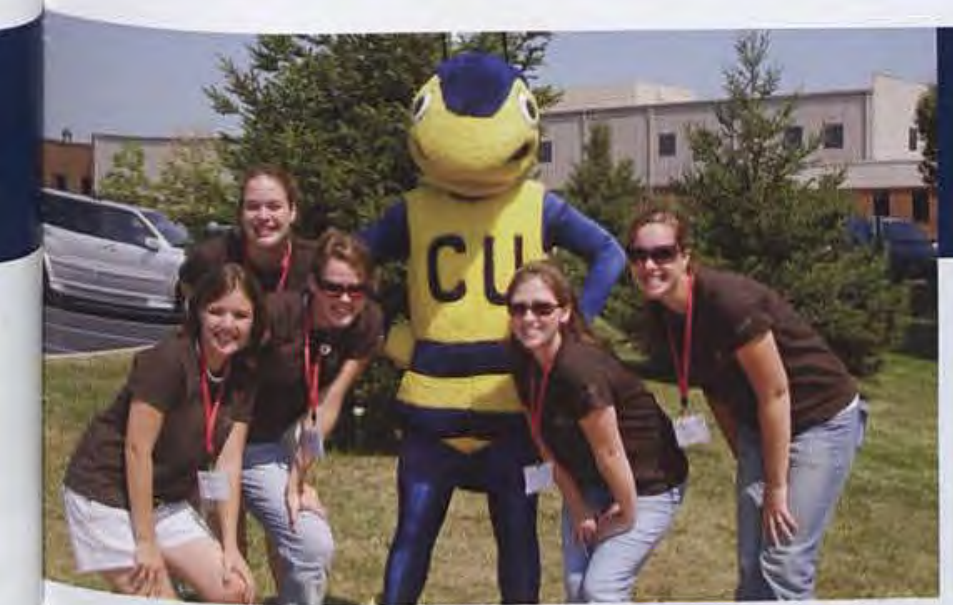

"I think one of my favorite things about being a Printy RA this year would have to be just being there for my girls. They are such amazing and godly women and $I$ am so thankful that God chose to use me in their lives this year." (Kelly Donohue, junior, Printy RA)
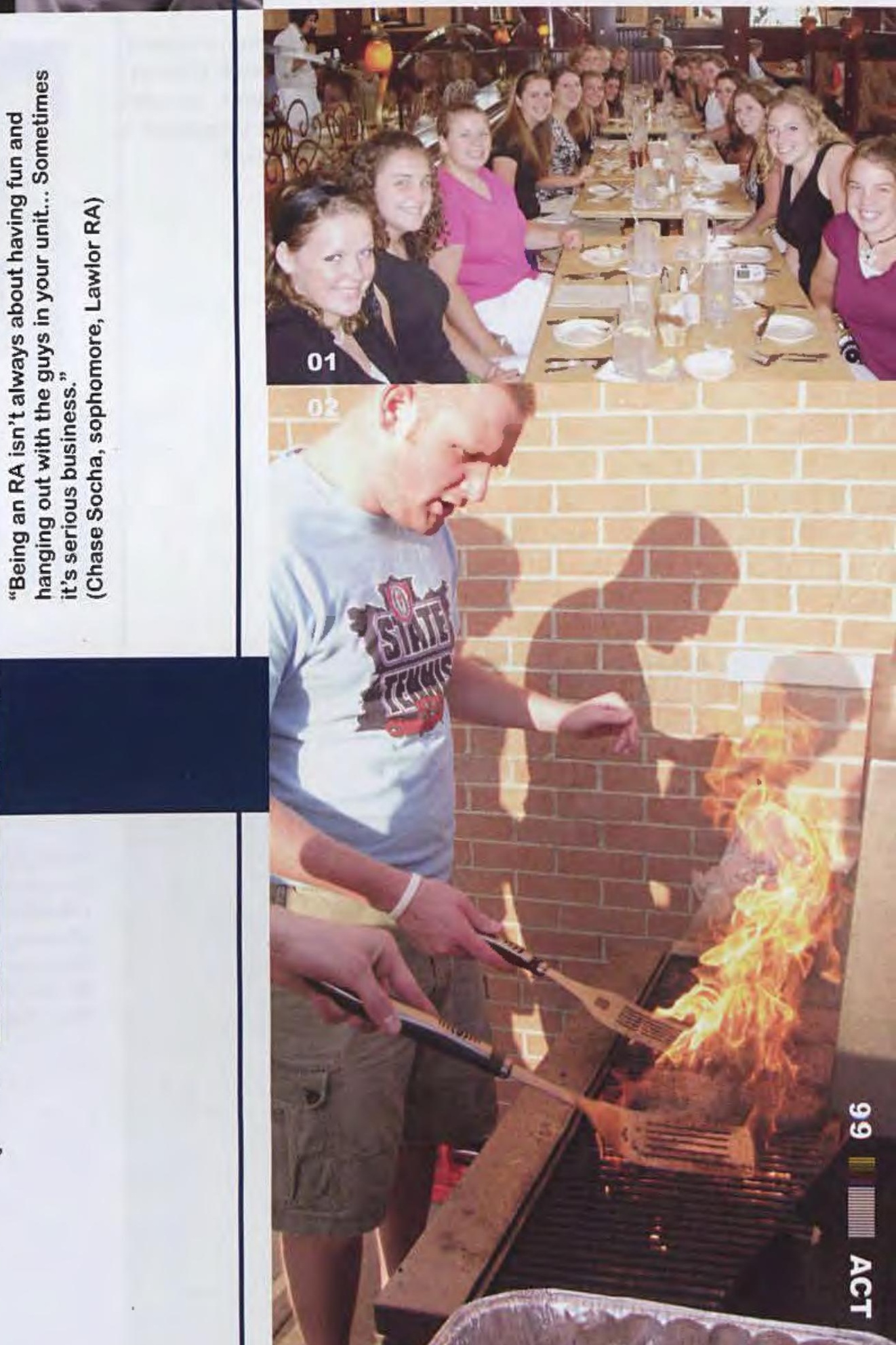
"To be honest, I was a little nervous to move into the dorm." (Greg Gallagher, freshman) Dorm life can be a little scary at first, but as we all find out, it's often one of the most rewarding experiences of college.

"Dorm life is a unique experience. In no other context will you have the opportunity to live with 30 people your age. Dorm life here at Cedarville adds flavor and fun to your four years of learning." (Julie Grollimund, junior) The 2007-2008 school year held much excitement for the residents of campus. Open dorms, Campus Christmas, Lawlor-ween, and Brock to the Rock are just a few examples of why living on campus can make your college experience that much better. Junior Erin SanGregory especially enjoyed Campus Christmas. "I live in McKinney, and my hall went all out with the theme 'Christmas in the White House.' We had the President, the First Lady, Secret Service officers, event planners, and even bakers! We had fun calling 'code red' a few times, especially when the judges came through."

"As an RA in Rickard, it was my job to make sure everything ran smoothly during open dorms. I was able to enjoy myself, but checking on my guys was my main task. I only had to lay down the law once or twice." (Wes Muntz, junior)

While dorm events hold their place on campus, some of the best memories can be just hanging out with friends. So after a year has passed we check back in with freshman Greg Gallagher. "I couldn't have imagined a better year. I can't wait until I'm a sophomore!"
Dorm life is so much more than what I thought it would be; laughing, crying, jumping, dancing, and most importantly gaining life long friends.

(Rachael Wasem, freshman)

"The Lawior/Hill football tradition was a ton of fun working together, and it paid off because we ended up beating the Hill!" (Joe Hatch, sophomore)

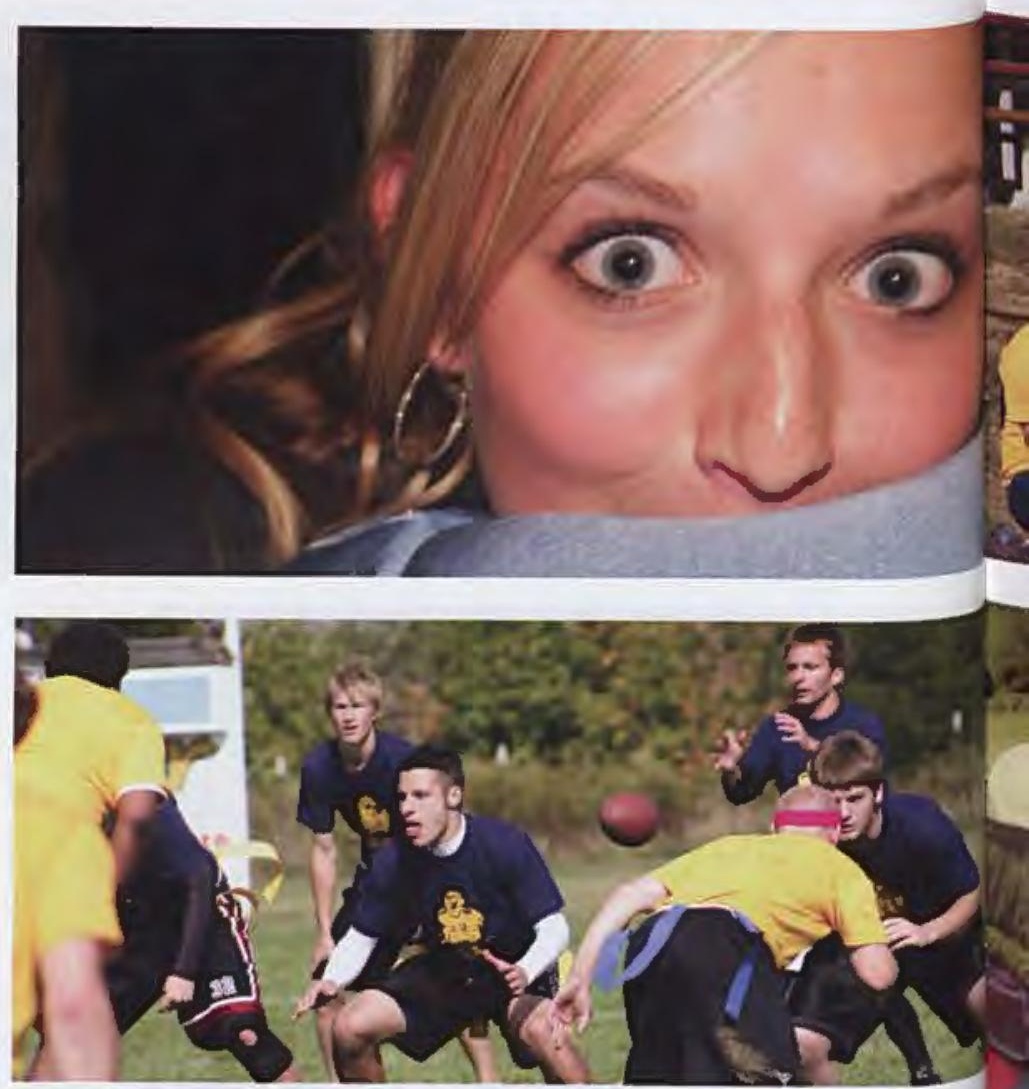

"Things I love about my dorm: stark white concrete walls, horrible smells because someone left milk out or brought in a dead animal, and the chance of being woken up in the middle of the night by a band of men yelling and screaming for no apparent reason, which I may or may not have been a part of." (Matthew Fox, junior) 
"The Lawlor/Hill football game is one of my favorite events of the whole year. I wouldn't live anywhere else but the Hill."

(Nicholas Dunn, sophomore)

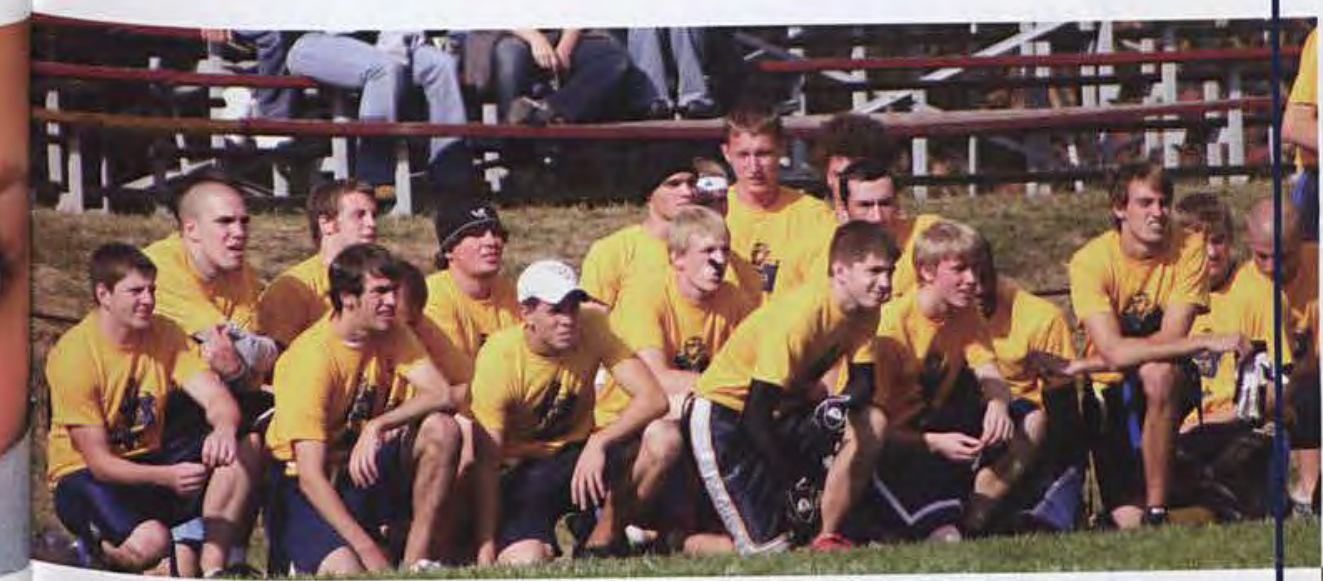

01 "I had so much fun playing quarterback for the Maddox Printy game. Everyone did a great job! I love this new tradition between the dorms, and I hope it continues for years to come!"

(Lynsey Fabian, Maddox RD)

02 "Lawlor v. The Hill. Lawlor dominated and is still the powerhouse football program of the freshman dorms!" (Adam Riehle, freshman)
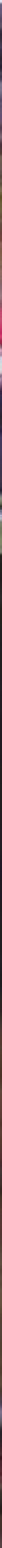

"We always make room for the ladies." (Baxter Stapleton, freshman)

02
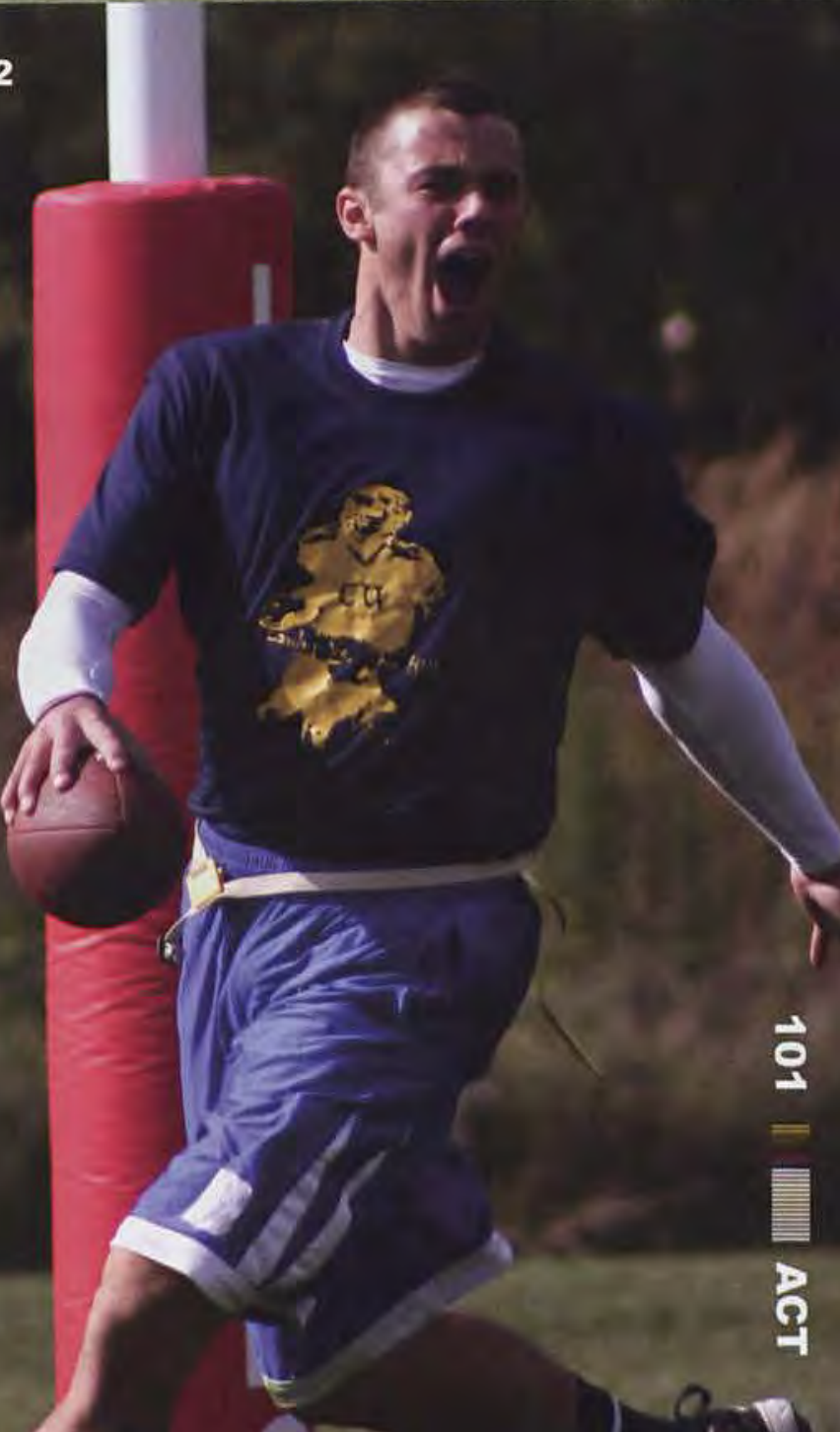
Sophomore Ricardo Alliman shows off his Jenga skills during a study break in the Hive.

Enjoying an escape from her dorm room, Ashley Dasuqi relocates herself in the Hive for some studying.
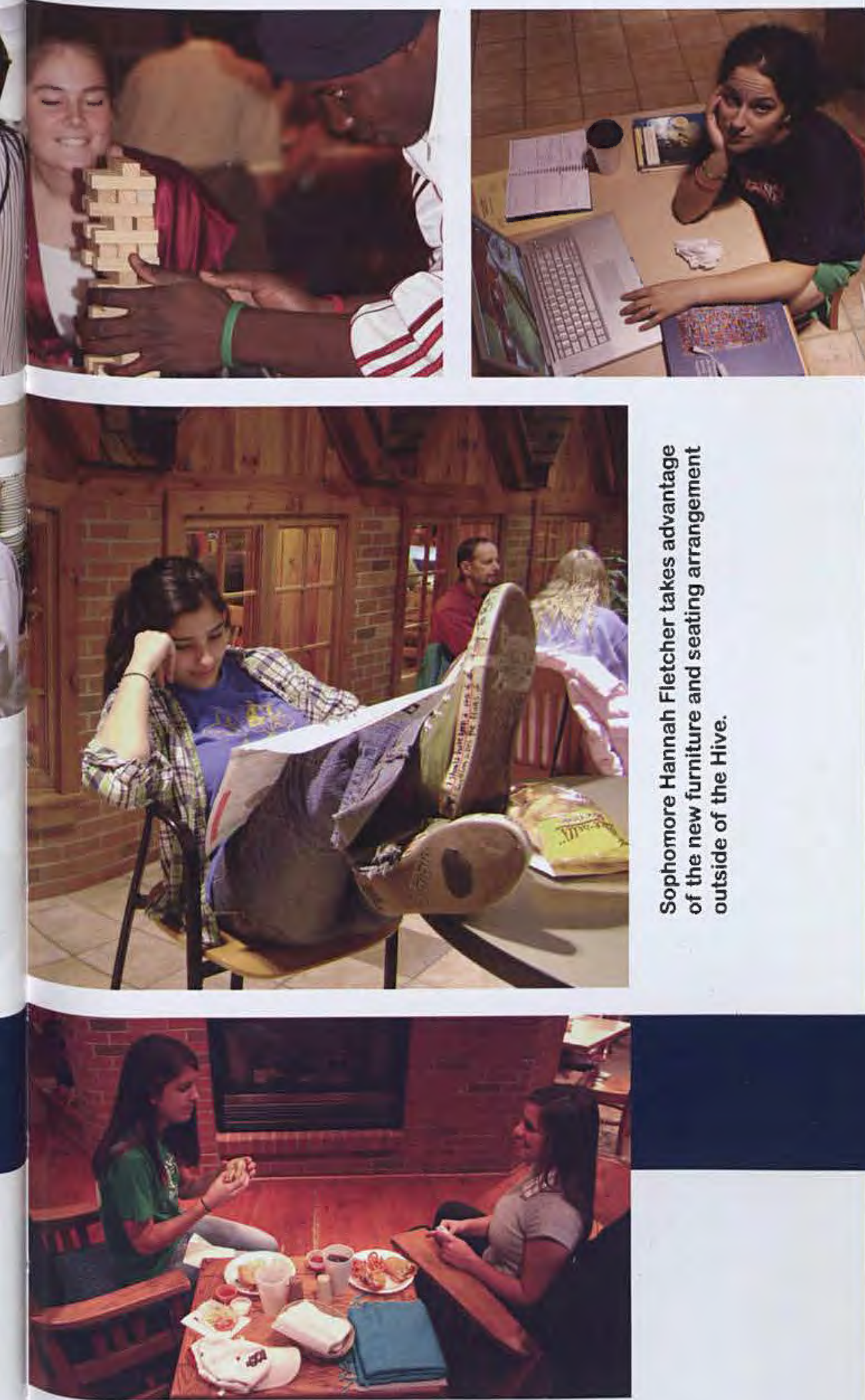

Sisters Angie and Amanda Rill enjoy a little time in the Hive to eat and catch up on their busy lives.
"Well, I love those people that come in the Hive all the time. I get to know names (but they never know mine). Sometimes instead of asking their names, l just put write it on the paper because I aiready know it. They always seem surprised that I know their name, but they come in there all the time so of course I know it. And then what do you do when, let's say, the SGA worship leader or chaplain comes in. They don't know me, but of course I know their name. Do l ask them their name regardless or just write it on the paper since most everyone on campus knows their name?"

(Larinda Marker, senior, Hive employee)

01 Food, games, studying, catching up or entertainment, there is no other place on campus as versatile as the Hive.

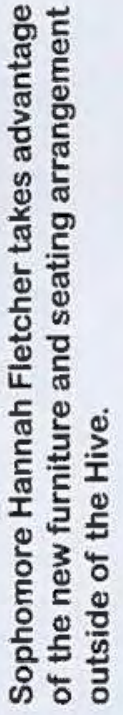

02

Vecinos is always a frequented stop throughout the day, but be cautious of that 9:50 A.M. stop, it's quite the rush.
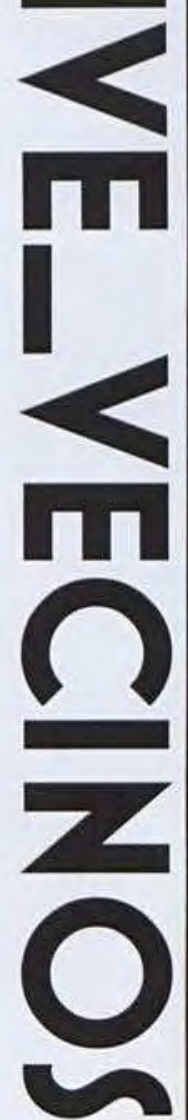
Classes. They're really the core reason why any student goes to college. At Cedarville, classes are definitely a central part of life. Everything goes on in classes.

From the serious: "For my online biology class, we read The Case for Our Creator. It was an amazing addition to the course and has given me great resources to witness to my family." (Georgiann McClure, sophomore)

To the funny: "When commenting on a prospective new lab, Dr. Hutchinsons commented, 'Now that is a good looking experiment!' Realizing the implications and possible applications of this phrase, I used it on a girl standing next to Dr. $\mathrm{H}$ later that lab period... just for fun." (Steven LoCicero, sophomore)

From the strenuous: "Some of our discussions in my Bible classes were so exciting and mentally invigorating! We could really work up a mental sweat." (Evan Wicker, senior)

To the basic: "Spring semester I was in Intro to Math where I learned how to count votes, calculate juggling patterns, and predict fish populations." (Adam Evans, junior)

From the academic: "At the end of every class with Deardorff, my head is spinning and I feel like I've discovered the key to all knowledge." (Kaitlin Dunnevant, junior)

To the...well, not so academic: "I would just like to say that this year there seemed to be quite a few more random body parts lying around the nursing lab than usual..." (Jessica Hinkle, sophomore)

Mark Miller leads a prayer in Dr. Blumenstock's Personal Evangelism class.

Dr. Bruce Curlette challenges the minds of the music majors.
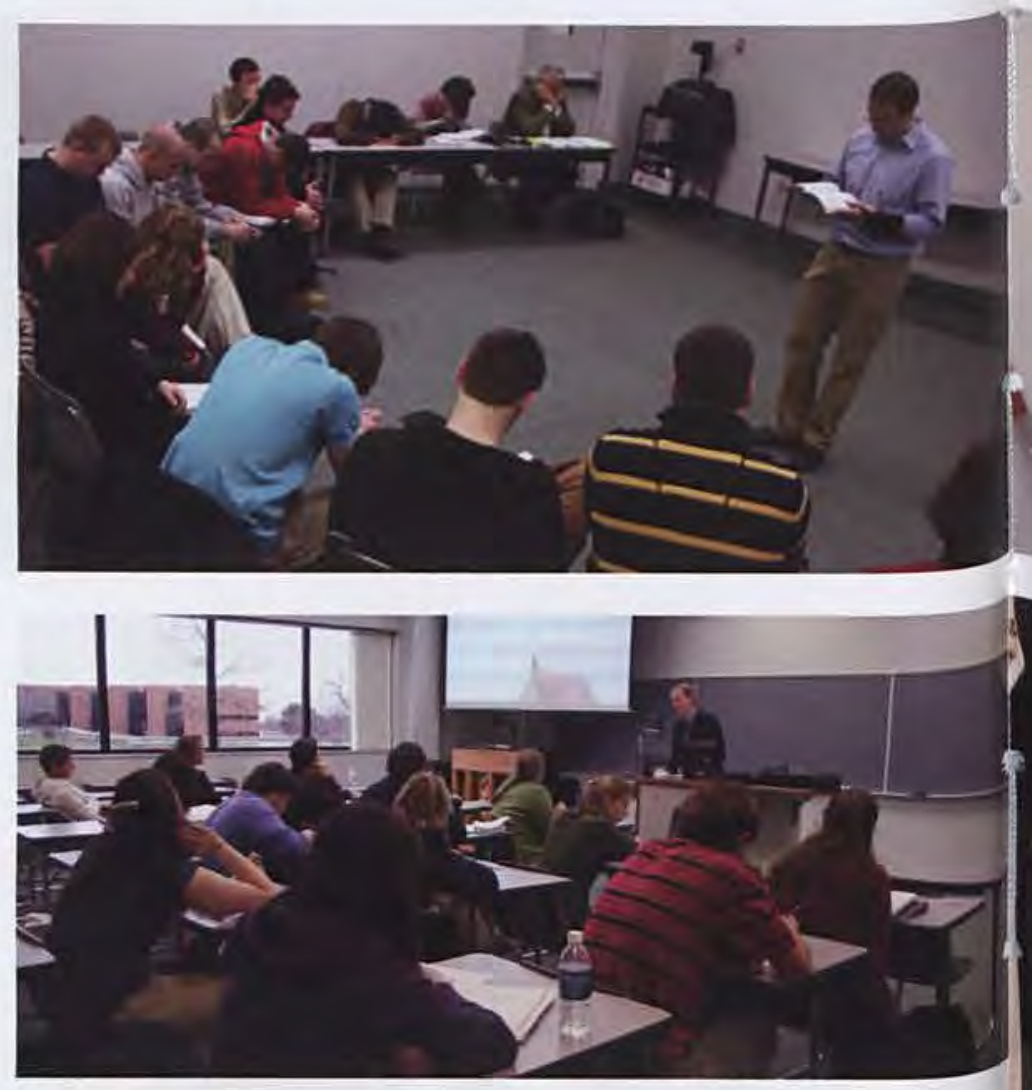
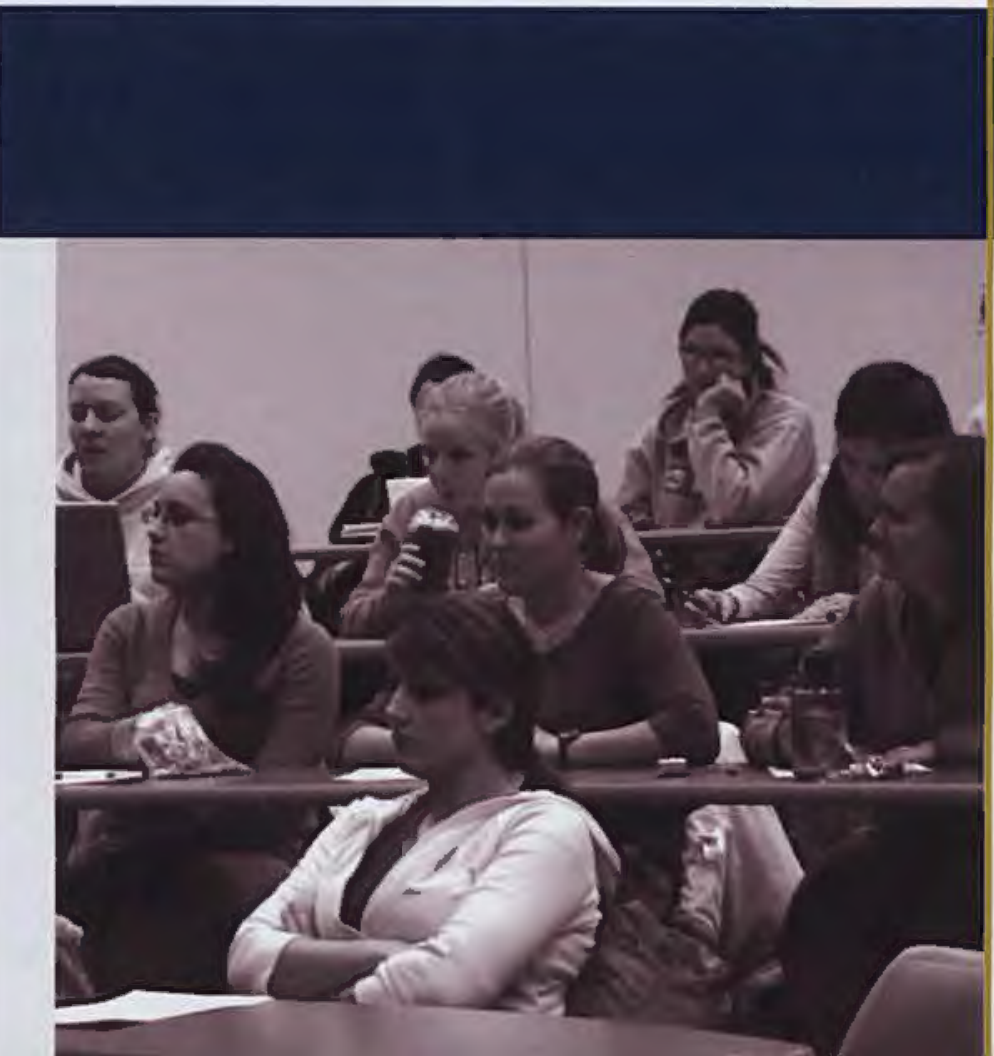

Calling all nursing majors! Ashley Coale and other diehard senior nursing majors are amused, thirsty, interested, and asleep for the class Adult and Child Health. Or was it Nursing Theory? They all become a blur when senioritis hits anyway. 
Cedarville University offered students around 20 differentintramural sports, from table tennis to bike hikes to chasing a giant pumpkin for $\mathbf{5 0 0 0}$ meters. Some of the more competitive team sports included basketball, co-ed Ultimate Frisbee, and men's and women's flag football. "The most fun aspect of participation, for me, has been team mascots. For instance, there are these guys out there who call themselves "Ray Nitschke's Blind Fury." They play football and softball. They're what intramurals are all about." (Scott Kordic, junior) For those who don't know, Nitschke was a linebacker for some great Green Bay Packers' teams. Mascots have become a method for creating team persona. Some notable team names besides Nitschke this year were Curdled Milk, Trojan Rabbits, and Positive Town.

While it is enjoyable to hear such creative and witty team names, it didn't seem to prove beneficial when finals came along. Several of this year's winners, including men's and women's volleyball, ultimate Frisbee, and men's and women's 3-on-3 basketball, never chose a unique name. Many of the brackets this season were completed with such names as "G7" and "G31." It appeared that, at least for this season, a team could not possess both a remarkable name and a remarkable record.
"Lushious green grass, billowing white clouds, balmy spring breezes and a pleasant temperature - the perfect setting for a game of ultimate frisbee." (Joel Losch, senior)

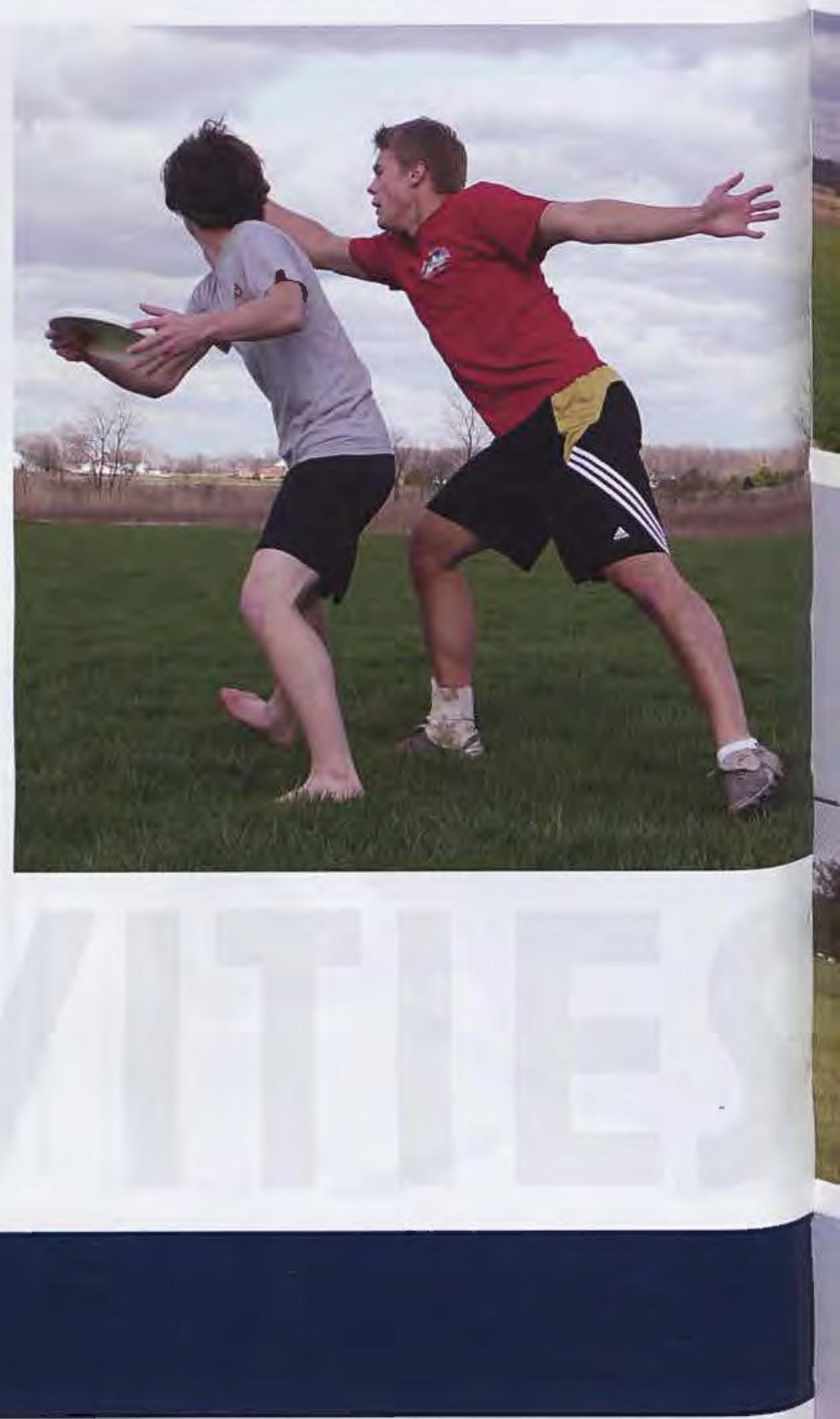

The fact that they are playing flag football probably won't stop this quarterback from getting creamed like corn unless he's really fast. 
This player makes an intense catch, giving his team the upper hand.
"Ultimate frisbee is probably the most popular and one of the most competitive intramural sports here at Cedarville" (Ryan Smith, junior)
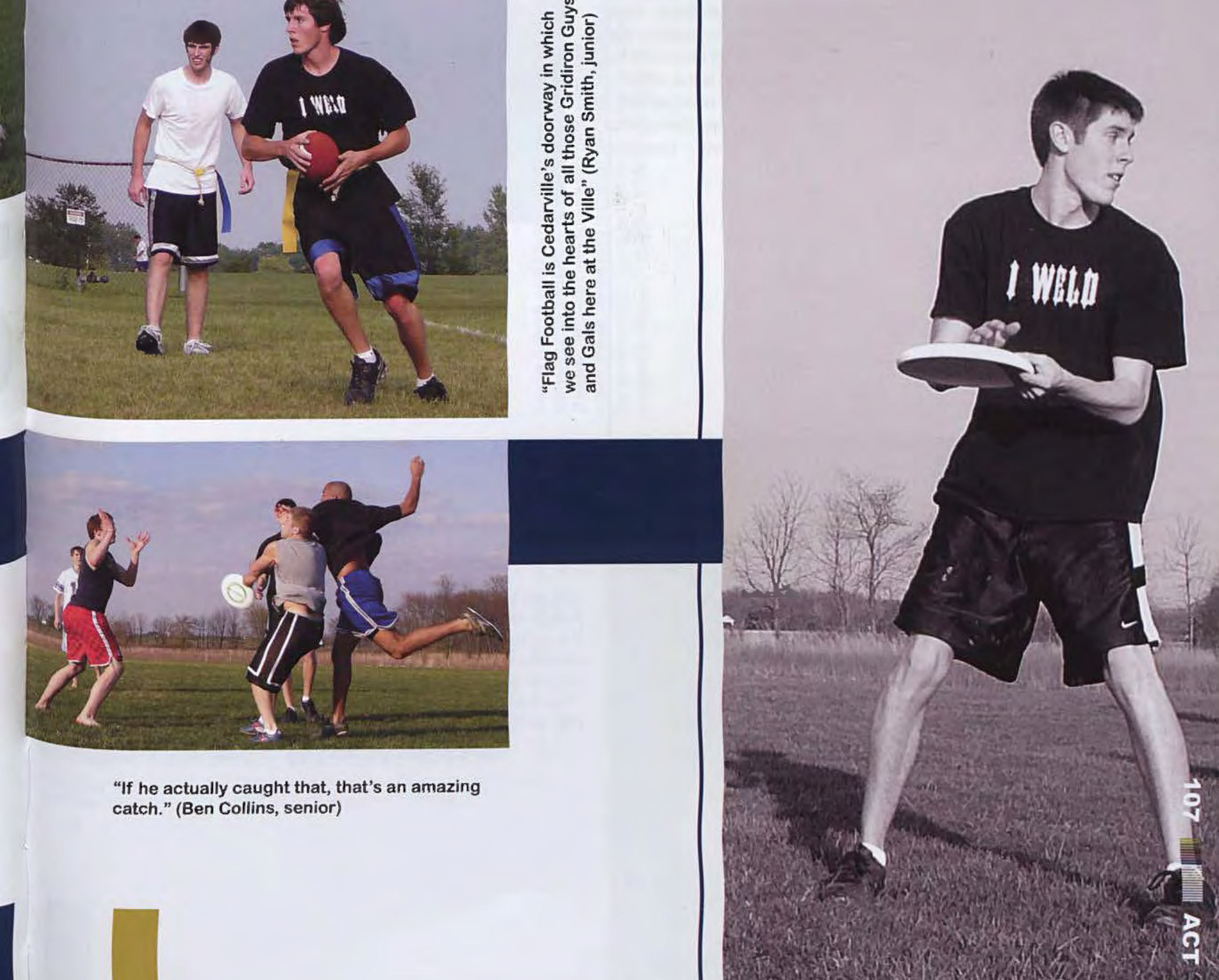

"If he actually caught that, that's an amazing catch." (Ben Collins, senior) 
Students had many different ways to show their talent, from Integrated Business Core, to Senior Recitals and Art shows, to Senior Theatre Projects. A student-run project existed for any interest.

Integrated Business Core had two groups: one sold the calendars and the other sold basketball hoops. "IBC was a great experience that challenged me and helped me develop a better mind of what happens in the business world. This business also helped me in my other classes as I am better at preparing for projects and presentations. 1 also made a lot of friends through this experience which is just as important to me as the business skills I learned." (Benjamin Cowell, junior, financial analyst of IBC group)

Throughout the year, students enjoyed many Senior recitals and art projects. "It was something I planned and prepared for and ended up being a wonderful way to end my college career. Hanging my work suddenly made the past four years very tangible, very real. I'm proud of the way things ended up." (Suzanne Wilson, senior graphic design major)

Throughout the year there were also several Senior Theatre Projects which were open to anyone to come and enjoy. "I was very glad for the opportunity to do my own show. Most schools and theatre programs do not offer quite the same opportunities for students to create, build, and perform their own productions. And for anyone who does not think that theatre majors do much work, the senior theatre project is a key example to prove otherwise. Suffice it to say that much time, effort, and, of course, money was spent on this production, but I loved every minute of bringing The Star Spangled Girl by Neil Simon to life." (Phil McLeod, senior theatre major)
"Gracia Brown's talent for piano was evident in her graceful performance at her junior recital."

(Alise Merrin, sophomore)

Sophomore Allison Schulert and Junior Mallory Travis take in the display at "Art in the Open."
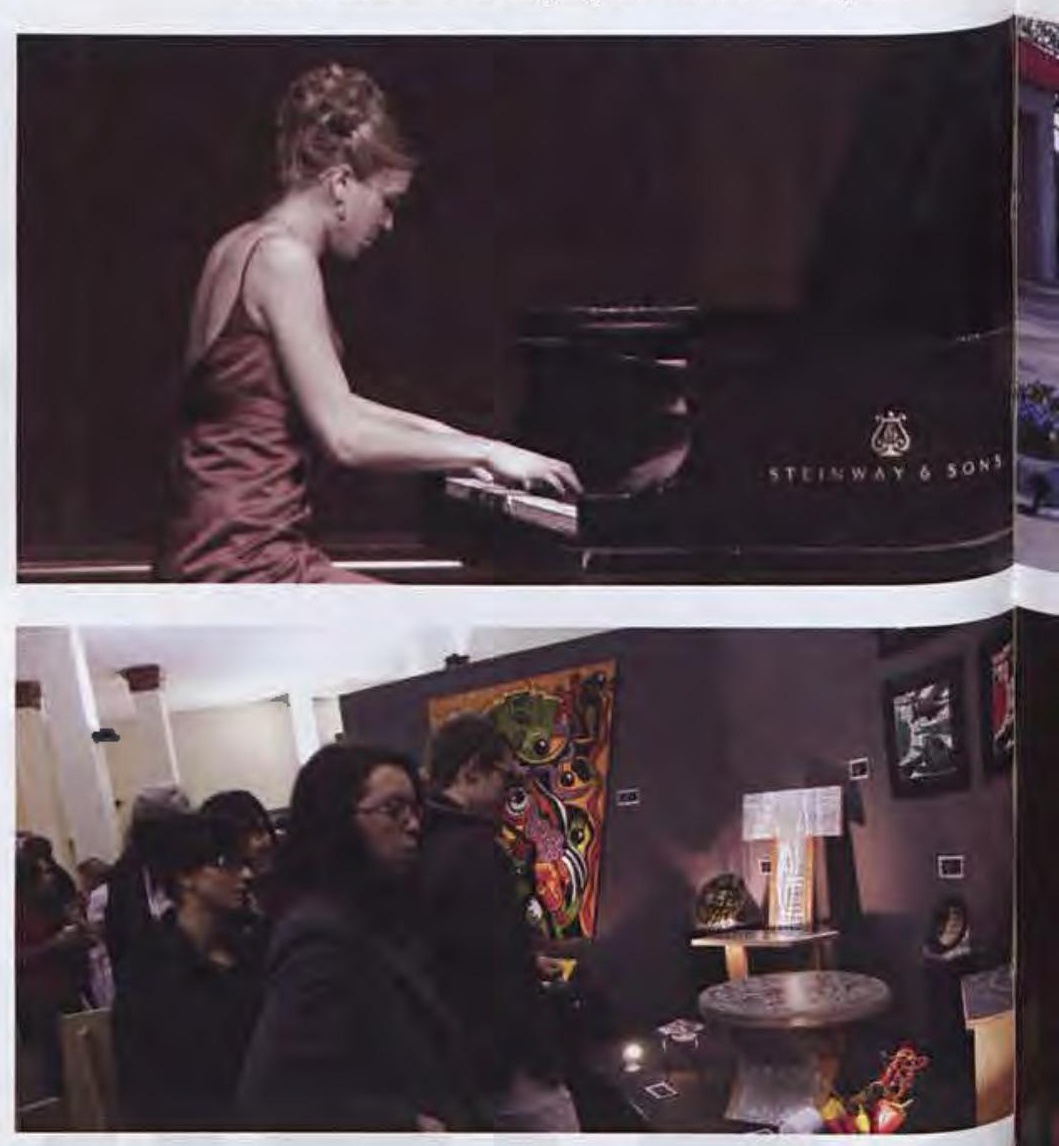

"Emma's Child was a fabulous show, and the people working with Eric (Mishne) and me made it even better. It was a stretching experience, as Jean was a character unlike any I had ever played, but in the end, I pulled it off and it was the best way to end my theatre career at Cedarville." (Meredith Brooke Lang, senior) 
"THE STP PROCESS WAS A FANTASTIC WAY TO END FOUR YEARS IN THE THEATRE PROGRAM. WE WORKED WITH OUR FRIENDS AND PEERS TO DO SOMETHING GREAT. BUT WHAT WAS GREATEST WAS

Cedarville hosts two engineering race teams: the CU Jackets Racing Team and the SAE Supermileage.

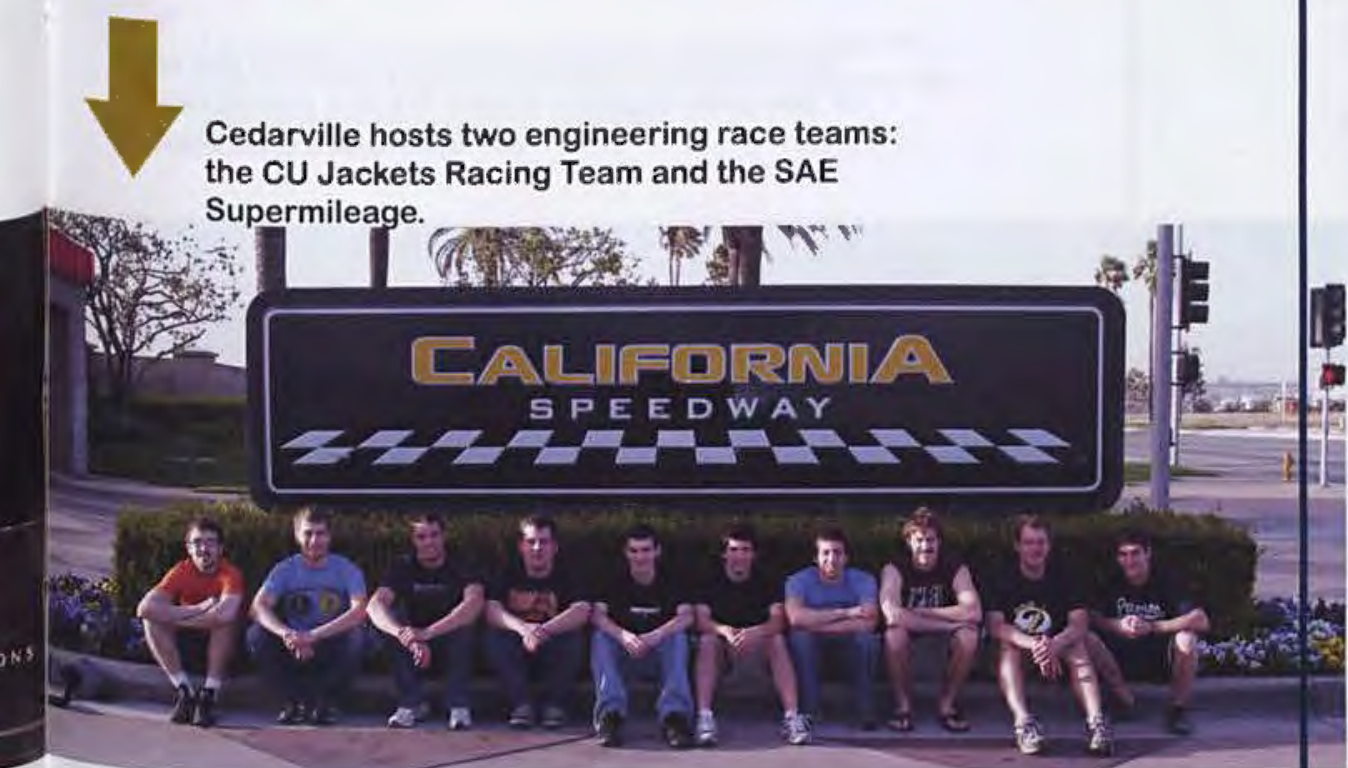

WATCHING GOD TAKE CARE OF EVERY DETAIL. IT REALLY WAS A TESTIMONY TO GOD USING OUR PERFORMANCE ART FOR HIS GLORY."

- KELSEY NELSON, SENIOR

01 Faculty, staff, and students enjoy the Faculty Art Exhibition, which features many unique pieces.

02

Junior Maraliz Campos imitates Janet Bauernschmitt's painting "Elegance," which won the Elliv award for Best Campus Artwork.
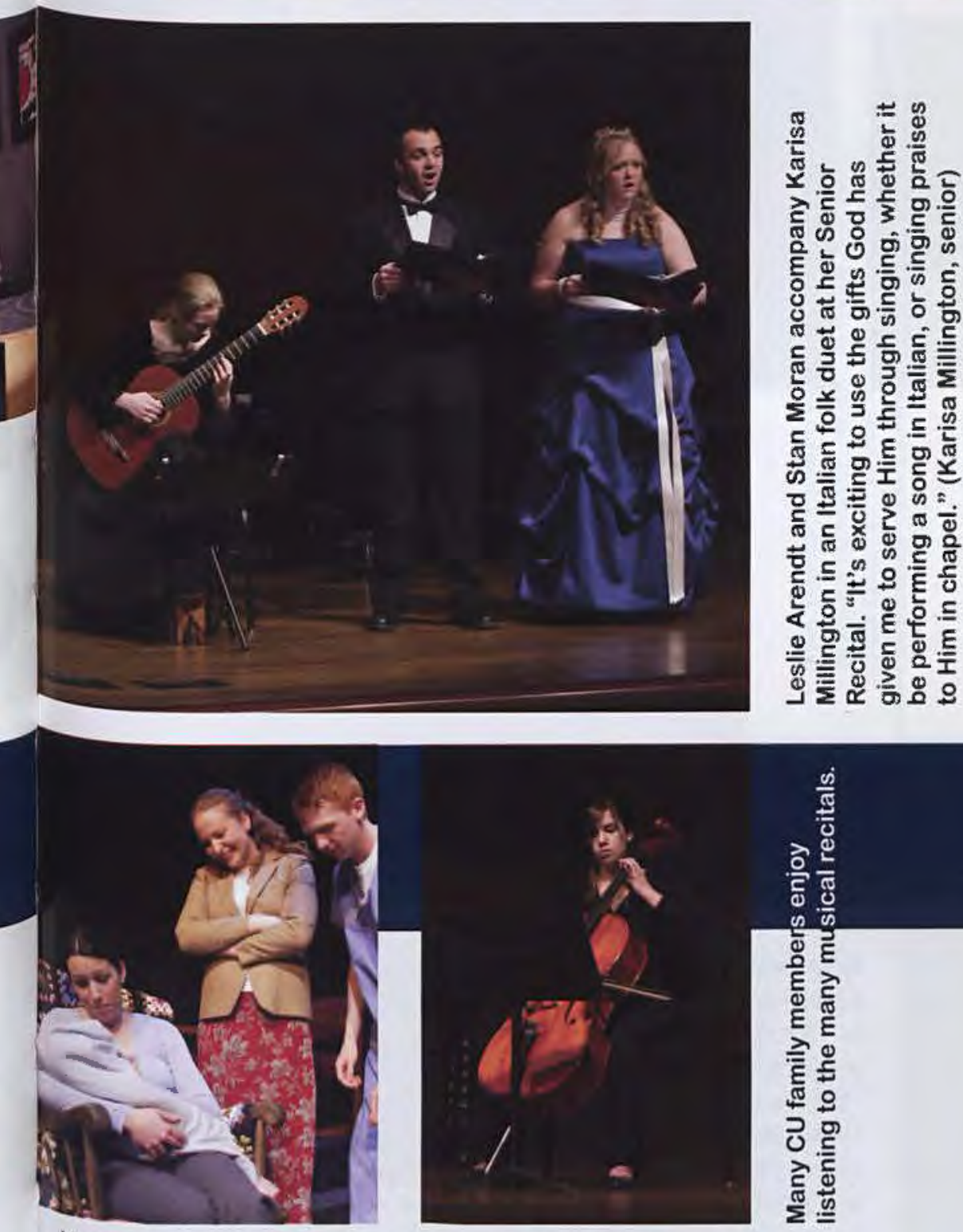

Katy Russell and Erik Strebig look over Meredith Brooke Lang and her baby in an emotional presentation of Emma's Child.

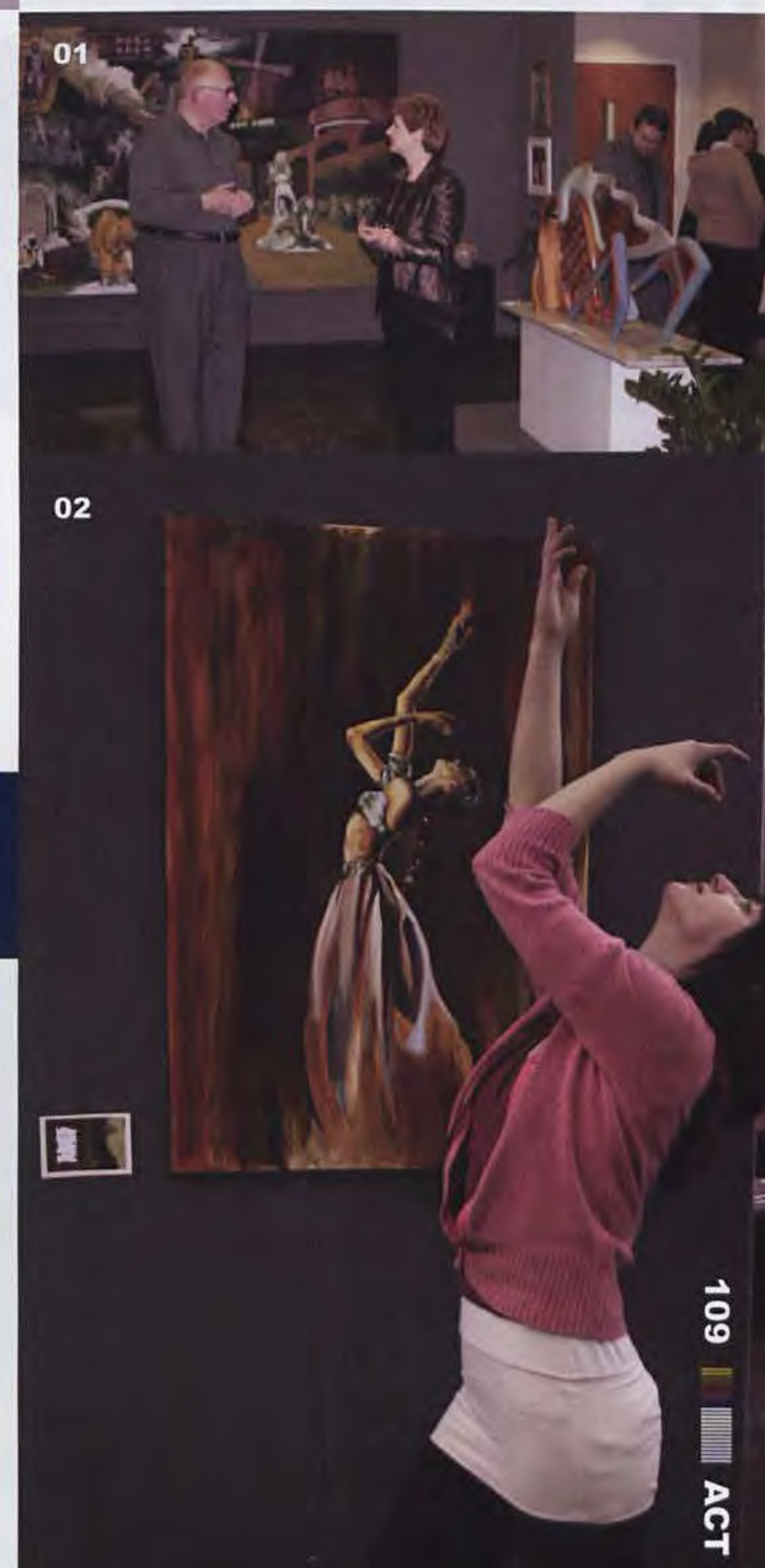


Students take part in the "alternative weekend" sponsored by SGA in hopes tp raise money for the "Home of Hope."

"Art Week was such a good opportunity for students to express themselves creatively and blend that with their passion for a world in need." (Melissa Martin, sophomore)

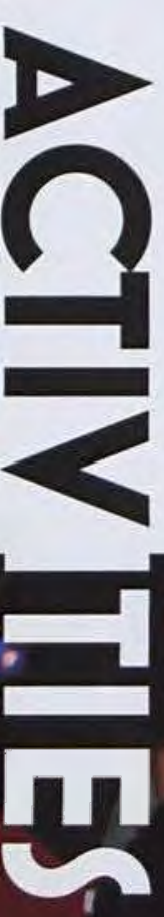

Sophomore Derek Stockwell embraces the role of Sherlock in SGA's dinner theatre presentation of "Sherlock's Last Case."
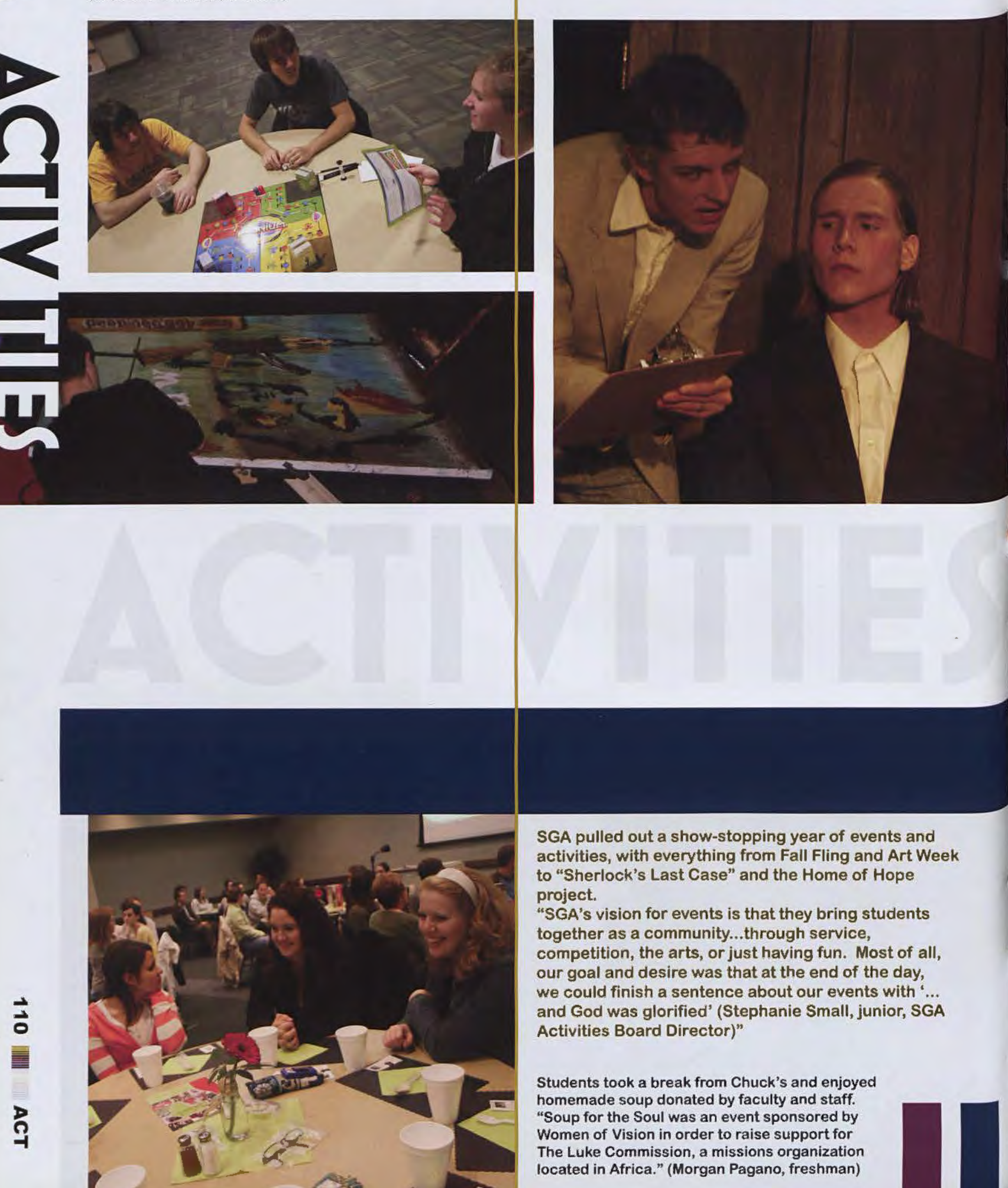

SGA pulled out a show-stopping year of events and activities, with everything from Fall Fling and Art Week to "Sherlock's Last Case" and the Home of Hope project.

"SGA's vision for events is that they bring students together as a community...through service, competition, the arts, or just having fun. Most of all, our goal and desire was that at the end of the day, we could finish a sentence about our events with '... and God was glorified' (Stephanie Small, junior, SGA Activities Board Director)"

Students took a break from Chuck's and enjoyed homemade soup donated by faculty and staff. "Soup for the Soul was an event sponsored by Women of Vision in order to raise support for The Luke Commission, a missions organization located in Africa." (Morgan Pagano, freshman) 
Chaplain Craig Houser conveyed his passion for the Word of God and love for his fellow Cedarville students through SGA chapels.
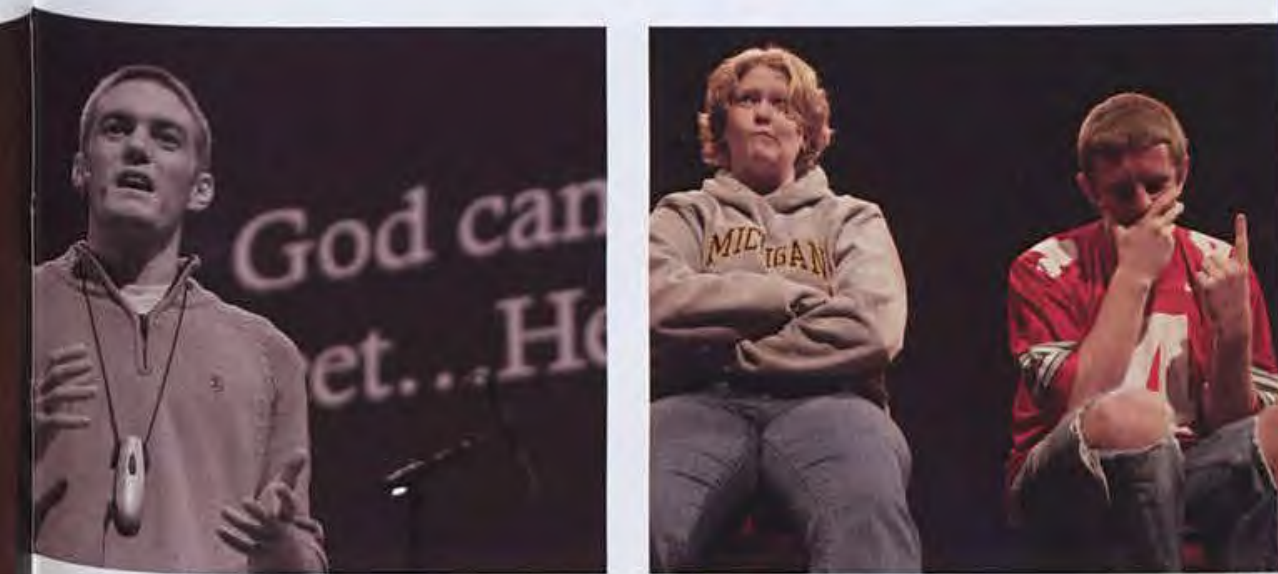
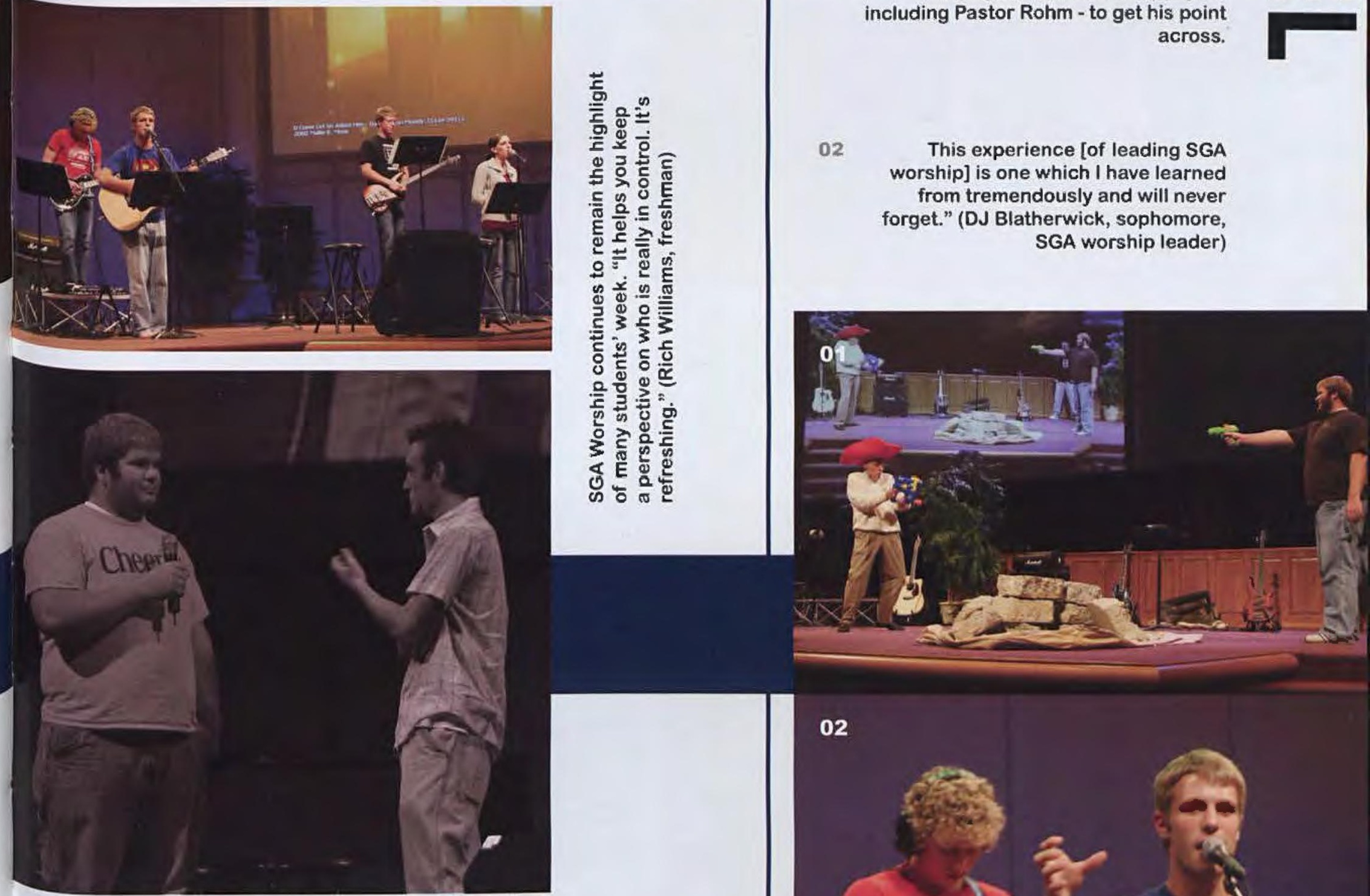

02

Senior Mike Angle became a beloved figure in SGA chapel, often acting out many of the visual illustrations - even to the point of running up and down the balcony stairs seven times.
01

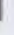
variety of methods and people including Pastor Rohm - to get his point

This year's SGA chapels featured everything rom Chaplain Craig Hauser's walk through of generosity in the Home of Hope offering. Chapeis can sometimes feature short, comedic videos, or in one case a stunt dummy being pushed off the chapel balcony illustrate a point about the Old Testament. chapel] makes Friday's magical [and Walton, sophomore) Yet through the goofy potential, SGA chapel remains a great time students to worship together and a great way to end the week.

$$
\text { across. }
$$

This experience [of leading SGA worship] is one which I have learned from tremendously and will never forget." (DJ Blatherwick, sophomore,

SGA worship leader)

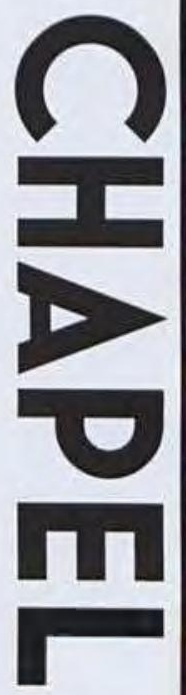

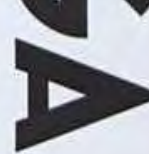


This year Cedarville University had the privilege of hosting four concerts on our campus thanks to the Student Center Activity Board.

Building 429 graced the Cedarville stage this past January with a free concert, sponsored by K-LOVE. Involving every person into the show and providing a time of corporate worship, Building 429's concert was a great way to start off the spring semester.

Josh Bales was back this year for another two-day series in chapel as well as a special concert in the Hive showcasing some of his other music. "Josh Bales is very refreshing in the way he is able to incorporate both traditional and modern worship styles." (Emily Broersma, senior)

The most unique concert of the year was when Christian hip-hop artist, Tedashii, came to visit. "It wasn't your typical Cedarville concert, which I appreciated. I think culturally diverse musicians should be encouraged to perform more frequently on this campus. We need to be exposed to more voices like Tedashii's." (Kelly Pankratz, sophomore)

The final and biggest concert of the year was headlined by Third Day. Opening for this CCM artist were Sanctus Real, December Radio, and debut band Revive. The show was incredible and the worship completely authentic. "The Third Day concert was so much fun! It was just a great time of praising our God. The focus wasn't on the performers but on the One who gifted them with their obvious talents." (Sarah Jacobson, sophomore)
Kicking off the new semester, Building 429 led students in an interactive and worshipful concert.

Building $\mathbf{4 2 9}$ got the whole crowd involved when the audience came on stage to show off their dance moves.
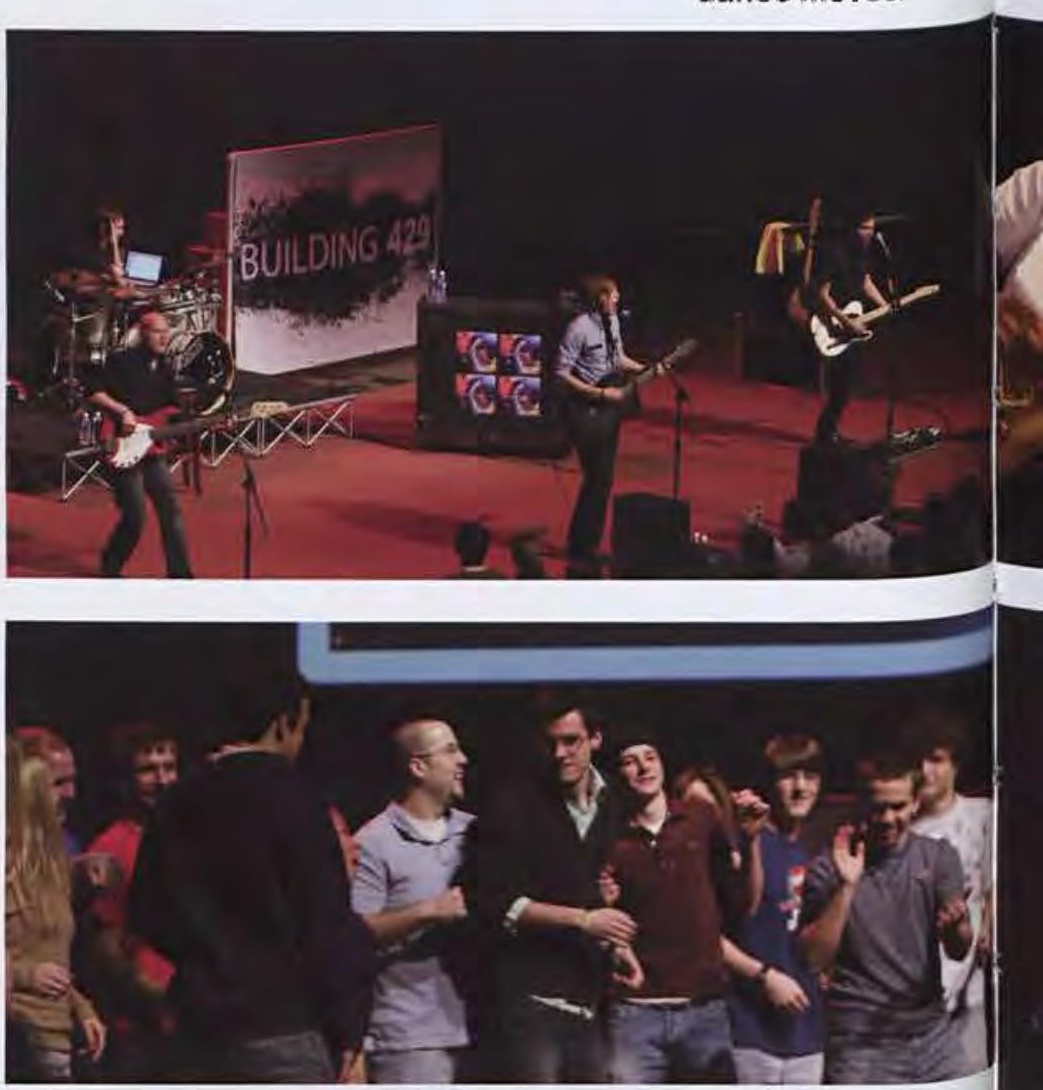

Third Day's Mac Powell closes out a night of worship, entertainment, and fellowship. 
"THE CDISIS OF TODAY

IS THE JOKE OE

TOMORROW"

- H.G. WELLS 

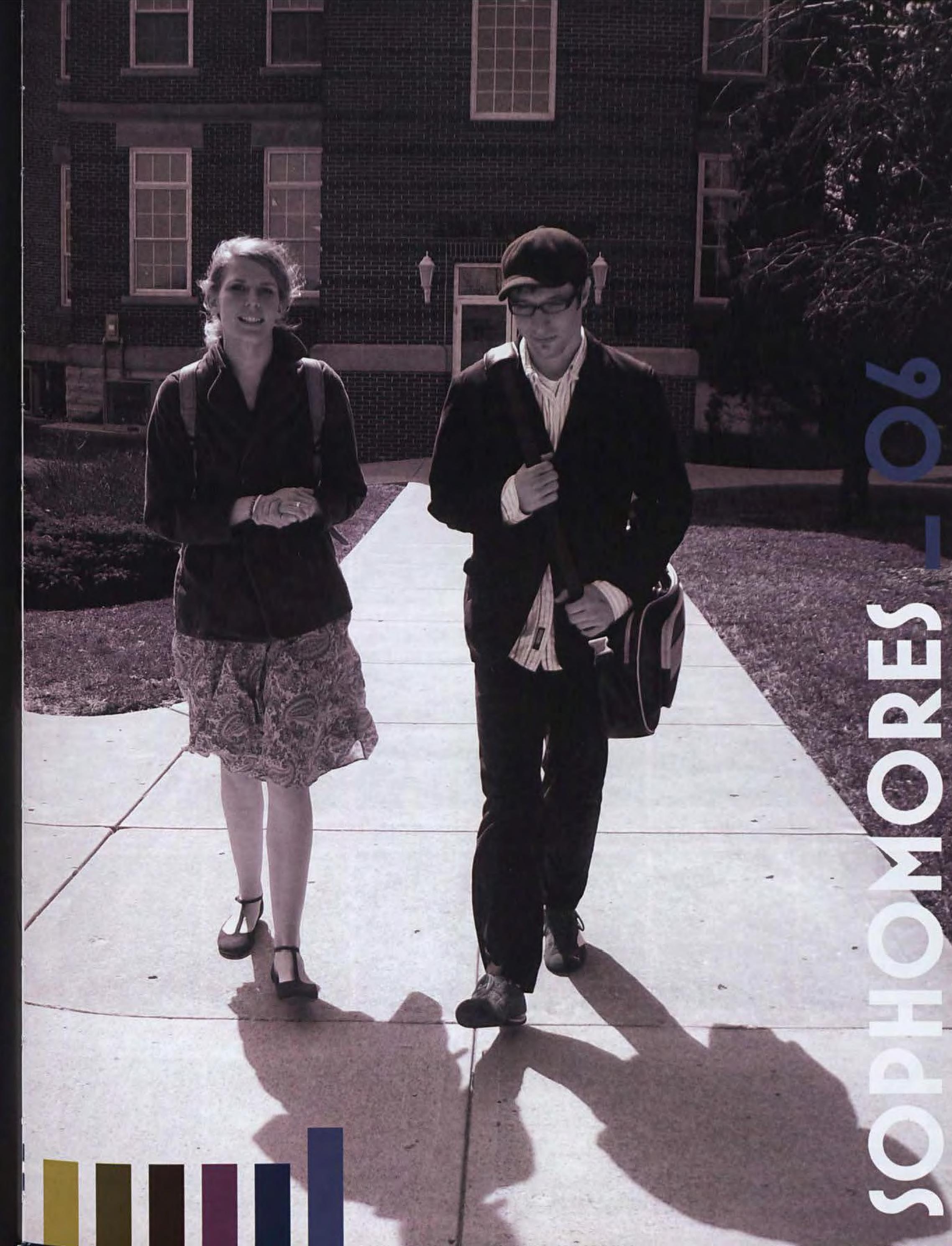

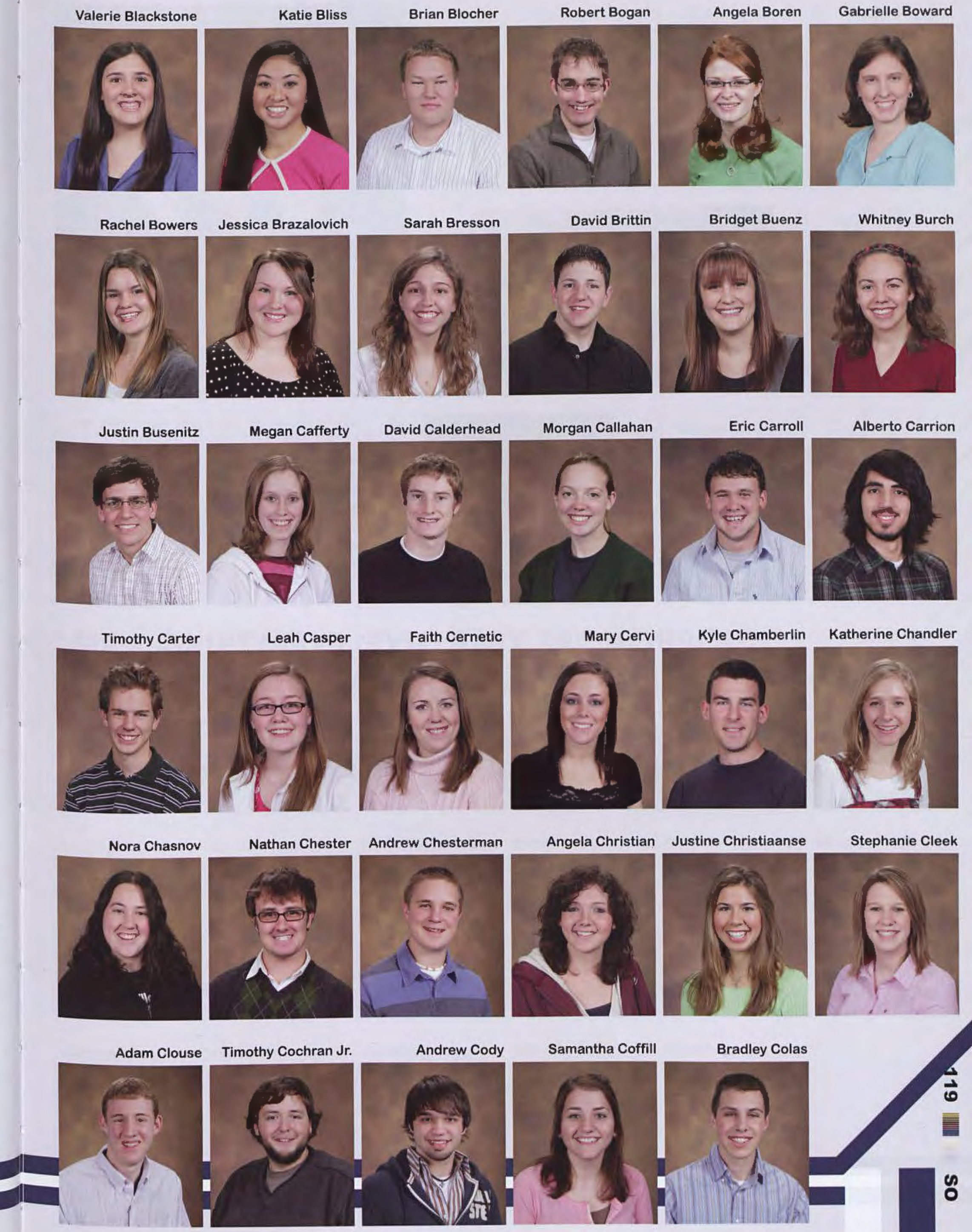

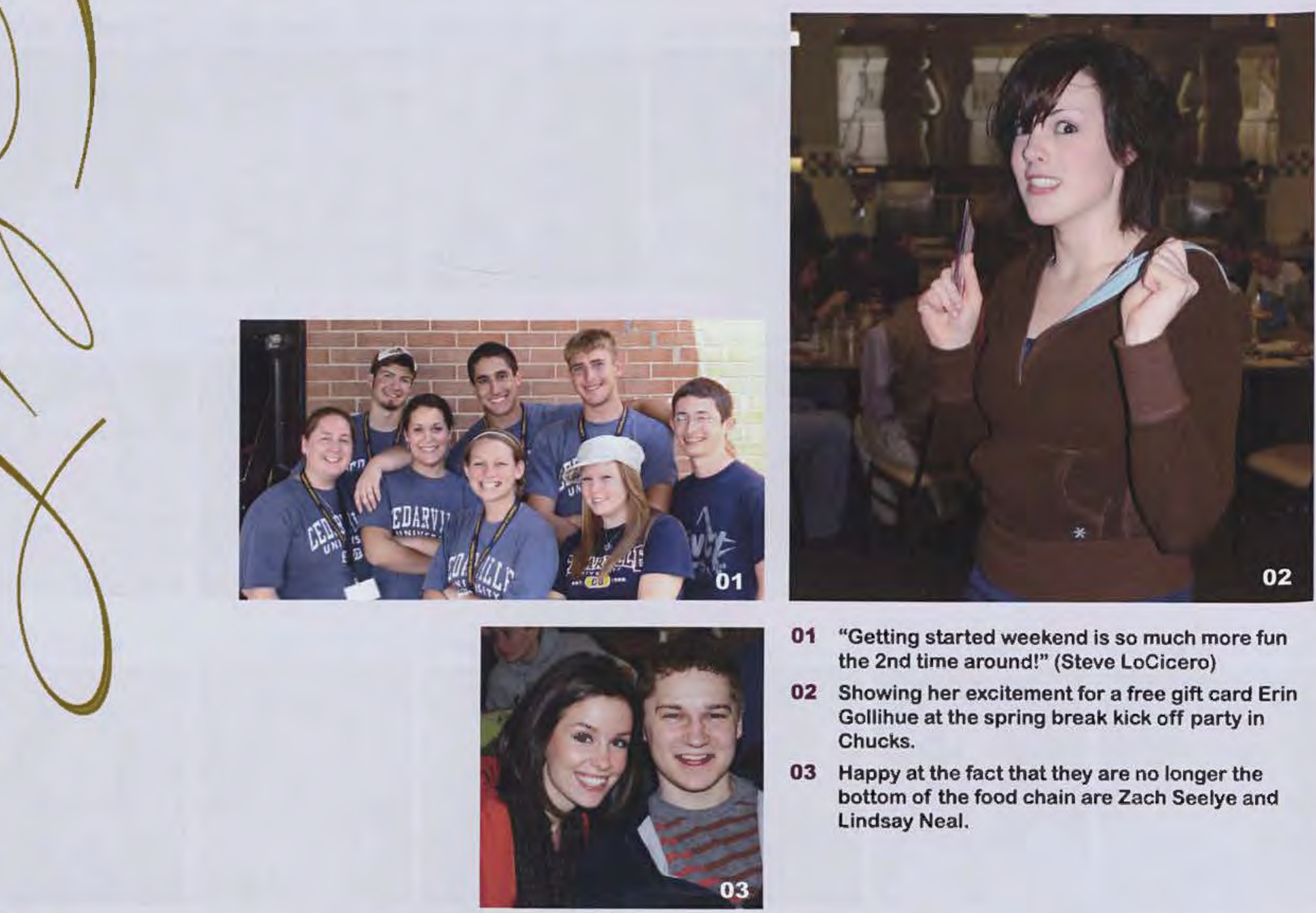

01 "Getting started weekend is so much more fun the 2nd time around!" (Steve LoCicero)

02 Showing her excitement for a free gift card Erin Gollihue at the spring break kick off party in Chucks.

03 Happy at the fact that they are no longer the bottom of the food chain are Zach Seelye and Lindsay Neal.

\section{"SOPHOMORE YEAR GIVES EVERYTHING A BIT MORE MEANING AND PROPELS STUDENTS ON TO FURTHER GOALS AND ASPIRATIONS-SINCE WE'RE NO LONGER FRESHMEN!" _LIZ SWEENEY}

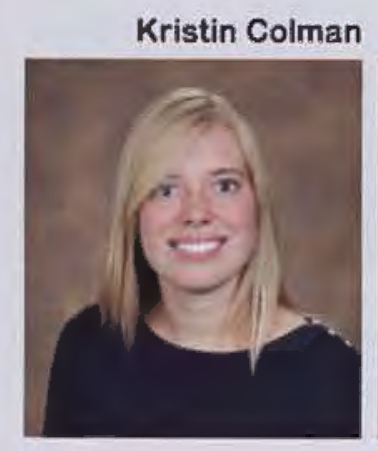

Luke Comers

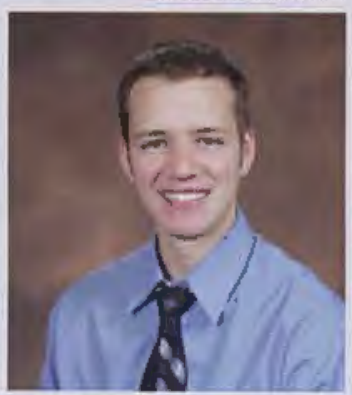

John Cooper

을

C

Trisha Comers
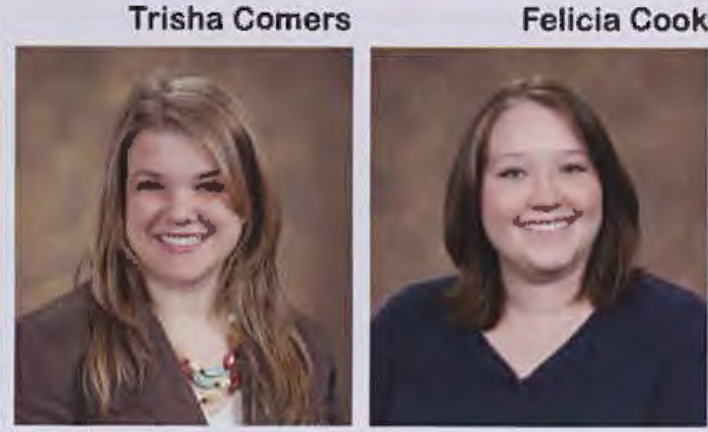

Mara Cordial

Jonathan Coulter

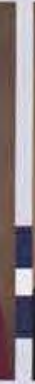

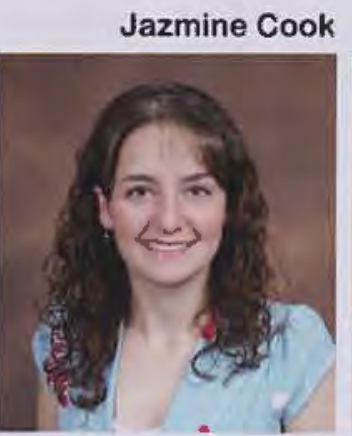

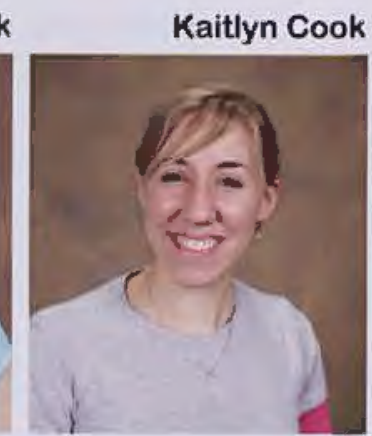

Chad Cox

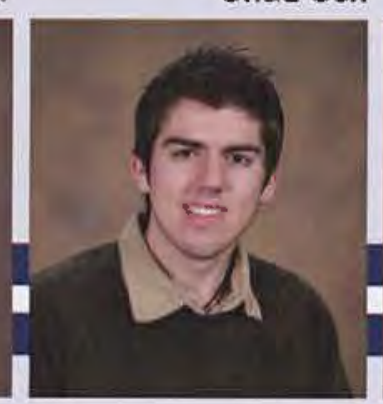

Michael Cox

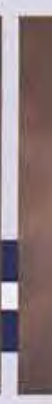



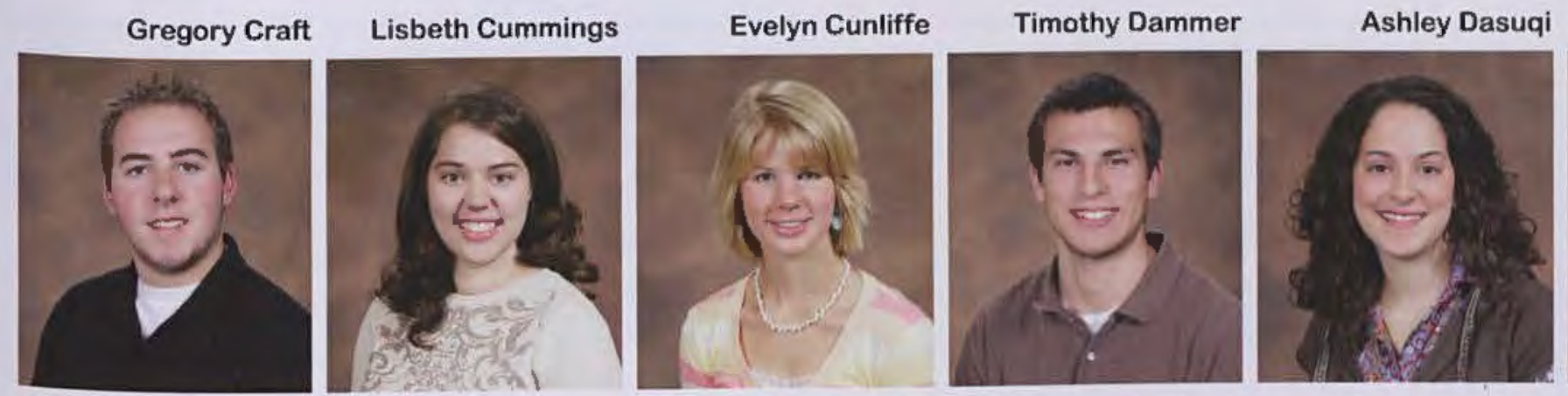

Courtney Davis
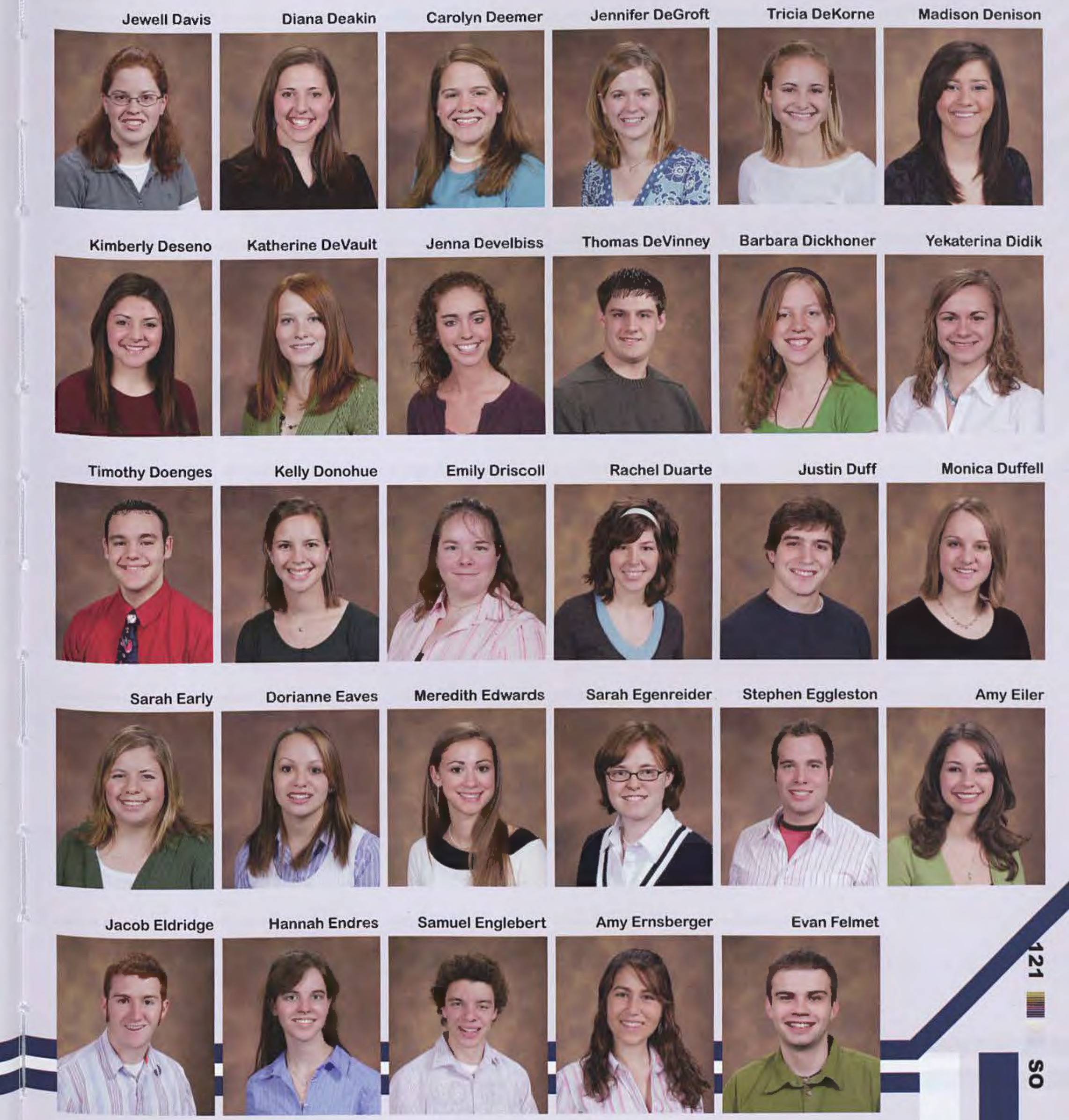

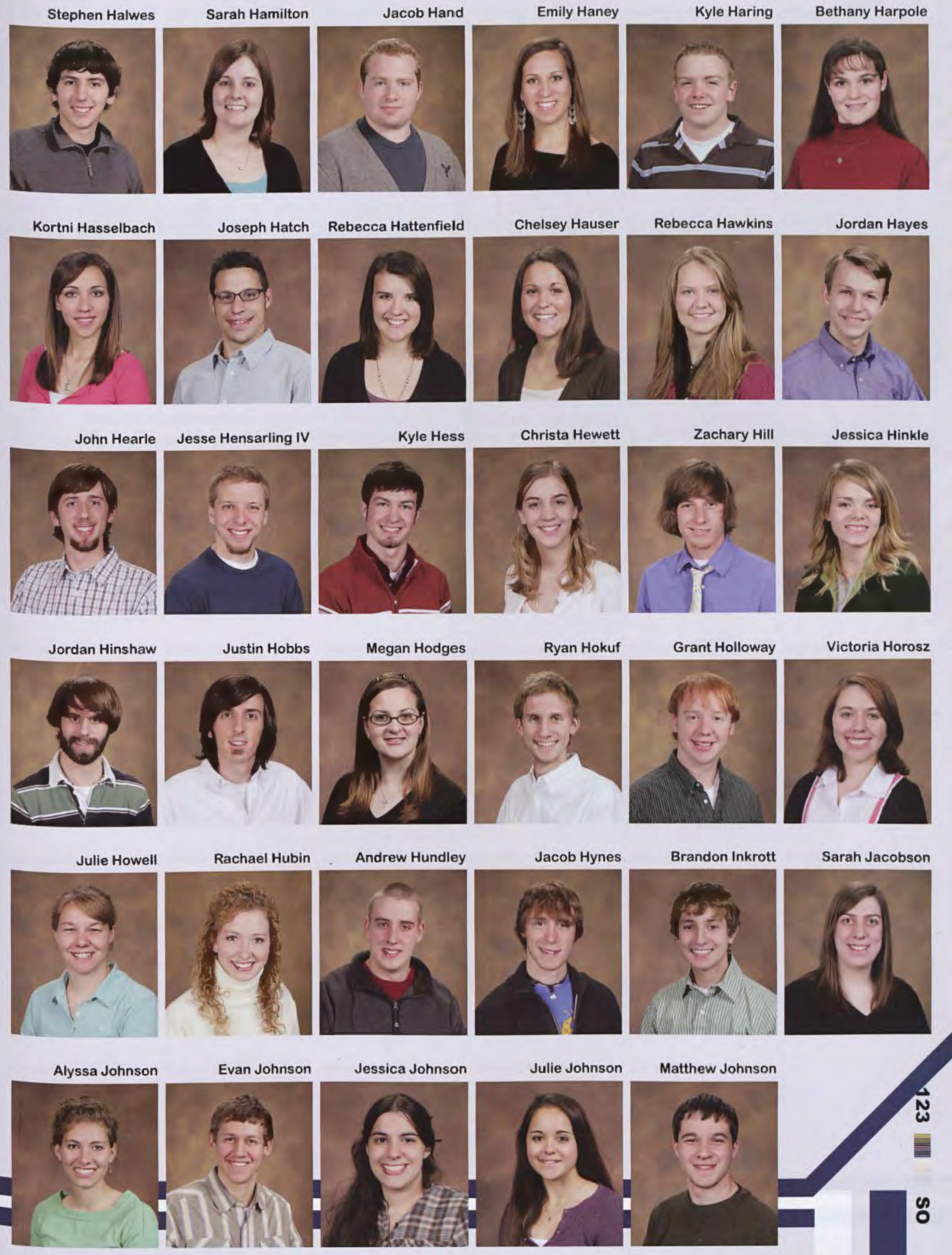

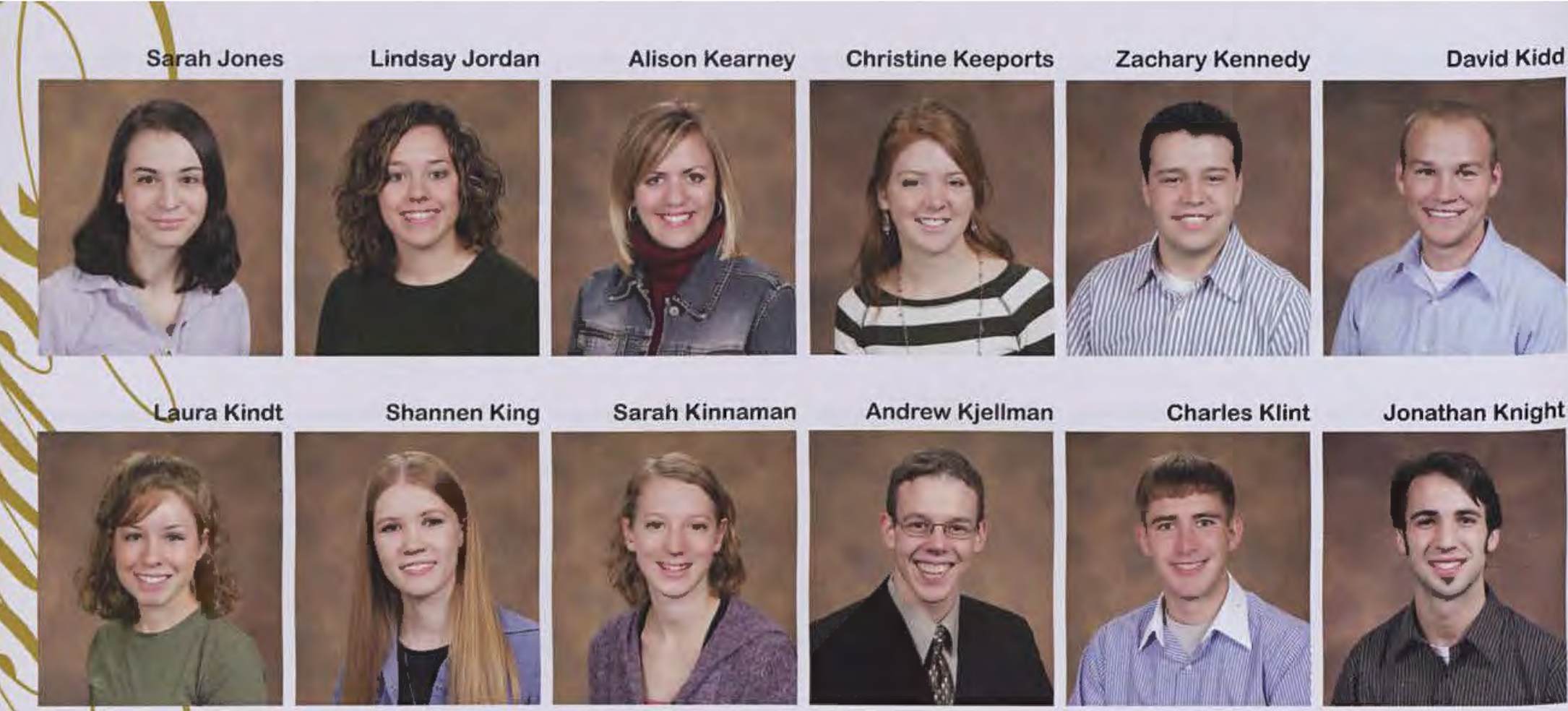

Benjamin Kochanowski
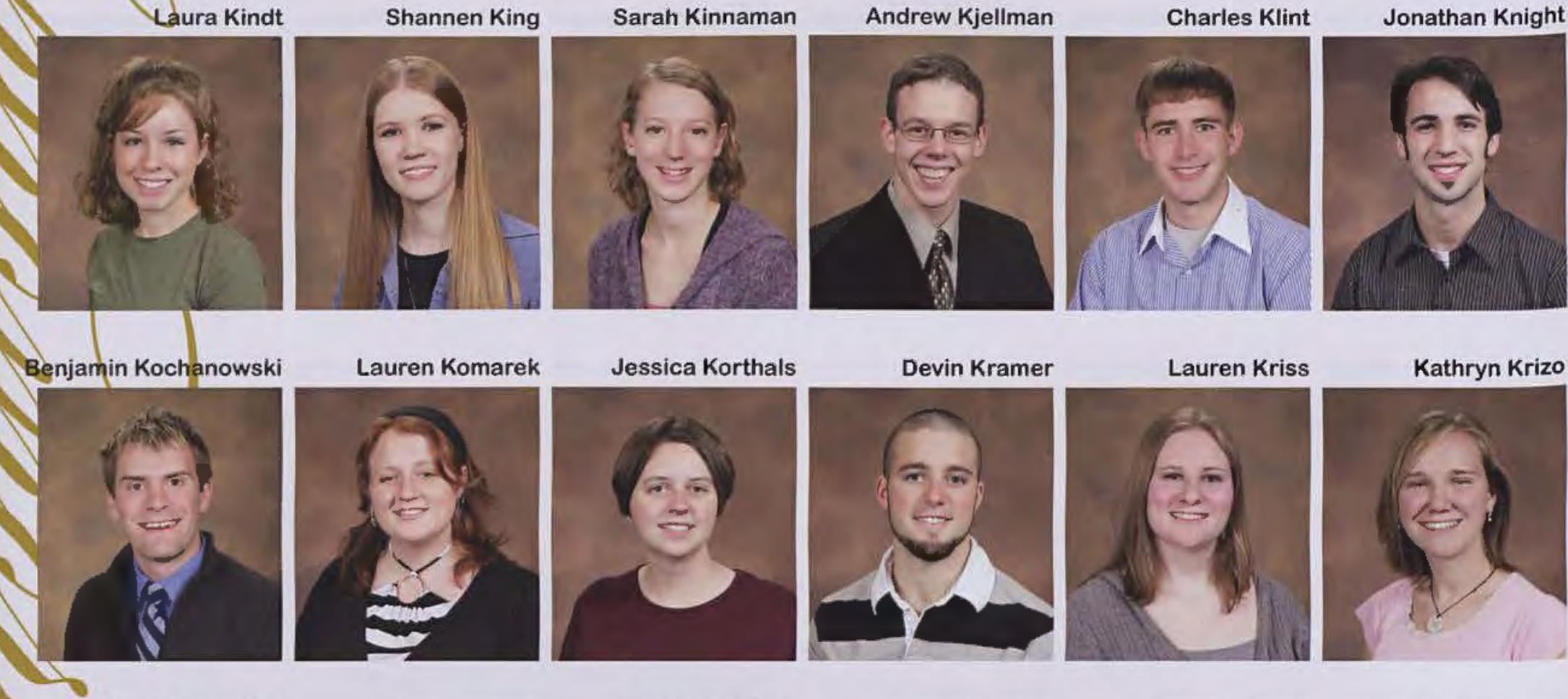

Erin Landers
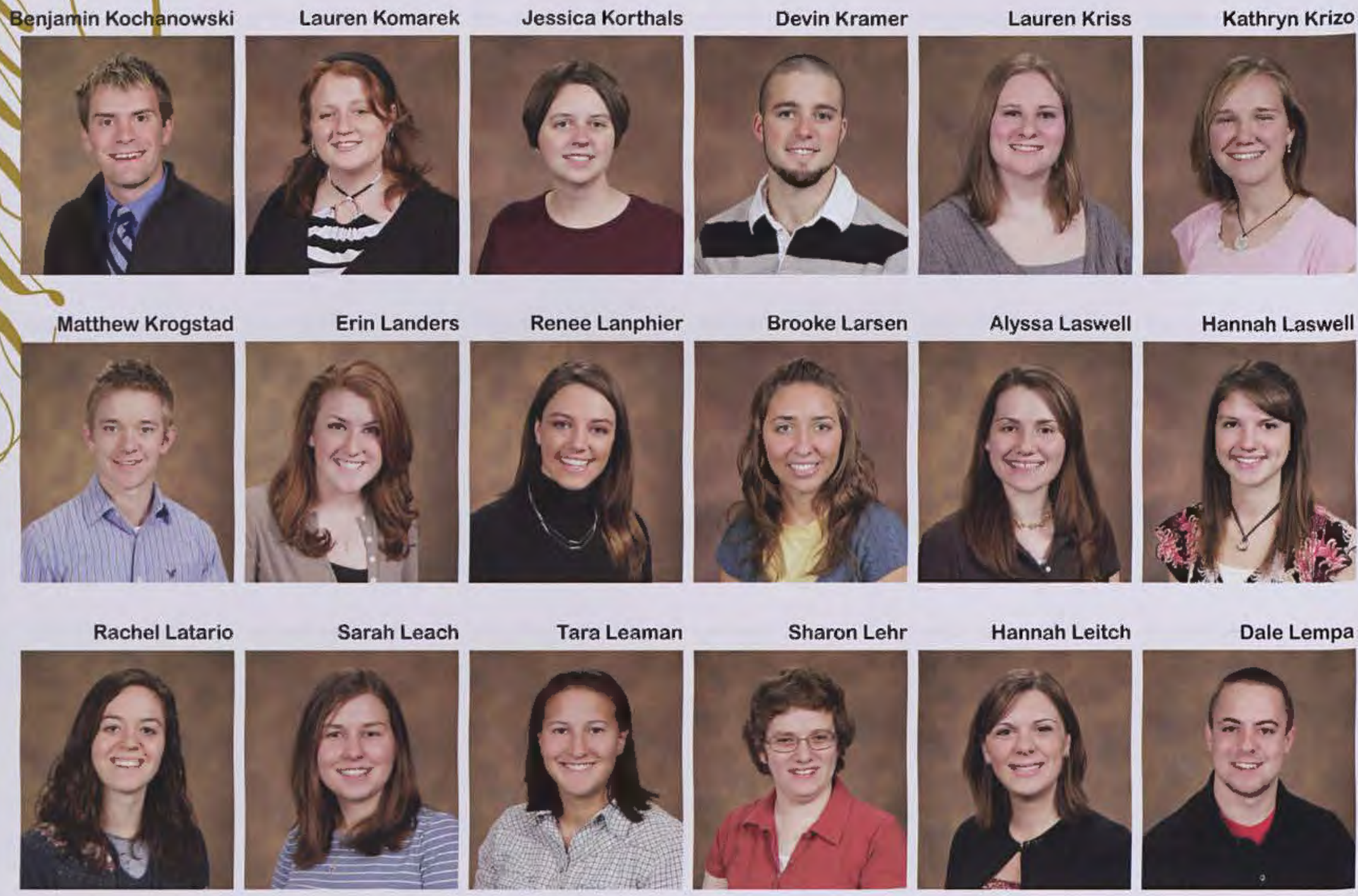

Dale Lempa
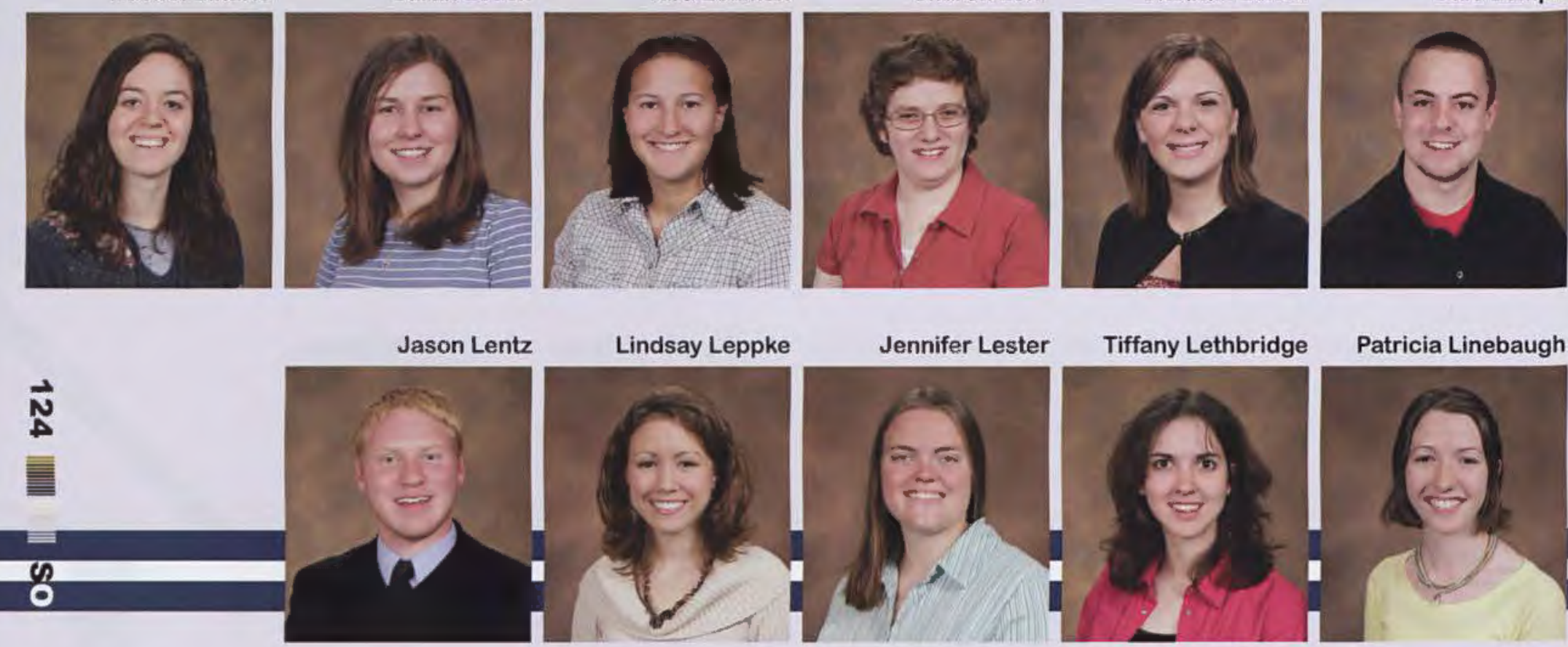


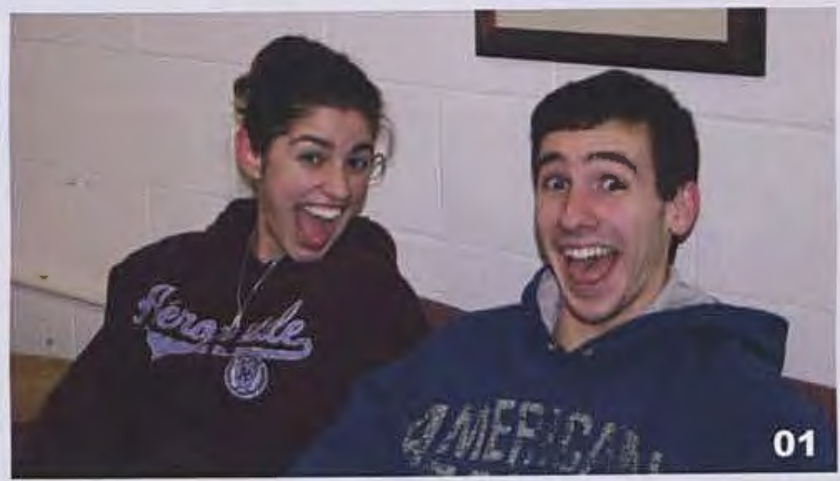

Lovin' sophomore year are Mychaela Sherry and 01 Scott Bardakjy.

Finding an interesting use for Applebee's appetizer plates are Katy Russell, Alyssa Johnson, Krista Ray, Yekaterina Didik, and Rachel Gilin.

Brennan Smith shows his ability to multi-task.

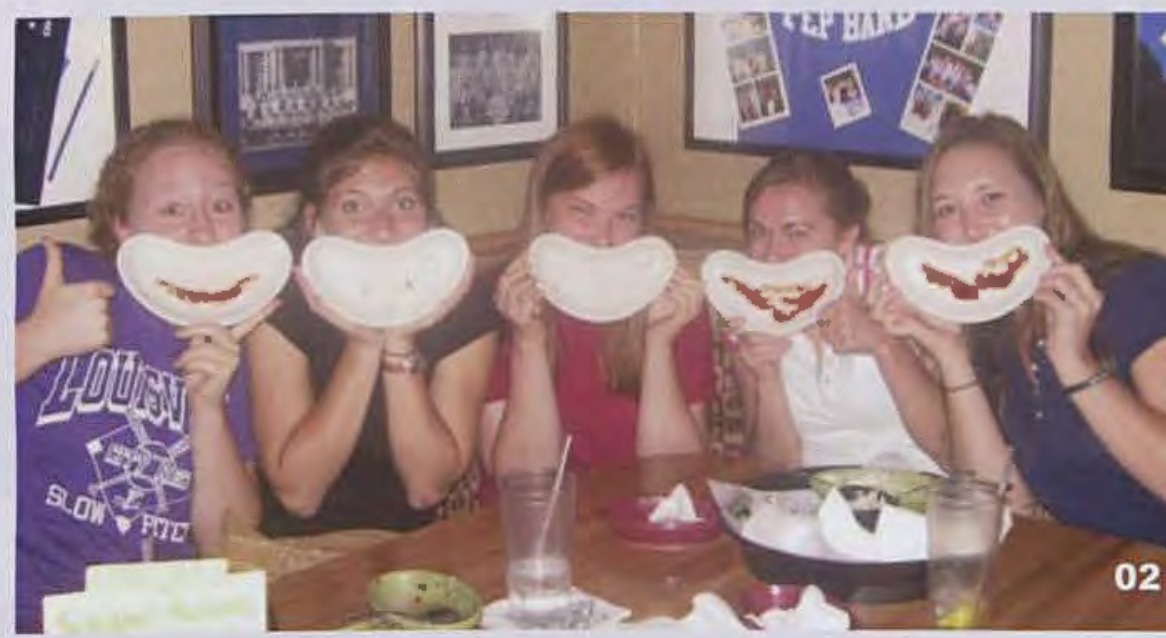

02

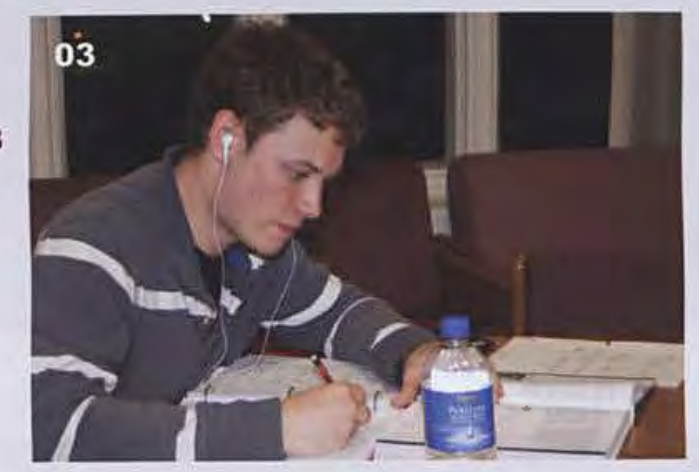

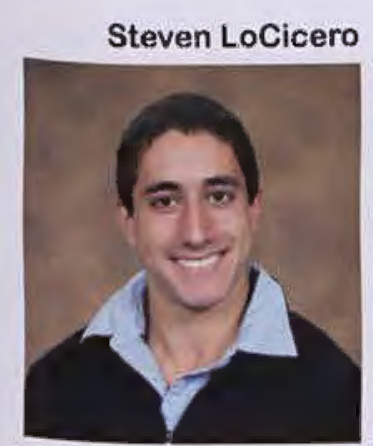

Whitney Lyons

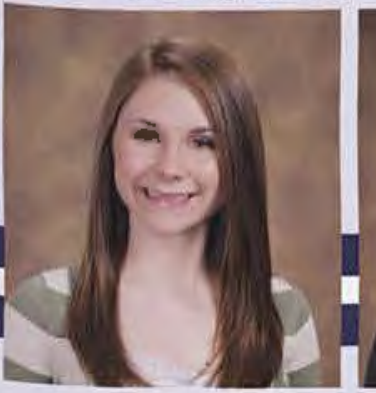

Paul Locke

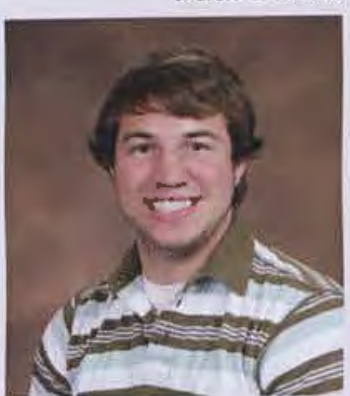

Peter Mage Jacquelyn Malmstrom

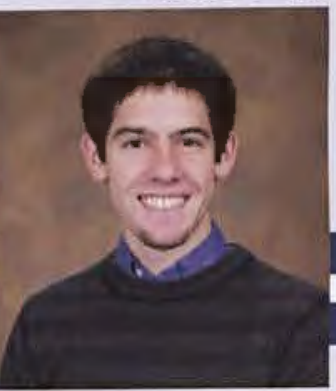

Andrew Long
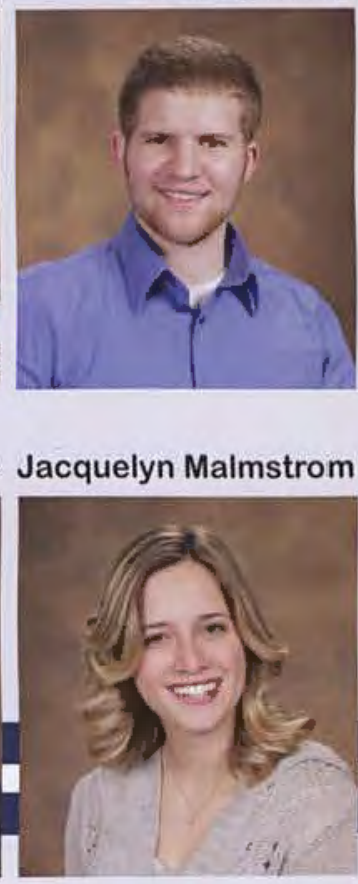

Elyse Looyengoed
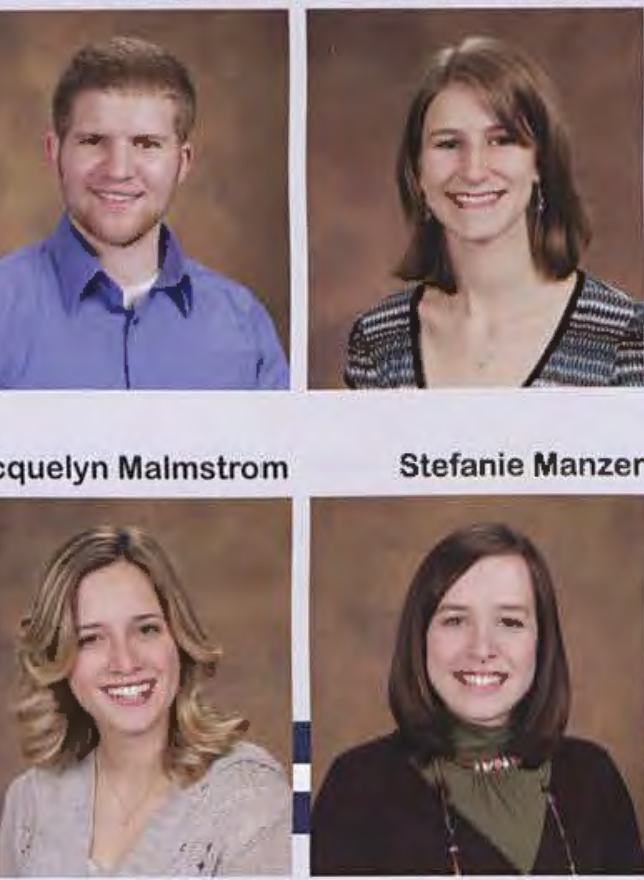

Stefanie Manzer

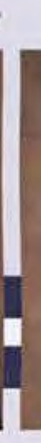

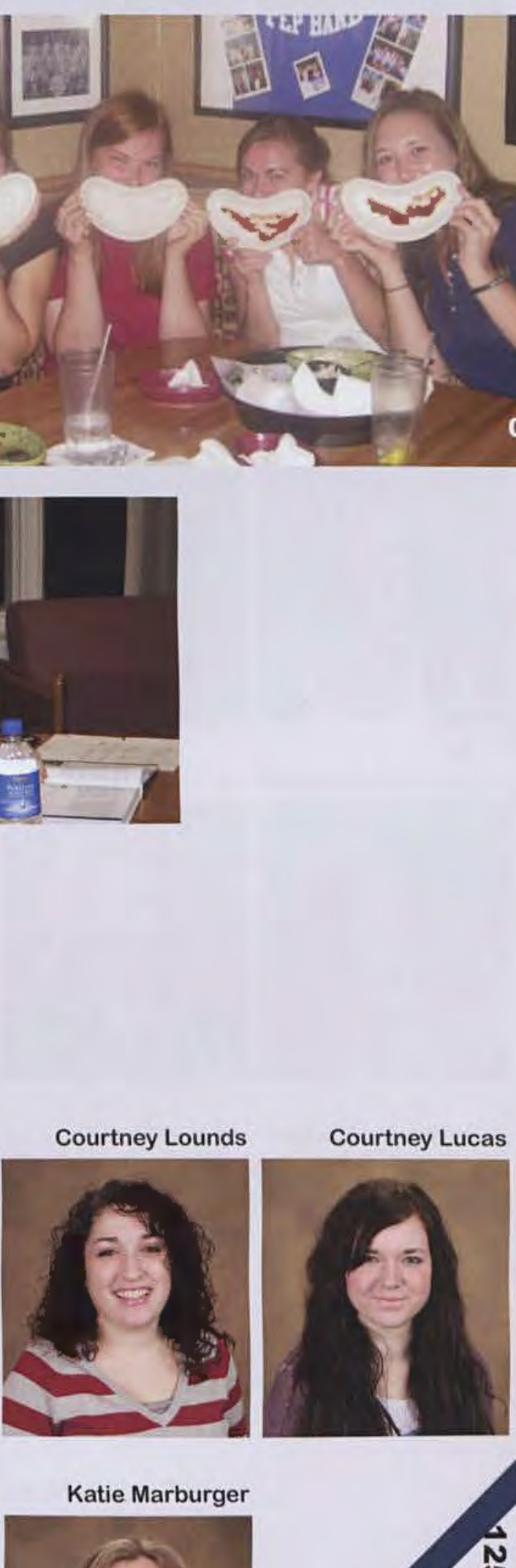

Katie Marburger 

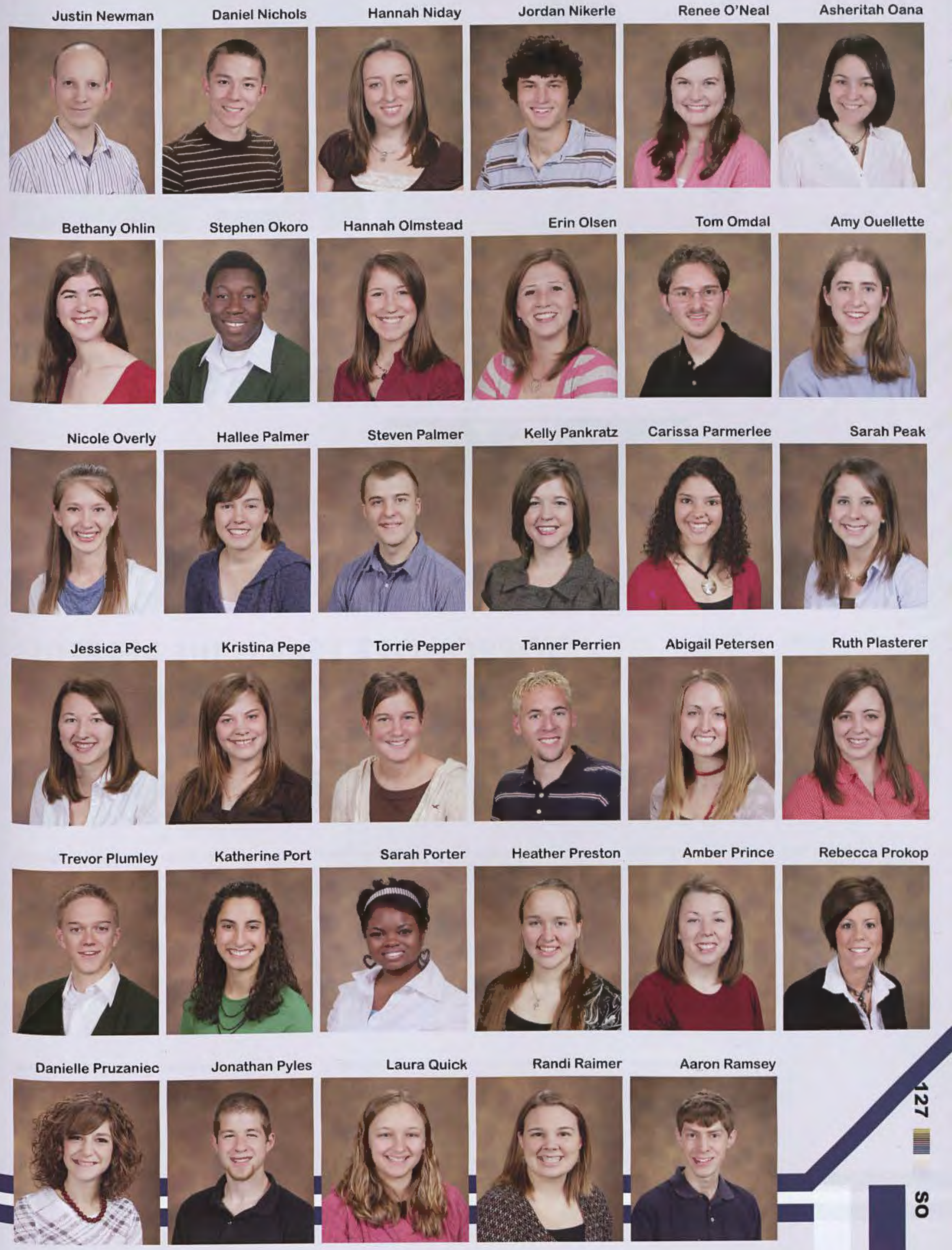

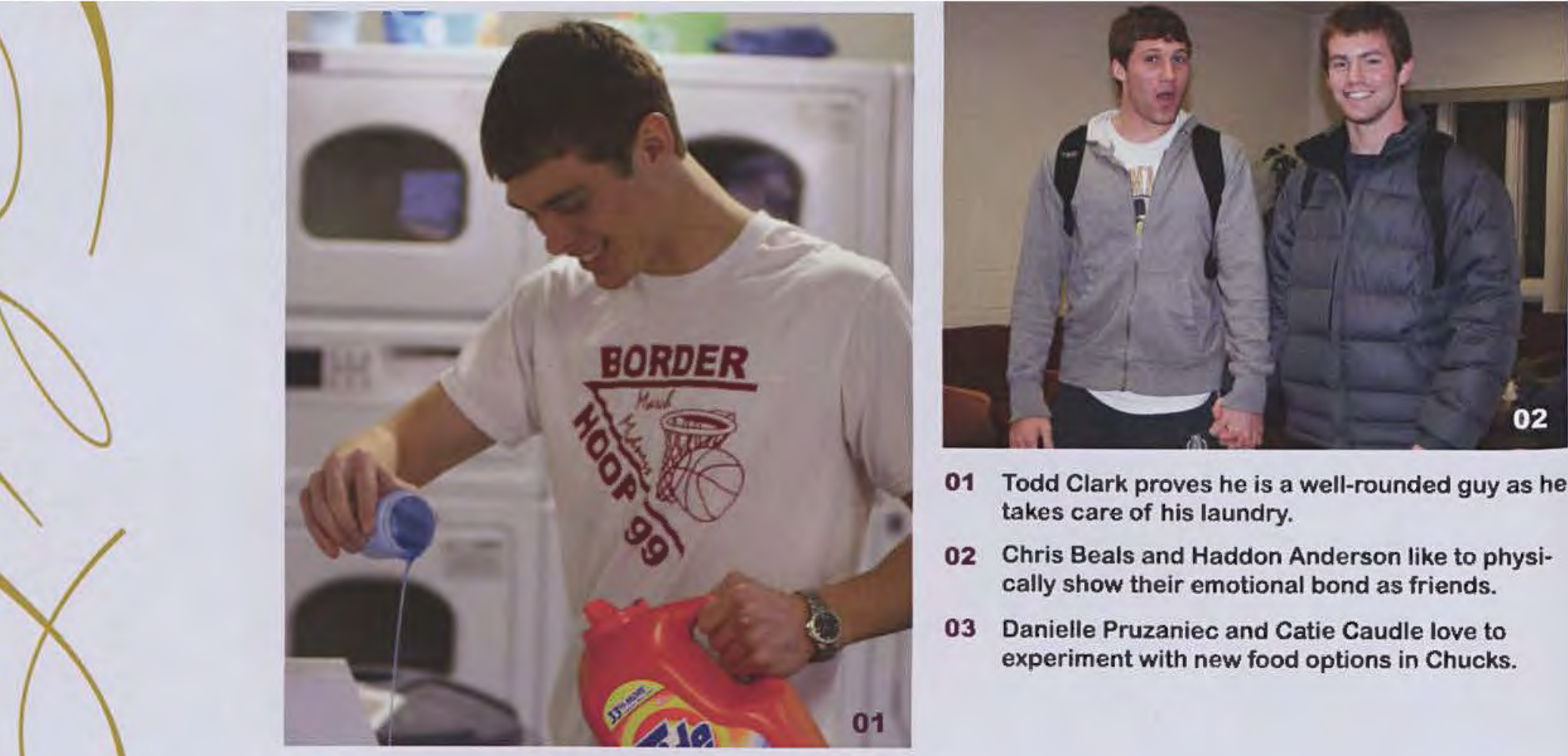

01 Todd Clark proves he is a well-rounded guy as he takes care of his laundry.

02 Chris Beals and Haddon Anderson like to physically show their emotional bond as friends.

03 Danielle Pruzaniec and Catie Caudle love to experiment with new food options in Chucks.

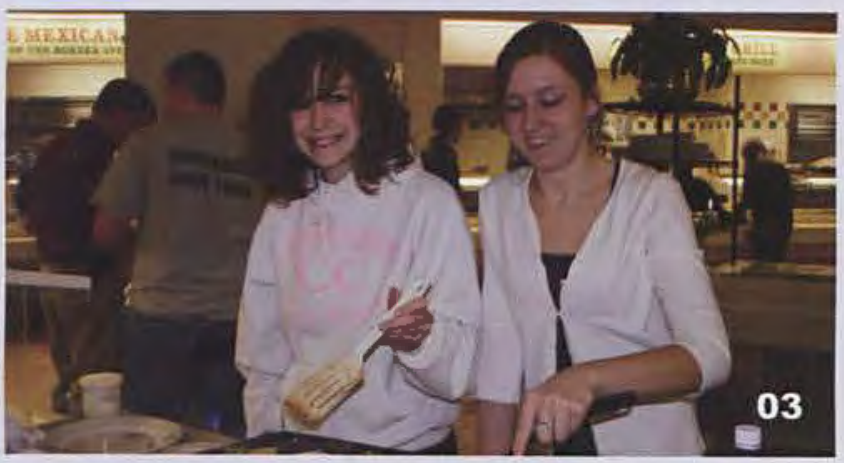

\section{"SOPHOMORE YEAR IS THE PERFECT TIME TO DEEPEN FRIENDSHIPS - SOME NEW AND SOME OLD." -GENELLE SCHEDLBAUER}
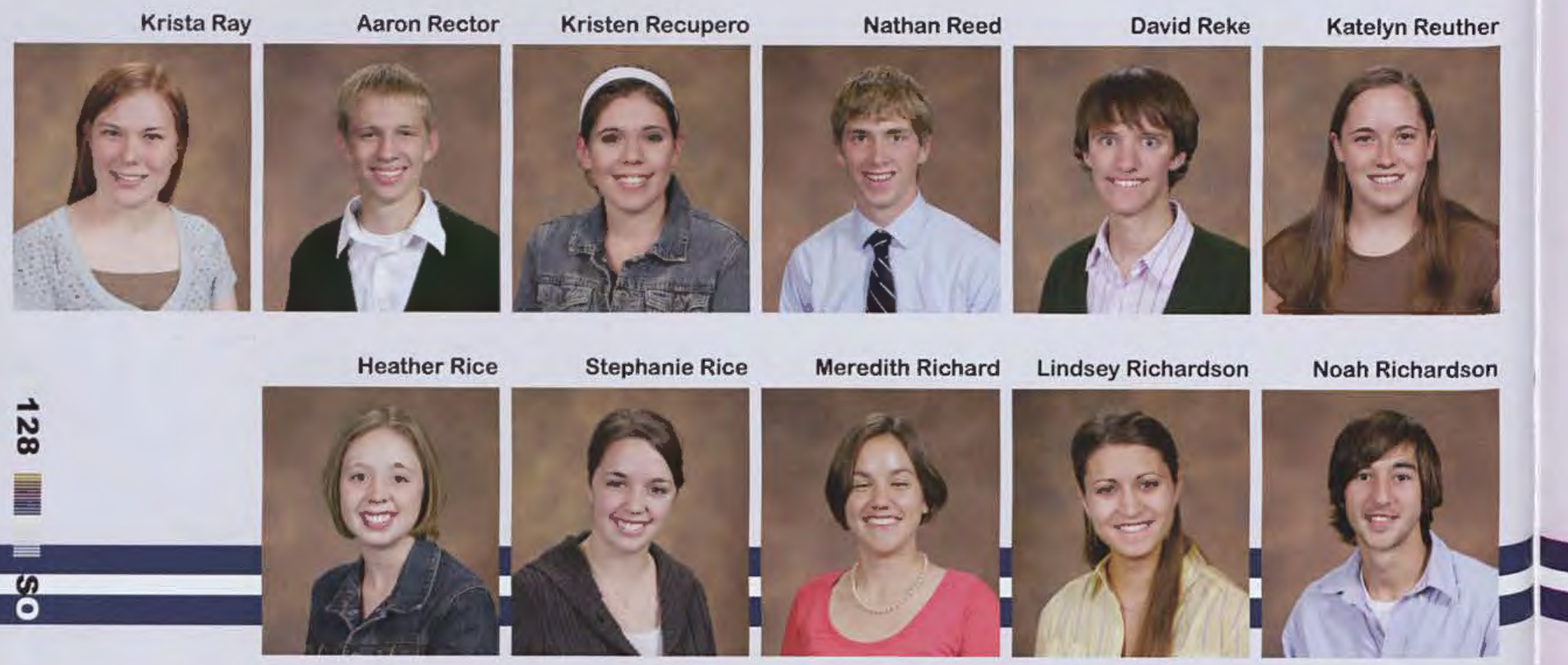

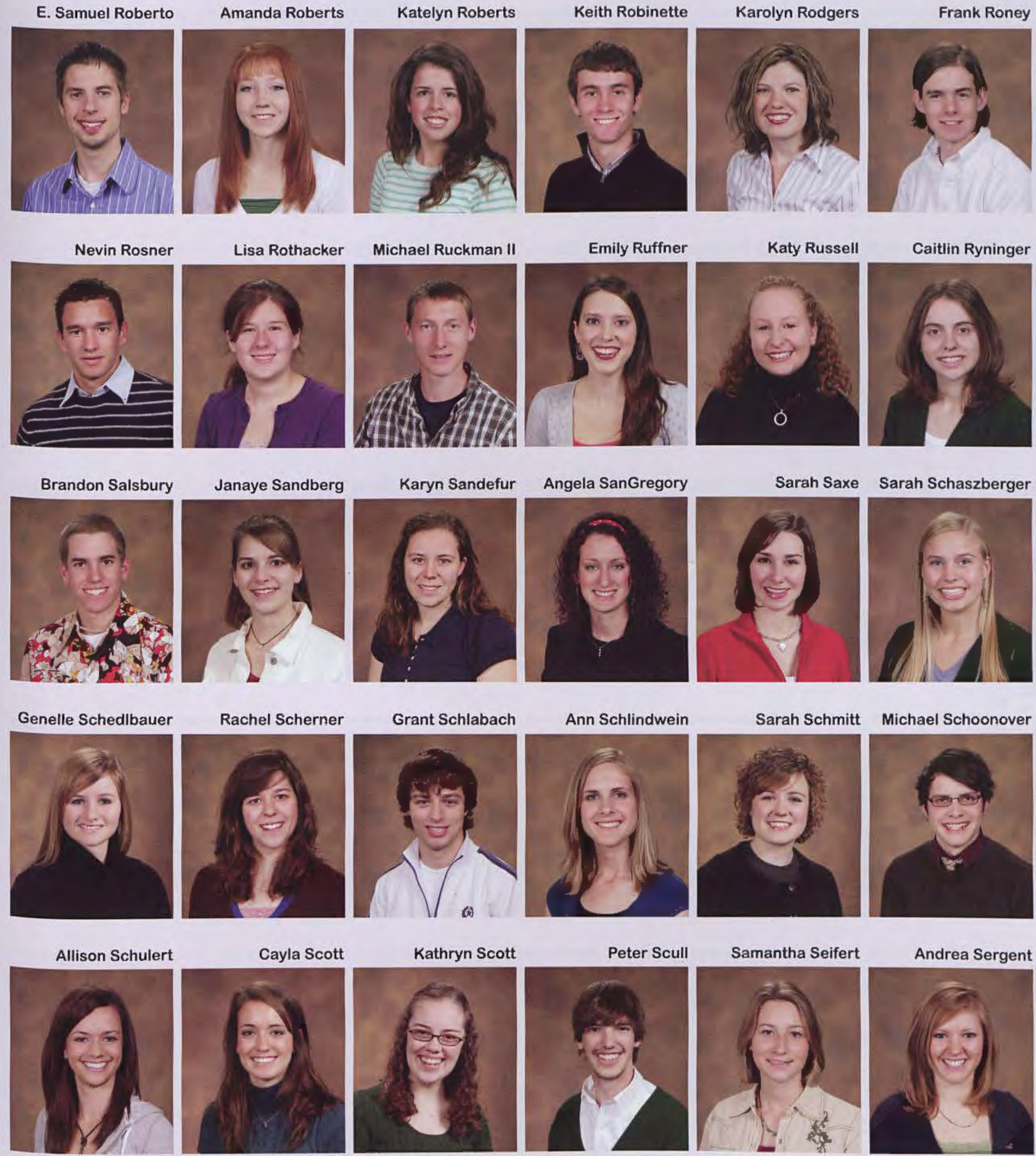

Andrea Sergent
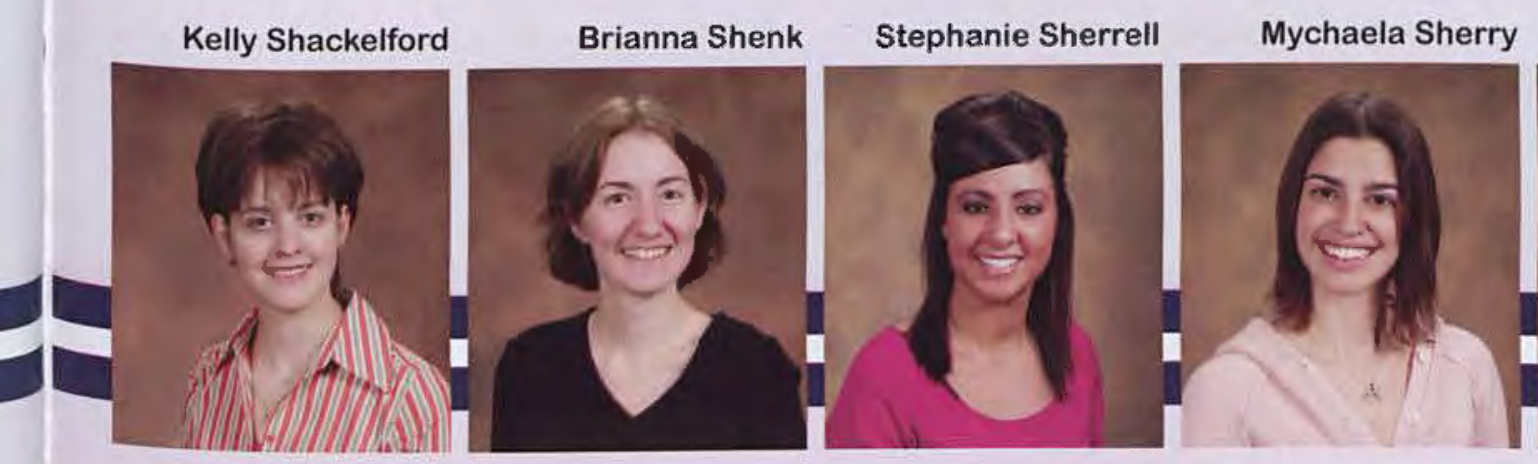

Ami Shetler

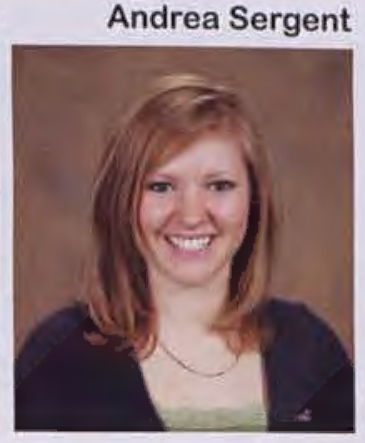



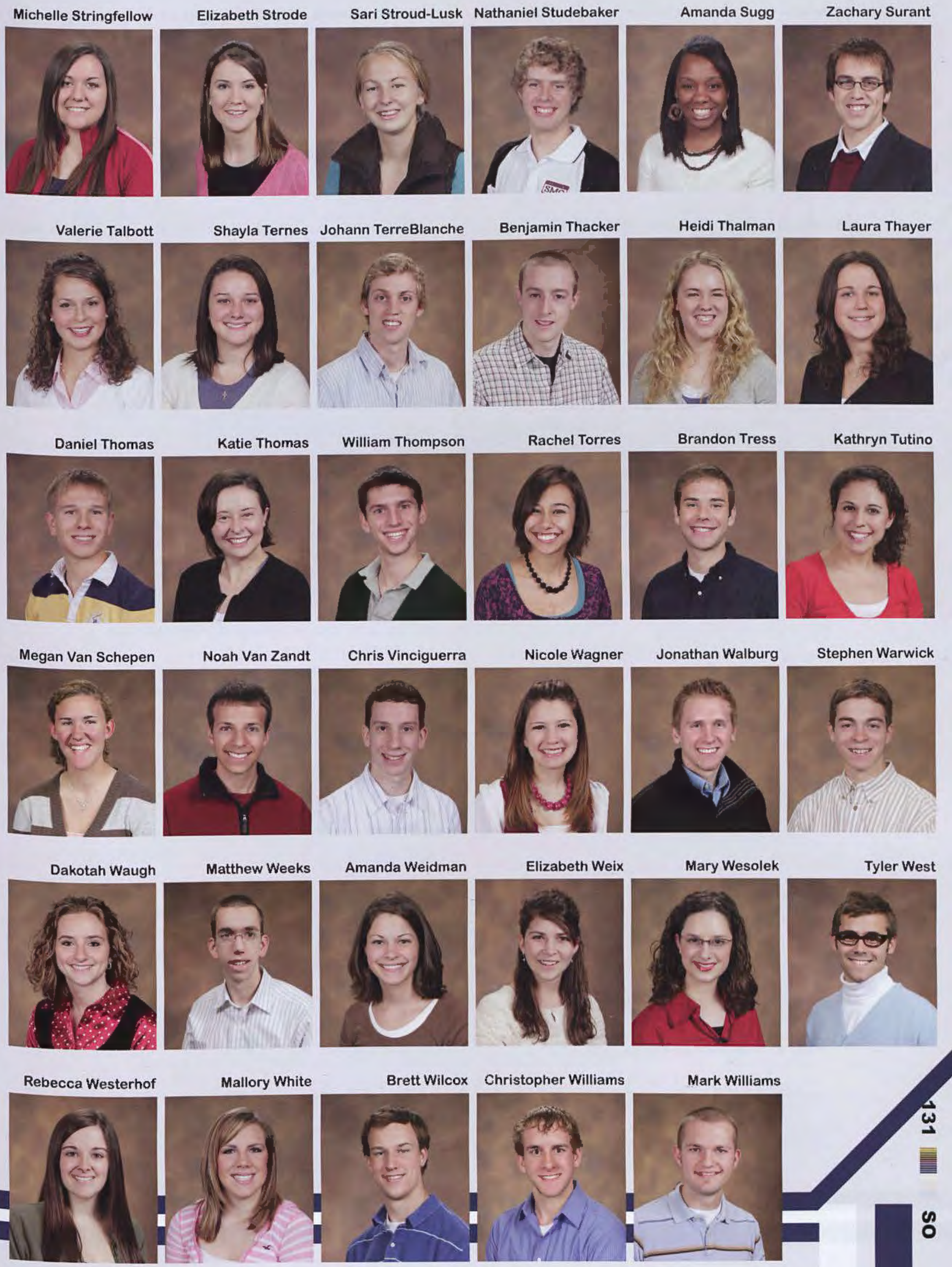

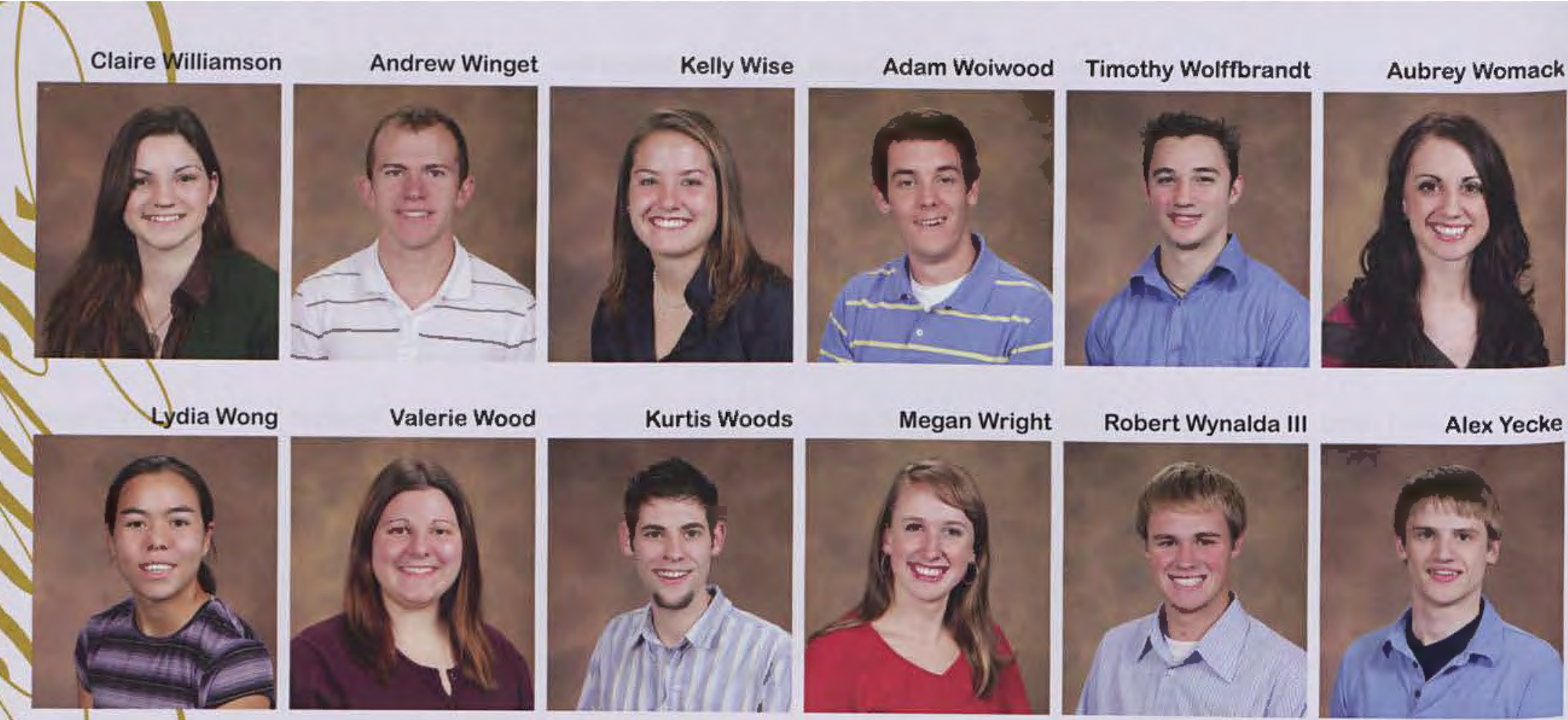

Rachel York
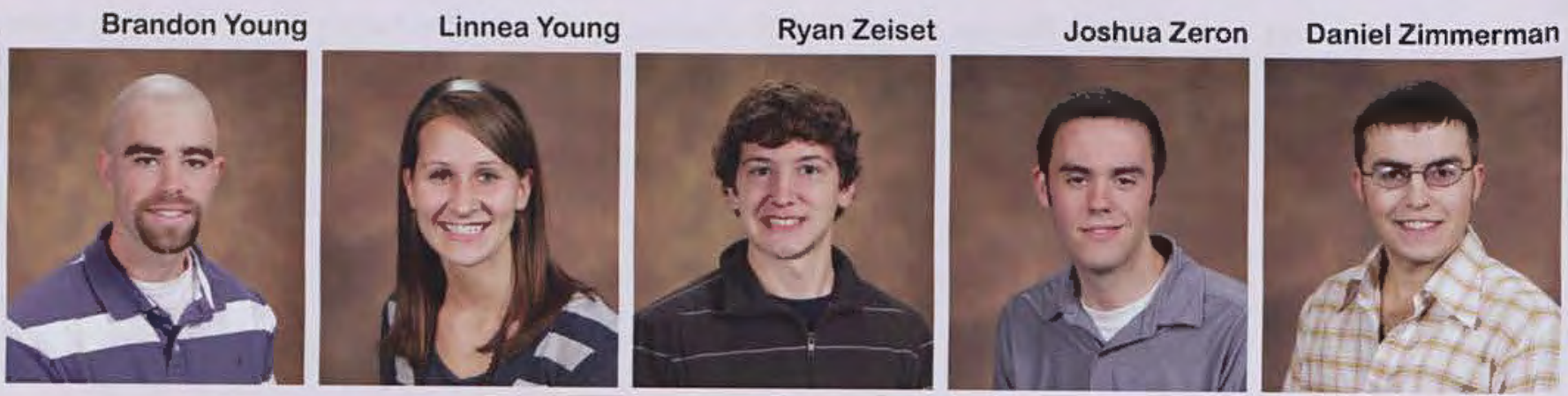

$\mathbf{\omega}$
$\mathbf{n}$

क

0 


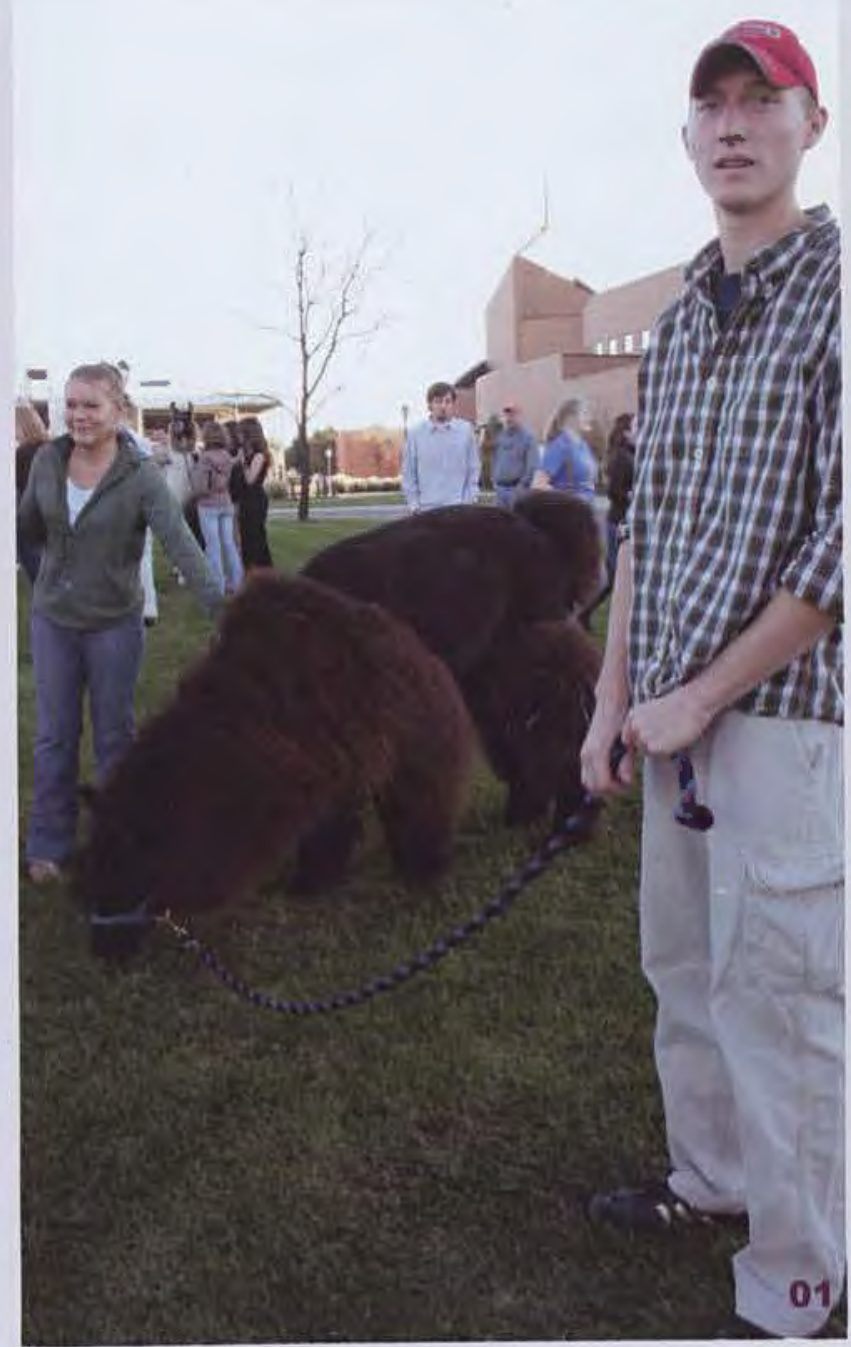

Mike Ruckman always causes a stir when his 01 llamas visit campus.

Joe Price and Brandon Salsbury enjoy the food 02 and fun at the freshman/sophomore spring pienic.

Jessica Korthals, Whitney Muhlenkamp, and 03 Alyssa Johnson take a tractor ride at friend, Corrinne Jones' house.
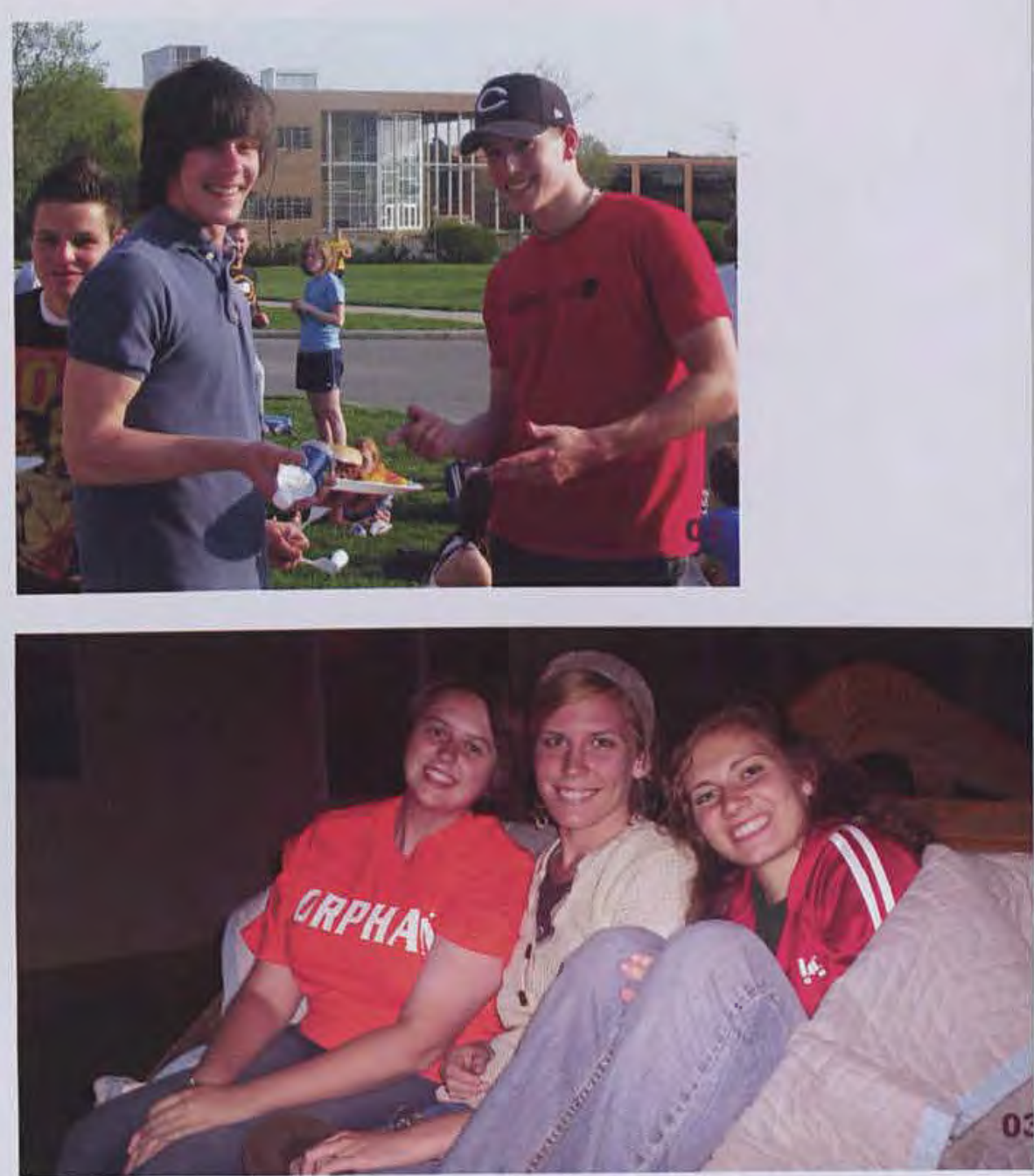

\section{"DURING SOPHOMORE YEAR WE DEVELOPED INSIDE JOKES, BECAME ESTABLISHED IN OUR MAJOR, AND LEARNED THE FASTEST ROUTE FROM RICKARD TO THE OTHER SIDE OF CAMPUS AVOIDING THE BIBLE BUILDING CONSTRUCTION." _JOSH WITRY}




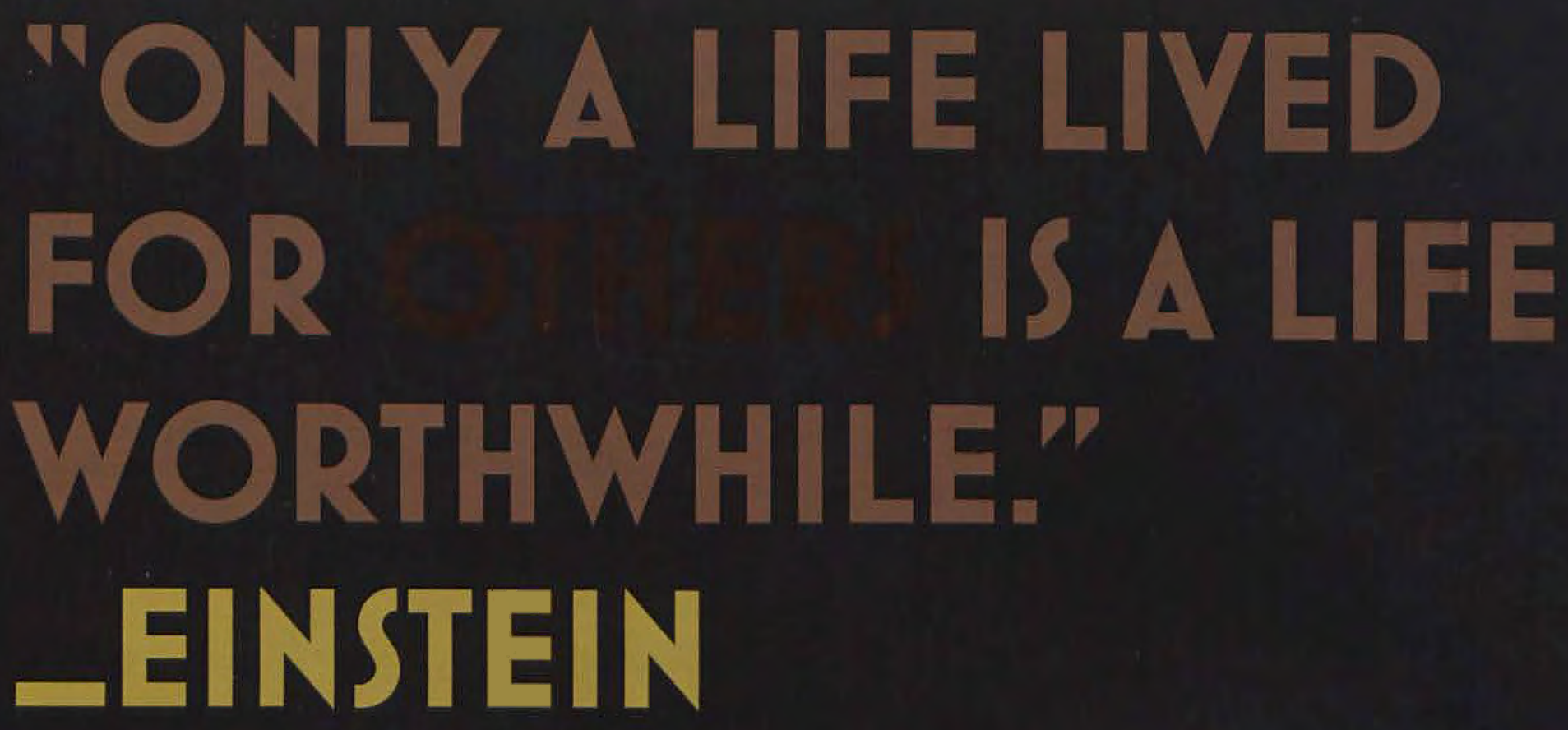




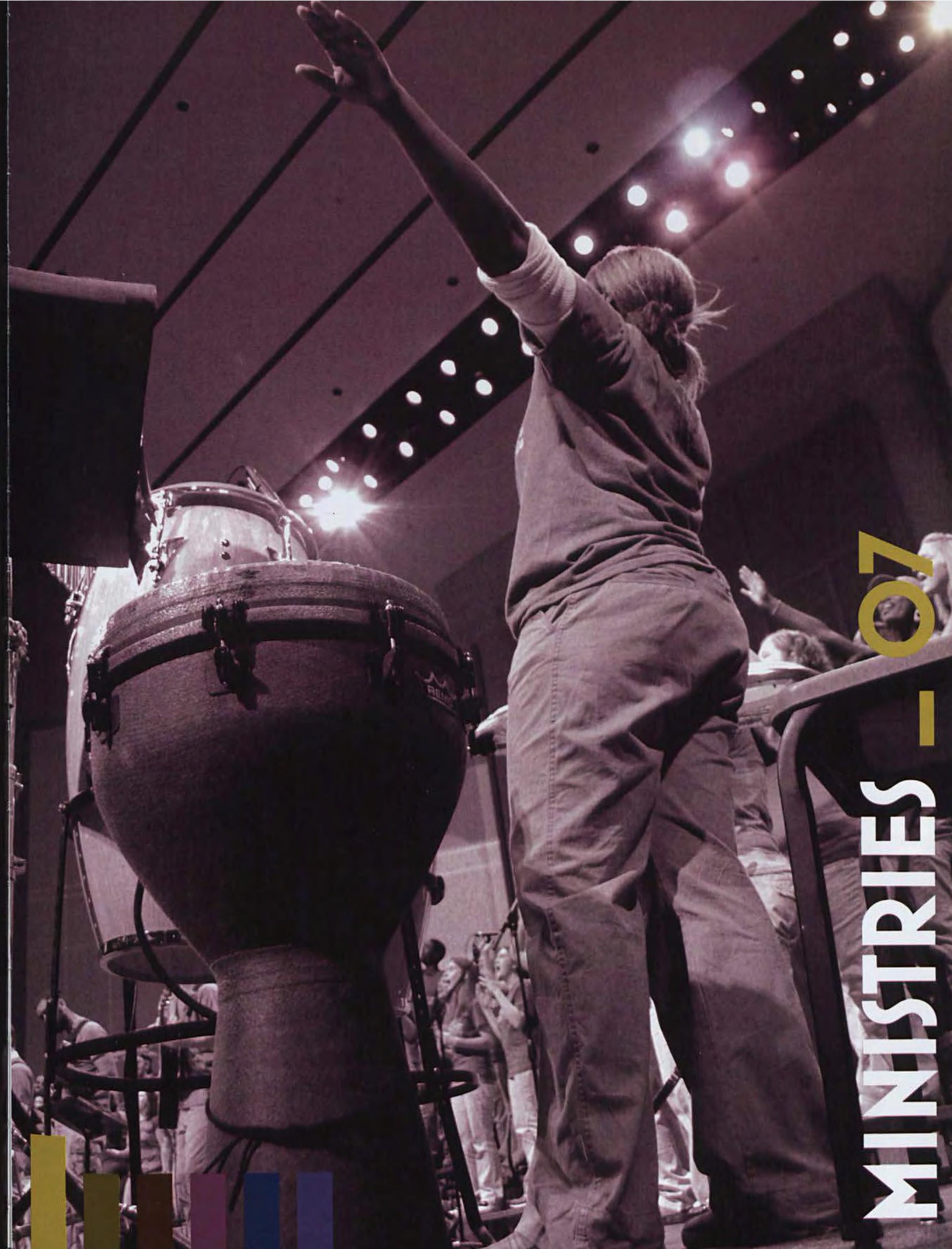




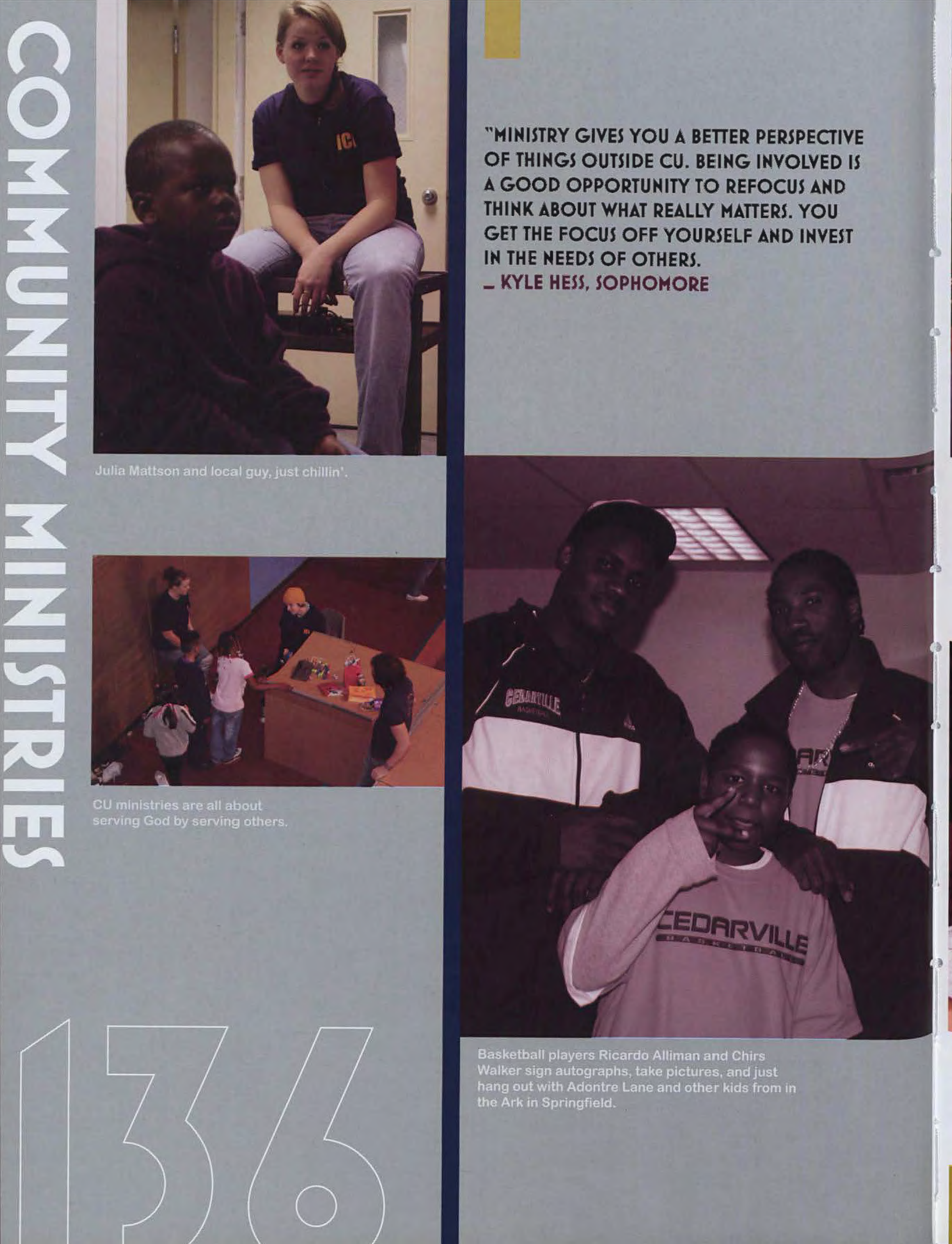




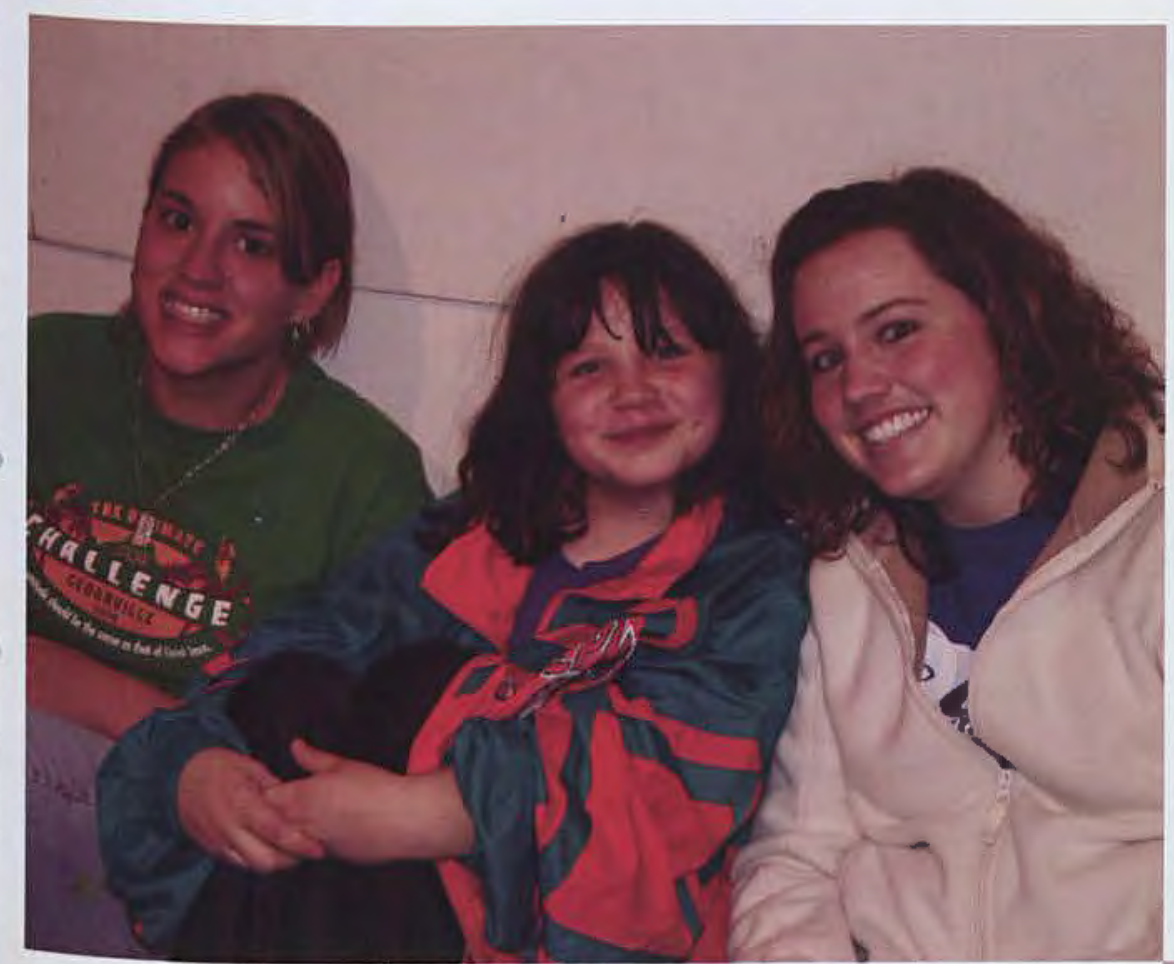

"MY MINISTRY WAS GREAT! I GOT TO JUST HANG OUT AND GET TO KNOW SOME LOCAL TEENS. IT WAS A MUCH NEEDED BREAK AFTER A WEEK OF SCHOOL WORK." - BRENT PERSUN, FRESHMAN

Ashley Groce and another CU student smile with a young girl from their ministry.

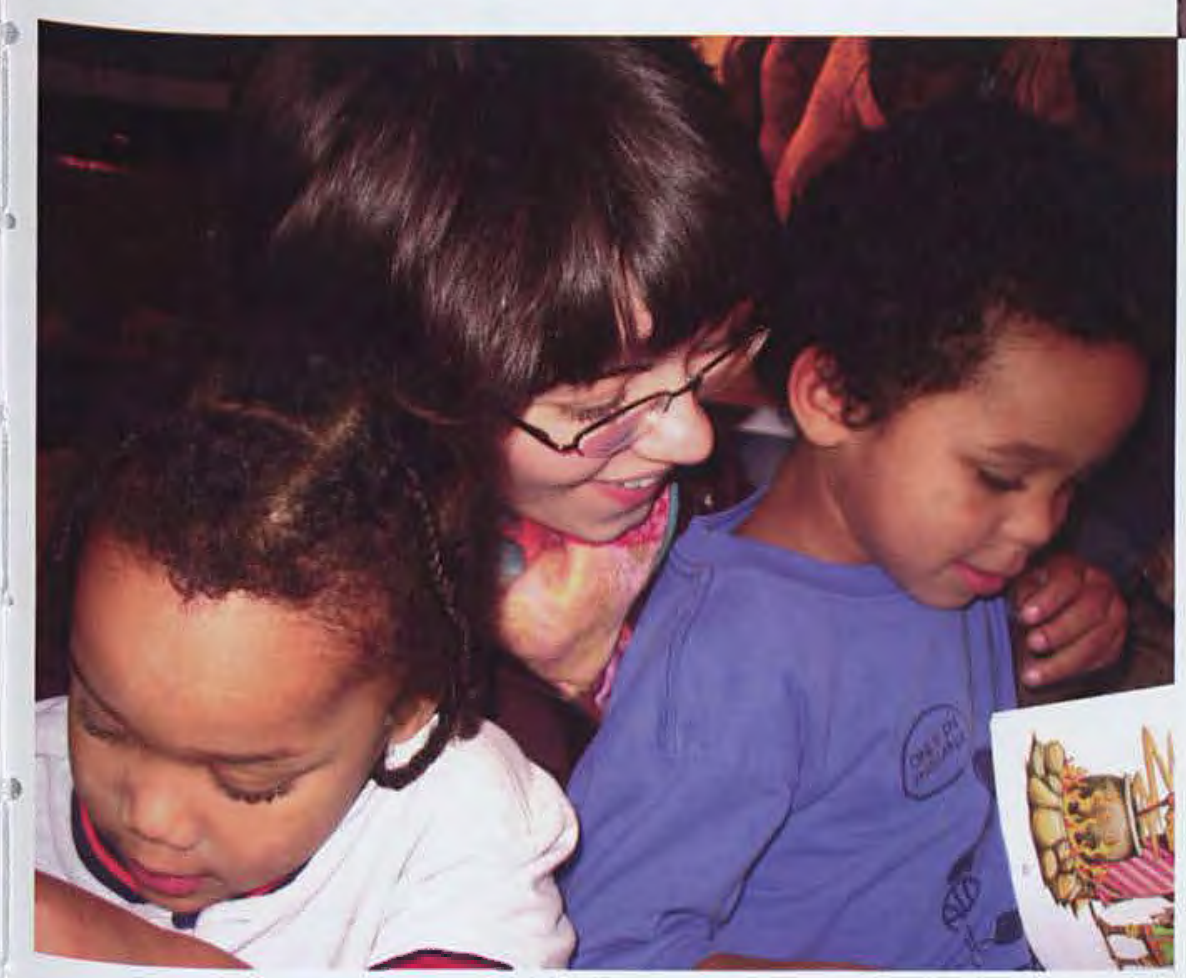

Jen Davis was great at just loving on the kids in their ministries.

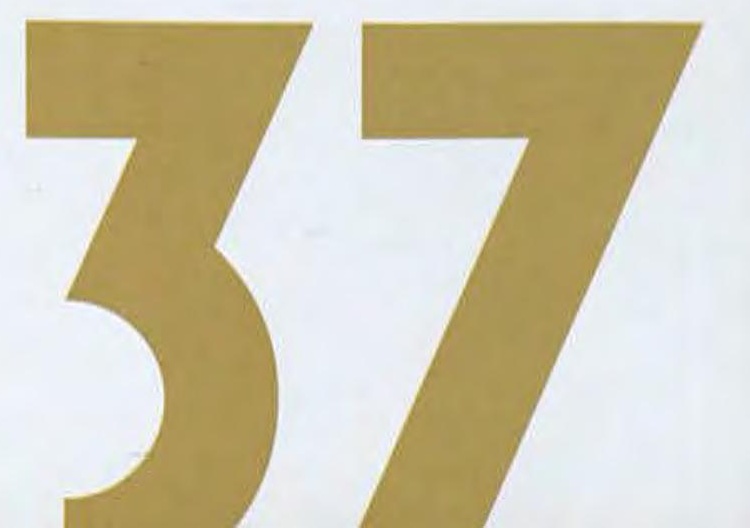




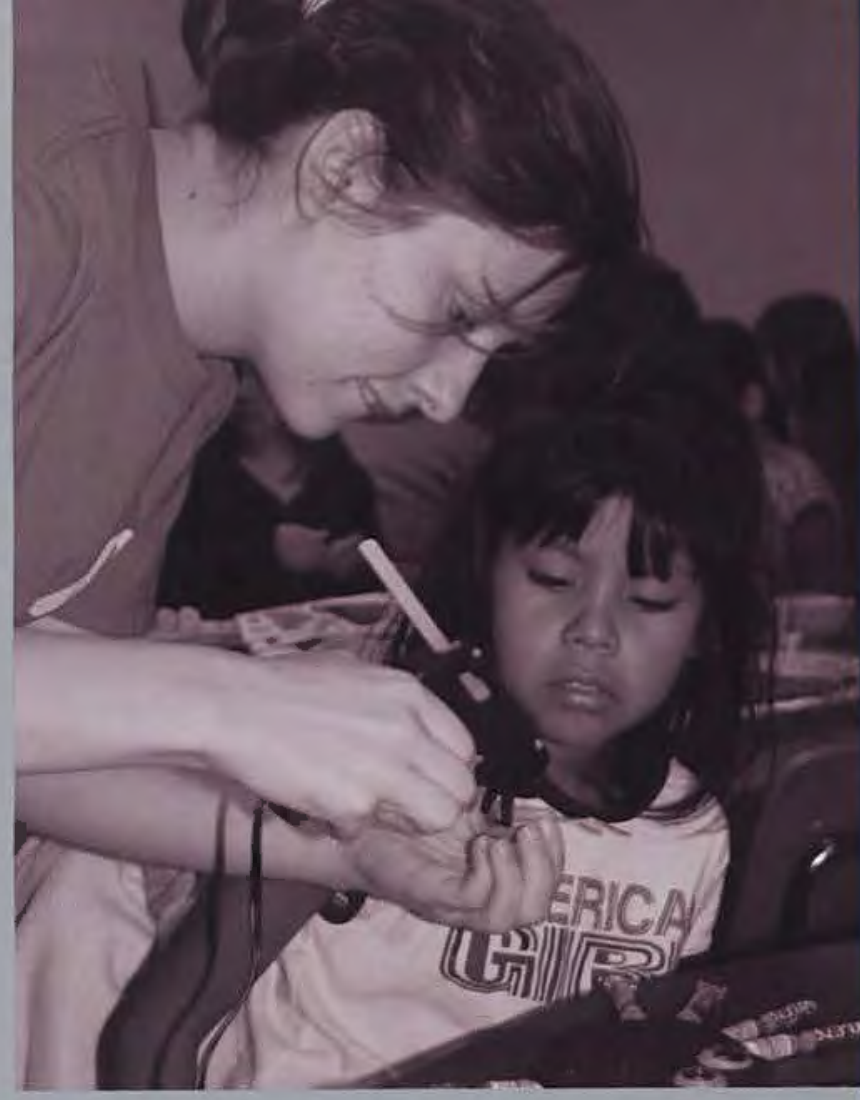

"I TRY NOT TO CATEGORIZE WHAT I DO FOR JESUS AS 'MINISTRY' BECAUSE I FEEL LIKE THAT TERM PUTS A GAP BETWEEN ME AND THE PERSON/PEOPLE I'M SERVING. IT MAKES IT SEEM AS THOUGH THEY ARE LACKING AND NEED MY SERVICE WHILE I HAVE IT ALL TOGETHER AND HAVE SO MUCH TO OFFER THEM. IF ANYTHING, THE PEOPLE I SERVE HAVE BEEN GIVEN TO ME BY GOD TO TEACH ME WHAT IT MEANS TO SERVE AND SHOW ME WHERE I AM LACKING. I HAVE LEARNED SO MUCH ABOUT JESUS THROUGH THE PEOPLE I SERVE AND I PRAY THAT THEY CAN SEE JESUS IN ME, TOO."

- ANGELA CHRISTIAN, SOPHOMORE

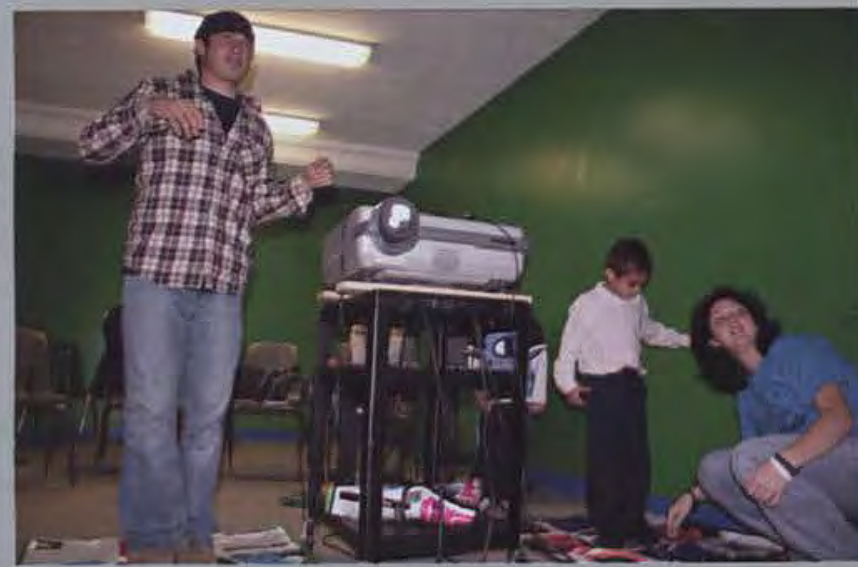

Malking crafits with a hot-glue gun is just one of the many talents you can pick up on a ministry team.

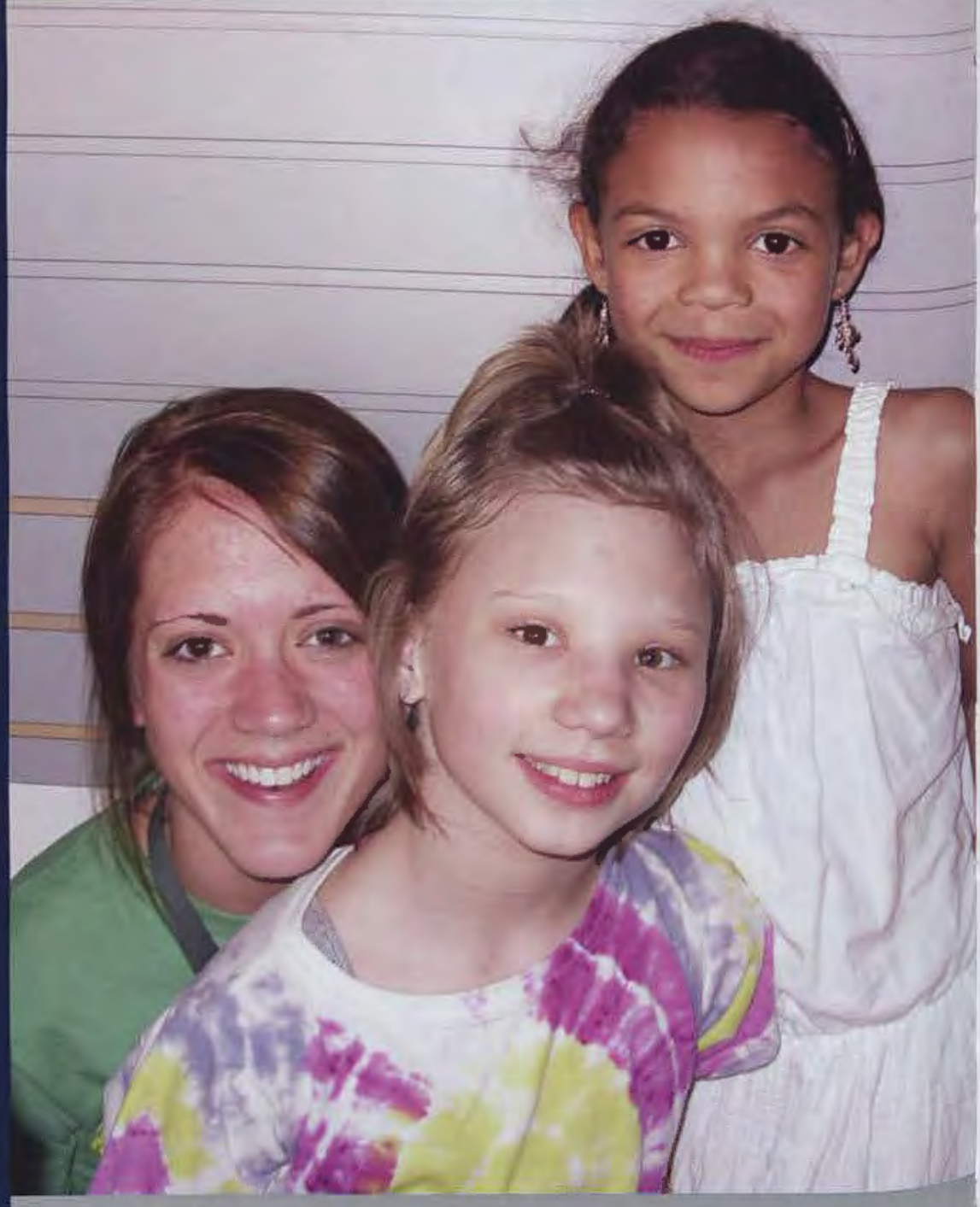

Josh Gigliotti and Angela Christian work with Inner City Impact in Chicago.

And by work I mean play DDR. Nice moves Josh.
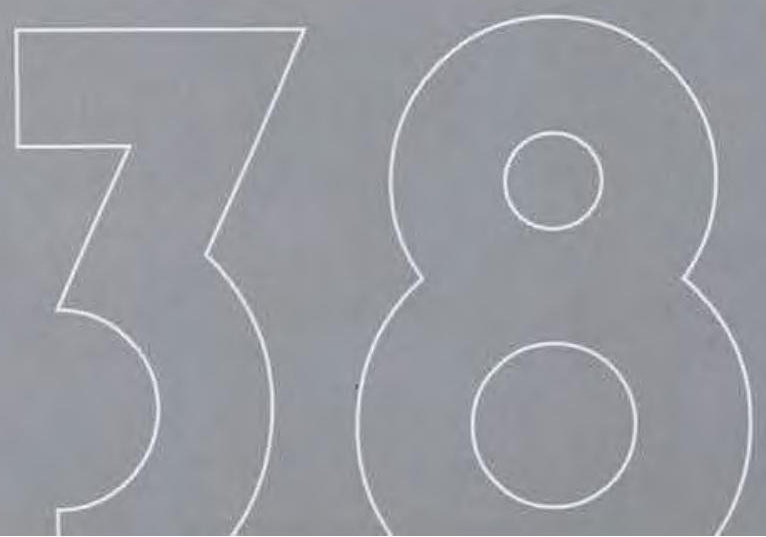

Elise O'Neal smiles with her girls from Dayton

Gospel Mission. 


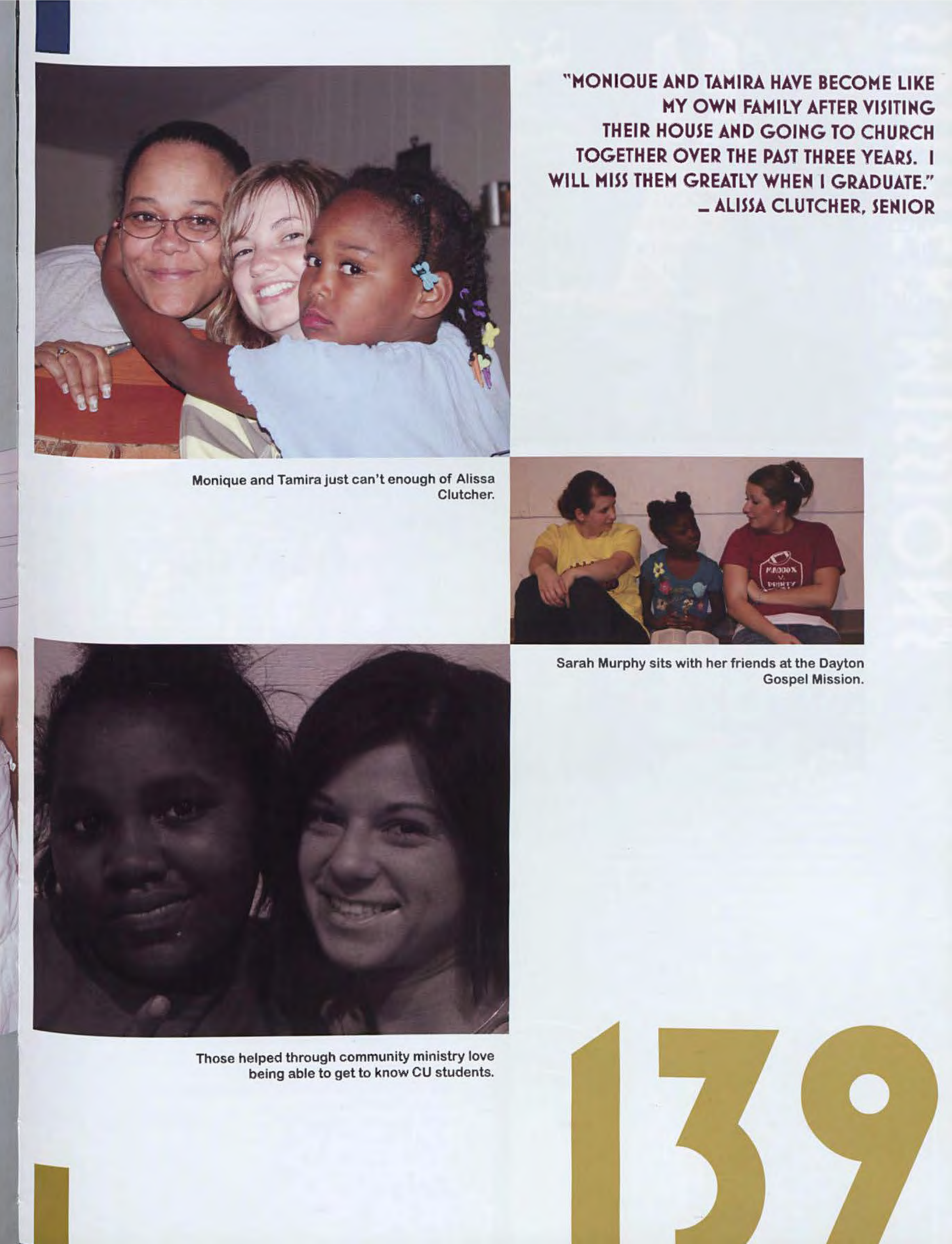




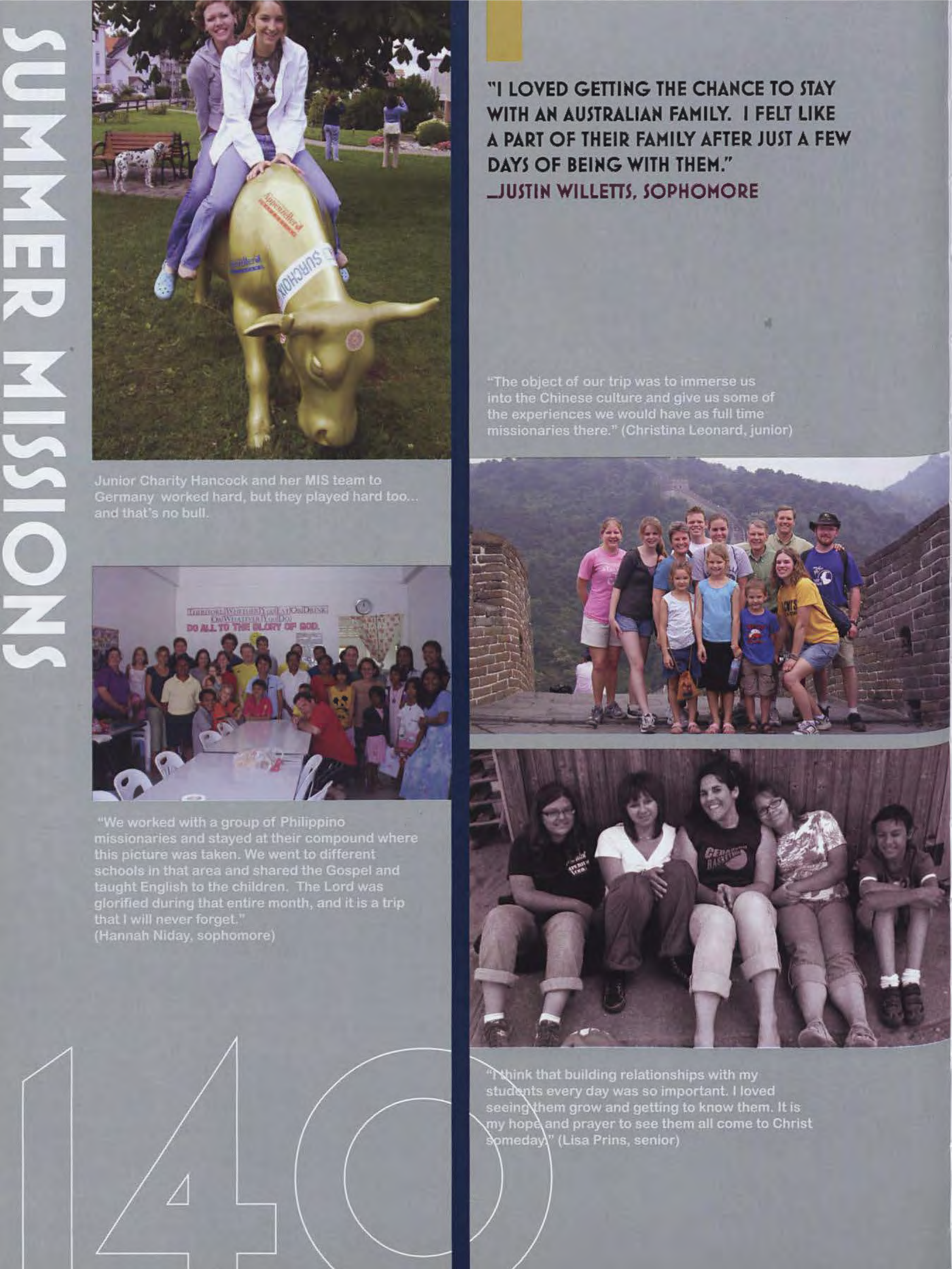




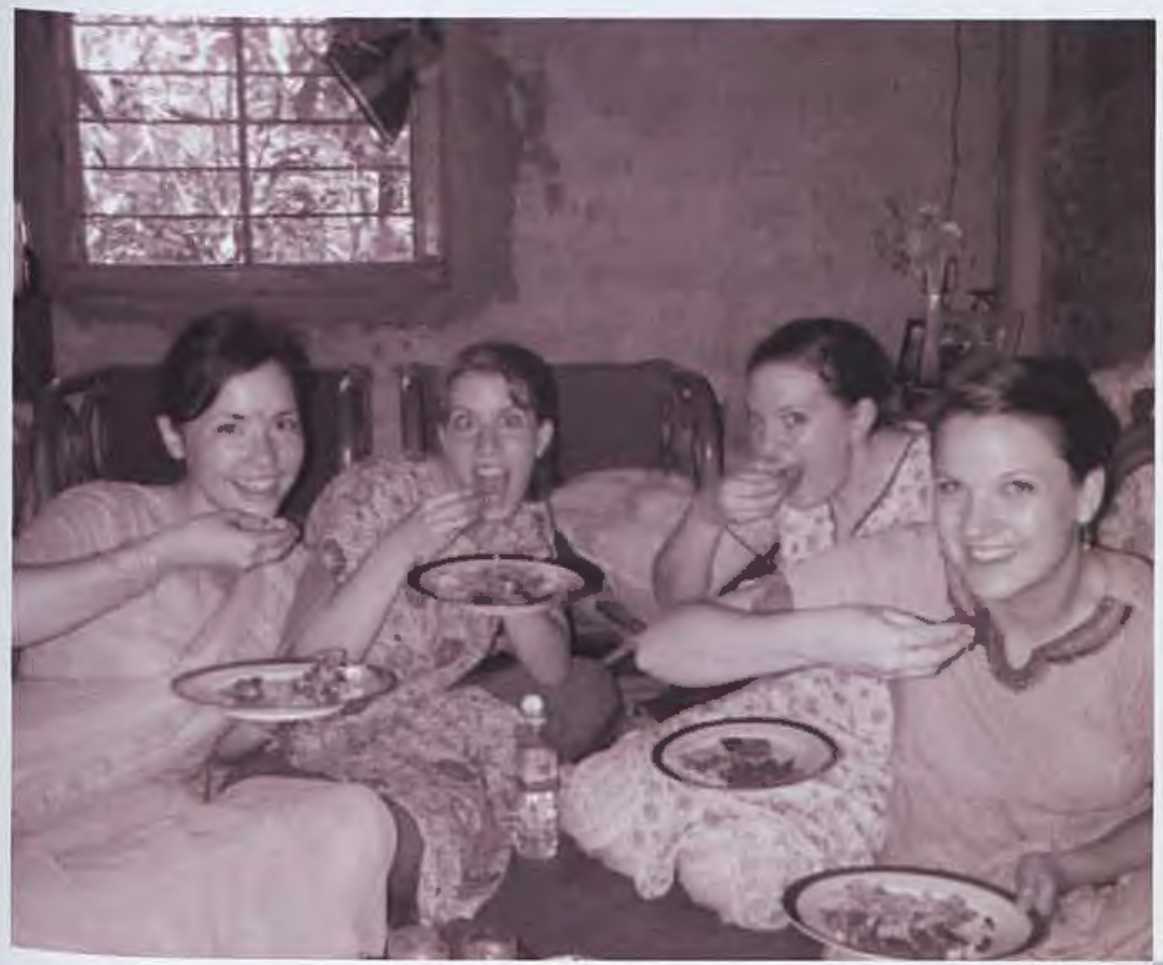

"THE MOZAMBIQUE TEAM SPENT THREE WEEKS LAYING A NEW CHURCH FLOOR (DIRT, ROCKS, AND CEMENT), PAINTING, AND VARIOUS OTHER CONSTRUCTION JOBS. IT WAS AMAZING TO SEE THE LOVE OF THE LORD JESUS CHRIST CROSS LANGUAGE AND CULTURAL BARRIERS. WE ALSO CAME BACK CONTINUALLY THANKFUL FOR ELECTRICITY AND RUNNING WATER!" -DEA FALLIN, JUNIOR

"What did I learn in Bangladesh? I learned that what I have in mind and what God has in mind are two totally different things. I imagined long days in the hospital ministering to the physical needs of the Bengali people. Instead I learned what the life of a missionary nurse is really about. It's about the people and their spiritual needs. The hospital is simply a tool God uses to help deliver His message." (Lachelle Richter, senior)
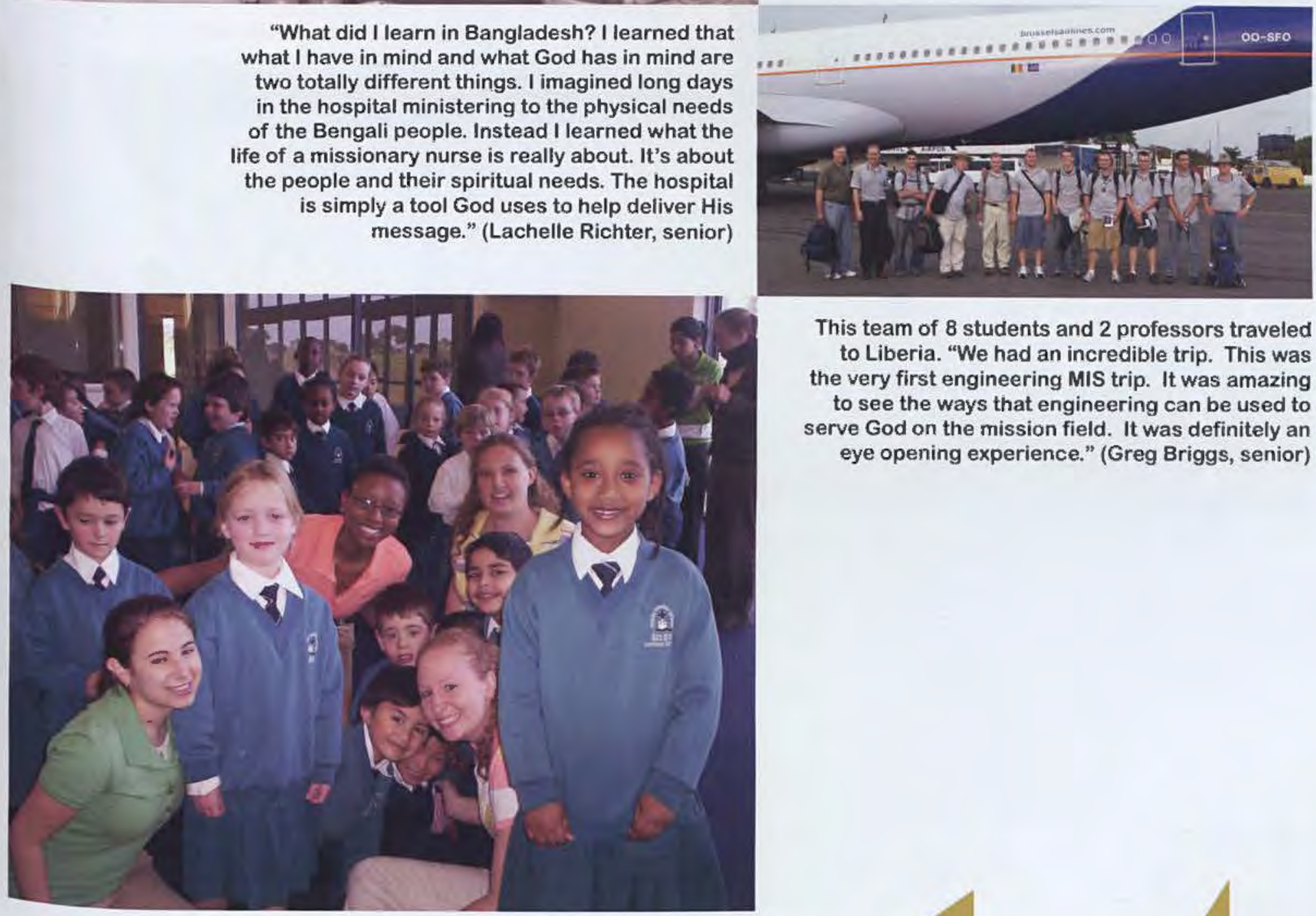

This team of 8 students and 2 professors traveled to Liberia. "We had an incredible trip. This was the very first engineering MIS trip. It was amazing to see the ways that engineering can be used to serve God on the mission field. It was definitely an eye opening experience." (Greg Briggs, senior)

The girls of the music/drama Australia enjoy spending time with their elementrary audience after a morning of skits, singing and handing out

"Iollies". 


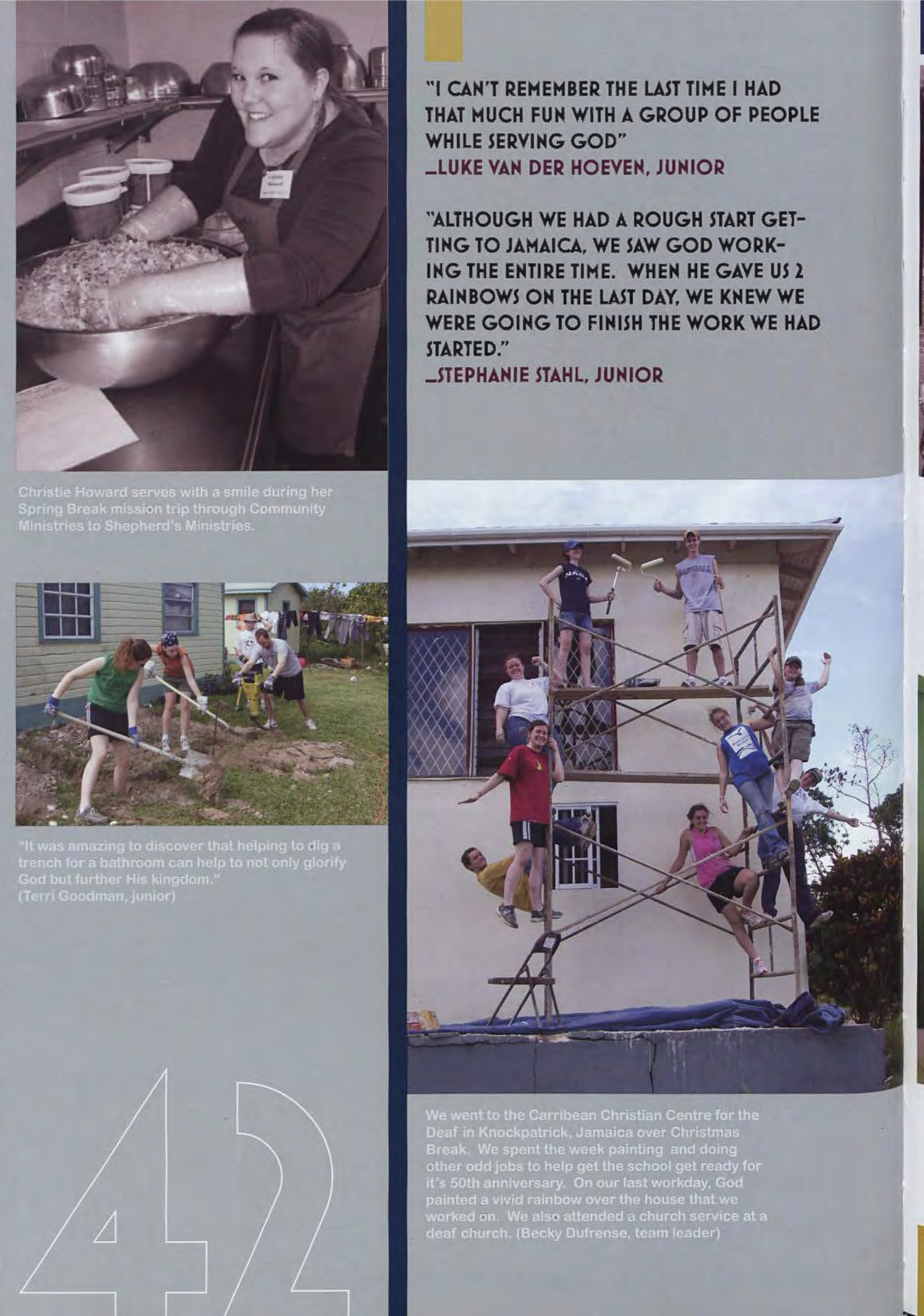




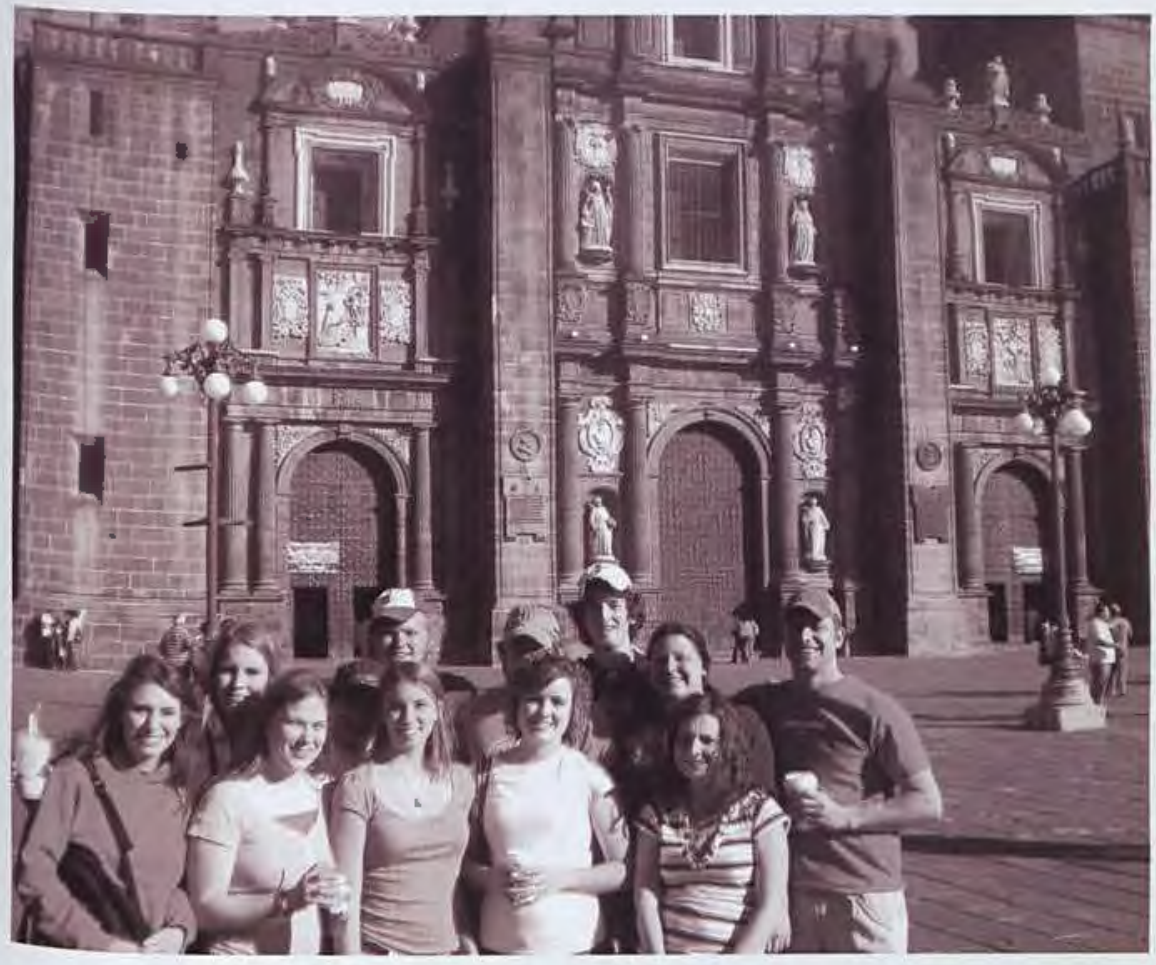

"We went to Mexico to staff Puebla Christian School's Spiritual Emphasis Camp. We were the counselors, worship band, and game leaders which made for a busy, crazy, amazing week. I learned, along with many of the campers, the importance of being rooted in Christ and letting Him show His strength through my weakness." (Krista Ray, sophomore)

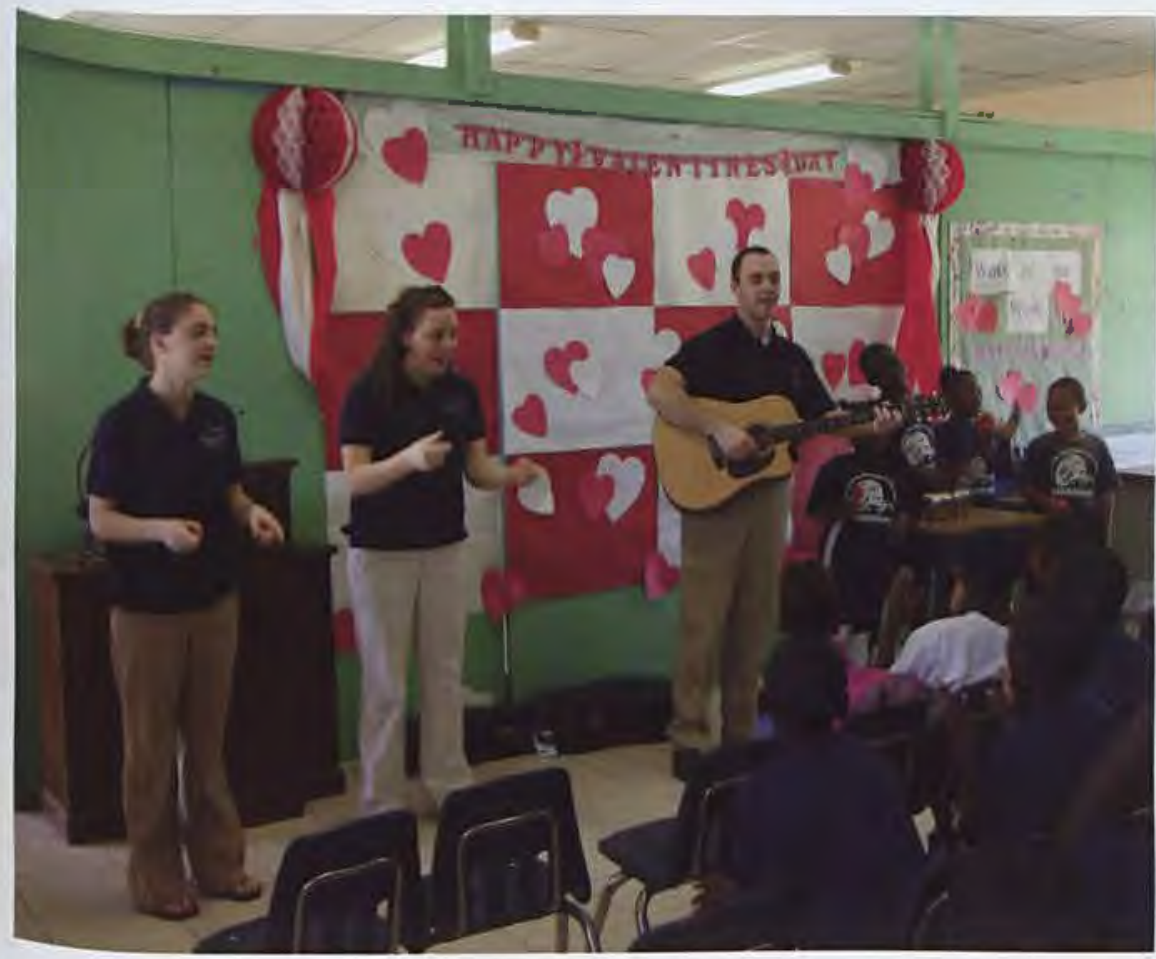

"Leading the young students in praise songs in Eleuthera, Bahamas was great because they all loved music so much." (Stan Moran, junior)

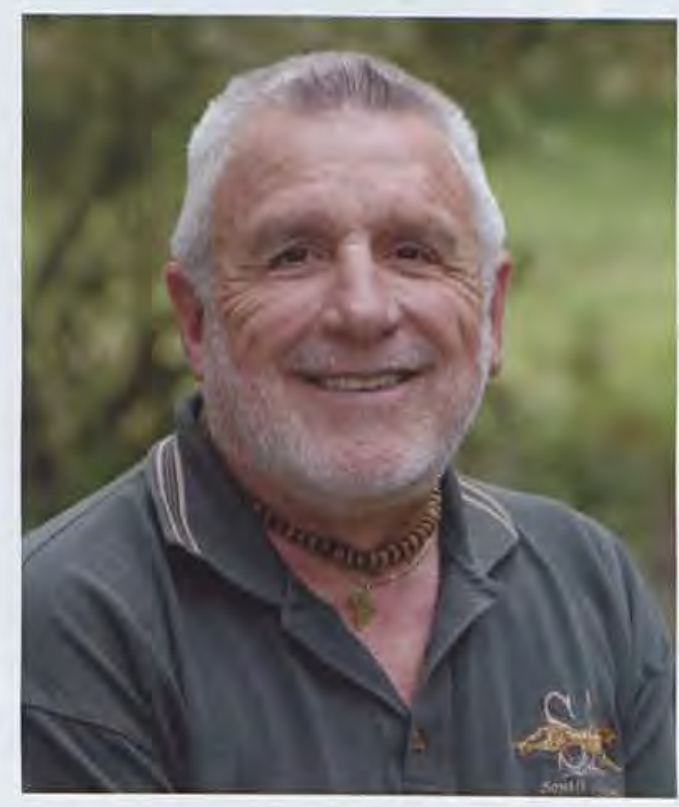

"I must go," says Dr. David Drullinger, about his upcoming move to Cape Town, South Africa. "If I didn't go, my

heavenly Father would take me to the woodshed!"

Drullinger is very passionate when he talks about his future in South Africa - a future that includes working at a church plant - Mount View Baptist Church - and teaching college courses at the Church Ministry Institute. After visiting in 2004 and again in 2007, a love for the country and the people fostered in Drulinger's heart.

Leaving behind a 19-year teaching career at Cedarville University, Drullinger plans to spend the rest of his life in South Africa. "I first gave my life to missions as a freshman at Bob Jones University," said Drullinger. "I'm answering a 50-year-old call. You're never too old, I guess."

Drullinger goes as a career missionary appointed by Association of Baptists for World Evangelism. In addition to working with the church plant, he will teach college courses such as Wisdom Literature, Greek, and theology. The people of South Africa are very open to Christianity, and they are slowly learning that only God can heal the wounds that are the result of years of apartheid and civil strife.

Dr. Drullinger most looks forward to "the opportunity to use all of the experiences, gifts, and skills of the last fifty

years." What will be the hardest part of going? Leaving the classroom. "I love my colleagues and the university," Drulinger said, "but the heart of Cedarville is its students." 


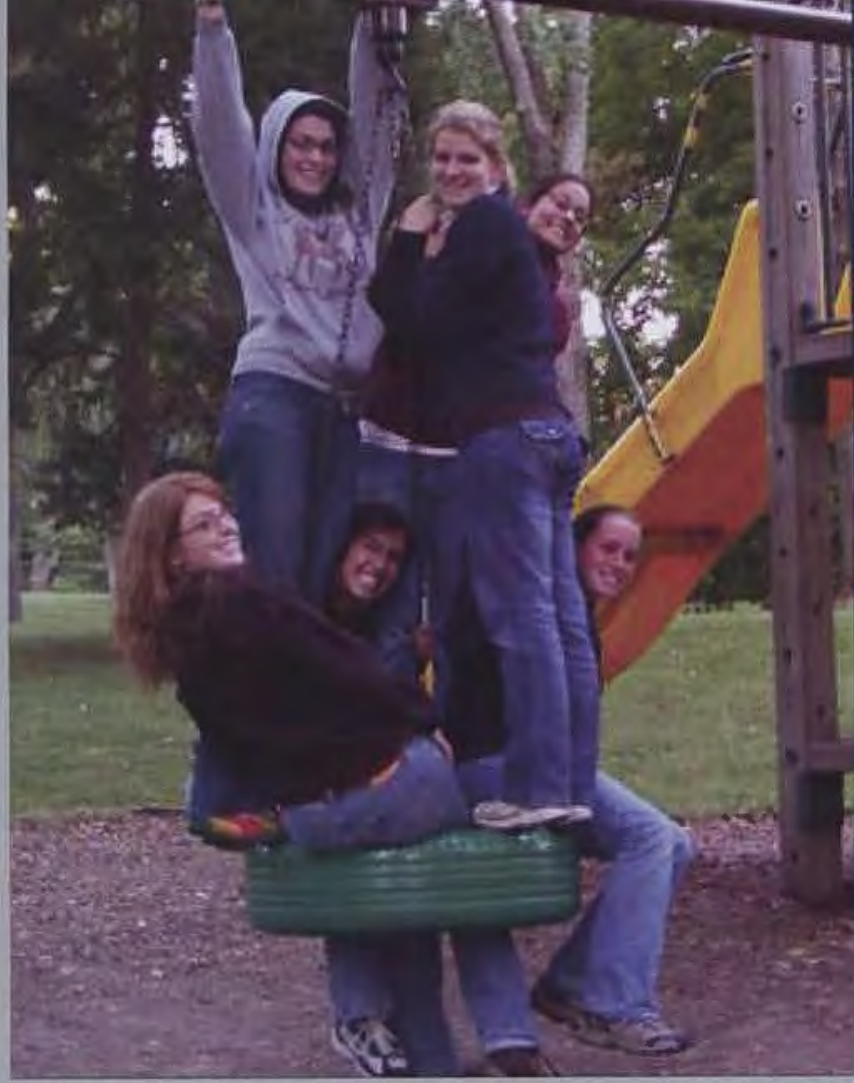

$\sqrt{6}$

Not that the girls "tire' di from their disciple study

but they decided to pick a different spot for thier

meeting

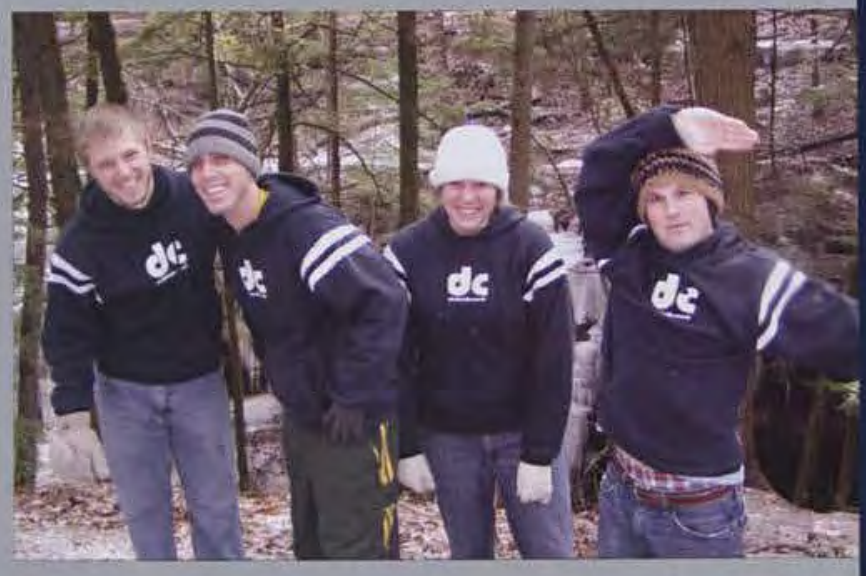

Discipleship group leaders enjoy spending same

time together before they spend time with their

individual groups

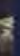

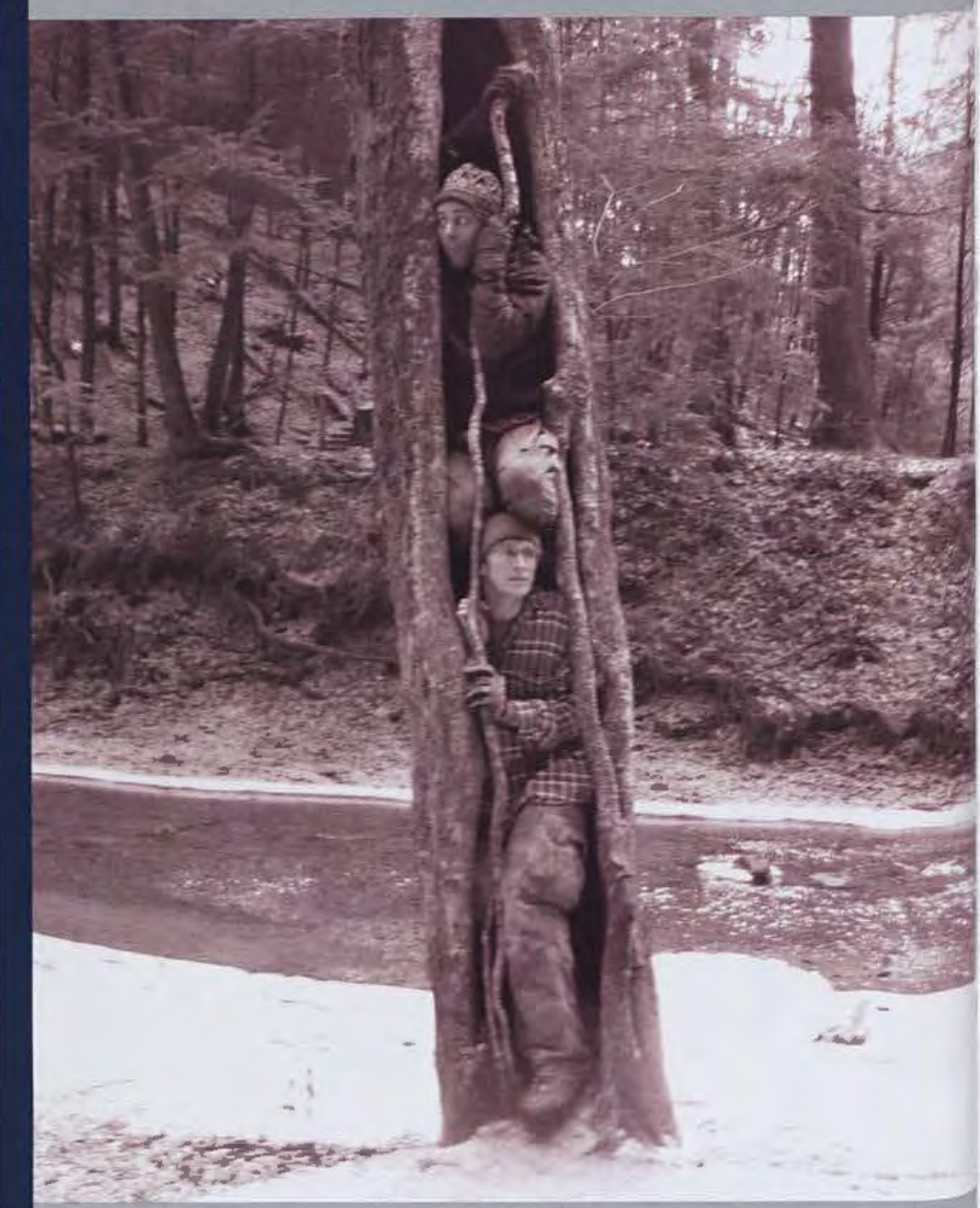

"BEING A DSGL HAS BEEN SUCH AN INCREDIBLE PRIVILEGE!! I LOVE ALL THE FUN WE HAVE HAD, BUT MOST IMPORTANTLY WE HAVE LEARNED AND GROWN A LOT TOGETHER THIS YEAR BY STUDYING THE NAMES OF GOD AND UNDERSTANDING THE IMPLICATIONS THAT THIS HAS IN OUR LIVES."

_VALERIE BLACKSTONE, SOPHOMORE

This year there were 890 students involved

in discipleship ministries but ". ...numbe

definitely anen't the foous of the ministry, but it I

encoluraging to see so many students gravitating

toward involvement in discipleship small group

Director of Diselpleship Ministries 


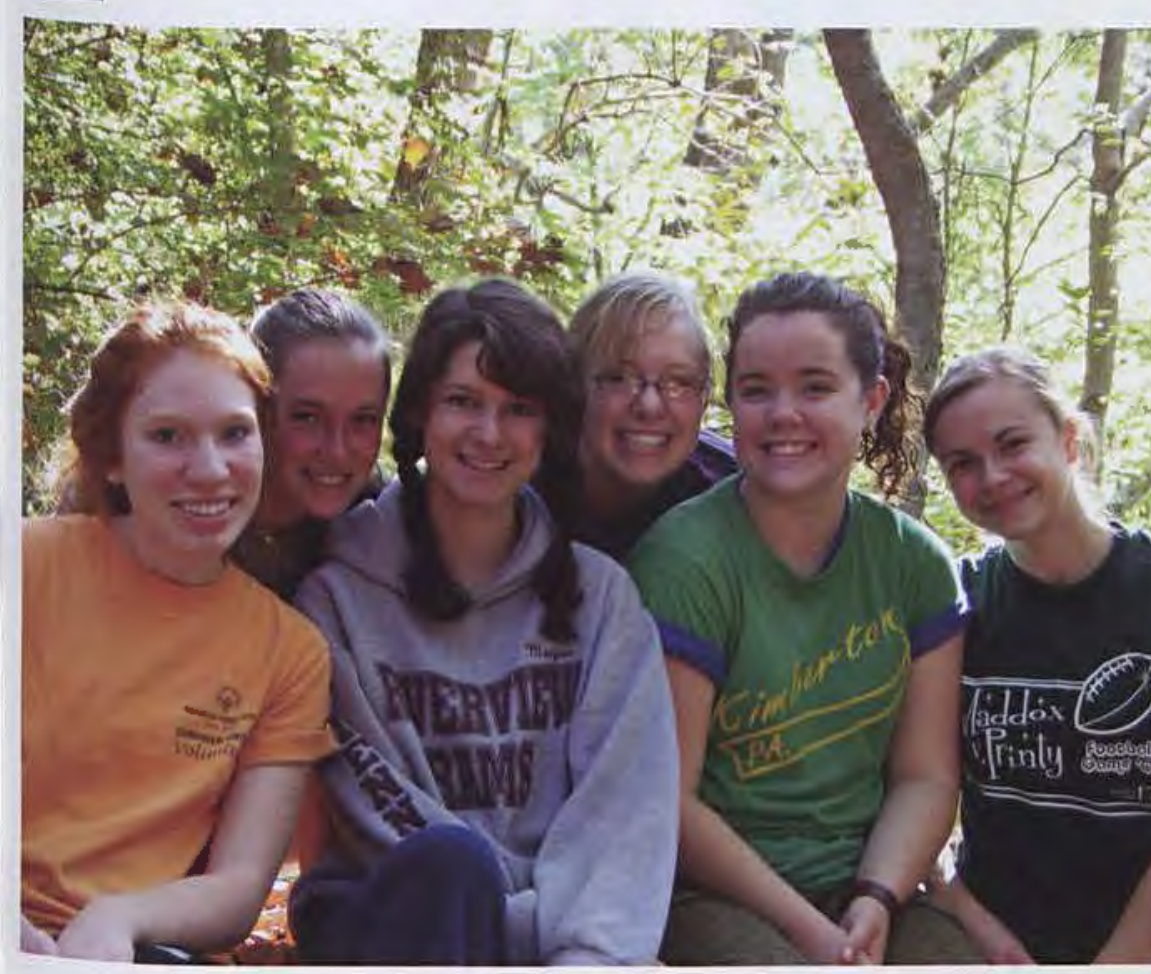

"I love meeting with these girls each week. We get to study God's word together and talk about the Lord... and just having fellowship with one another is so good." (Caribeth Wolfe, freshman)

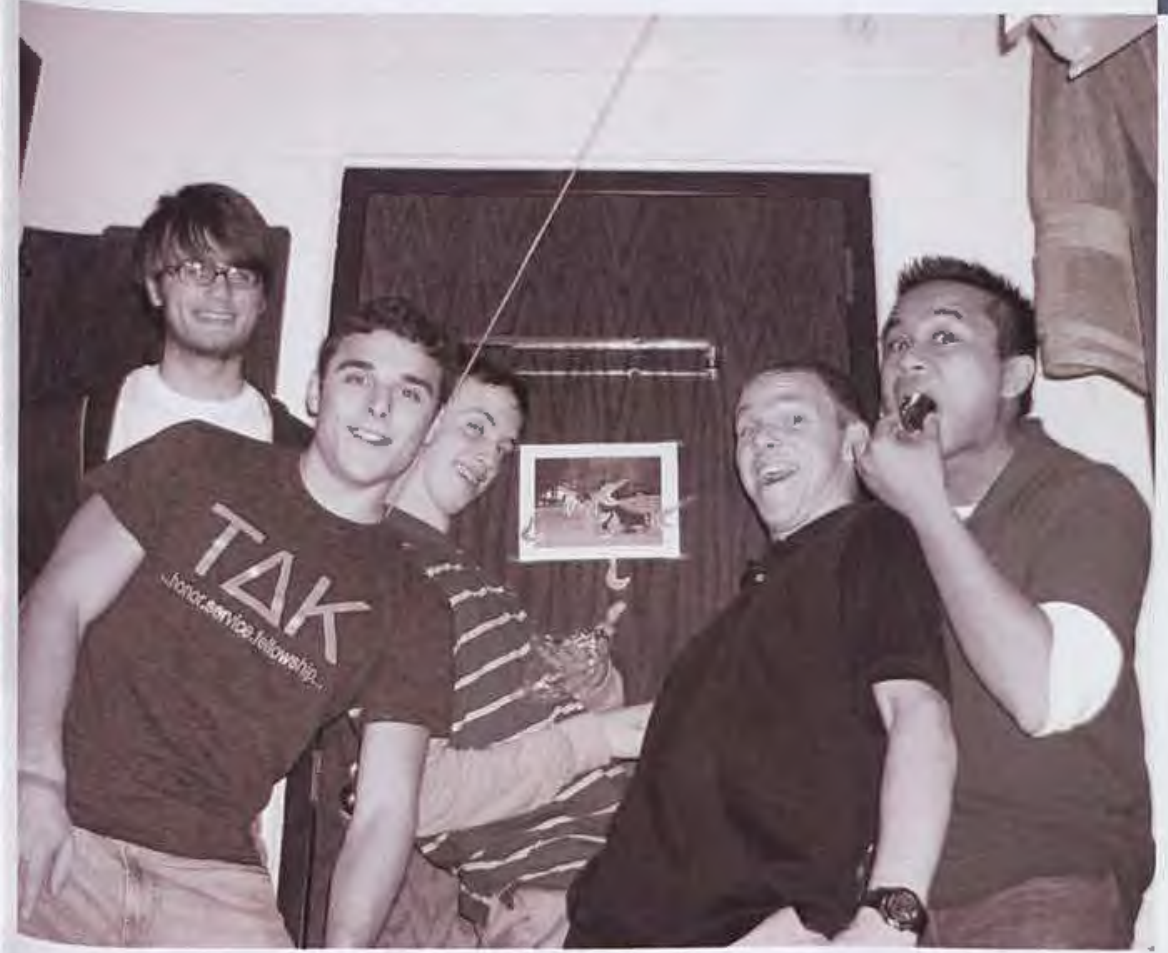

"It was just a great time to be truly comfortable with a group of guys so we could have fun and be challenging to one another in our walks with Christ." (Ryan Samueisen, senior)
"THE BEST PART ABOUT DSGL IS THE COMMUNITY AND RELATIONSHIPS BUILT WITHIN THE GROUP. AS A LEADER THIS YEAR, I'VE BEEN ABLE TO GET TO KNOW SEVERAL AMAZING WOMEN OF GOD AND GROW WITH THEM AS WE SEEK OUT HIS HEART. MY FAVORITE MEMORY WITH THEM HAS BEEN SITTING IN A TREE AT NIGHT LOOKING AT THE STARS TALKING ABOUT WHAT HEAVEN WILL BE LIKE." -SARAH BRANDT, SOPHOMORE

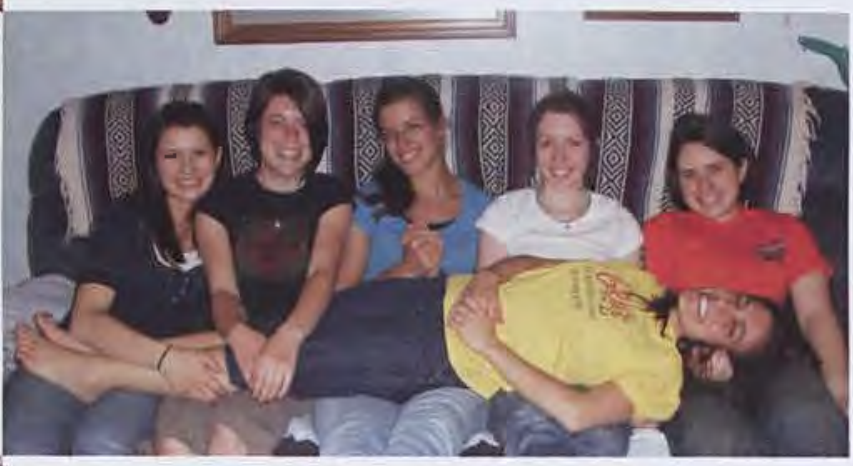

Discipleship isn't just about lying around. These girls were able to grow plenty. 

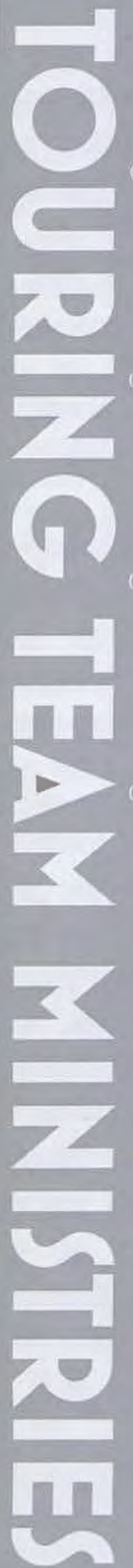

(Jerica Ward, junior, HeartSong Blue)

If I could sum the nast summer of ministry

I would call it 'stretching.' You are stretched

beyond yoar comfort zone to fove the people an

your team and the strangers you meet - Which

experience. Ministry is so exciting !"

(Rachel Mundy, sophomore, Master's Puppets 1)

The most powerful thing that has happened
this year is the emphasis that has been placed

upon being completely satisfied with Cod and

Sod alone: My most favarite times this year have

together in prayer, seeking to do what Gad

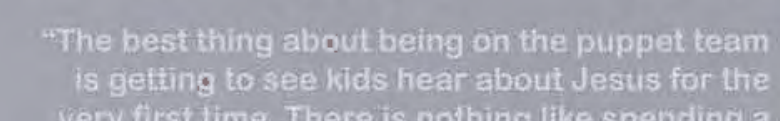

Week with a group of children and at the end of
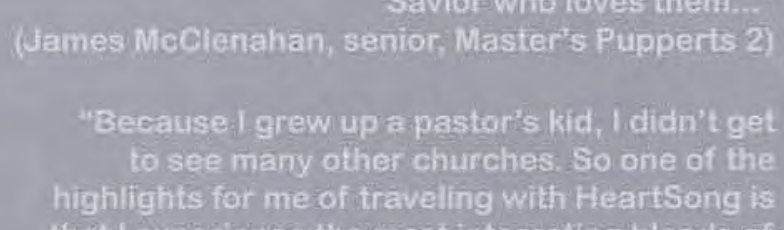

that I experience the most interesting blends of

otherwise. It also rooks your world a little bit to
other

see that there isn't just ore way a church needs

(JB Waggoner, junior, Heartsong Orange)

"Cod used the drama to inject truth snd hope

right into the middle of deep wounds. Watching
God tug at the hearts of many, and praying with

way I View drama, ministry, and the working of

(Jonathan Knight, sophomore, Lifeline Players)
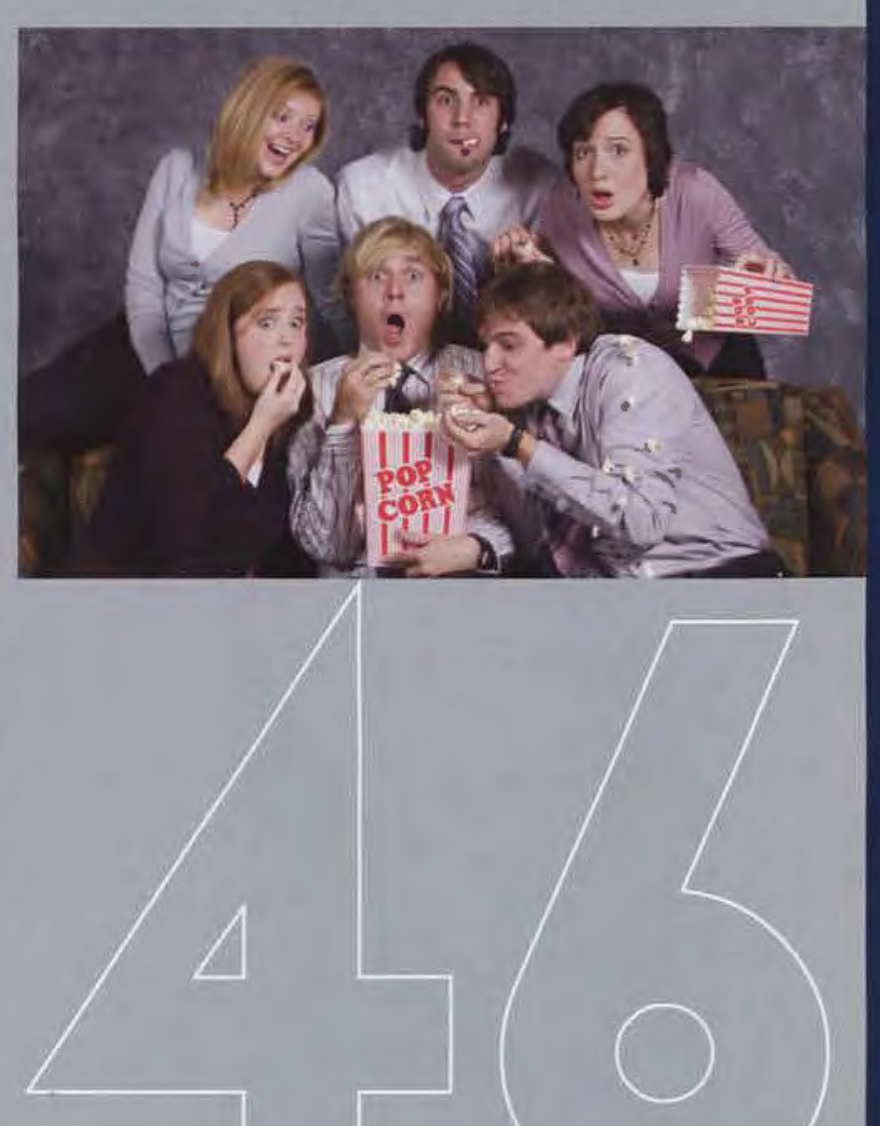
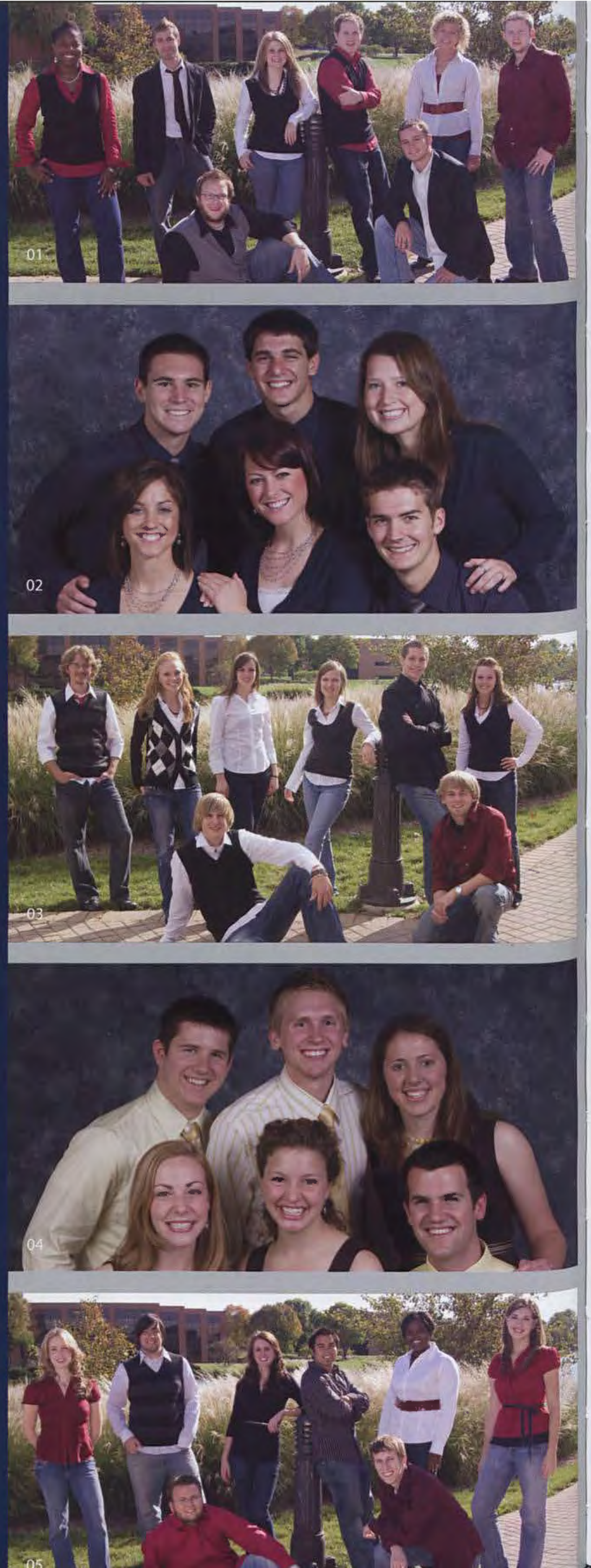

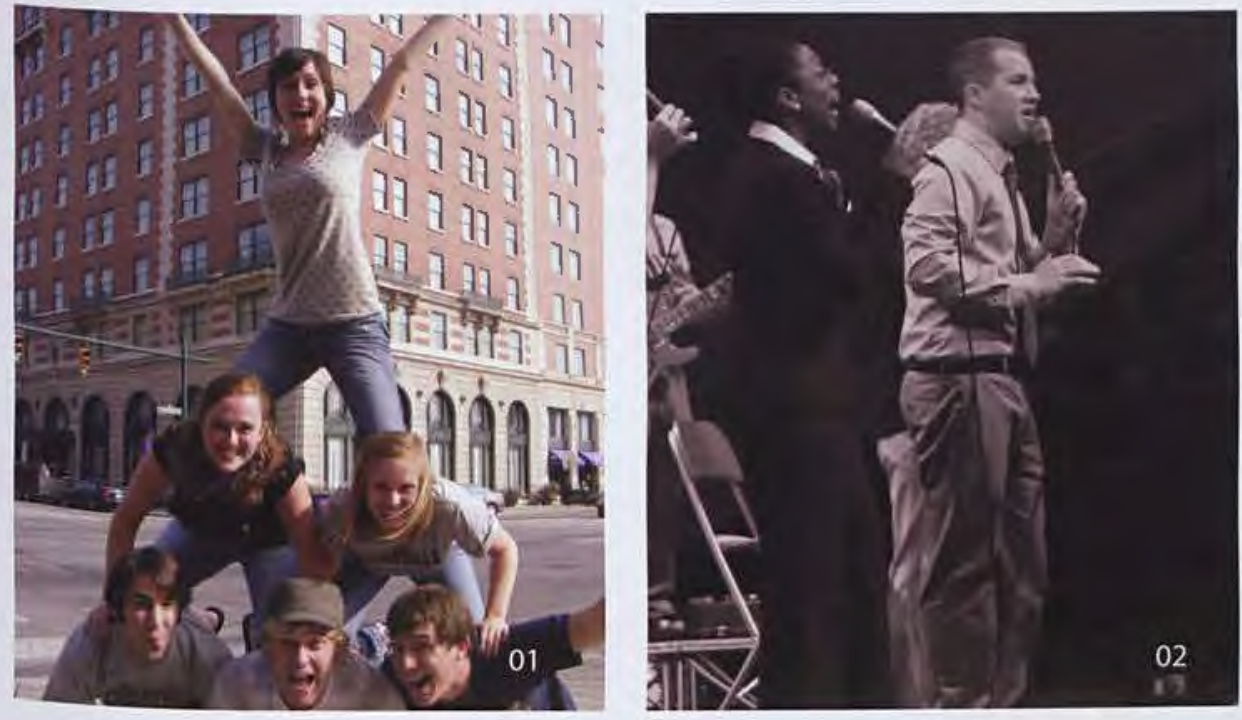

01

"I love this group of amazingly talented people!!! Serving alongside of them has been a rich blessing in my life, and I am so thankful for the wonderful opportunity that God has given me..." (Andrea Sergent, sophomore, Lifeline Players)

Q2 HeartSong vocalists Jerica Ward and Lukas Seelye lead students in worship as a part of HeartSong chapel and to celebrate the teams' annual $C D$ release.
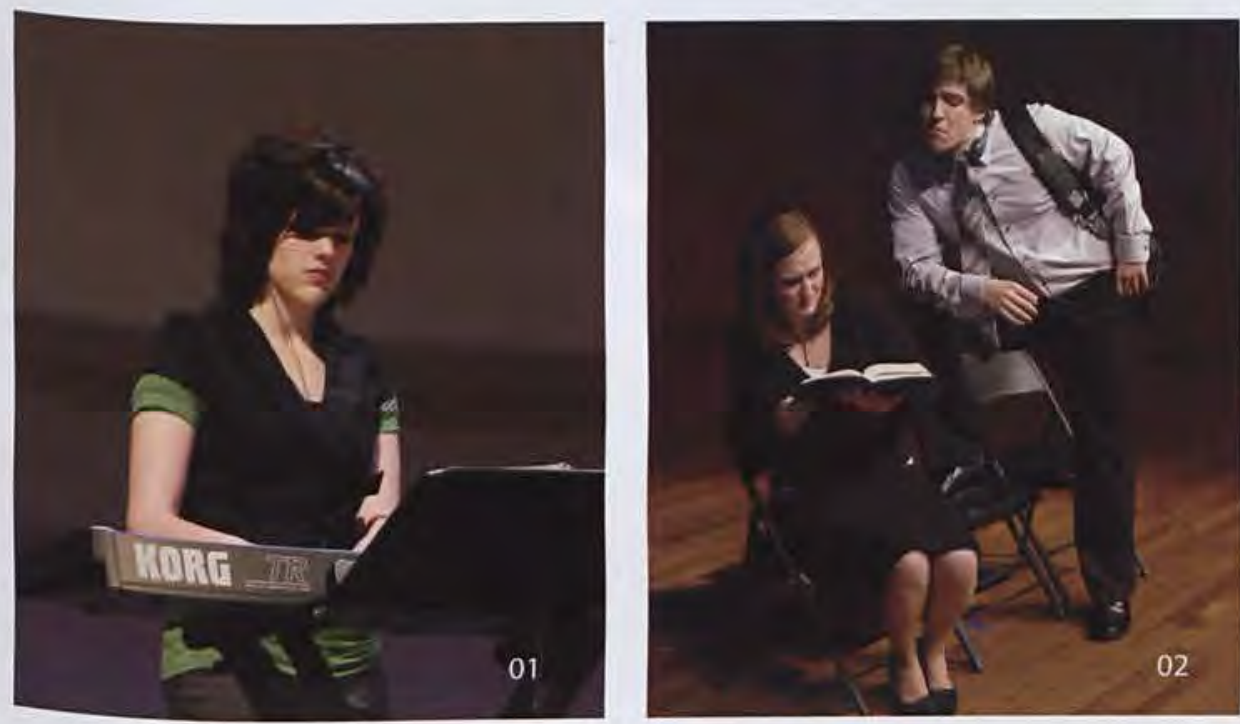

Sophomore Erin Gollihue can often be caught in
"TRAVELING AROUND AS A TEAM AND MEETING MANY PARTS OF THE BODY OF CHRIST HAS BEEN AMAZING!! AS A TEAM WE HAVE GROWN VERY CLOSE AND LOVE MINISTERING TOGETHER TO THOSE THAT WE COME IN CONTACT WITH." -SETH FLAMM, FRESHMAN, MASTER'S PUPPETS I

"I HAVE GROWN SO MUCH BEING ON A TOURING TEAM THIS YEAR. I'VE MADE SOME NEW FRIENDS THAT ARE PRETTY MUCH LIKE FAMILY TO ME NOW." _JUSTIN WILLETTS, SOPHOMORE, HEARTSONG ORANGE

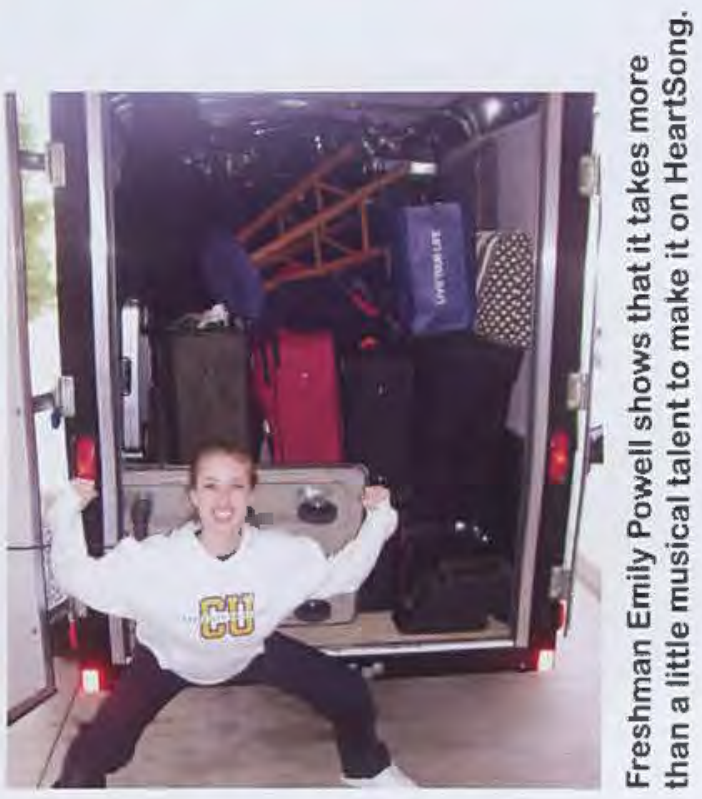
the background dancing and playing her keyboard.

02

01

"As a member of The Lifeline Players, I got to witness first-hand the incredible effects of drama ministry in the lives of a variety of individuals. These ministerial opportunities, coupled with the laughs and fun of fellow team members, have made the touring team experience an indispensable part of my time here at Cedarville." 

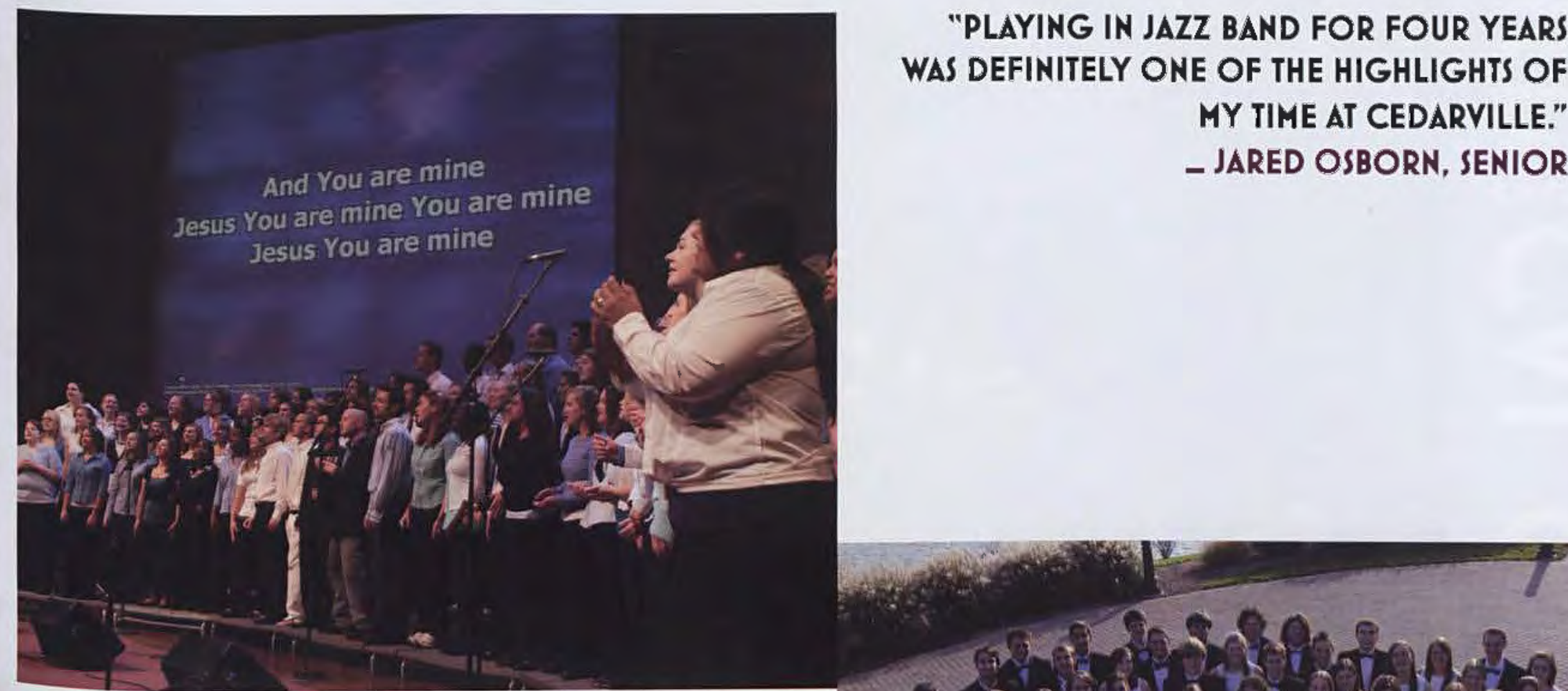

"Since my freshman year I have been a member of One Voice. I keep coming back because it gives me a great opportunity to minister to surrounding communities, and the music is unlike any other on campus." (Alexis Brown, junior)
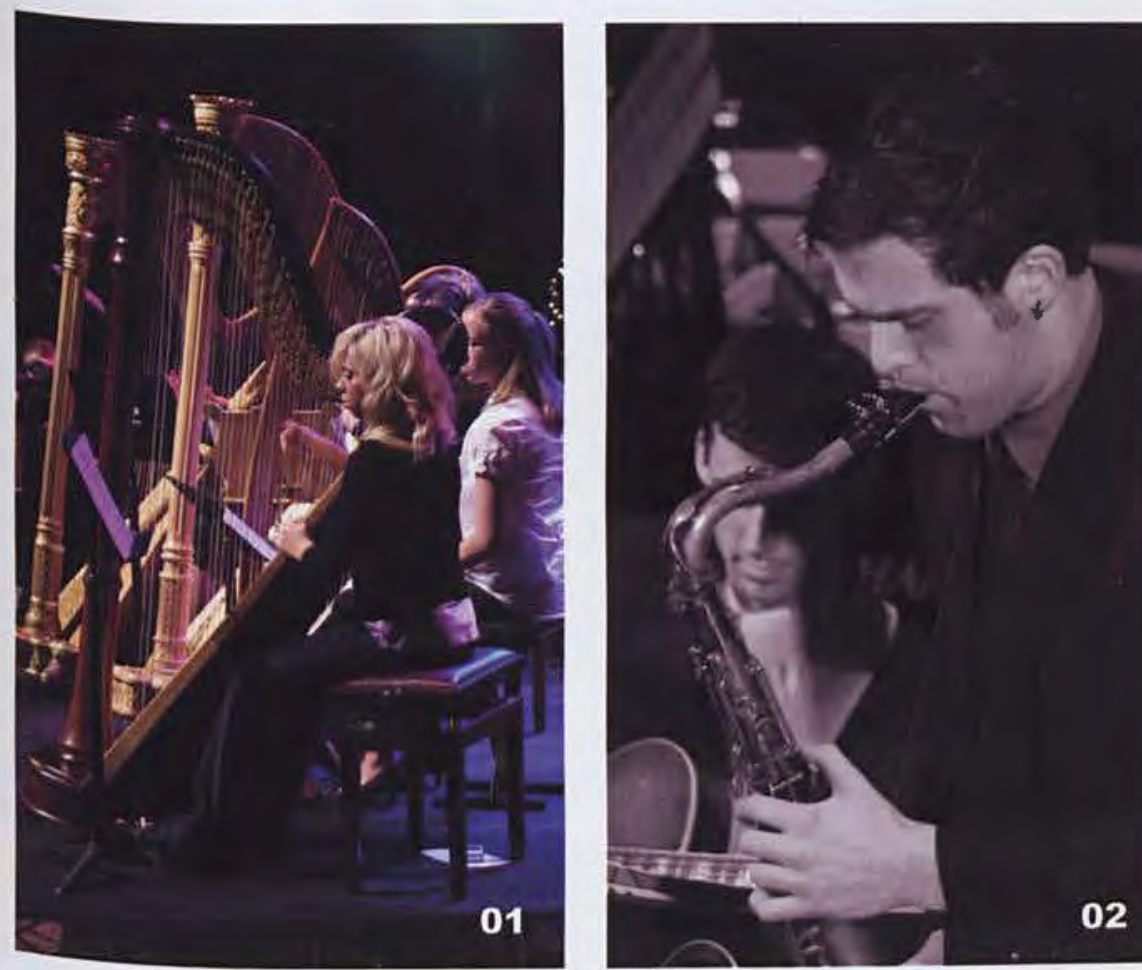

01

Toryn Olson plucks her harp in the Harp Ensemble for the $\mathbf{2 0 0 7}$ Christmas Concert in the Dixon Ministry Center Chapel.

Nate Molby brought down the house with his saxophone in the 2007-2008 CU Jazz Band.
"Chorale provided me with an excellent opportunity to tune my voice, praise my savior, and sing with the girl who is now my wife!" (Jesse Lansford, senior) 

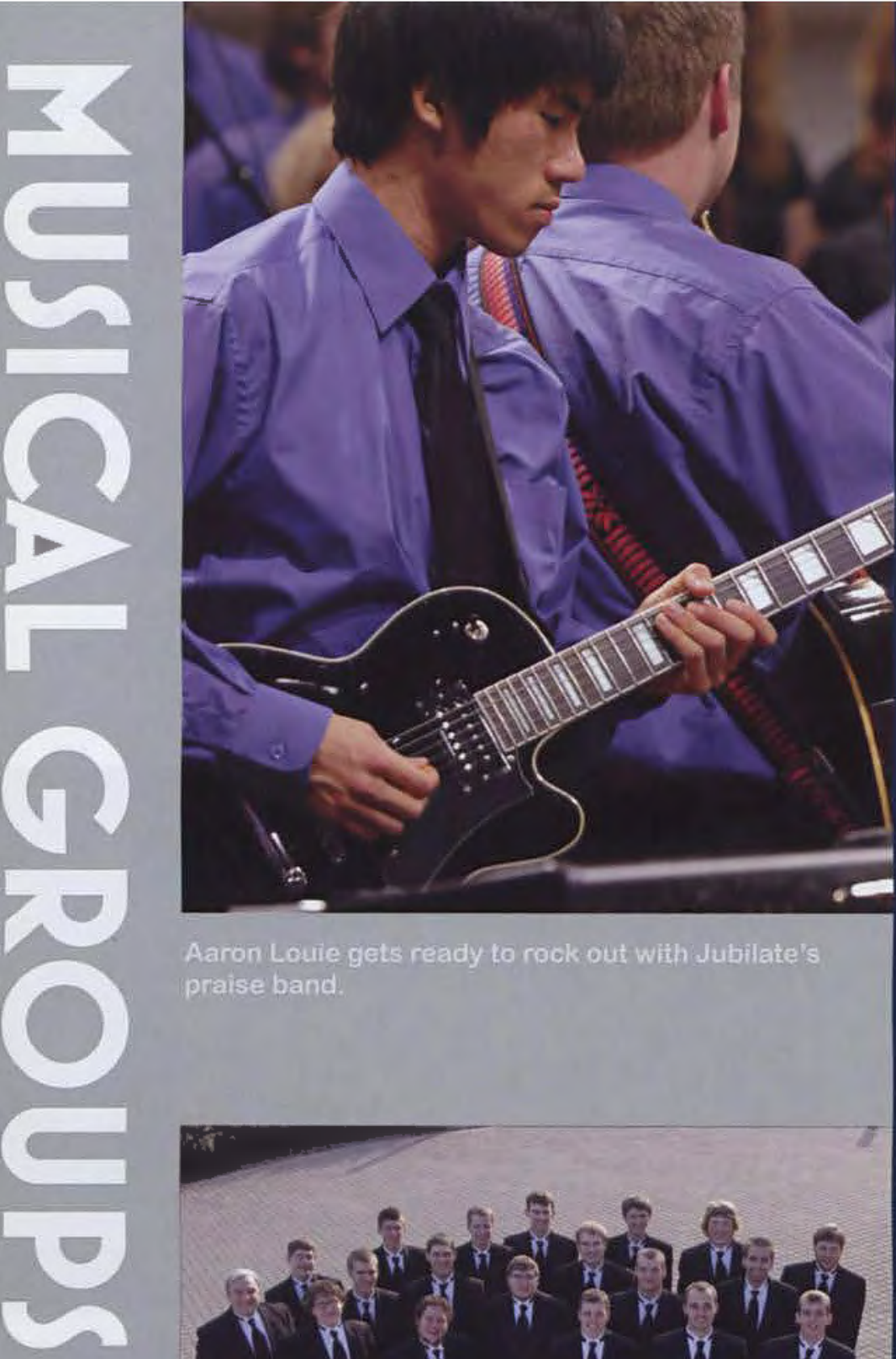

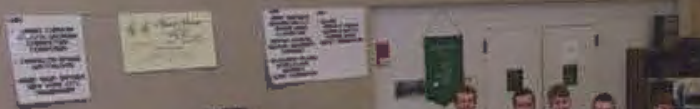

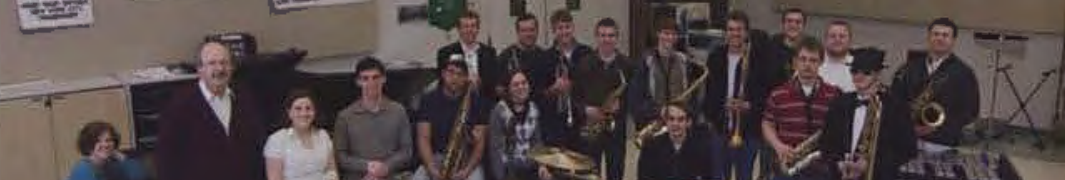
4.

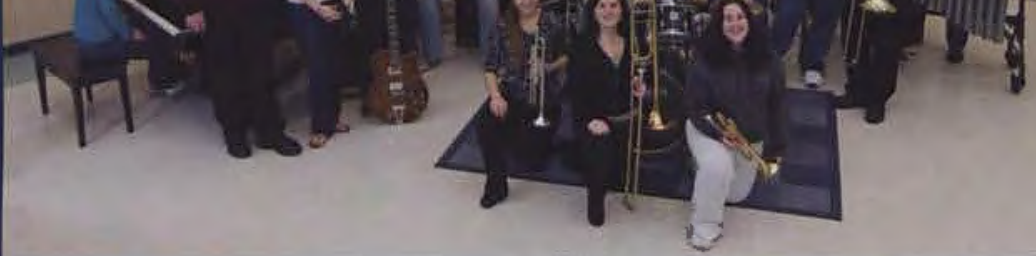

"Jazz band is a greal group of people, and it was really a joy to play with and become firiends with many of my fellow musiclans there."

(Jared Osborn, sention)

Aaron Loule gets ready to rook out with Jubilate's praise band.

\section{m}

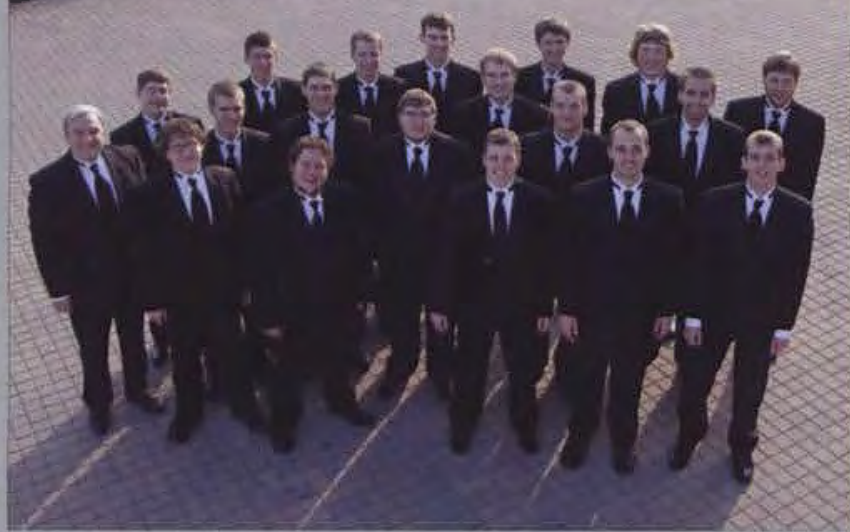

"Glee Club is a great time for guys to get together and not only sing but also get to know one another and have a gpod time." (Stan Moran, junior)

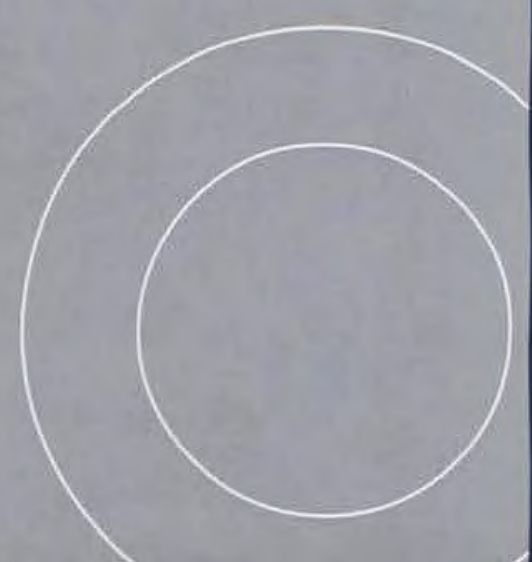

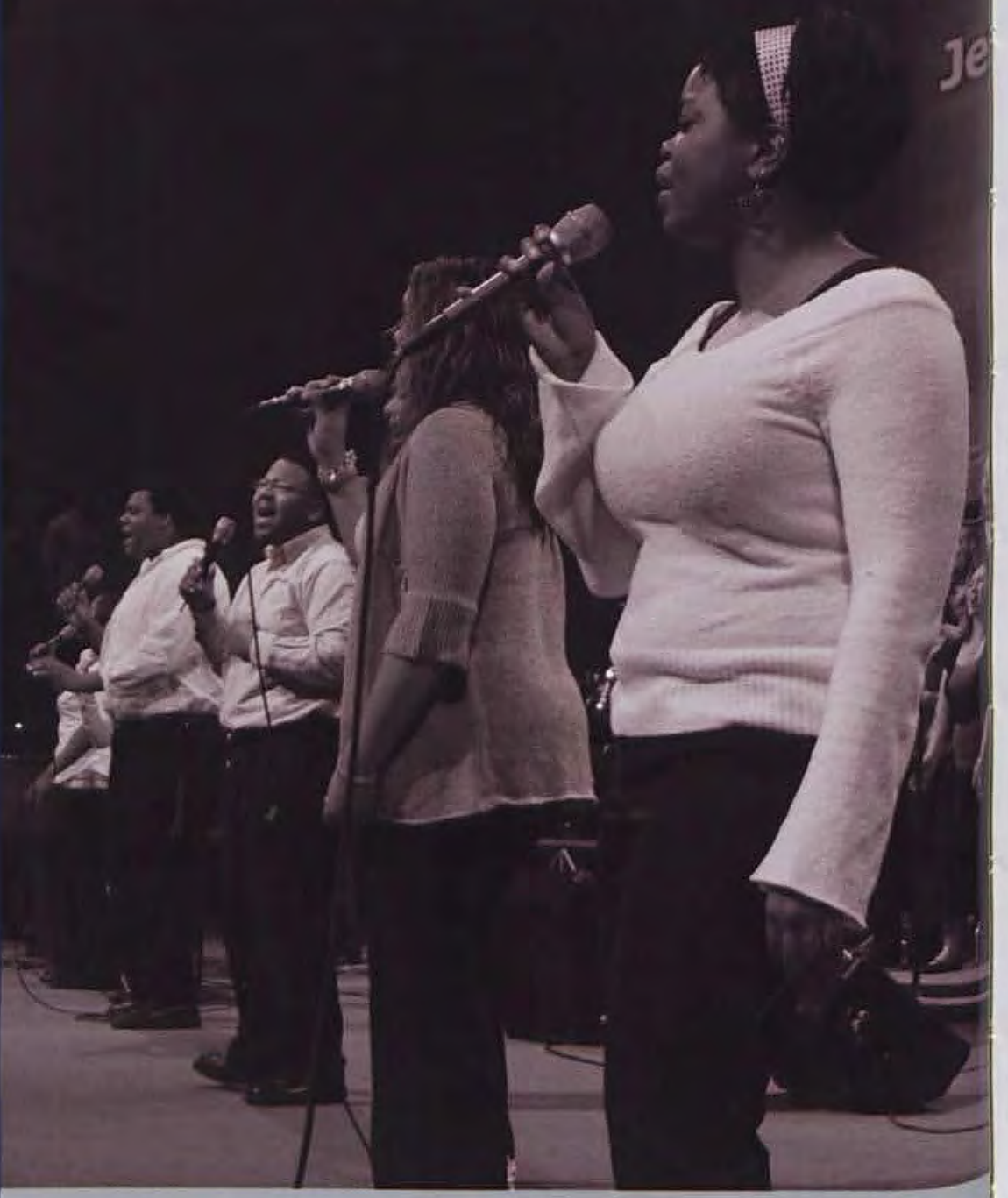

"There is nothing like praising an AWESOME and POWERFUL God" (Sarah Porter, sophomore) 


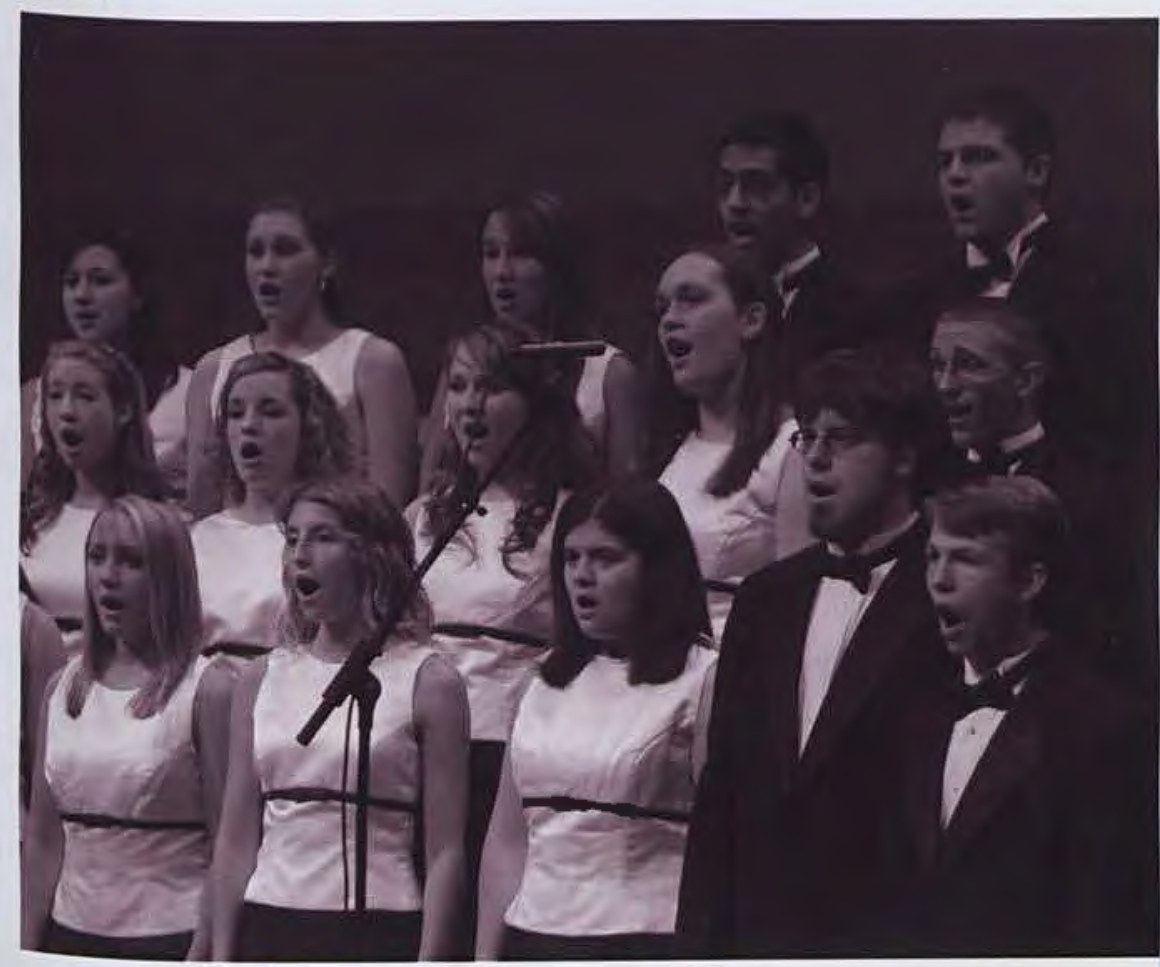

"JUBILATE WAS A GREAT CHANCE TO IMPROVE MY SINGING WHILE WORSHIPING GOD WITH MY FRIENDS. IT WAS DEFINITELY ONE OF THE MOST REFRESHING PARTS OF MY DAY." _ JUSTIN SIDES, SOPHOMORE
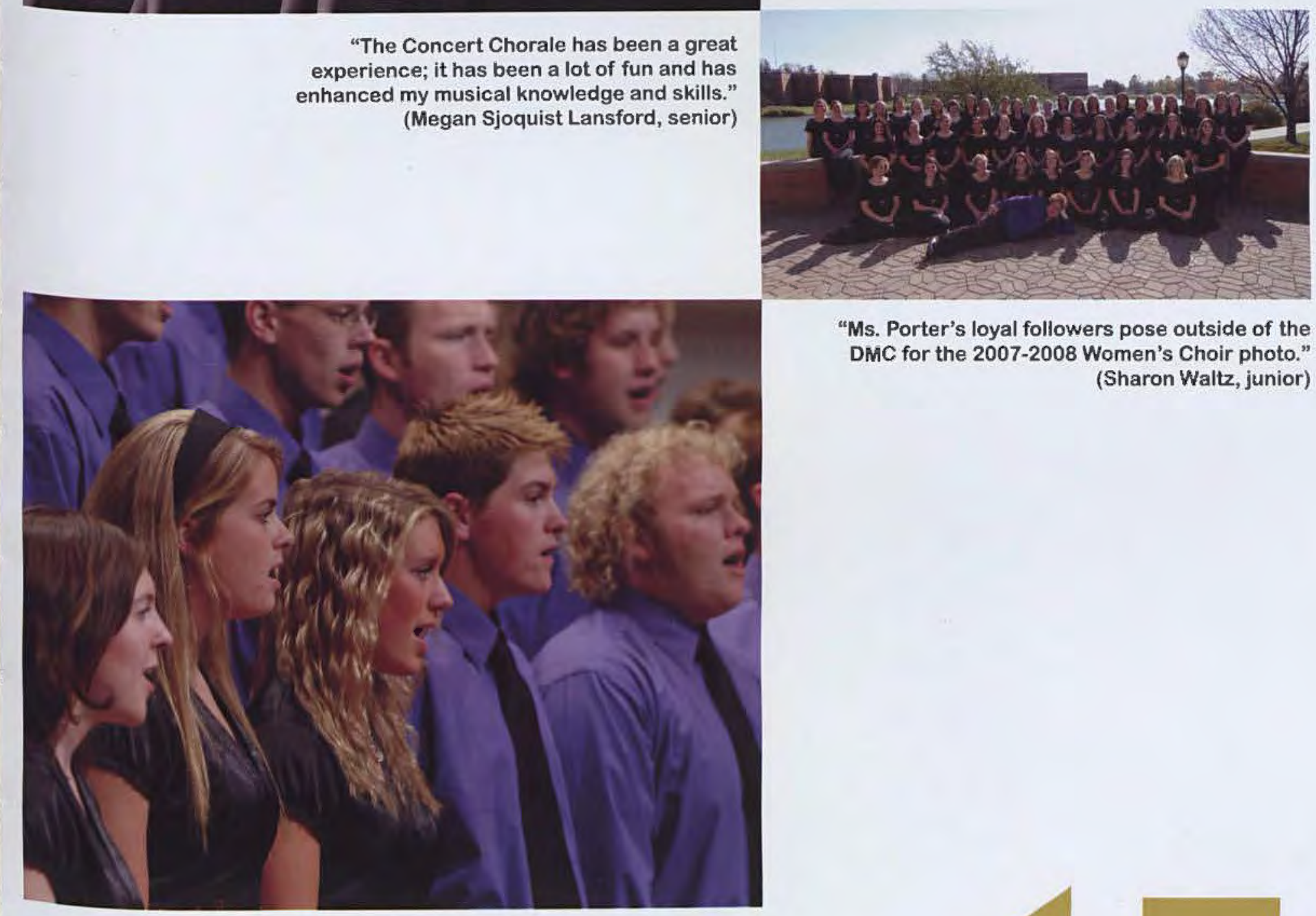

"The Concert Chorale has been a great experience; it has been a lot of fun and has enhanced my musical knowledge and skills."

(Megan Sjoquist Lansford, senior)

"A musical sensation ringing throughout your body." (Micah Kilmer, freshman)

"Ms. Porter's loyal followers pose outside of the DMC for the 2007-2008 Women's Choir photo."

(Sharon Waltz, junior) 


\section{${ }^{7} \bigcirc \bigcirc \mathrm{NG}$}

TO THINGS IS HALF THE

PLEASURE OF THEM"

- LUCY MONTGOMERY 


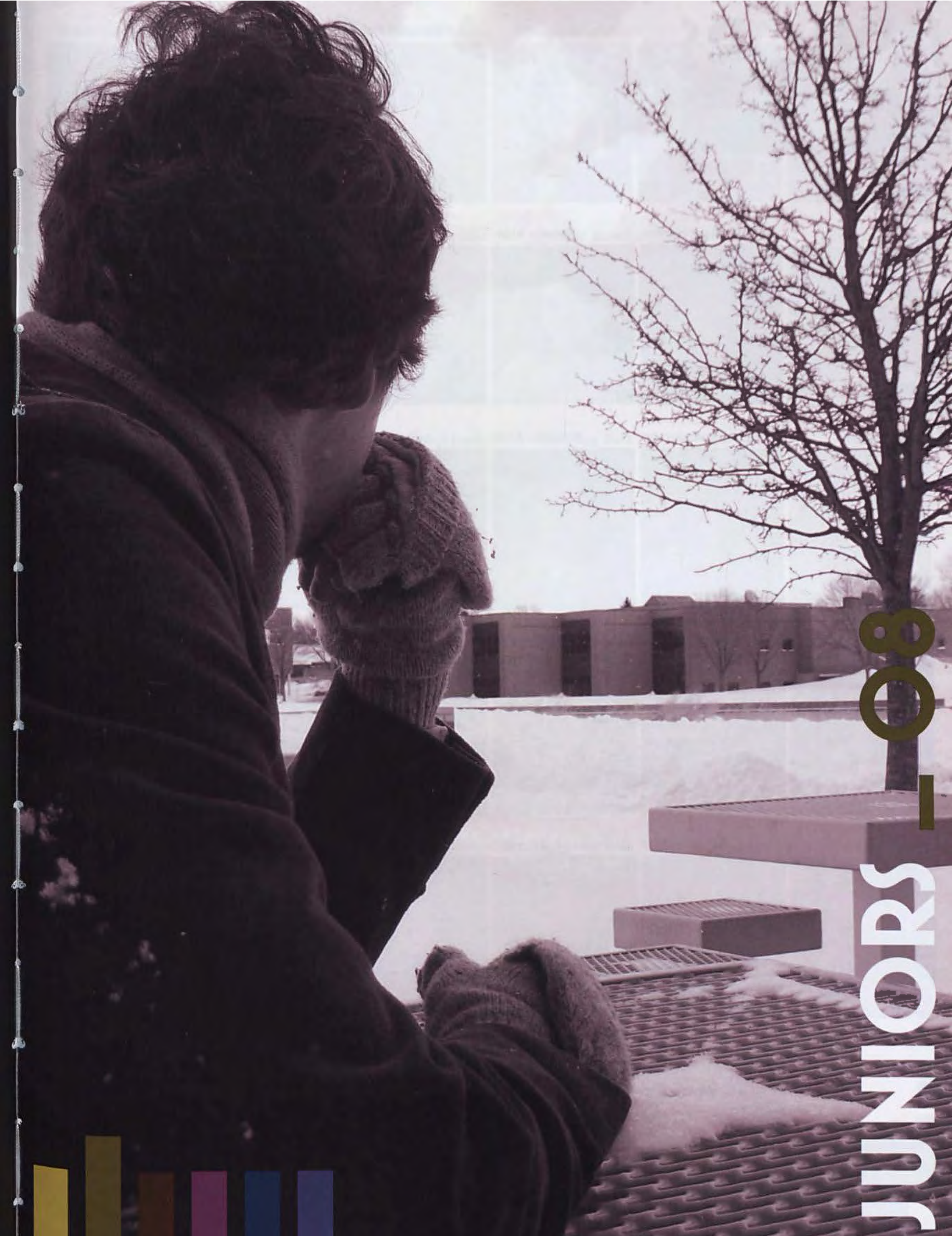



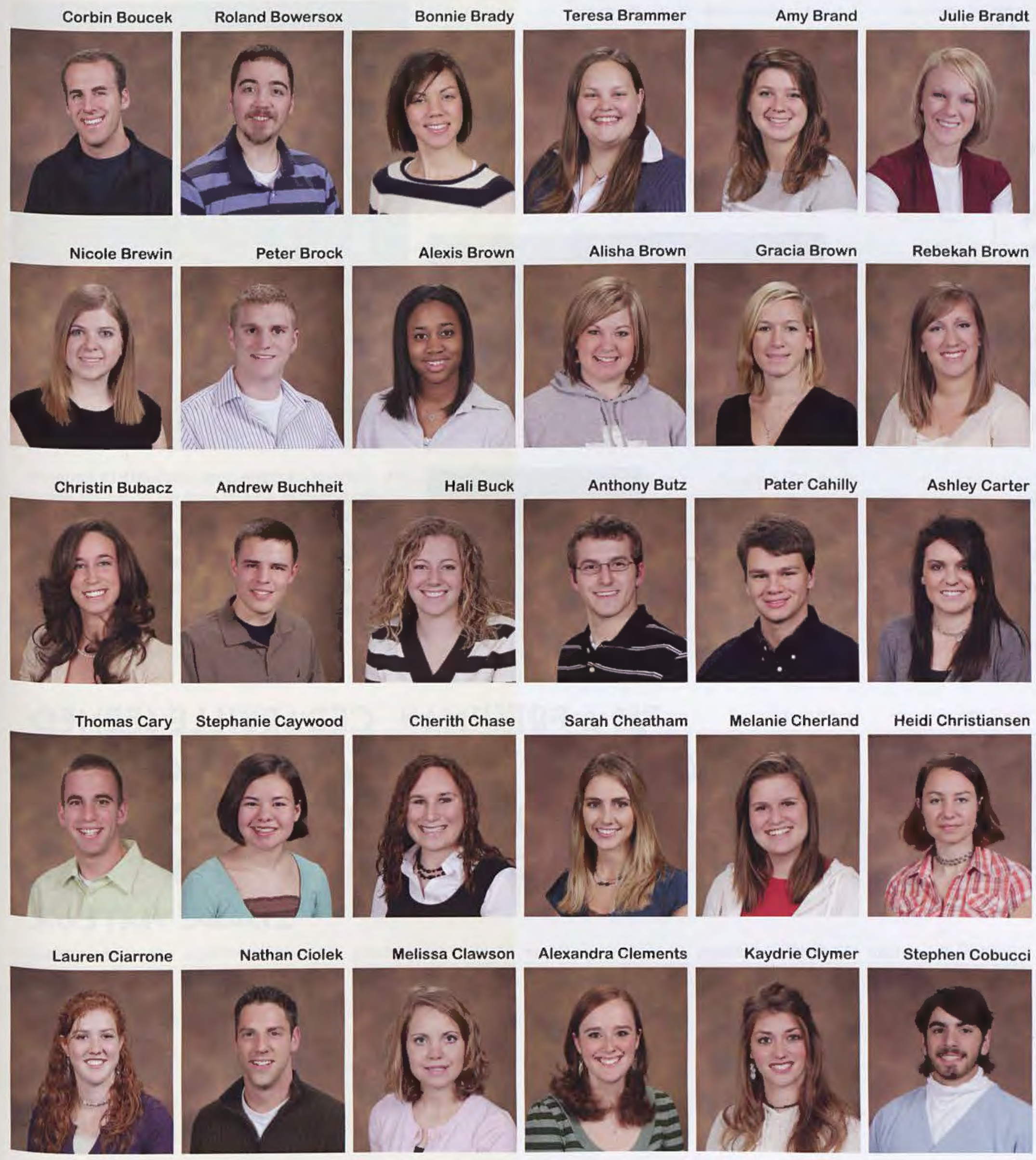

Stephen Cobucci
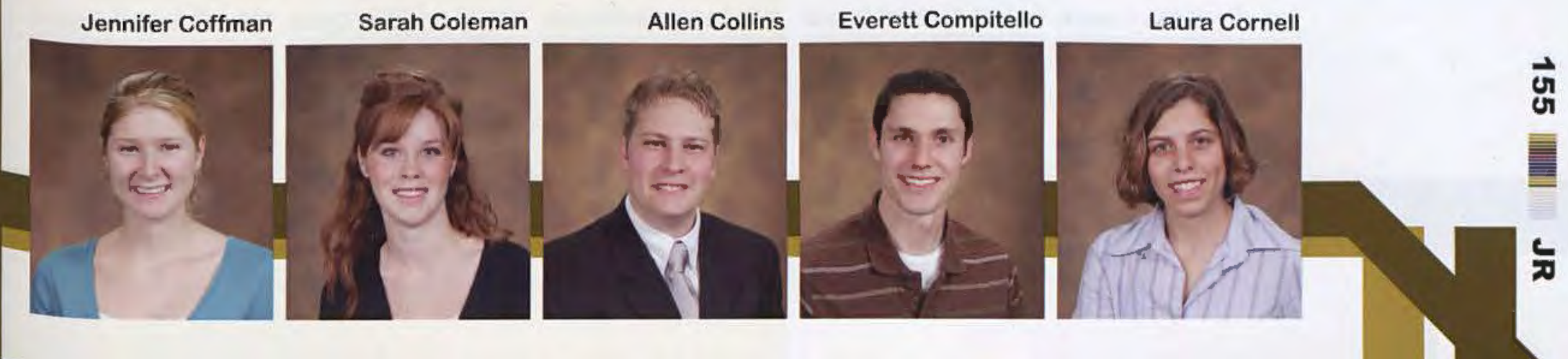

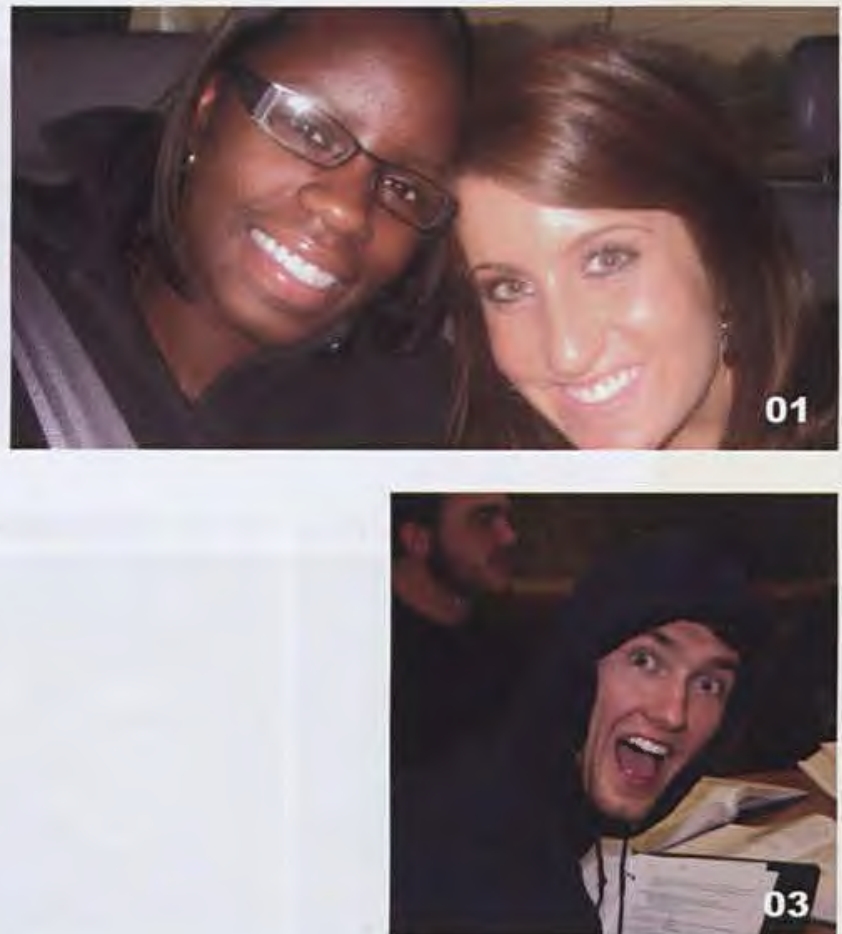

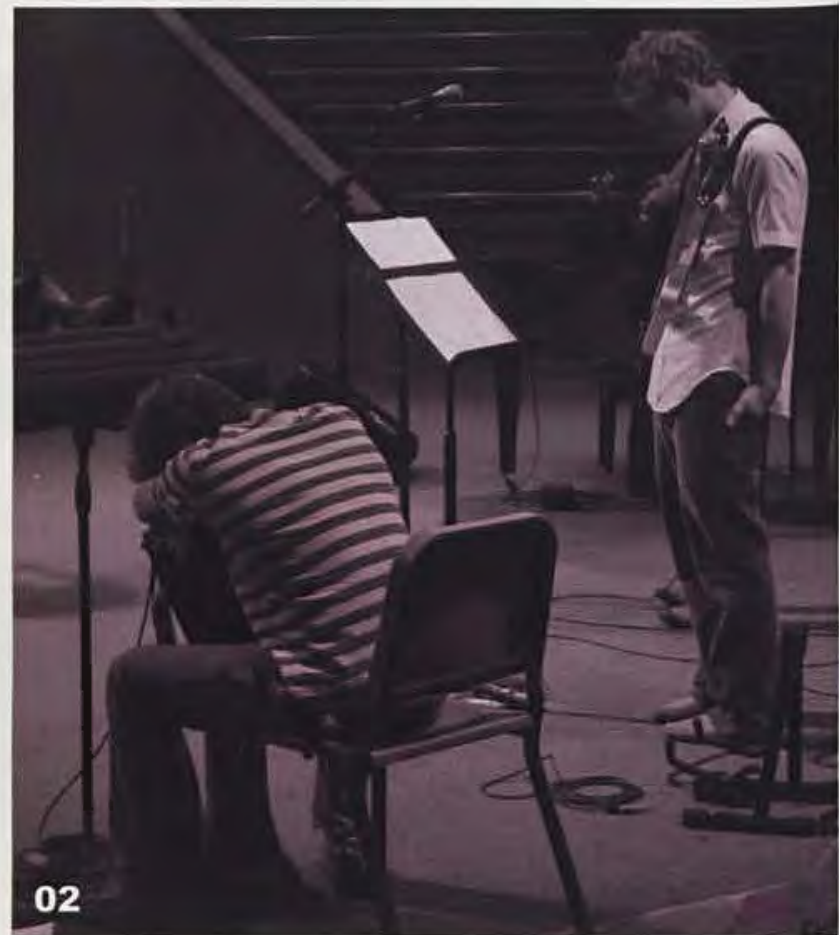

01 Tonisia Jackson and Kim Battista squeeze together in a back seat for some off-campus fun.

02 Josh Gigliotti and Nate (William) Sherwood bow for prayer while they help lead chapel.

03 Matt Fox sports typical junior attire - the hoody.

\section{"AS A FRESHMAN, CEDARVILLE SEEMED GRAND AND INTIMIDATING; SINCE THEN, I'VE MANAGED TO DEMYTHOLOGIZE OUR SCHOOL, BUT NOW IT'S HOME."} _ISAAC MAYEUX
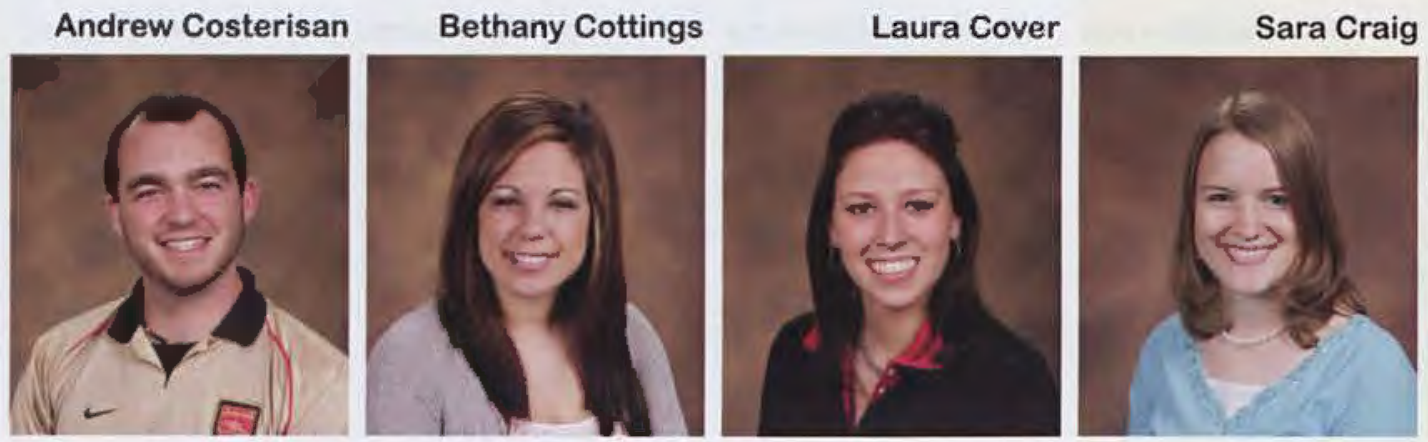

Sarah Crichlow

Lisa Crowder

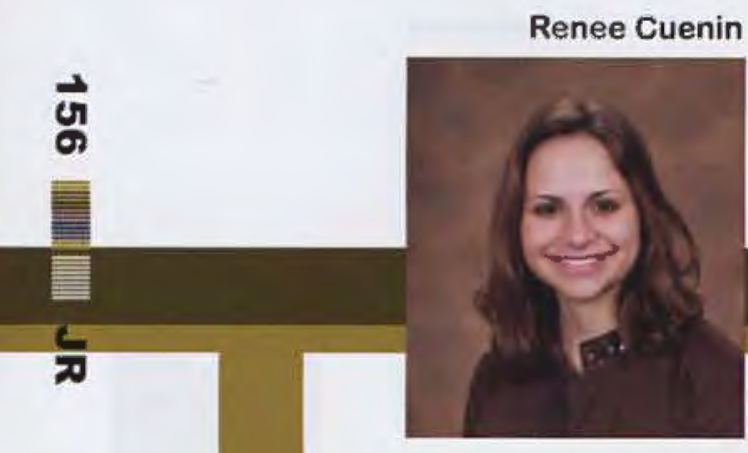

Jenna Culver
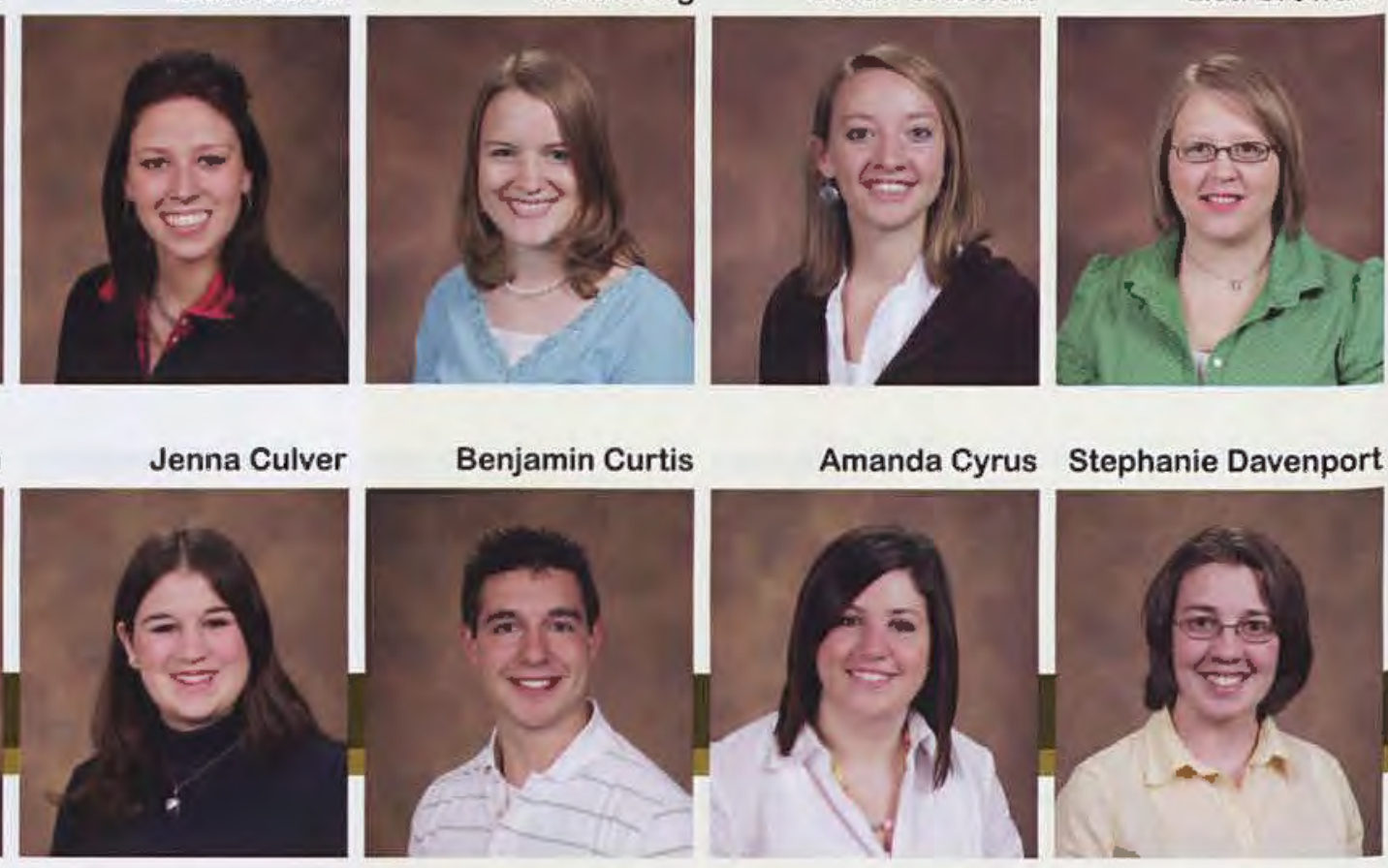

Amanda Cyrus

Stephanie Davenport 

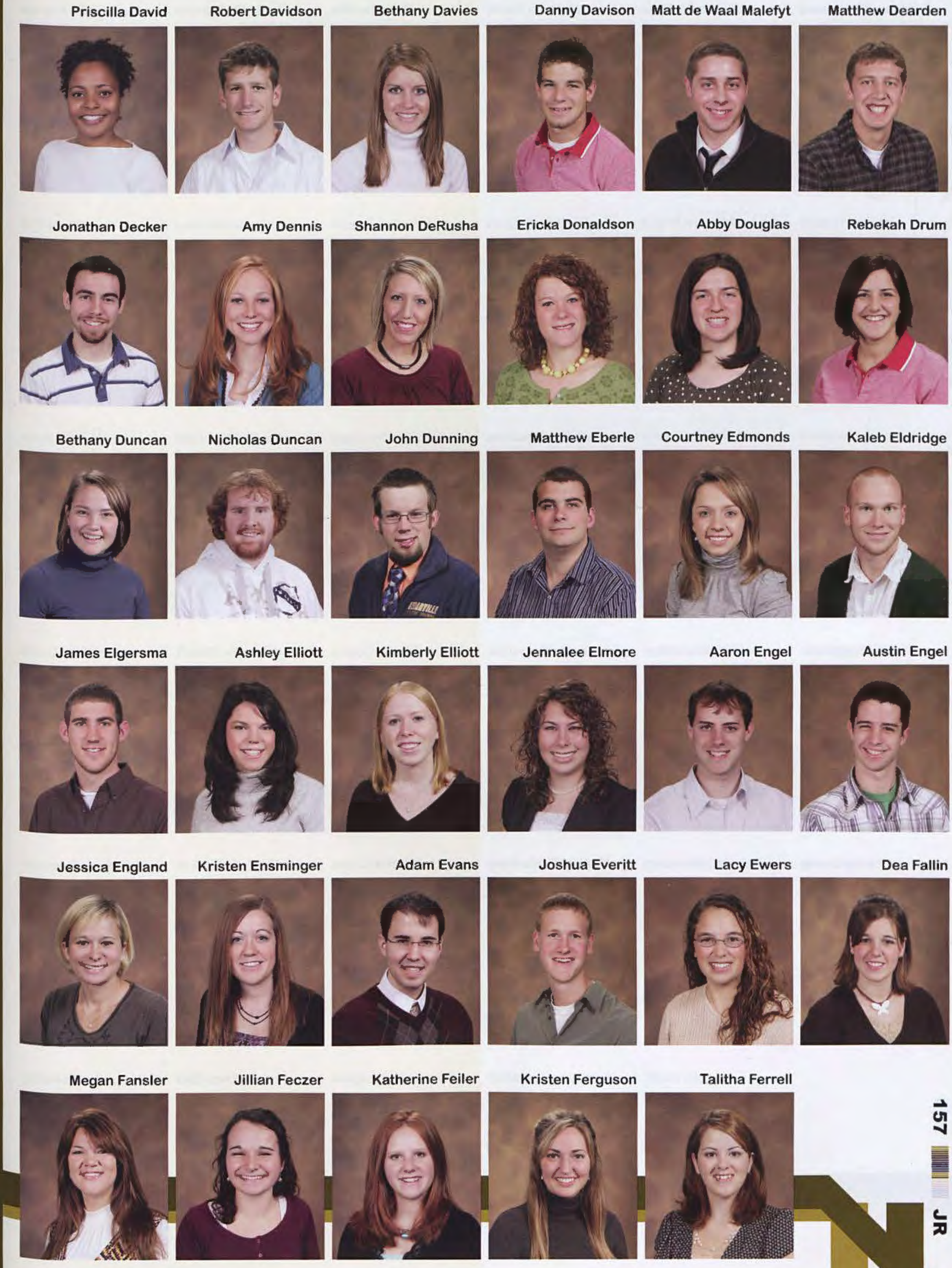

Talitha Ferrell 

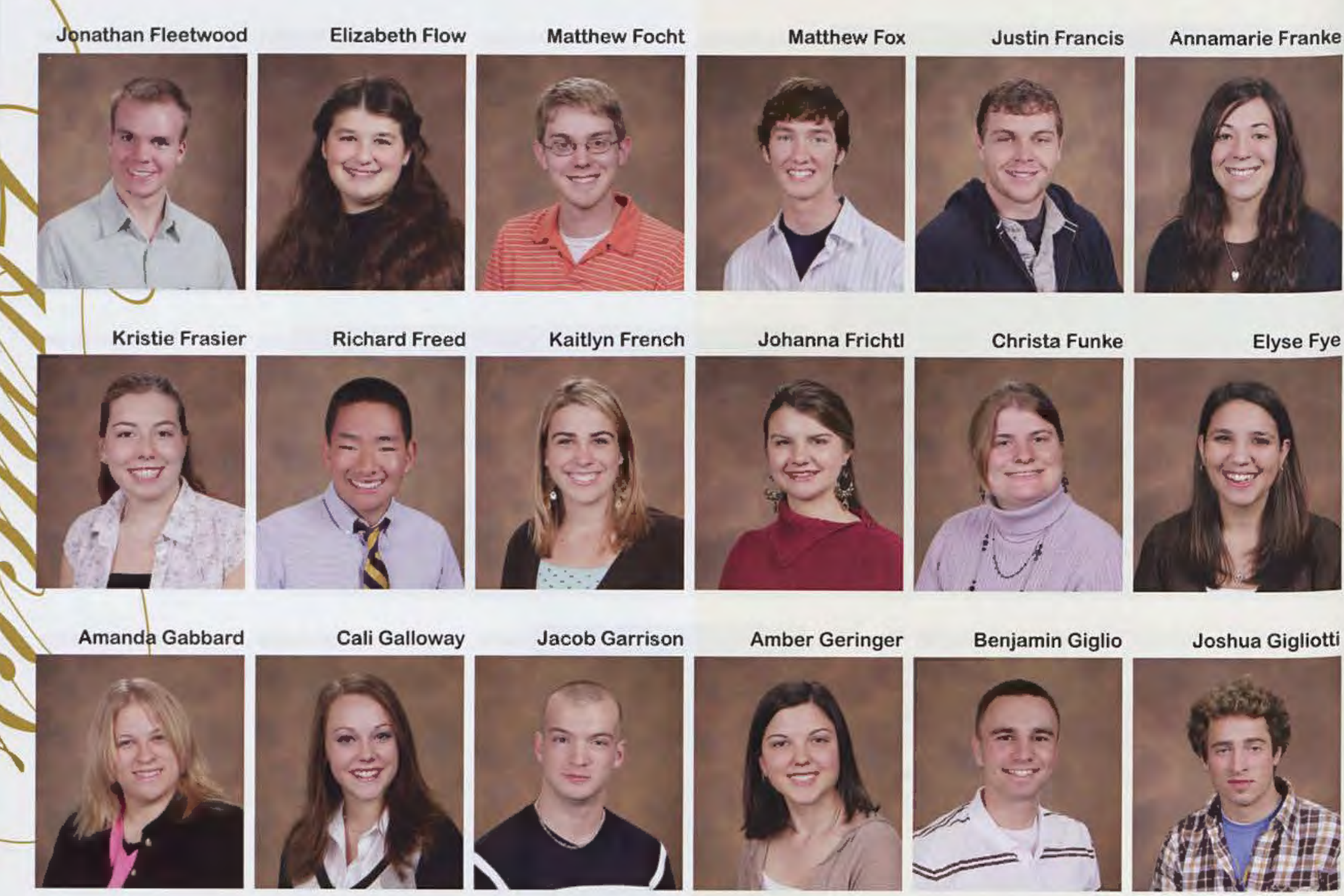

Joshua Gigliotti
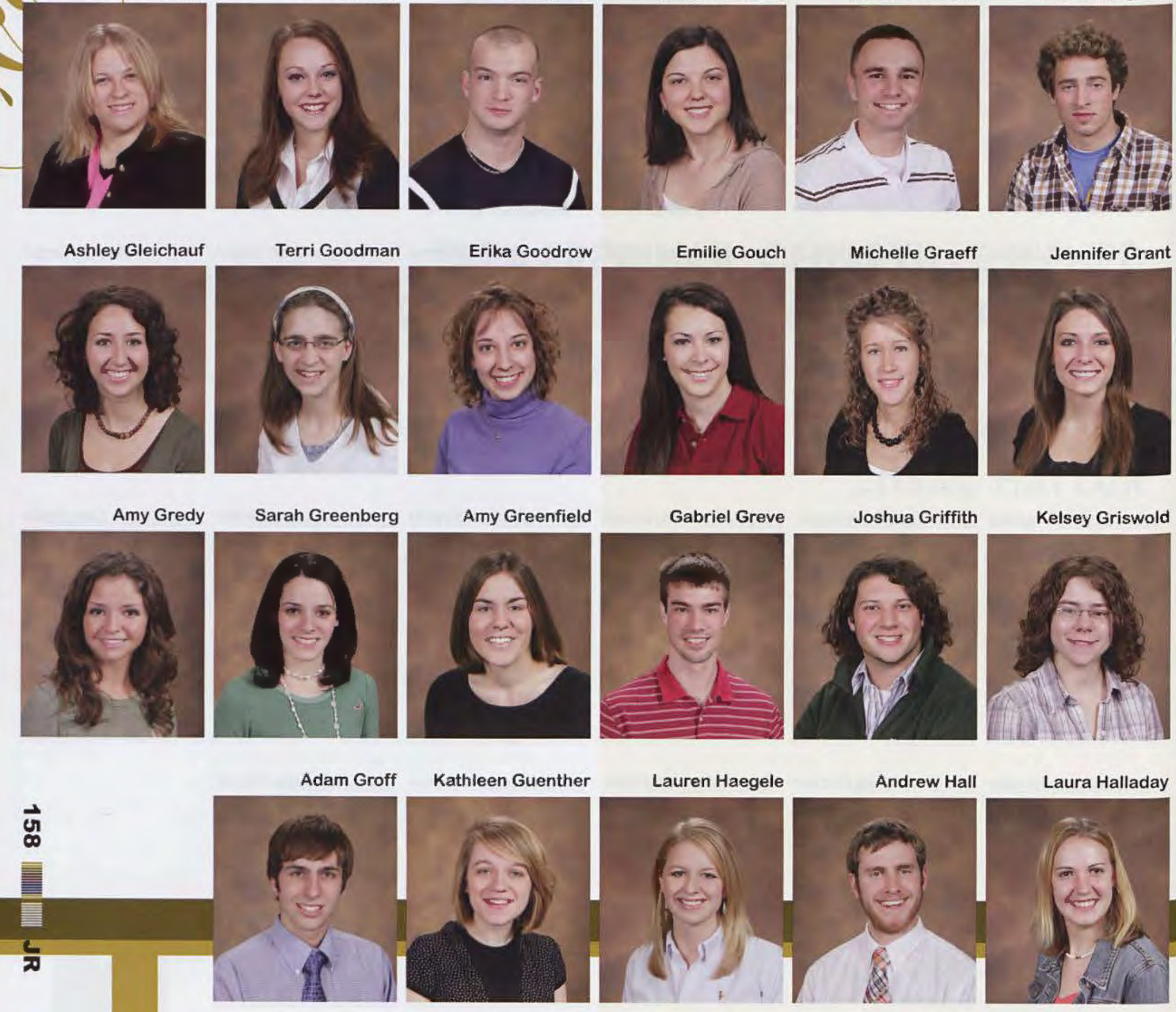

Laura Halladay

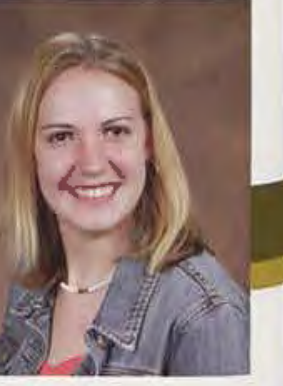



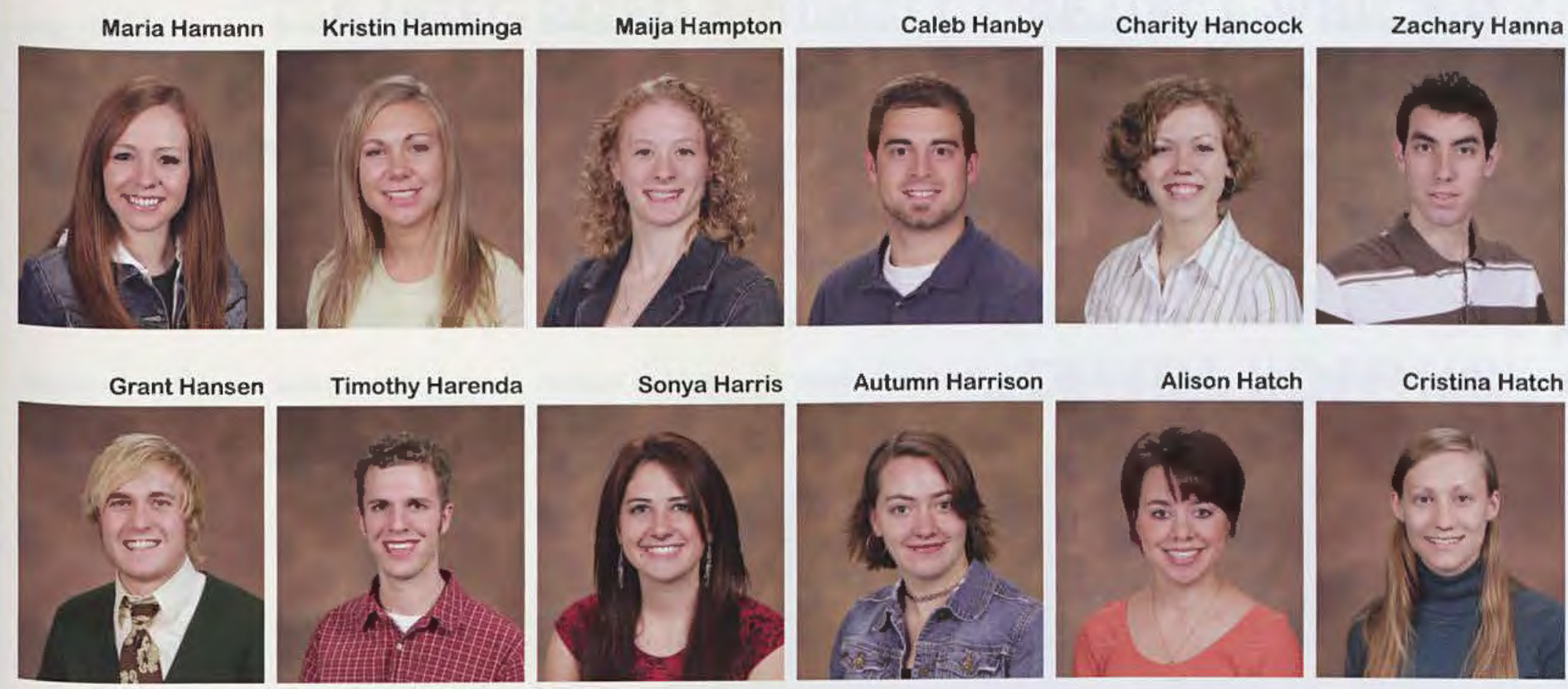

Alison Hatch

Cristina Hatch
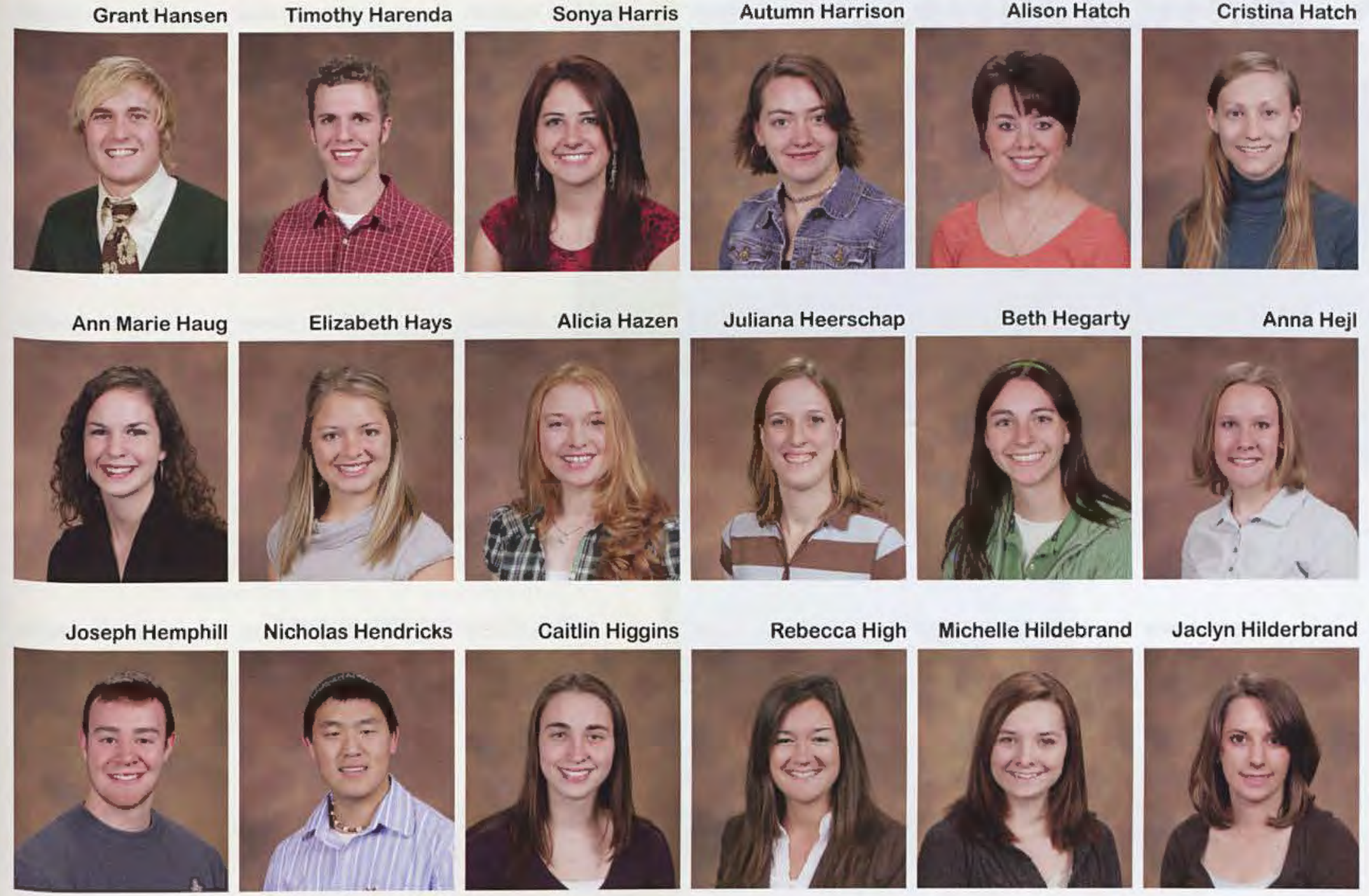

Anna Hejl
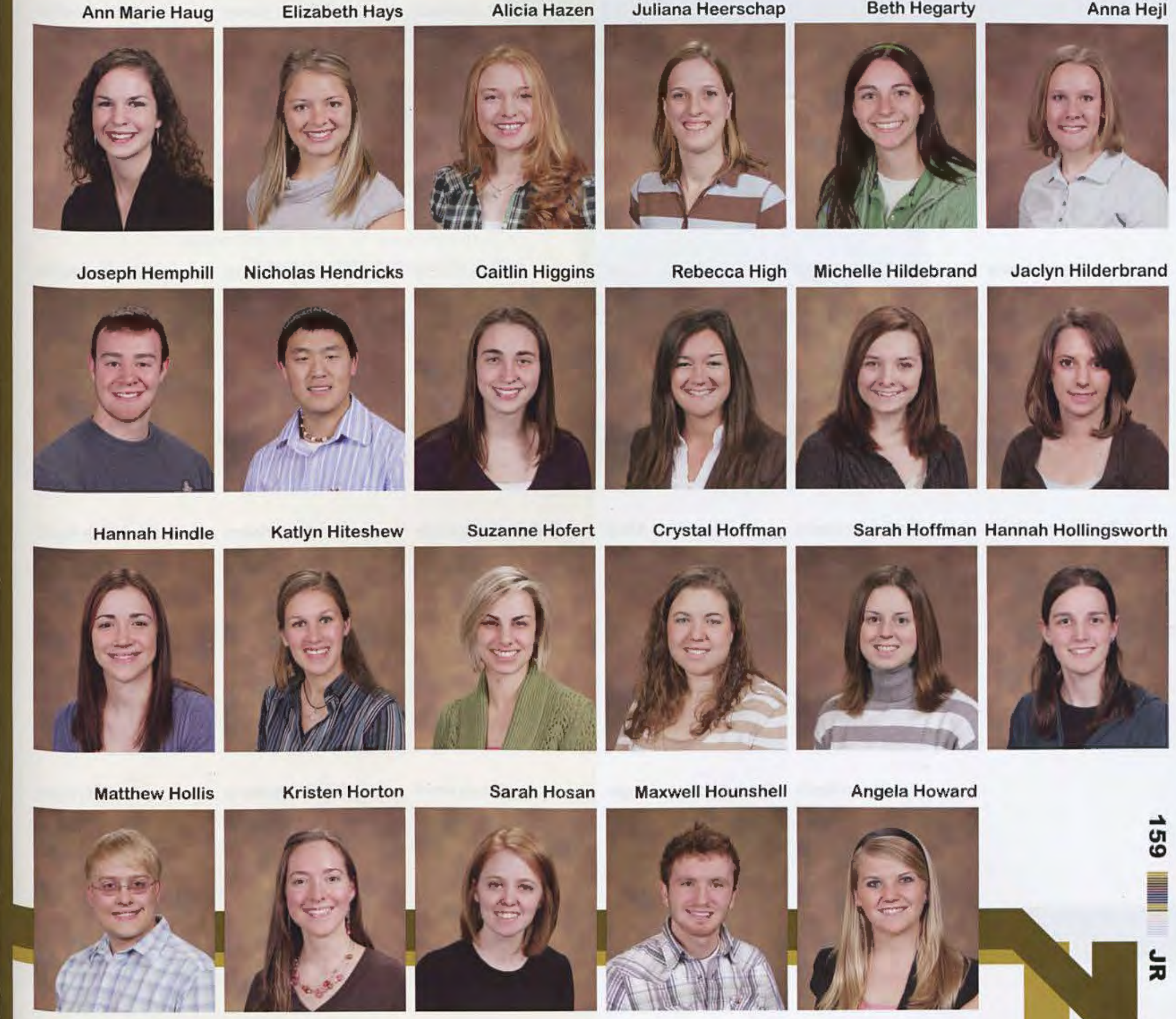

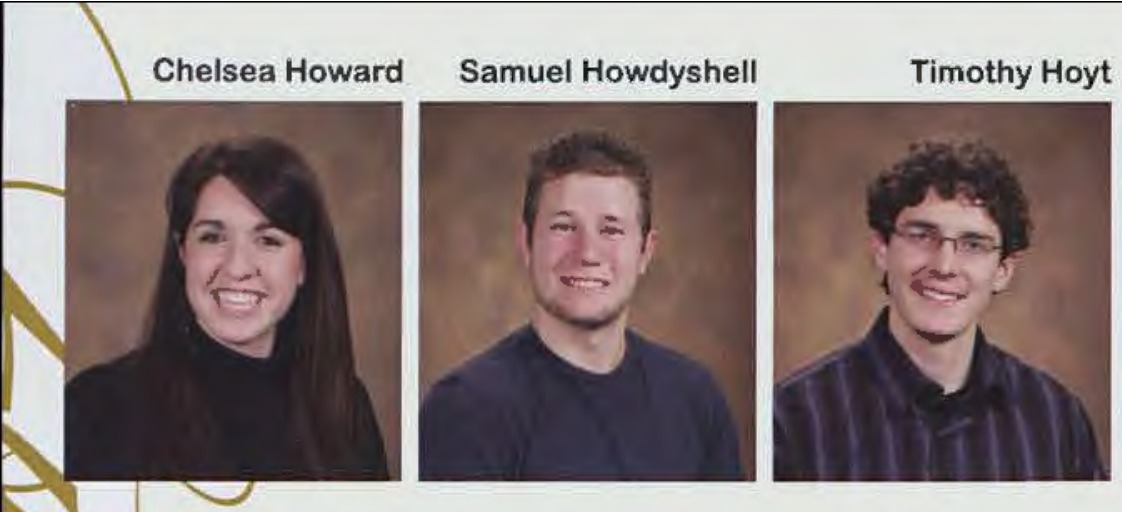

Aaron Ikehara
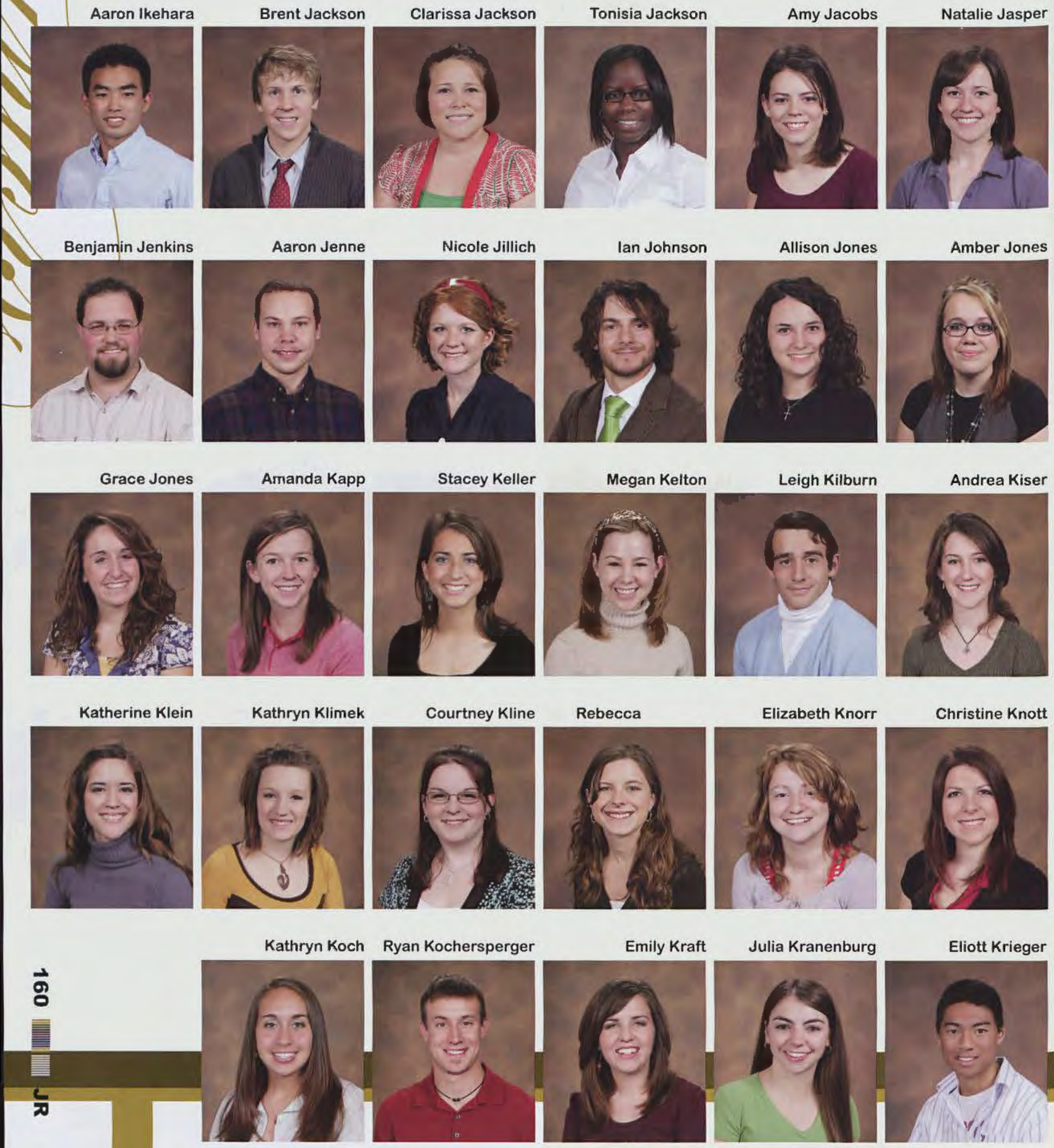

Emily Kraft

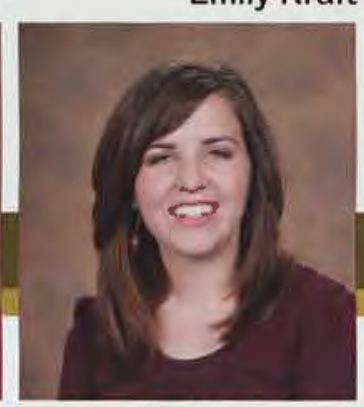

Julia Kranenburg

Eliott Krieger
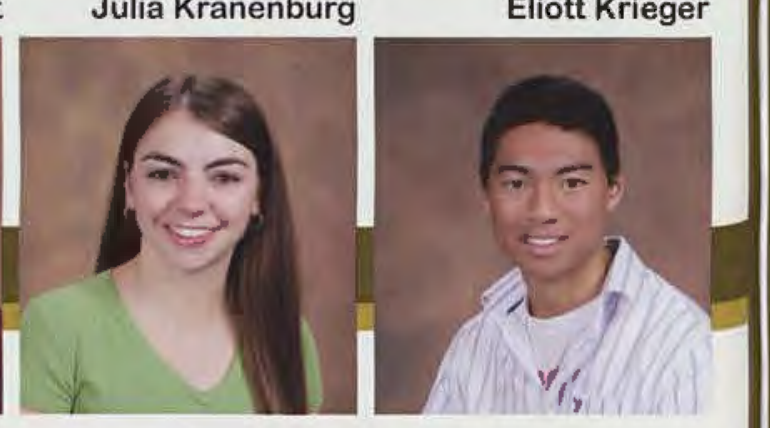
"THE INTEGRATED BUSINESS CORE (IBC), WHICH IS OFFERED TO JUNIOR BUSINESS MAJORS, HAS ALLOWED ME NOT ONLY TO LEARN A GREAT DEAL ABOUT STARTING AND OPERATING A BUSINESS, BUT ALSO TO MAKE TRULY SOME AMAZING 'FRIENDS FOR LIFE."'
-CRYSTAL HOFFMAN

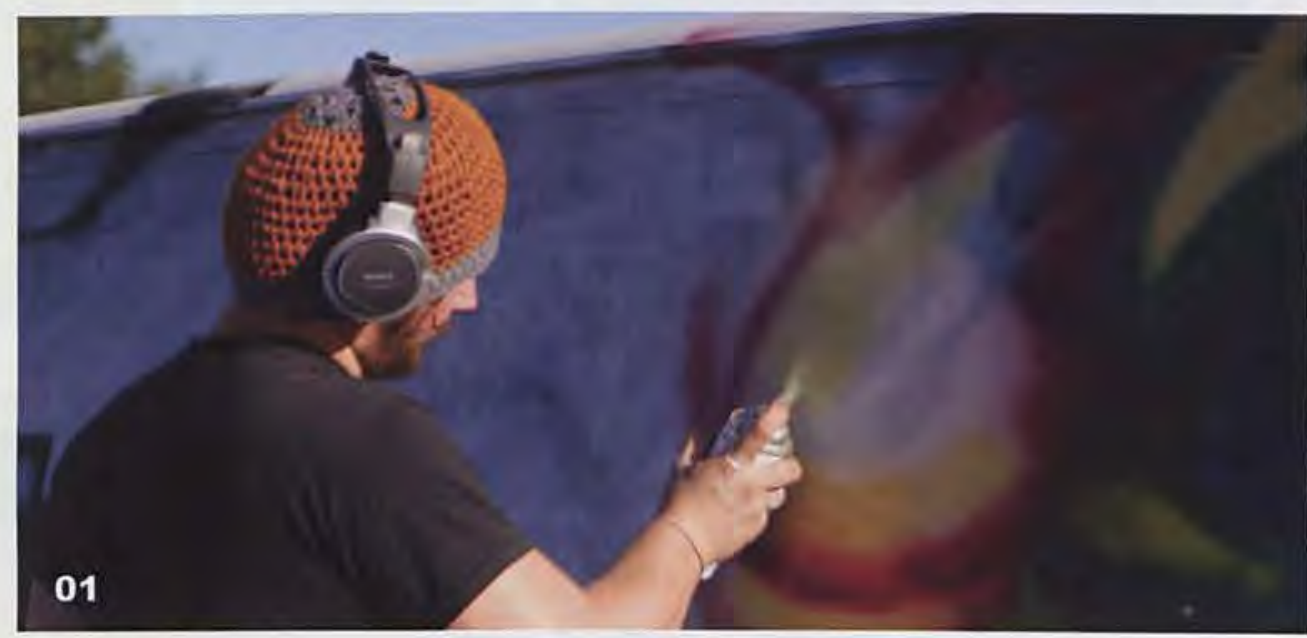

The juniors aren't lacking 01 in thieir artistic talent. Jeremy Steckel and Sonya Harris spend 02 some time in front of the computer, a favorite pastime of students.
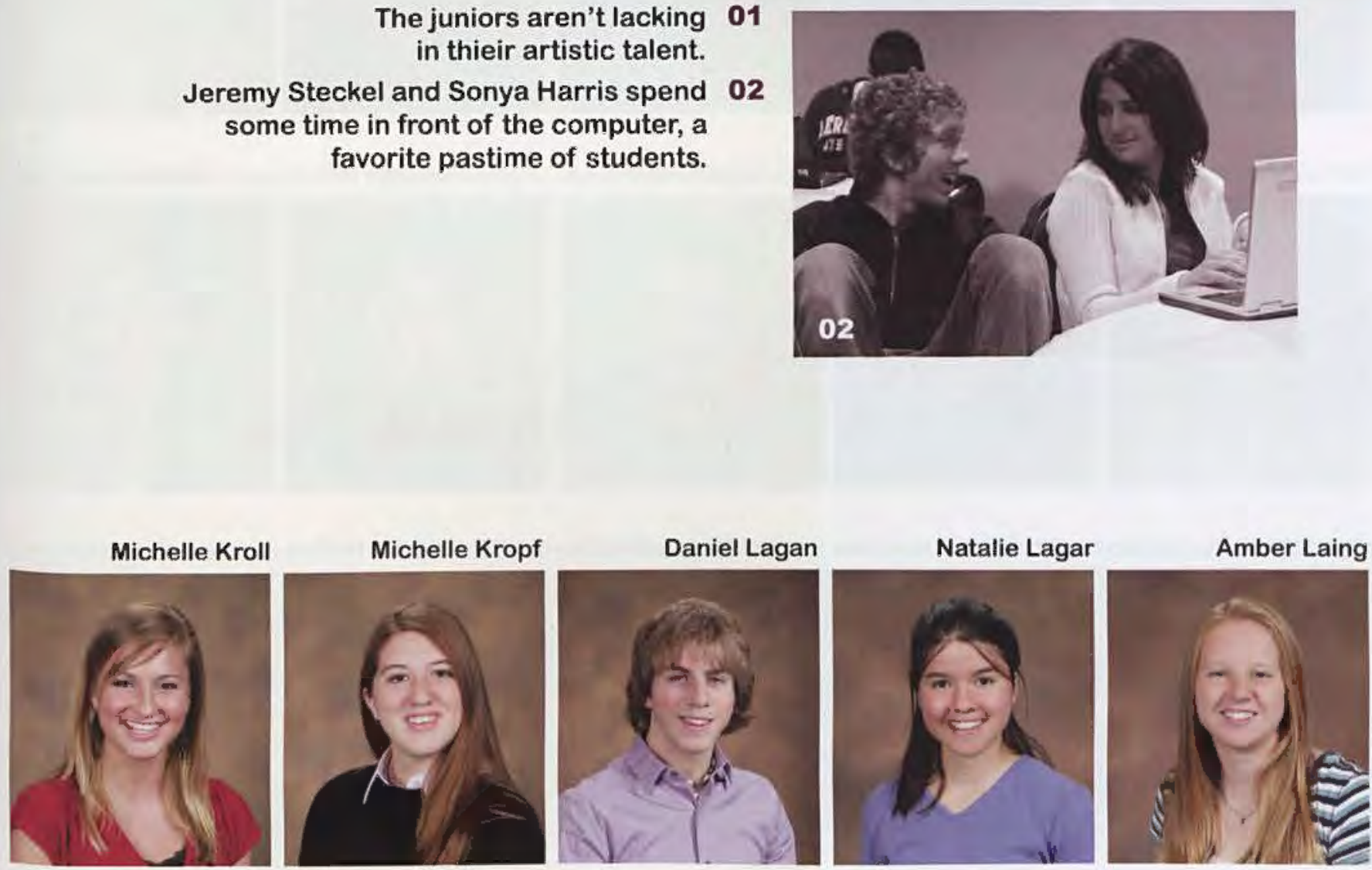

Sandra Larsen Ashleigh Laswell Weslea Law Joel Lawrence Jesse Lear
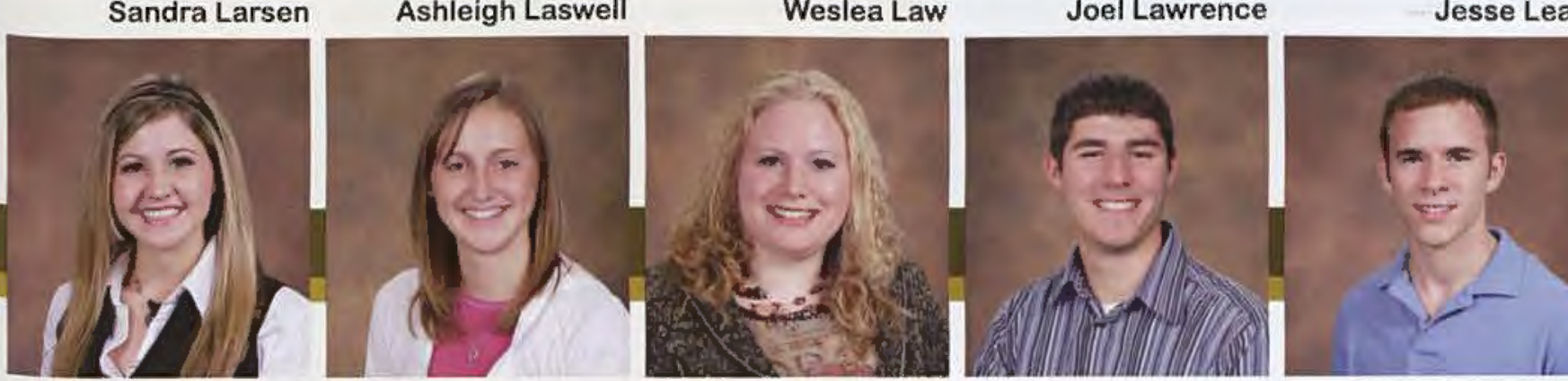

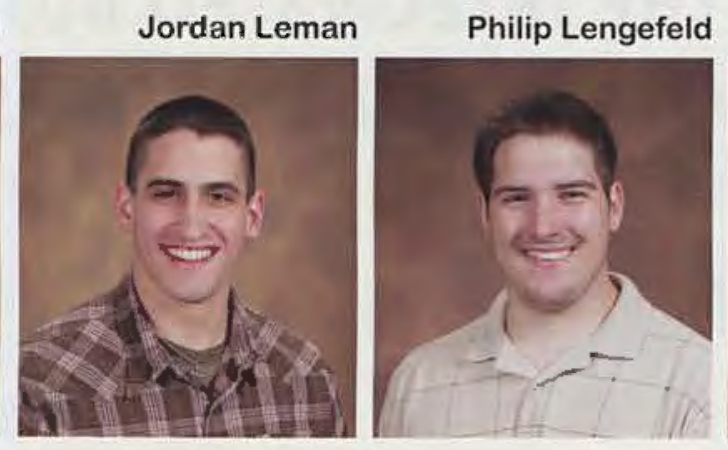

Christina Leonard
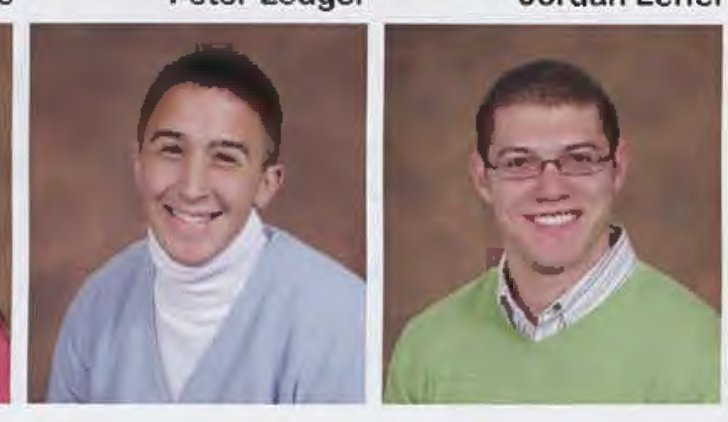

Kyle Linden

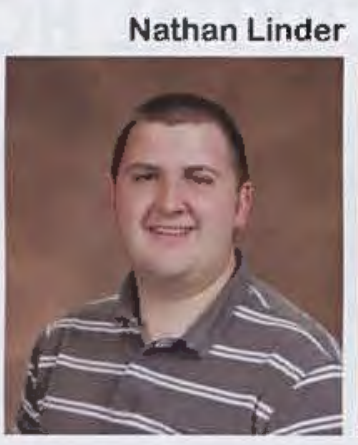

Kara Lindemann

Jordan Link
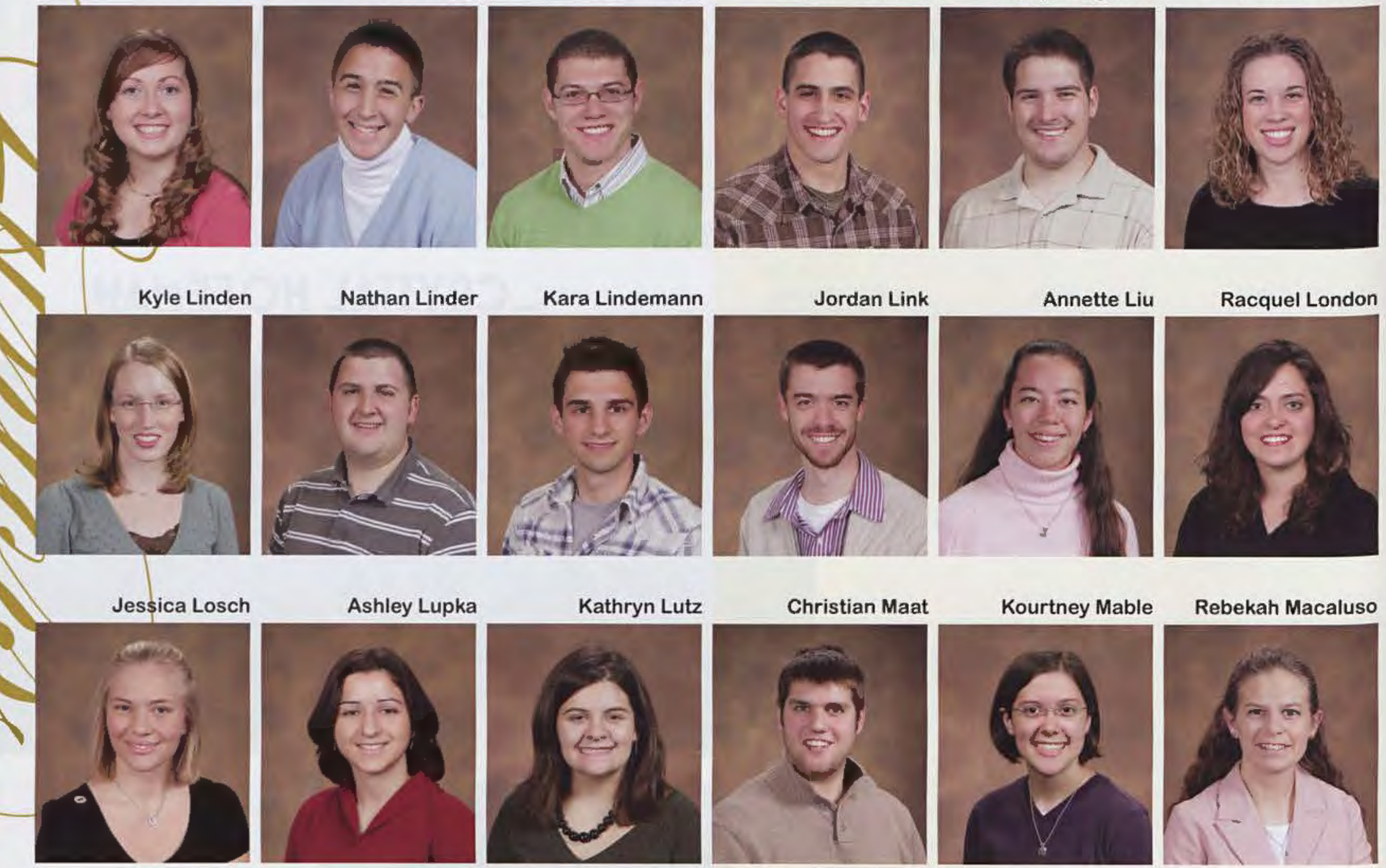

Racquel London
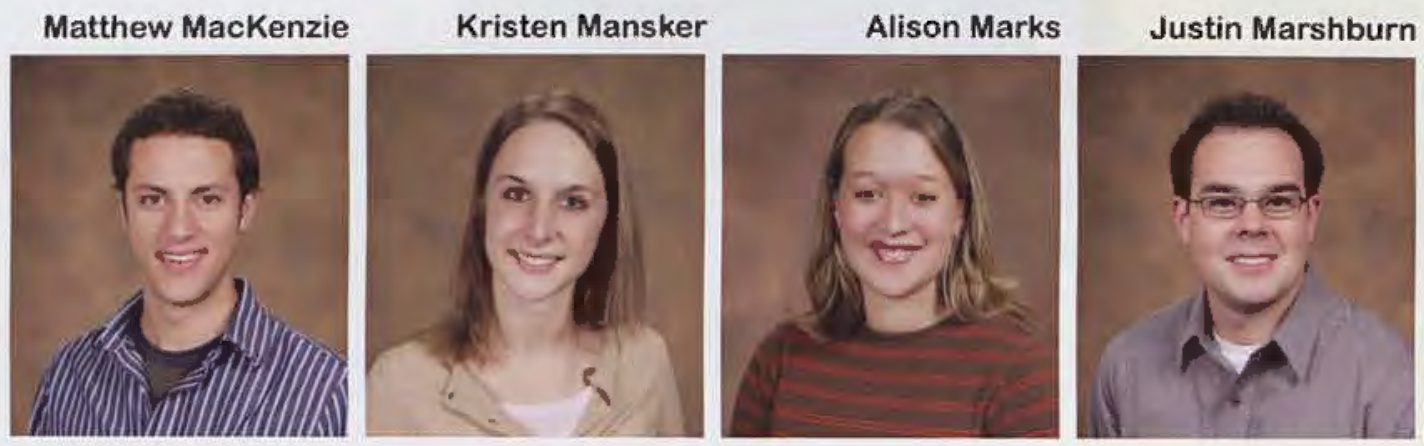

Amanda Martin
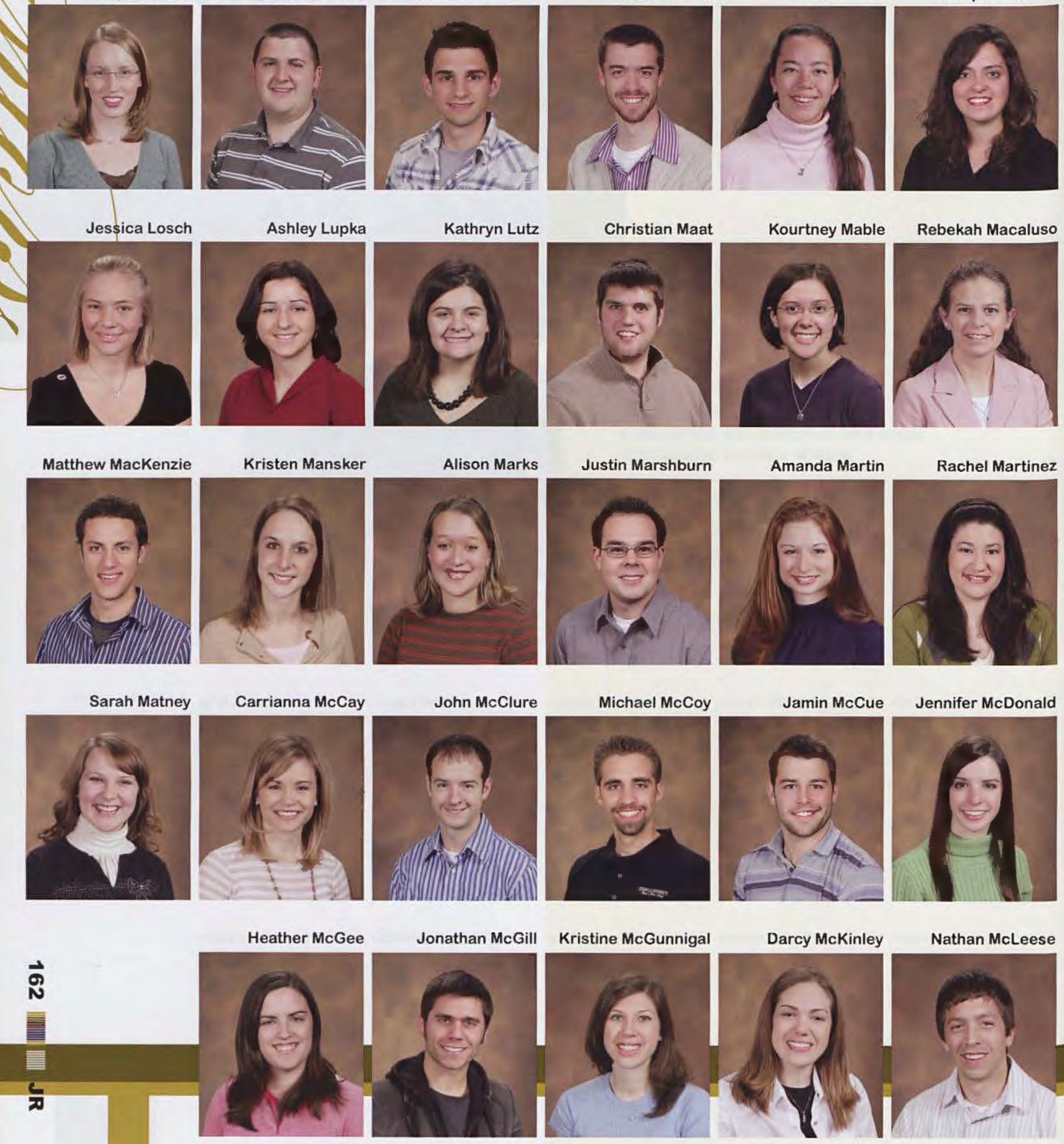

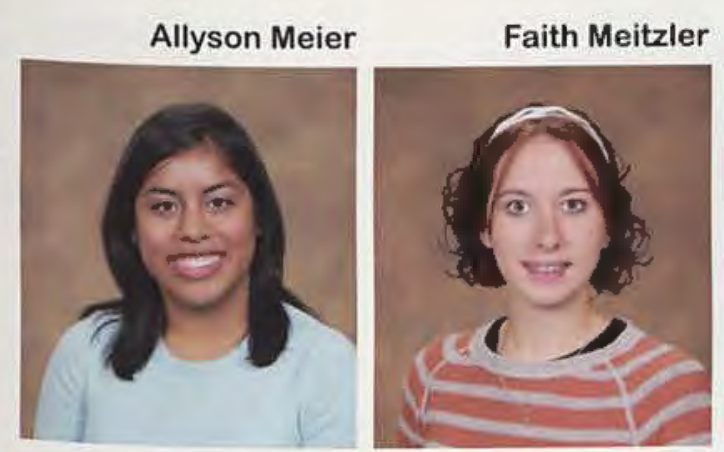

Angeline Melendez

Lynn Mellum

Kena Mena

Megan Mertus
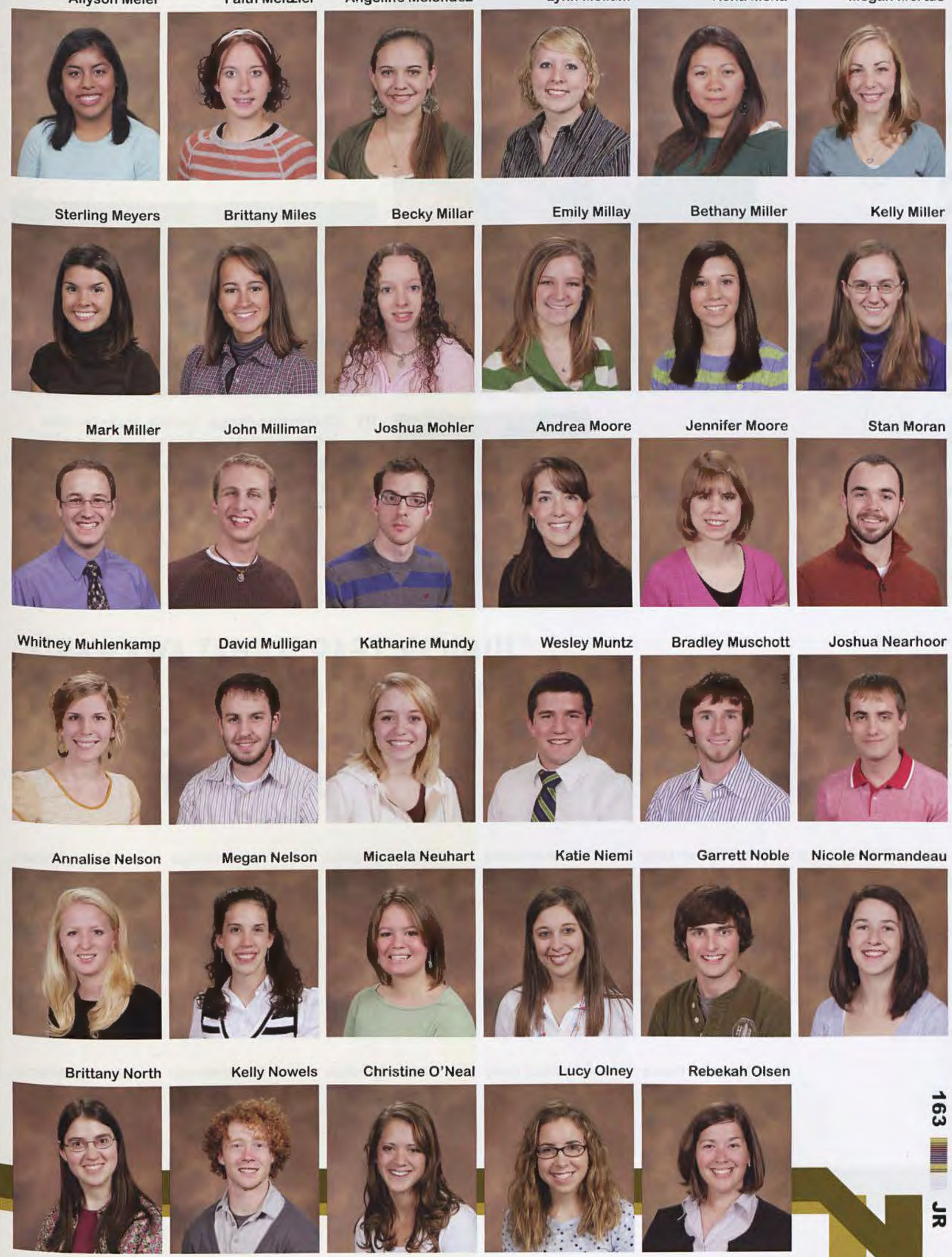

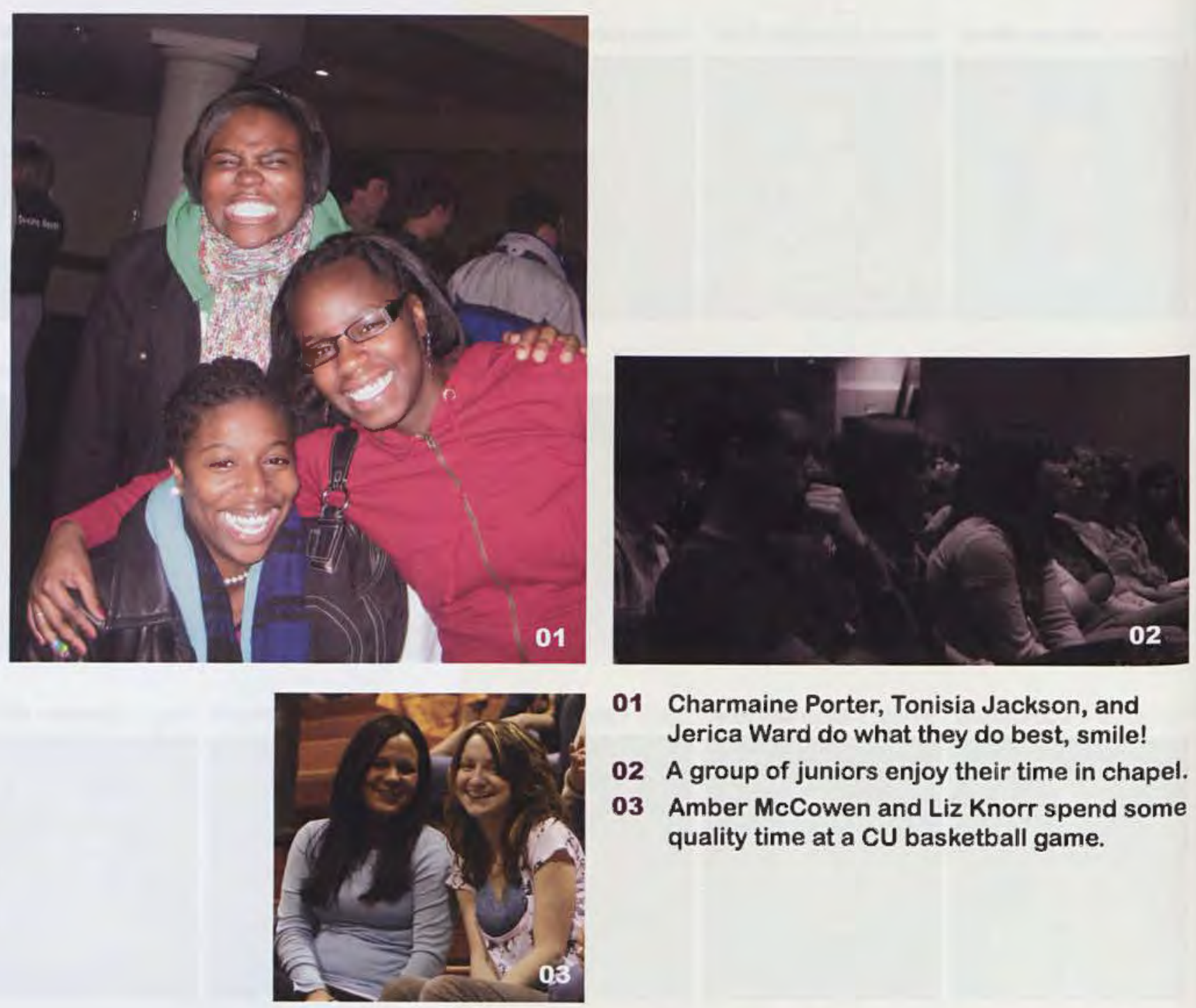

01 Charmaine Porter, Tonisia Jackson, and Jerica Ward do what they do best, smile!

02 A group of juniors enjoy their time in chapel.

03 Amber McCowen and Liz Knorr spend some quality time at a CU basketball game.

\section{"JUNIOR YEAR IS THAT AWKWARD TIME BETWEEN LIVING ON THE HILL AND LIVING OFF CAMPUS!" _DUSTIN WINCHESTER}
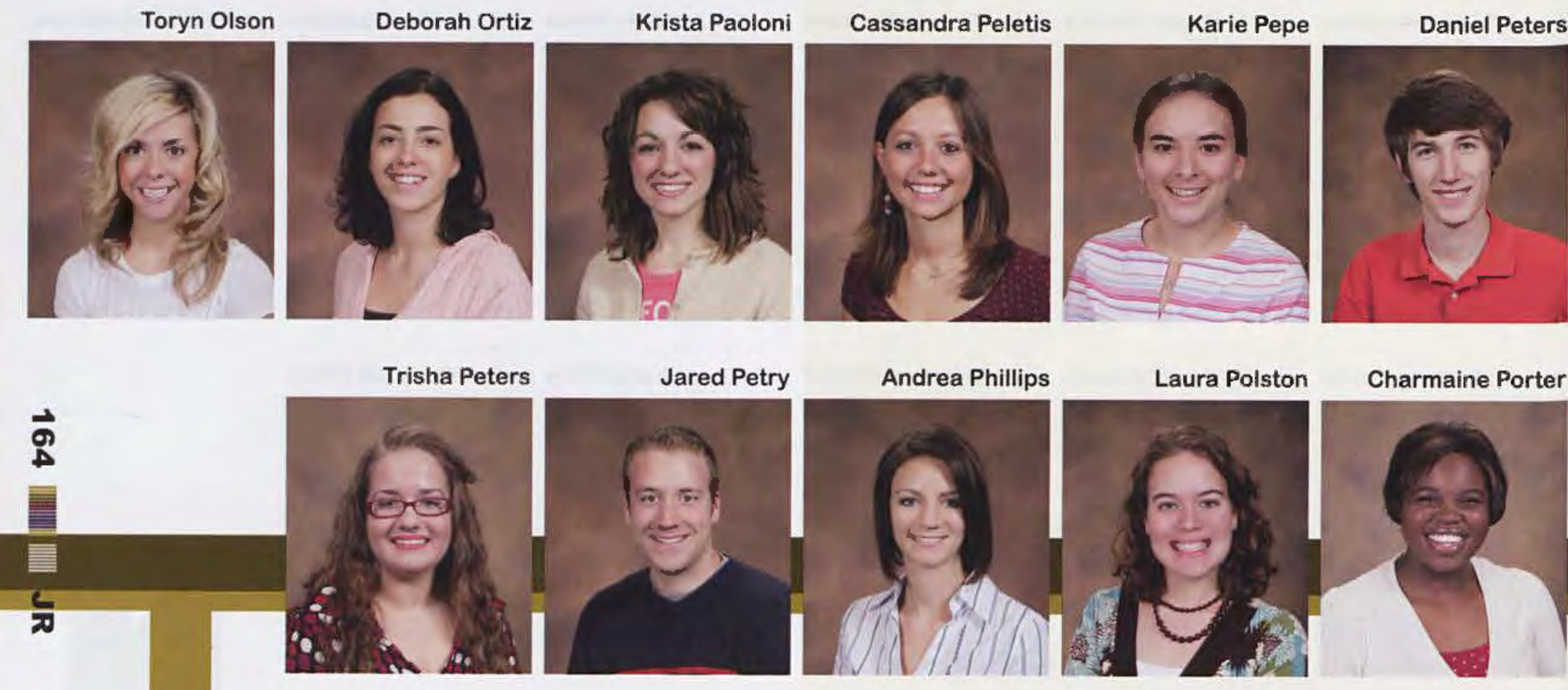

Andrea Phillips

Laura Polston

Charmaine Porter
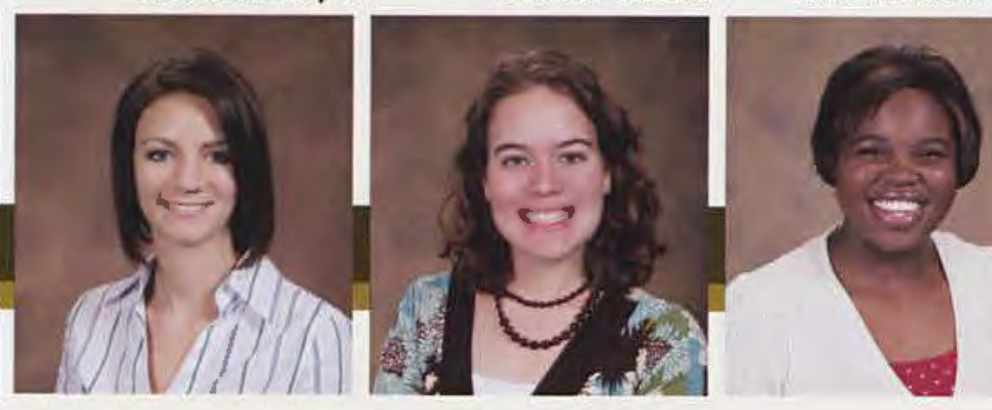

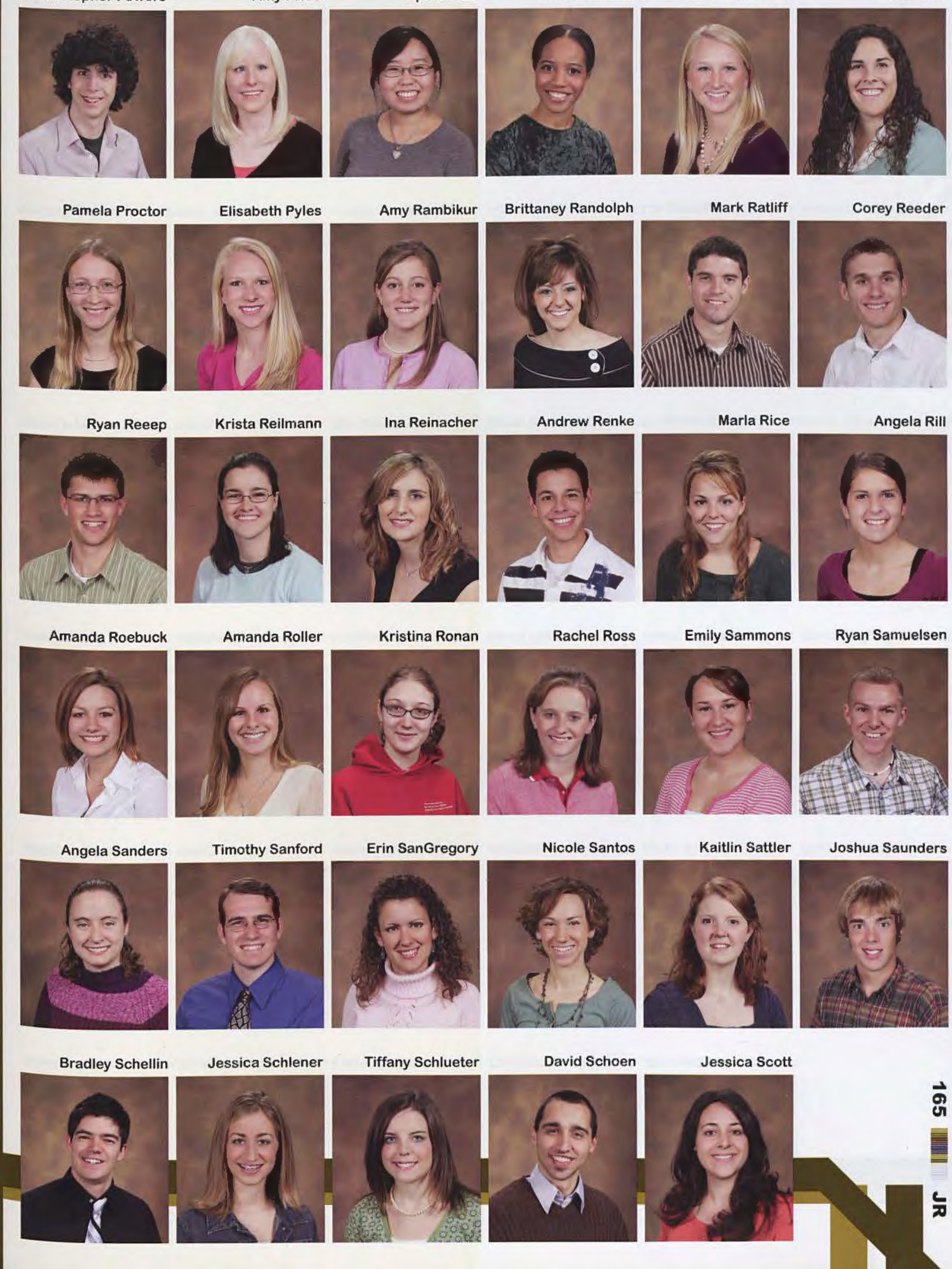

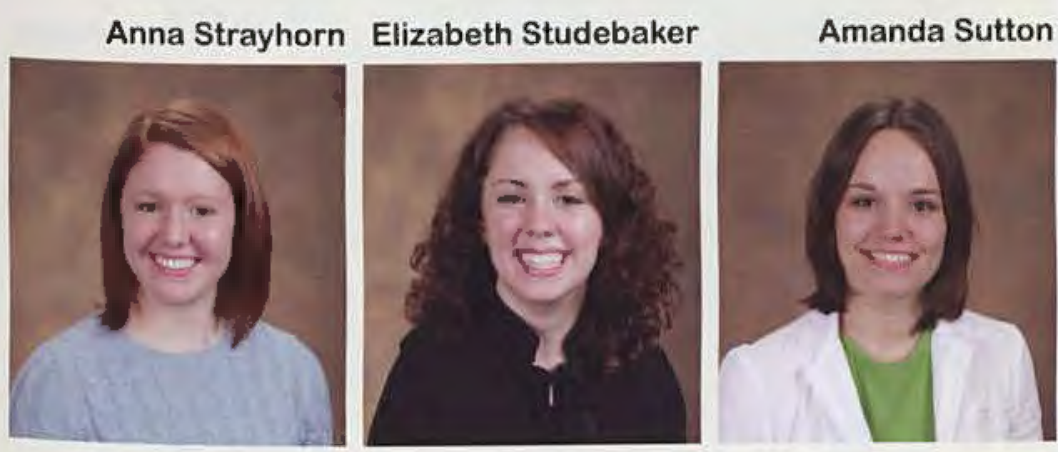

Caleb Svendsen
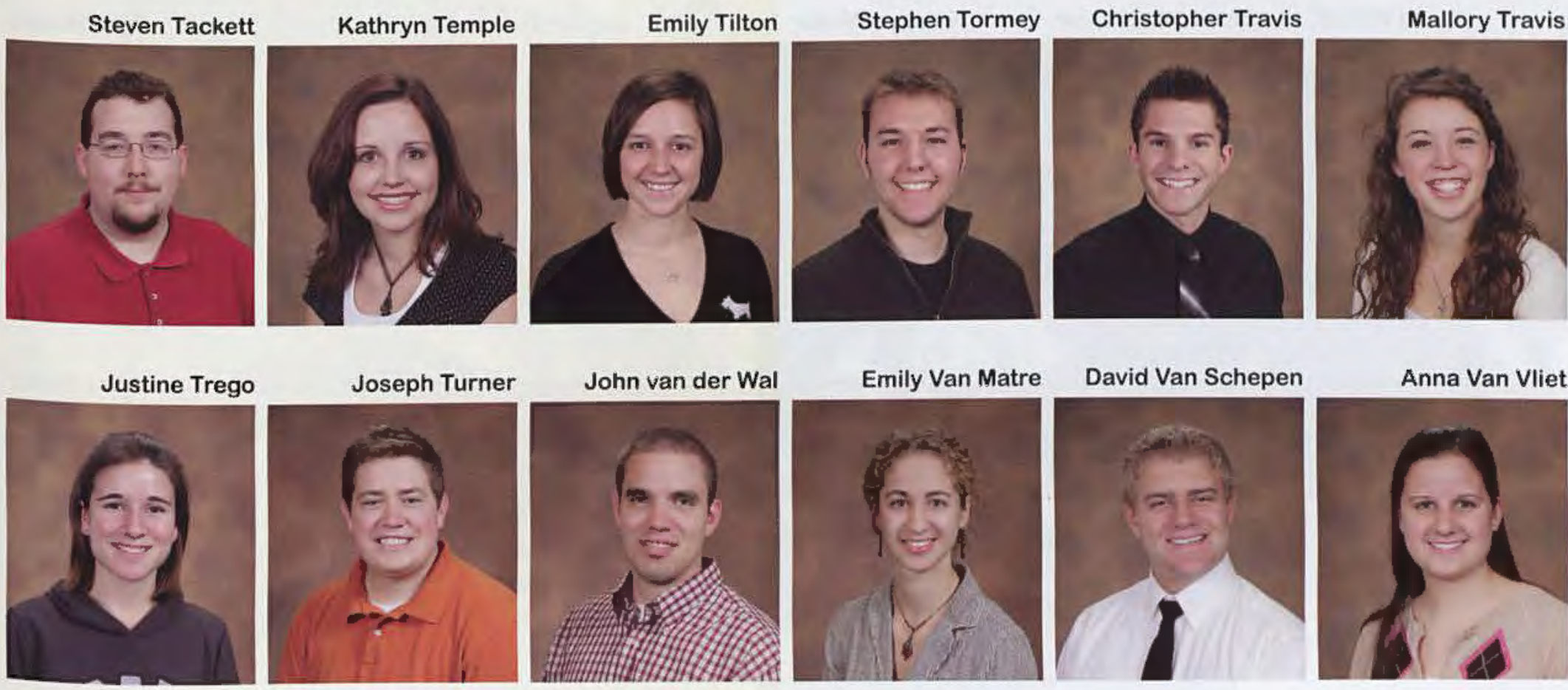

Anna Van Vliet
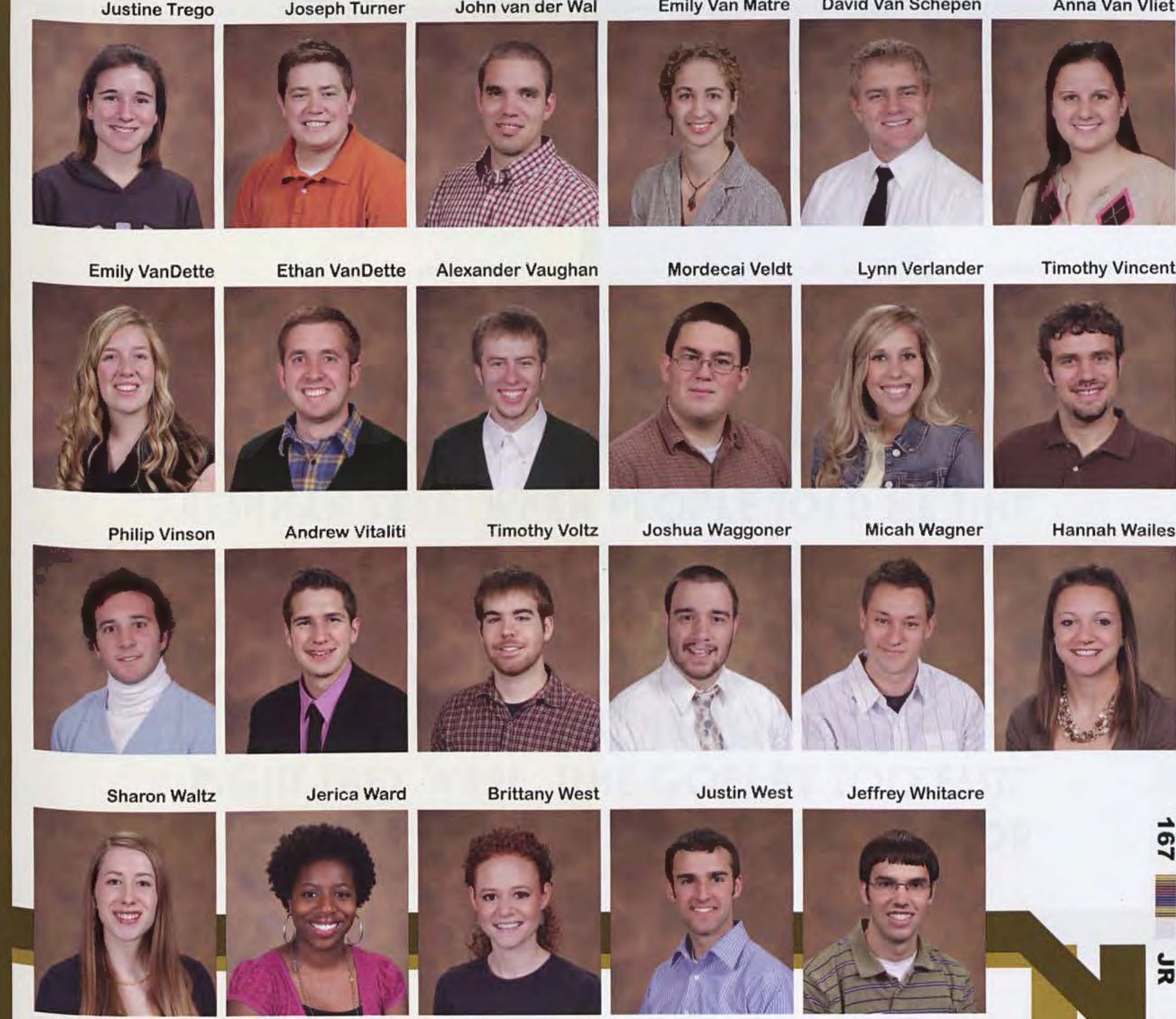

Brittany West

Justin West

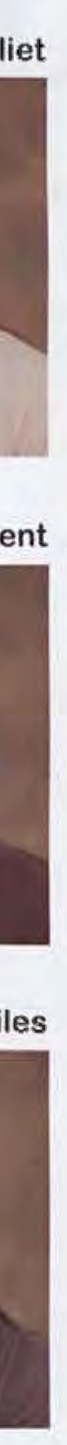



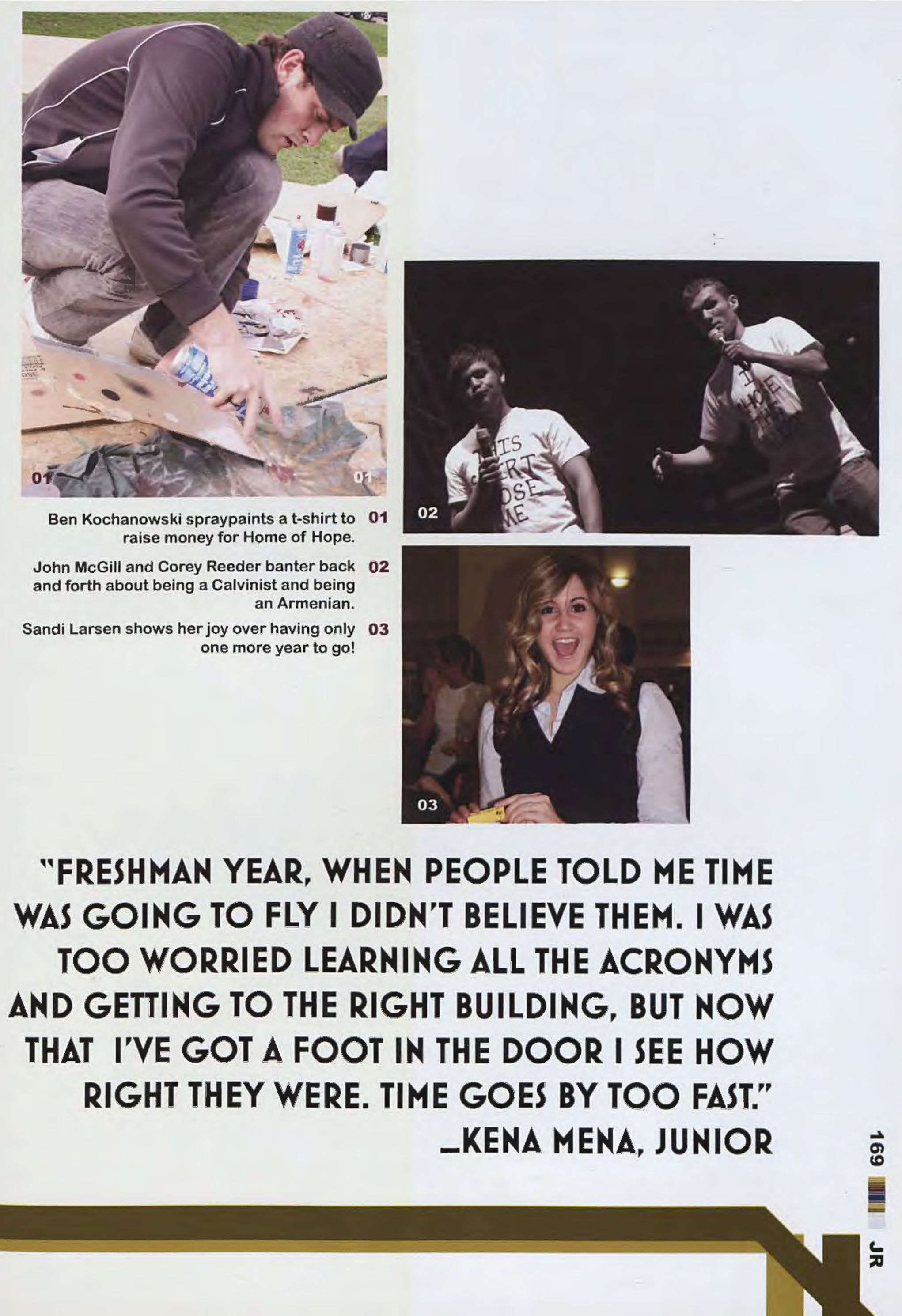
"ANACTIVE MIND

CANNOTEXISTIN AN

NACTVE BODY"

GEN. PATTON 


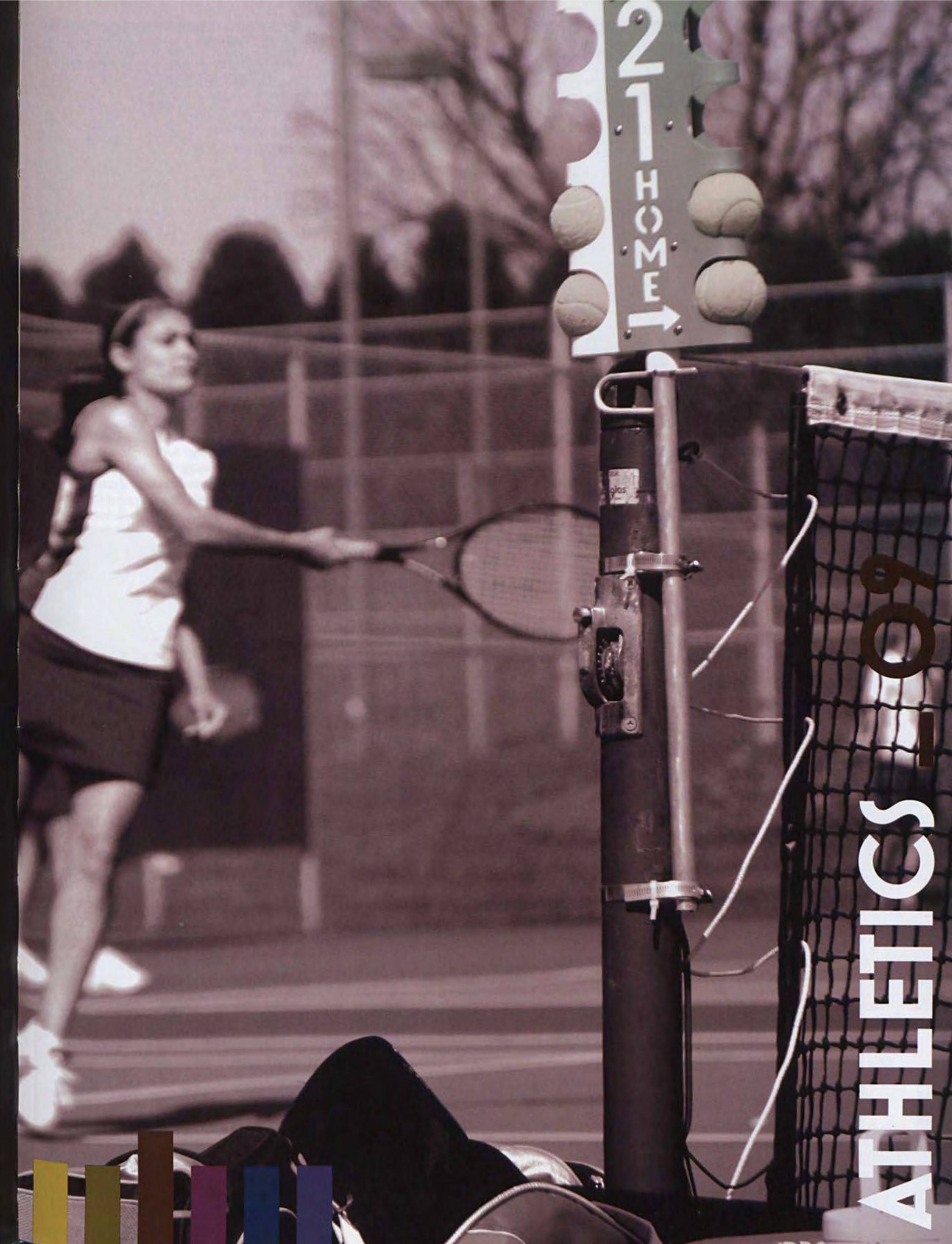


"IT'S BEEN A GREAT FOUR YEARS, AND THE BOYS HAVE MADE IT ALL WORTHWHILE. THEY HAVE TAUGHT ME THINGS THAT I COULD NEVER HAVE LEARNED INSIDE THE CLASSROOM."

\author{
- KEN DAVIS, SENIOR
}

\section{"OUR TEAM IS HOT, AND THEY SHOWED IT ON} THE FIELD."

- GRACE KOHL, FRESHMAN "...the soccer brotherhood has been one of my greatest experiences here at Cedarville. Some of my favorite moments from the season would be watching Tim Green do his various celebrations and fist pumps, along with Cobucci and his cardboard box in the locker room." (Tyler Scott, junior)

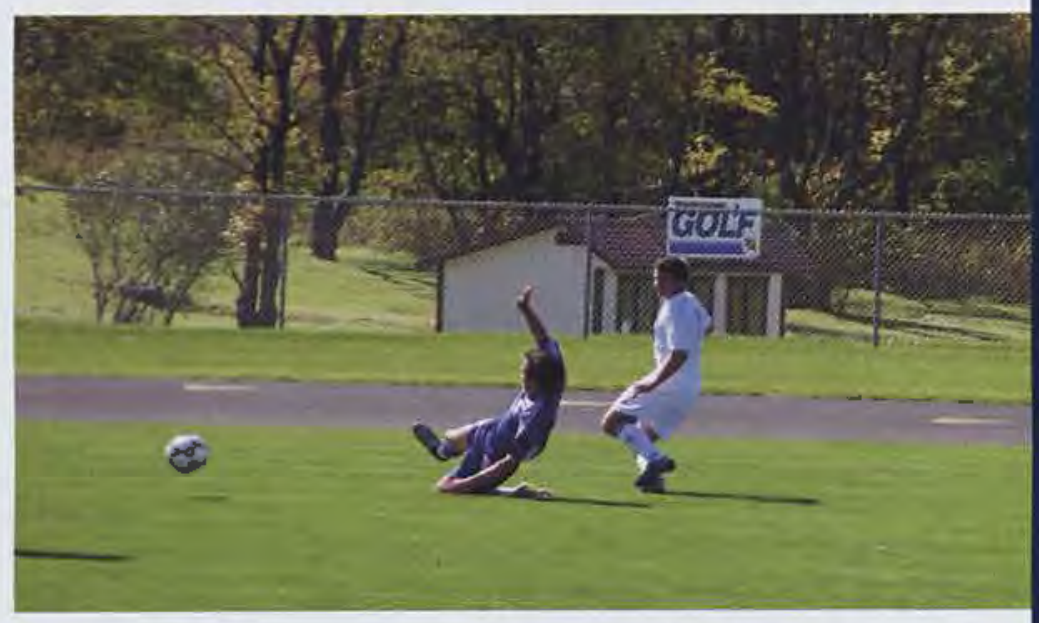

"One of my most meaningful memories from this year was the opportunity our whole team had to share our testimonies with each other on a trip to Indiana. It was a great encouragement, can't be experienced on the soccer field."

(Ryan Chaney, sophomore) and I think it really helped our team grow together in a way that

"One of my favorite parts about the soccer season is the long bus trips that we take. We have a team vote to pick a movie to watch, and all of us guys in the back of

the bus always yell "Anarchy!" until they finally put in the movie that we want to watch." (Ryan Lustig, junior)

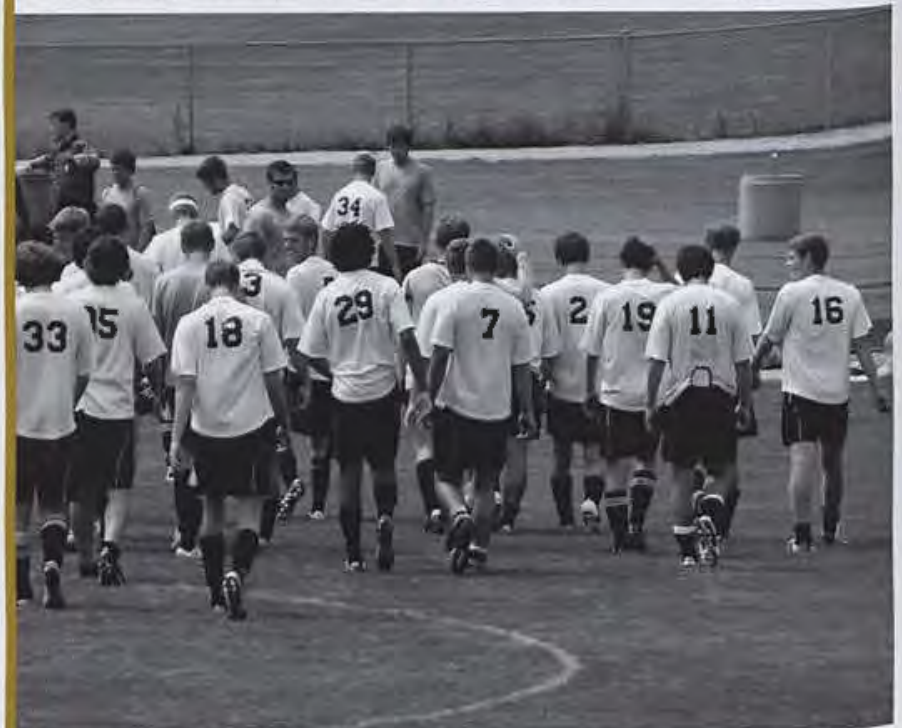

"I saw amazing effort this year. Although every game wasn't a win, they were still enjoyable to watch.

The Jackets fought to the end on every game. They always walked off the field with good Christian sportsmanship." (JoyAnna McBride, sophomore)

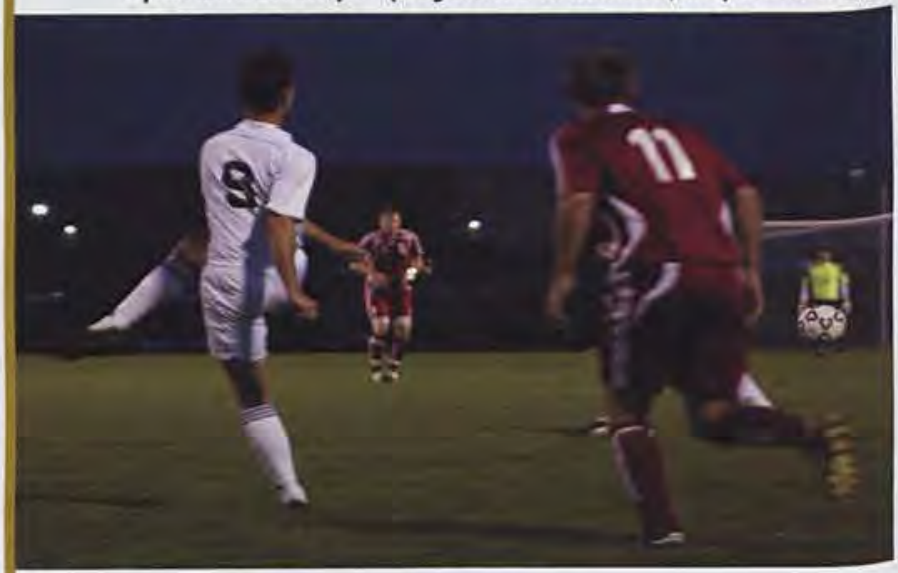

"Our goalie, Jon Norton, kept us in some close games this year. Also, Luke Griffiths and Ryan Chaney were two sophomore defenders that really stepped it up. As defenders they don't get much on the stats sheet, but they were always solid on the back line."

(Joshua Gelser, senior)
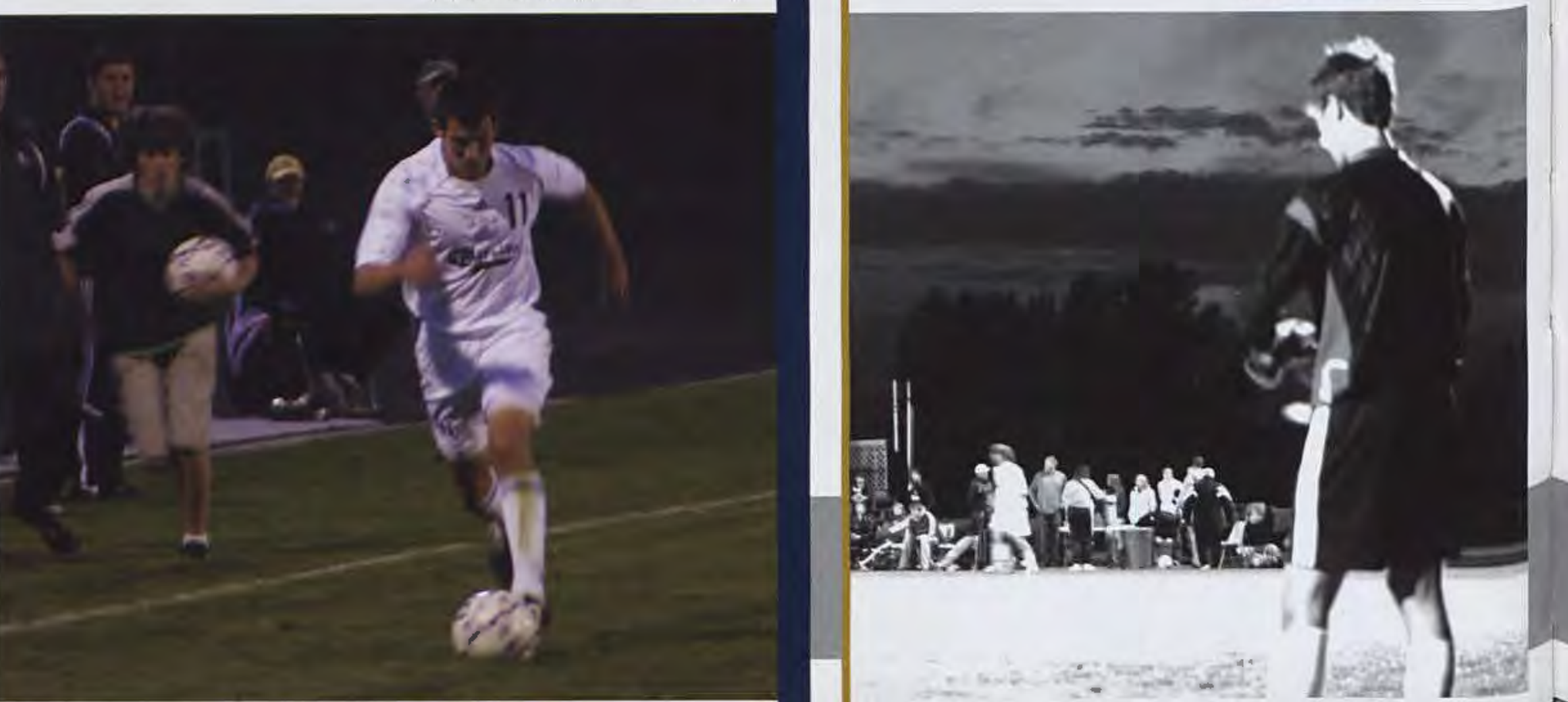


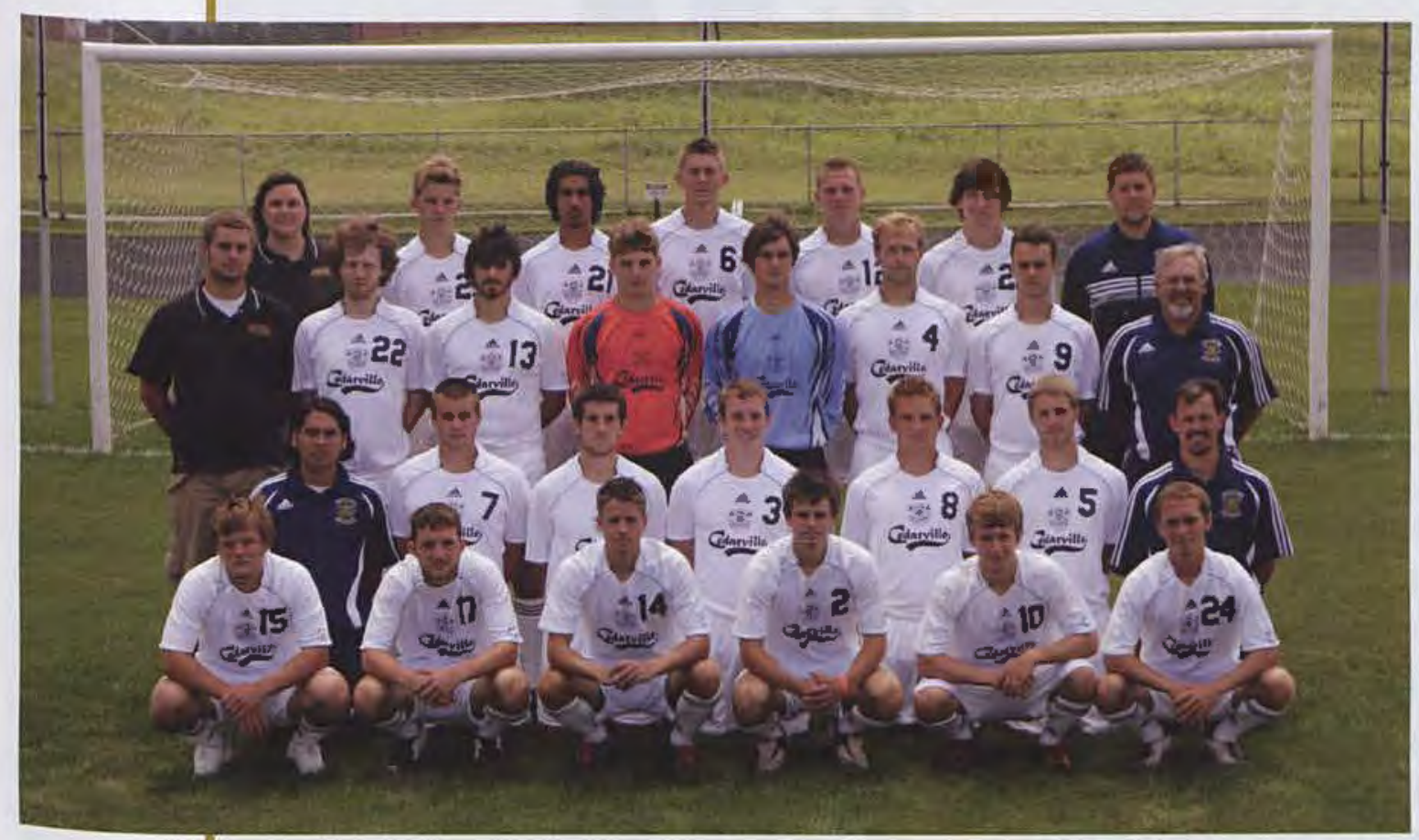

(front row left-to-right) Chase Riber, Logan Riber, Ken Davis, Ryan Hyde, Jordan Leach, Matt George.

(second row) Assistant Coach Ivan Batista, Ryan Lustig, Ryan Chaney, Tyler Scott, Jason Heuer, D.J.

Blatherwick, Assistant Coach Brent Davis.

(third row) Student Athletic Trainer Caleb Hanby, Luke Griffith, Stephen Cobucci, Kevin Bender, John Norton, Josh Gelser, Tim Green, Head Coach Ben Belleman.

(Back row) Associate Athletic Trainer Lisa Martin, Jason Bender, Scott Crawford, Kyle Segebart, Matt Niemiec, Zach Hill, Assistant Coach Ken Winter.

Wilmington

Mid-Continent

Vanguard\#

Trinity International\#

Roberts Wesleyan+

Indiana Wesleyant

Wittenberg

Milligan

Malone

Walsh*

Mount Vernon Nazarene*

Shawnee State*

Ohio Dominican*

Rio Grande*

King

Urbana*

Houghton

Ohio Dominican**

Spring Arbor++

* American Mideast Conference

\# Bethel Classic; Mishawaka, Ind.

+ Dave Jones Memorial Classic; Cedarville

** AMC Qualifying Tournament

++ NCCAA Midwest Regional

L $0-1$

L $0-1$

L 1-2
W 1-0

L 1-2

L 2-3

W $1-0$

T 2-2 (2ot)

L $1-2$

L $1-3$

W 1-0 (2ot)

W 2-1

T 0-0 (2ot)

W 2-1

L $0-3$

L $0-3$

W 1-0

W 3-1

T 1-1 (2ot)
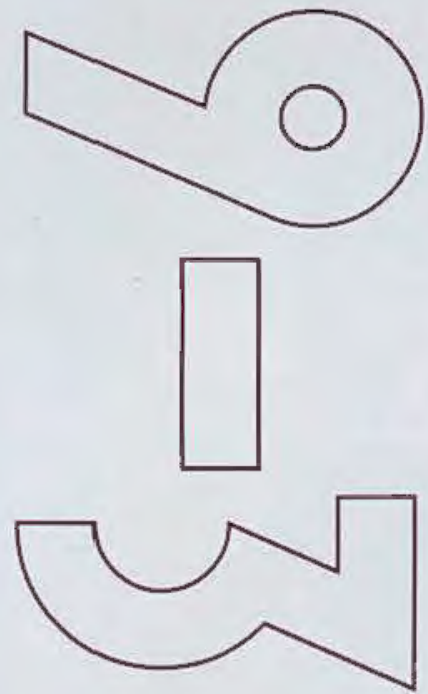

\section{3ㄹㅁㅁㅔ $\triangle M C$}

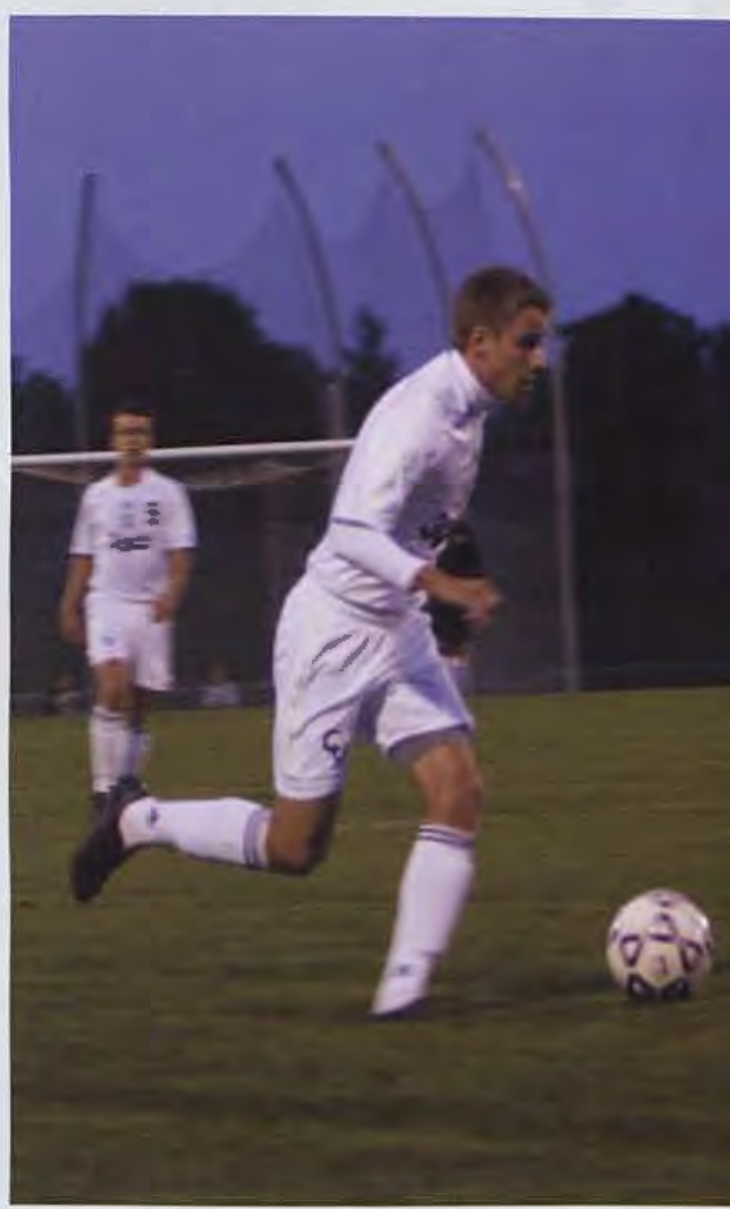

"One time in Houghton's cafeteria, one of their students was playing the piano, and Tim Green got up with him to do a little freestyle rap about Cedarville. All he got out was 'We are Cedarville' before he started laughing. Everyone was looking at us 'cause we were just being loud and having a good time."

(Matthew George, junior) 
"EVEN THOUGH OUR TEAM STRUGGLED WITH MANY INJURIES, I KNEW THAT EVERY GIRL OUT ON THE FIELD WAS GIVING HER ALL. THIS ALWAYS GAVE ME THE STRENGTH TO KEEP GOING, WHETHER THROUGH PHYSICAL THERAPY, OR EVEN IN THE LAST GAMES OF THE SEASON."

-HANNAH WAILES, JUNIOR

"THROUGH MANY TRIALS, GOD BROUGHT OUR TEAM TOGETHER AND REVEALED TO US THE IMPORTANCE OF PRAISING HIM WHETHER WE WIN OR LOSE. ULTIMATELY, OUR GOAL WAS TO PLAY AS A TEAM IN EVERY MATCH AND COME OFF THE FIELD KNOWING THAT WE GAVE OUR BEST EFFORT IN EVERY SITUATION."

\section{_KELLY WISE, SOPHOMORE}

It didn't take long for freshman midfielder Jessica Raring to earn her place on the Lady Jackets' team; at the September 22nd game against Asbury, Raring scored her first goal of her collegiate career.

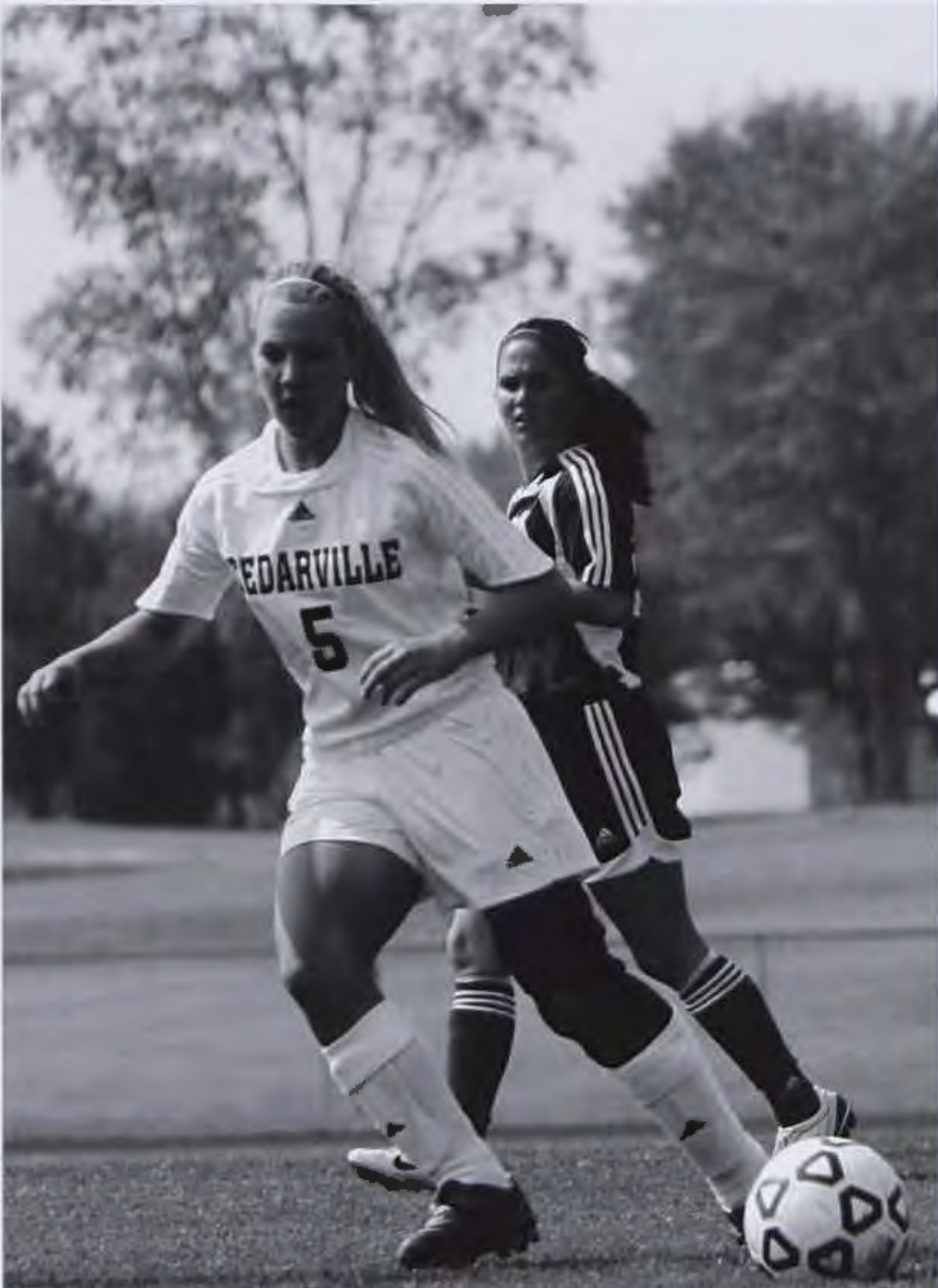

Lady Jackets defender Kristin Merkel was the sole senior player this year. On the night the team honored her years as a CU student and soccer teammate, the team clenched a 4-0 victory.

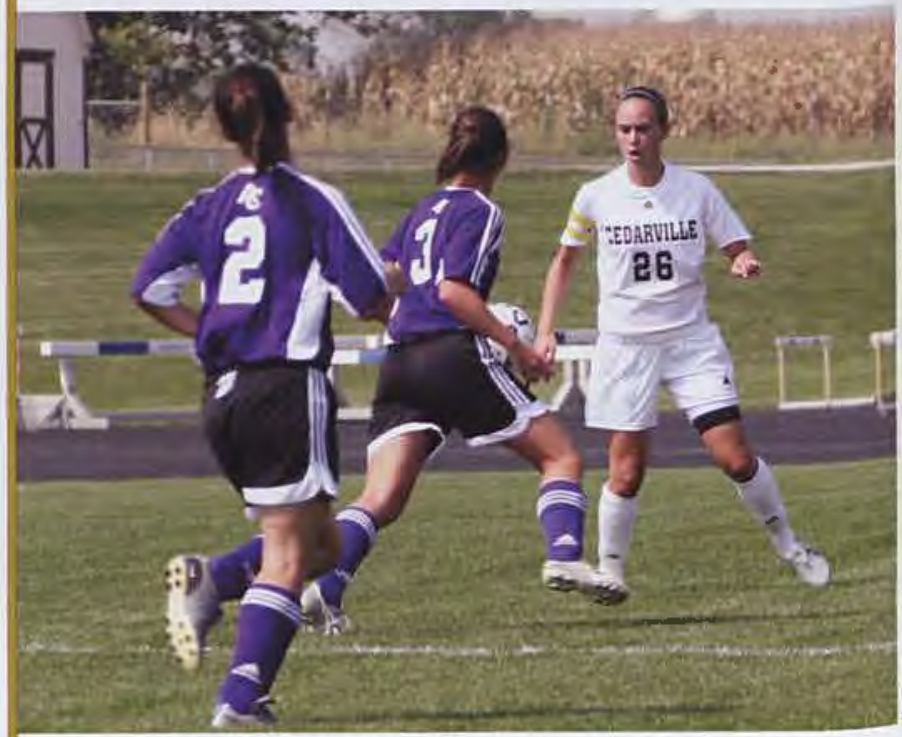

Dealing with her fair share of injuries, sophomore forward Kelly Wise didn't anything let get in her way from playing to the utmost degree. At season's end Wise was named to the American Mideast Conference South Division Second Team for the 2007 campaign.

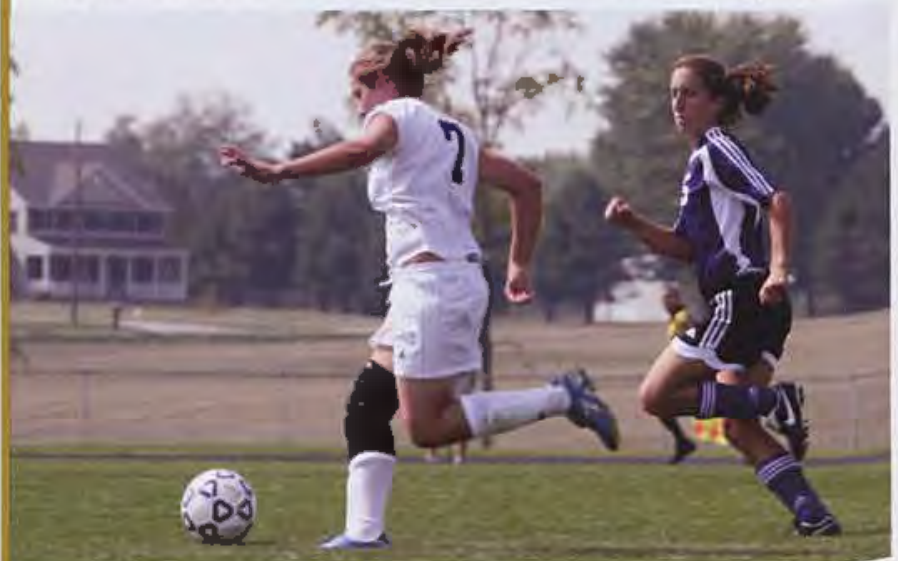

Junior forward Katie Koch clearly exhibits a talent for maintaining possession of the ball. Koch maintained the strongest overall record of the season.

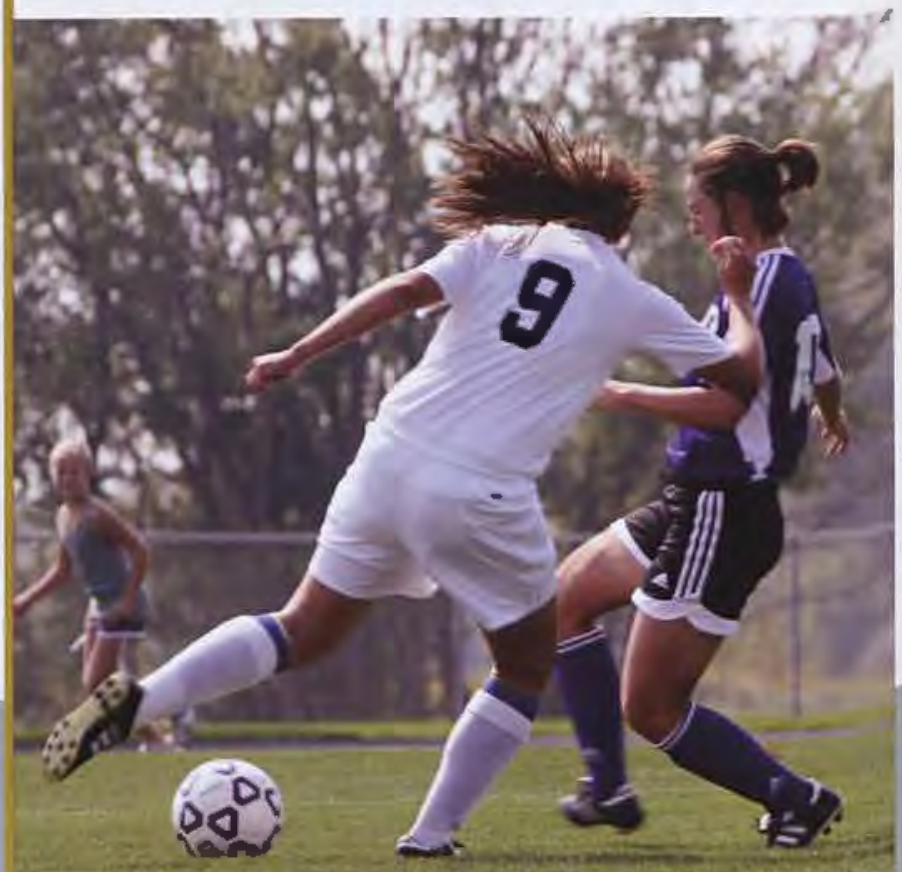


"VOLLEYBALL TO ME THIS YEAR WAS A

ROLLER-COASTER IN EVERY ASPECT OF THE SPORT. I HAD TRIALS SPIRITUALLY, PHYSICALLY AND EMOTIONALLY BUT OVER ALL GOD JUST USED ALL OF THAT TO BRING ME TO MY KNEES IN REMEMBRANCE THAT HE IS IN CONTROL OVER EVERYTHING."

-AMY GARNER, SOPHOMORE

"EACH team AND EACH GaMe We PLAYED WILL MOSTLY FADE FROM MEMORY, BUT WHAT WE DID FOR THE LORD AND THE DEEP BONDS OF FRIENDSHIP FORMED WILL LONG BE REMEMBERED."

_JUSTINE CHRISTIAANSE, SOPHOMORE

The girls open in prayer on their last home game of the year. This game also acted as senior night recognizing Sarah Zeltman.
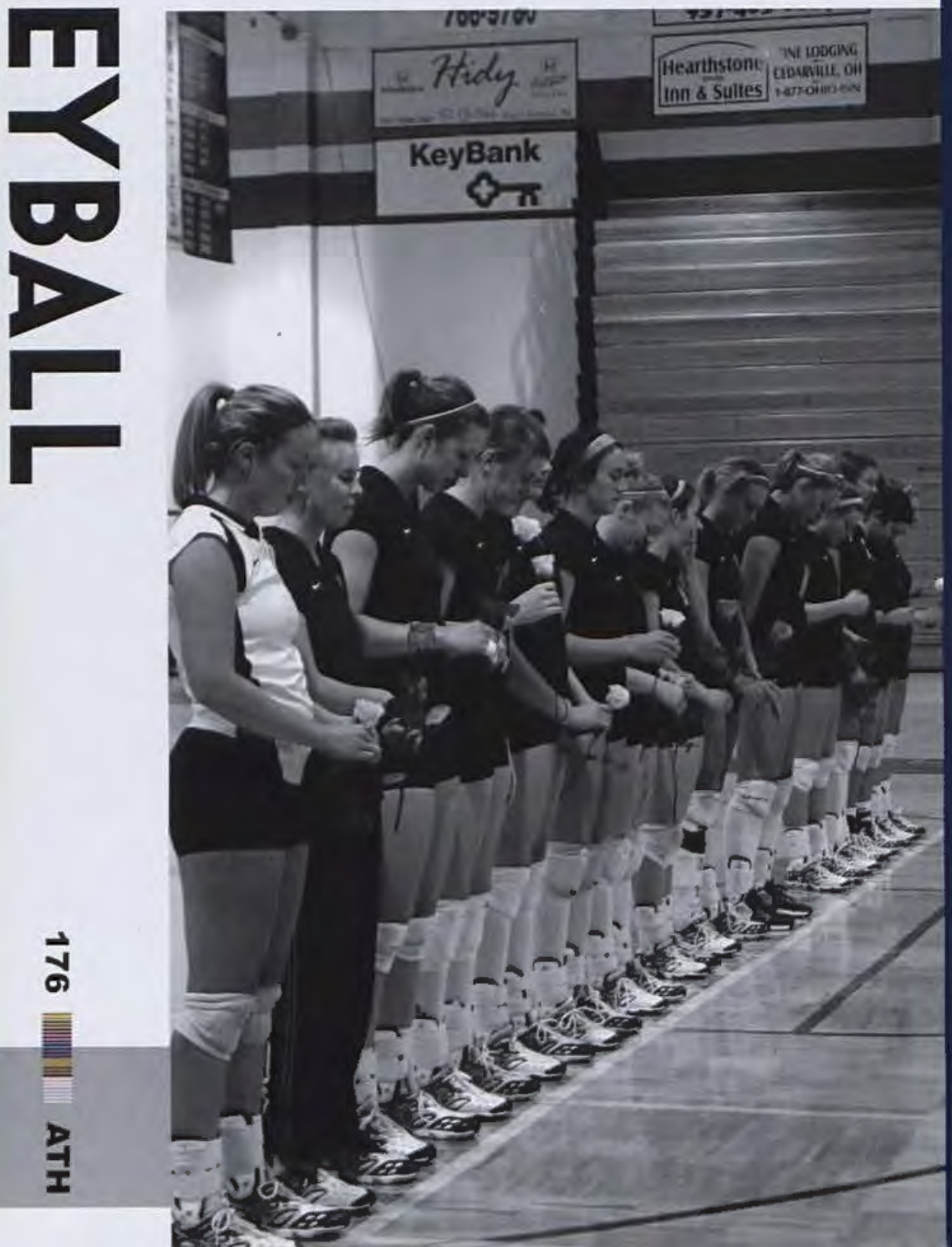

"I'll never forget the questions by fans and refs, recognizing that we seemed different than other teams. It presented such a great opportunity to witness about the real reason we play volleyball." (Kylee Husak, freshman)

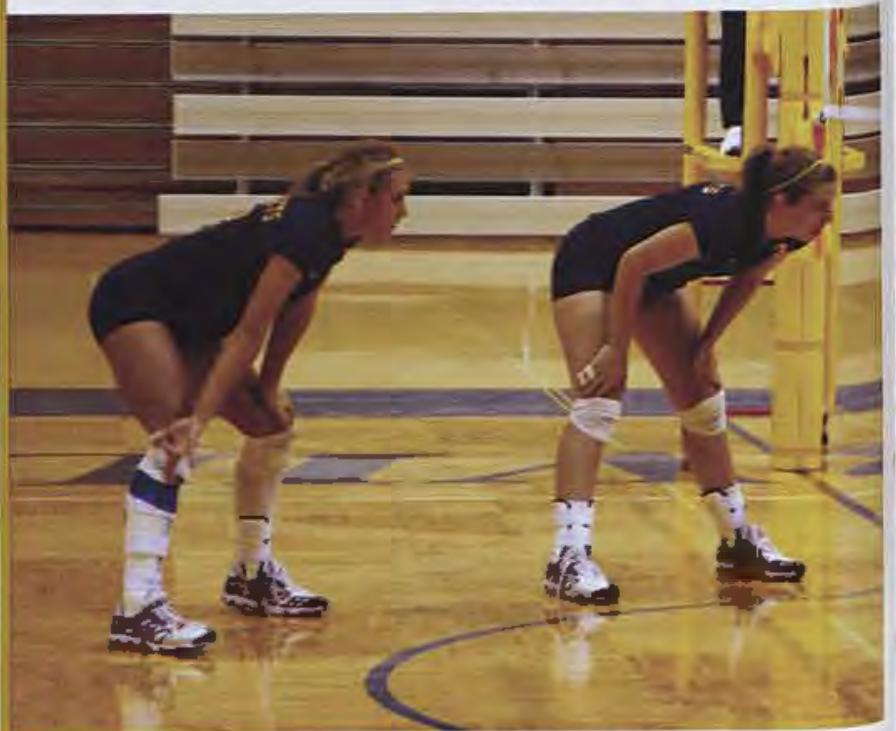

"It is amazing when we give God all the glory, what $\mathrm{He}$ can do, and the opportunities we had to share Christ with unbelievers! This was the highlight of my season!'

(Katie Moon, freshman)

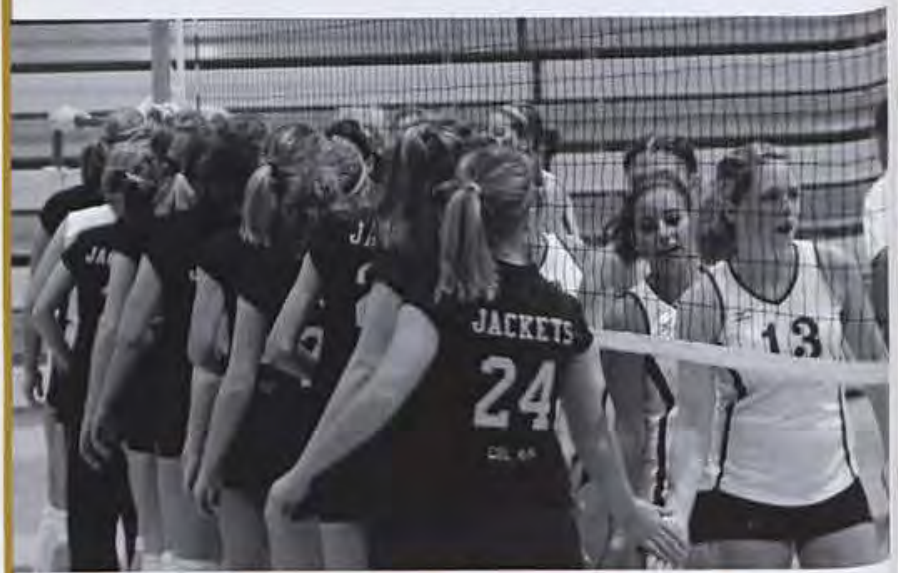

"We were a young team, and it was rough learning to play together. However, God blessed our efforts, and we had many exciting victories and He taught us about Himself along the way." (Libby Short, junior)

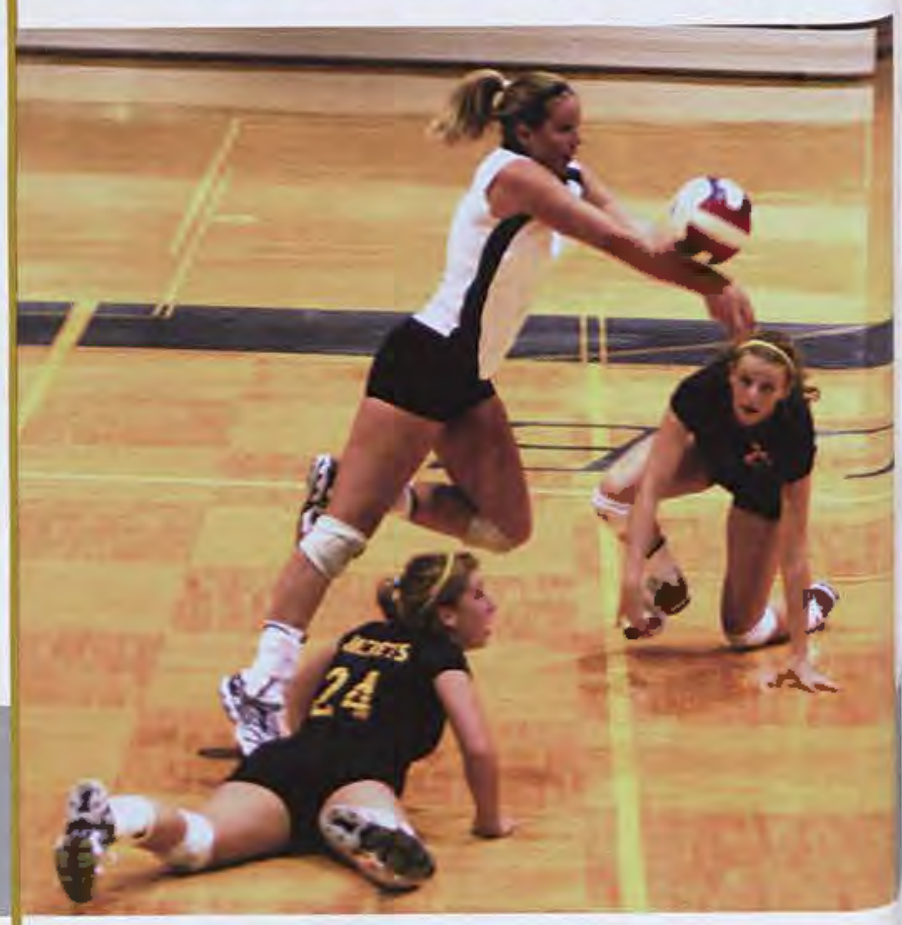




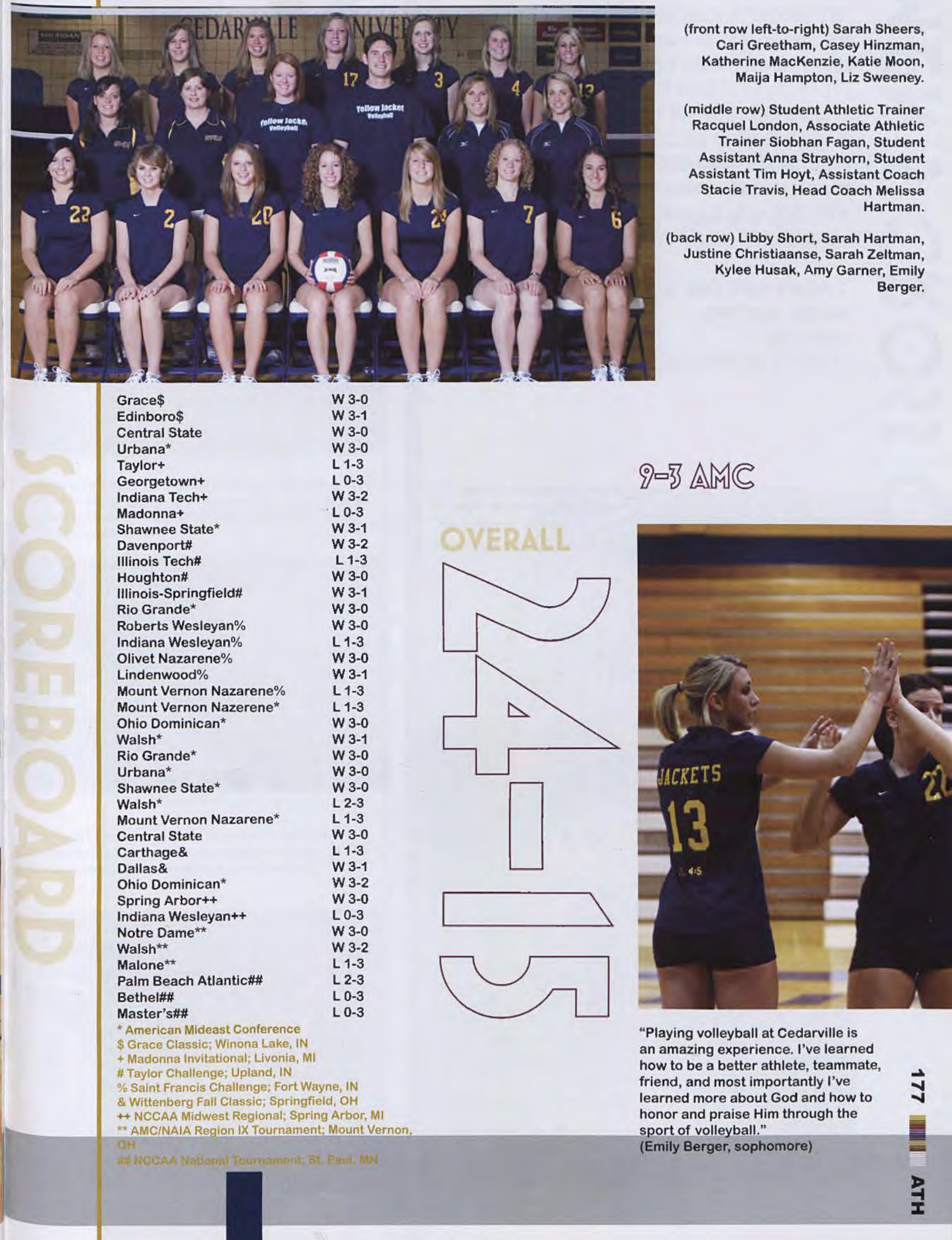




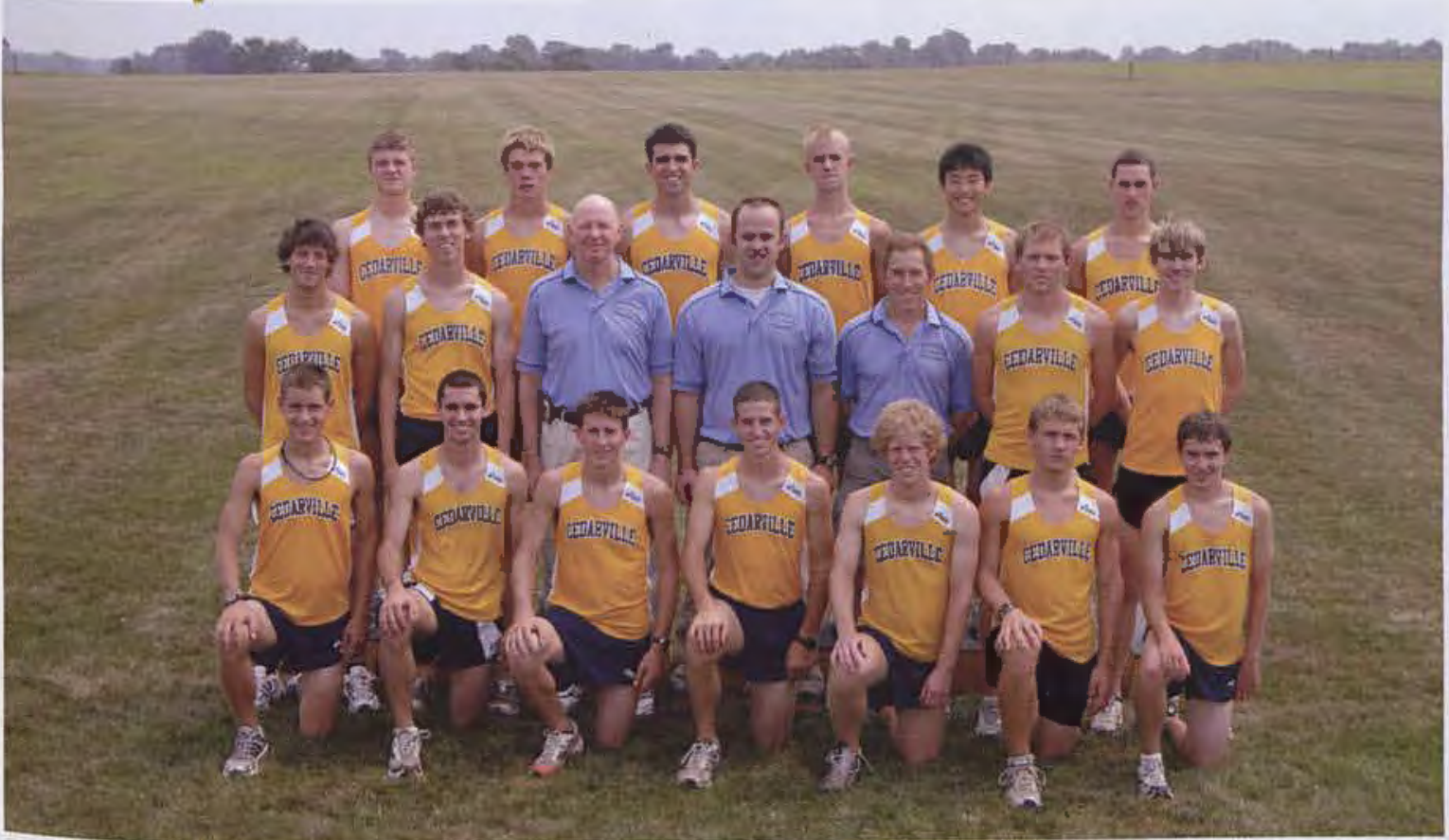

(kneeling left-to-right) Kevin Ruhlman,

Seth Campbell, Jordan Davies, Josh Wiseman, Joshia Maughon, Chris Vaughn, Alex Higley.

(middle row) Eric Kempton, Rob Trennepohl, Team Chaplain Bud May, Assistant Coach Steve Powers, Head Coach Paul Orchard, Jud Brooker, T.J. Badertscher.

(back row) Hollis Troxel, Joshua Saunders, Matt Silveira, Alex Moore, Paul Ikeda, Kevin Kuhn.

Queen City Invitational (5K)

4 th of 5

17th Annual Cedarville Invitational

2nd of 19

First Cedarville Open

1 st of 9

All-Ohio Intercollegiate

17 th of 39

Southeastern Classic

$3 r d$ of 22

AMCINAIA Region IX Championship

2nd of 13

NCCAA Nationals

4th of 22

NAIA Nationals

25th of 28

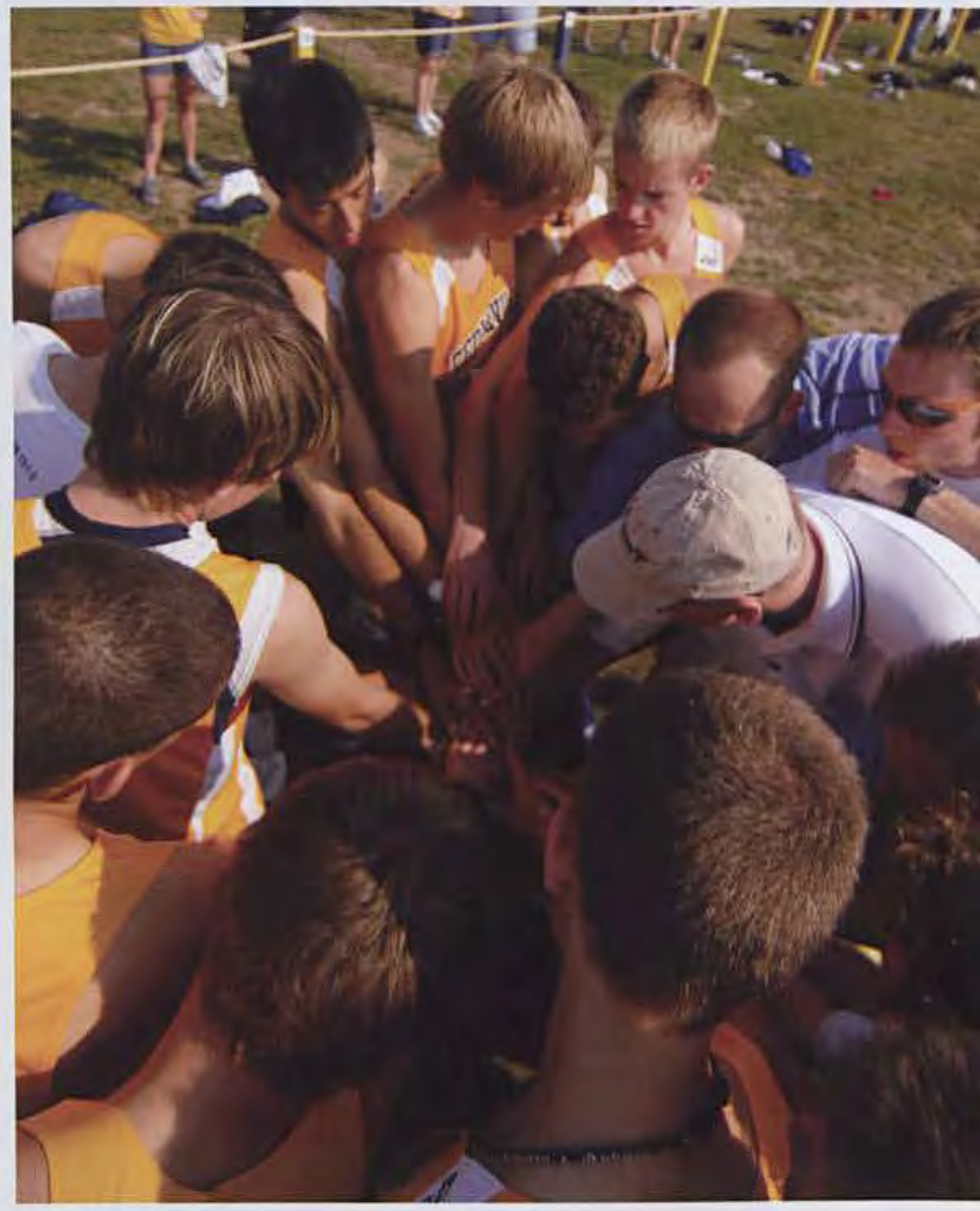

"Running frees up my mind and puts before me a goal to glorify God. Being on this team has helped me transfer the reason for running from myself to God." (Paul Ikeda, freshman) 
"RUNNING FOR CU HAS TAUGHT ME THAT IT IS NOT ONLY ABOUT THE SPORT, BUT SHARING EXPERIENCES WITH OTHER SISTERS IN CHRIST AND PRAISING JESUS WITH OUR TALENTS." -SHANNON DERUSHA, JUNIOR

"RUNNING CROSS COUNTRY AT CEDARVILLE IS AN AWESOME EXPERIENCE! TO BE ABLE TO TRAIN AND RACE FOR FOUR YEARS WITH A TEAM THAT LOVES GOD AND TAKES EACH STRIDE FOR HIS GLORY HAS BEEN A HUGE BLESSING!"

-MARIA BALCH, SENIOR

Junior Brittany Simpson, and seniors Audree Goodew and Leanne Crunelle gather together to reorient themselves to the true meaning of the sport, delighting in and glorifying God through their love of running.

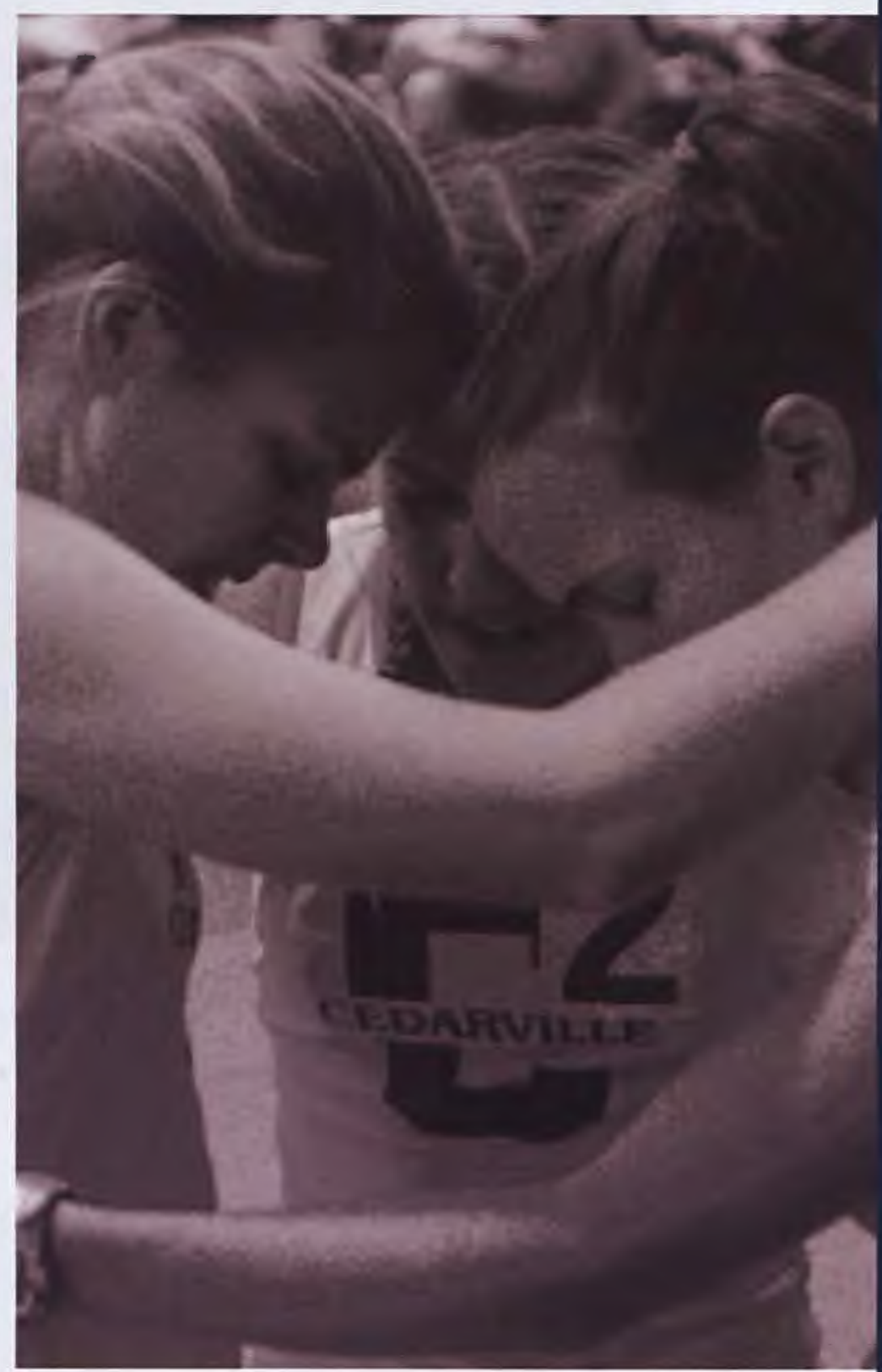

Not a rare sight in the least, the Lady Jackets cross country team huddles together for prayer and motivational words. These tactics clearly worked to the ladies' advantage; they ranked second overall in the NAIA.

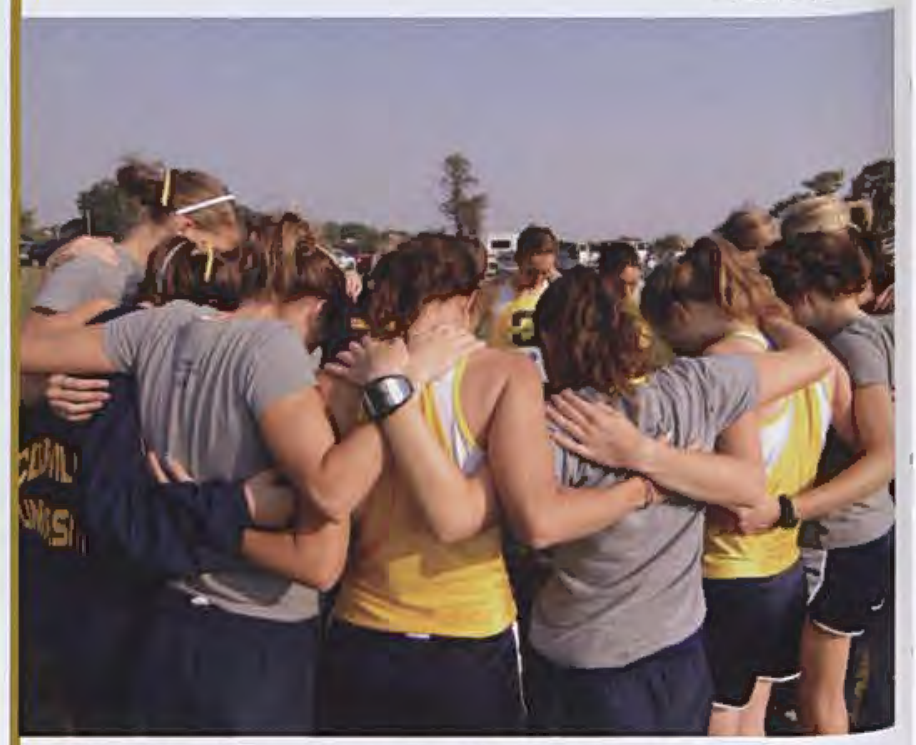

Leading the pack, senior Melissa Wysong (\#45) has had her fair share of difficulties throughout her cross country career. After sustaining an injury freshman year, Wysong has battled physical struggles and never lost the passion of the sport.

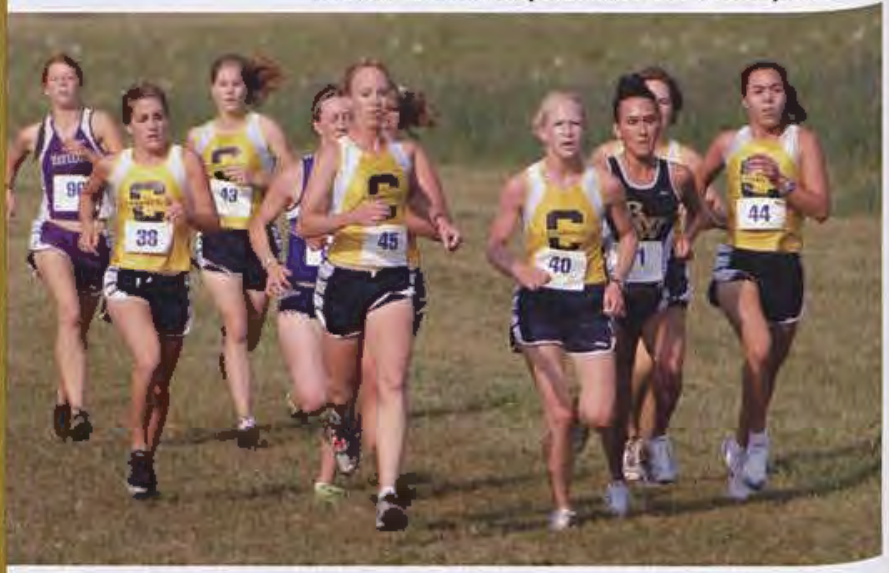

Audree Goodew, captain of the team for the 20072008 season, left Cedarville with an impressive array of records and achievements, including being chosen for the AMC first team in 2006. 


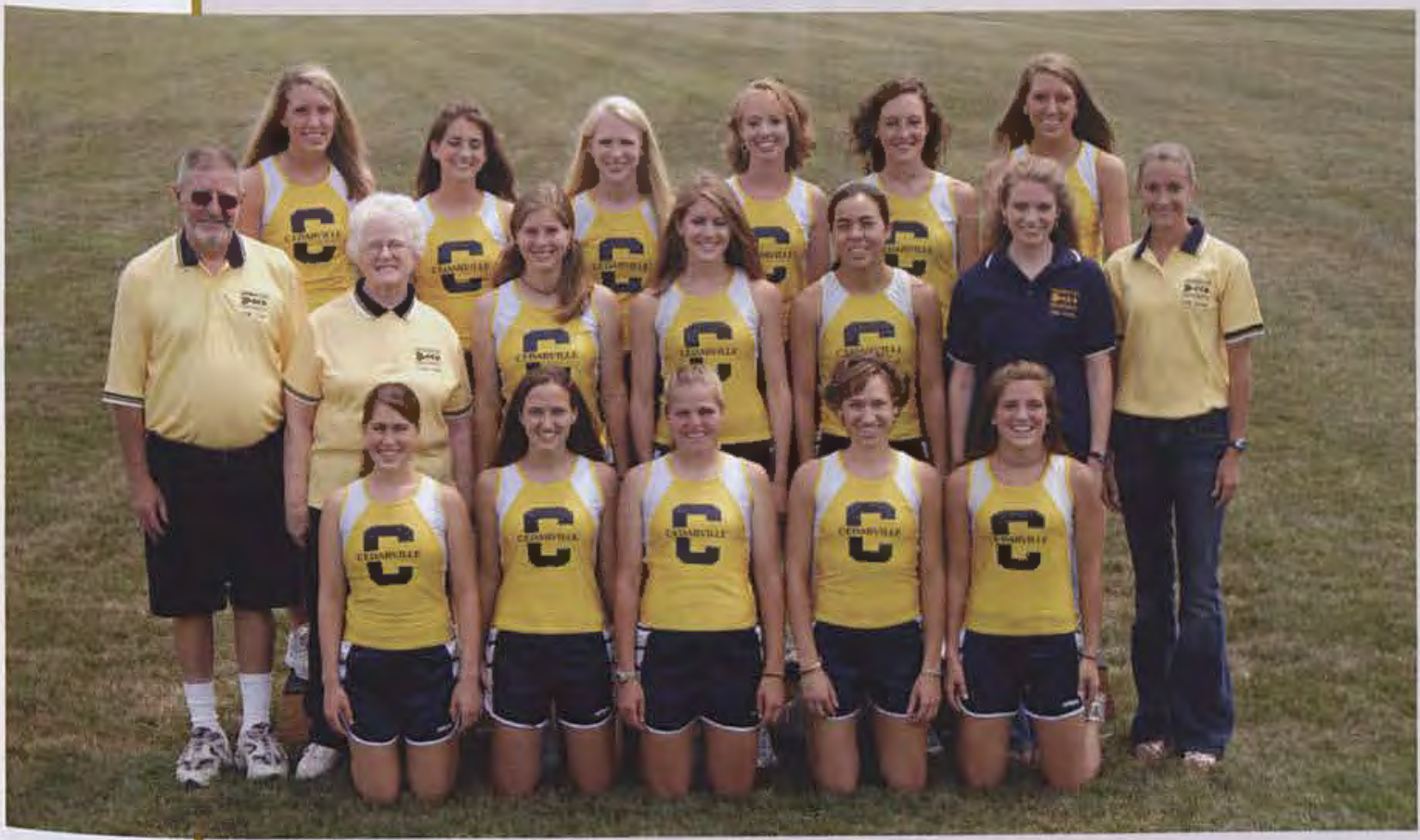

(front row left-to-right) Amy

Ernsberger, Leanne Crunelle, Brittany Simpson, Nicole Santos, Audree

Goodew.

(middle row) Head Coach Elvin King, Assistant Coach Joyce King, Jessica

Squier, Bethany Davies, Lydia Wong, Student Manager Elisabeth Feucht, Assistant Coach Keri Hilty.

(back row) Shannon DeRusha, Stacey

Keller, Elisabeth Pyles, Melissa Wysong, Maria Balch, Emily DeRusha.

Shawnee State Invitational

1st of 6

17th Annual Cedarville Invitational 2nd of 19

First Cedarville Open

1 st of 8

All-Ohio Intercollegiate

5 th of 44

Southeastern Classic

1st of 22

AMC/NAIA Region IX Championship 1 st of 12

NCCAA Nationals

1 st of 24

NAIA Nationals

2nd of 29

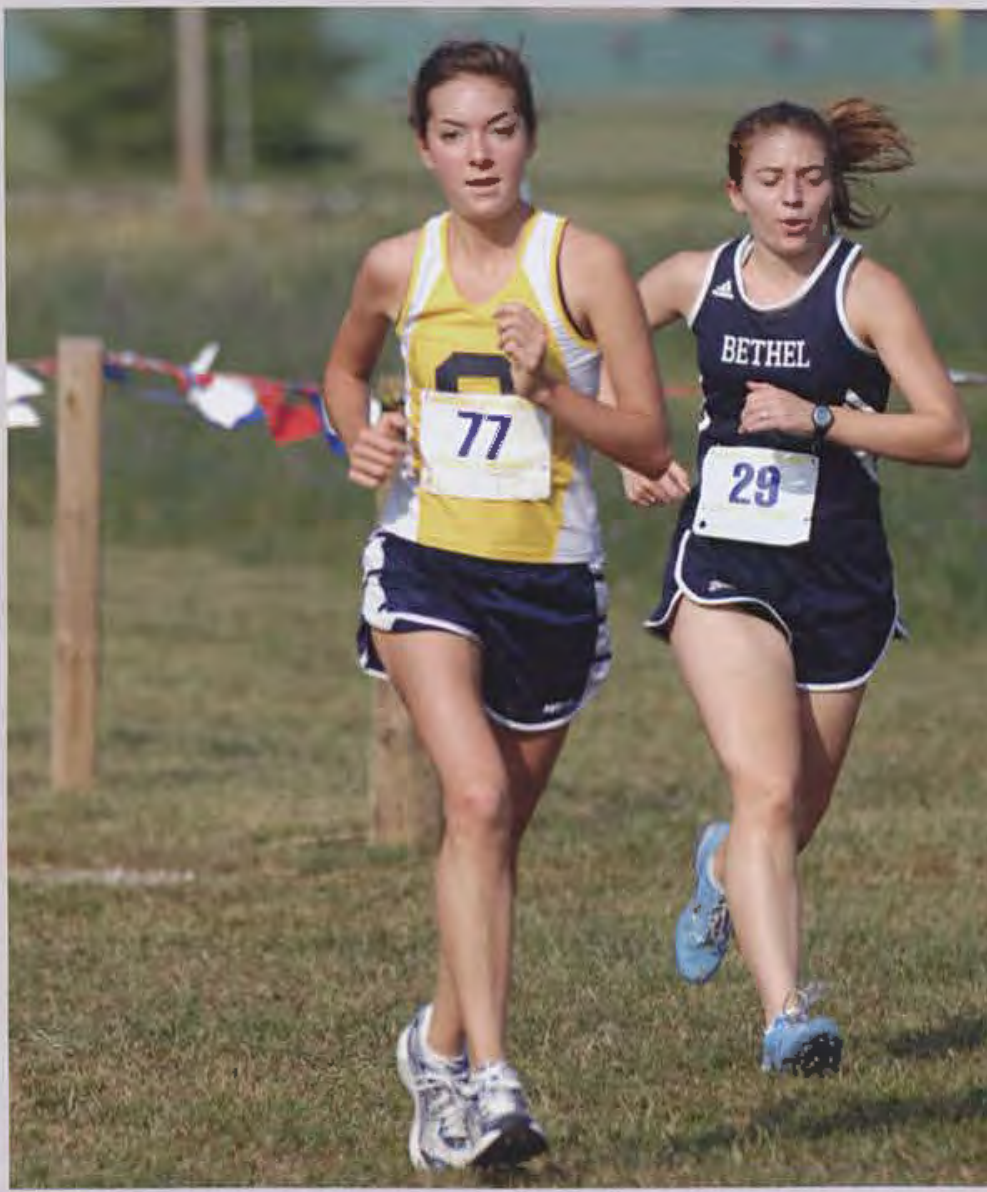

Leanne Crunelle presses forward to the finish line. 


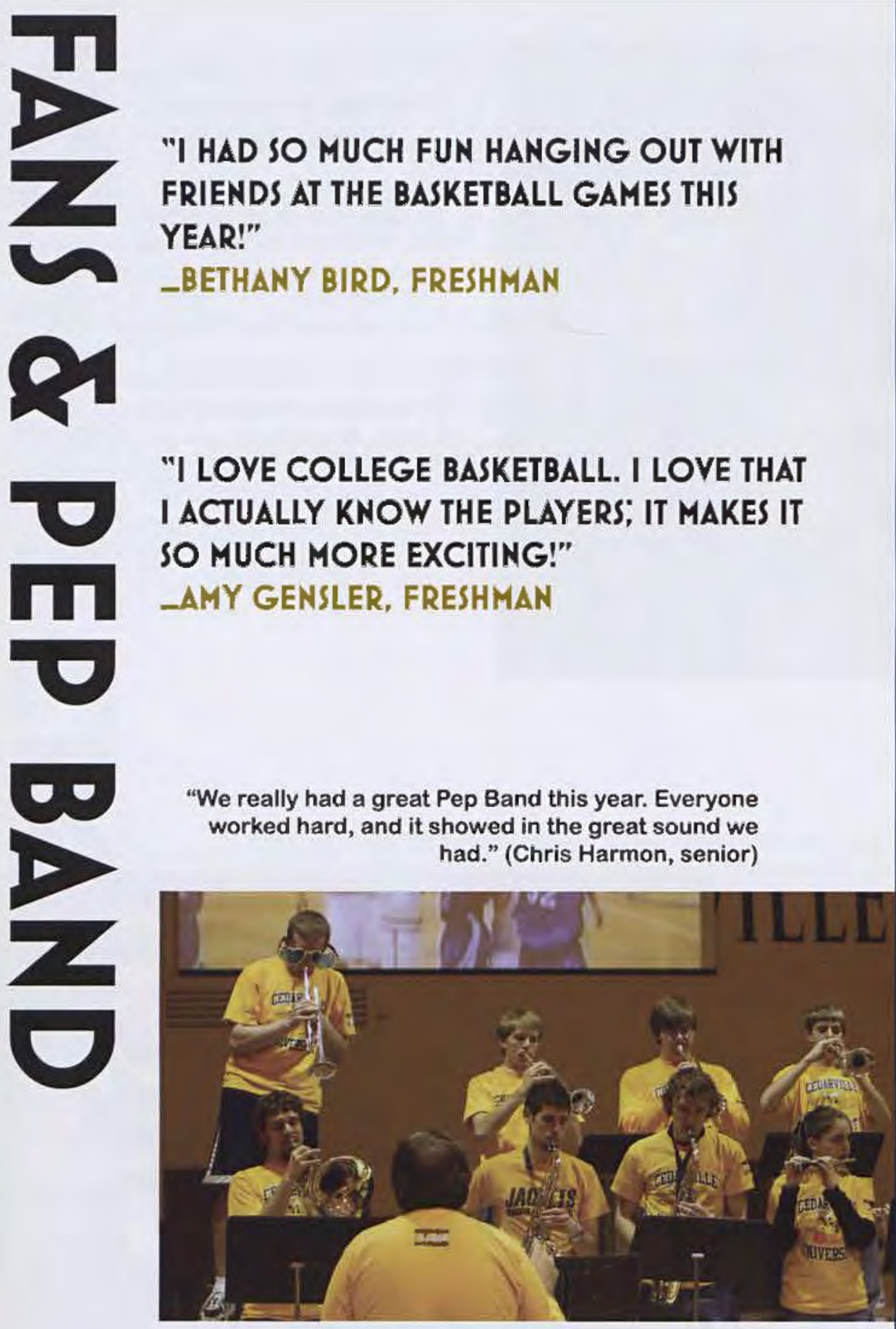

Terri Goodman, Heather Hayes, and Katharina Stevens support our basketball teams on the flute and piccolo.

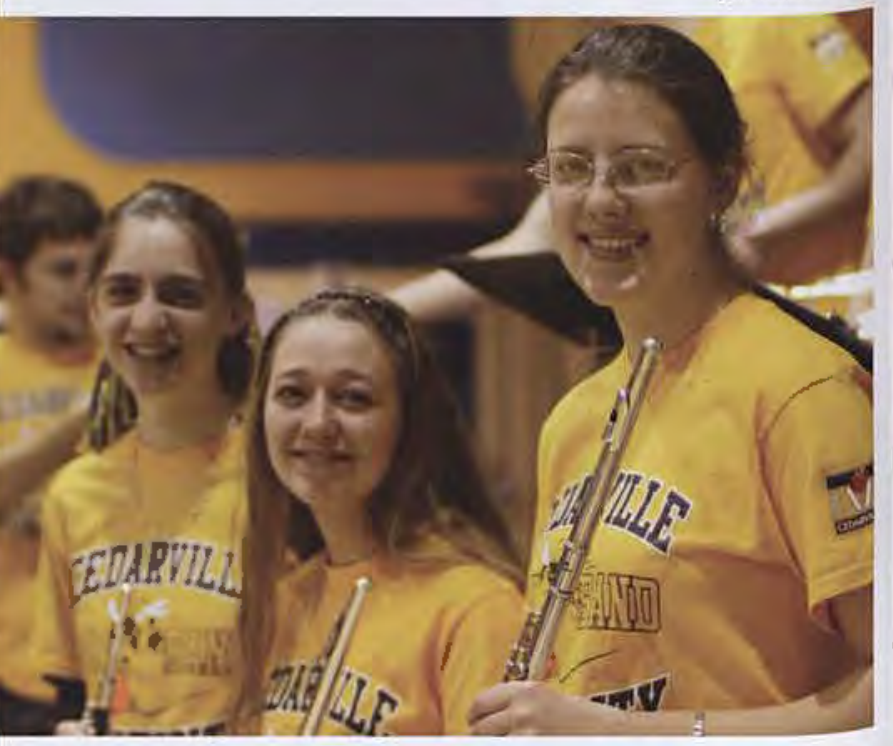

"The excitement and tradition of Pep Band always electrifies the Jacket basketball games."

(Anthony Hubin, senior)

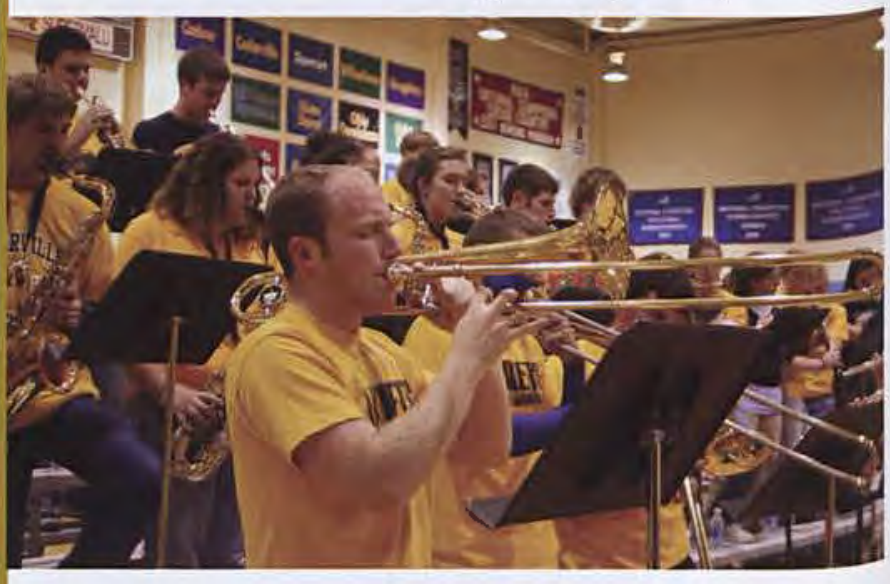

"I loved hanging out with my friends at the basketball games this year. I'm going to miss all of the fun times!" (Catherine Tasker, senior)

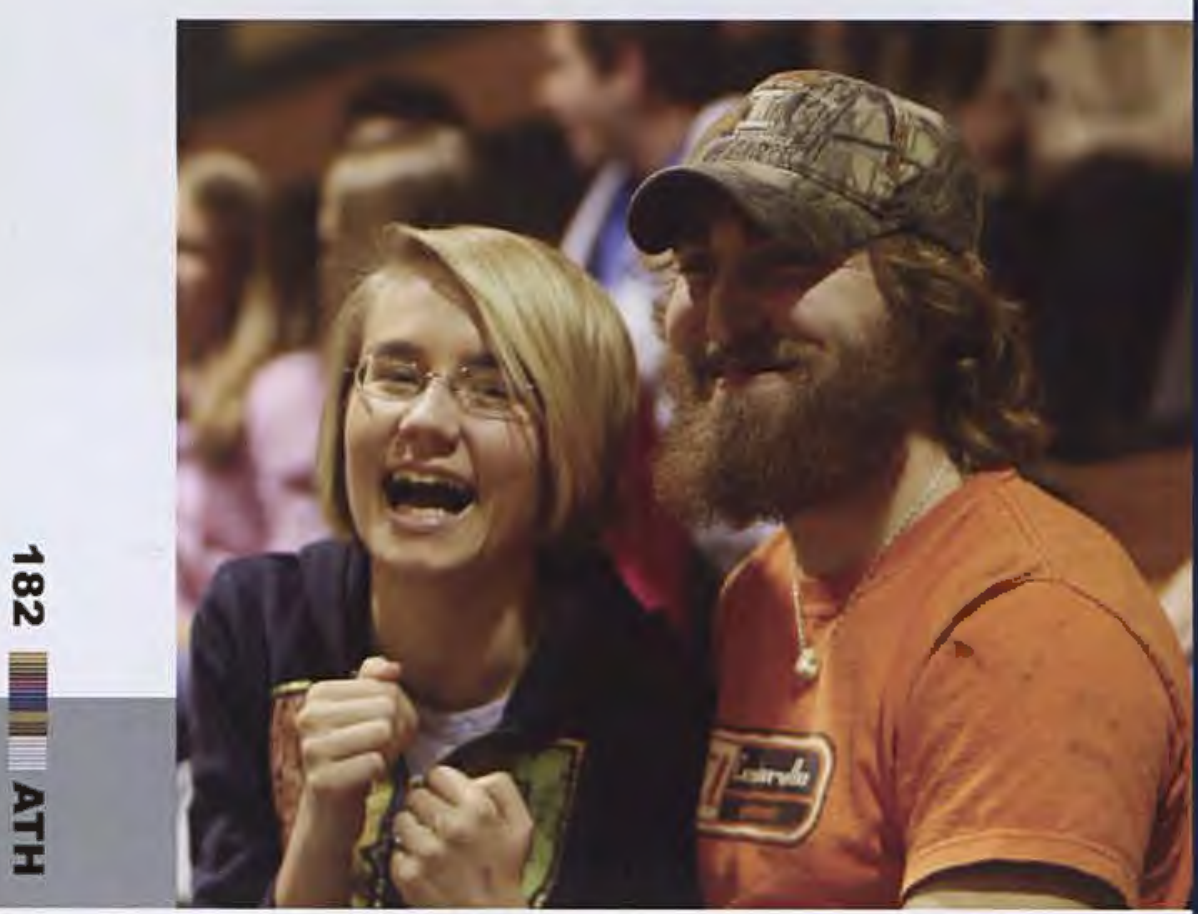

"It was a blast getting to play 'Eye of the Tiger' in Pep Band this year." (Kurtis Woods, sophomore)

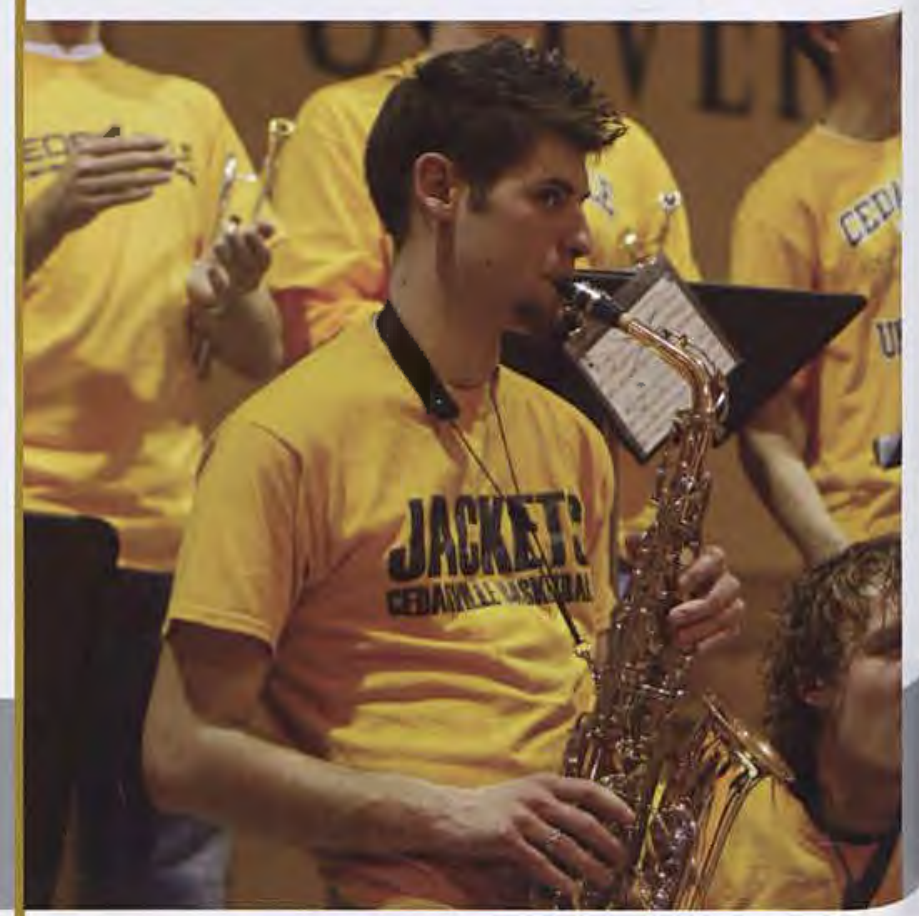


"THE MT. VERNON GAME WAS AMAZING

- IT WAS AWESOME TO SEE OUR FANS PULL TOGETHER AND SUPPORT OUR TEAM LIKE THAT. THE FACT THAT WE BEAT THEM MADE IT EVEN GREATER."

\section{-CHARITY HANCOCK, JUNIOR}

Sophomore forward Ricardo Alliman leaps over the competition to garner two valuable points for the Jackets. Alliman's total rebounds for the 2007-2008 season was an impressive 255 .

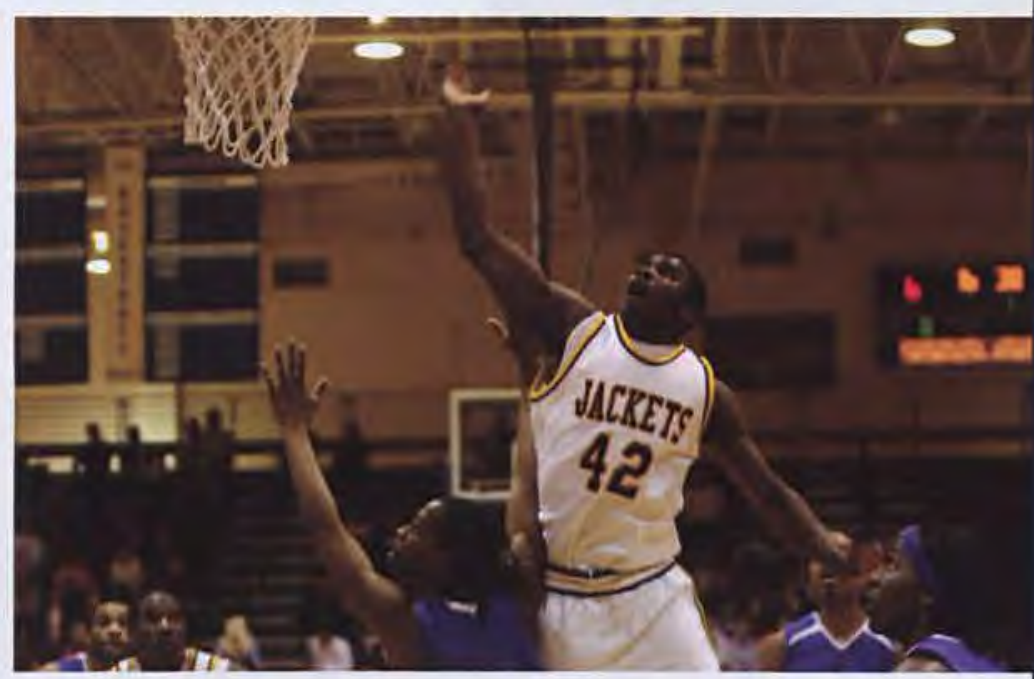

Jackets forward and sophomore Chris Walker avoids the distractions of the opposing team and concentrates on making the shot. Such strategies must have worked for Walker, who was ranked third on the team for scoring $\mathbf{1 0 . 5}$ per game.

Sophomore guard Chris Beals chooses the appropriate stance and goes for the freethrow shot. Beals boasts 57 successful freethrows out of 70 attempts.
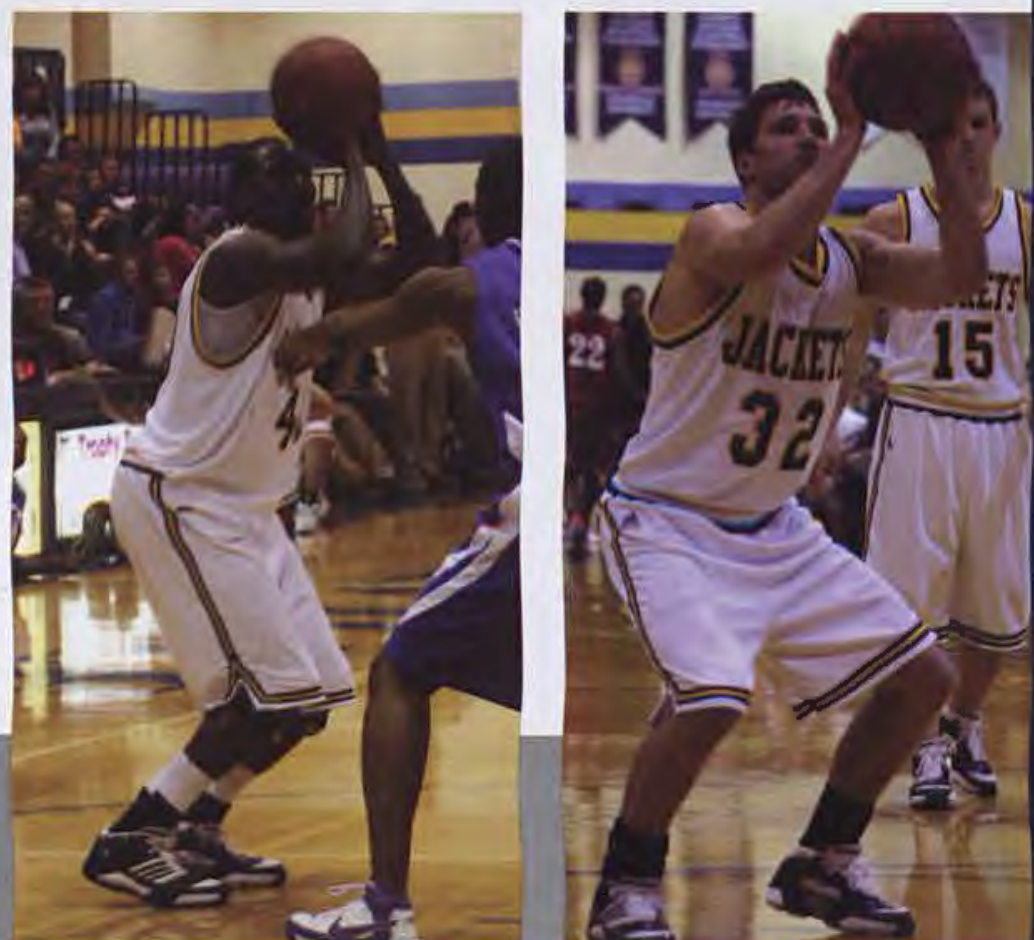

Each year, the coaches of the Jackets choose the final home game of the year to honor the seniors who will never play on the hallowed court again. This year,

the honored seniors were guards Joel Fowler and Ryan Short.

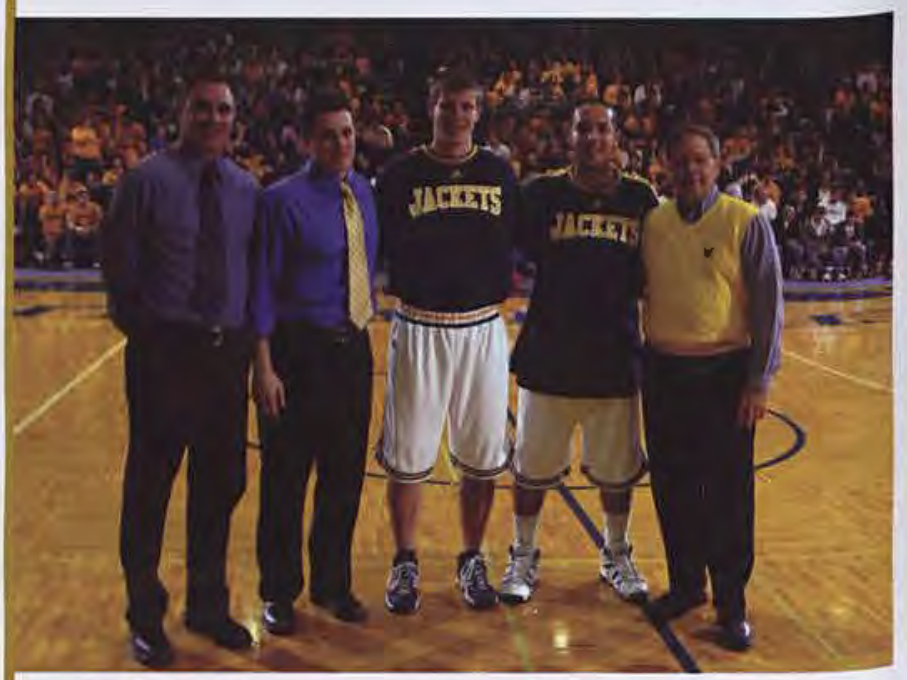

Keeping their well-trained eyes keenly on the ball, sophomore guards Haddon Anderson and Chris Beals work hard to keep the Wittenberg score low. The Jackets won 73-58, defeating Wittenberg for the first time in three years.

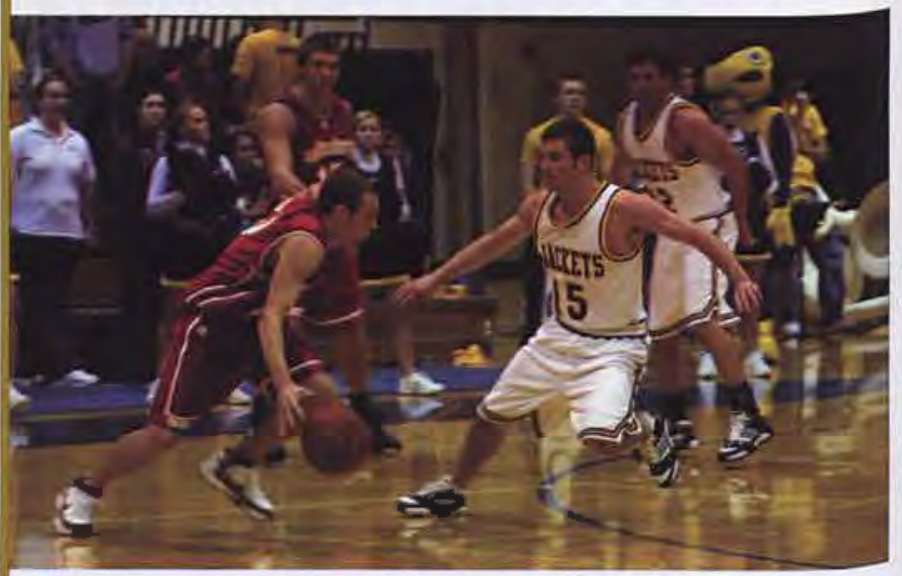

The men's Jackets basketball team huddles together

for renewed focus and an energized spirit. Junior guard Ryan Reep was elected captain this season and was responsible for leading the team and maintaining high spirits in the midst of uncertainty.

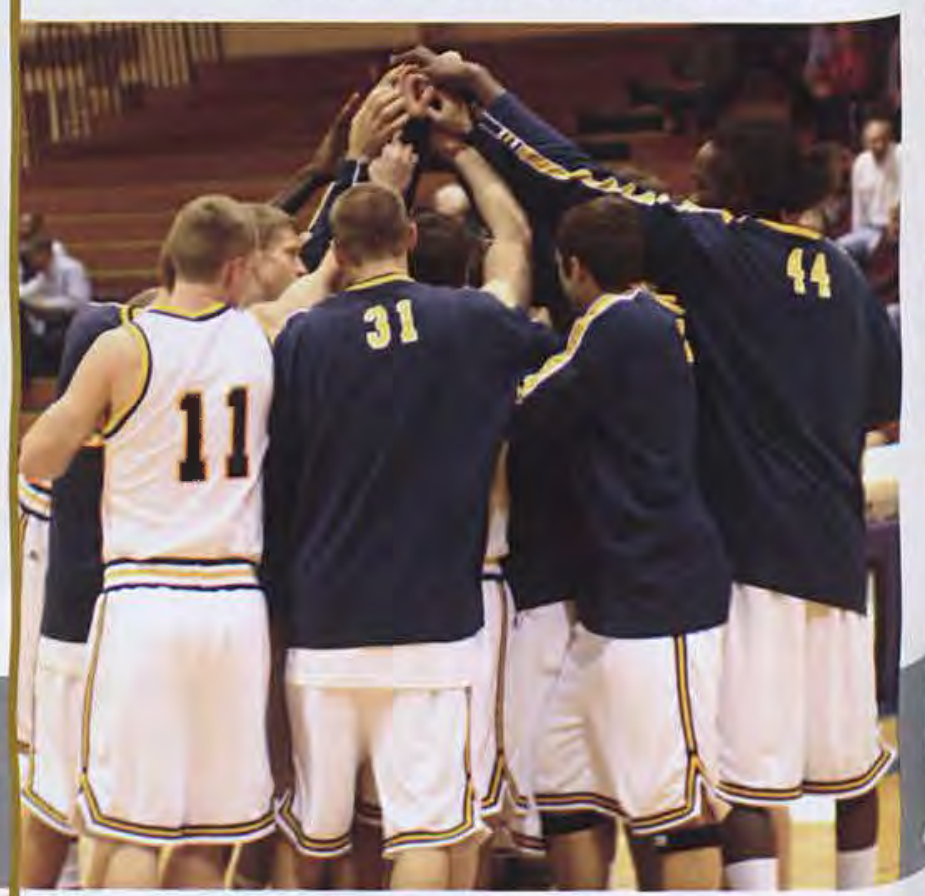




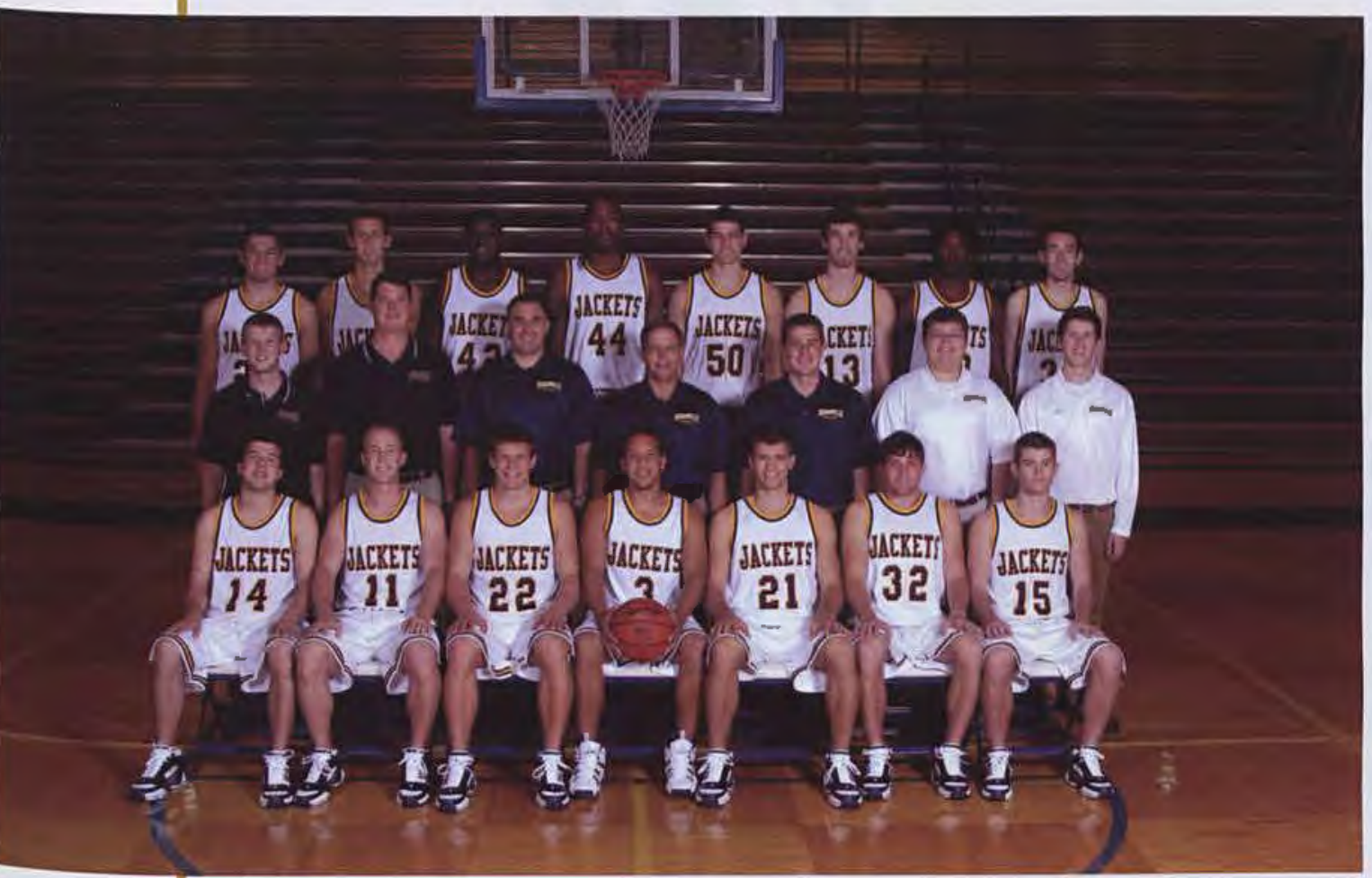

(seated left-to-right) Matt Dunton, Grant Walker, Ryan Short, Joel Fowler, Ryan Reep, Chris Beals, Haddon Anderson.

(middle row) Student Athletic Trainer Woody Blocker, Head Athletic Trainer Chris Cross, Assistant Coach Andy Allgrim, Head Coach Ray Slagle, Assistant Coach Pat Estepp, Student Assistant Ryan Mosher, Student Assistant Ryne Oller.

(back row) Adam Riehle, Brandon Sok, Ricardo Alliman, Daniel Rose, Kenny Reep, Zach Westrum, Christopher Walker, Matt Harner.

Huntington

Trinity Christian+

Lindsey Wilson+

Malone

Saint Francis (Ind.)

Notre Dame

Wooster

Wittenberg

Columbia\#

Ohio State-Marion\#

San Diego Christian\%

Master's\%

Point Park

Mount Vernon Nazarene*

Ohio Dominican*

Urbana*

Walsh*

Shawnee State*

Wilberforce*

Rio Grande*

Ohio Dominican*

Mount Vernon Nazarene*

Walsh*

URBANA*

Wilberforce*

Shawnee State*

Rio Grande*

Ohio Dominican**

Malone ${ }^{\star \star}$

Jamestown++

MidAmerica Nazarene++

* American Mideast Conference

+30 th Annual Cedarville Classic; Callan Athletic Center

\# Taylor Classic: Upland, IN $\%$ Master's Classic; Santa Clarita, CA

* AMC Tournament

++17 th Annual NAIA Division II National Tournament; Point Lookout, MO

L 75-77

L 70-75

W 98-49

W $82-80$

W 103-94

W 94-88

W 65-61

W 73-58

L 54-65

W 104-83

W 89-60

W 73-63

W 103-74

L 54-83

W 82-70

W 74-48

L 55-77

L 63-65

W 88-73

W 73-67

W 82-80

W 86-74

L 82-87

W 82-58

W 101-71

W 74-43

W 77-70

W 81-67

W 84-83

W 83-59

L 73-79

Allan Athletic 
"I ENJOYED THIS YEAR SO MUCH. IT WAS DEFINITELY A GROWING SEASON, INDIVIDUALLY AND AS A TEAM. EVERYONE WORKED HARD ALL SEASON, AND WINNING NCCAA NATIONALS WAS A GREAT WAY TO END THE SEASON!" -ALISON LEMON, SOPHOMORE

\section{"THIS WAS A VERY MEMORABLE YEAR FOR} OUR TEAM, AND I LOVED BEING A PART OF IT. WINNING A NATIONAL TITLE WAS AWESOME, BUT WHAT I LOVED EVEN MORE WAS THE ENCOURAGEMENT I RECEIVED FROM MY COACHES AND TEAMMATES. THEY ARE A GREAT GROUP, AND I AM BLESSED TO HAVE THEM." _LACIE CONDON,SOPHOMORE

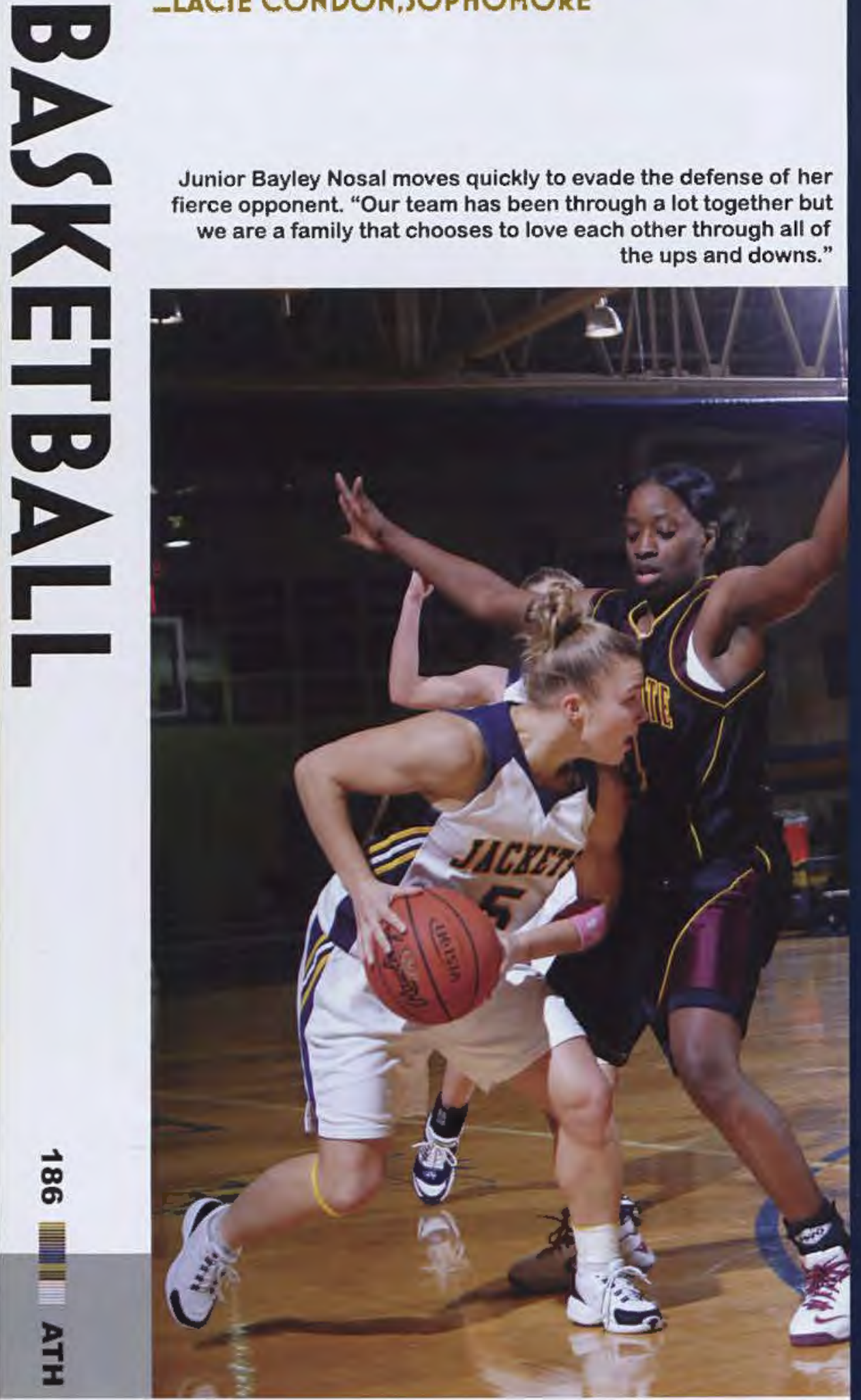

"It is about first and foremost honoring $\mathrm{Him}$ then using the gifts He has given me to be an encouragement to the people he has allowed me to come in contact with." (Mary Stockdale, senior)

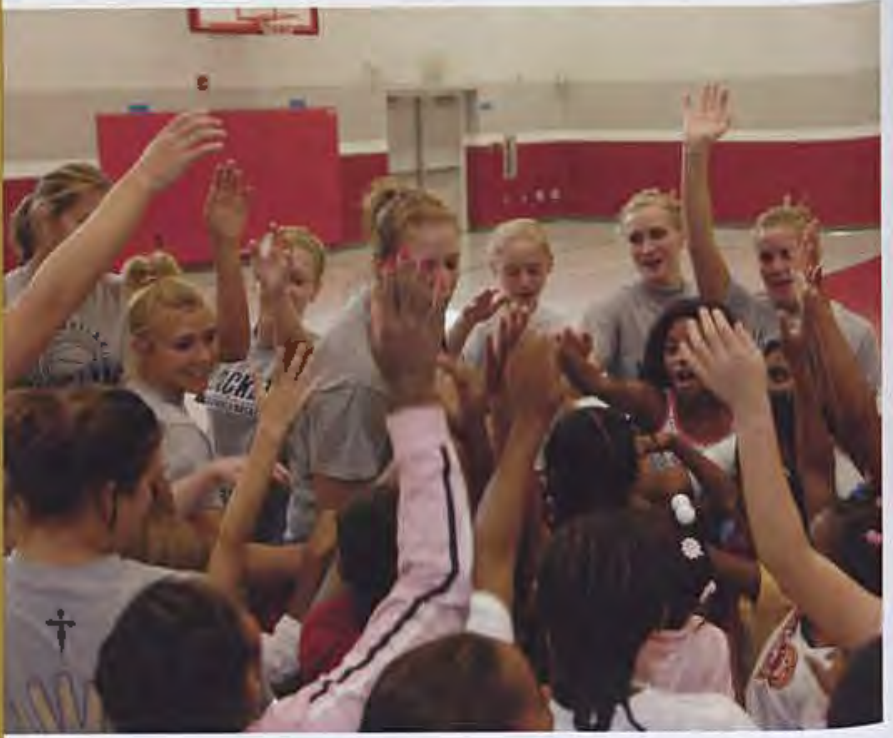

The Lady Jackets impact their opponents in numerous ways, one being the group prayer before games. The ladies prove that it is more than just a game.

"As a Christian basketball player I need to put God first, others second and then myself. This means that I need to remember that I play basketball for God's glory, and not my own fulfillment." (Aubrey Siemon, freshman) 


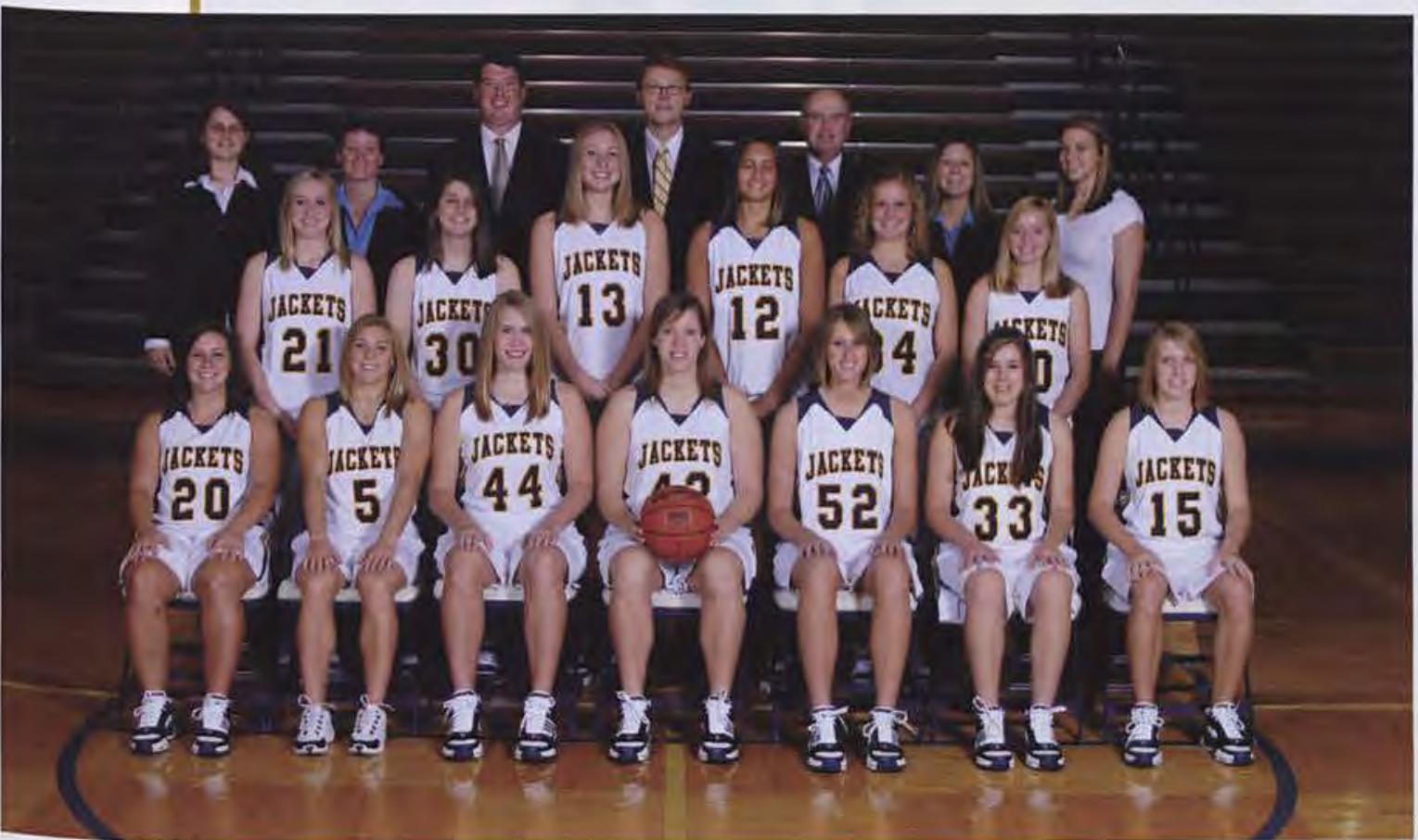

(front row left-to-right) Lacie Condon,

Bayley Nosal, Emily Noble, Mary

Stockdale, Alisha Lee, Kristine Rucker,

Alison Lemon.

(middle row) Lydia Miller, Stefanie

Rodgers, Jenna Smith, Aubrey

Siemon, Stephanie Latham, Rachel

Hurley.

(back row) Student Assistant

Heather Grooms, Assistant Coach

Lori Huckaby, Head Athletic Trainer

Chris Cross, Head Coach Kirk Martin,

Assistant Coach Dan Schetter,

Assistant Coach Lynsey Fabian,

Student Assistant Kim Workman.

Daement

Malonet

Georgetown\#

Bryan\#

Taylor

Notre Dame

Central State

Georgetown

Northwestern Ohio

Nyack\%

Lindsey Wilson $\%$

Madonna\%

Ursuline

Mount Vernon Nazarene*

Ohio Dominican*

Urbana*

Walsh*

Shawnee State ${ }^{*}$

Wilberforce*

Rio Grande*

Ohio Dominican*

Mount Vernon Nazarene*

Walsh*

Urbana*

Wilberforce*

Shawnee State*

Rio Grande*

Ohio Dominican**

Colorado Christian++

Oakland City++

Hope International++
W 90-87

W 84-56

L 69-74

W 72-48

L 64-65

L 73-82

W $81-61$

L 66-76

W 83-58

W 62-39

L 68-84

L 46-53

W $87-81$

W 61-59

L 53-64

W 72-71 (ot)

W 79-74

L 62-89

L $68-71$

W 78-68

L 52-68

W 58-52

L $71-80$

L 50-70

W 84-51

L 64-72 (ot)

W 63-61

L 52-71

W 69-61

W $83-70$

W $80-77$ (ot)

* American Mideast Conference

+ Cedarville Classic; Callan Athletic Center

* Bryan Classic; Dayton, TN

* AMC Tournament

++ NCCAA National Tournament; Oakland City, IN

$\%$ Warner Southern Tournament; Lake Wales, FL

\section{7 $\triangle M C$}

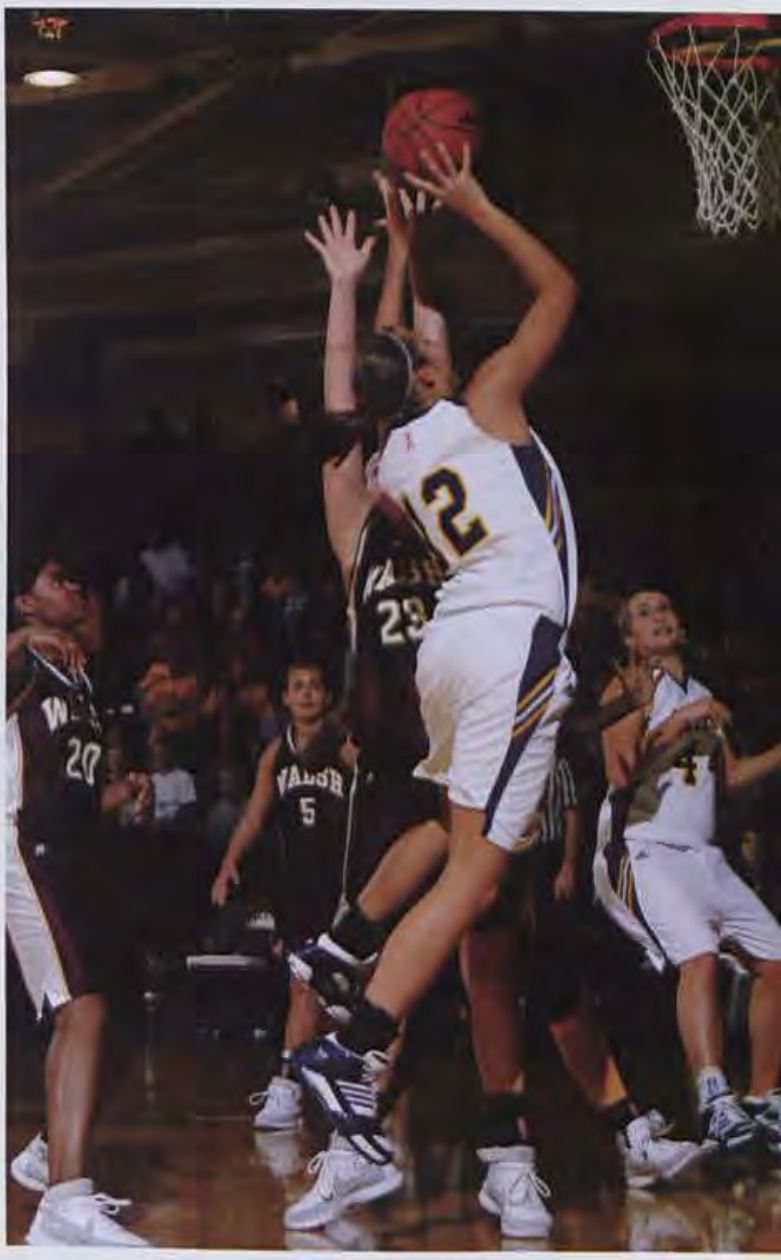

Of the several benefits of the 2007-2008 basketball season, the team missions trip to the Dominican Republic was especially beneficial to freshman Aubrey Siemon, who credited the trip for reminding her to "play your hardest no matter the circumstances and to represent a good testimony on the court." 
"I WAS THE GUY THAT ALWAYS MADE FUN OF MALE CHEERLEADERS. THIS PAST YEAR HAS BEEN SO MUCH FUN AND WE'VE BECOME A CLOSE FAMILY, I CAN'T WAIT UNTIL NEXT YEAR!"

_PAUL LOCKE, JUNIOR

"WE HAD SO MUCH FUN AND WORKED SO HARD TOGETHER AND ENDED UP ACCOMPLISHING SOME REALLY AMAZING THINGS TOGETHER."

-RACHEL JUDD, SOPHOMORE

Due to the Jackets Cheerleaders' impressive and effortless skill, many spectators take the squad's acrobatic feats for granted. Here, senior Ashley Coale balances precariously atop the shoulders of sophomore Steve LoCicero.
"I loved being a part of the squad this year. The cheerleading team got to be like my second family. We have learned and grown together in Christ, and it has been a tremendous encouragement as well as a lot of fun!" (Katherine Watson, freshman)

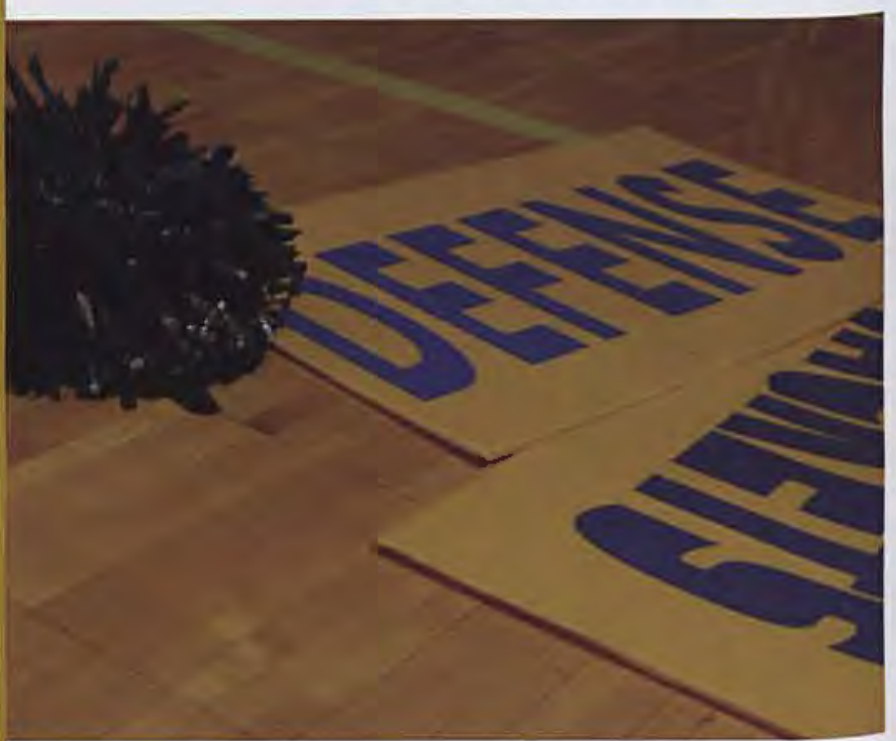

The squad looks on with their special Breast Cancer awareness uniforms for moonlight madness.

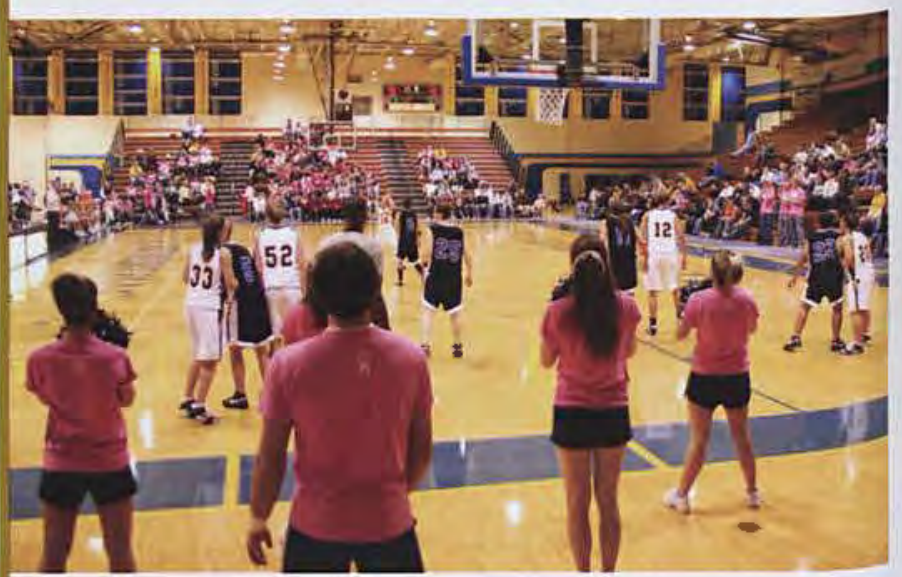

The stunts and balance movements that the cheerleaders execute at each game require a great deal of comfort and trust within the squad.

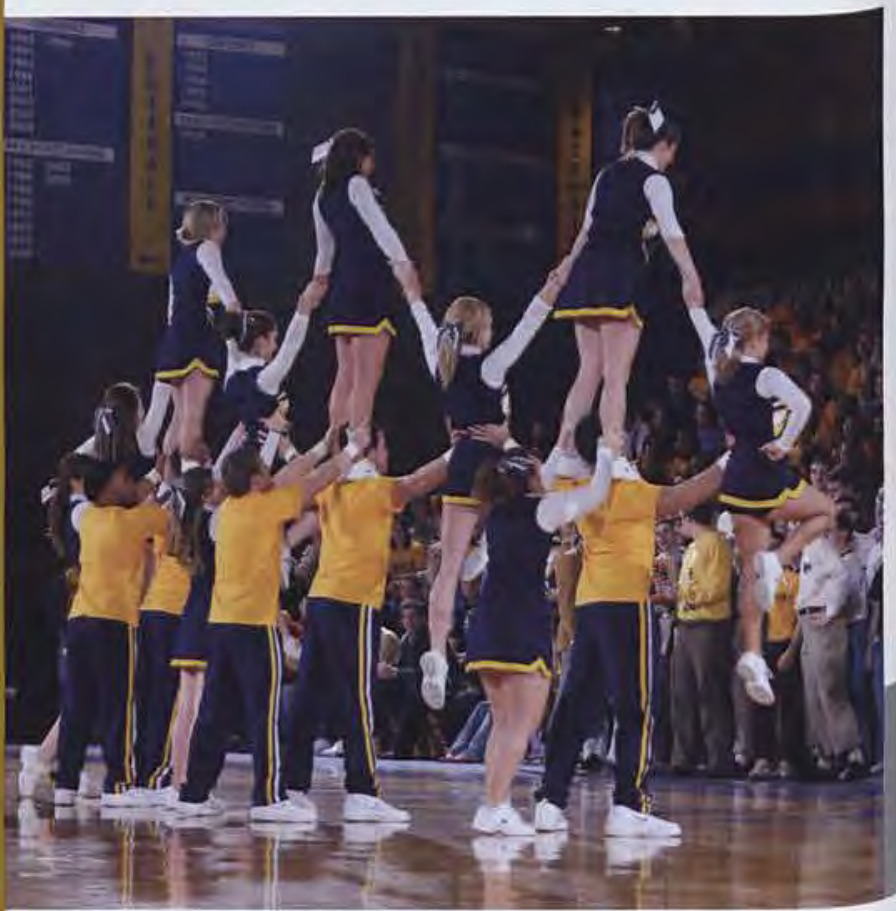


Sophomore Jenna Develbiss makes sure she remembers her cheers in order to effectively encourage the basketball team. The Jackets Cheerleading Squad faithfully attends each game, entertaining fans while enlivening $\mathrm{CU}$ spirit.

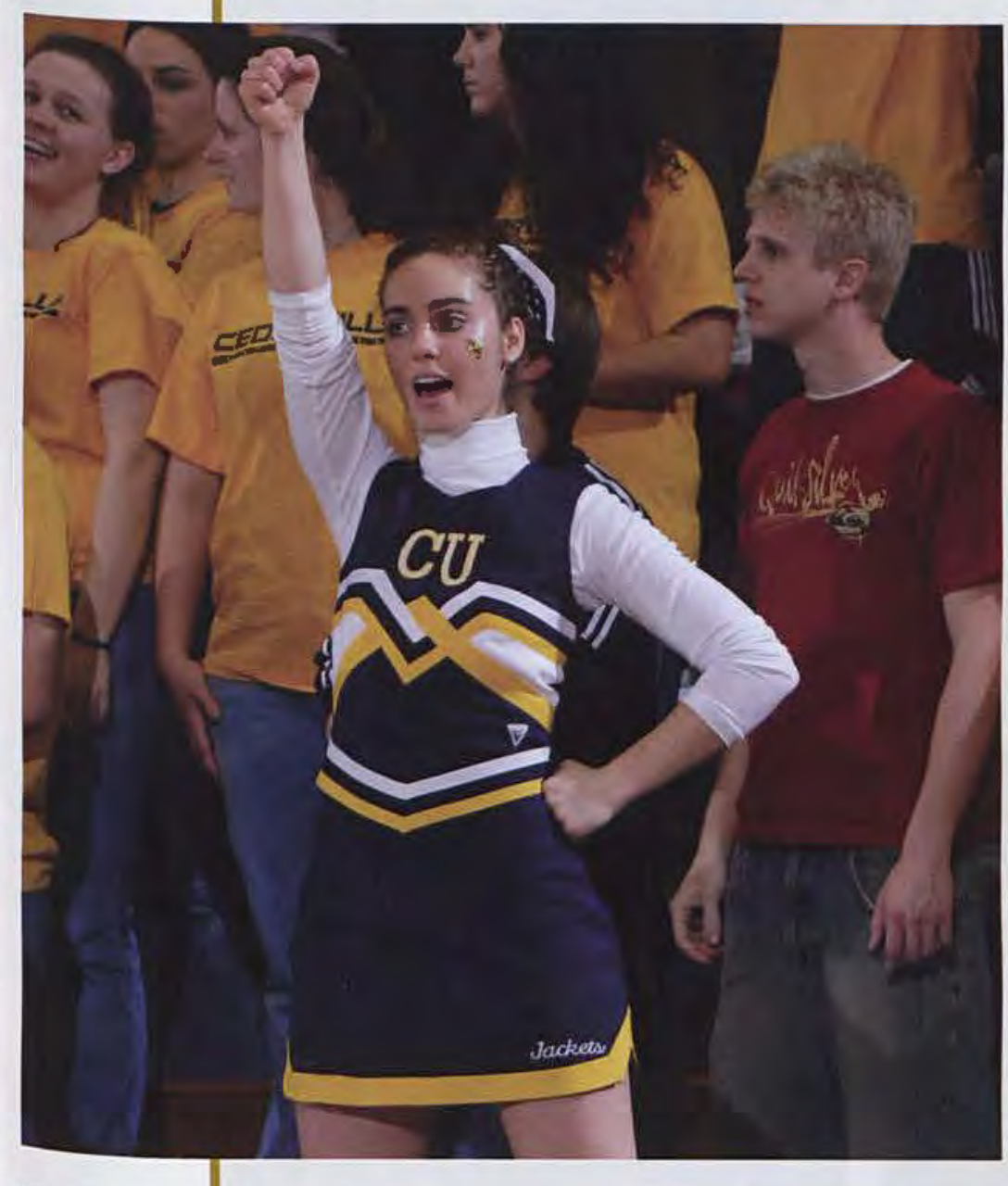

Performing such a complicated and involving stunt like this requires a level of closeness not seen in some athletic teams. "I loved cheerleading this year because of the team members." (Jessica England, senior)
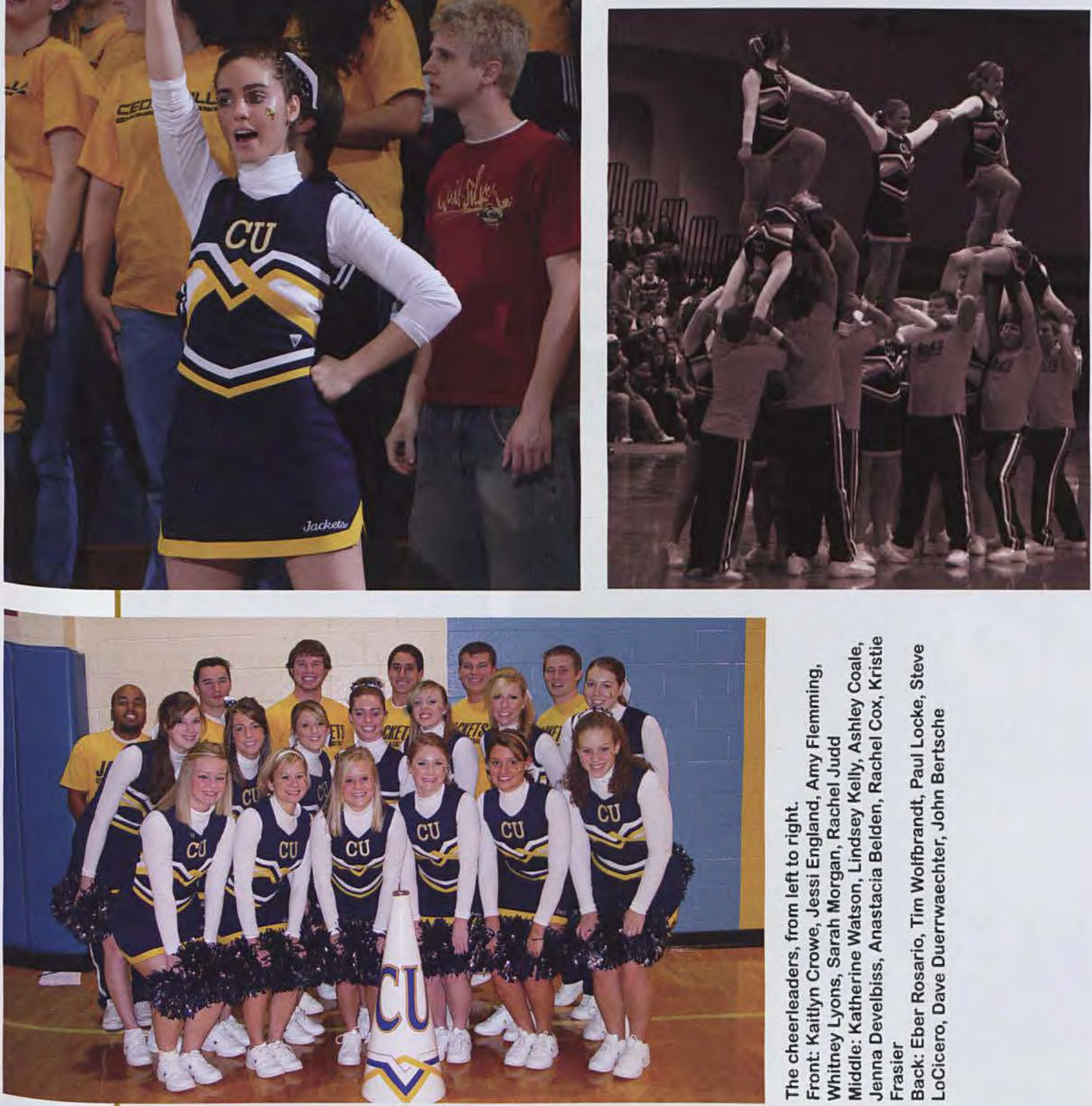
"GETTING TO KNOW THE GUYS ON THE TEAM THROUGHOUT THE YEAR HAS BEEN AWESOME. WHILE MY GAME STRUGGLED THIS YEAR, HAVING THOSE GUYS AS FRIENDS HAS MADE IT A BIT EASIER."

\section{-MATTHEW YEITER, FRESHMAN}

"THROUGHOUT THE YEAR, OUR TEAM REALLY HAD TO COME TOGETHER AND TRUST EACH OTHER TO PLAY WELL, BECAUSE ANY OF THE STARTING FIVE HAD THE ABILITY TO CONTRIBUTE OR PICK UP THE SLACK FOR SOMEONE WHO WAS STRUGGLING, AND THAT WAS A BIG KEY TO THE SUCCESS WE HAD." -MATT KROGSTAD, SOPHOMORE

"We have a purpose other than to hit little white balls all over green grass," said junior Trevor Bowman. "But it's a game we take seriously. If we're going to represent Cedarville and Jesus Christ, it means performing to the best of our ability."
Junior Brandon Ojala focuses intently on his swing. Ojala was a significant contributor to the Jackets golf team during the Mount Vernon Nazarene University Classic.

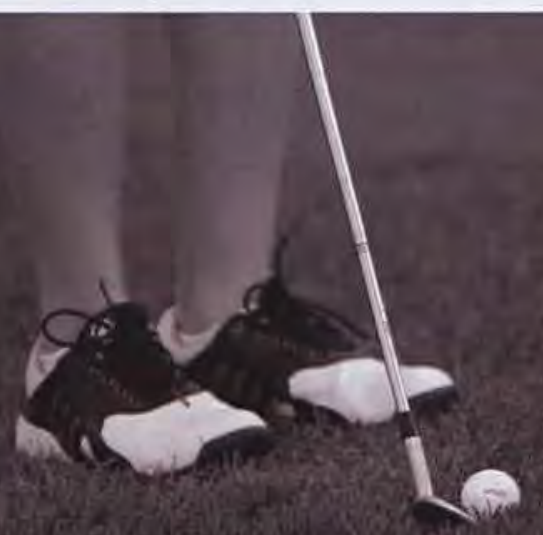

Brett is one of the two Biglers that make up the golf team from the 2007-2008 season. Little brother Nick, a freshman upstart, joined the team after playing four consecutive years at his former high school.

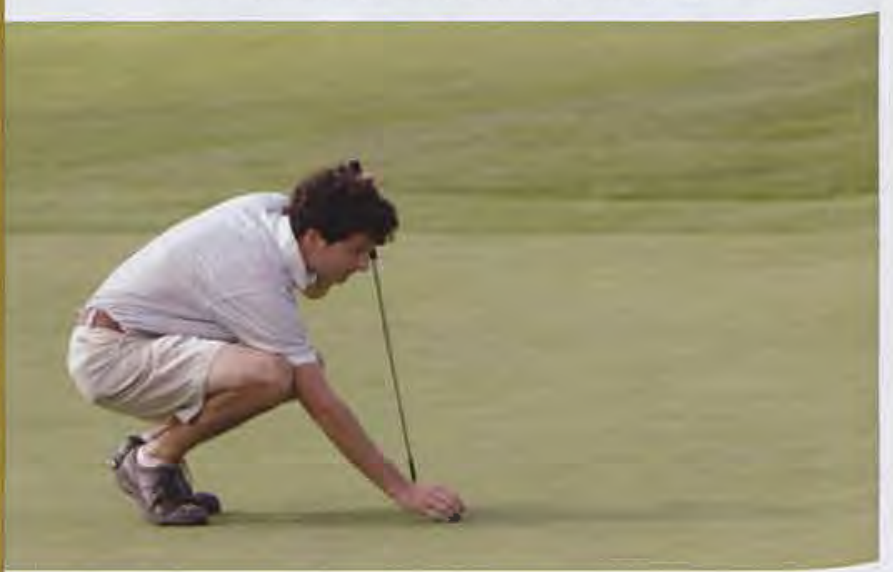

Brett Bigler, junior, keeps his eye trained on the ball's location. Playing his third consecutive year with the Jackets this season, Brett achieved a career best: a 36-hole score of 147. 


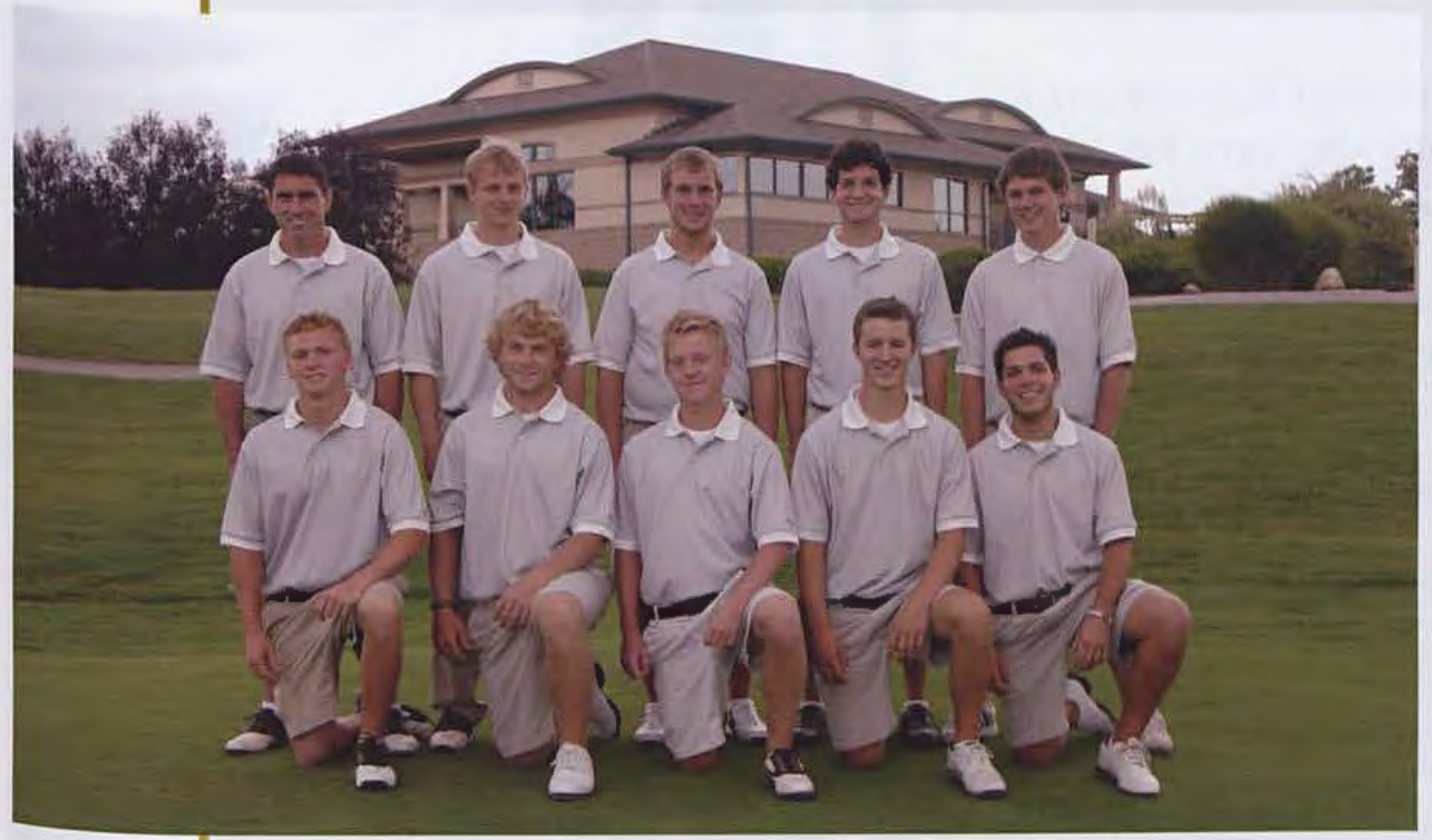

(kneeling left-to-right) Brendan Ojala, Trevor Bowman, Matt Krogstad, Trent Roach, Nick Bigler.

(standing) Head Coach Ryan Bowen, Dan Atkeson, Matthew Yeiter, Brett Bigler, Student Assistant Daniel Servi.

Tiffin Invitational

6th of 9

Urbana Invitational

2nd of 9

Huntington Invitational

2nd of 4

NCCAA Nationals

tie 5 th of 18

Campbellsville Invitational

4th of 9

Southeastern Ky. Intercollegiate

tie 8 th of 22

27th Annual CU Invitational Country Club of the North 1st of 9

Mt. Vernon Nazarene Classic

1 st of 8

NAIA Classic

6 th of 14

AMC/NAIA Region IX

5 th of 10

Junior Trevor Bowman and sophomore Matt Krogstad discuss logistics with head coach Ryan Bowen. Bowen himself has his fair share of $\mathrm{CU}$ golf experience; he was a number one player for three out of his four years of playing at Cedarville when he was a student, from 1988-1991.

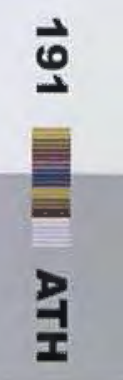




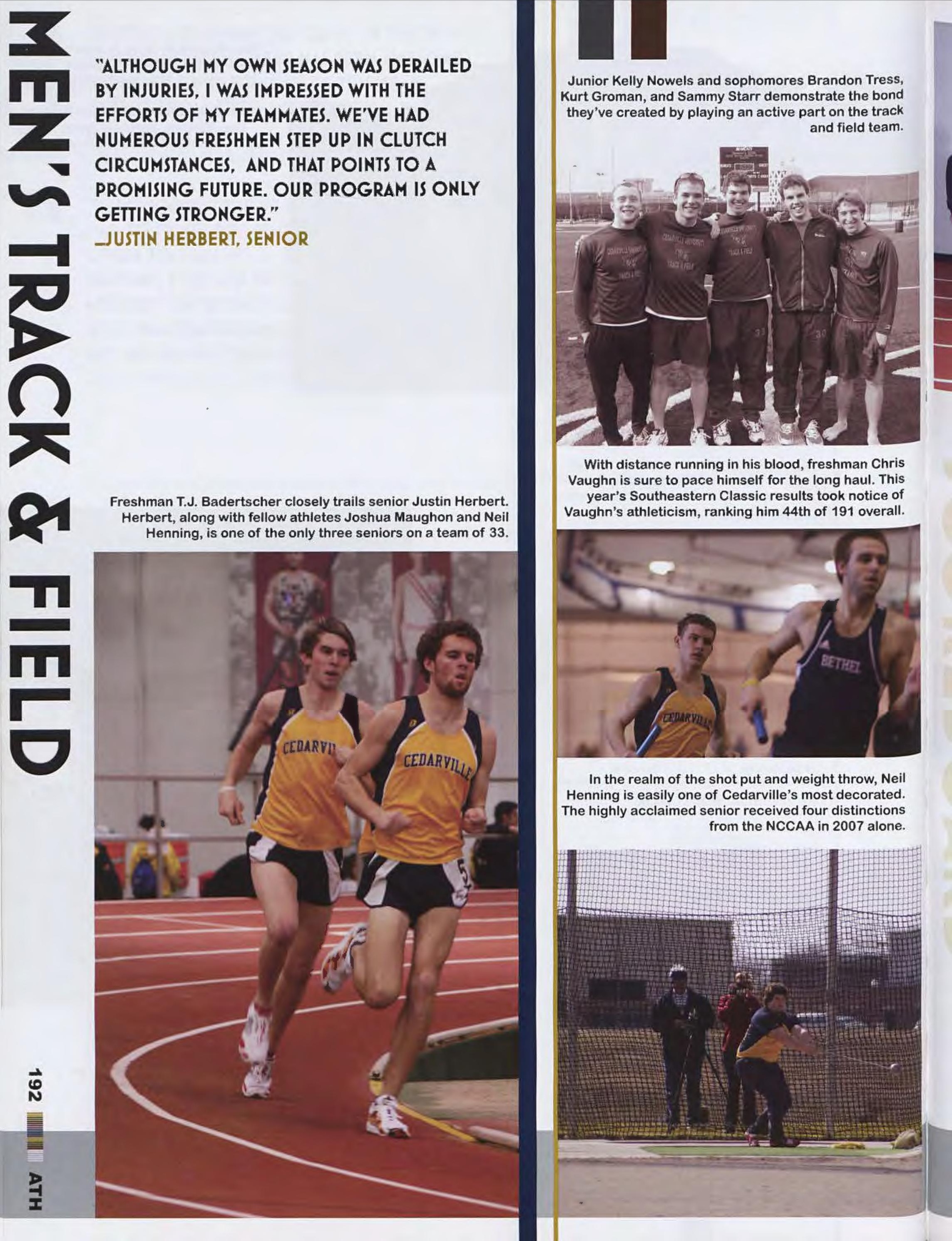




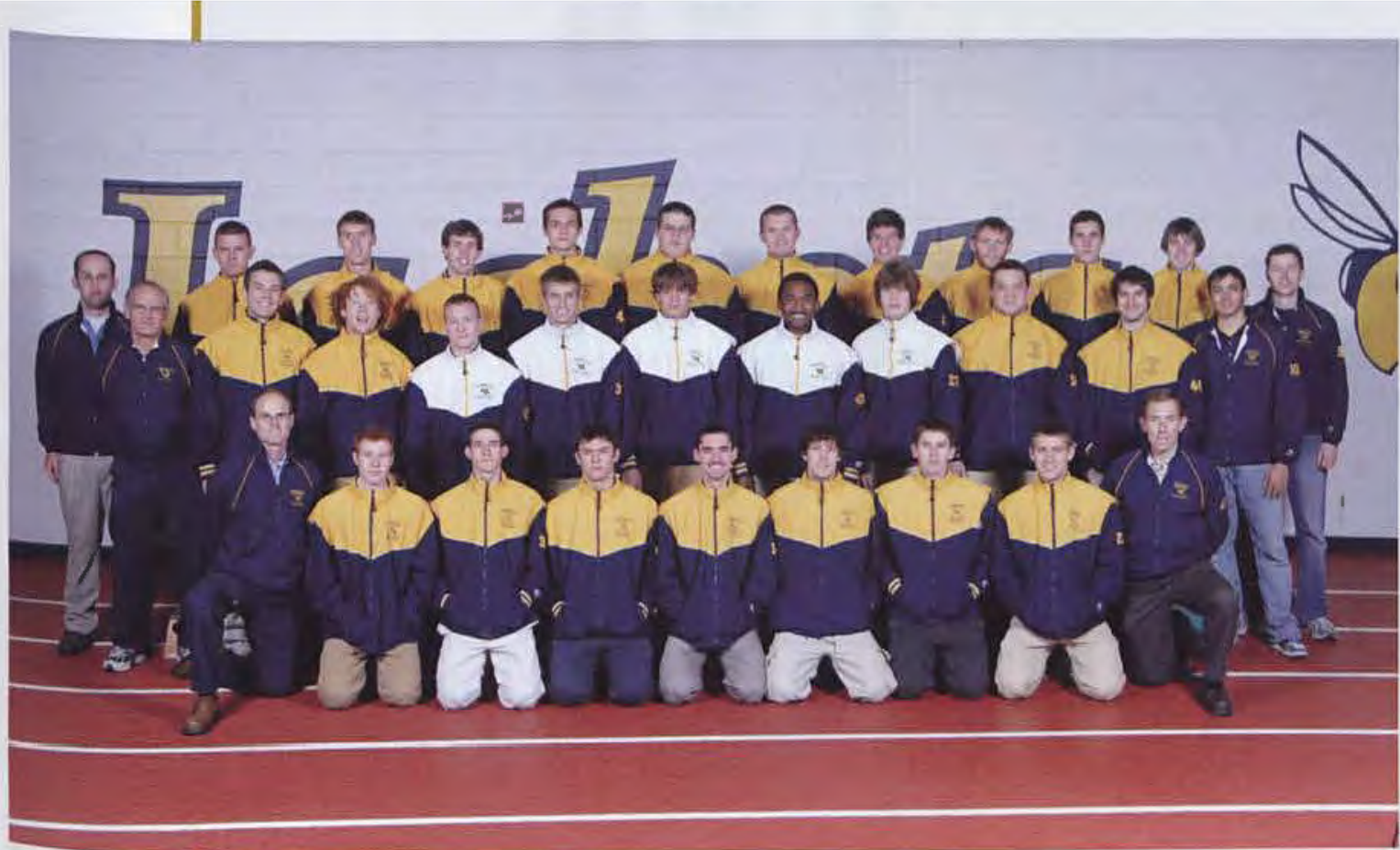

Grant Bacon, T.J. Badertscher, Michael Beight, Marcus Benjamin, Jud Brooker, Seth Campbell, Jordan Davies, Matt Gerton, Kurt Groman, Stephen Gruenberg, Neil Henning, Justin Herbert, Paul Ikeda, Eric Kempton, Kevin Kuhn, Christian Maat, Joshua Maughon, Ben Michaud, Jordan Molstre, Alex Moore, Kelly Nowels, Robert Rasnick, Kevin Ruhlman, Joshua Saunders, Matt Silveira, Travis Smith, Sammy Starr, Rob Trennepohl, Brandon Tress, Hollis Troxel, Chris Vaughn, Mark Williams and Josh Wiseman

INDOOR

Cedarville Invitational

Capital Invitational

$$
1 \text { st of } 9
$$

Indiana Relays

1st of 8

Ohio Northern

Non-Scoring

3rd of 9

Findlay Open

Non-Scoring

NCCAA Indoor Championship

4th of 12

NAIA Indoor Championship

8 th of 89

OUTDOOR

Emory Invitational

Cedarville Open

2nd of 21

1 st of 12

Cincinnati Invitational 14 th 18

Tennessee Relays Non-Scoring

Miami Invitational 7 th of 11

AMC Championship 2nd of 7

NCCAA Outdoor Championship 6th of 15

NAIA Outdoor Championship 22nd of 97

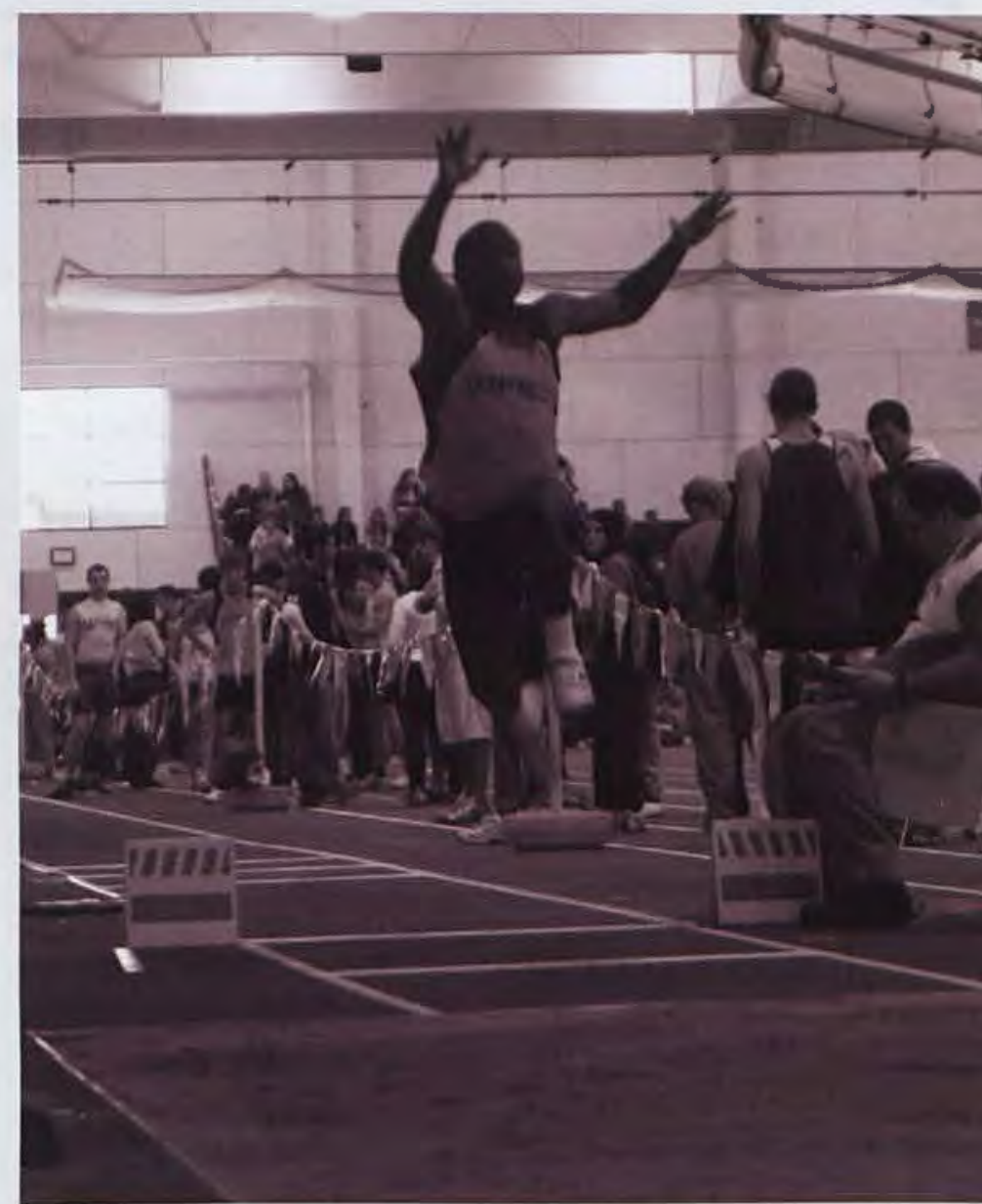

A master of the long jump, junior Travis Smith aims for a record-breaking long jump. Smith reached a record high this season with a 19-9 outdoor long jump at this year's CU Open. 
"ONE OF MY BEST MEMORIES HAS TO BE THE 'TWEENER' SHOT. WHILE BRENT SEEMS TO BE THE ONLY ONE TO HAVE A HANDLE ON IT, THAT DOESN'T STOP COACH FROM LETTING US MAKE FOOLS OF OURSELVES TRYING TO DO IT IN PRACTICE."

-DANIEL ORMSBY, FRESHMAN

"BEATING ERSKINE 5-4 IN THE FIRST MATCH OF THE SEASON WAS GREAT. THIS WAS A REALLY IMPORTANT WIN FOR US, BECAUSE THEY HAD BEATEN US 5-4 THE PREVIOUS TWO YEARS AND WE BEGAN THE SEASON WITH A GOOD WIN." -BRENT MARTIN, SENIOR

Senior Dan Ballard relishes on one of his last matches at Cedarville. "Regardless of our record, we have great guys that I like being around and it has just been really fun to be a part of this team."
Doubles partners Brent Martin (senior) and Caleb Speicher (sophomore) maintain the "gentlemanly" reputation of Tennis by shaking hands with Tiffin, their fierce opponent.

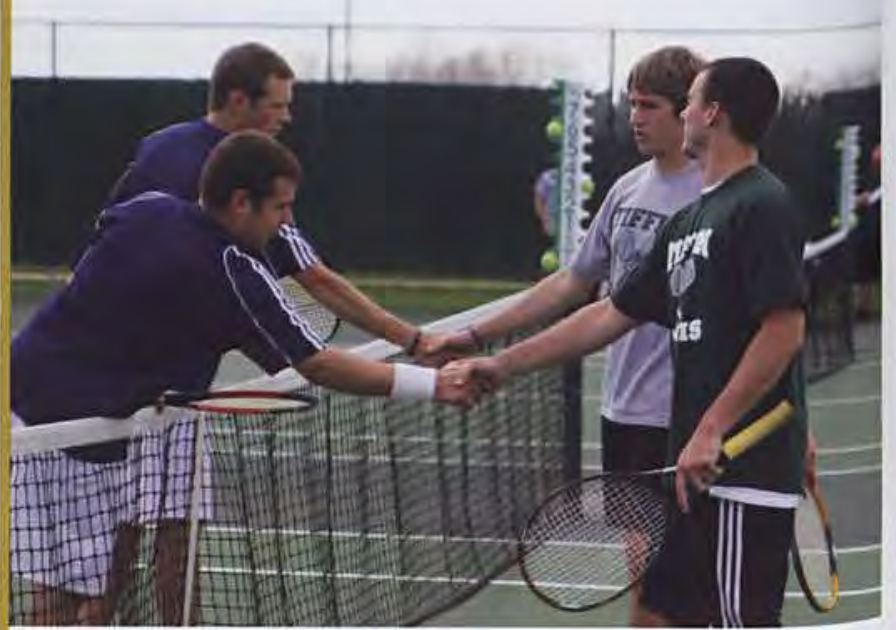

Among the several memorable moments of the 20072008 Tennis season, junior Kevin Furst mentions a few prominent ones: "sitting in our crowded tenpassenger vans with the guys," and "Caleb Speicher's crazy schizophrenia on the court."

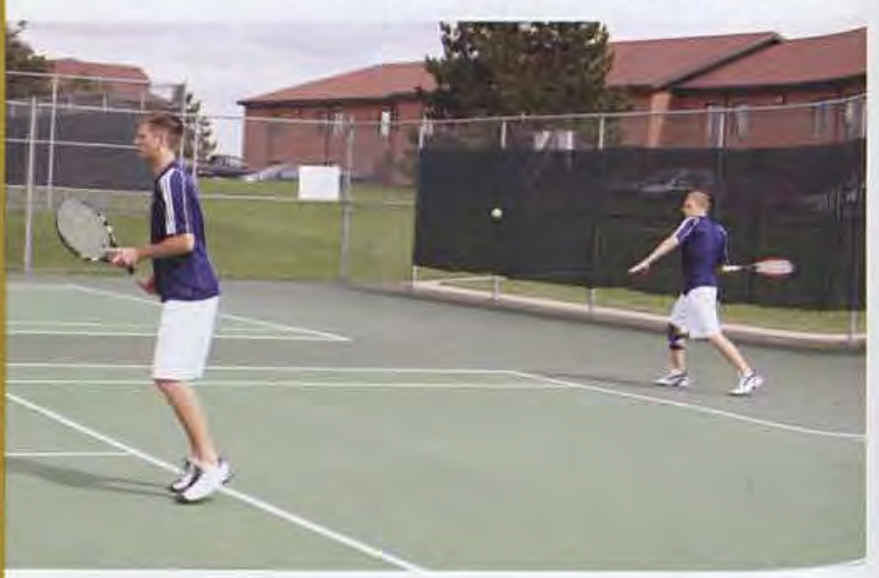

Made unmistakable by his intimidating knee brace, junior Kevin Furst winds up a powerful serve that will prove next to impossible for his opponents to receive. 


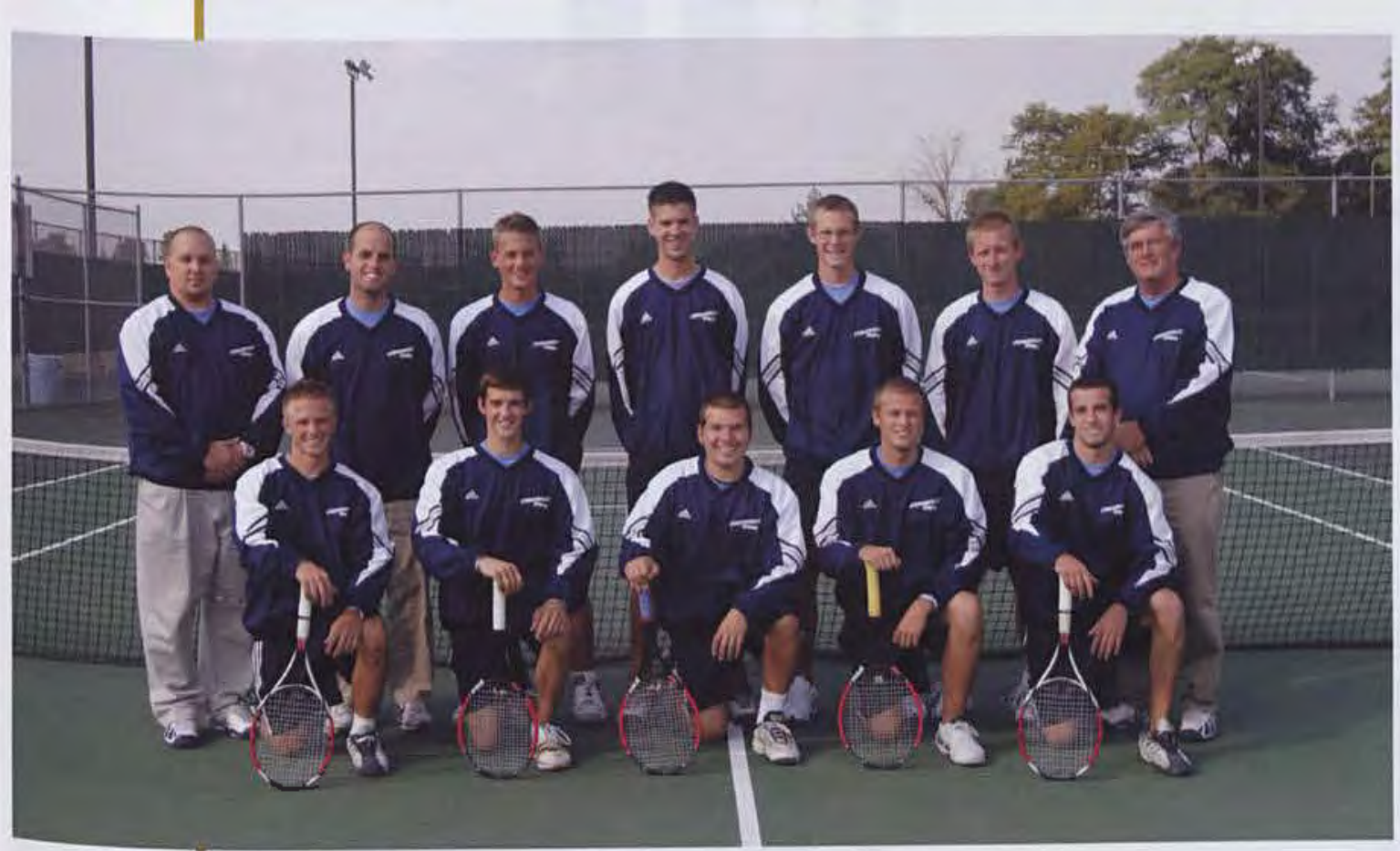

(kneeling left-to-right) Derek Hostetter,

Daniel Ormsby, Caleb Speicher, Kyle

Kirby, Zach Rost

(standing left-to-right) Assistant Coach Jamie Hand, Team Chaplain Bob Lutz, Jeff Whitcomb, Dan Ballard, Brent Martin, Kyle DeBoer, Head Coach Alan Edlund.

$\begin{array}{ll}\text { Erskine } & \text { W 5-4 } \\ \text { Northwestern Ohio\# } & \text { W 8-1 } \\ \text { Northern Kentucky\# } & \text { L 1-8 } \\ \text { Findlay\# } & \text { W 7-2 } \\ \text { Huntington } & \text { L 3-6 } \\ \text { Indiana Wesleyan\# } & \text { L 4-5 } \\ \text { Wabash (at Wittenberg) } & \text { L 3-6 } \\ \text { Wittenberg } & \text { W 6-3 } \\ \text { Malone } & \text { L 4-5 } \\ \text { Ohio Dominican } & \text { W 5-4 } \\ \text { Walsh\# } & \text { L 4-5 } \\ \text { Bethel (Ind.)\# } & \text { W 7-2 } \\ \text { Asbury } & \text { W 9-0 } \\ \text { Roberts Wesleyan } & \text { W 6-3 } \\ \text { Tiffin } & \text { W 5-4 } \\ \text { Notre Dame } & \text { W 7-2 } \\ \text { Walsh } & \text { L 4-5 } \\ \text { North Greenville\% } & \text { L } 2-5 \\ \text { Olivet Nazarene\% } & \text { L 0-5 }\end{array}$

+ NAIA Region IX Tournament; North Canton, Oh $\%$ NCCAA National Tournament; Marion, Ind. \# Indoor matches; home played at Springfield Racquet Club

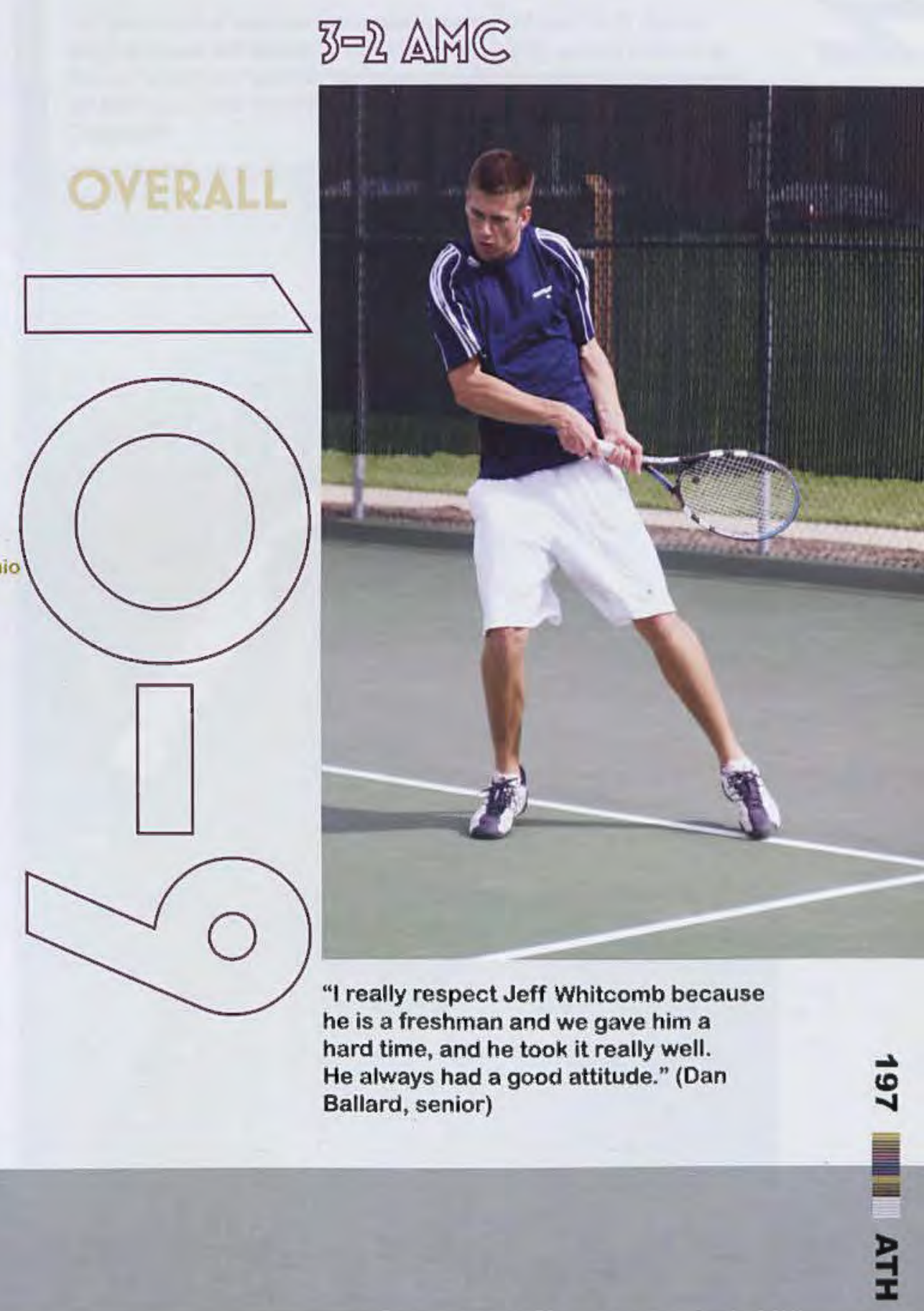


"MY FAVORITE MEMORY FROM THIS YEAR IS SPRING BREAK AND EVERYTHING THAT IT ENTAILED...FROM OUR SLEEPER-BUS TO THE BEAUTIFUL WEATHER TO THE GIGANTIC HOMEMADE DINNERS WE ATE EVERY NIGHT AND THE CHANCE TO BOND WITH THE IO OTHER GIRLS ALL LIVING TOGETHER IN THE SAME HOUSE!"

- SARAH ANDERSEN, JUNIOR

\section{"ALL OF THE GIRLS ON THE TEAM ARE GREAT ENCOURAGERS AND HUMBLE, CHRIST-CEN-} TERED INDIVIDUALS. TO BE ON A TEAM WITH IO OTHER GIRLS THAT REALLY KNOW WHAT IT MEANS TO LOVE ONE ANOTHER WAS SUCH AN HONOR AND PRIVILEGE."

-ANNA STRAYHORN, JUNIOR

Senior Melinda Workman especially bonded with fellow '08 graduate Olivia Dolph. "I especially enjoyed the times we sat down to share ideas with one another concerning how to lead the team as seniors. Her friendship on and off the court will be missed."
Another hit is successfully returned by sophomore Georgiann McClure. To McClure, playing Tennis for the Lady Jackets means more than competition.

"Each lady on the team is very special to me, and I care about them all a lot."

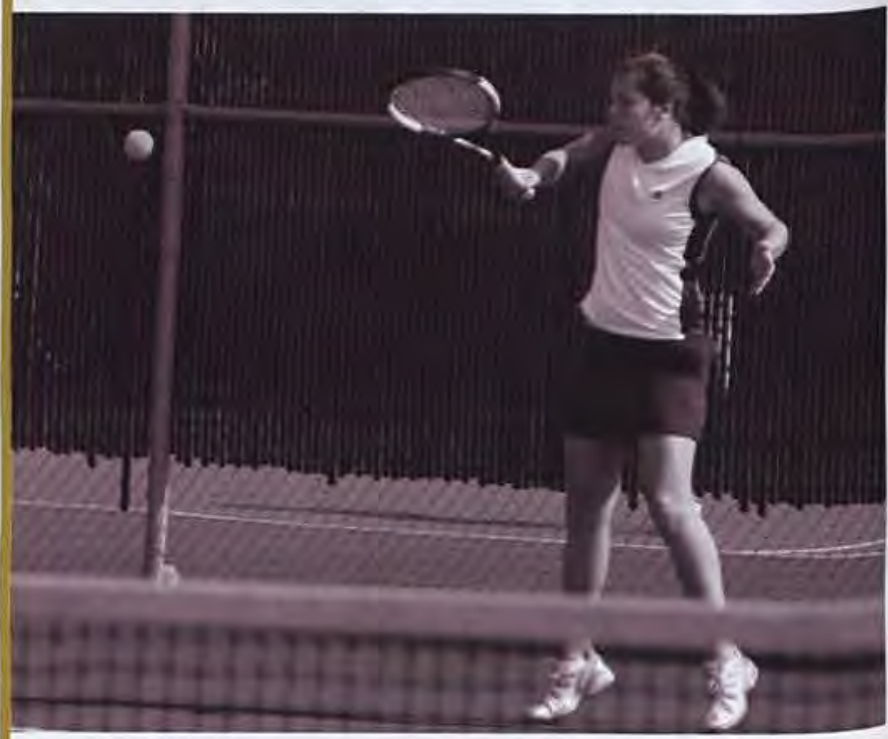

Preparing for one of her typically powerful serves, freshman Joy Kellogg brought an impressive repertoire with her when she joined this Jackets this year; Kellogg won the Greater Buckeye Conference Player of the Year three straight years in a row.

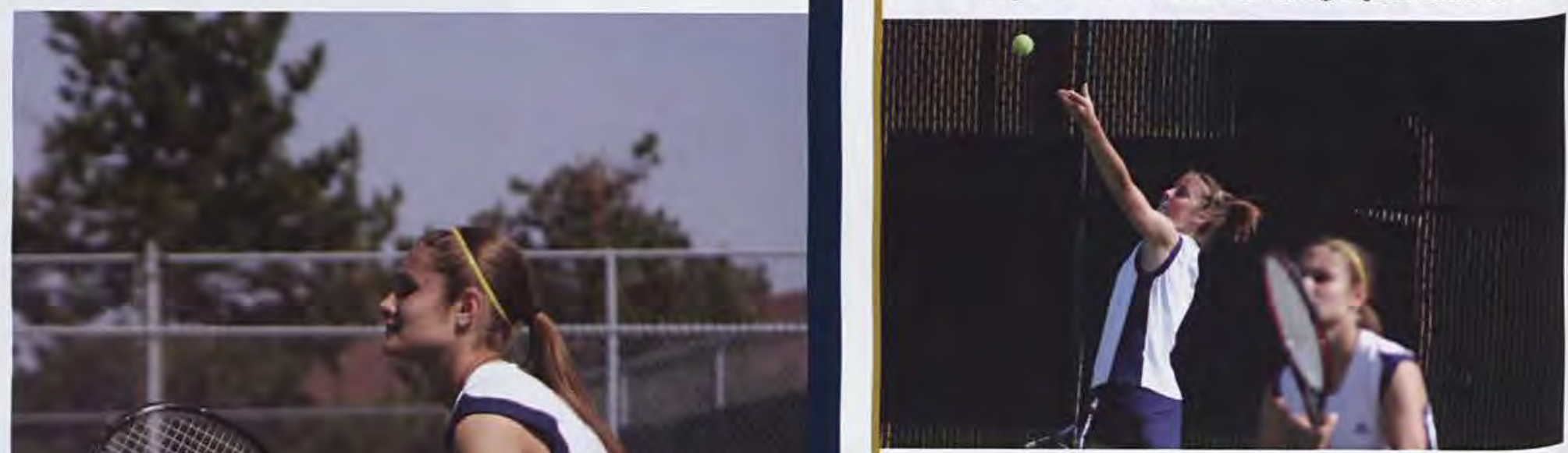

Starting as a freshman and continuing to play until the end of her senior season, Alisa Rutt regards being a part of this team as an integral part of her college career. "I've learned so much about life through competing and playing on a team; it's an experience that I wouldn't trade for anything." 


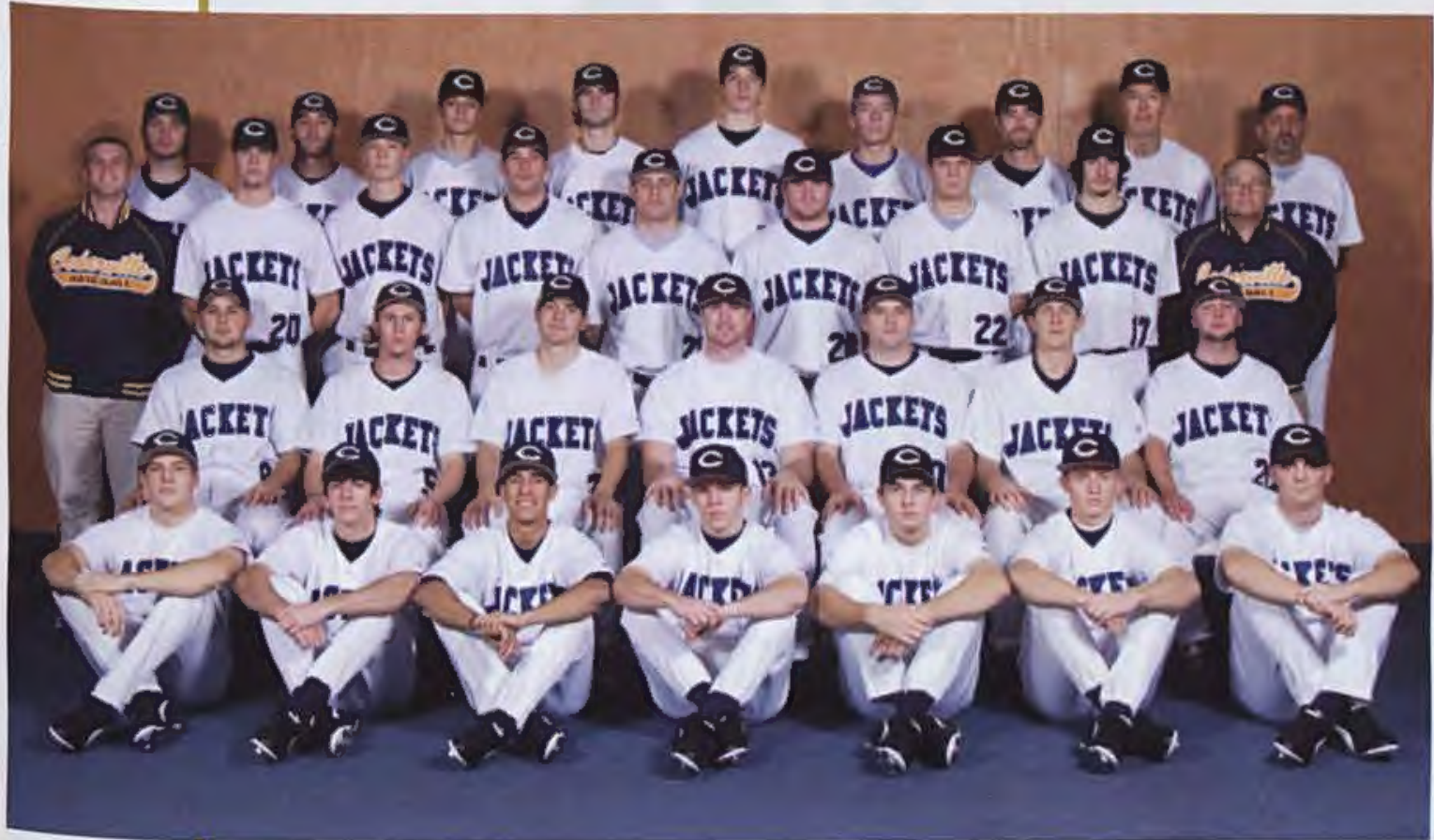

(front row, left-to-right) T.J. Taylor

Mike Hageman, Phil Cruz, Nate

Wilson, Zachary Sorensen, Tyler Rost, Jonathan Smith.

(second row) Paul Wilson, Matt Owens,

Derek Woloshyn, Matt Houchin, Pete

Kraus, Jared Griest, Matt Totten.

(third row) Student Athletic Trainer

Peter Brock, Mitch Vella, Jordan

Shumaker, Micah Wilson, Jordan

Siefkes, Joshua Chamberlin, Brady

Workman, Nathan Wallace, Associate Athletic Trainer Bob Duchardt.

(back row) Assistant Coach Kie Boynton, Assistant Coach Eric Wilson, Rob Wasem, Clint Price, Colby Stoltzfus, Andrew Lockridge, Brandon Young, Assistant Coach John Meyer, Head Coach Mike Manes.

Asbury

Florida College

Evangelt+

Grace+

Hannibal-LaGrange+

Robert Morris (III.)+

Evangel+

Indiana Wesleyan+

Grace+

Northwestern+

Grace\#

Concordia (Mich.)\#

Walsh*\#

Point Park *\#

Wright State

Mount Vernon Nazarene*

Malone*

Ohio Dominican*

Notre Dame*

Wilmington

Ohio Dominican*

Urbana*

Shawnee State*

Earlham

Indiana Northwest

Miami-Middleton

Shawnee State*

Earlham

Rio Grande*

Rio Grande*

Urbana*

Cincinnati-Clermont

Valparaiso

Indiana Wesleyan\%

Indiana Wesleyan\%

Oakland City\$

Bluefield\$

Geneva\$

* American Mideast Conference

+ Clearwater Invitational; Clearwater, FL

\# Home games at the Athletes in Action Sports Com-

plex, Xenia

$\%$ NCCAA Midwest Regional; Cedarville (Best 2-of-3)

$\$$ NCCAA National Tournament; Struthers, Ohio
L 5-9

W 18-3,L 5-13

L $1-7$

W 9-1

L 3-9

W $10-5$

W 6-5

L 5-9

W $9-2$

L 2-3, L 2-9

L 0-11, L 0-11

W $2-0$, W $5-3$

L 1-17

L 0-7, L 2-12

L 3-5, L 1-8

L 3-11, L 1-8

L 4-5, W 5-3

W 7-6

L 0-10, L 2-7

W 3-2, L 4-15

L 1-6, L 6-7

W 9-6

W 17-0, W 15-0

W 9-0

W 2-0, L 3-9

W 6-2, W 12-0

L 7-12, L 2-3

W12-11, W10-8

L 1-3, W 6-5

W $10-3$

L 6-13

L 1-6,W 6-3

L $1-6$

L 7-9

W 13-11

L 8-10
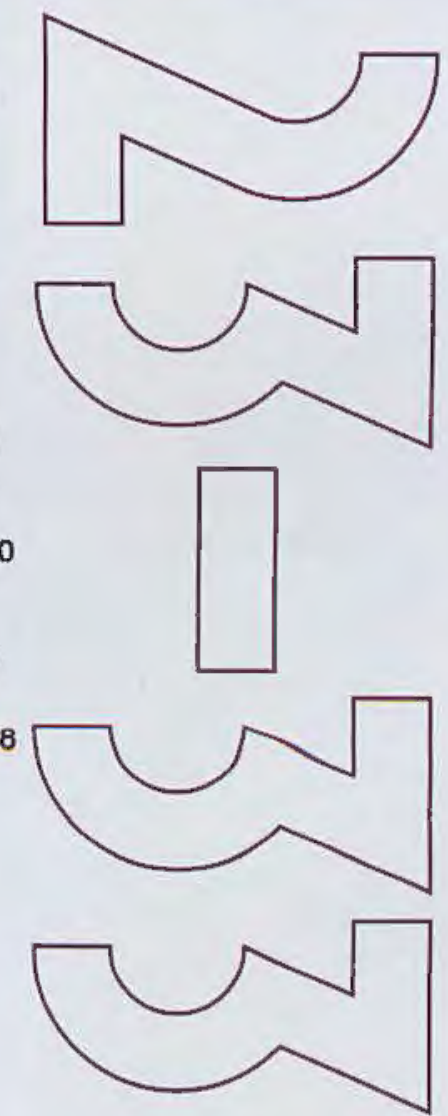
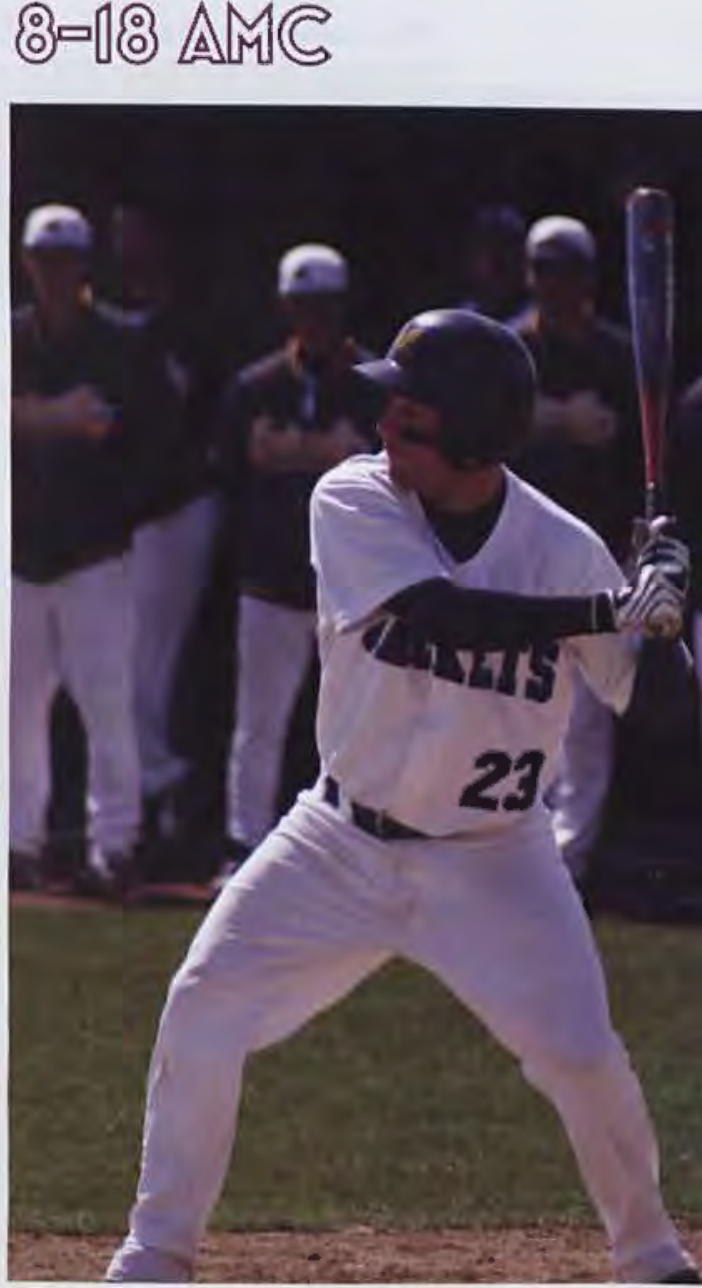

The Yellow Jackets Baseball team knew the importance of hard work and dedication. "Every game is a reflection of the player who plays it. Autograph your work with excellence." (Micah Wilson, junior) 


\section{"CU SOFTBALL IN THE SPRING OF 2008 CAN BE DESCRIBED ONLY AS "TONS OF FUN IN EVERY WHICH WAY." \\ -WES ROWE, HEAD COACH}

Keeping an eye on the action with unmistakable concentration, sophomore Jenna Fox makes sure her base is effectively covered. Fox led her team this season, with a .983 fielding percentage

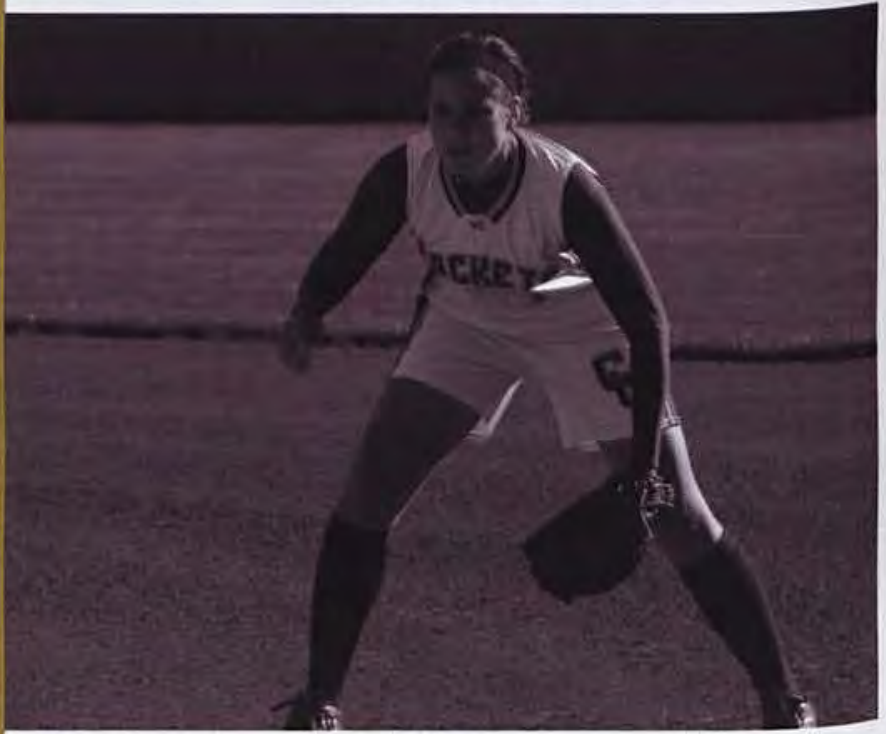

"Though our record reads winning a little less than half our games, we grew in a lot of ways that we never expected. The softball team will continue to have a lot of success in the coming years." (Mallory White, sophomore)

the good and the bad. We never gave up. Our team as a whole became so close and everybody was willing to make sacrifices

to help us improve." (Sara Koepke, sophomore)

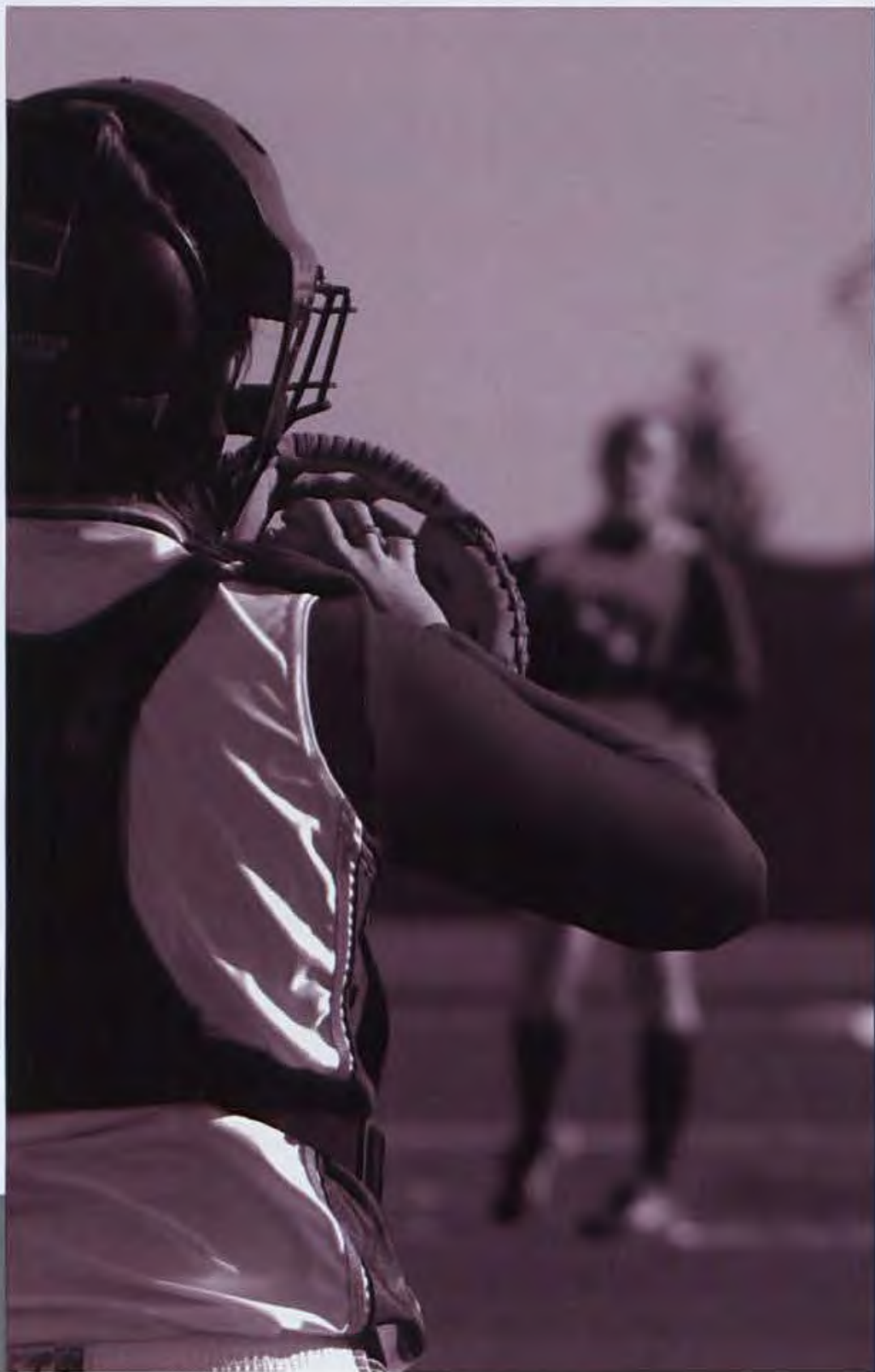


(front row left-to-right) Charissa Rowe, Sarah Harnica, Andrea Walker, Sarah Hoffman, Sara Koepke, Jessica Reyes.

(middle row) Rachel Ross, Aubree Munson, CrystalRae States, Jenna Fox, Hannah Carter, Mallory White,

Christina Zorn.

(back row) Student Manager Laura Halladay, Student Athletic Trainer Grace Sims, Assistant Coach Joy Fagan, Assistant Coach Dave

Freese, Head Coach Wes Rowe, Head Assistant Coach Dave Stewart, Assistant Coach Kari Flunker, Associate Athletic Trainer Lisa Martin, Student Manager Stephen Grist.

Valley City State+

Point Park+

King's (Pa.)+

Hannibal LaGrange+

Carlow+

Rochester (Mich.)\#

Bluffton

Wilmington\#

Siena Heights\#

Rio Grande*

Rio Grande*\#

Indian Wesleyan\#

Shawnee State $\#$

Ohio Dominican*

Mount Vernon Nazarene*

Mount Vernon Nazarene*

Urbana*

Ohio Dominican*

Spring Arbor\%

Indiana Wesleyan \%

Spring Arbor\%

Indiana Wesleyan $\%$

Urbana*

Shawnee State*

* American Mideast Conference

+ Cocoa Expo; Cocoa Beach, FL

$\%$ NCCAA Midwest Regional; Spring Arbor, MI

* Home games at the Alhletes in Action Sports Complex, Xenia

L 3-6

L $0-2$

W 4-3

L $7-8$

L 3-10

L. $0-11$
L 3-10, L0-3

W 2-1, W 11-8

W 1-2, L 3-2

W 3-2, W 11-5

L 2-10, L 2-9

W 4-0, W 7-3

W 6-1, W 8-0

L 4-6, L 9-10

L 5-14, L 0-14

W 8-7, L 2-10

L 3-7, W 5-3

L 1-2, L 1-4

W 6-4, W 1-0

L. 0-8, L 4-6

W 4-1, L 1-10

L 0-7, L 1-4

W 5-3, L. 3-4

W 4-0, W 2-1
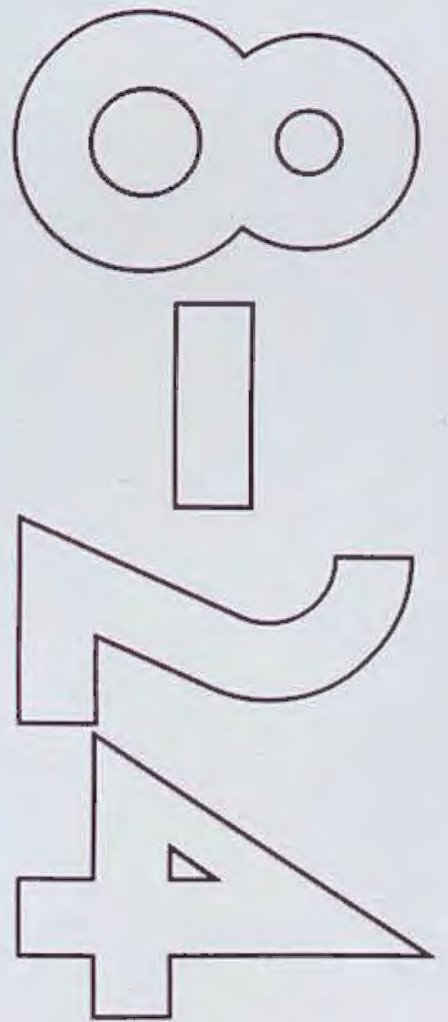

$7013 \mathrm{AMC}$

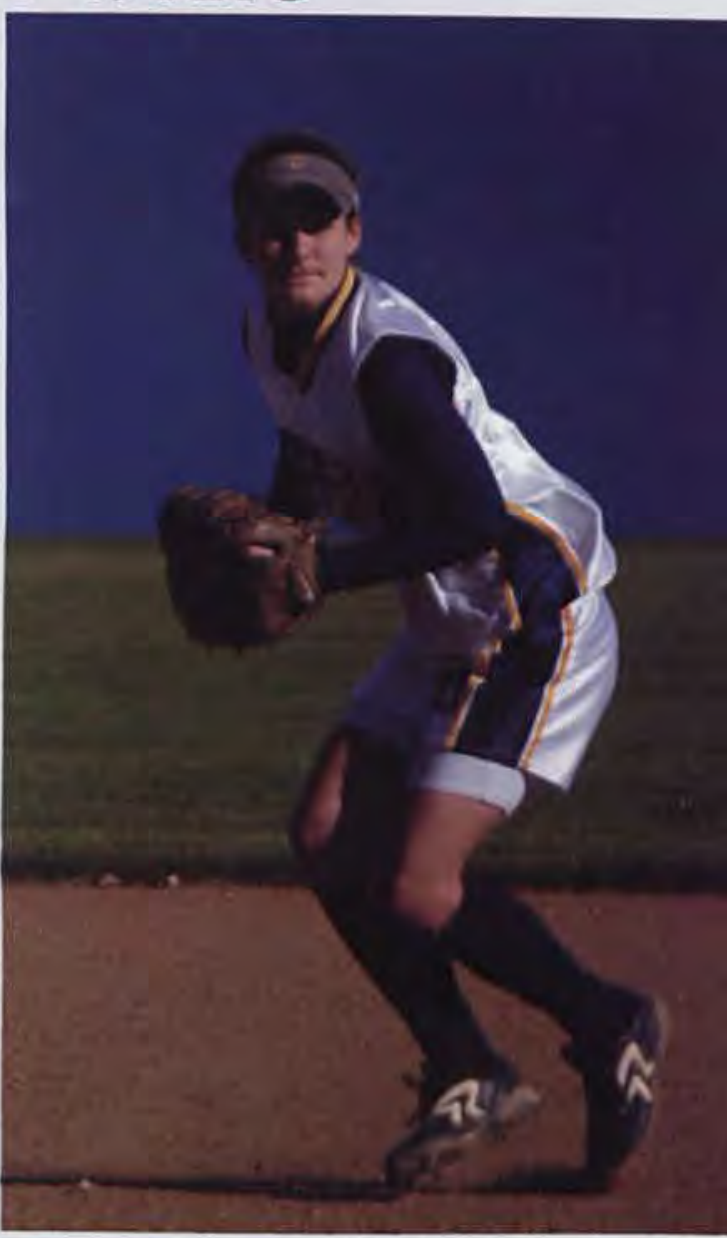

Senior and co-captain Andrea

Walker makes a quick and effective turn to make her throw to first base. 
"I LOVED HOW WE REALLY STRIVED TO BE A TEAM AND HOW OUR RELATIONSHIPS GOT STRONGER WITH EACH OTHER THROUGHOUT THE WHOLE ENTIRE SEASON. NO MATTER WHAT HAPPENED, WE WERE ONE AND ALWAYS THERE FOR EACH OTHER. WHEN I FRACTURED MY NOSE BEFORE OUR VERY FIRST GAME, I HAD TO WEAR A FACE MASK, AND EVEN THOUGH I HATED IT, MY TEAMMATES ALWAYS WERE ENCOURAGING ME THROUGHOUT THE WHOLE SITUATION." _JERNELLE WARD, FRESHMAN

"Getting to know the guys on the team throughout the year has been awesome. While my game struggled this year, having those guys as friends has made it a bit easier." (Matthew Yeiter, freshman)

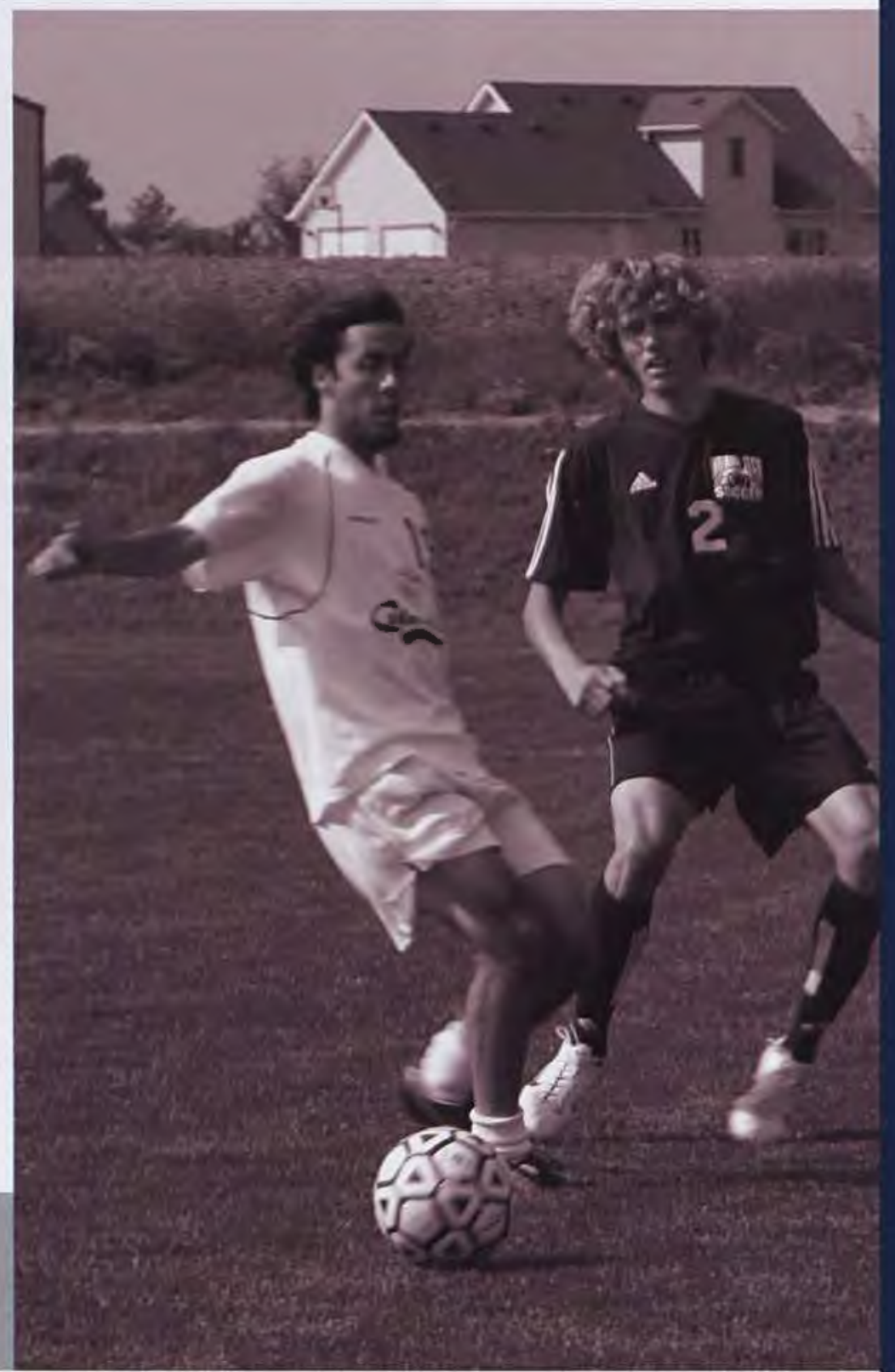

"My favorite part of being on a JV team is that you are kind of looked at as an underdog. People tend to not expect as much out of JV players, so you really have the opportunity to surprise and impress them." (Sarah Hoffman, junior)

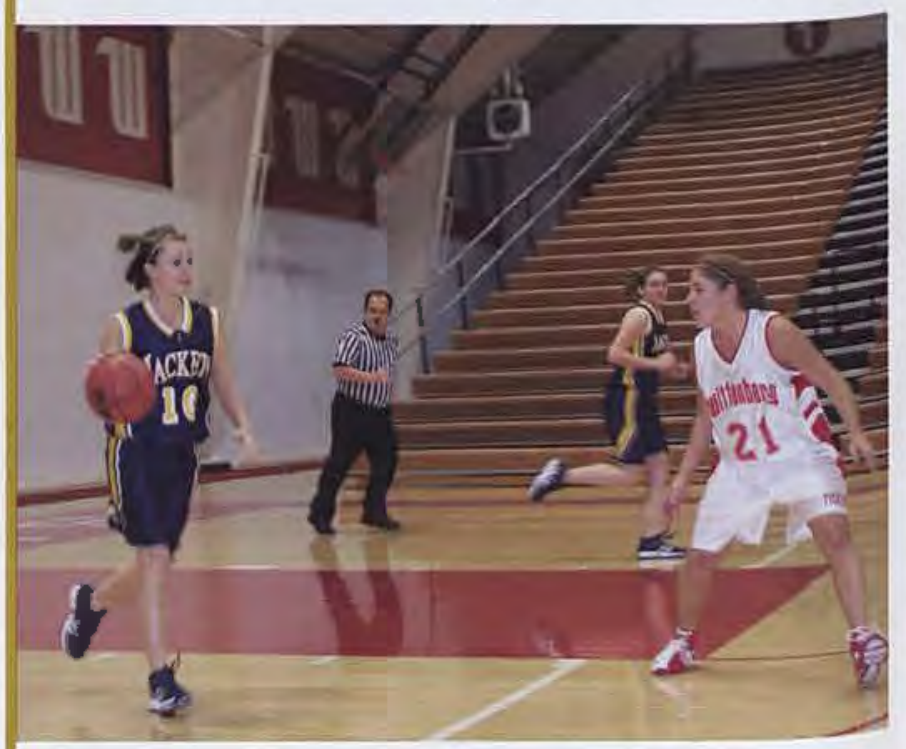

"Throughout the year, our team really had to come together and trust each other to play well, because any of the starting five had the ability to contribute or pick up the slack for someone who was struggling..."

(Matthew Krogstad, sophomore)

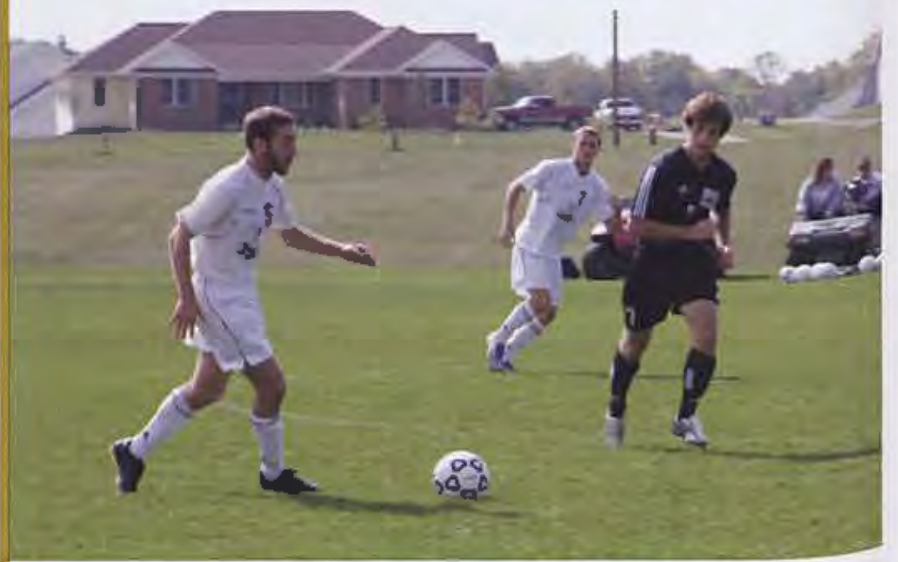

"I think JV sports are important because it allows students to continue to be challenged to grow and develop as a student athlete at the collegiate level, but it is not as demanding as a varsity sport."

(Lynsey Fabian, JV women's basketball coach)

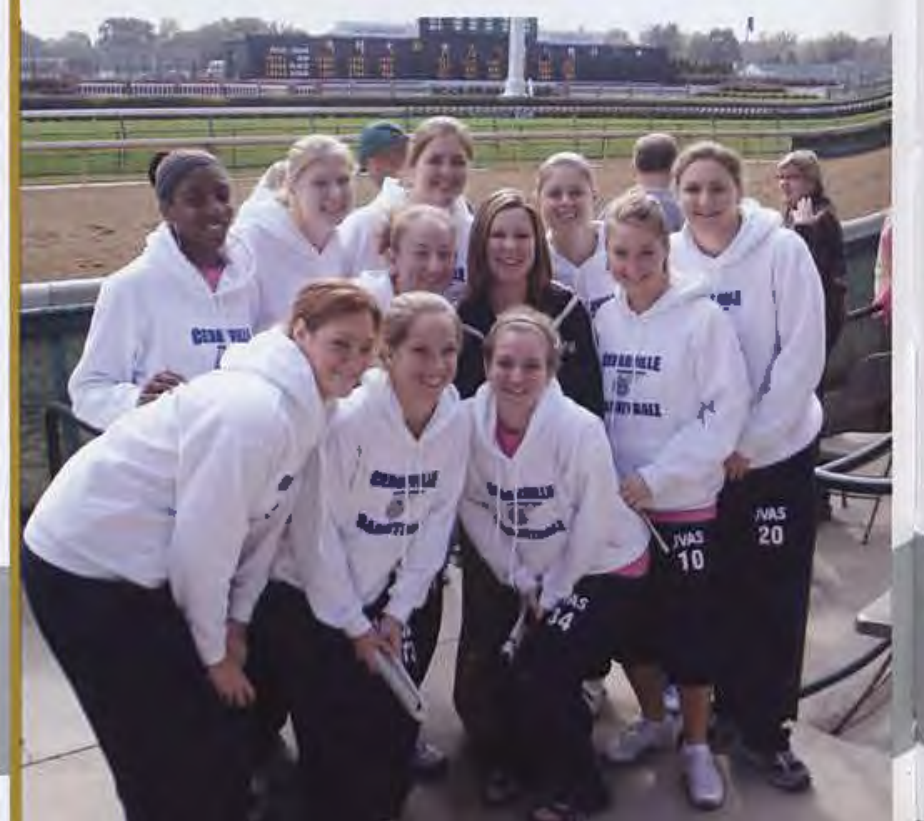


"The girls played with so much heart and intensity and, more importantly, selflessly and as one unit. I'm really proud of the determination and perseverance the girls demonstrated to finish the season!" (Lynsey Fabian, JV women's basketball coach)

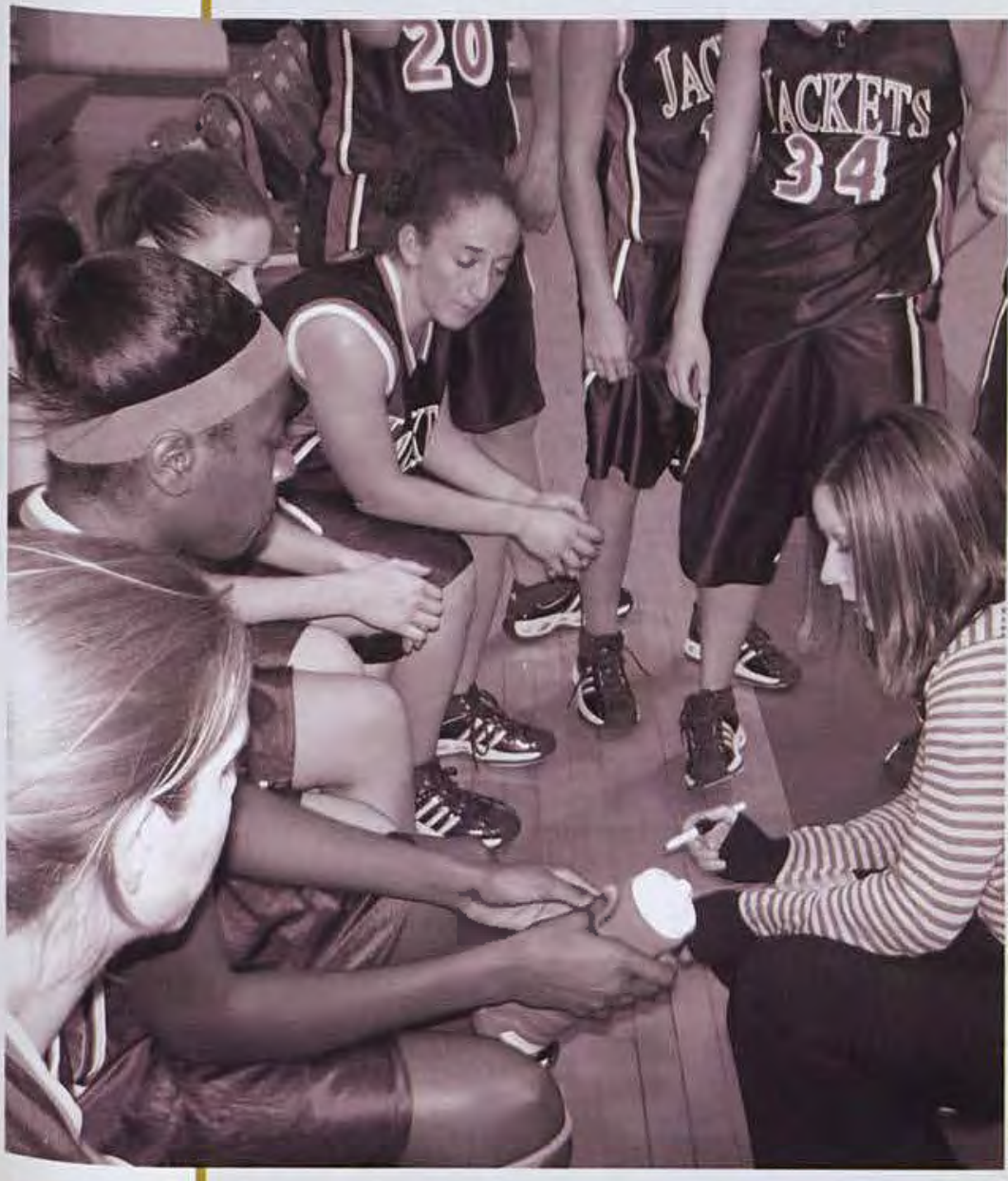

Up and coming $\mathrm{CU}$ soccer player looks for an open player to make a throw to.
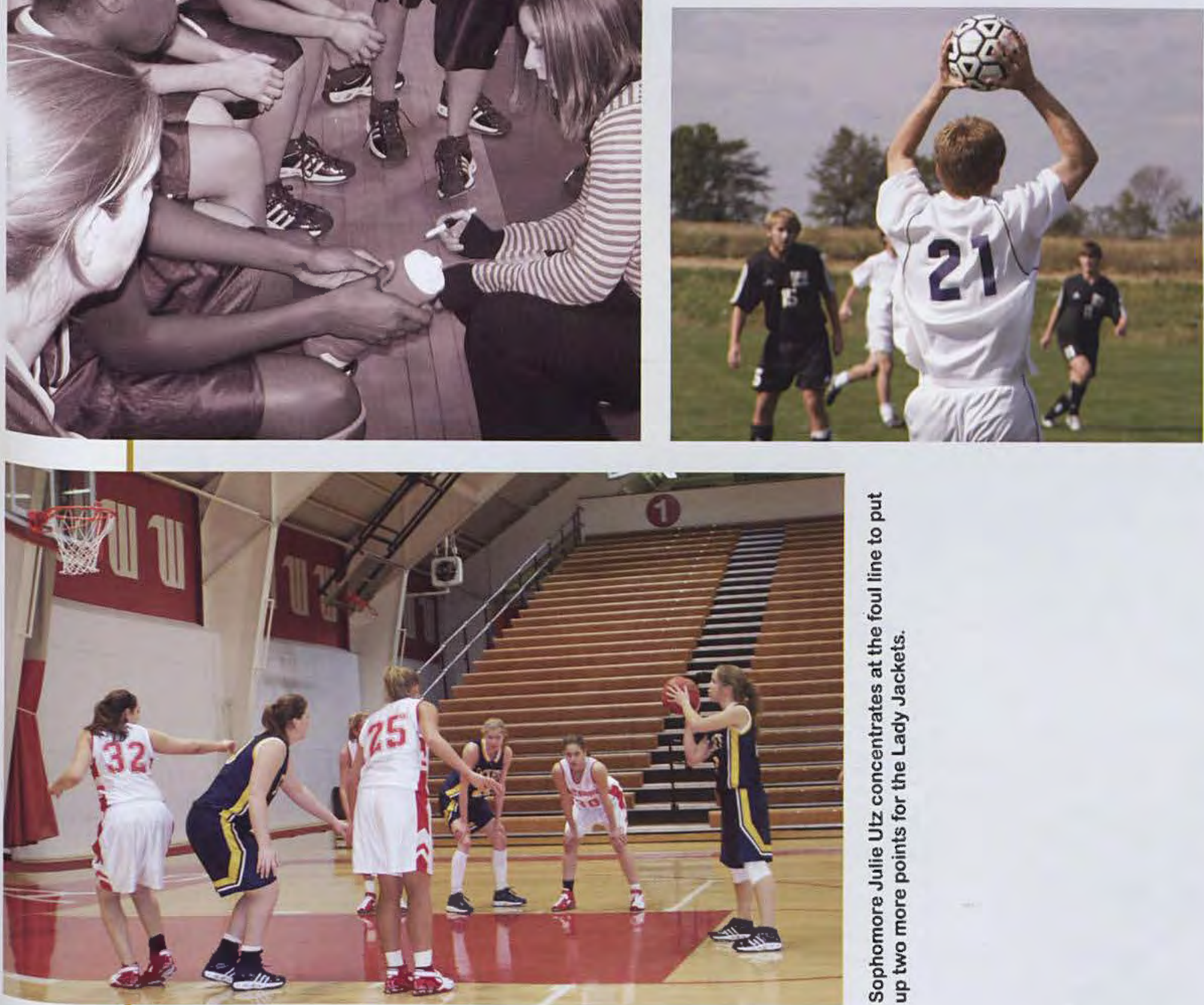

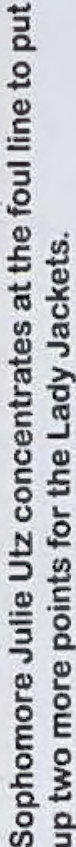


WHERE WILL COME

A TME WHEN YOJ

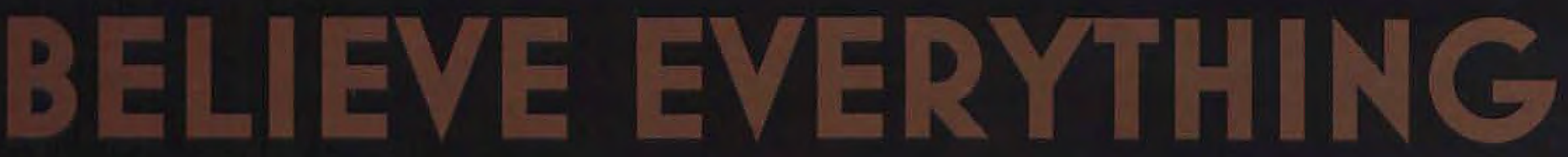

IS FINISHED, THAT WILL

BETHE :ECDNANC,

- LOUIS LAMOUR 

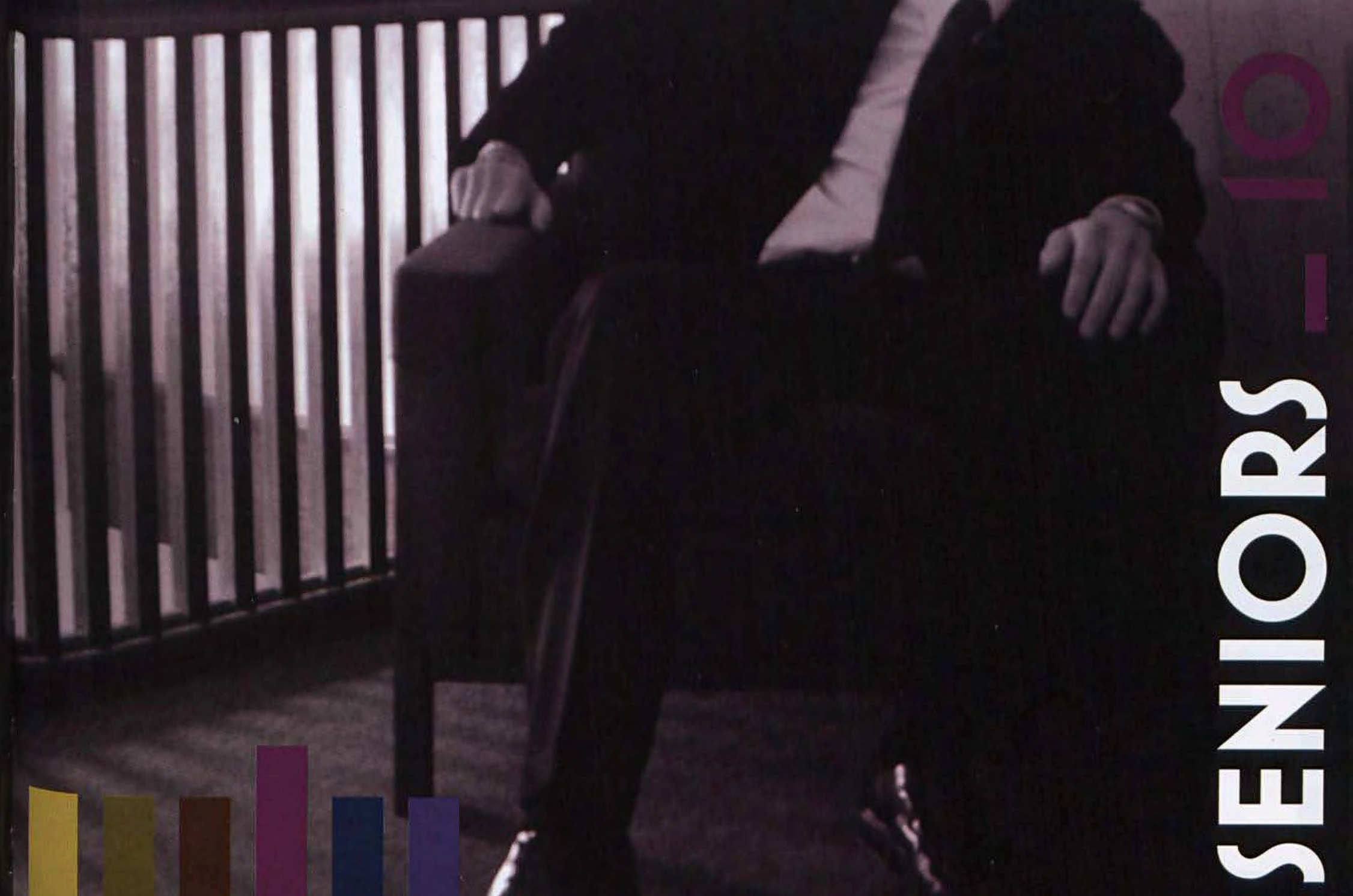


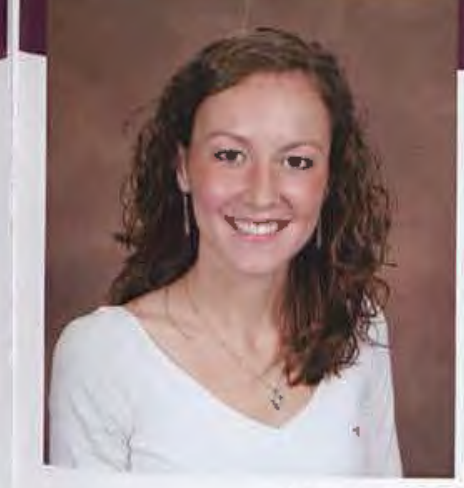

Maria Balch Biology

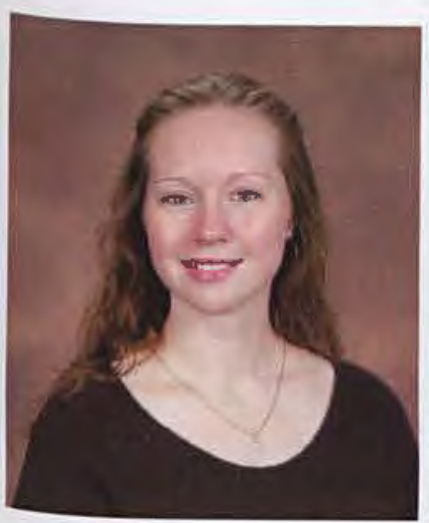

Julia Basford Nursing

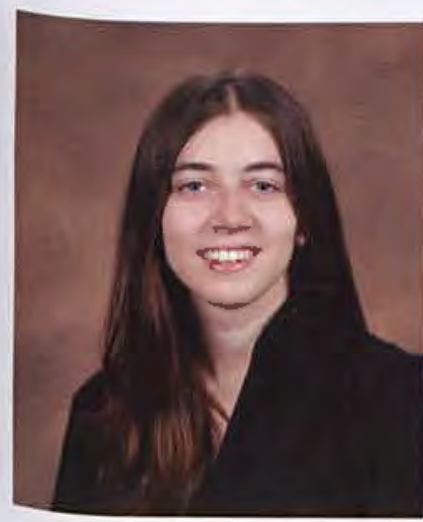

Lauren Berry

Middle Childhood Education and Multi-Age Special Education

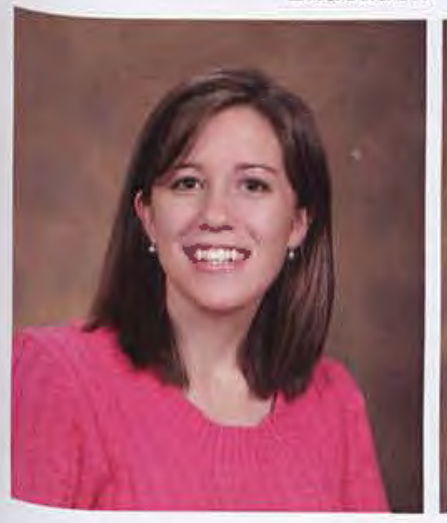

Jordana Bonardi

Early Childhood Education

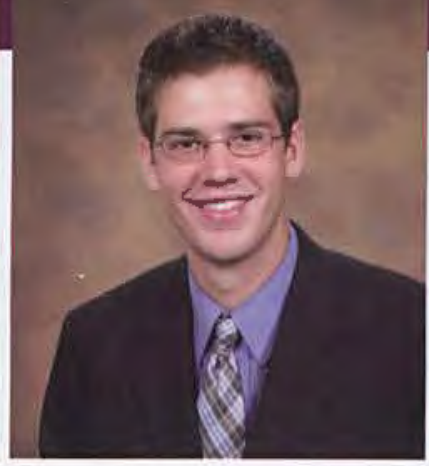

Daniel Ballard Computer Engineering

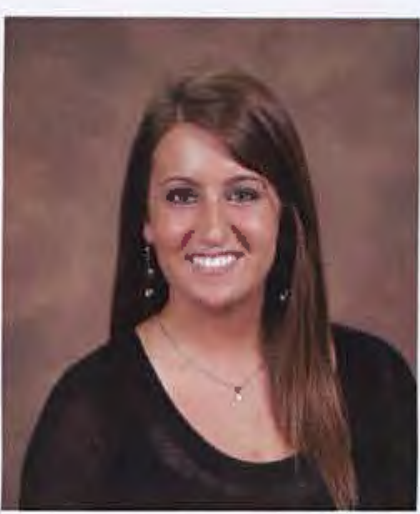

Kimberly Battista Nursing

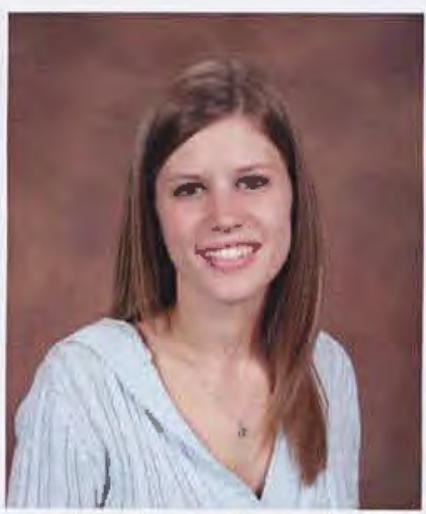

Kathryn Biehl Nursing

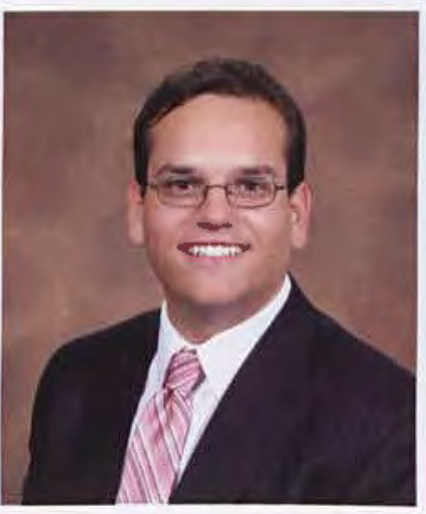

Thomas Borck Political Science

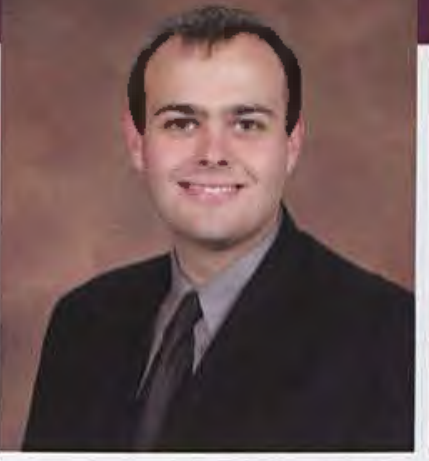

Jonathan Banks Criminal Justice

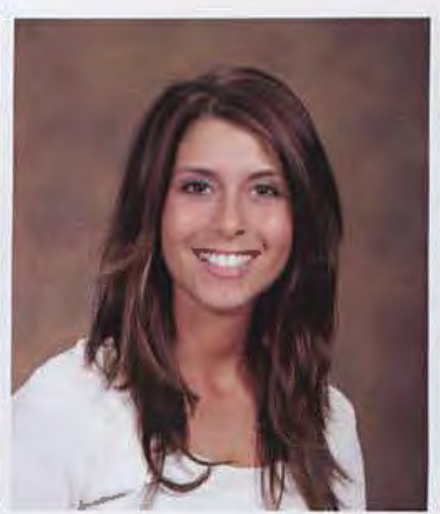

Janet Bauernschmitt Studio Art
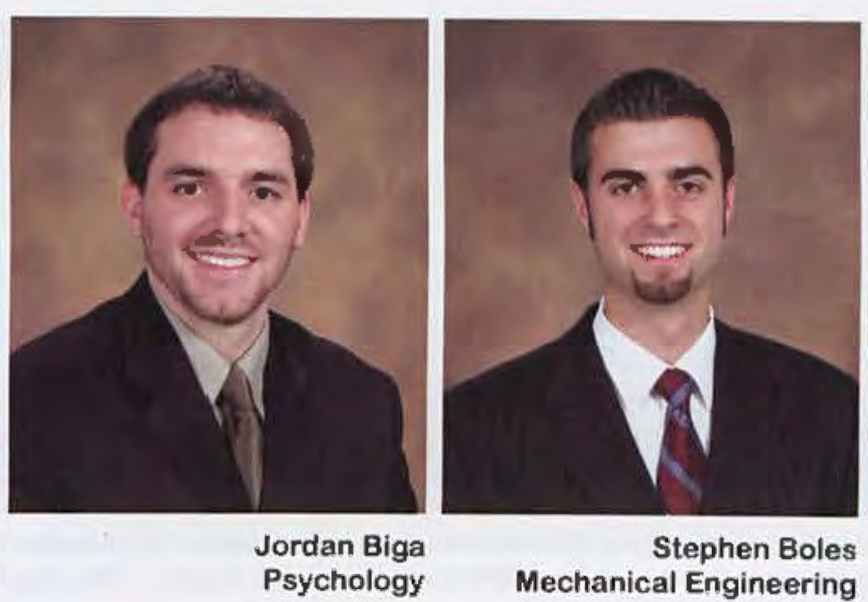

Stephen Boles Mechanical Engineering

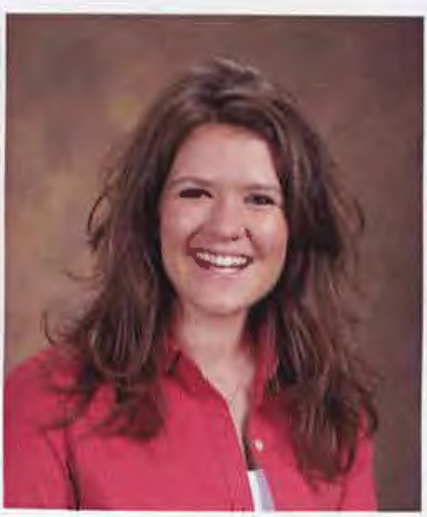

Michelle Boudreat Nursing

Andrew Barber Mechanical Engineering

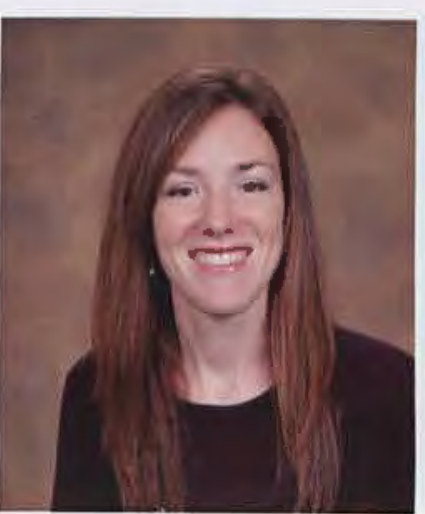

Sarah Behn

Graphic Design

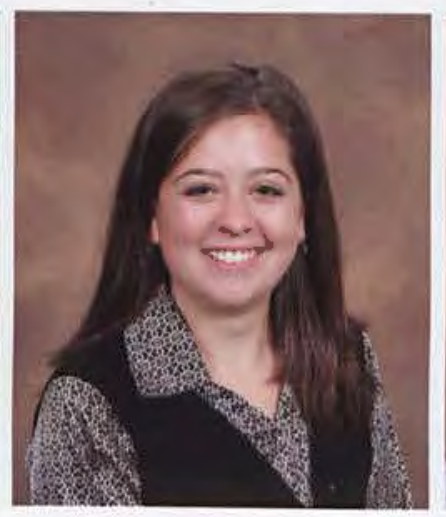

Melanie Bowers Psychology

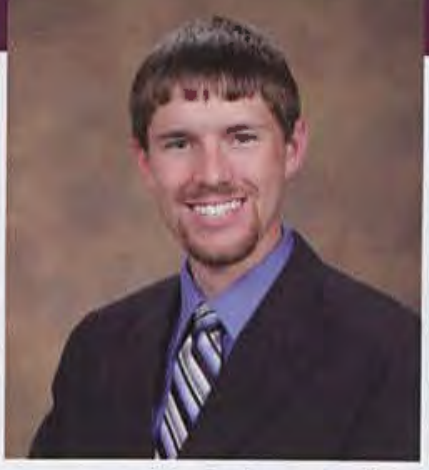

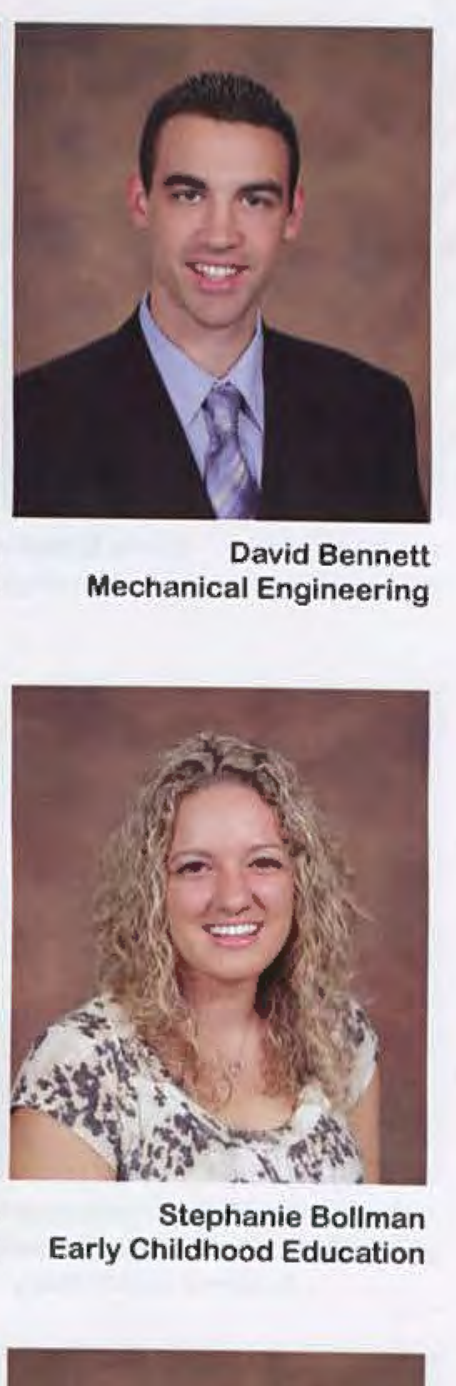

Stephanie Bollman Early Childhood Education

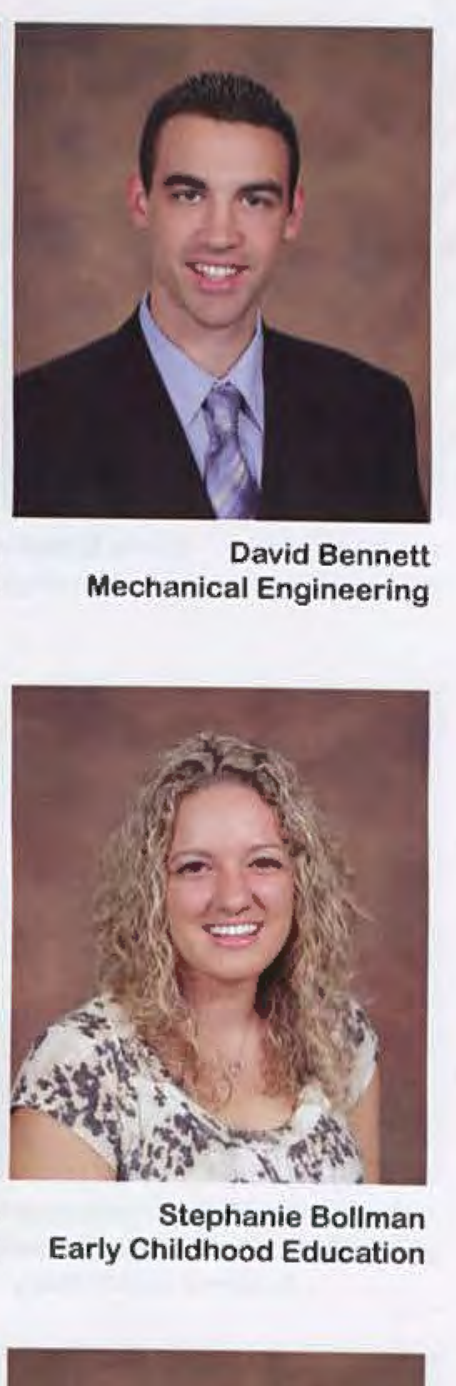

David Bennett Mechanical Engineering

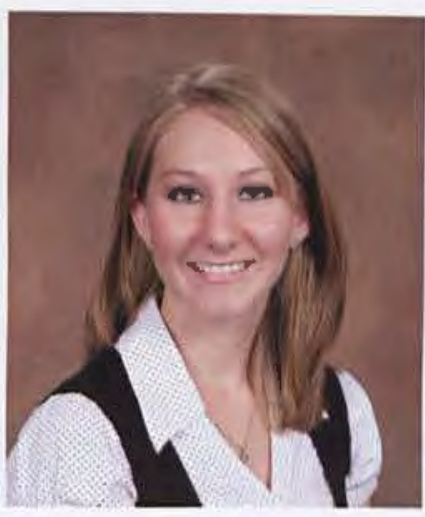

Amanda Bowersox Nursing 


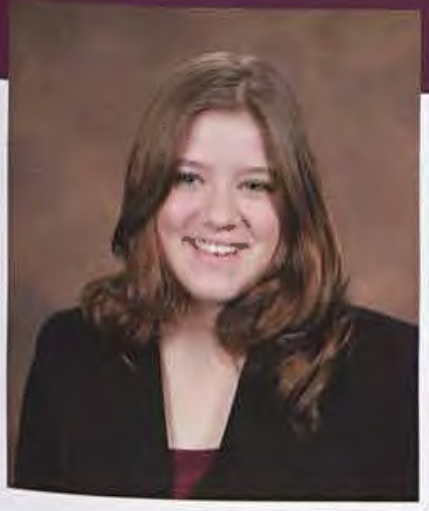

Rhonda Byers Psychology

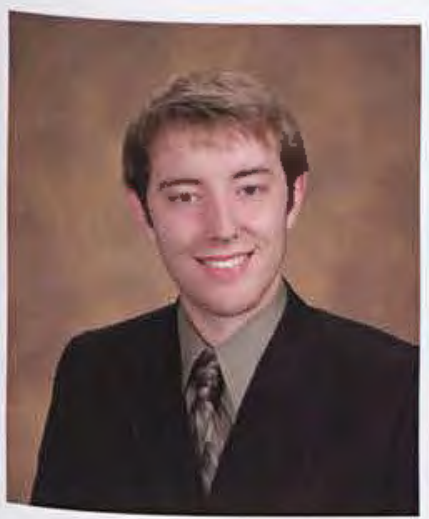

Jeremiah Carsey Finance

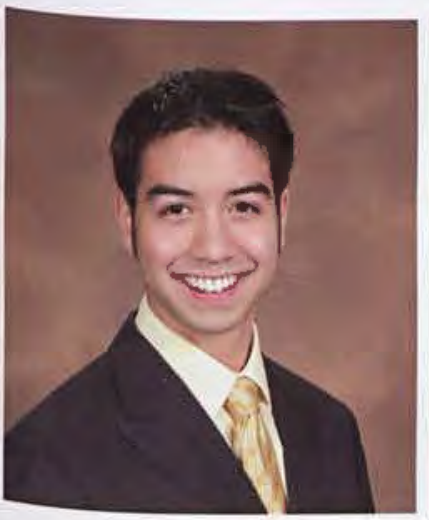

Evan Chiu

Computer Science

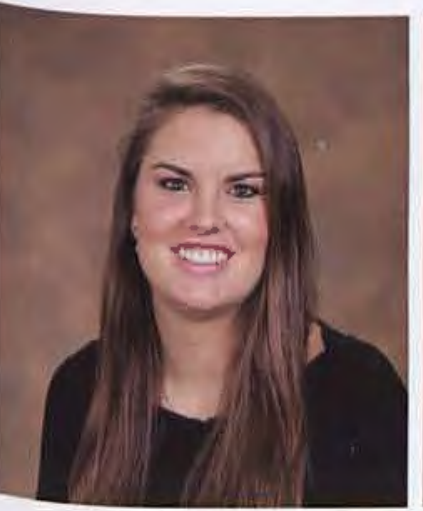

Rachel Coakley Nursing

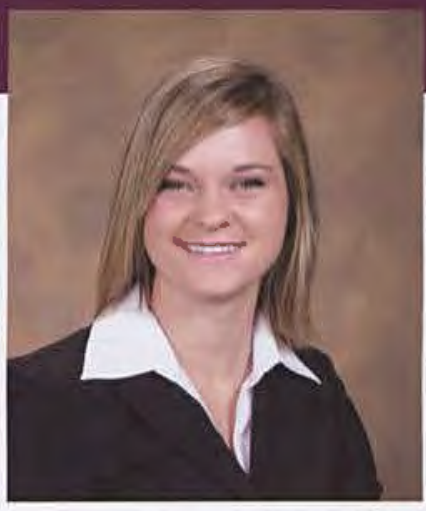

Melissa Byler Early Childhood/Special Education

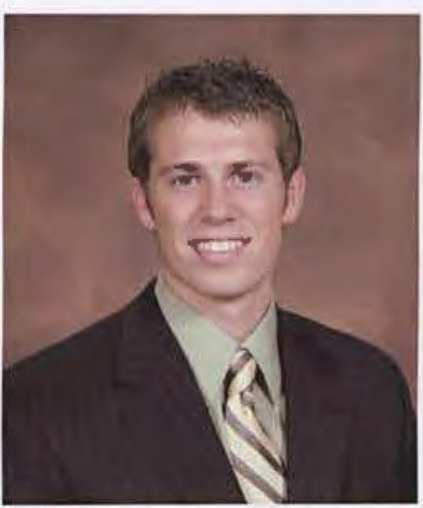

Evan Carter Business Management

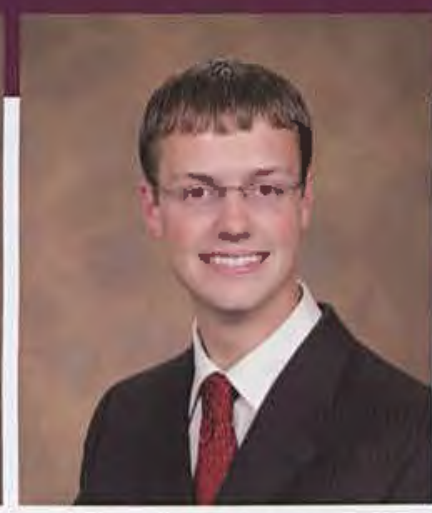

Christopher Byus Mechanical Engineering

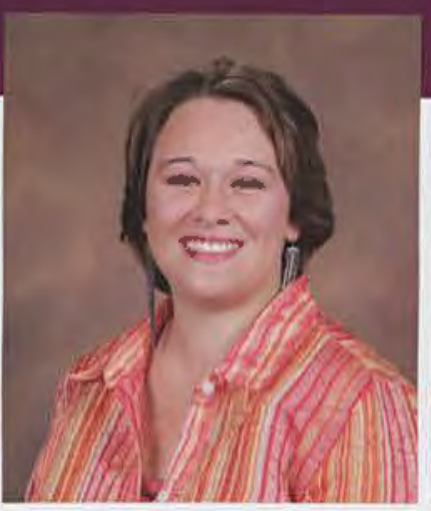

Erin Cahilly Youth Ministry, Christian Education

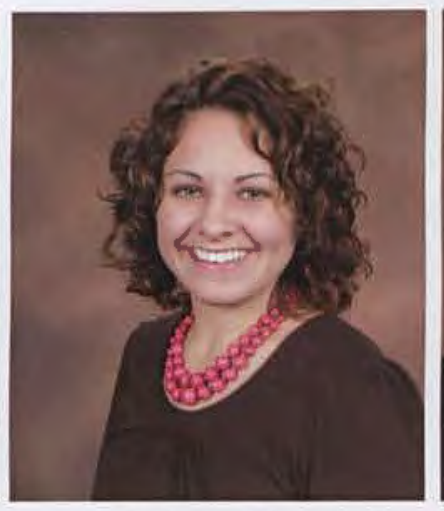

Bethany Chamberlain Nursing

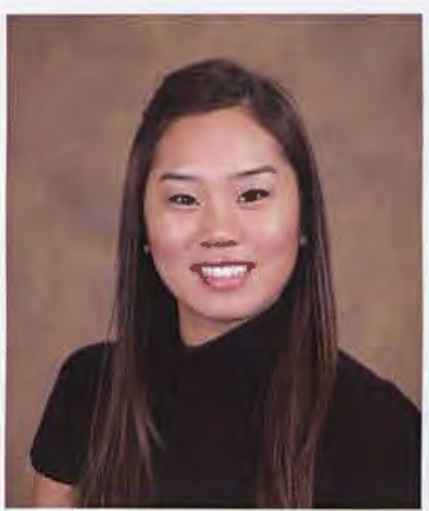

So Mang Cho Comprehensive Communication

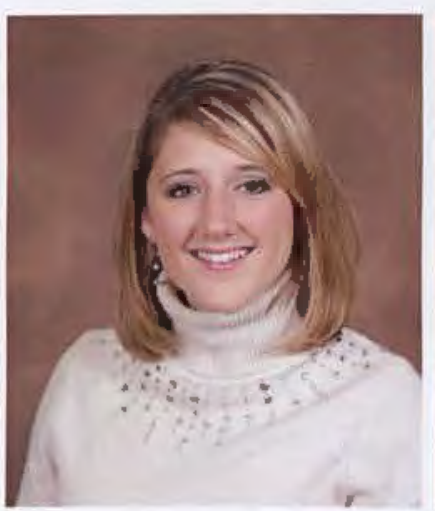

Ashley Coale Nursing

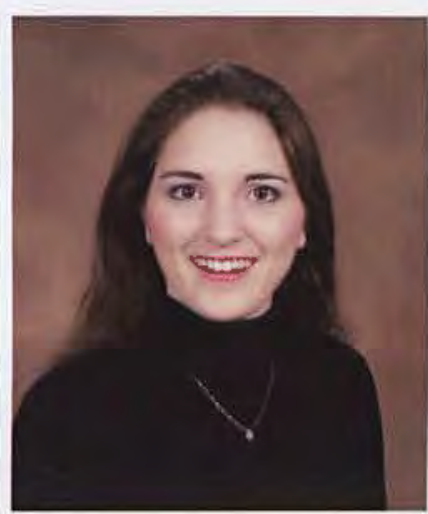

Sarah Christofer Music Performance

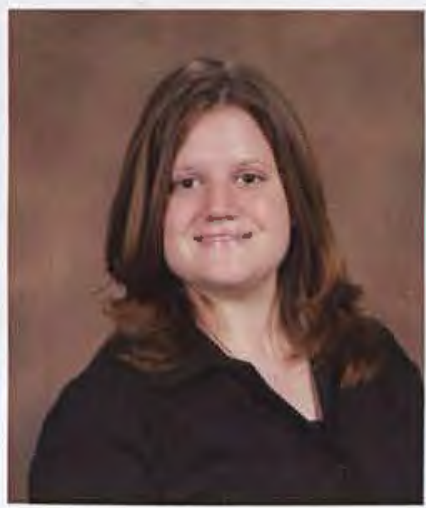

Joanna Coffelt Biology

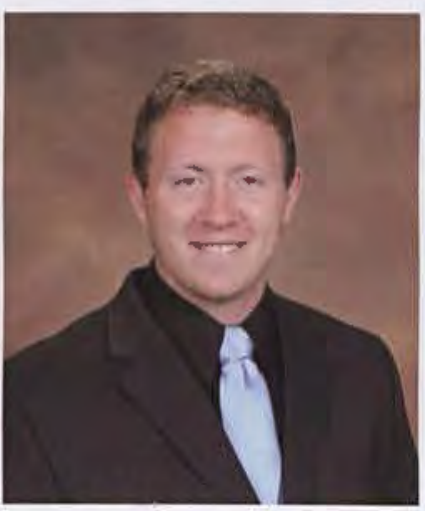

Micah Chambers Psychology

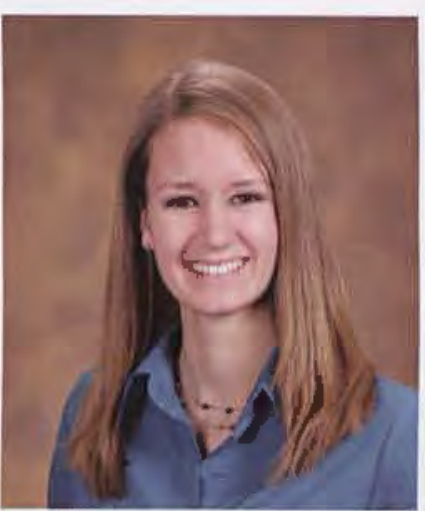

Krista Clark Accounting

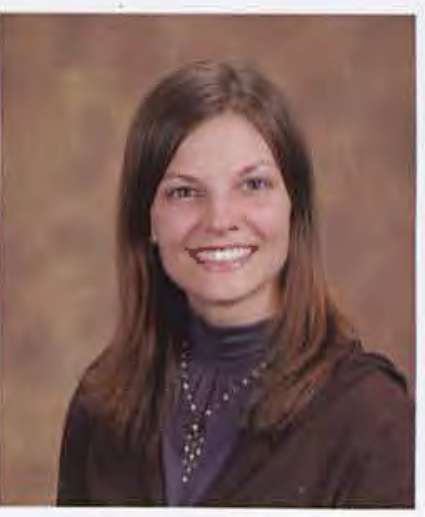

Michelle Cohoon Studio Art

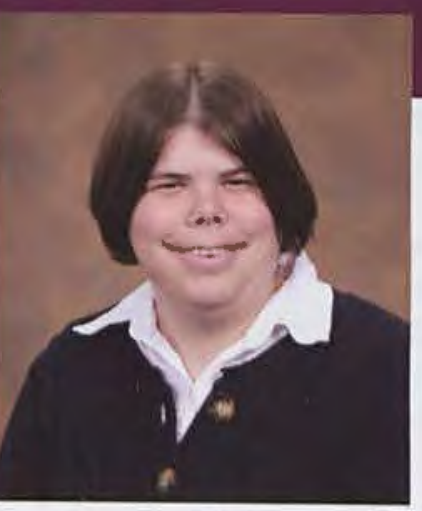

Erin Campbell History

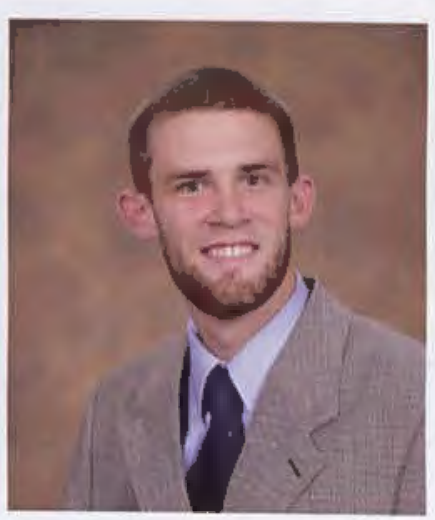

Robert Childs Communication Arts

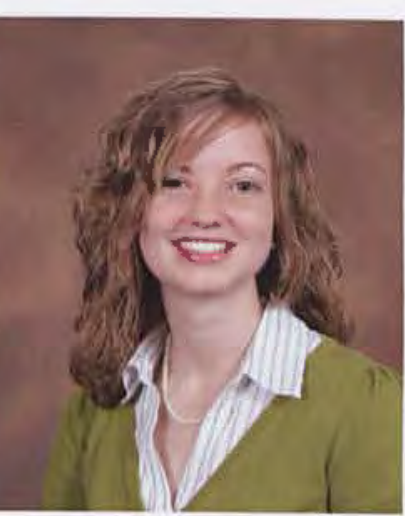

Alissa Clutcher Nursing

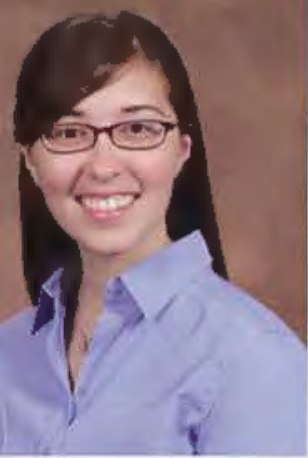

Bethany Colas English 


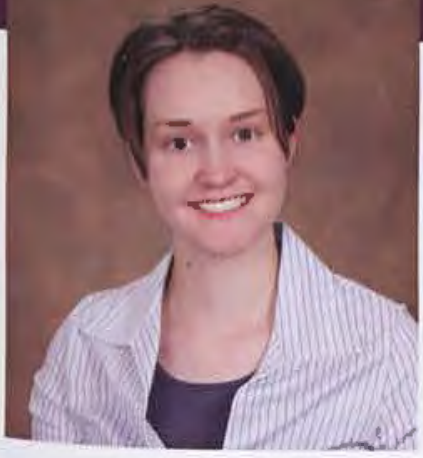

Anna Cummings English

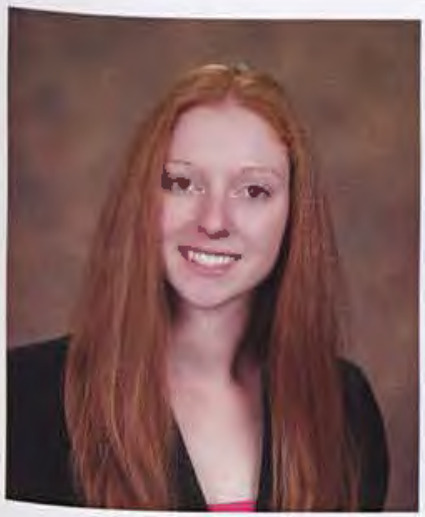

Natalie Dallas Applied Psychology Counseling

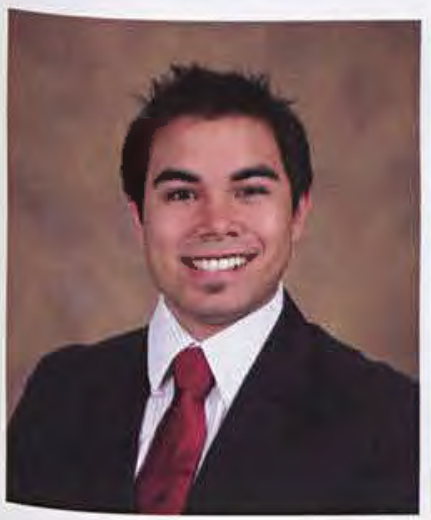

Richard Davies Business Management

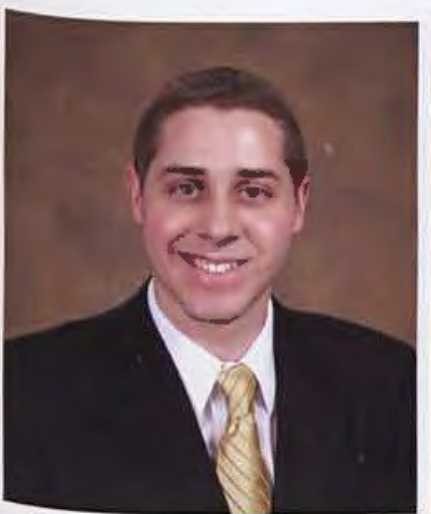

Matthew de Waal Malefyt Business Management

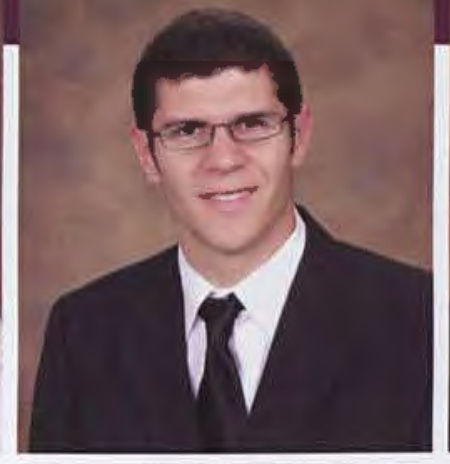

Patrick Cunningham Pastoral Studies

Early Childhood Education

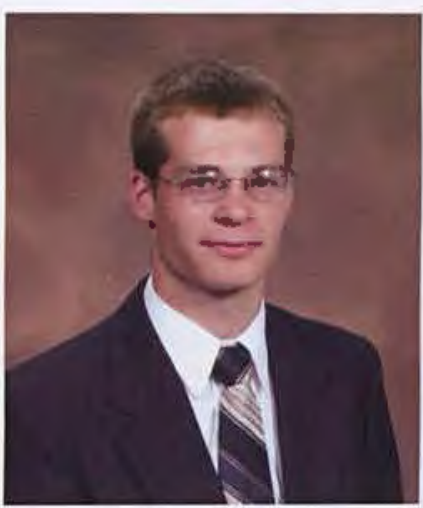

Matthew Dammer Graphic Design

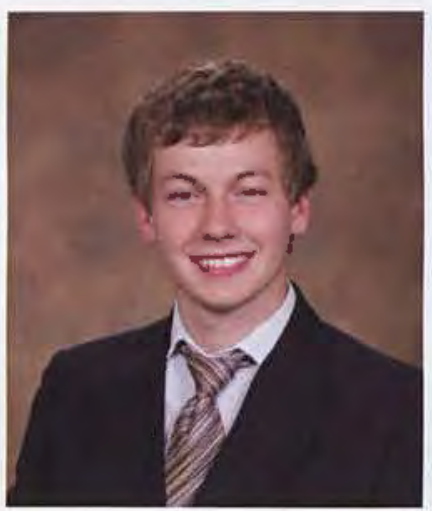

Adam Davis Business Management

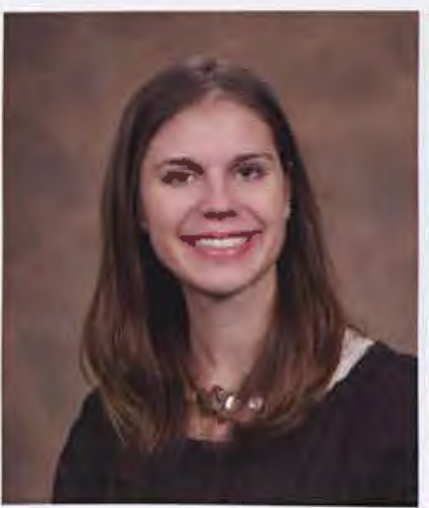

Merissa DeVries

Nursing

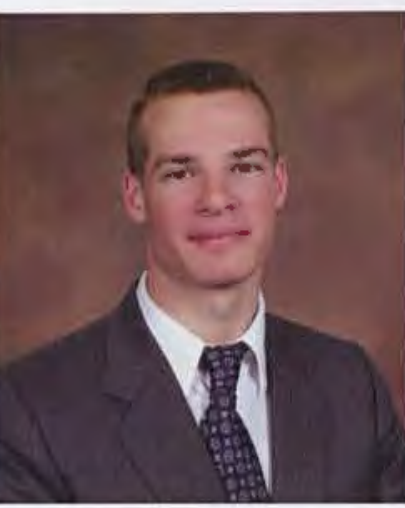

Nathan Dammer Criminal Justice
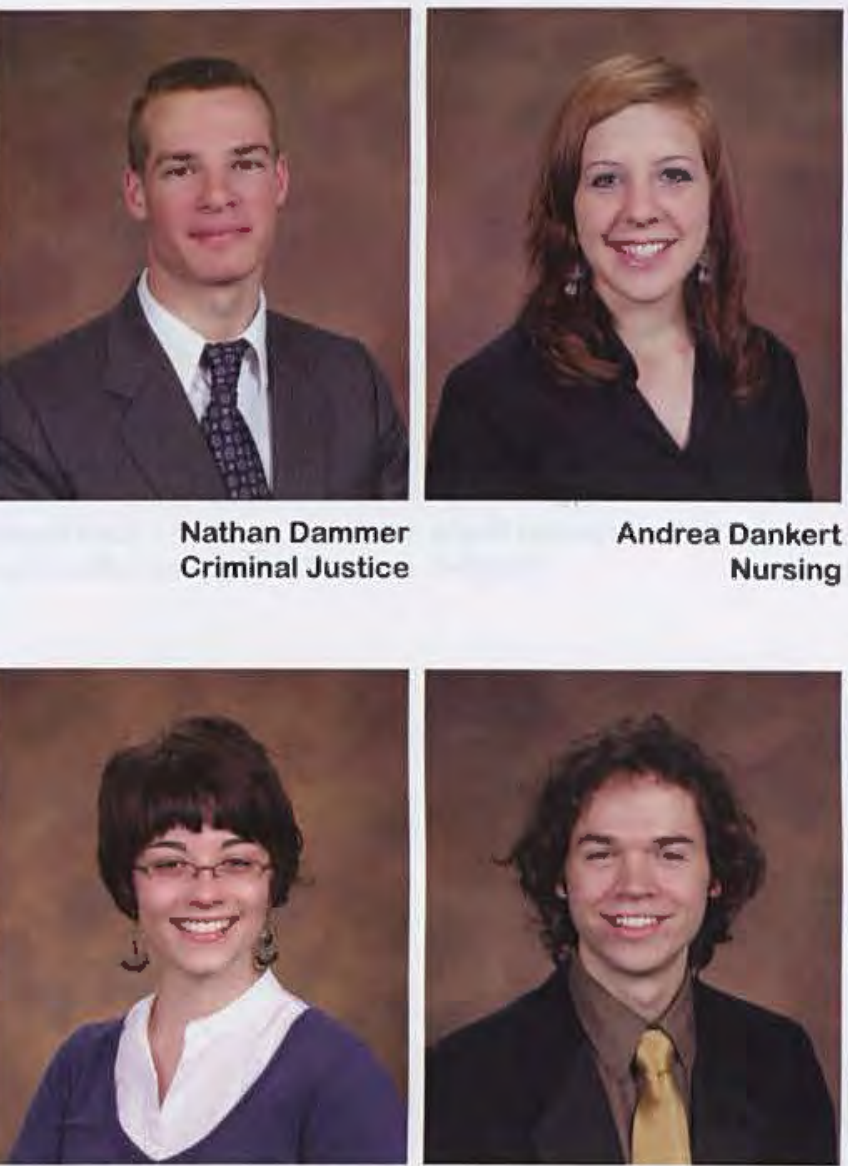

Jennifer Davis Nursing

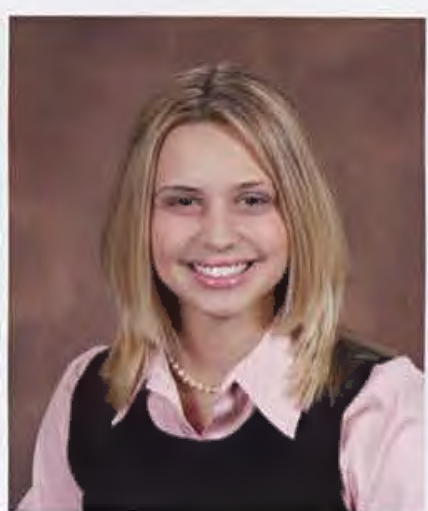

Lindsay Di Donato

Business Management and Marketing

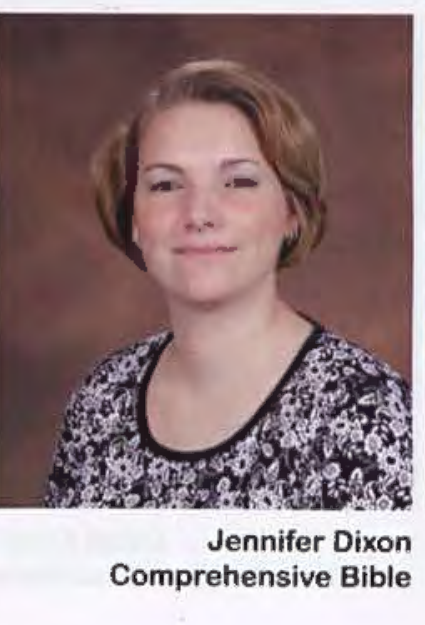

Andrea Dankert

Nursing

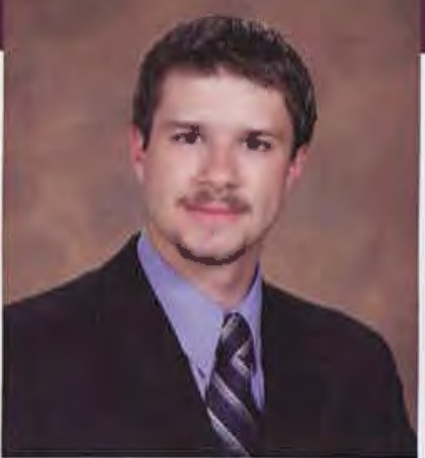

Andrew Curtis Mechanical Engineering

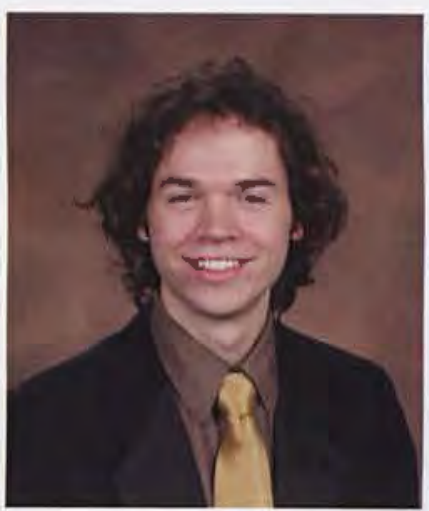

Matthew Davis

Music Composition

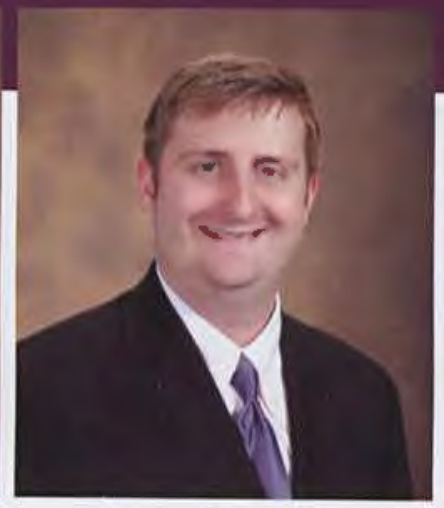

Daniel Czaplicki Criminal Justice

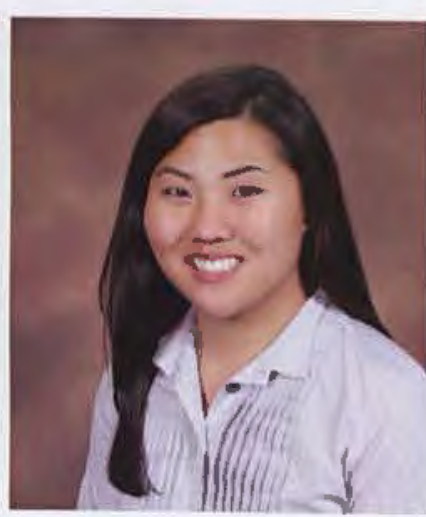

Jessica Daugherty Technical \& Professional Communication

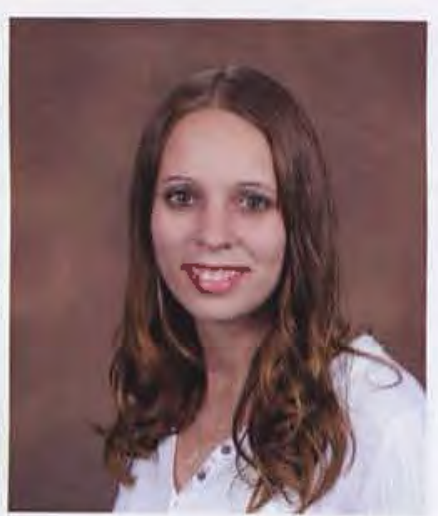

Michelle Davis Middle Childhood Education
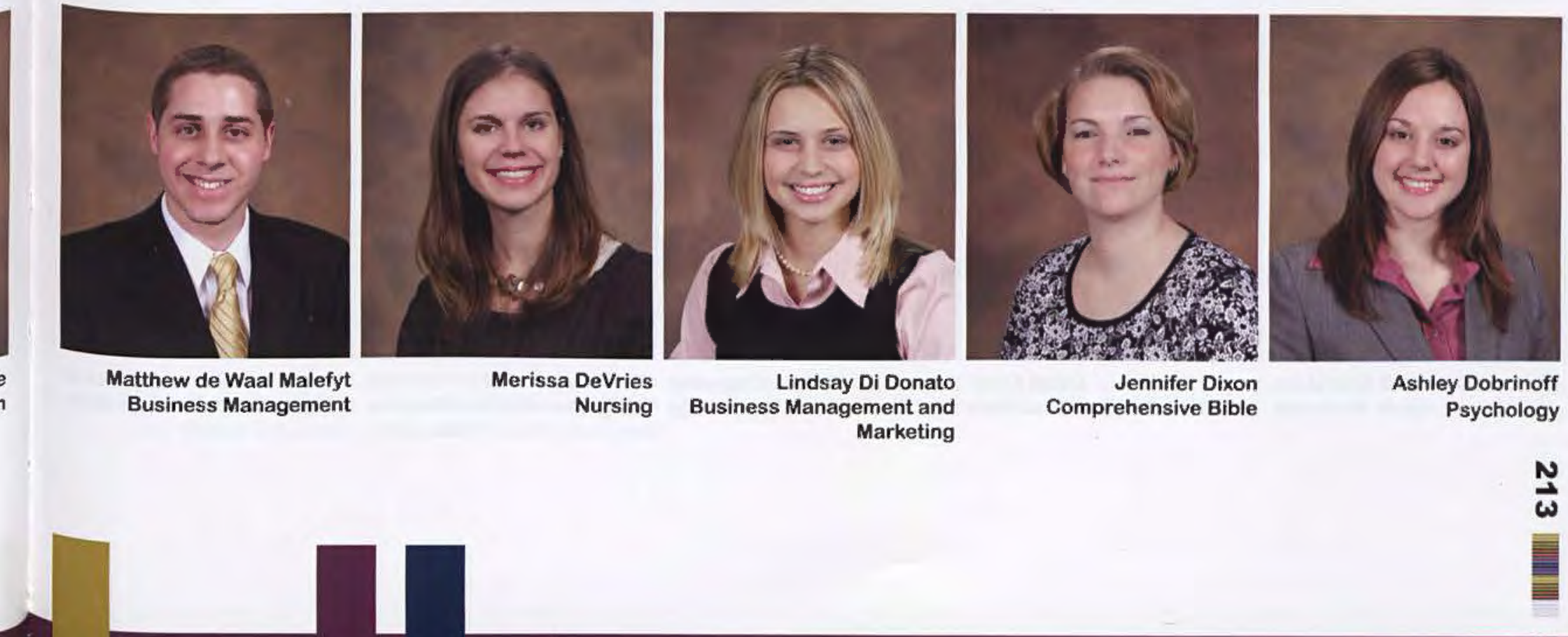


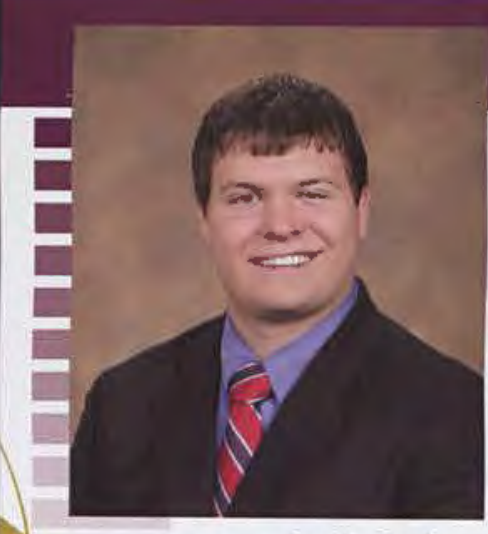

Justin Dodson Pre-seminary Bible

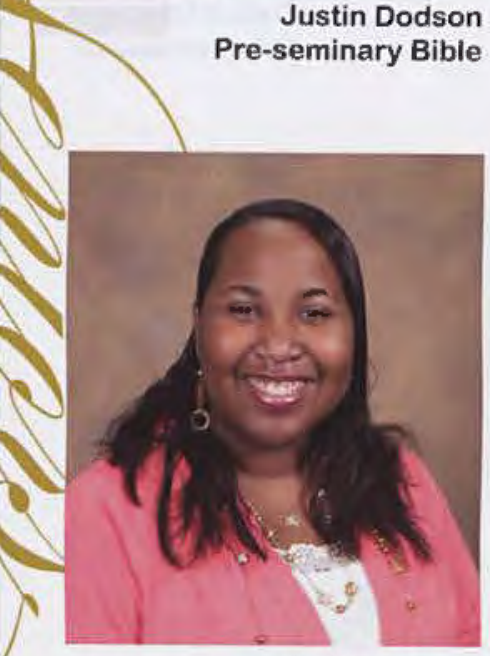

Arielle Dorsey Christian Education

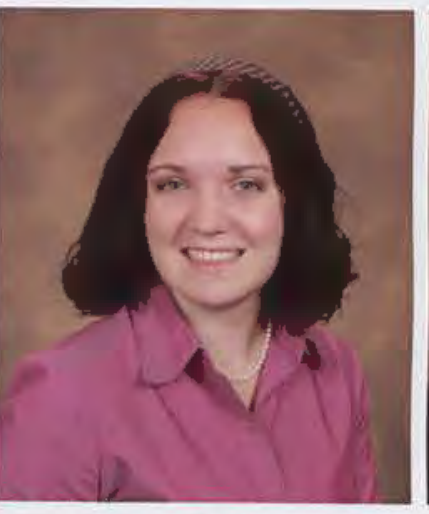

Courtney Eaton Early Childhood Education

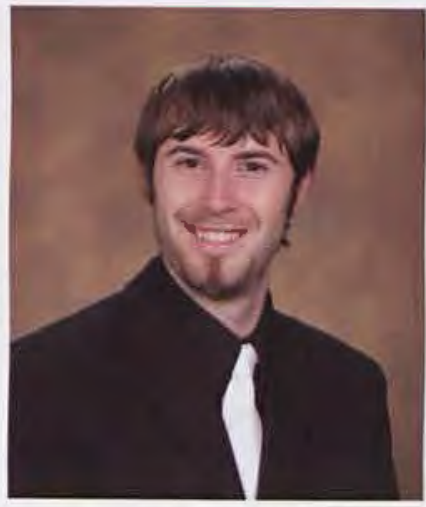

Joshua Erlandson Youth Ministries

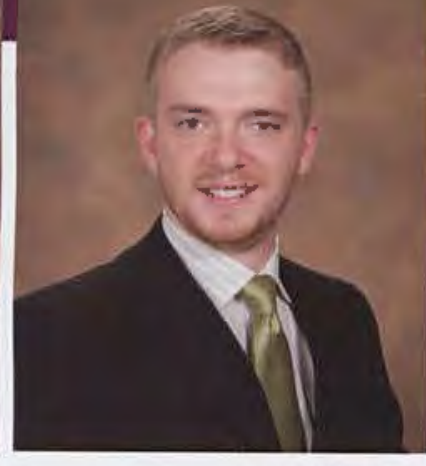

Daniel Doleys Pre-seminary Bible

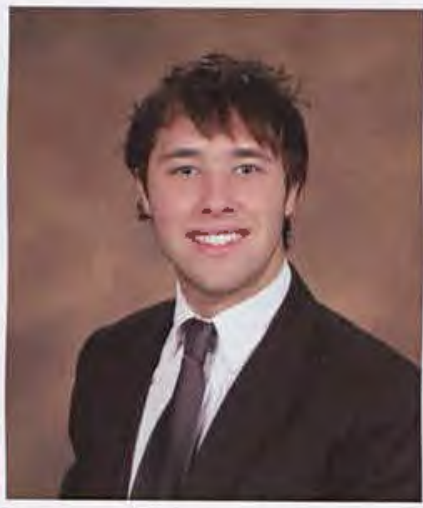

Brandon Doyle English

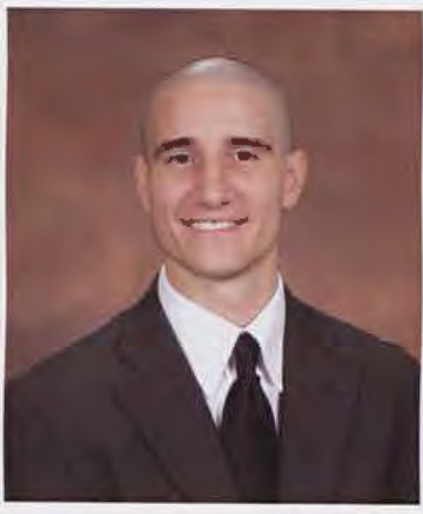

Karl Eiker Integrated Math Education

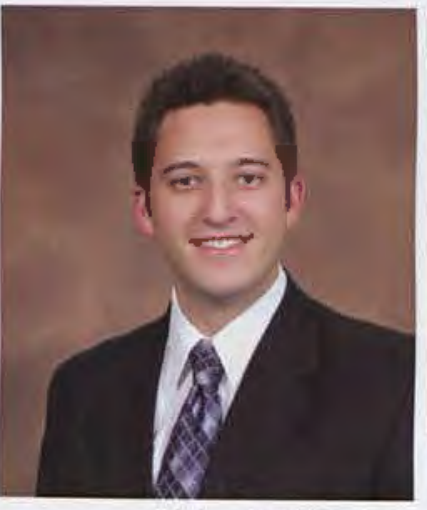

Caleb Ernst Bible Teacher Education

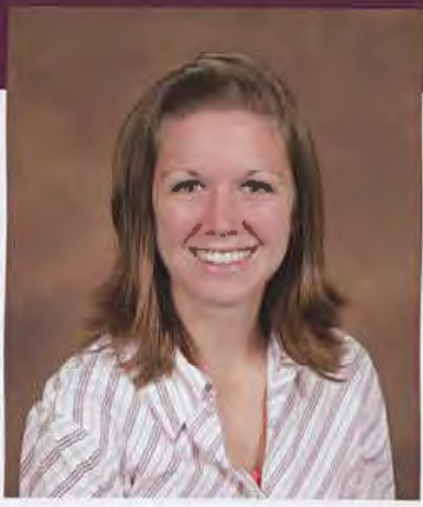

Olivia Dolph Marketing

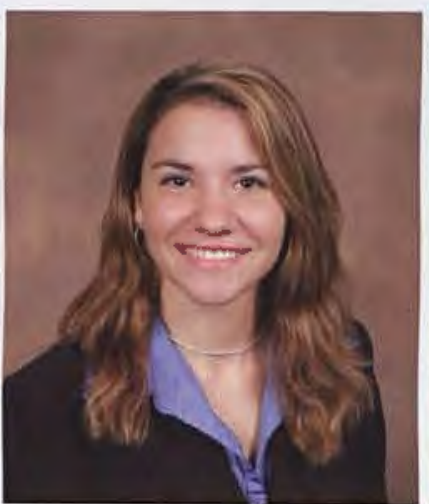

Lani Duell Nursing

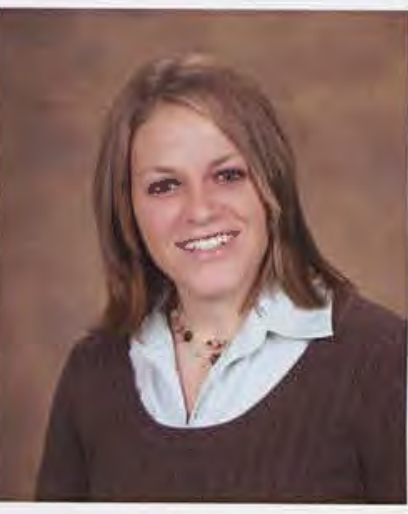

Amanda Einselen Christian Education/Youth Ministry

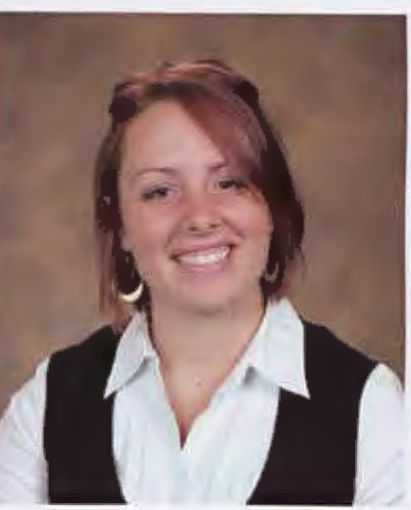

Tiffany Erspamer Psychology

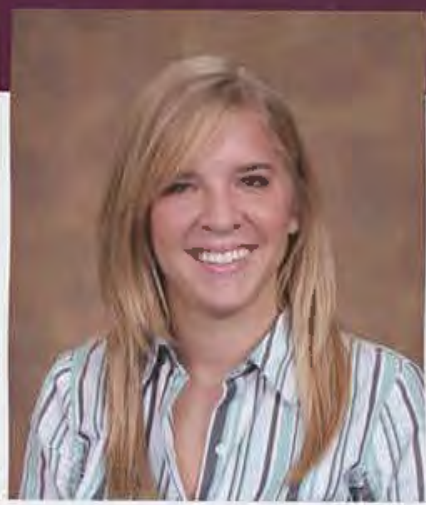

Brittany Donald Communication Arts

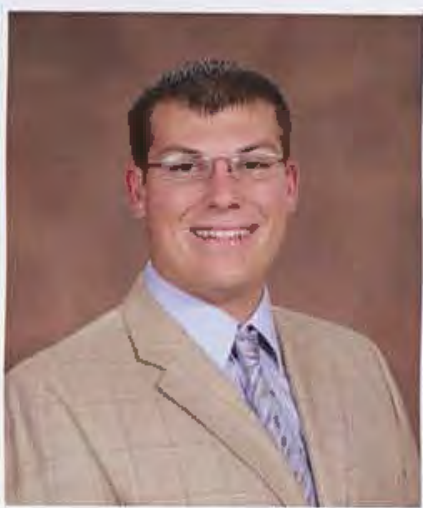

David Duerrwaechter Mechanical Engineering

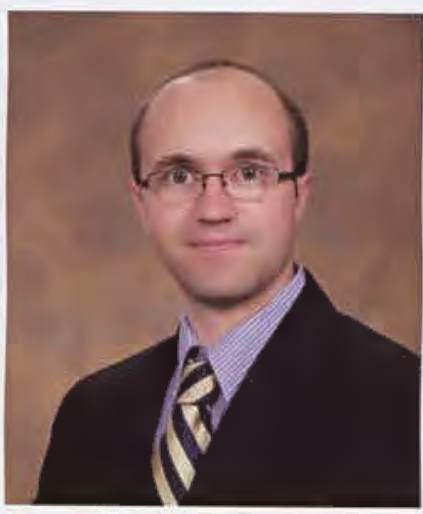

David Elgena Graphic Design and Studio Art

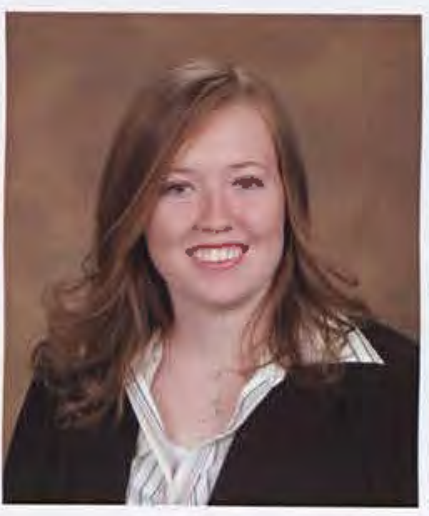

Rebecca Erwin Integrated Physical Science Education

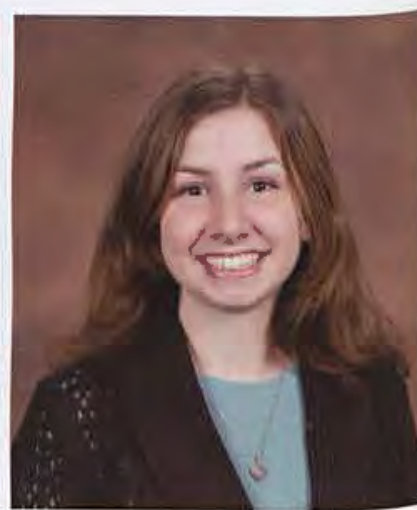

Valerie England Communication Arts

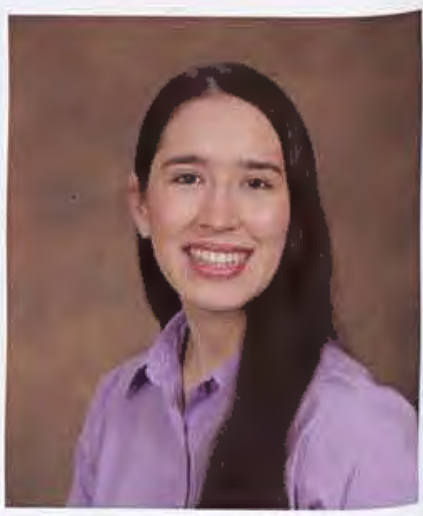

Pamela Eustace Music and Political Science 


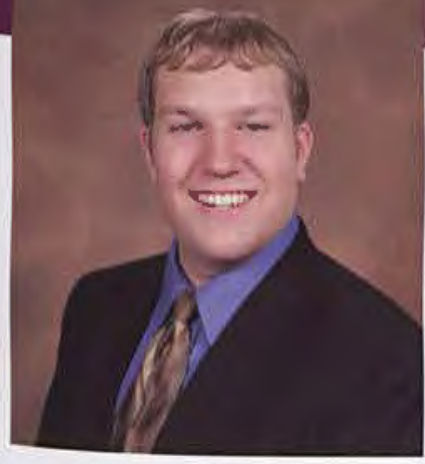

Jonathan Evans Electrical Engineering

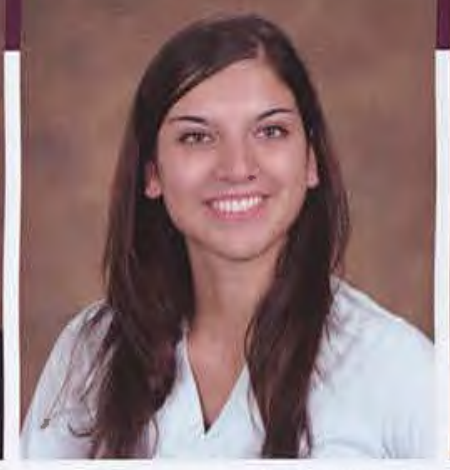

Abby Everett Nursing

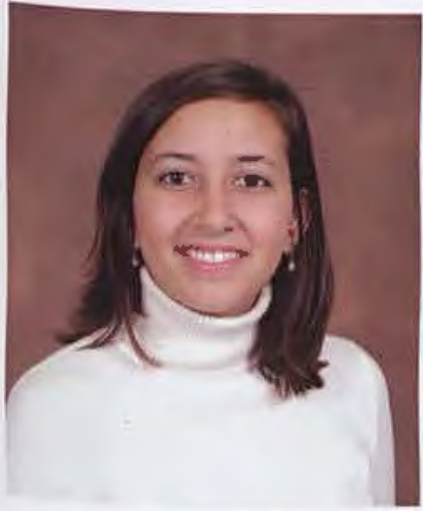

Kristie Febo Spanish

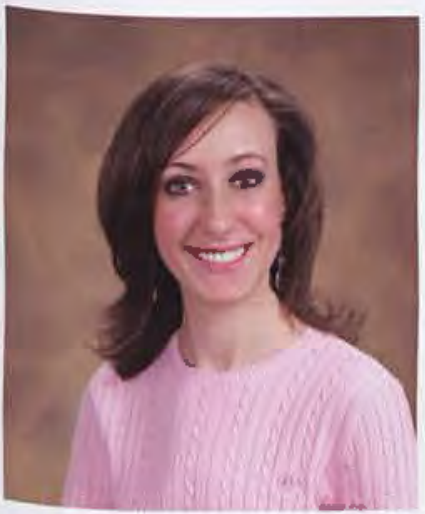

Mallory Fisher Political Science

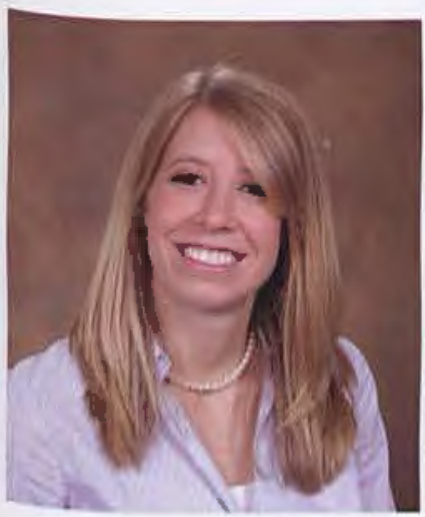

Holly Foreman

Early Childhood Education and Special Education

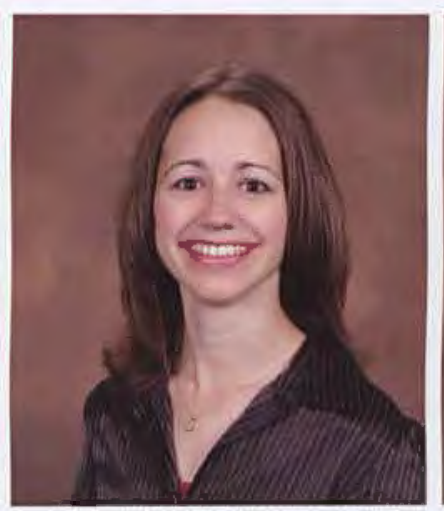

Sarah Feiler Early Childhood and Special Education

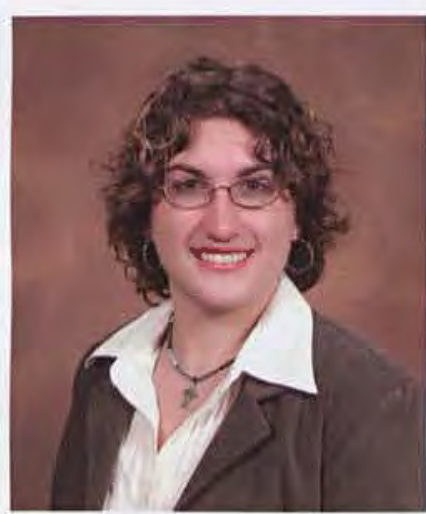

Crystal Flippin Graphic Design

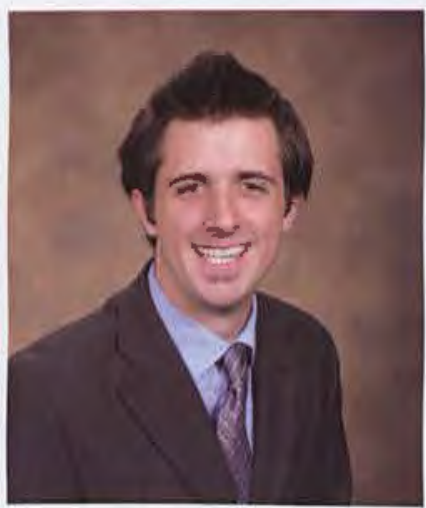

Justin Foulk

Global Economics and International Business

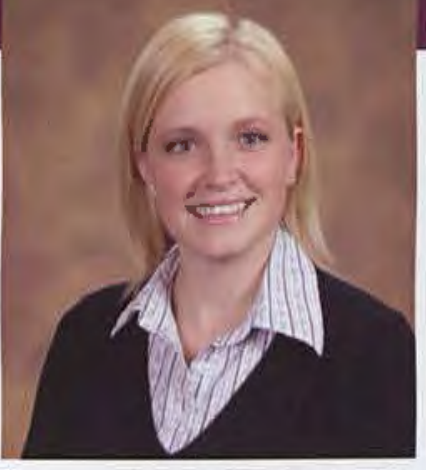

Shannon Everswick Music, Vocal Emphasis

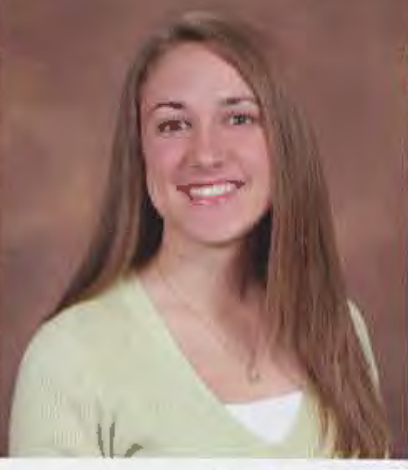

Katelyn Farrar Early Childhood Education

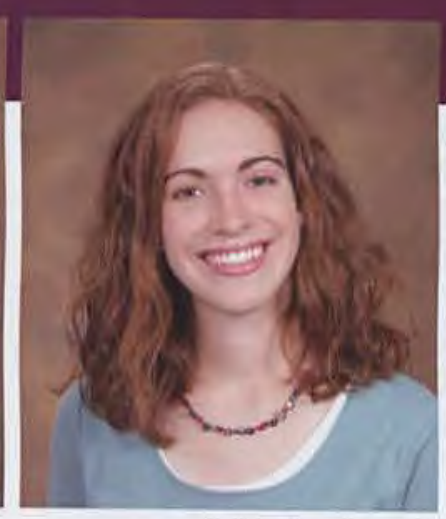

Katherine Farrell Integrated Social Studies Education and History

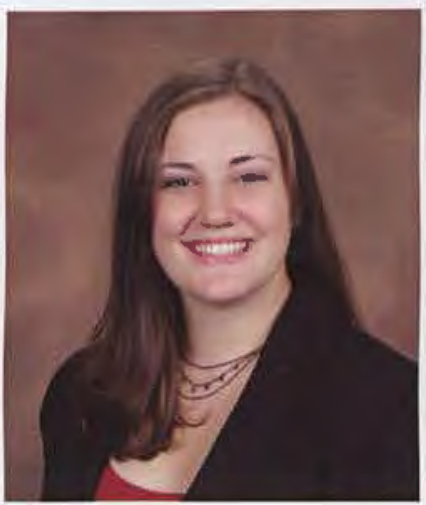

Ann Felix Marketing and Finance

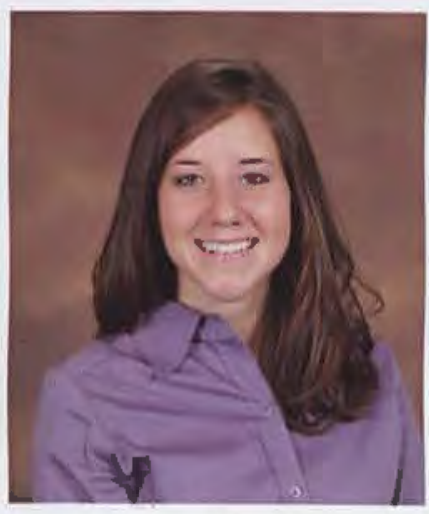

Jenna Ferguson Nursing

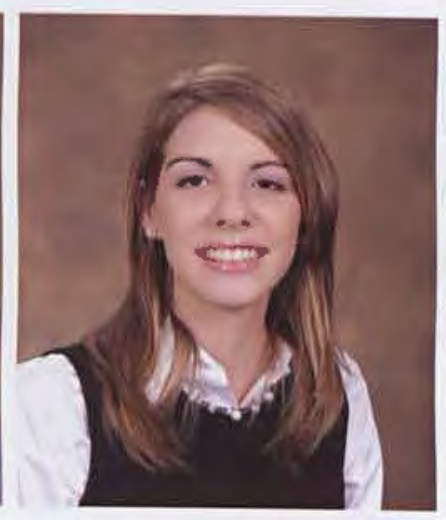

Ashley Fisher Middle Childhood Education

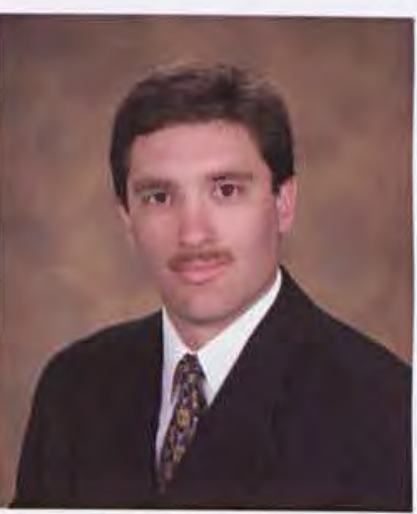

Timothy Ford Pre-seminary Bible

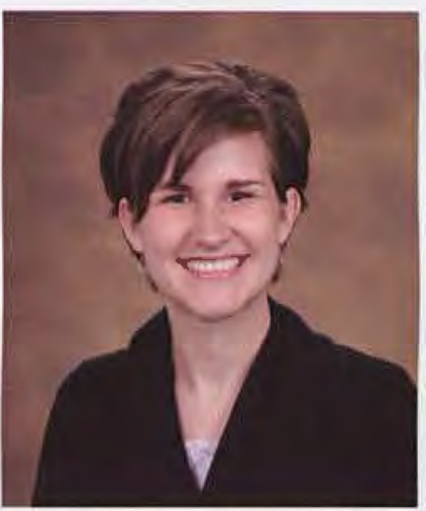

Jennifer Flynn International Studies

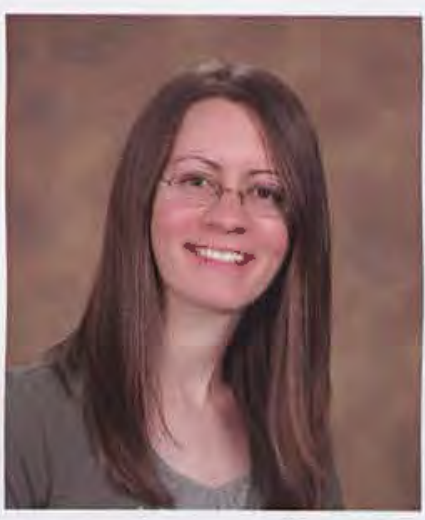

Ann Foley

Middle Childhood Education and Spanish

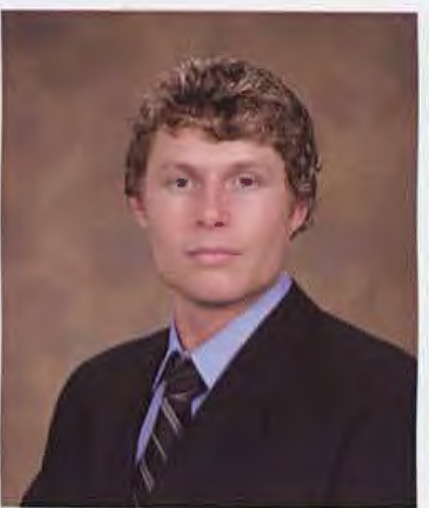

Josh Francis Studio Art

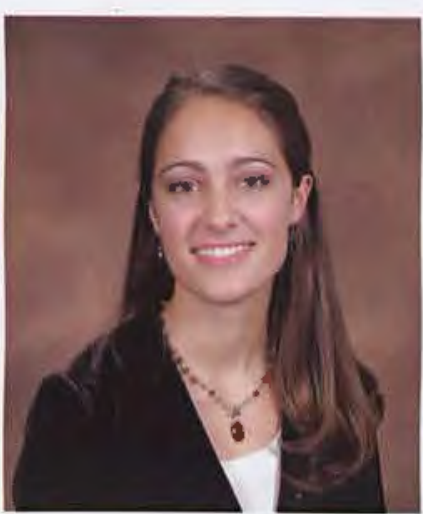

Heidi Fraser Keyboard Pedagogy

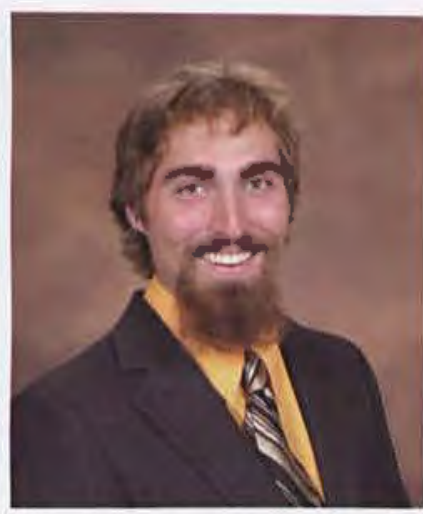

Joshua Ferederick Electronic Media 


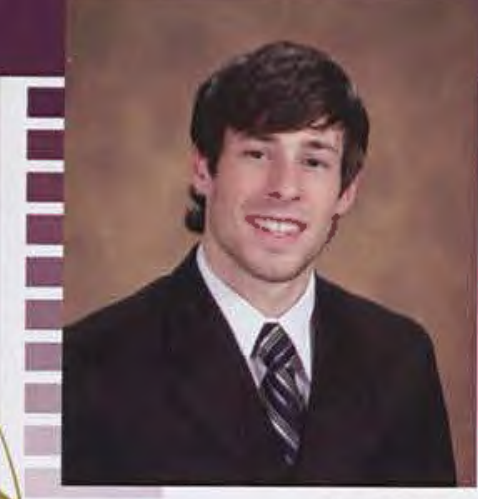

Austin Frey Exercise Science

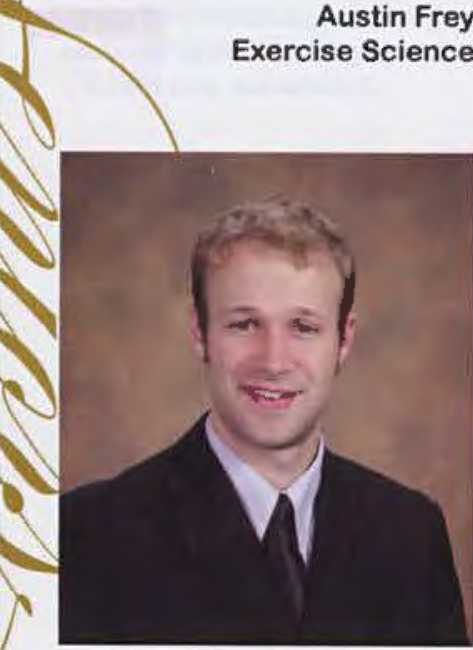

Joshua Gelser Mechanical Engineering

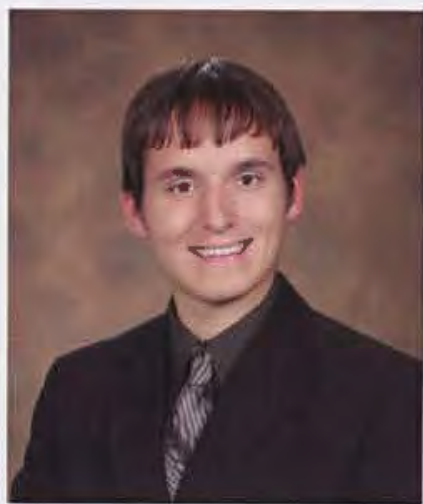

Peter Gohdes Mechanical Engineering

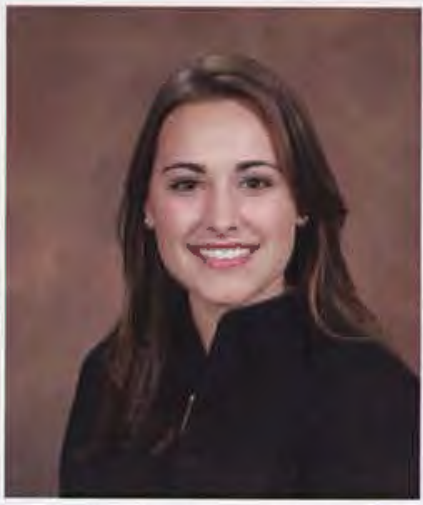

Elizabeth Graves Nursing

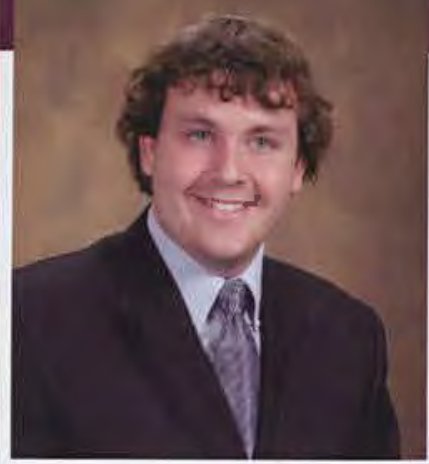

Nicholas Fridenmaker Youth Ministry and Christian Education

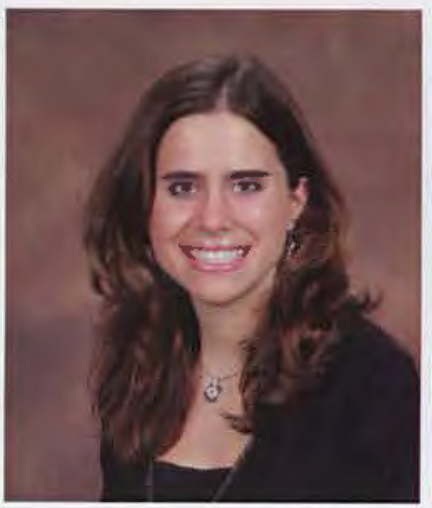

Stefanie George Nursing

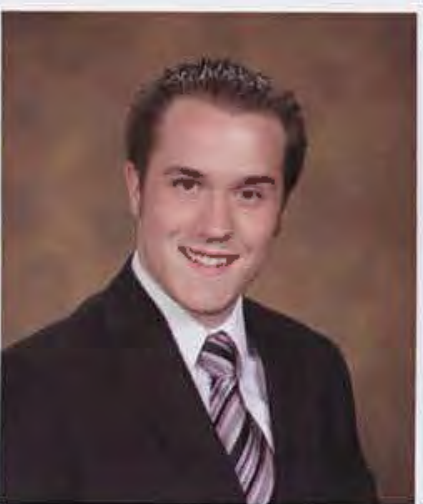

Adam Golden Psychology

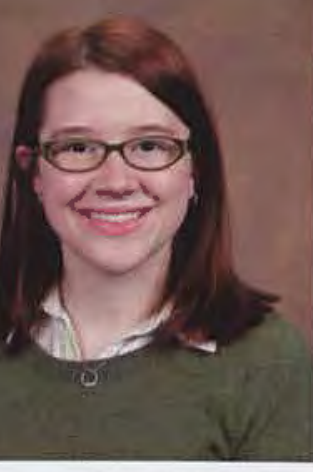

Sarah Galloway Nursing

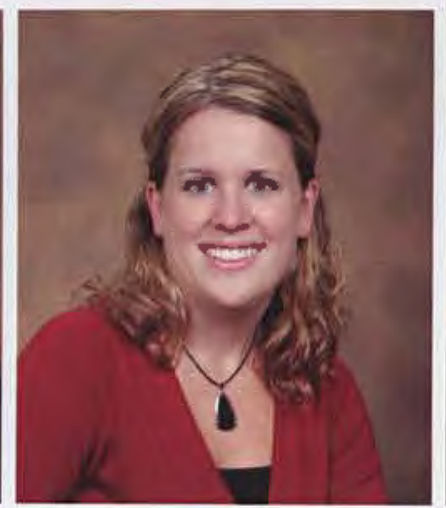

Elizabeth Gerard Nursing

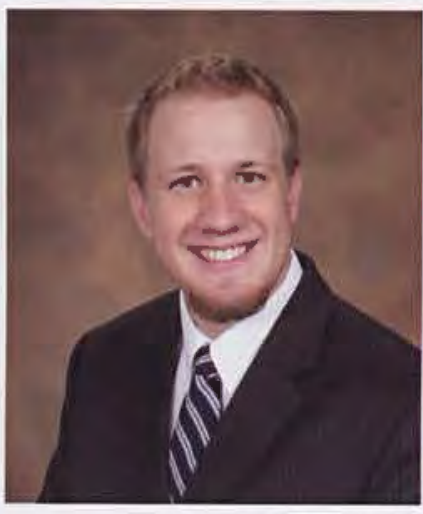

Robert Gole Finance

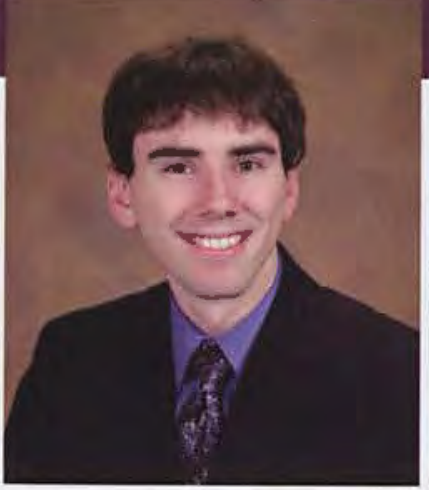

Keith Gardner Computer Engineering

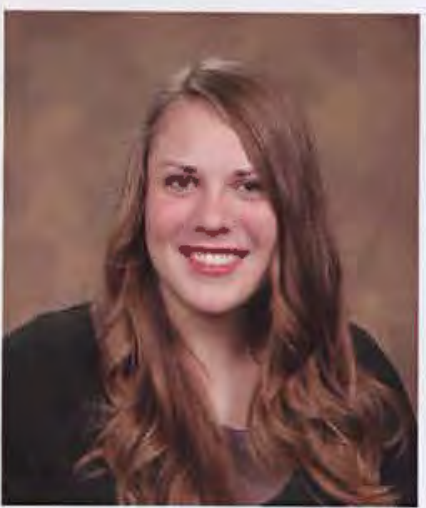

Megan Gier

Math

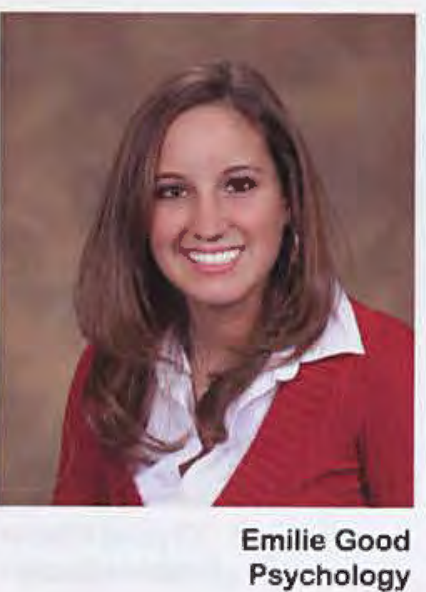

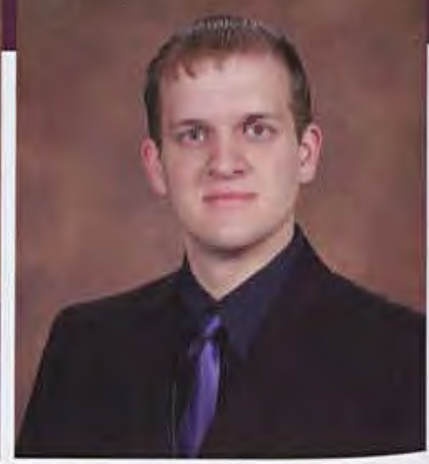

Joshua Garling Computer Science

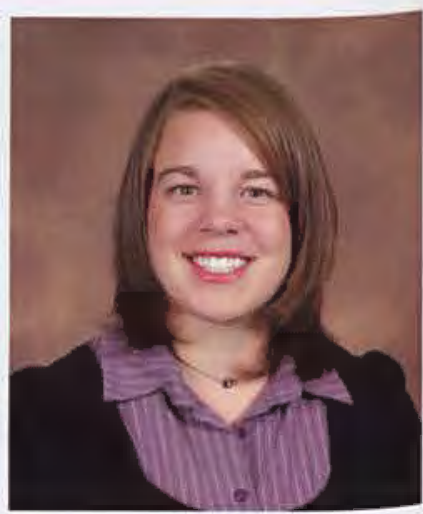

Jacinda Gillette Social Work

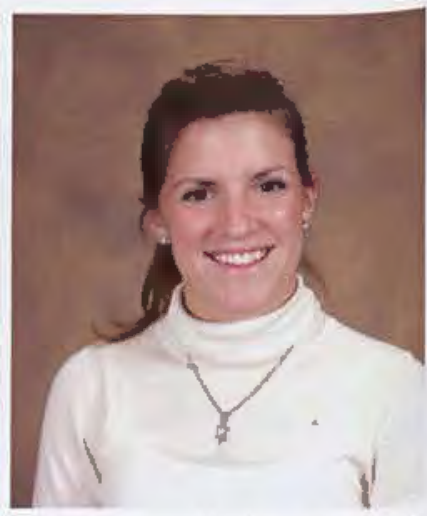

Audree Goodew Sociology

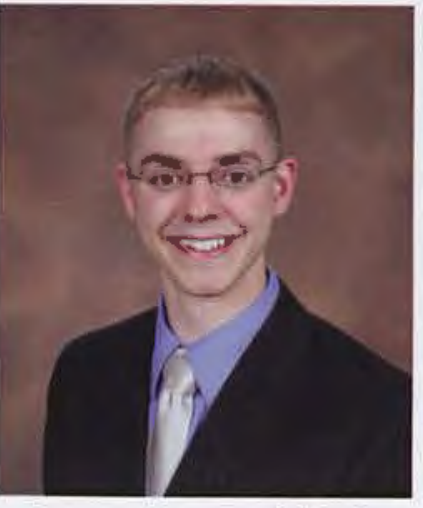

John Gray Nursing

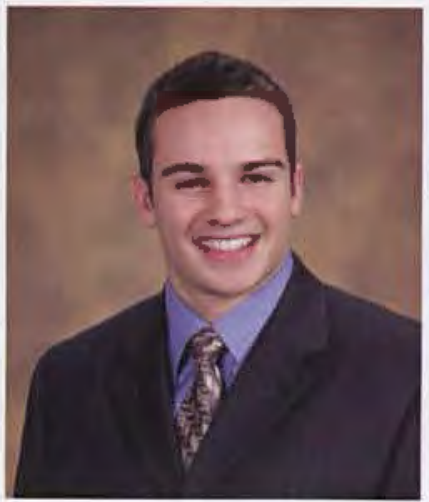

Stephen Green Multi-Age Physical Education

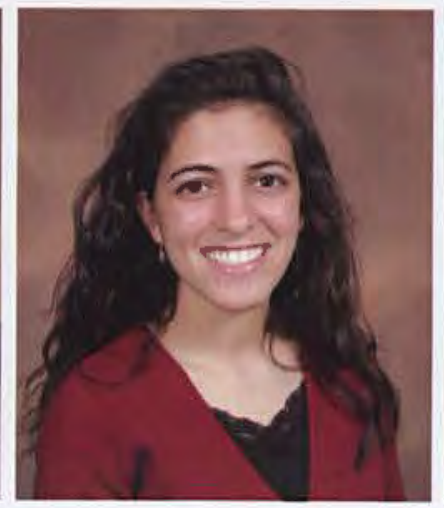

Leah-Ruth Greenberg Nursing

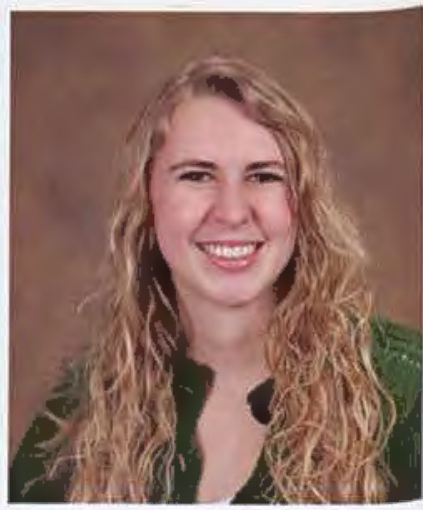

Kimberly Greer Christian Education and Youth Ministries

몽 

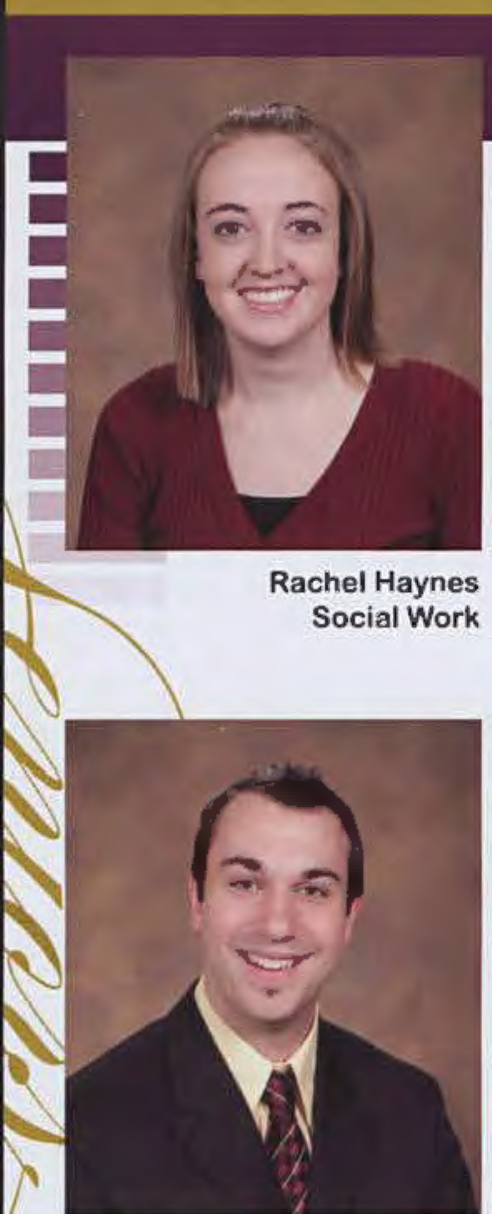

Joshua Herbolt Electronic Media

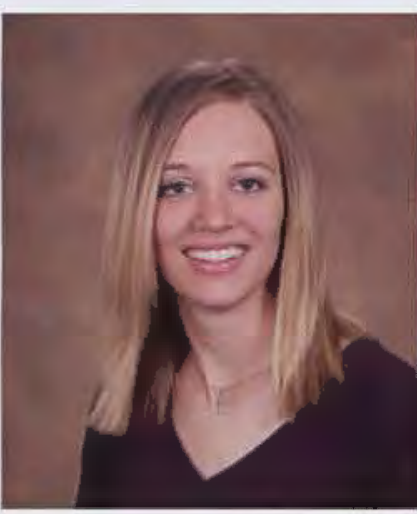

Lindsey Hlad Nursing

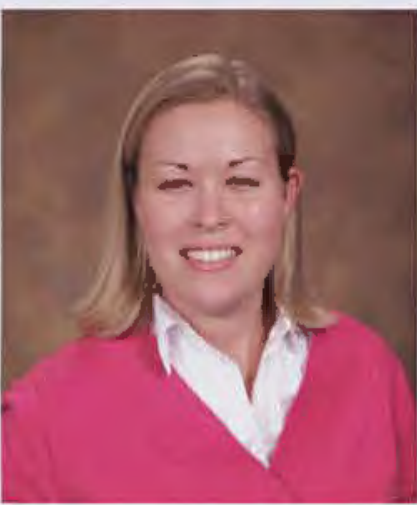

Jessica Honeycutt Nursing

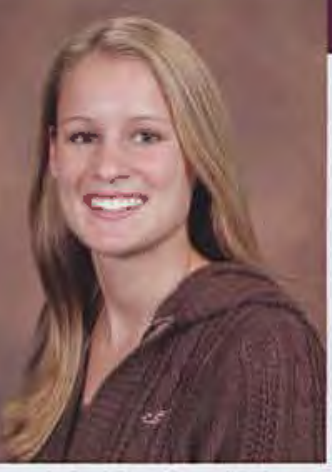

Heather Heagy Nursing

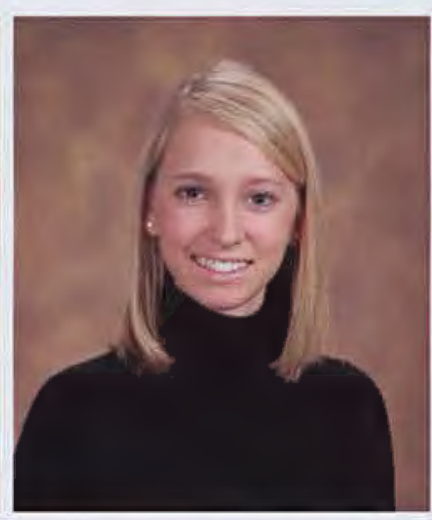

Brittany Herbst Early Childhood Education

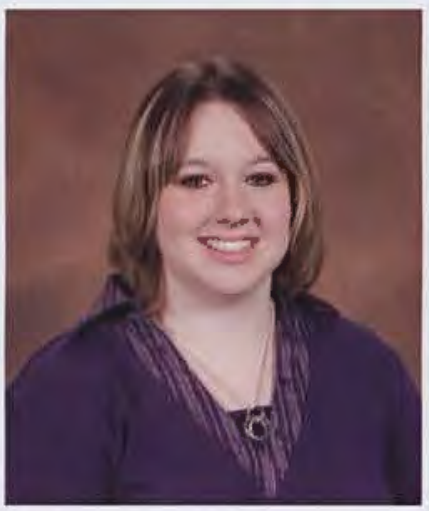

Rachel Hobbs

Nursing

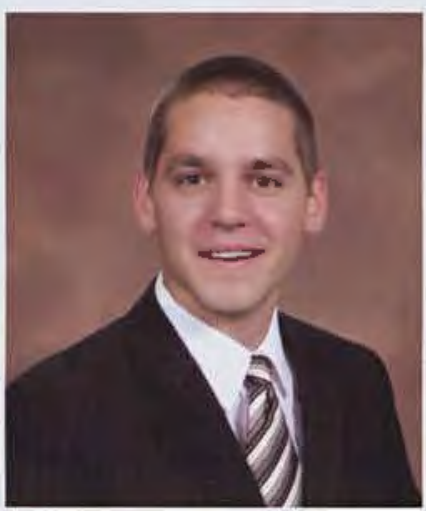

Ragen Horst Business Management

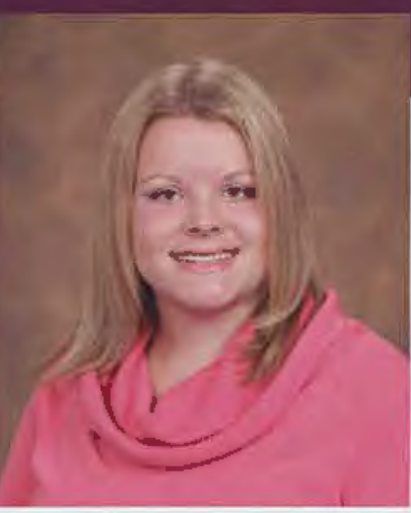

Leslie Heiss Nursing

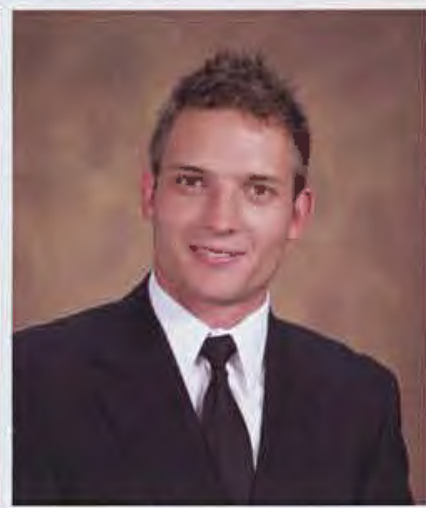

Jason Heuer Business Management

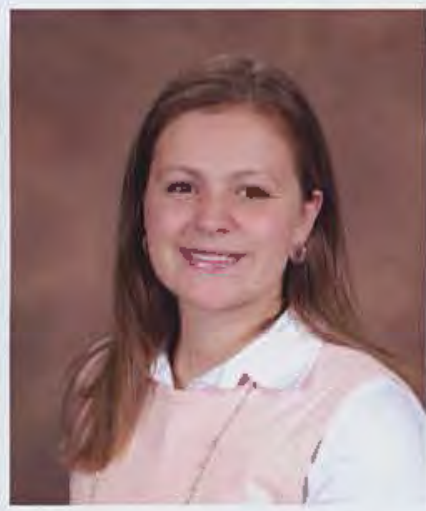

Chelsie Hoffman Middle Childhood Education

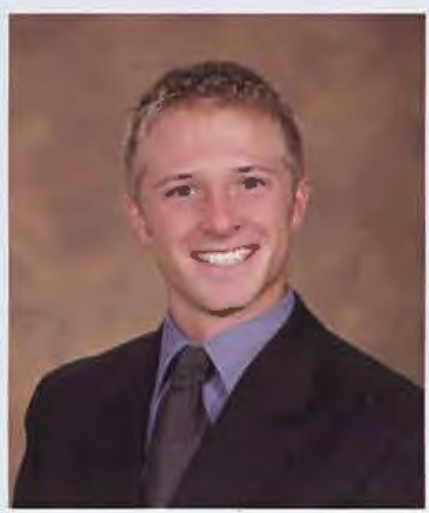

Derek Hostetter Pre-seminary Bible

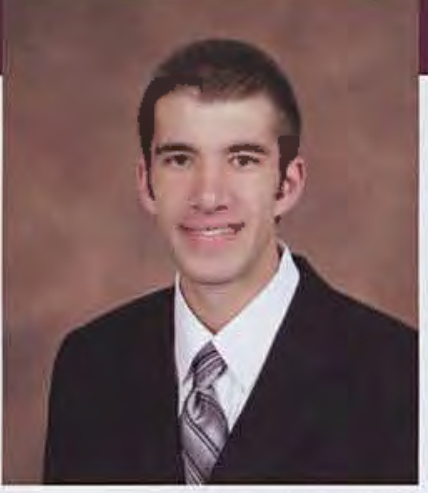

Andrew Henricks Political Science

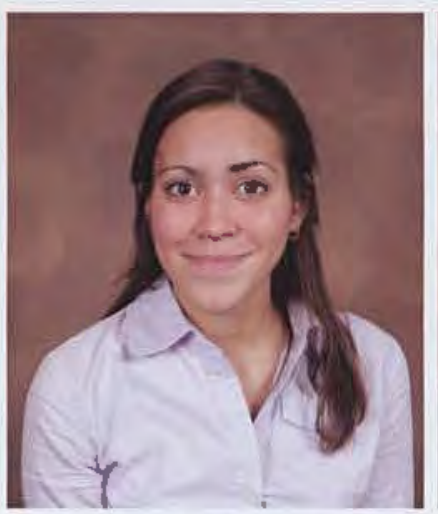

Stephanie Hilerio

Nursing

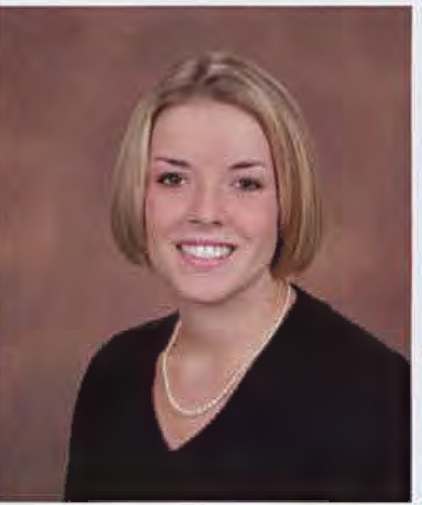

Jada Holloway Applied Psychology

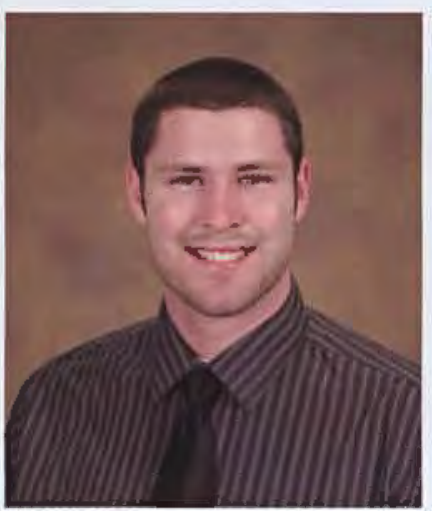

Matthew Houchin Exercise and Sport Science

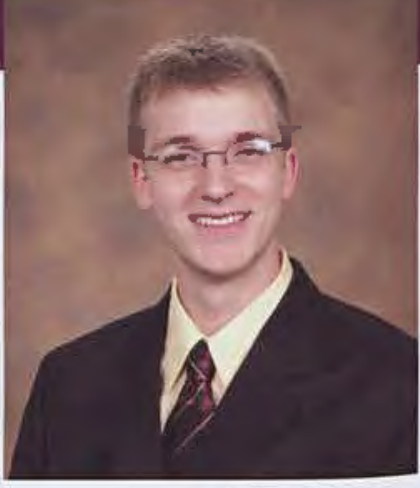

Caleb Hensley Electronic Media

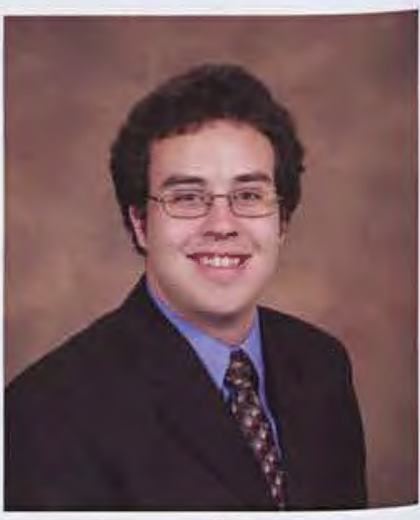

Nathan Hinks

Electrical Engineering

点 


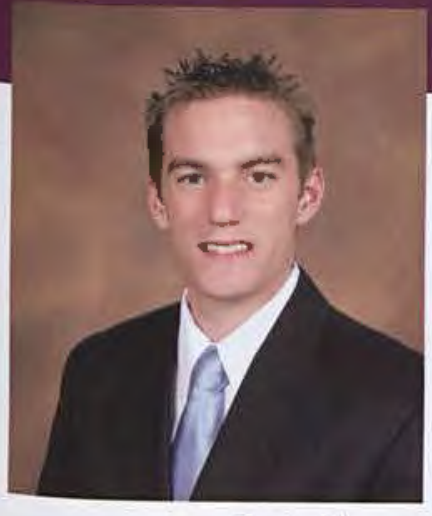

Craig Houser Youth Ministry and Christian Education

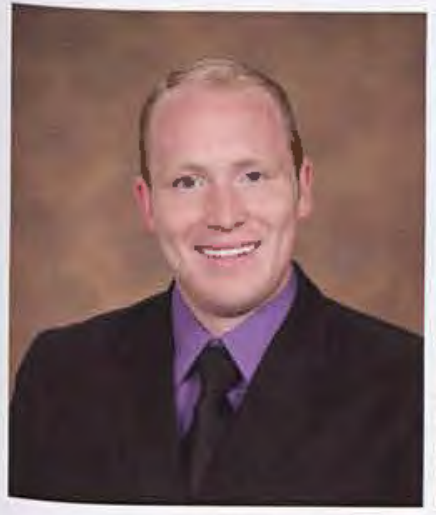

Anthony Hubin

Church Music Ministries

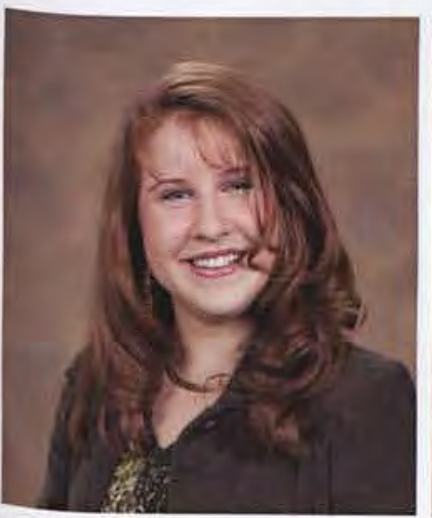

Brittany Jackson Communication Research

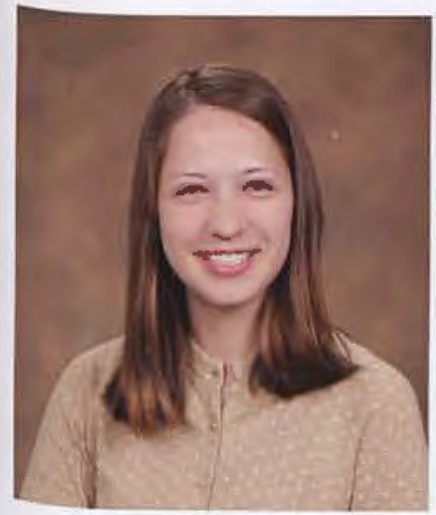

Amber Janssen Sociology

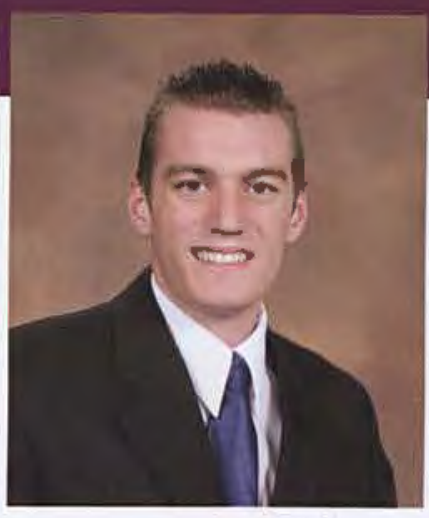

Dale Houser Accounting and Finance

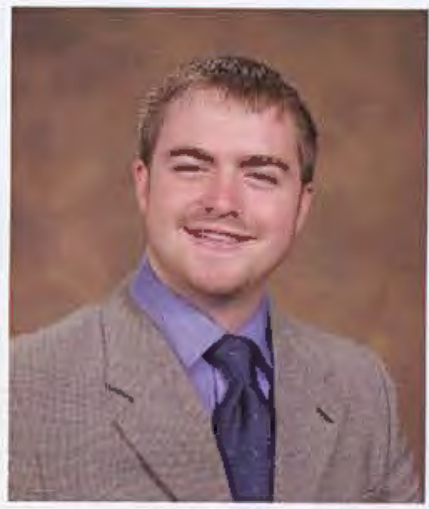

Joshua Hueni Business Management

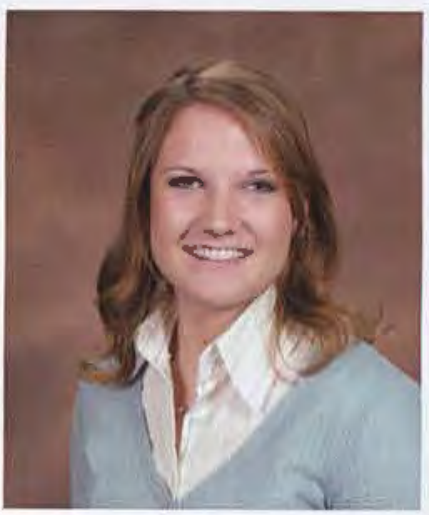

Jennifer Jackson Nursing

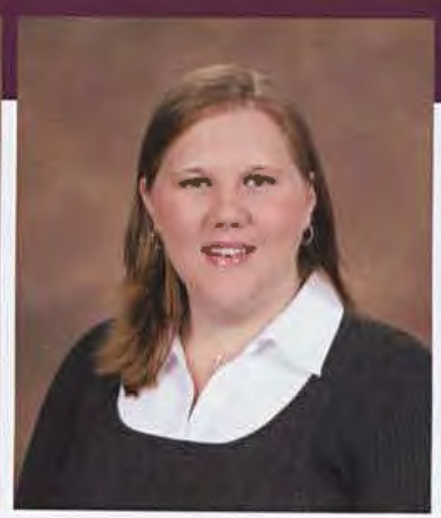

Christie Howard Nursing

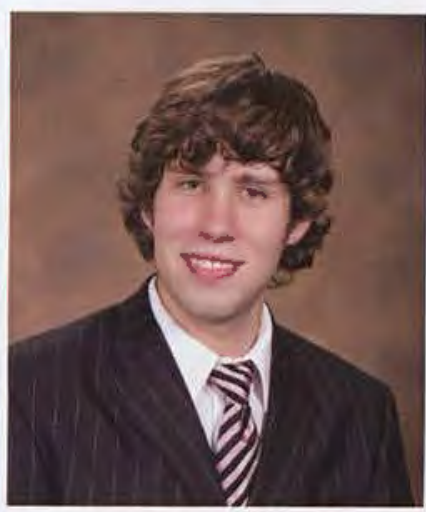

Phillip Hundley Marketing

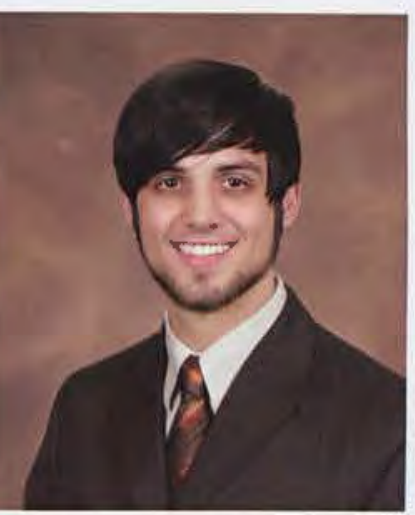

Kyle Jackson Electronic Media

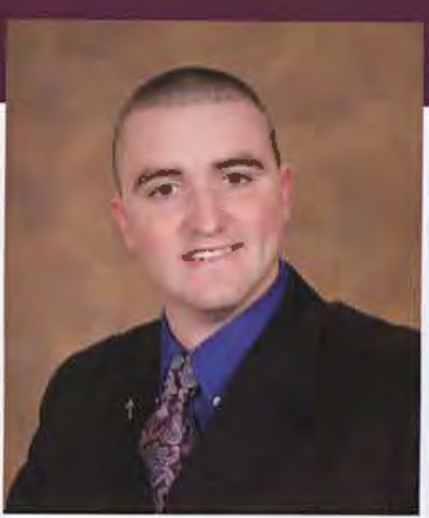

James Howard Pastoral Studies

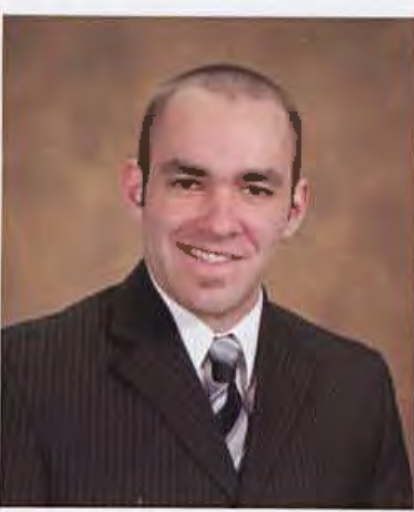

Eben Infante Biology

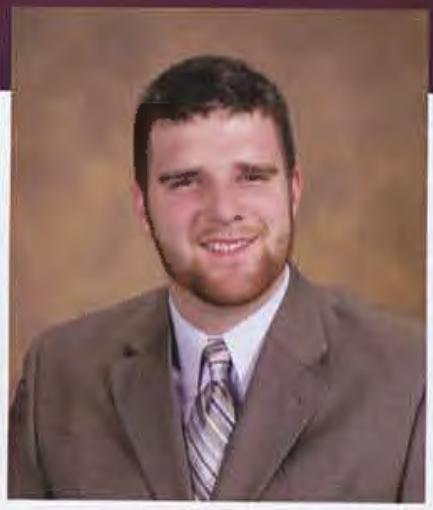

David Howdyshell Middle Childhood Education

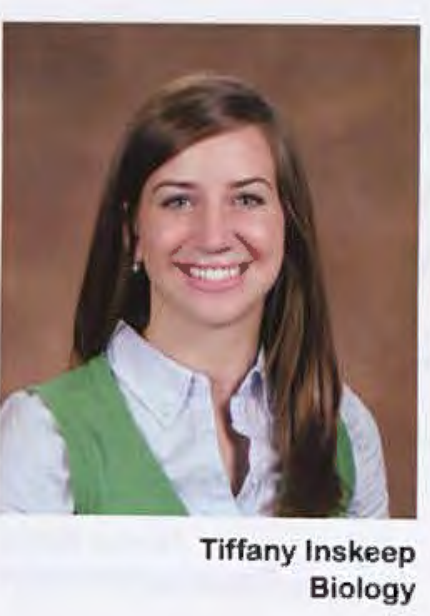

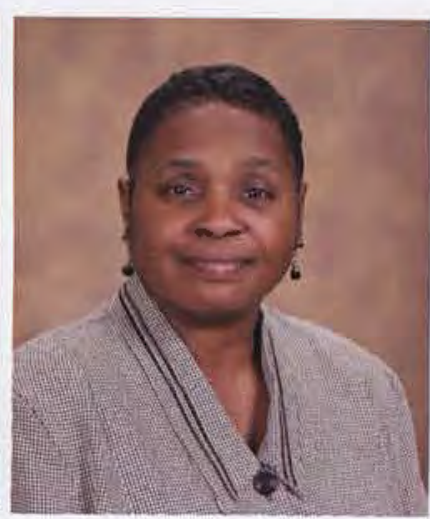

Cecelia Jacobs Sociology, Theology, Psychology

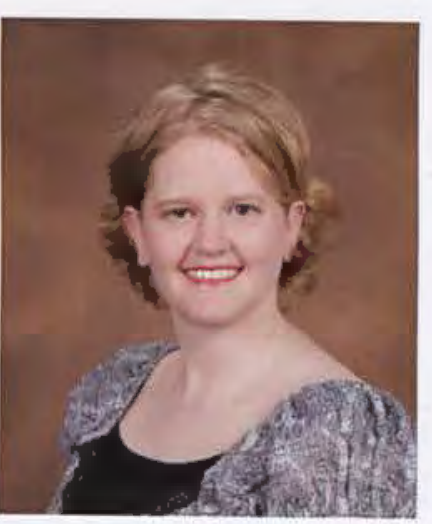

Ashley Jacobson Nursing

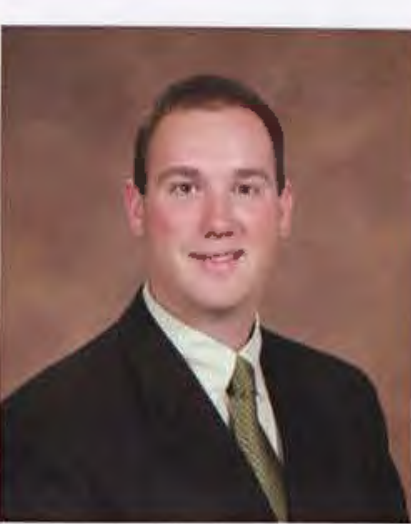

Jesse Jordan Pastoral Studies

Alicia Johnson Marketing
Courtney Johnson Psychology

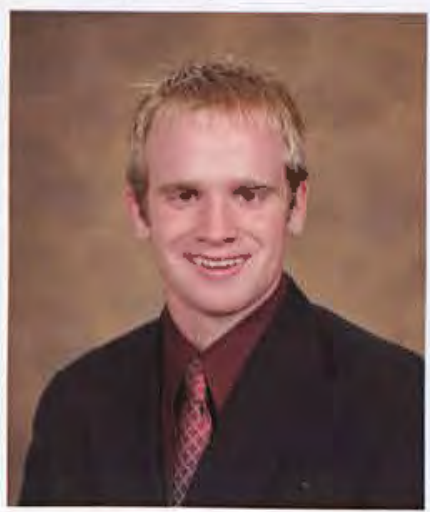

Steven Johnson Marketing 


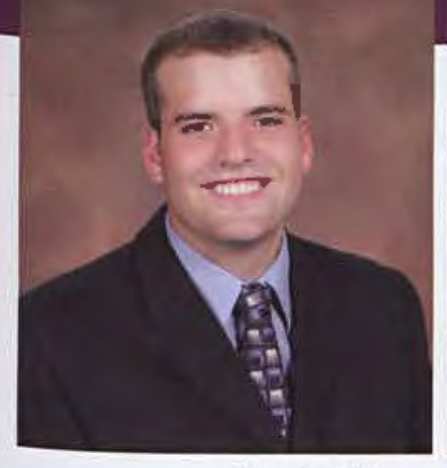

Charles Kraus Pre-seminary Bible

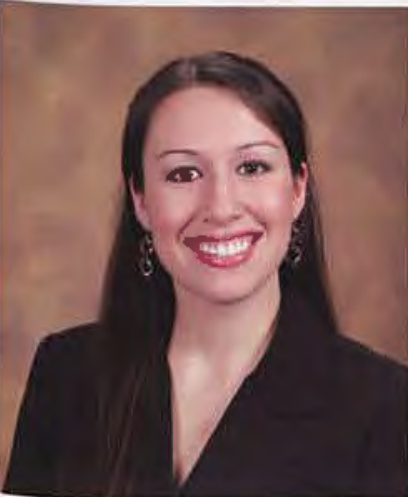

Meredith Lang Theatre

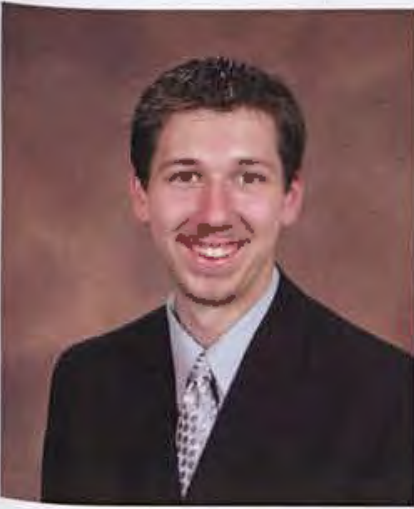

Jonathan Lawler Pre-seminary Bible, Psychology

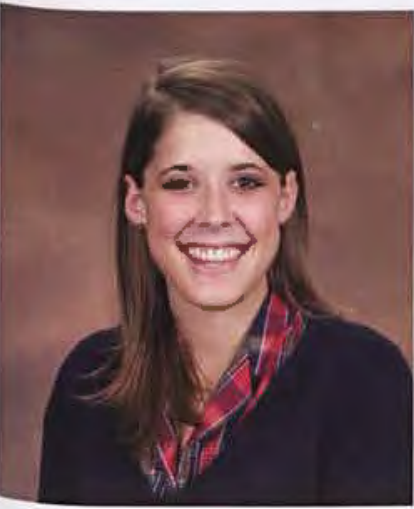

Johannah Leightenheimer English

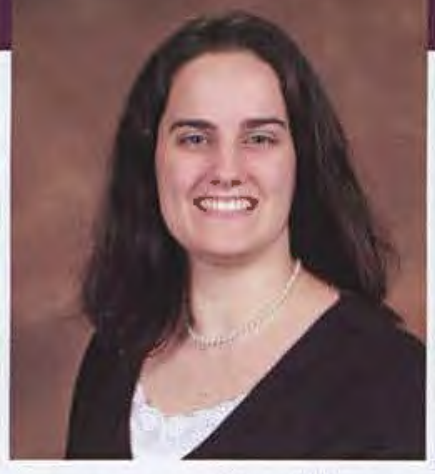

Carol Kreeger Nursing

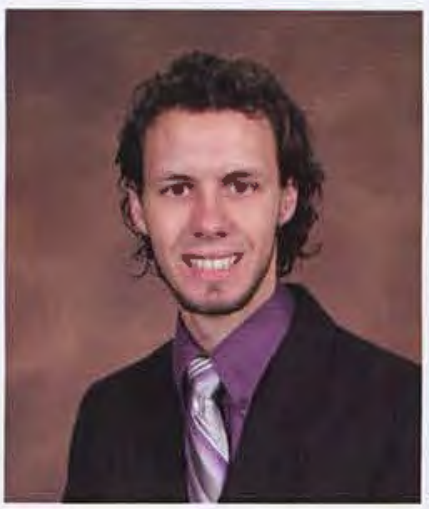

Ryan Lang Mechanical Engineering

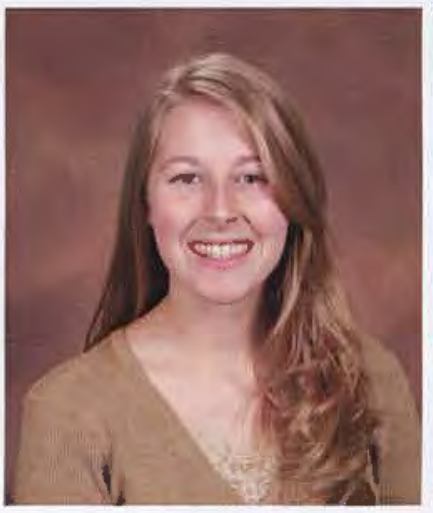

Jessica Lawrence Applied Psychology

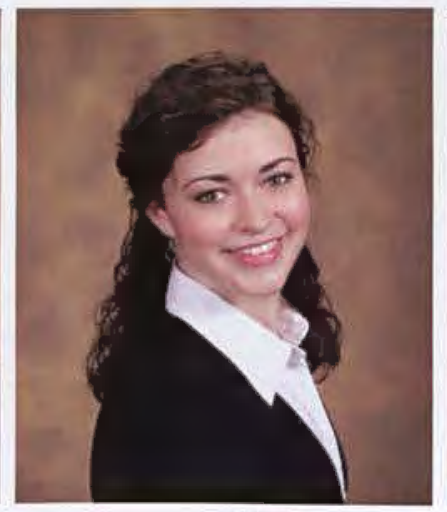

Melissa Lewis Integrated Mathematics Education

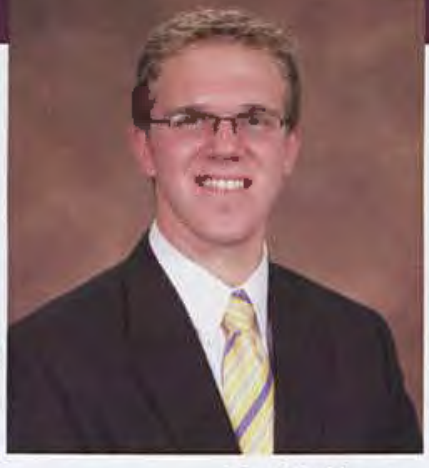

Devin Krupka Accounting and Finance

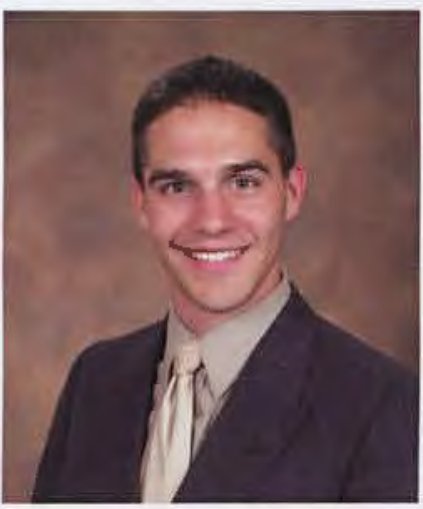

Jesse Lansford Mathematics

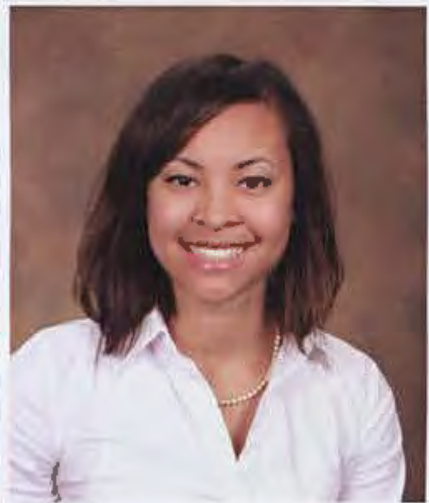

Laura Lee Mathematics

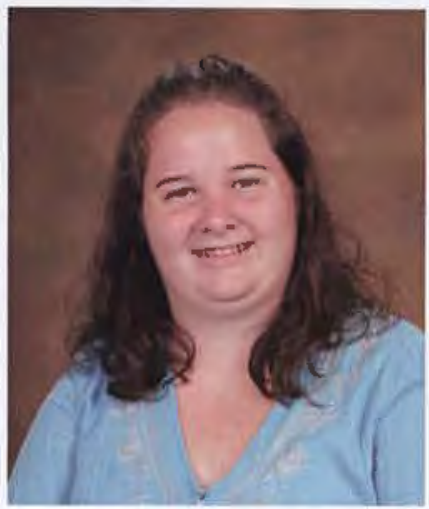

Kimberly Lincoln Applied Psychology

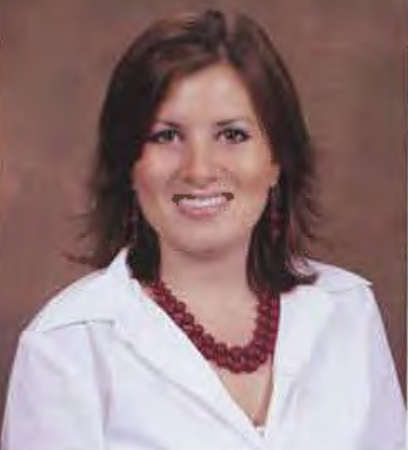

Laruen Kaake Psychology

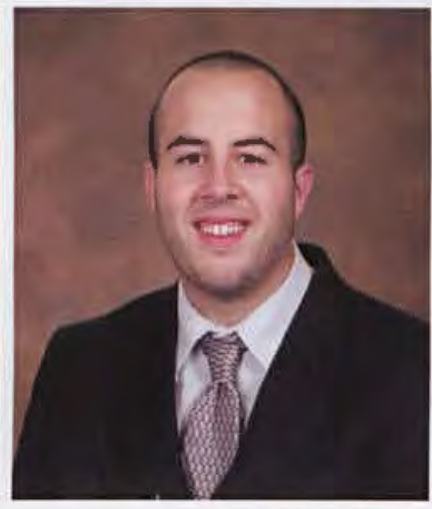

Eric Lapata Youth Ministries

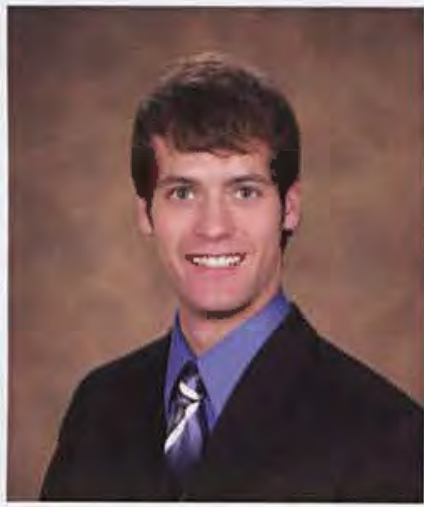

Michael Lee Exercise Science

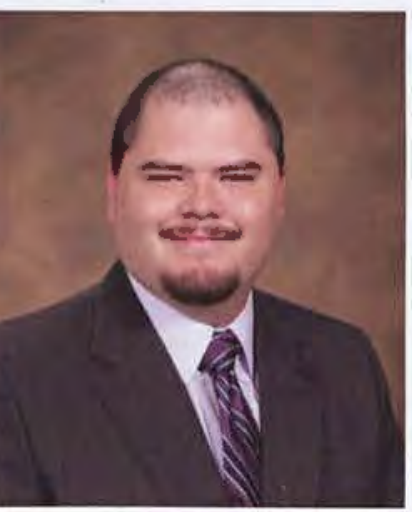

Michael Lincoln Sport Management

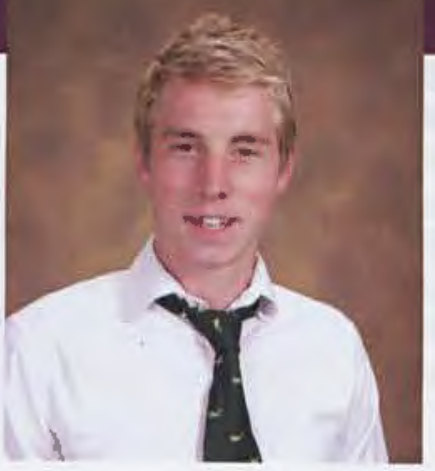

Joel Lagan International Studies, Social

Sciences

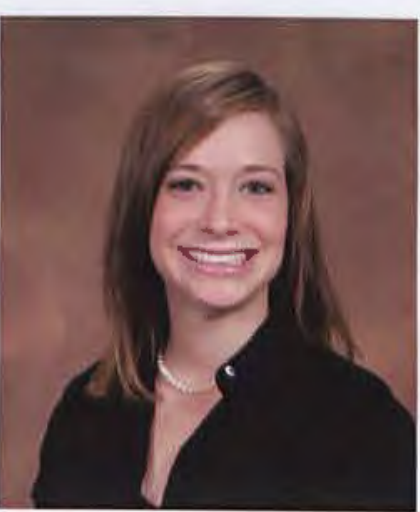

Lisa Largent Communication Arts

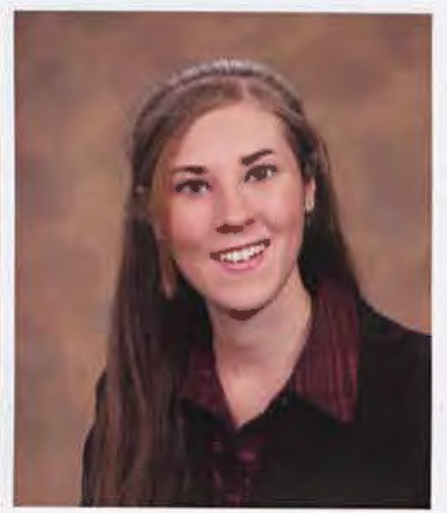

Lindsay Lehmann Technical and Professional Communications, Spanish

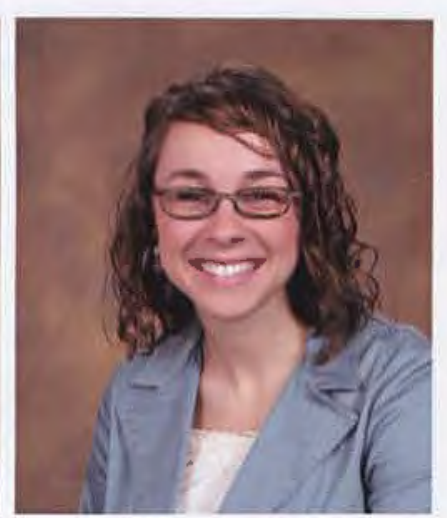

Katherine Lippman Organizational Communications 


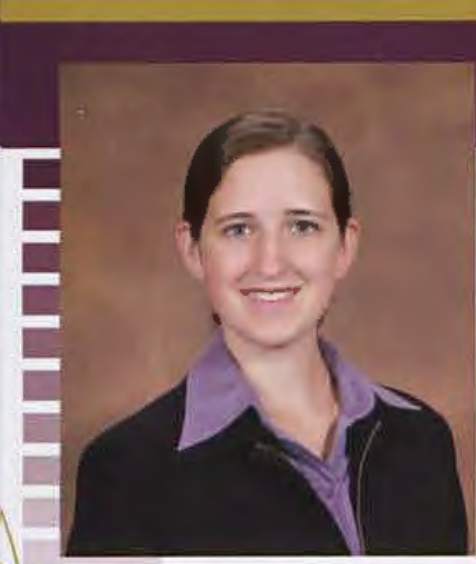

Amanda Littell Graphic Design

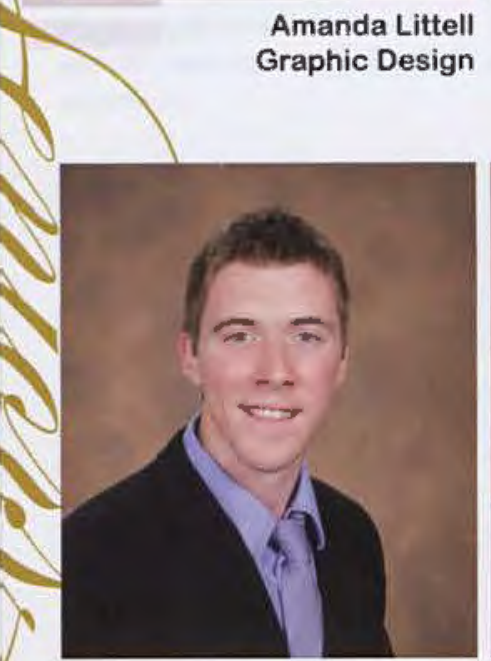

Garrett Lowe

English

Integrated Physicals

Education

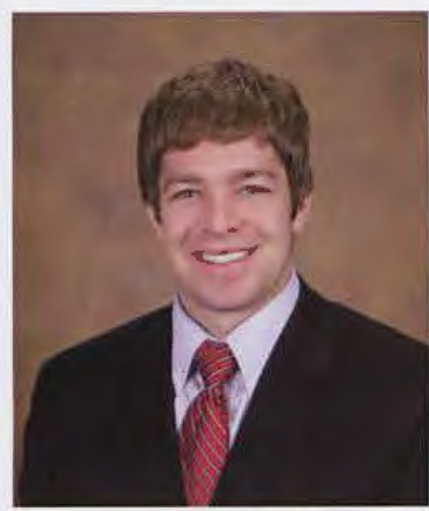

Daniel Magee History and Political Science

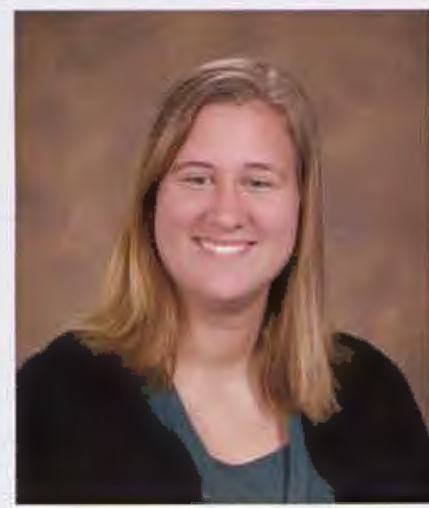

Larinda Marker Nursing

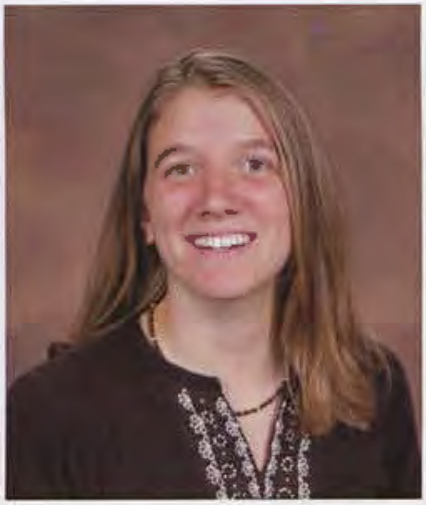

Larissa Malik Biology

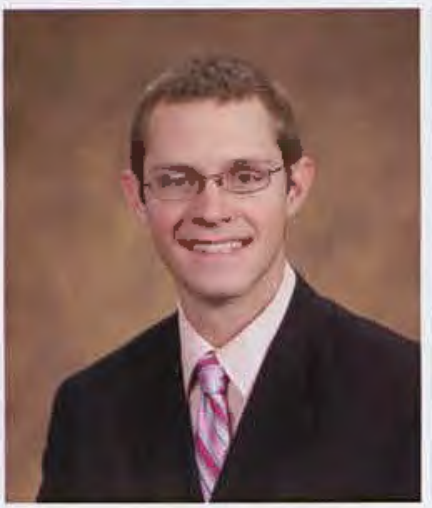

Brent Martin Sport Management

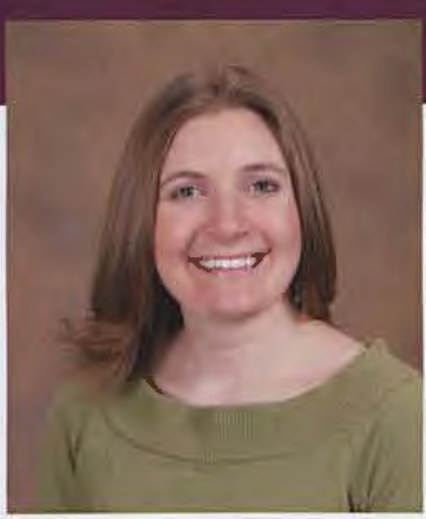

Katherine Loper Nursing

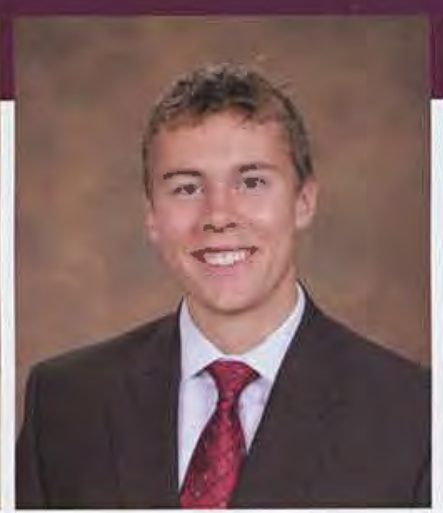

Joel Losch

Global Economics and International Business

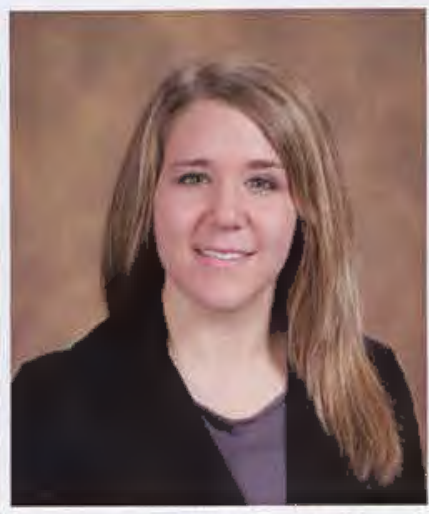

Sharayah Lucas Integrated Social Studies Education

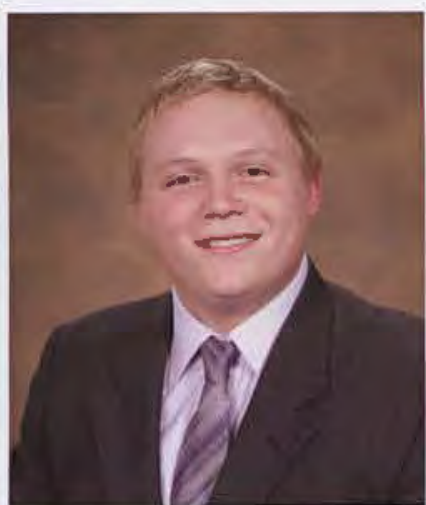

Christopher Malmstrom Comprehensive Bible

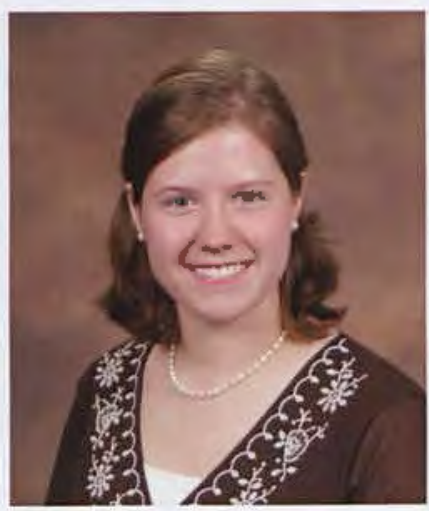

Elizabeth Martin Middle Childhood Education

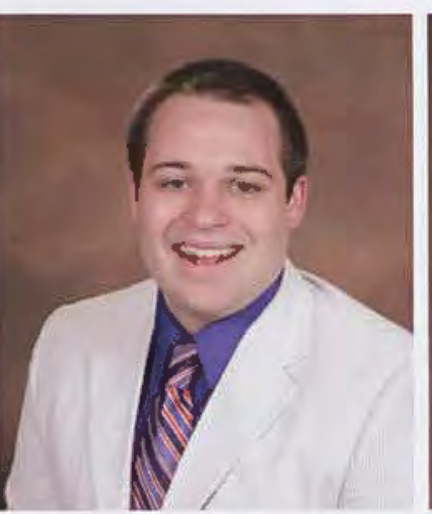

Clayton Ludlow Youth Ministry and Christian Education

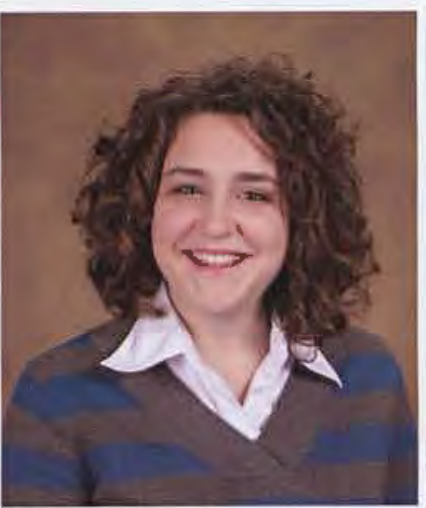

Lindsay Malone Comprehensive Communication

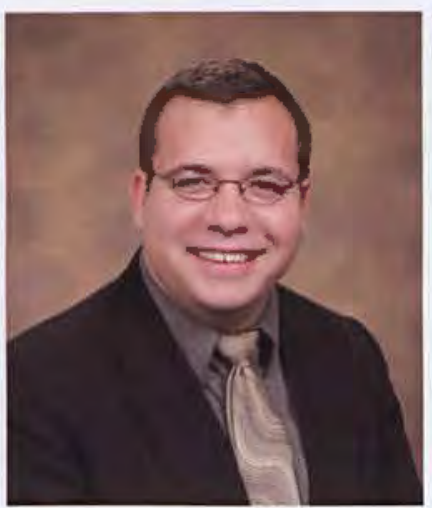

Micah Martin Music Performance

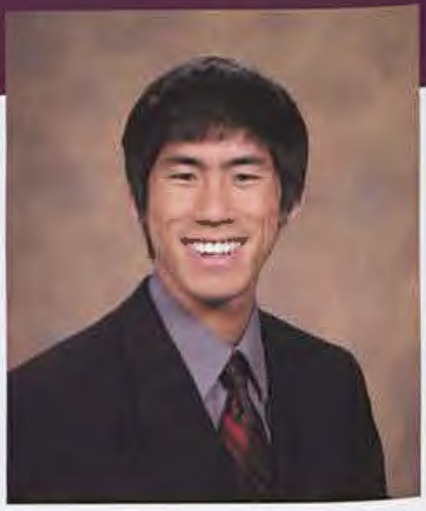

Aaron Louie Church Music Ministries

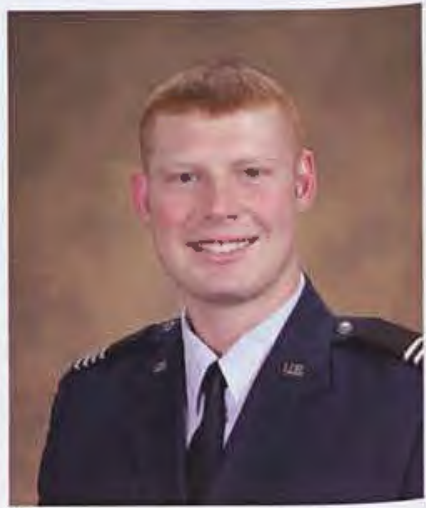

Justin Lyon Criminal Justice

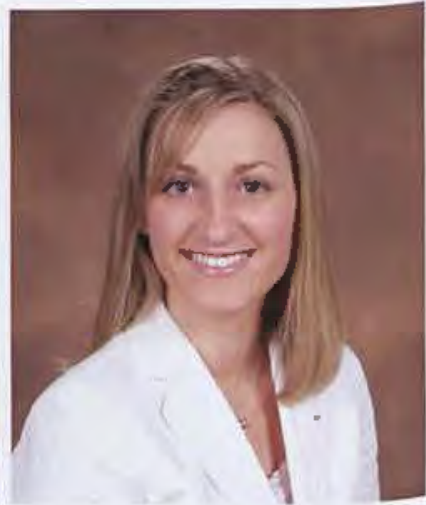

Jenna Marcum Philosophy and Communications

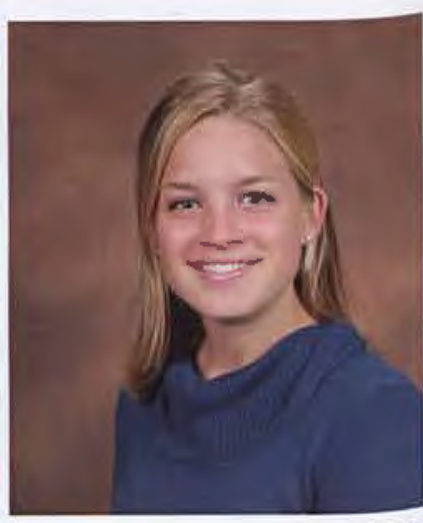

Julie Martz Middle Childhood Education 


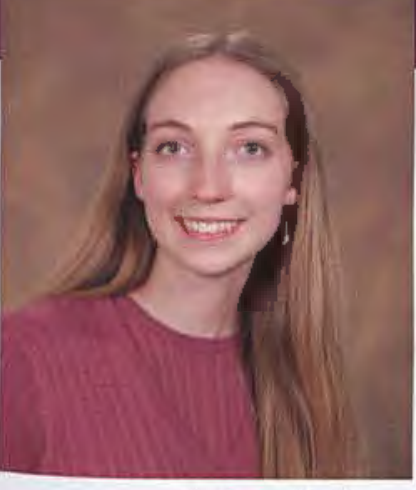

Melissa Mathews

English

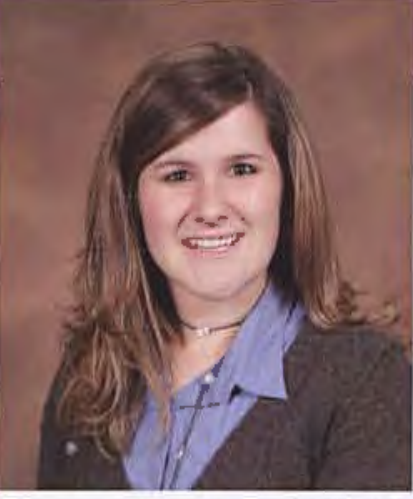

Lauren Mathis Middle Childhood Education

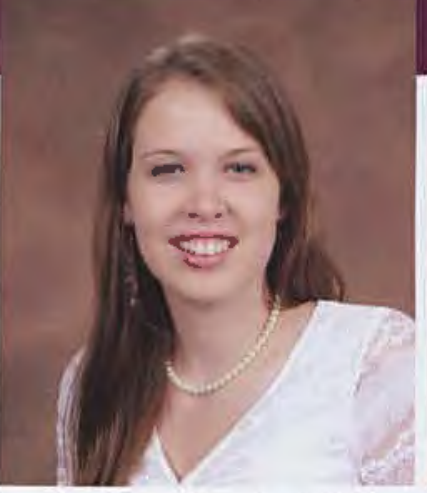

Kendra Mattson Middle Childhood Education

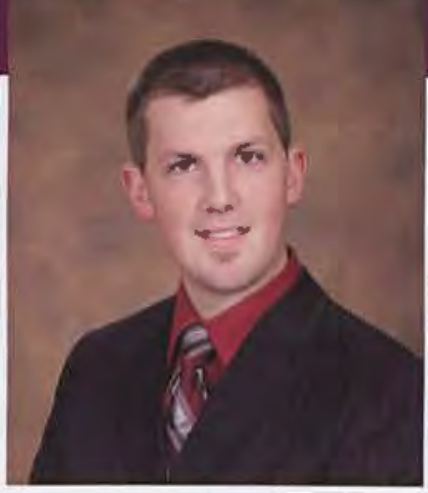

Matthew Maver Finance

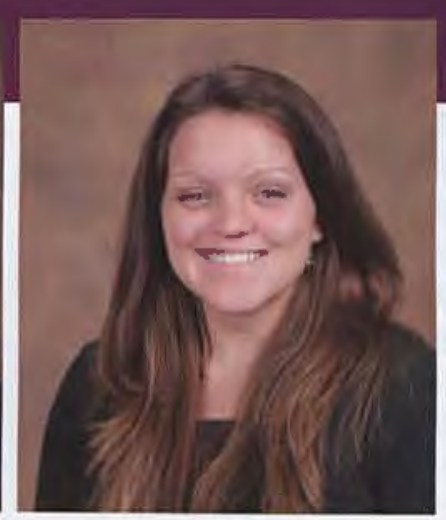

Nicole Maxwell Youth Ministry and Christian

Education

Biology and Integrated Life Science Education

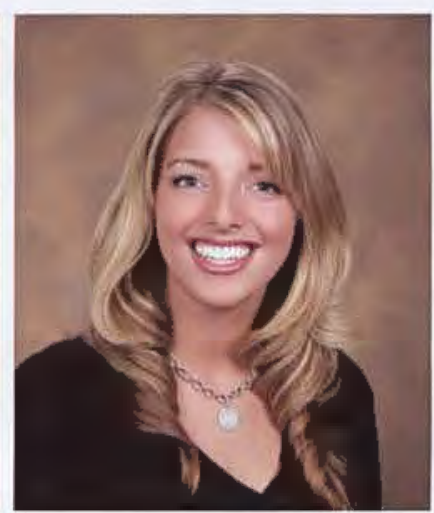

Kate McKee Exercise Science

Justin McCoy Pre-seminary Bible

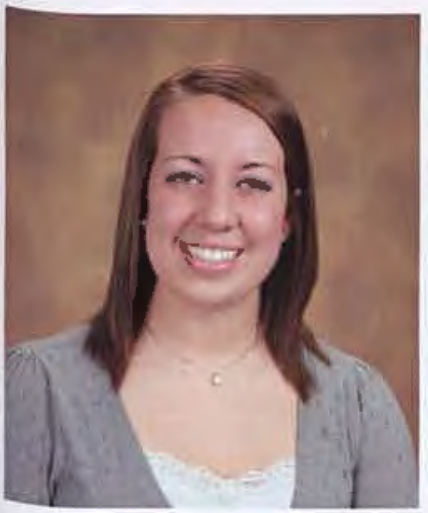

Julie McQueen Sports and Exercise Studies

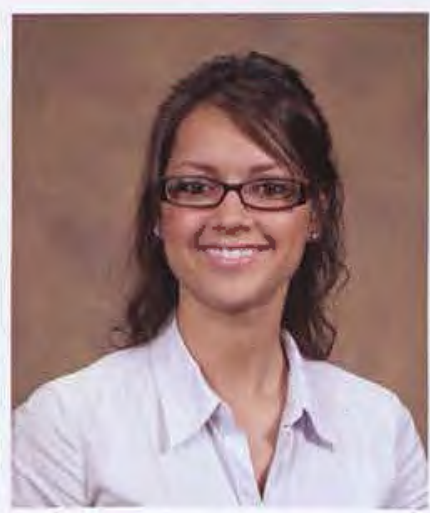

Anjuli Mehra Communication Arts

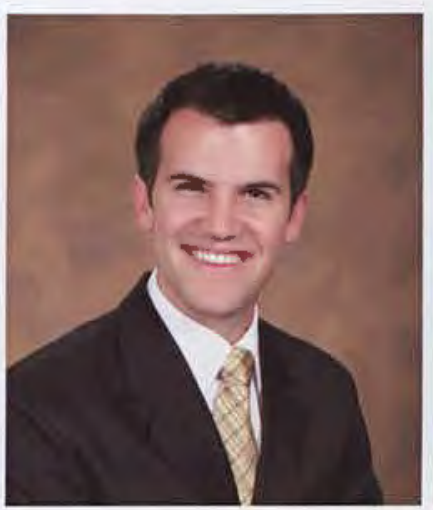

James McClenahan Pre-seminary Bible

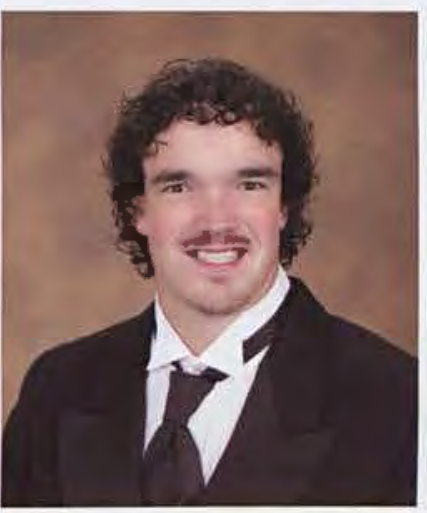

Robert McKenna Electronic Media

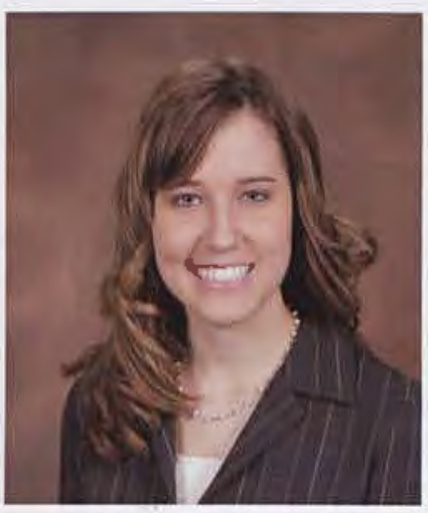

Amanda McCollim Nursing

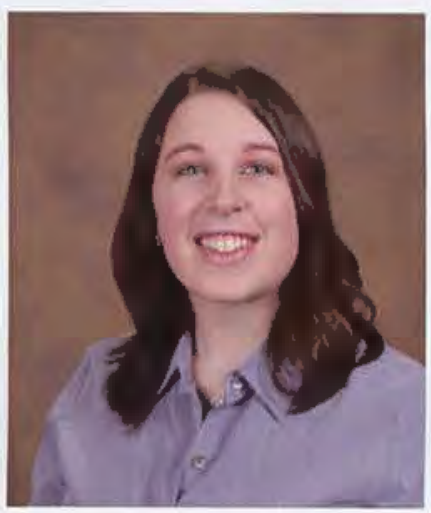

Amanda McKinley Nursing

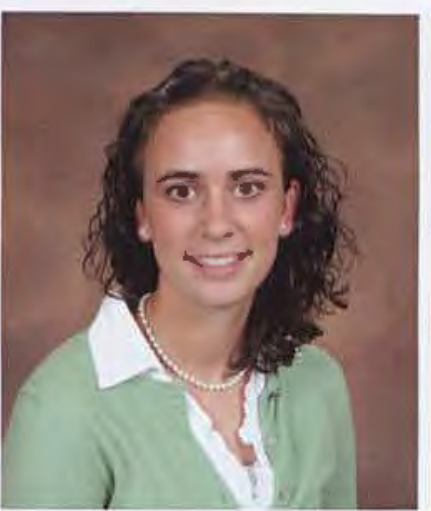

Kristin Merkel

Integrated Language Arts Education

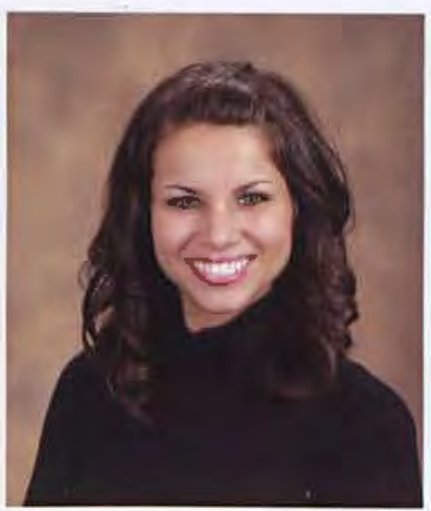

Marguerite Mikolon Exercise Science

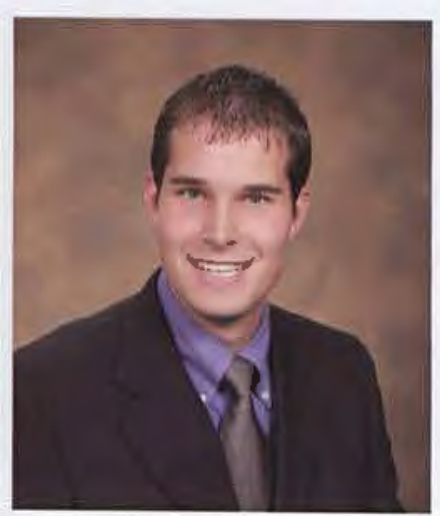

Caleb McCollim Finance

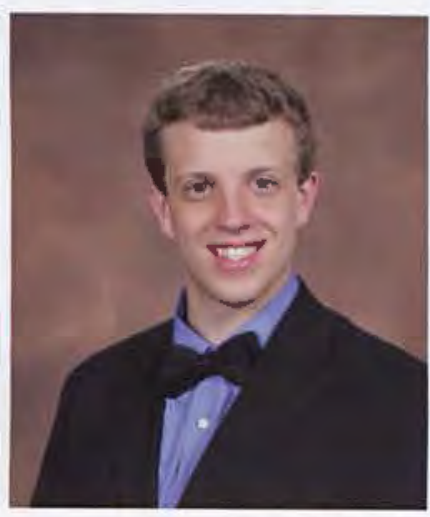

Philip McLeod Theatre

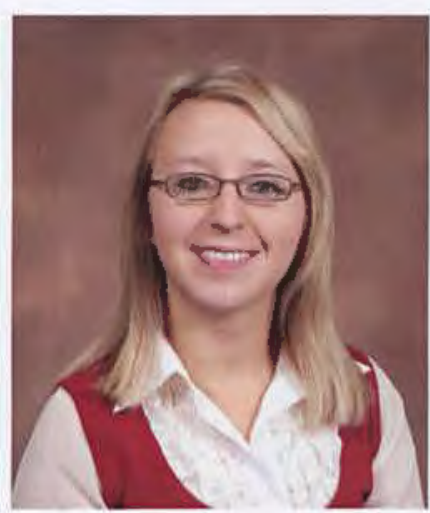

Bobbi Miller Youth Ministries 


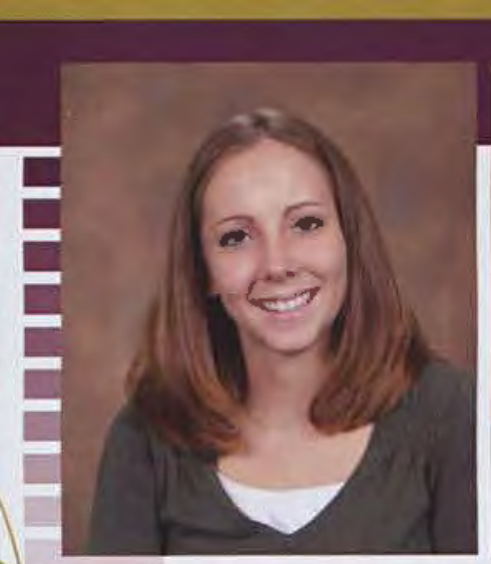
Early Childhood Education

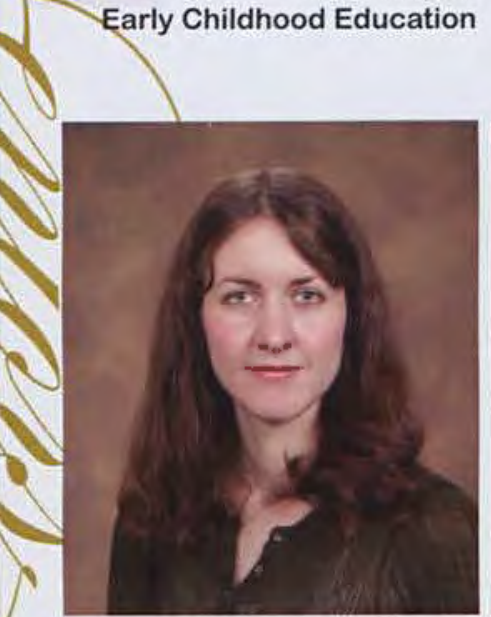

Whitney Miller English

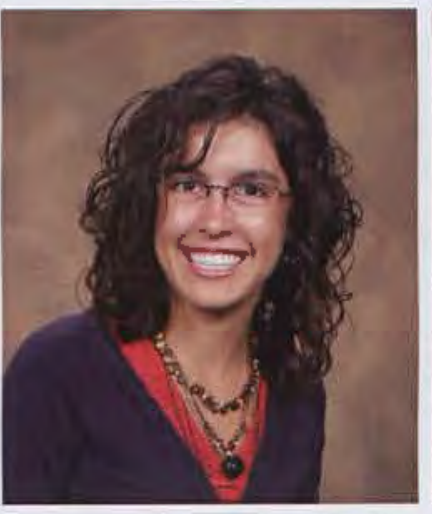

Loren Montes Nursing

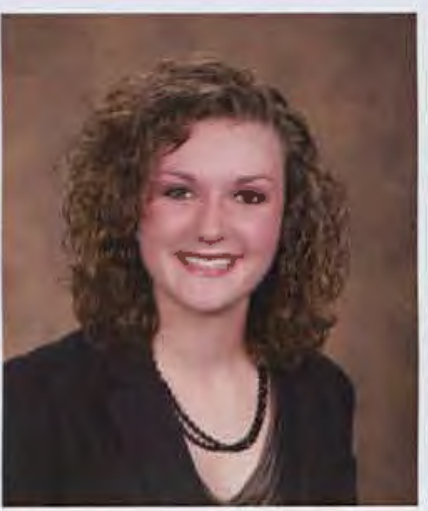

Danielle Morgan Communication Arts

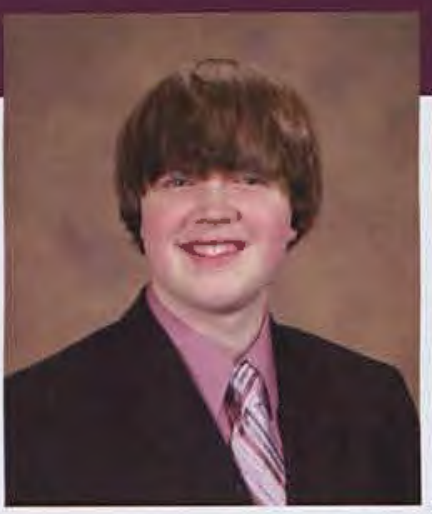

Jeremy Miller Mechanical Engineering

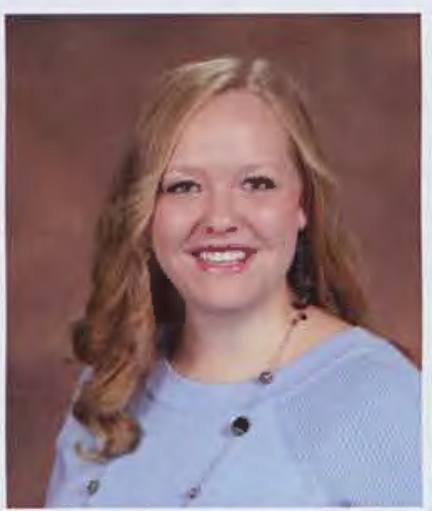

Karisa Millington

Multi-Age Music Education and Choral Track

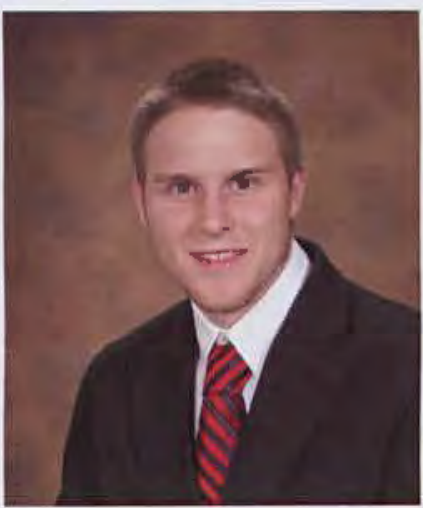

Scott Montie

Marketing

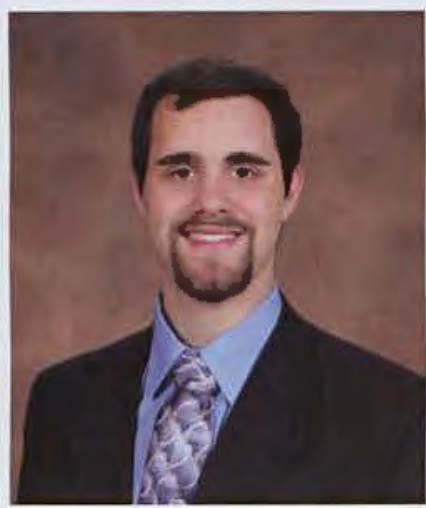

Jonathan Morgan Electronic Media

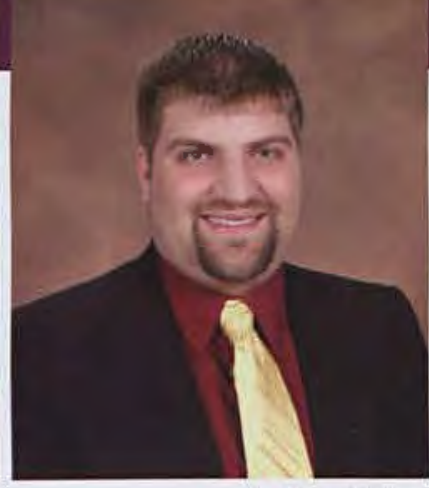

Joshua Miller History

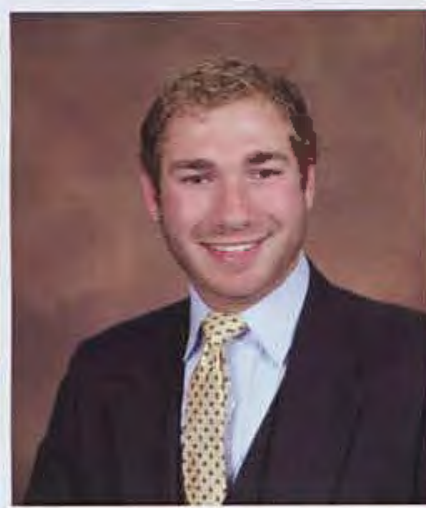

Eric Mishne Theatre

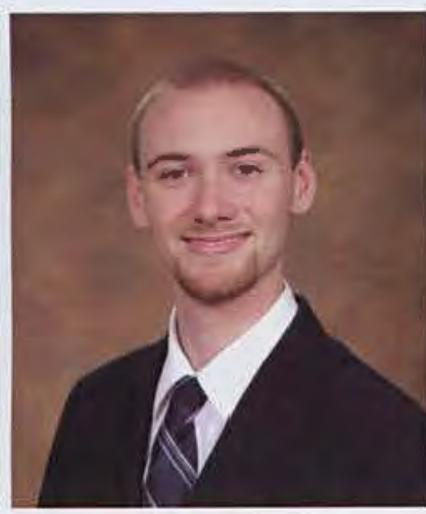

Kenneth Moore

Physics

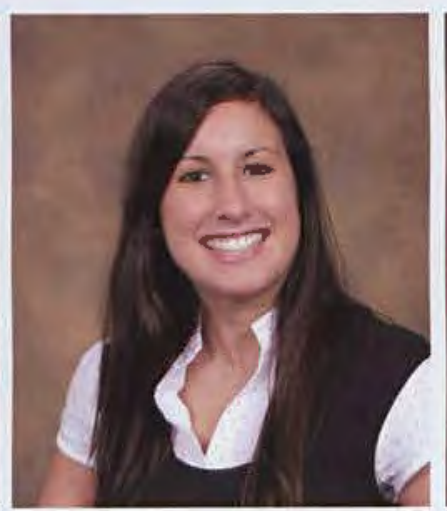

Jennifer Moriarty Business Management

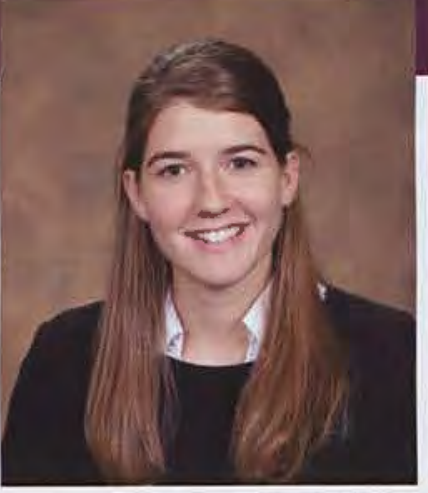

Sarah Miller Exercise Science

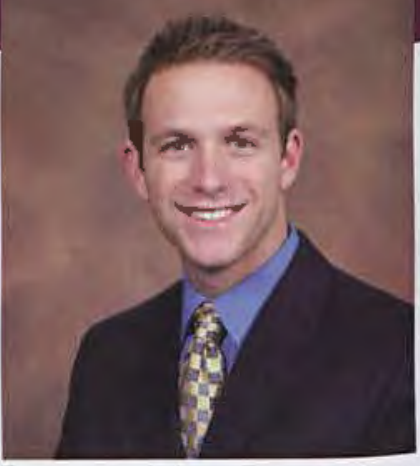

Scott Miller Mechanical Engineering

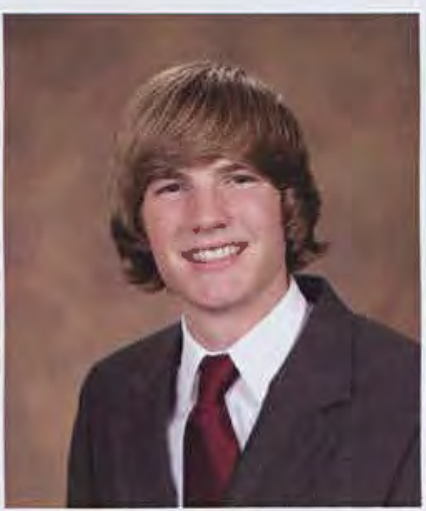

Scott Mitchener Pre-seminary Bible

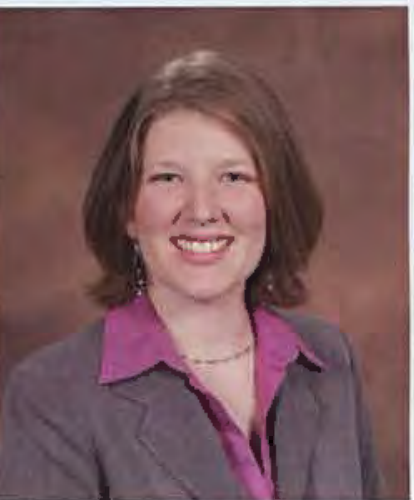

Nicole Moore

Theatre

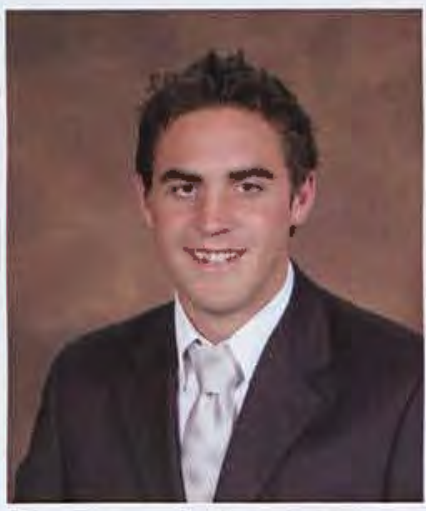

James Morrow Molecular and Cellular

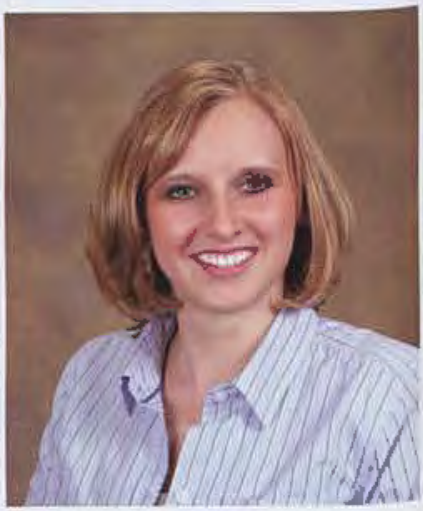

Emily Mohler Nursing and Psychology

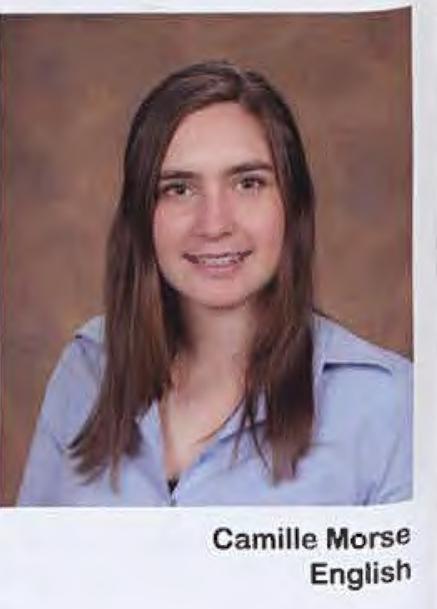

s

A 


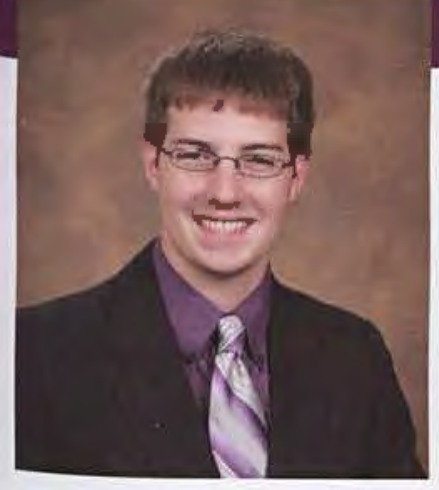

Joseph Moss Accounting

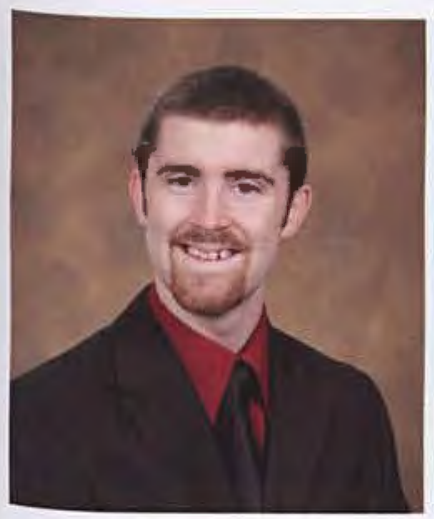

Dennis Nangle English

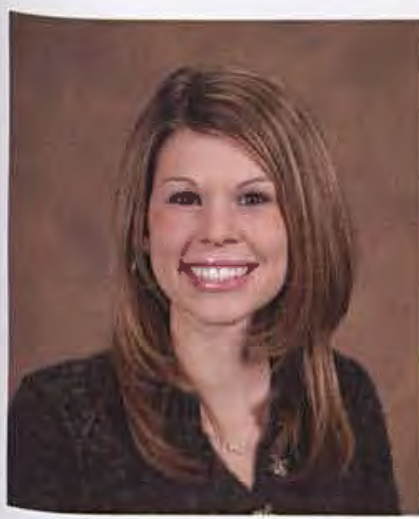

Allison Newfield Middle Childhood Education

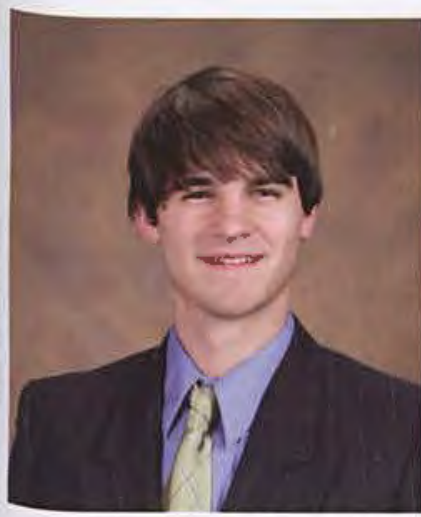

John Norton Electrical Engineering

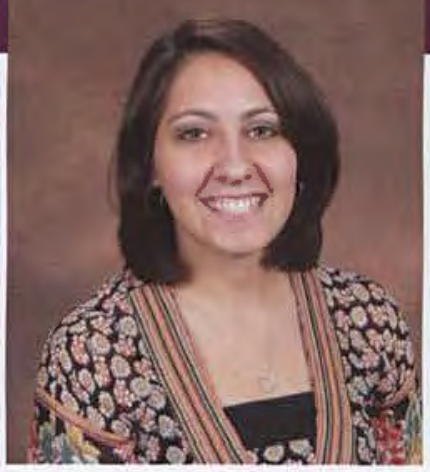

Susan Moss Music Education

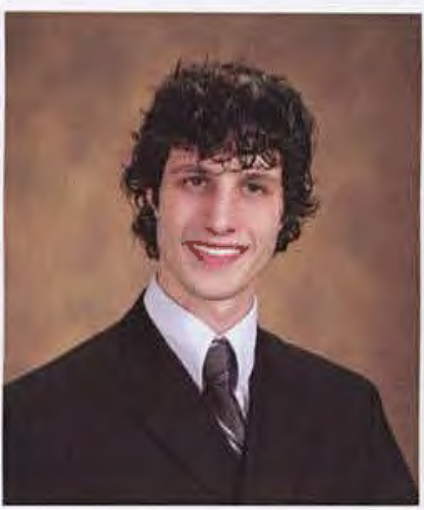

Philip Nanney Business Management

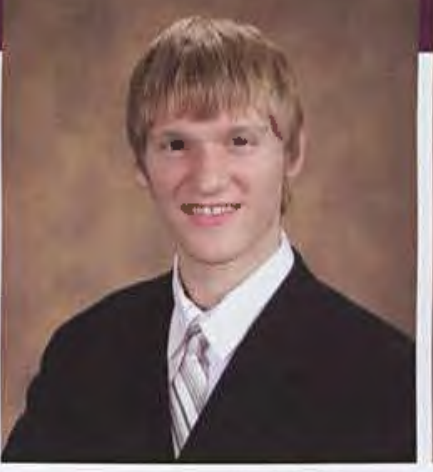

Caleb Mounts Management Information Systems

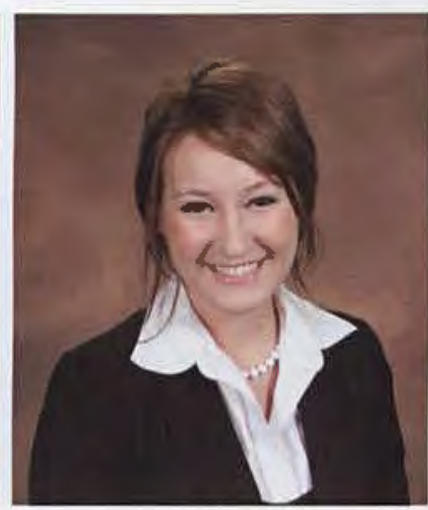

Kristen Neal Communication Arts

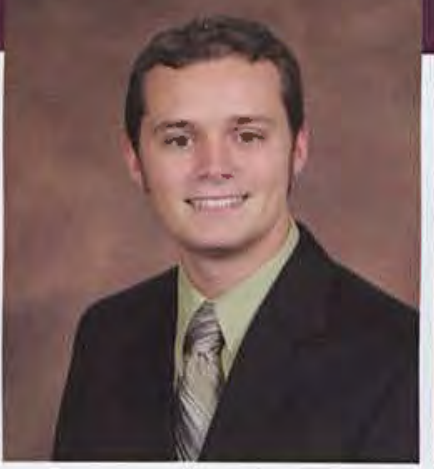

Justin Myers Computer Science

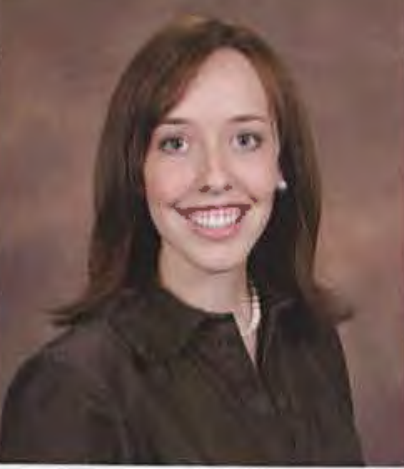

Leslie Myers International Business

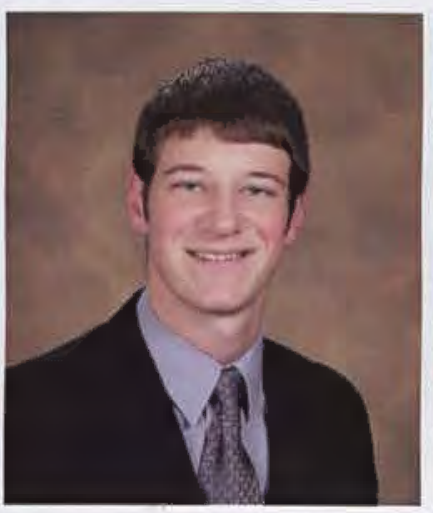

Brian Nelson Multi-Age Physical Education

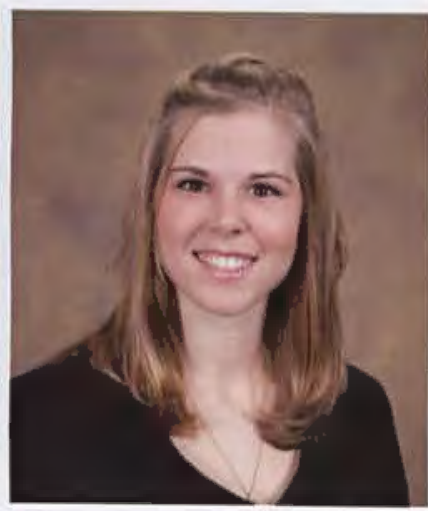

Kelsey Nelson Theatre

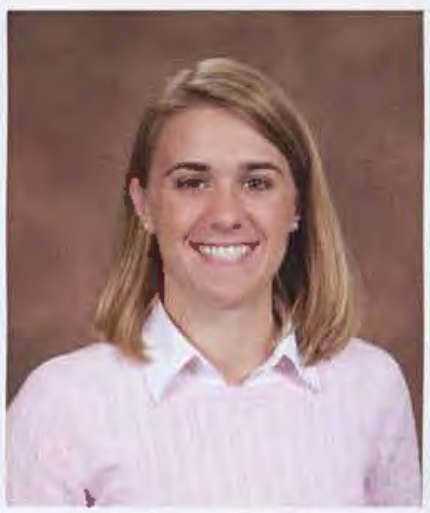

Sarah Niedermayer Integrated Mathematics Education

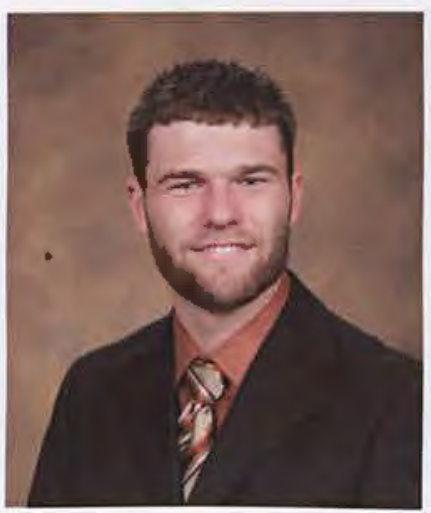

Joshua Norton Marketing

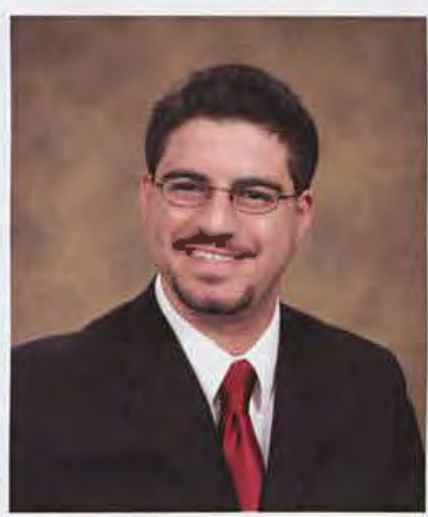

Jonathan Niknam Accounting

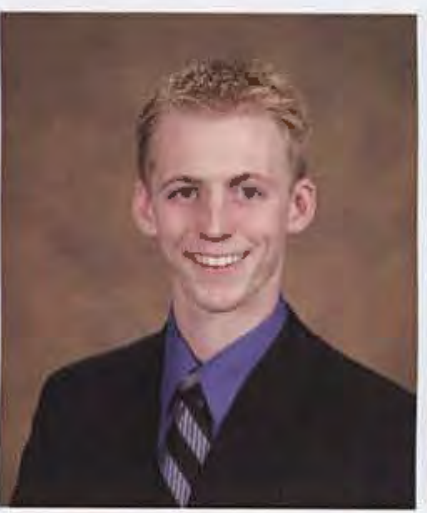

Bryan Norman Electrical Engineering

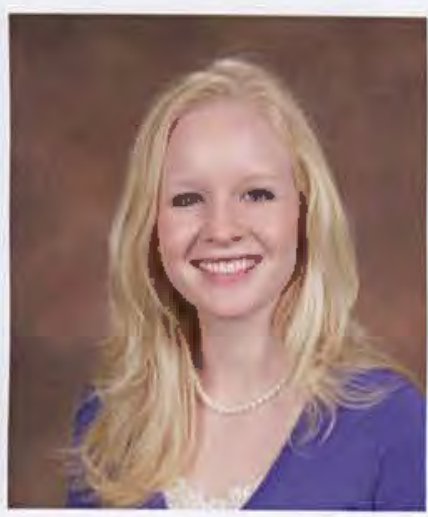

Linnea Norris Nursing

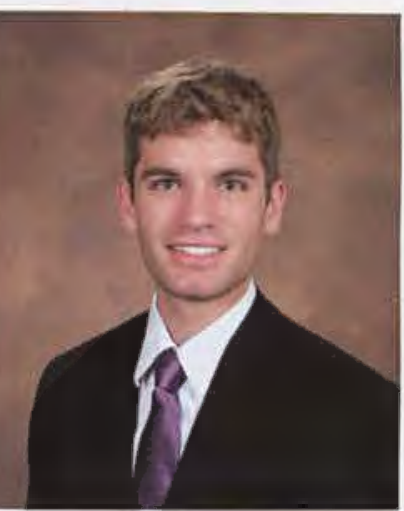

Joshua Ohms Studio Arts

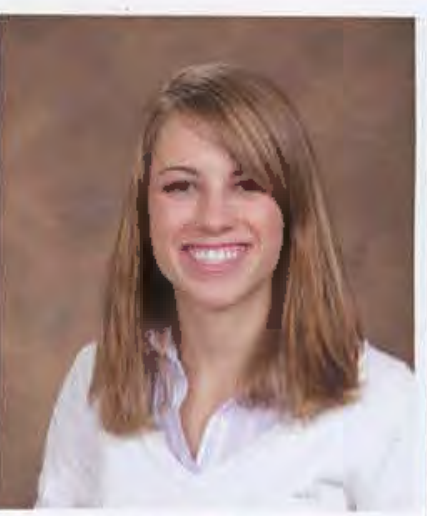

Whitney Oosterhouse Accounting

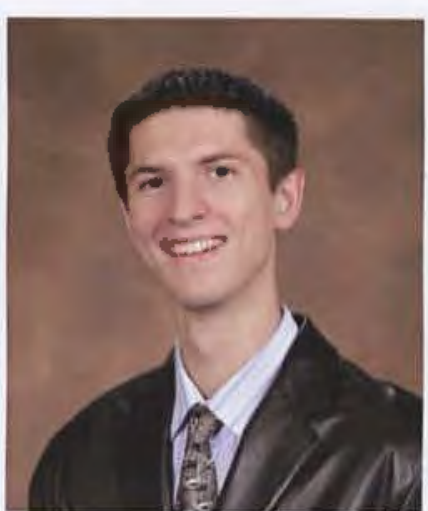

Paul Organ Mathematics 


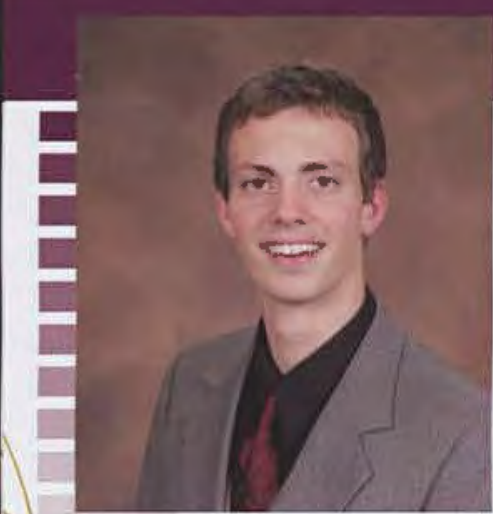

Joshua Ortiz

Finance

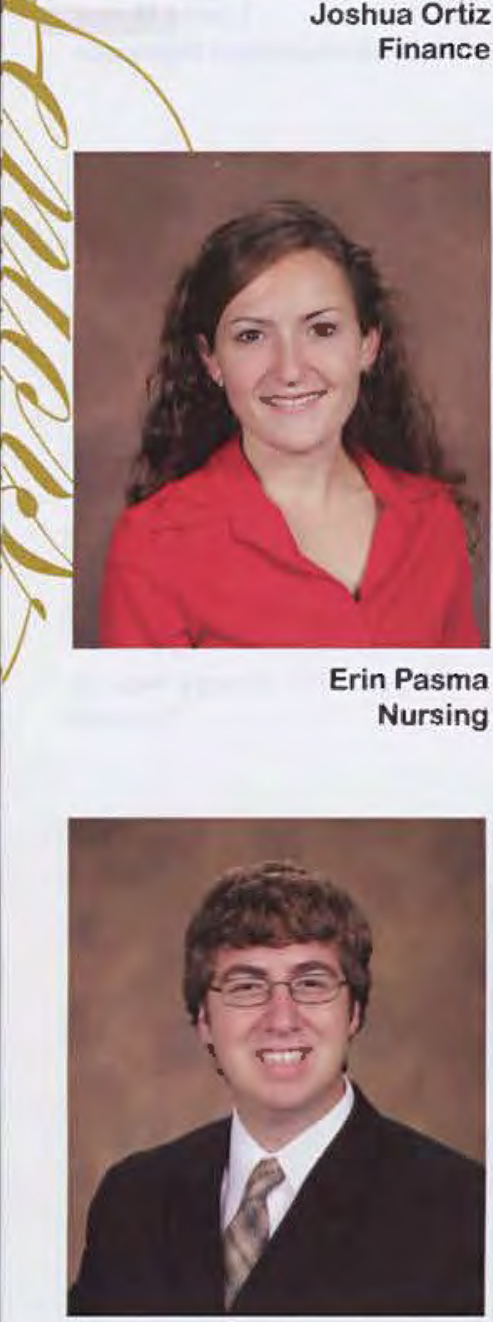

David Peterson Electronic Media

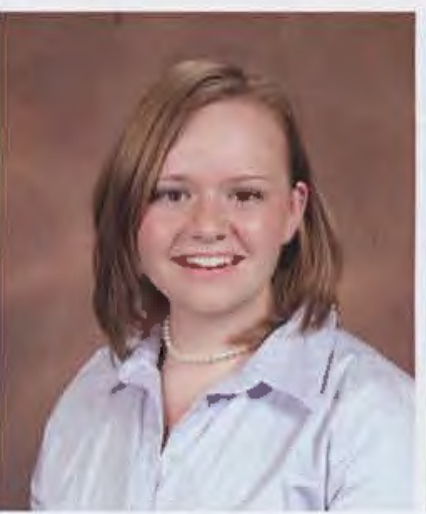

Katherine Philpott Nursing

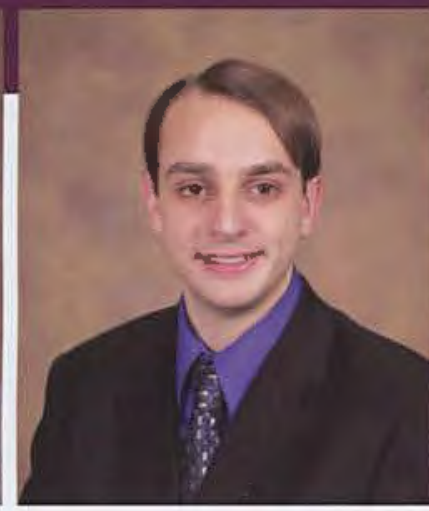

Jared Osborn

Computer Engineering

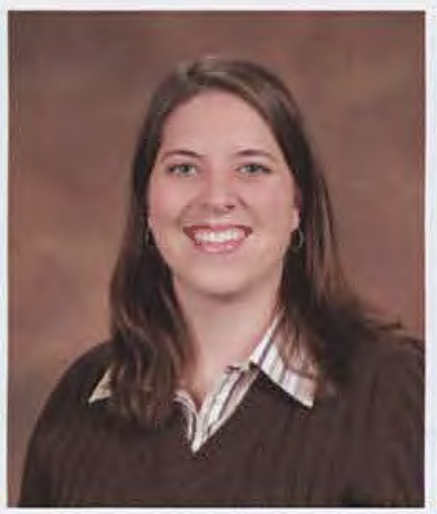

Rebecca Peak

English

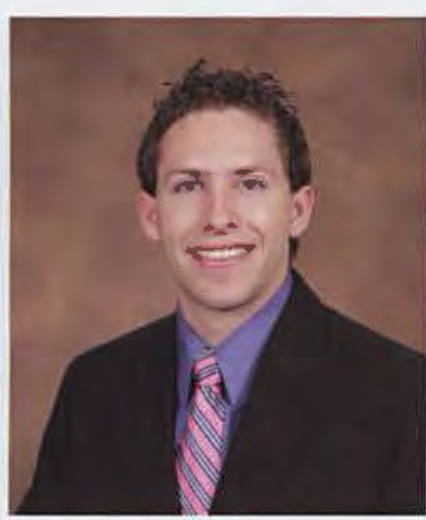

Joel Peterson Management Information Systems

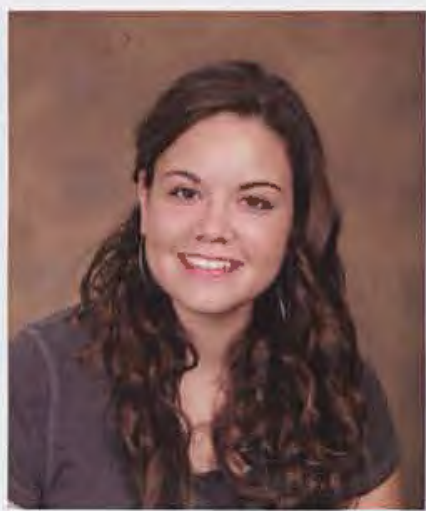

Kaitlyn Picazo

History

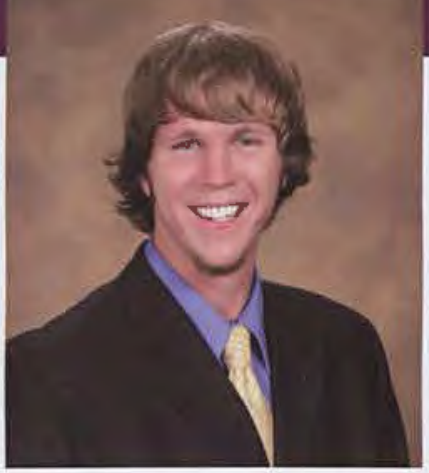

Matthew Owens

Finance

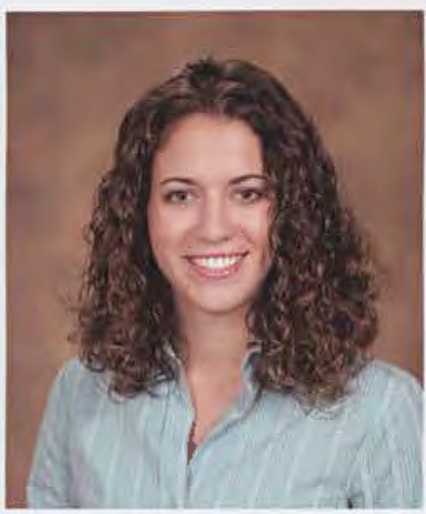

Katherine Pelon Marketing

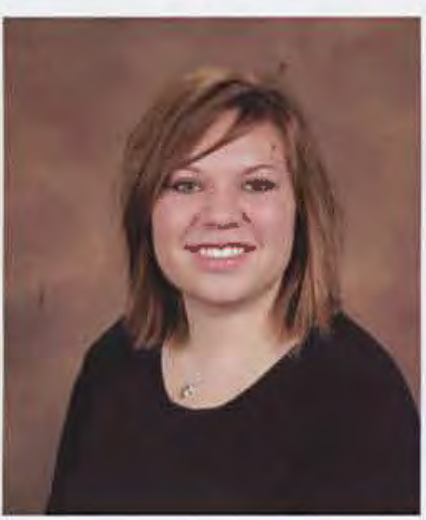

Erica Petry Studio Art

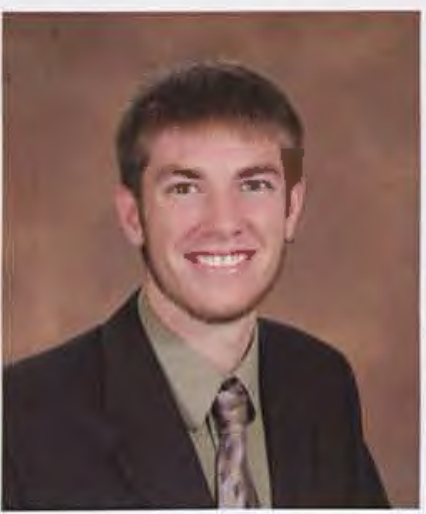

Timothy Piette Electrical Engineering

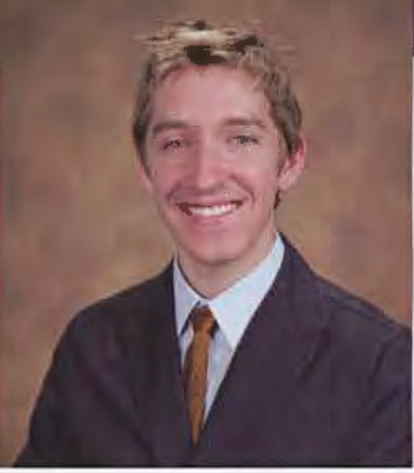

Daniel Parrott Electronic Media

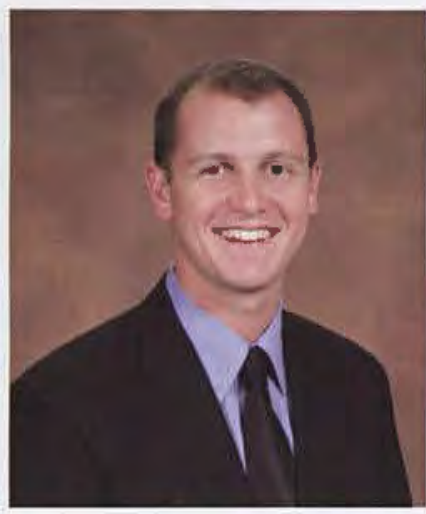

Joshua Perrel Mechanical Engineering

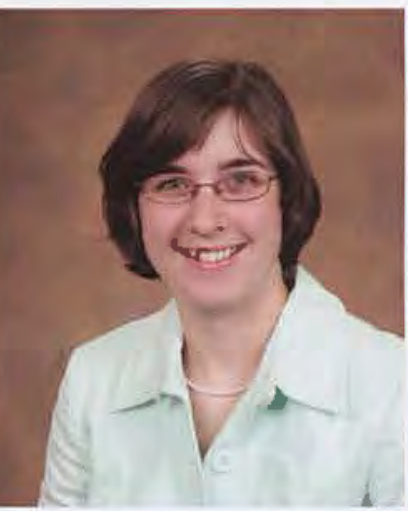

Paula Pheasant Nursing

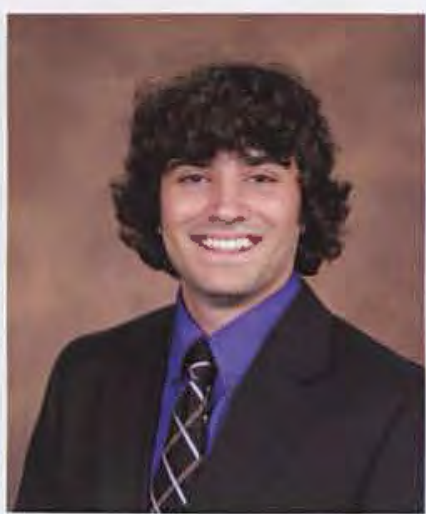

Daniel Pinkham History

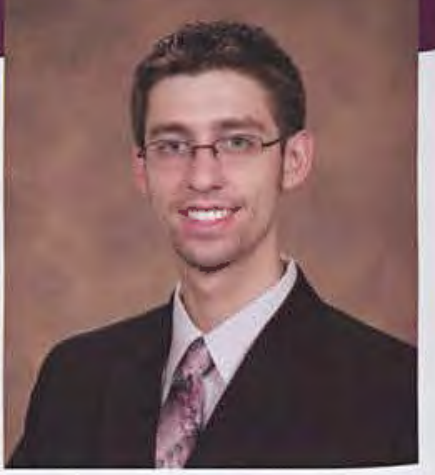

Nicholas Parry Computer Engineering

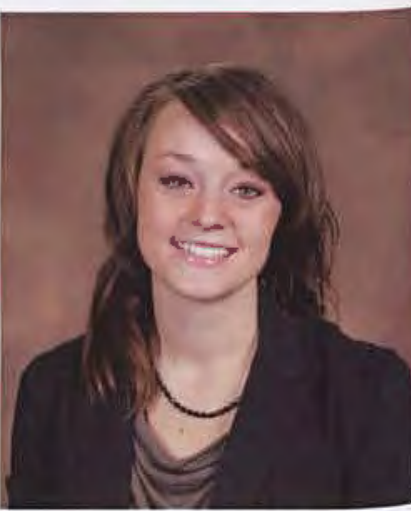

Sarah Petersen Communication Arts 


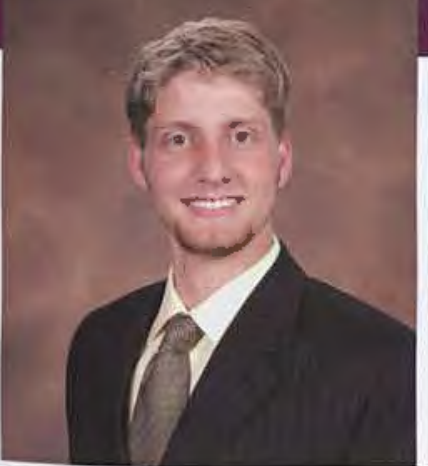

Jonathan Polsdorfer Electronic Media g 1

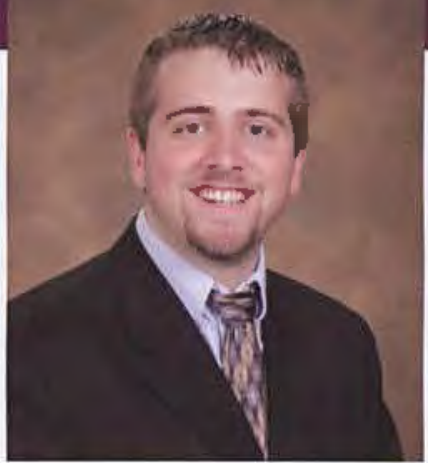

Andrew Powel

Technical and Professional Communication

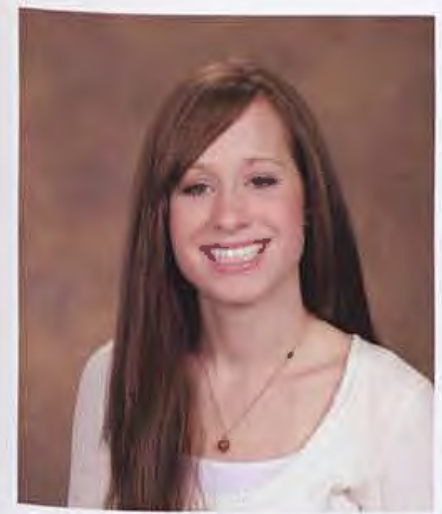

Robin Provo

Exercise and Sport Science

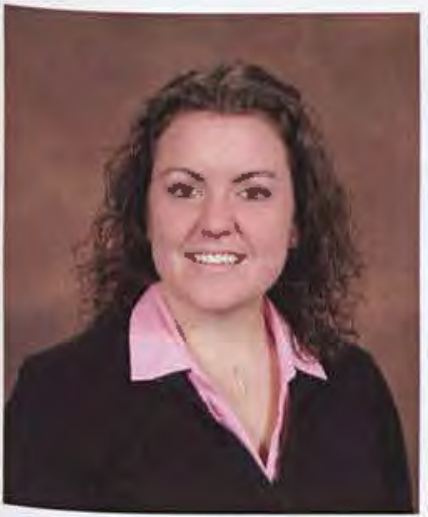

Stacey Reeder Multi-Age Spanish Education

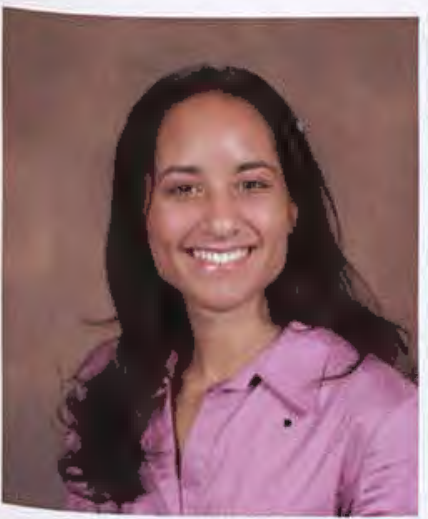

Christina Reyes Exercise and Sport Science

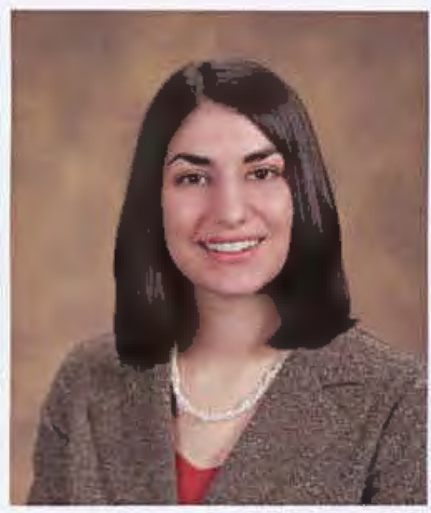

Christina Pupillo Sociology

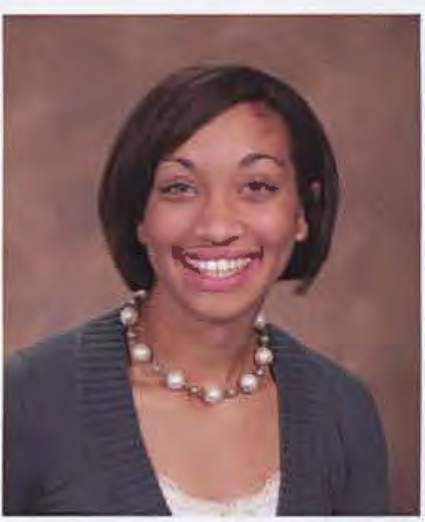

Courtney Reid Psychology

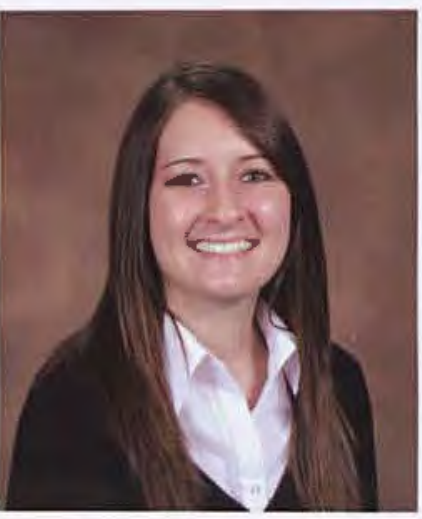
Social Work
Heather Rhoads

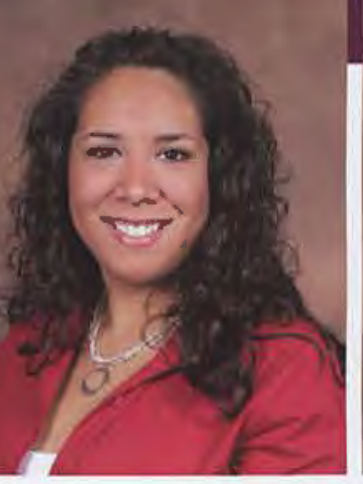

Kathleen Pritts International Studies

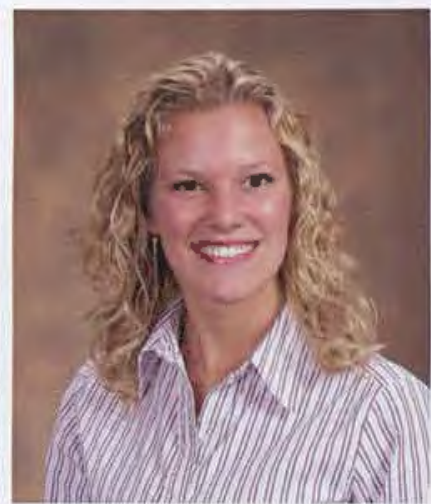

Elizabeth Rambiku Biology

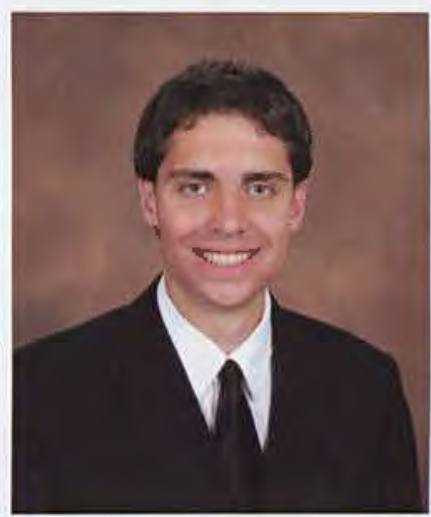

Timon Reiner History

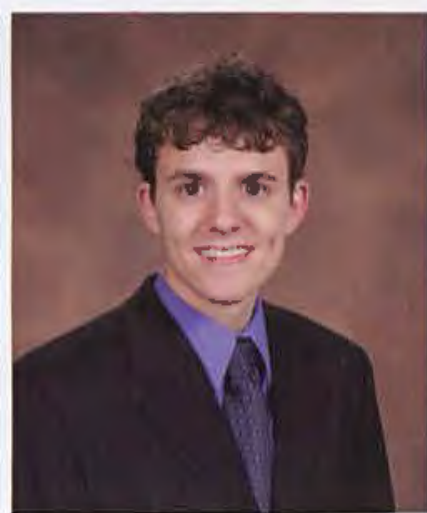

Keith Rice Mechanical Engineering

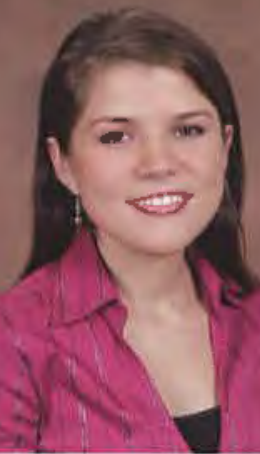

Nila Privedenyuk Finance

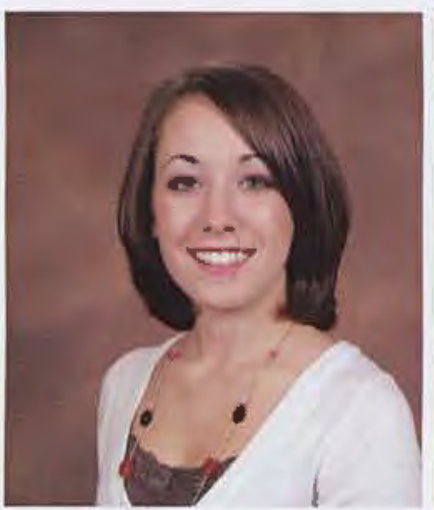

Kelly Ramsey Psychology

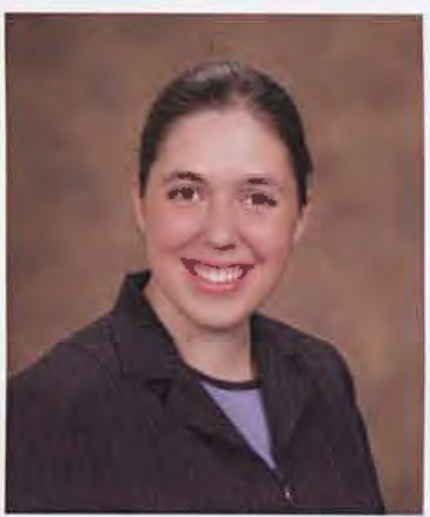

Anna Reiskytl International Studies and Missiology

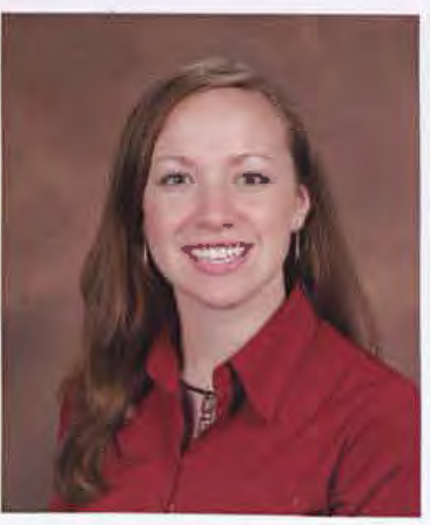

Mellissa Rice Integrated Social Studies Education

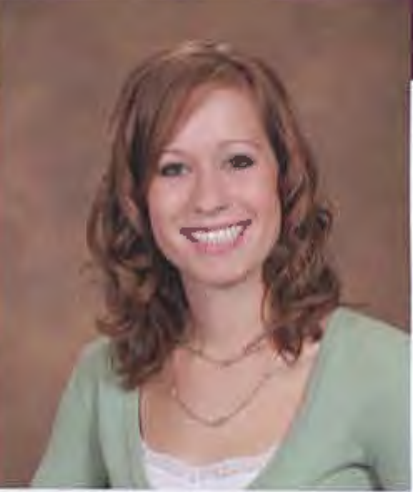

Renee Provo Nursing

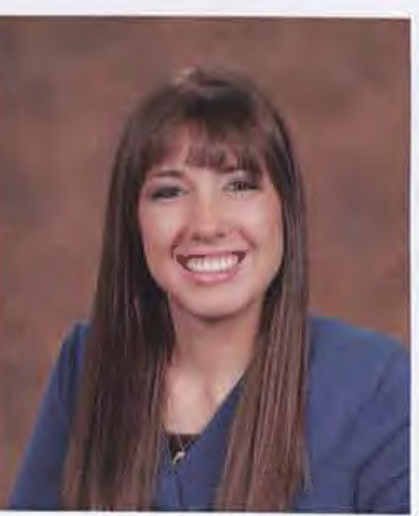

Danielle Randolph Middle Childhood Education

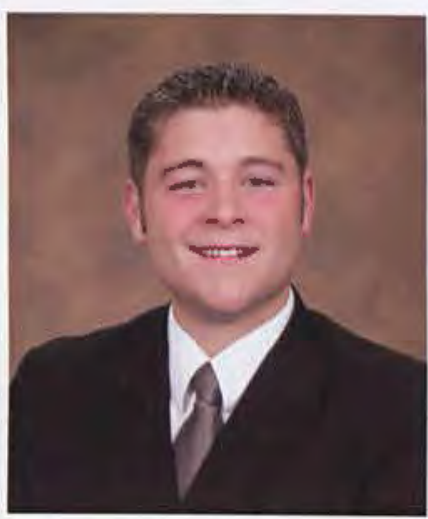

Caleb Rettig

Nursing

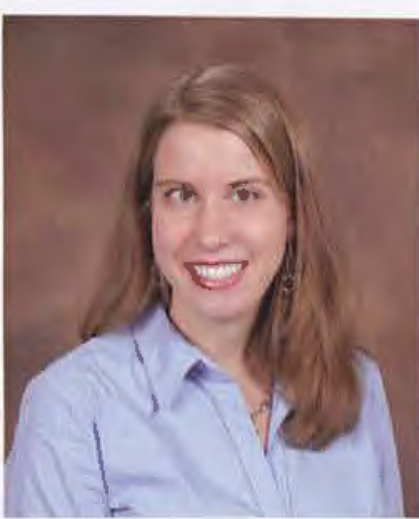

Lachelle Richter Nursing 


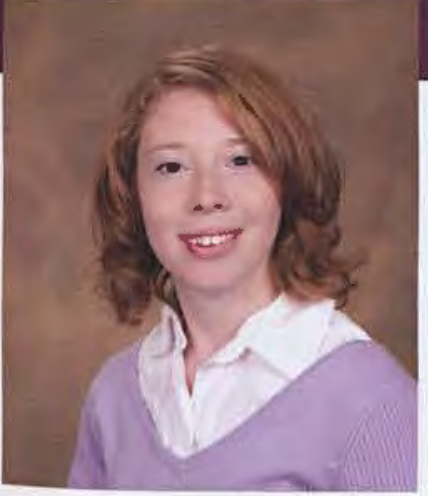

Stephanie Sanders Social Work

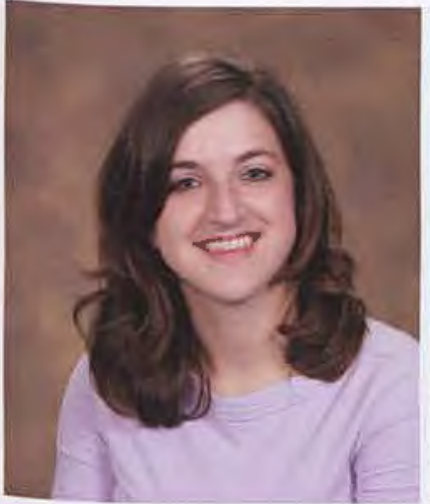

Kari Scheunemann Multi-Age Spanish Education

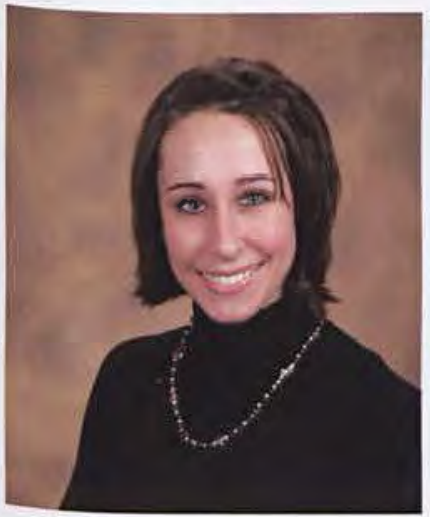

Rachael Schnepp Psychology

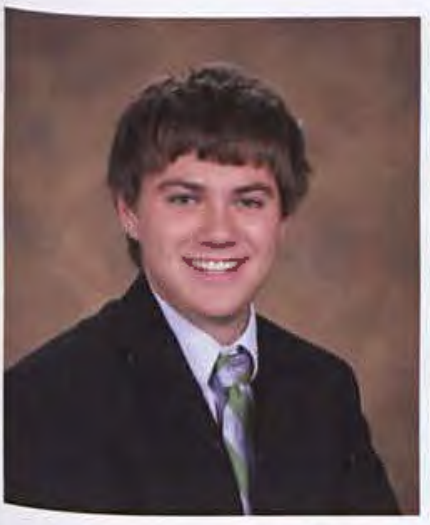

Daniel Servi

Multi-Age Physical Education

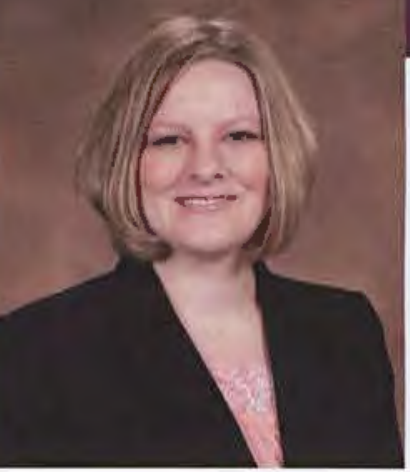

Amy Sandford Social Work

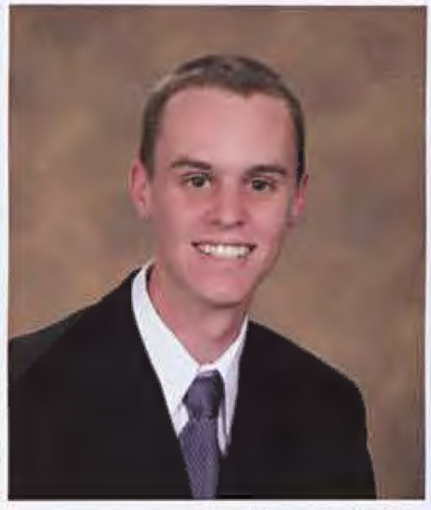

Ryan Schiller Finance and Accounting

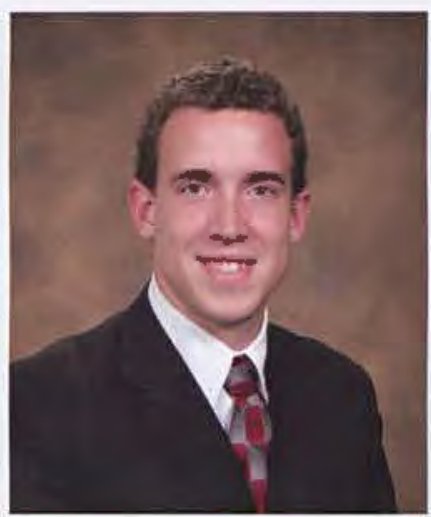

Zachary Scott Electrical Engineering

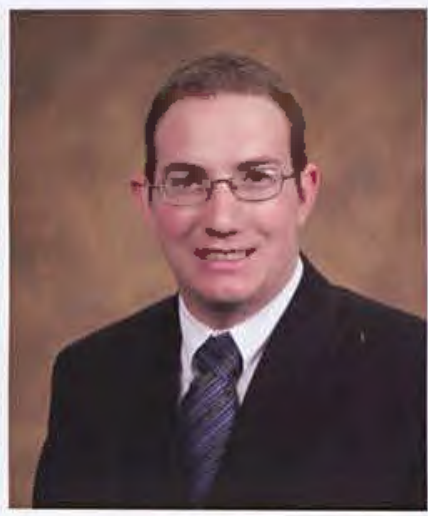

Adam Sheldon Christian Education and Youth Ministries

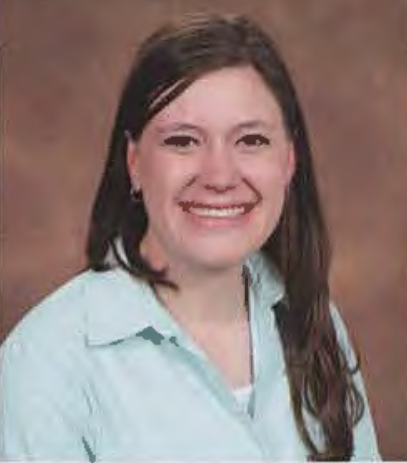

Jessica Sartori International Studies and Missiology

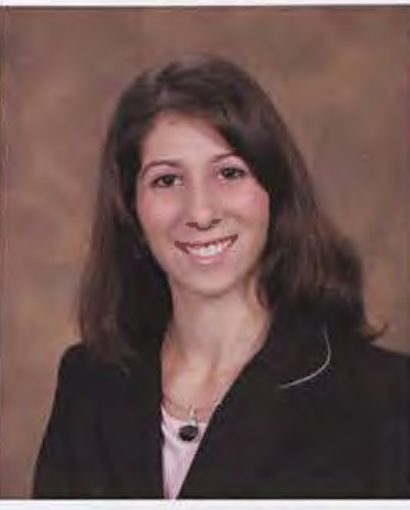

Jessica Schimment Early Childhood Education

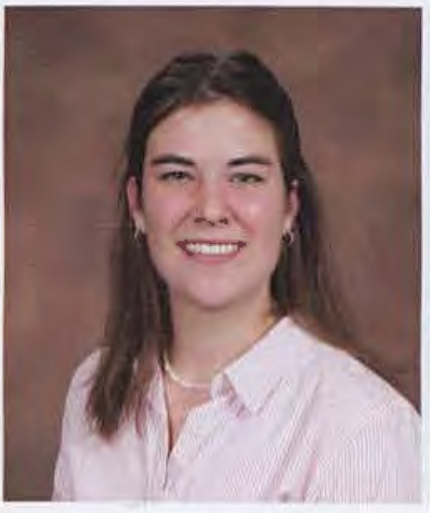

Frances Schmidt Nursing

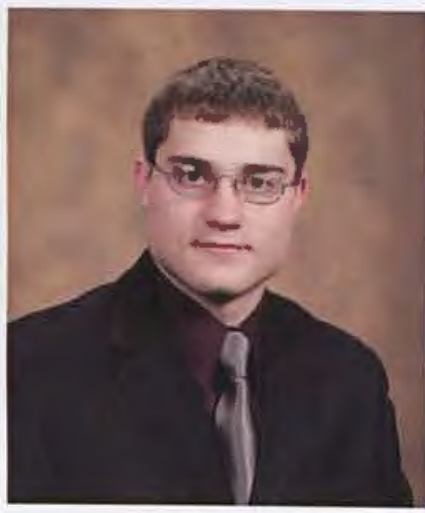

Matthew Schmidt Comprehensive Bible

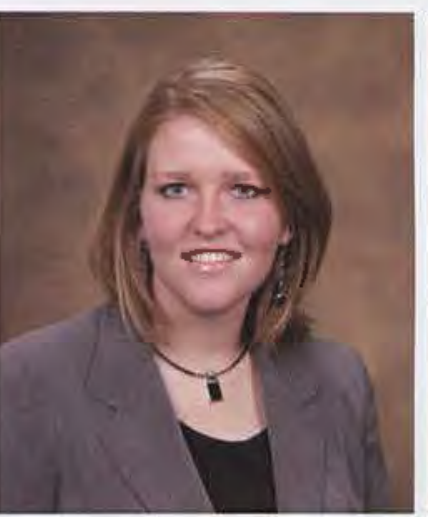

Bethany Seawell Social Work

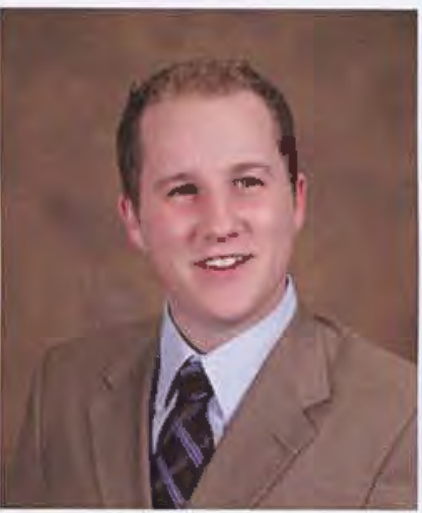

Lukas Seelye Nursing

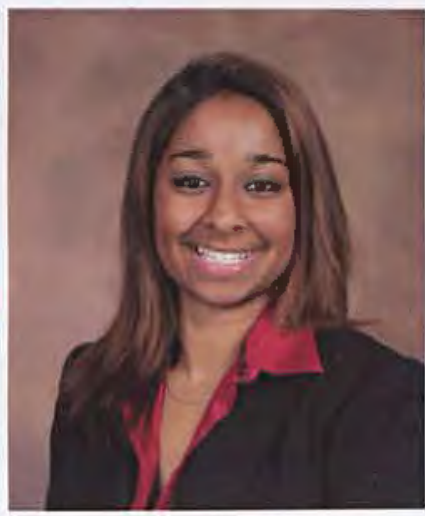

Karlee Shelton Psychology

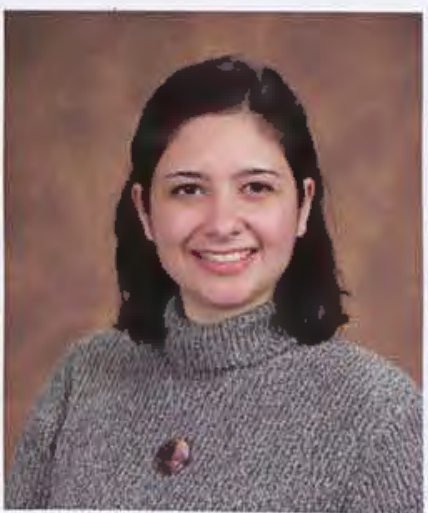

Sarah Sherick Bible Teacher Education
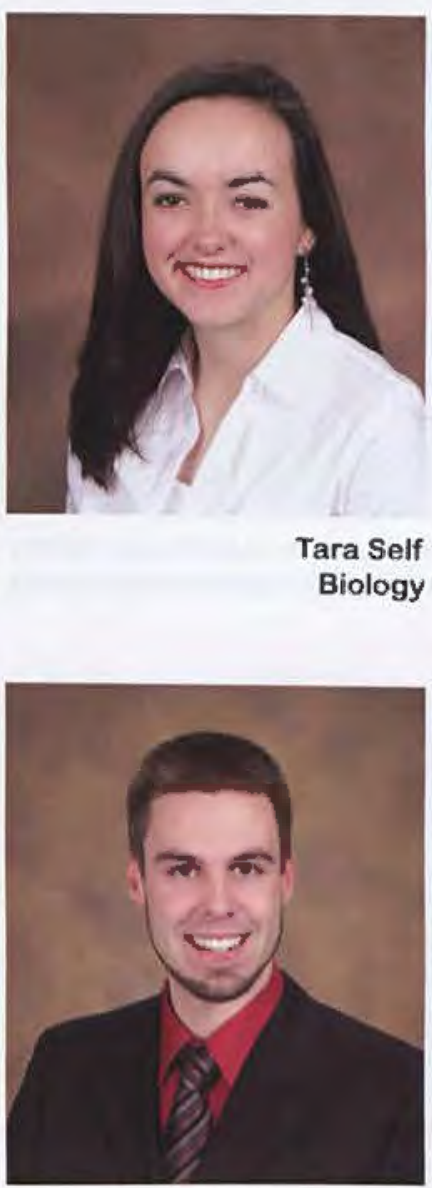

Roy Sherwood Jr. Pre-seminary Bible 


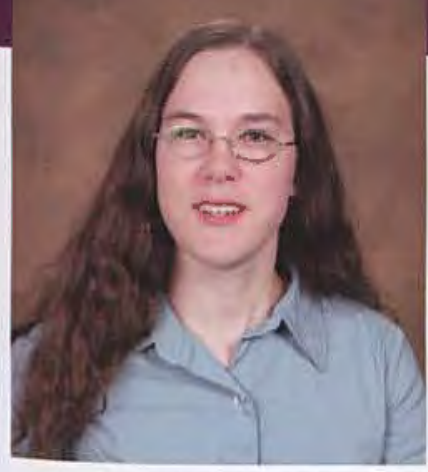

Elizabeth Steinbach Nursing

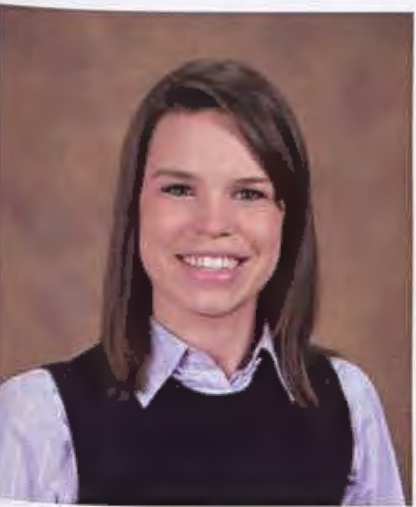

Jennifer Stevens Business Management

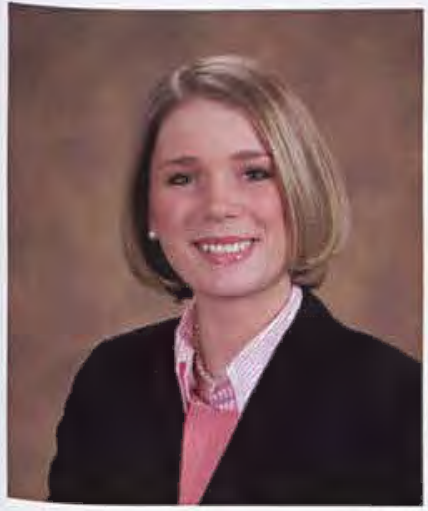

Lindsay Stone Social Work

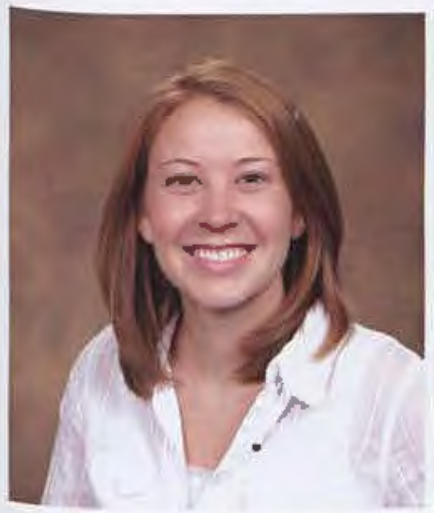

Elisabeth Sudlow Music Education

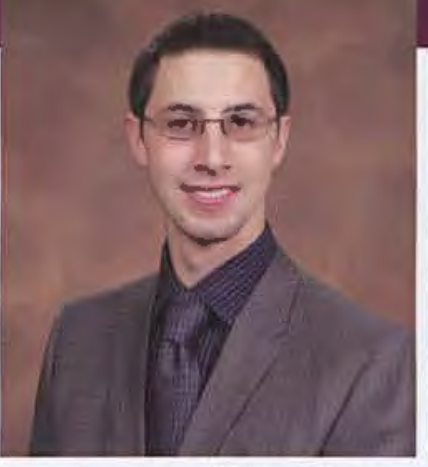

Michael Steiner Graphic Design and Studio

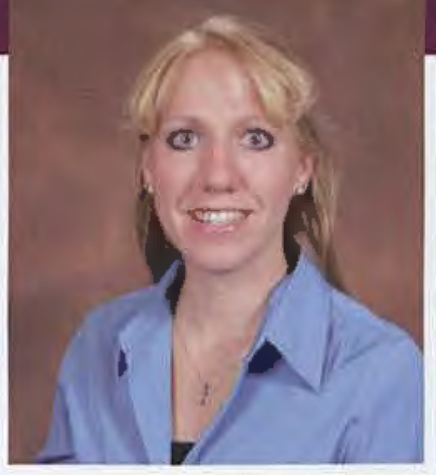

Kelly Steingass Nursing

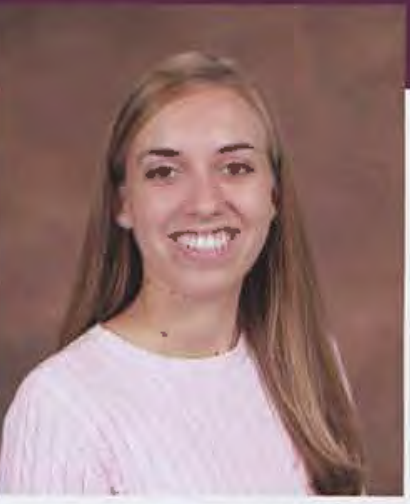

Amanda Stephens Middle Childhood Education Art

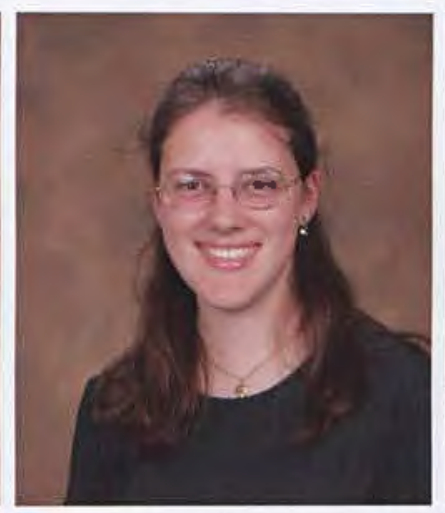

Katharina Stevens History

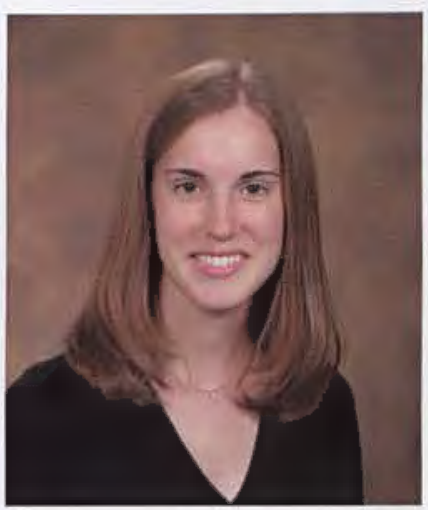

Caroline Stewart Nursing

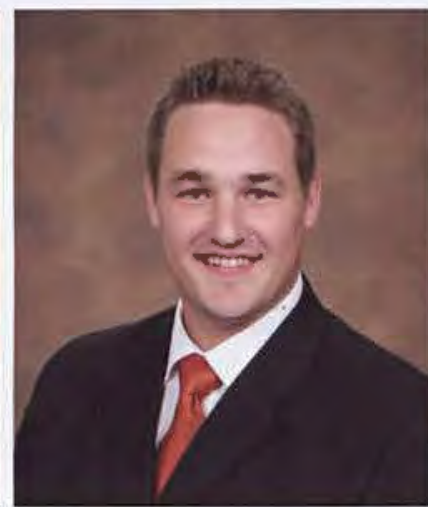

Jacob Stout Youth Ministry

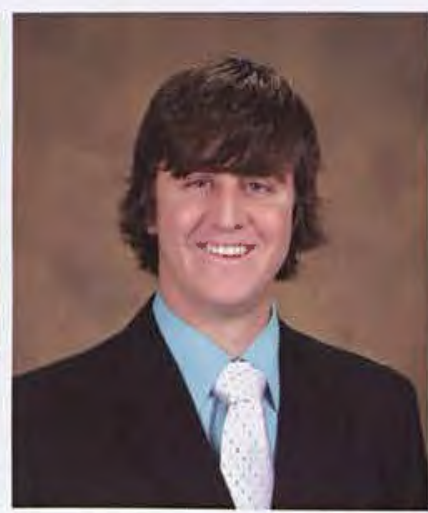

Benjamin Summers Marketing

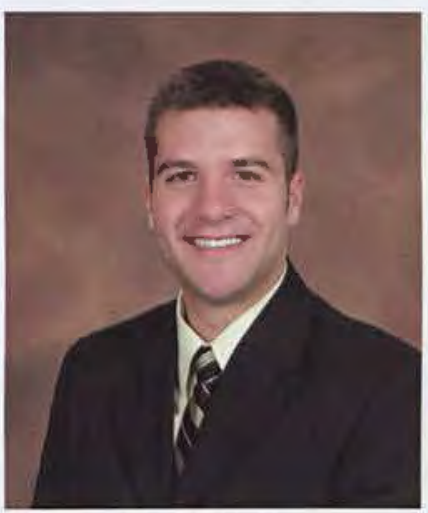

Michael Strawser Communication Arts

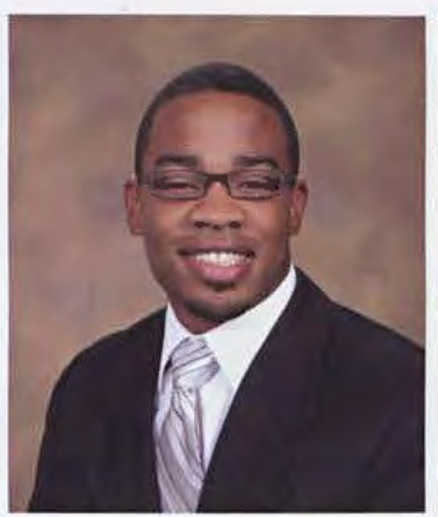

Stephen Sylvester Computer Science

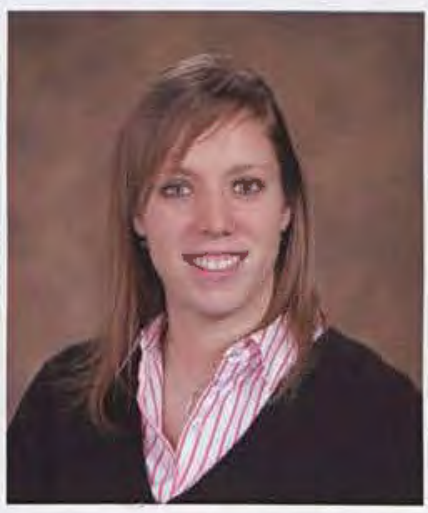

Mary Stockdale Exercise Science

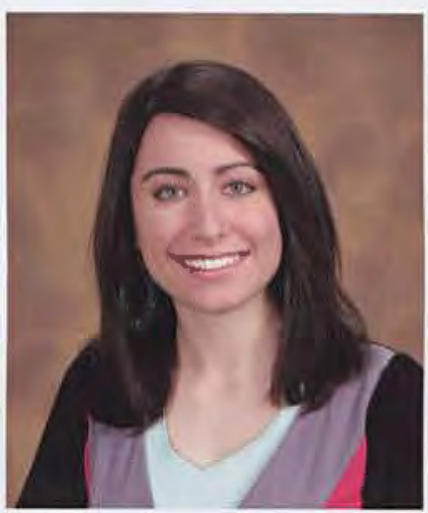

Elizabeth Strowd Exercise Science

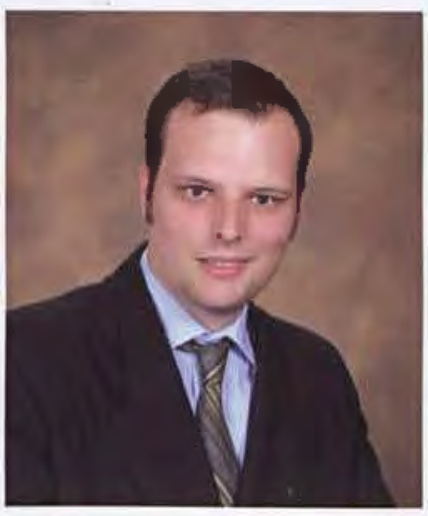

Steven Syme History

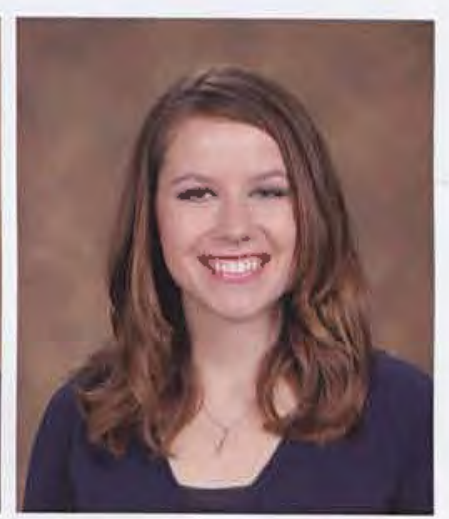

Deborah Strutton International Studies

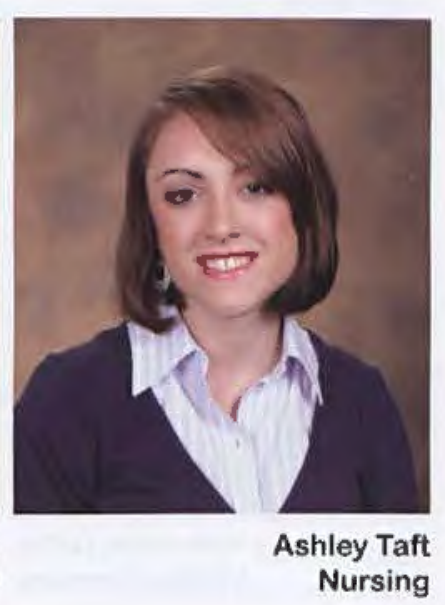




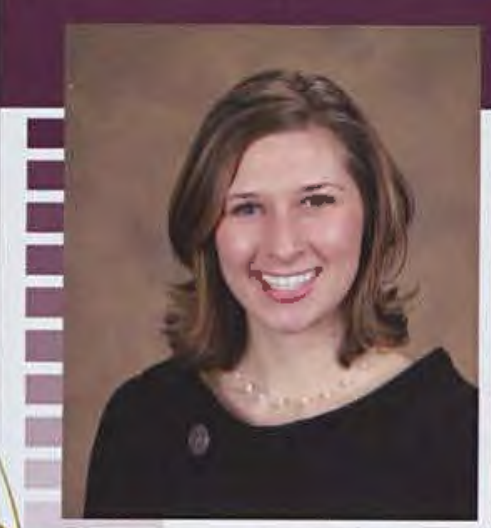

Katelyn Talbott Marketing and Business Administration

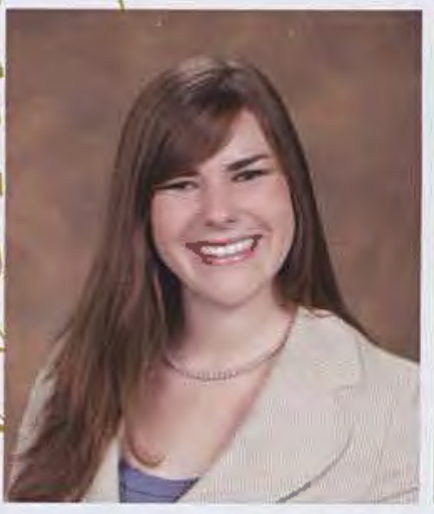

Holly Thomas Sociology

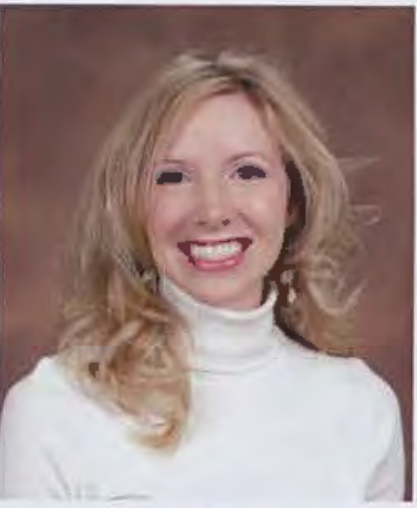

Brittany Traeger-Flesch Integrated Language Arts Education

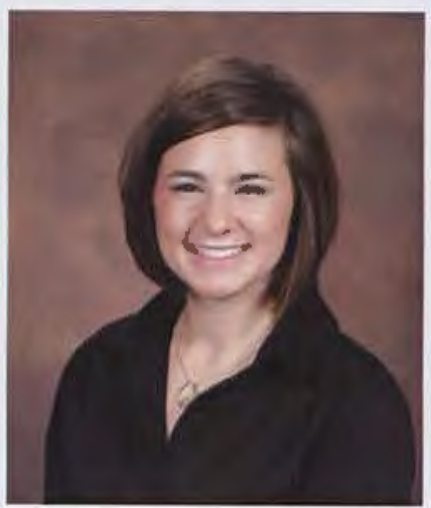

Katherine Tuttle Athletic Training

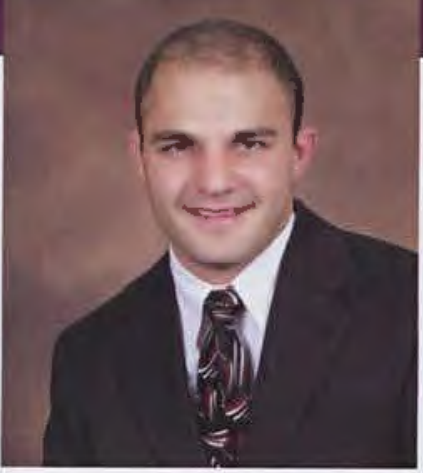

Andrew Talone

Finance

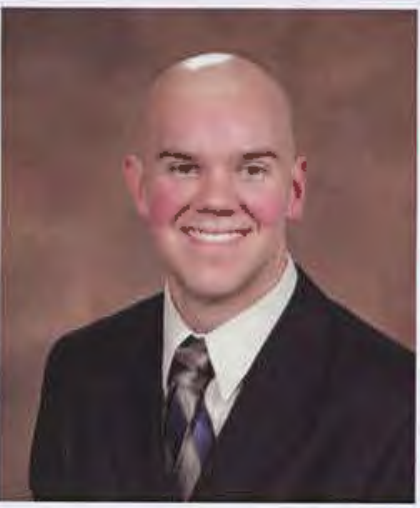

Ian Thomas Mechanical Engineering

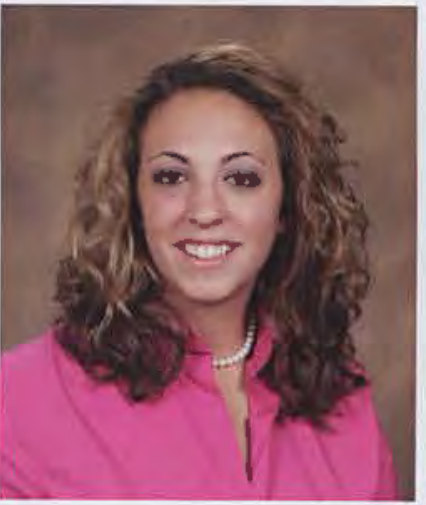

Kristin Troiano Nursing

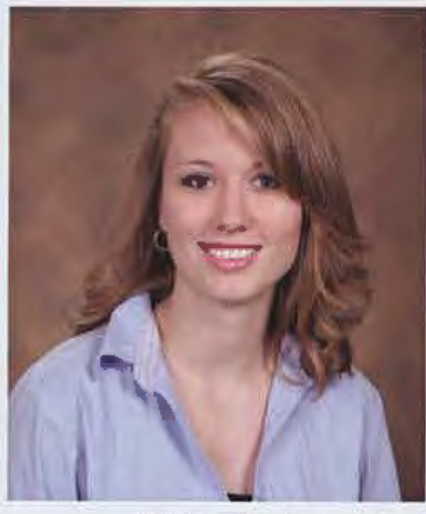

Michaela Thompson Organizational Communications

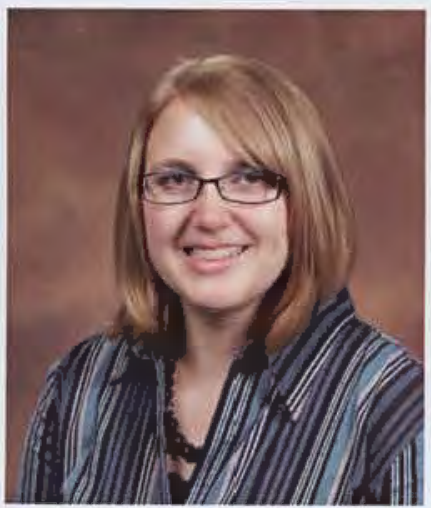

Cherie Tryon Middle Childhood Education

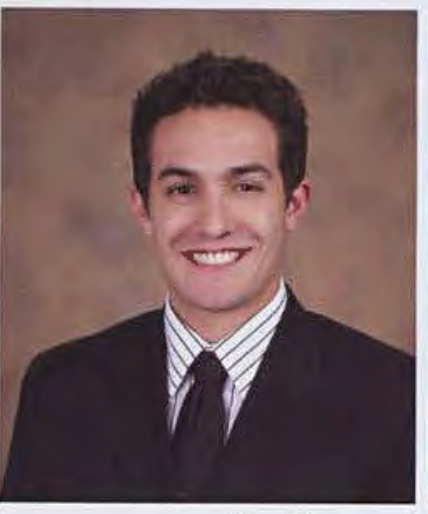

David Torres Business Management
Elizabeth Taylor Accounting and Finance

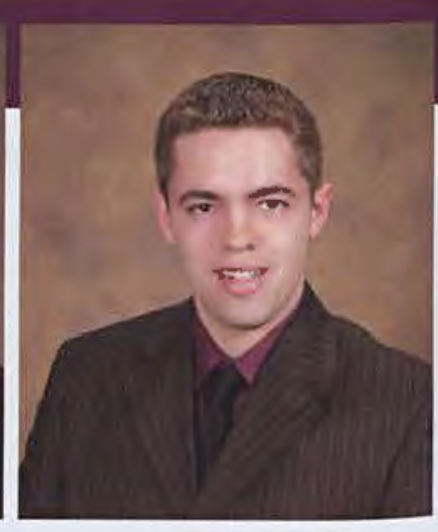

Robert Thalman English

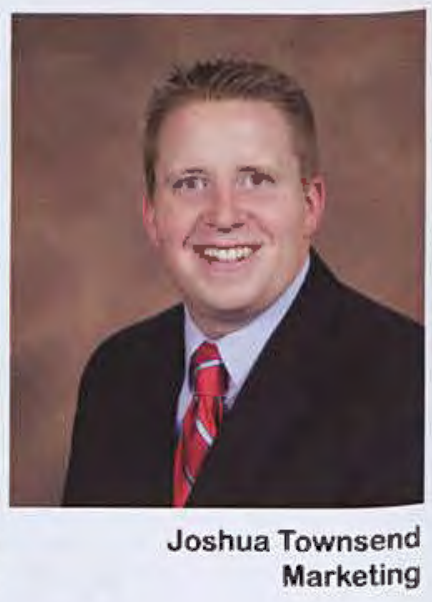

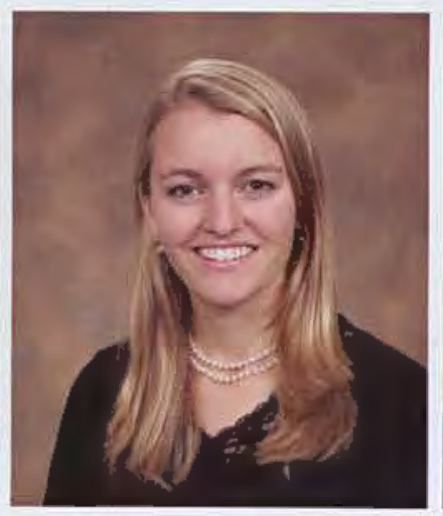

Katie Tucker Early Childhood Education

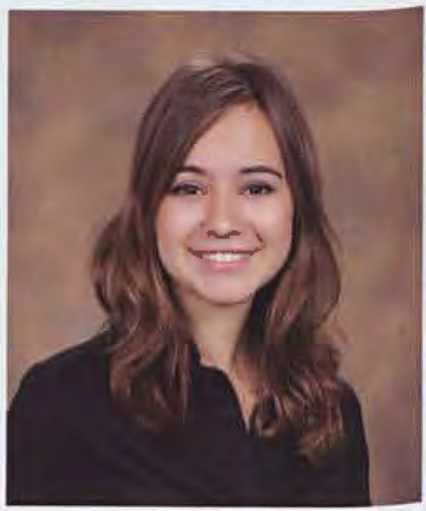

Lauren Tucker Psychology

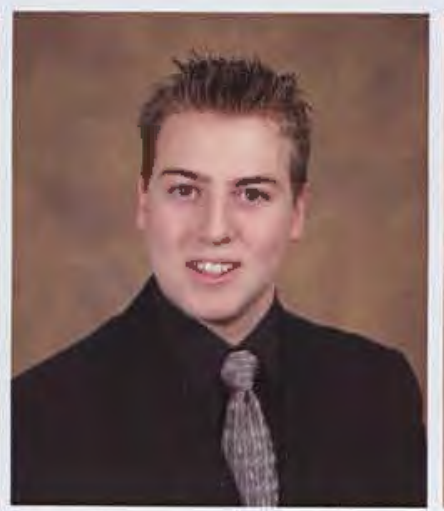

Alexander Unis Pre-seminary Bible

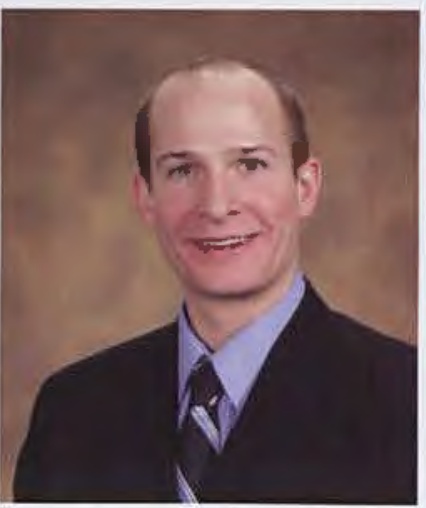

Robert Unis III Pre-seminary Bible

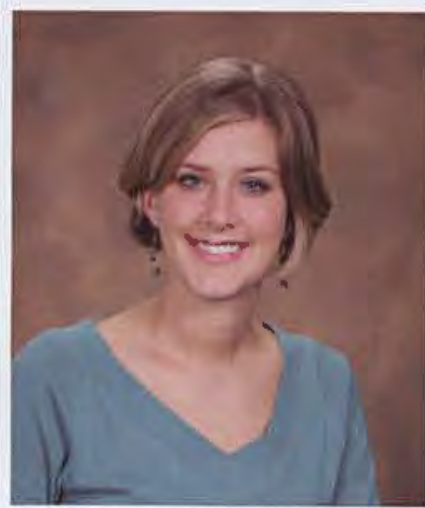

Michelle VandenBerg Social Work

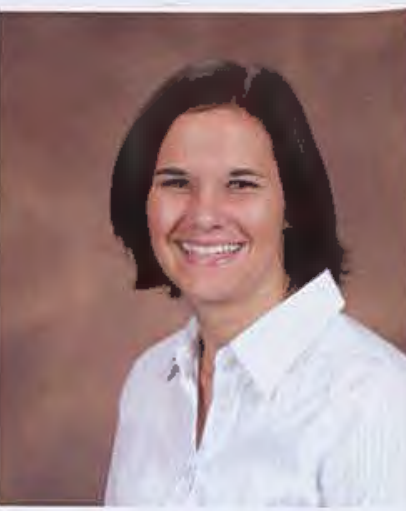

Shandra VanderZuwen Nursing 


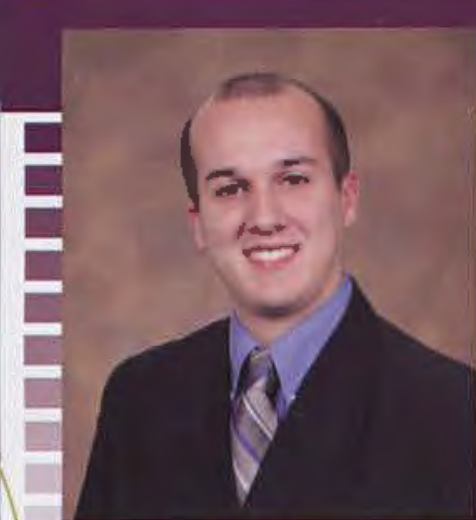

Joshua Willetts Pre-Seminary Bible and Youth Ministry

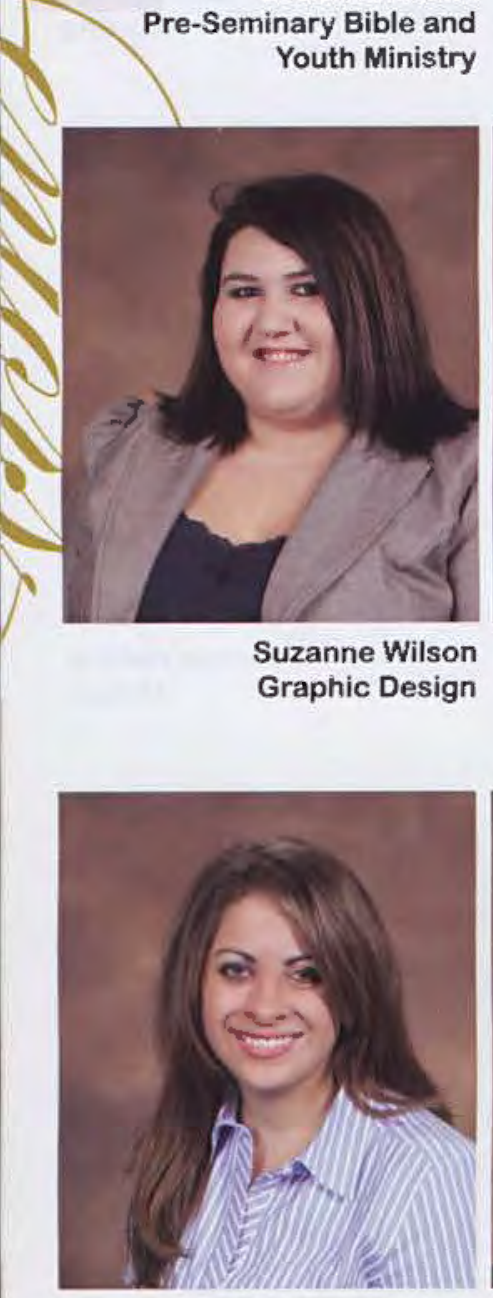

Amy Wright Criminal Justice

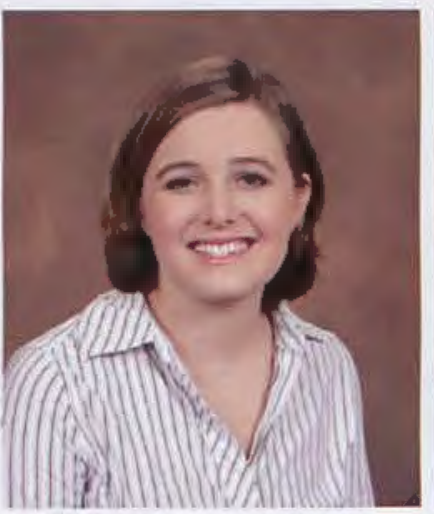

Caitlyn York English

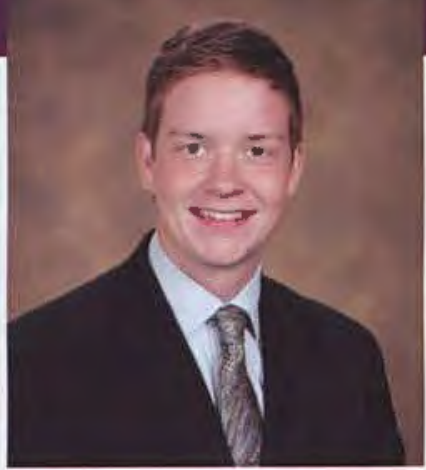

Garrett Williams

Mechanical Engineering

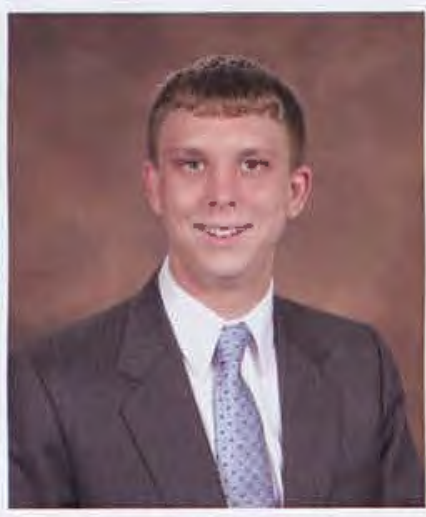

Thomas Woltman Management and Marketing

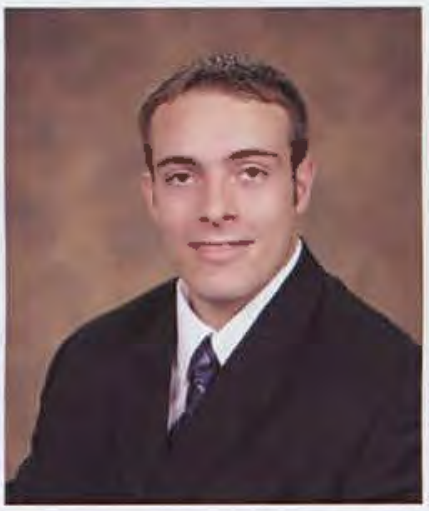

Craig Wright Criminal Justice

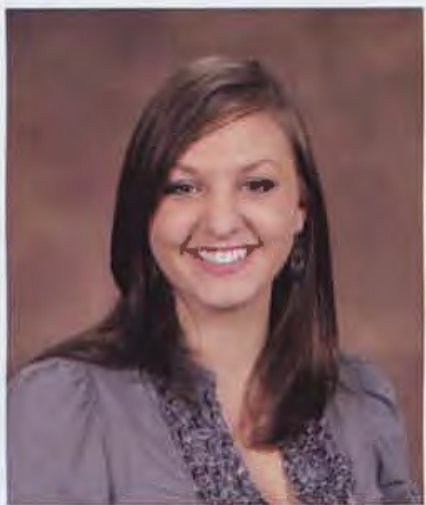

Hilary Young Studio Art

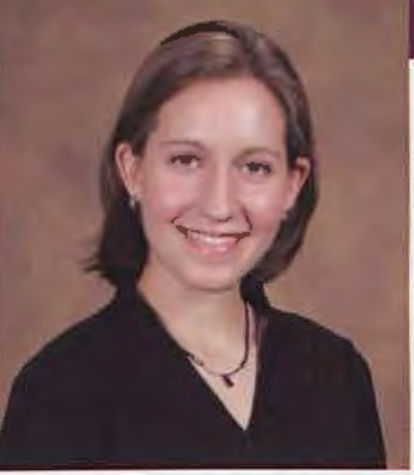

Karen Williams Political Science and International Studies

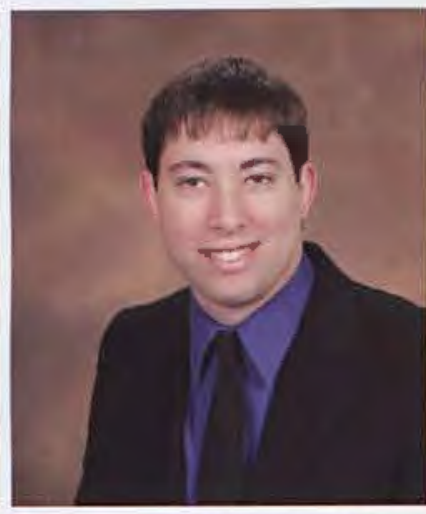

Nicholas Wood English

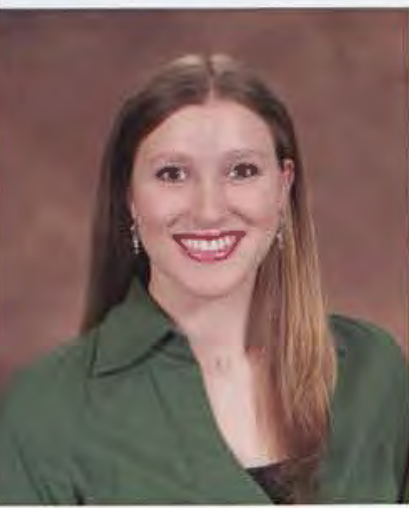

Elisa Yanega Music Education

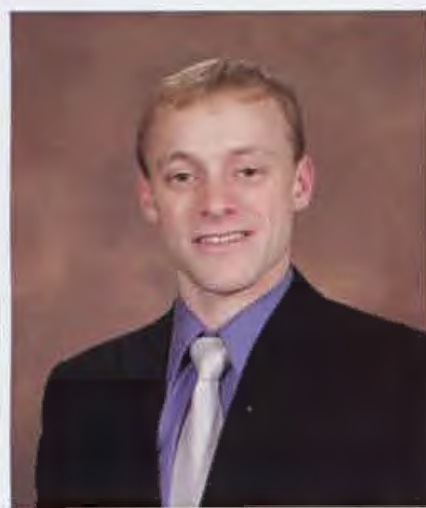

Richard Young Mechanical Engineering

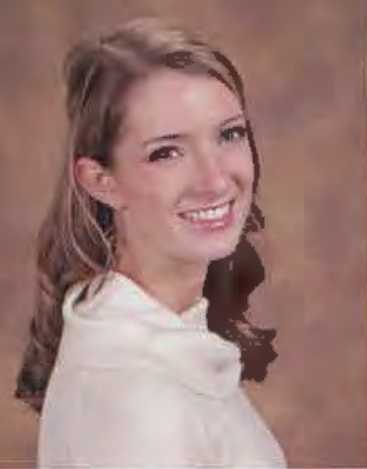

Kimberly Williams Theatre

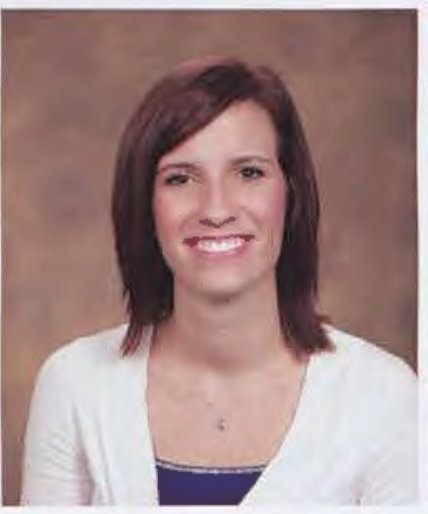

Alissa Woodwyk Psychology

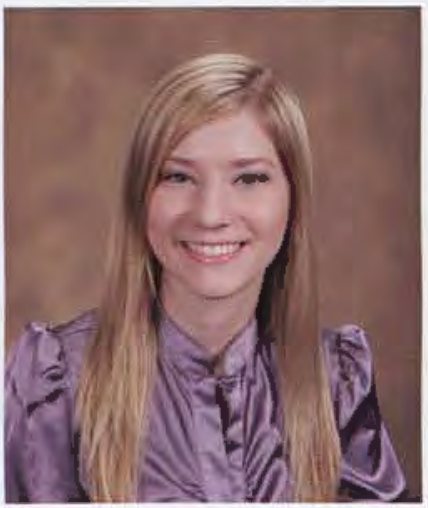

Alisa Yetter Sociology and Spanish

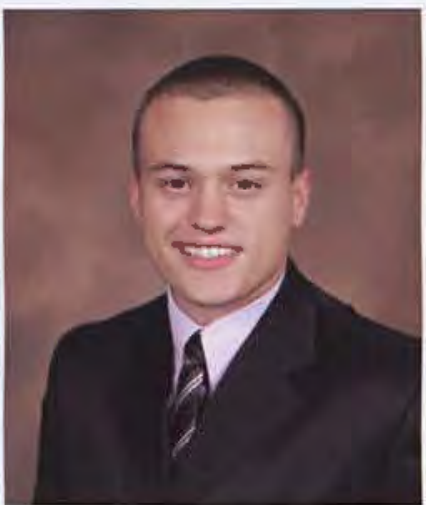

Jason Zastrow Pre-Seminary Bible

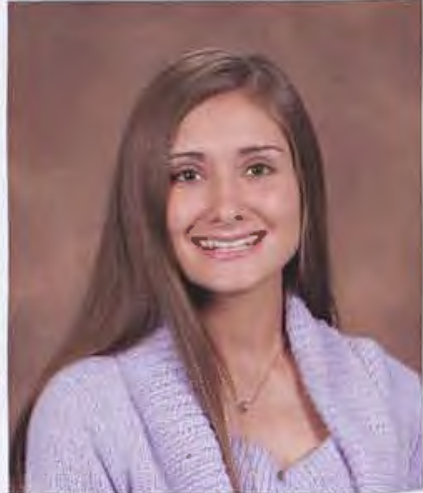

Melinda Workman Media Communication

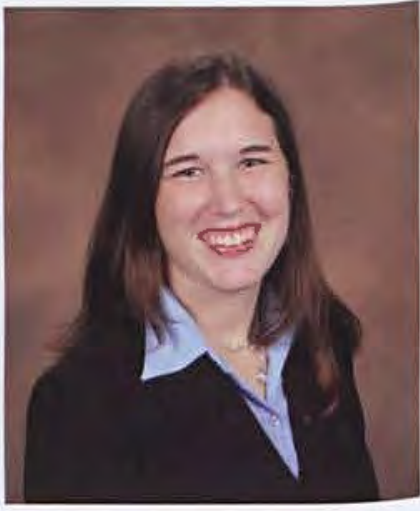

Lauren Yoder Electrionic Media

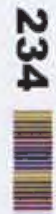




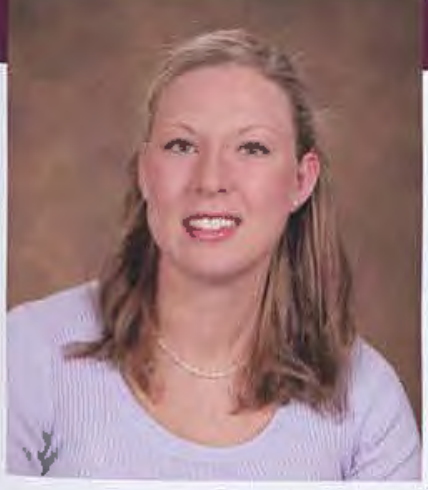

Sarah Zeltman Comprehensive Bible

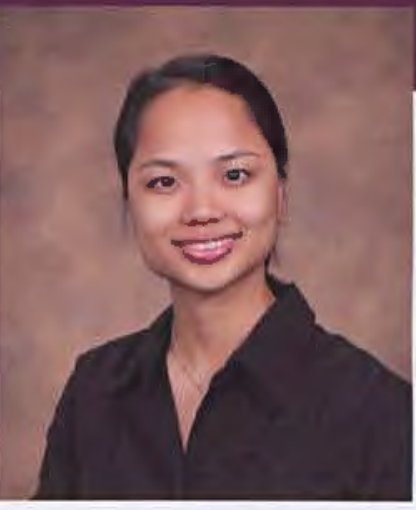

Bing Jia Zhang Psychology

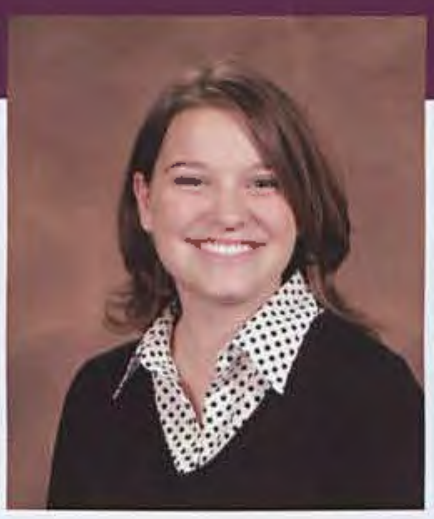

Laura Ziegenfus panish Education

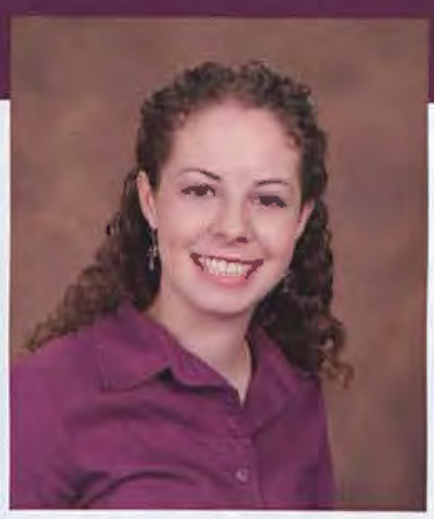

Kristina Zumbo Social Work

\section{"THIS YEAR WAS PRETTY INCREDIBLE, FUN, AND EXCITING...YOU CAN TELL BECAUSE MY GPA DROPPED. P.S. THIS YEARBOOK LOOKS AMAZING!" _DAVID ELGENA}
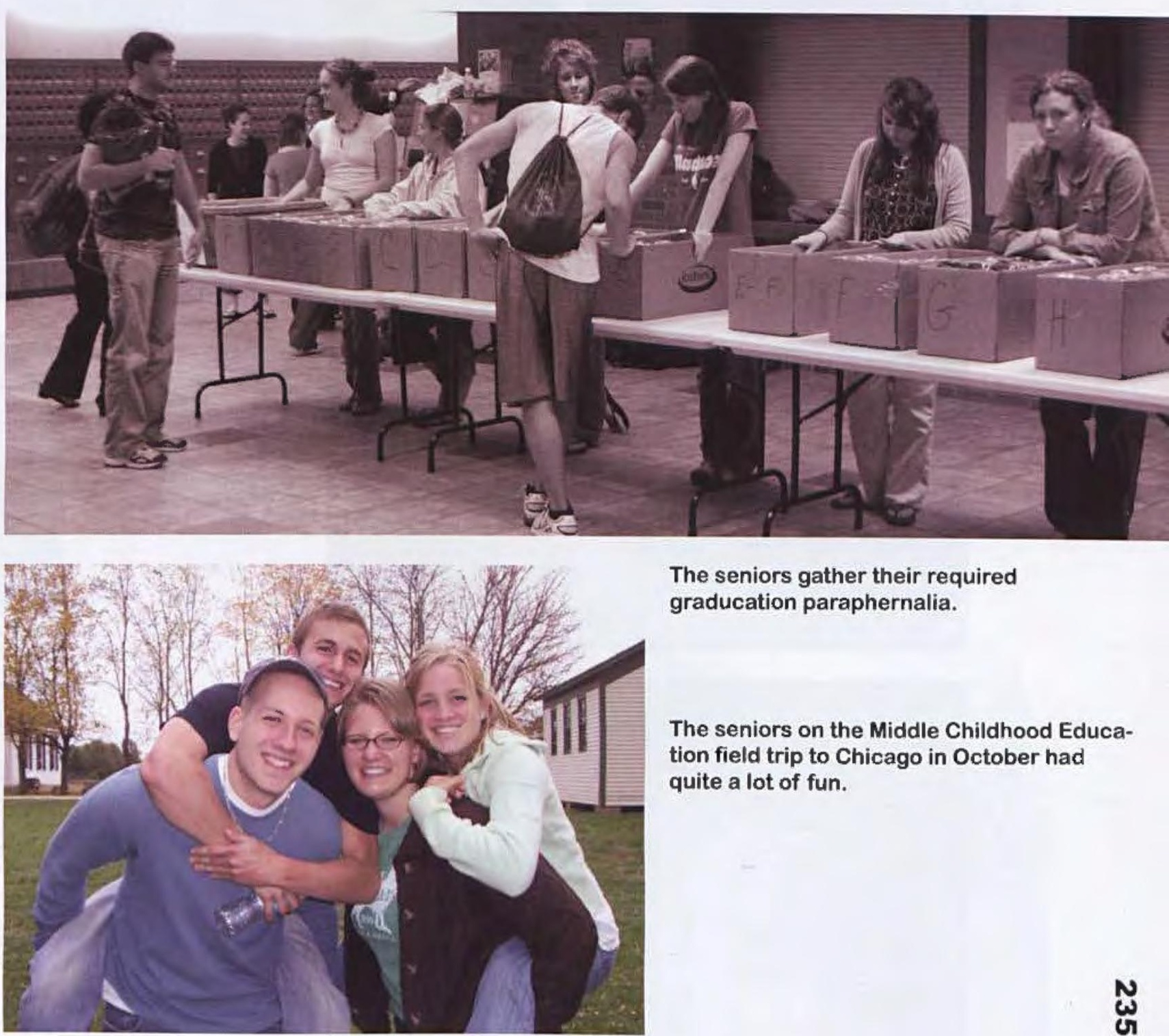

The seniors gather their required graducation paraphernalia.

on the Middle Childhood Education field trip to Chicago in October had quite a lot of fun. 


\section{"SENIOR YEAR BROUGHT SO MUCH OPPORTUNITY!}

THE HIGHLIGHT OF MY YEAR WAS TRAVELING TO ALABAMA WITH A GROUP FROM ONE VOICE TO DO A LIVE RECORDING." _ARIELLE DORSEY
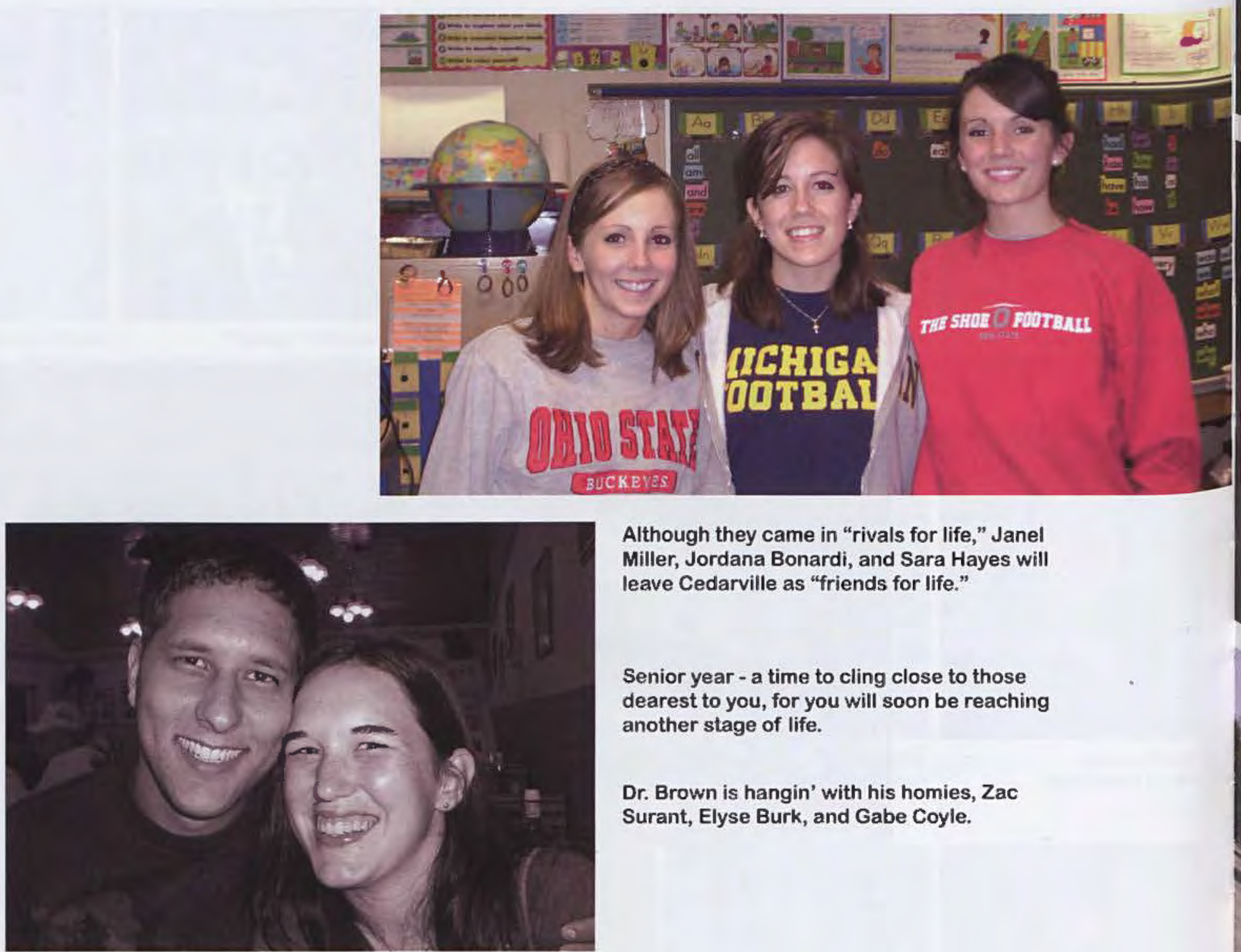

Although they came in "rivals for life," Janel Miller, Jordana Bonardi, and Sara Hayes will leave Cedarville as "friends for life."

Senior year - a time to cling close to those dearest to you, for you will soon be reaching another stage of life.

Dr. Brown is hangin' with his homies, Zac Surant, Elyse Burk, and Gabe Coyle.

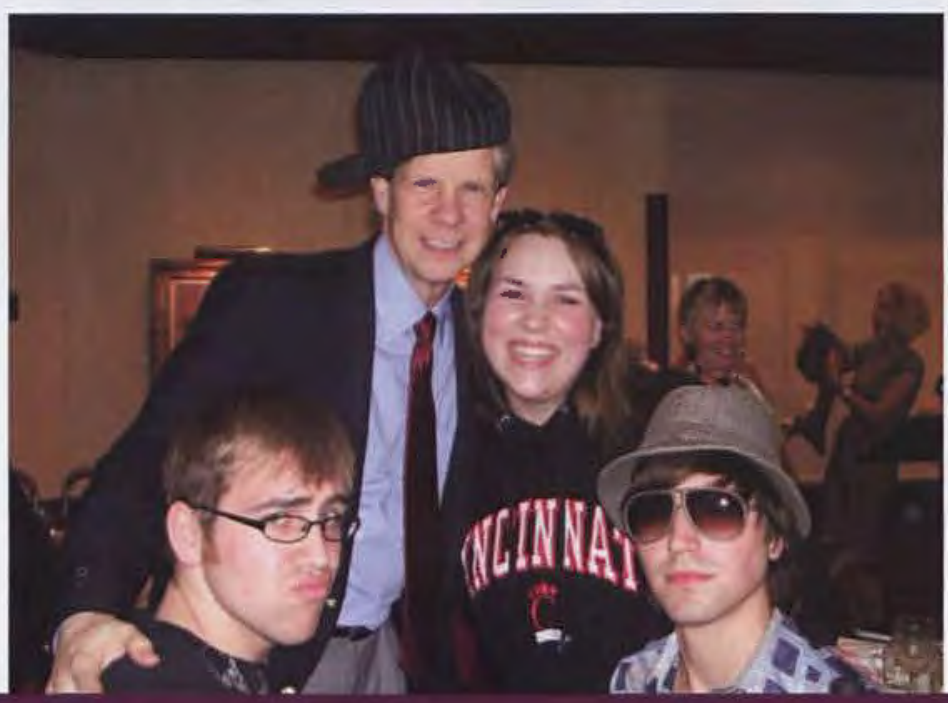


It's true. Behind every great man is a great woman. Or four.

Being a senior doesn't mean you have to stay in your dorm doing homework ALL the time.

Cherie Tryon and Christie Howard look towards thier bright future. Or is that just the camera flash?
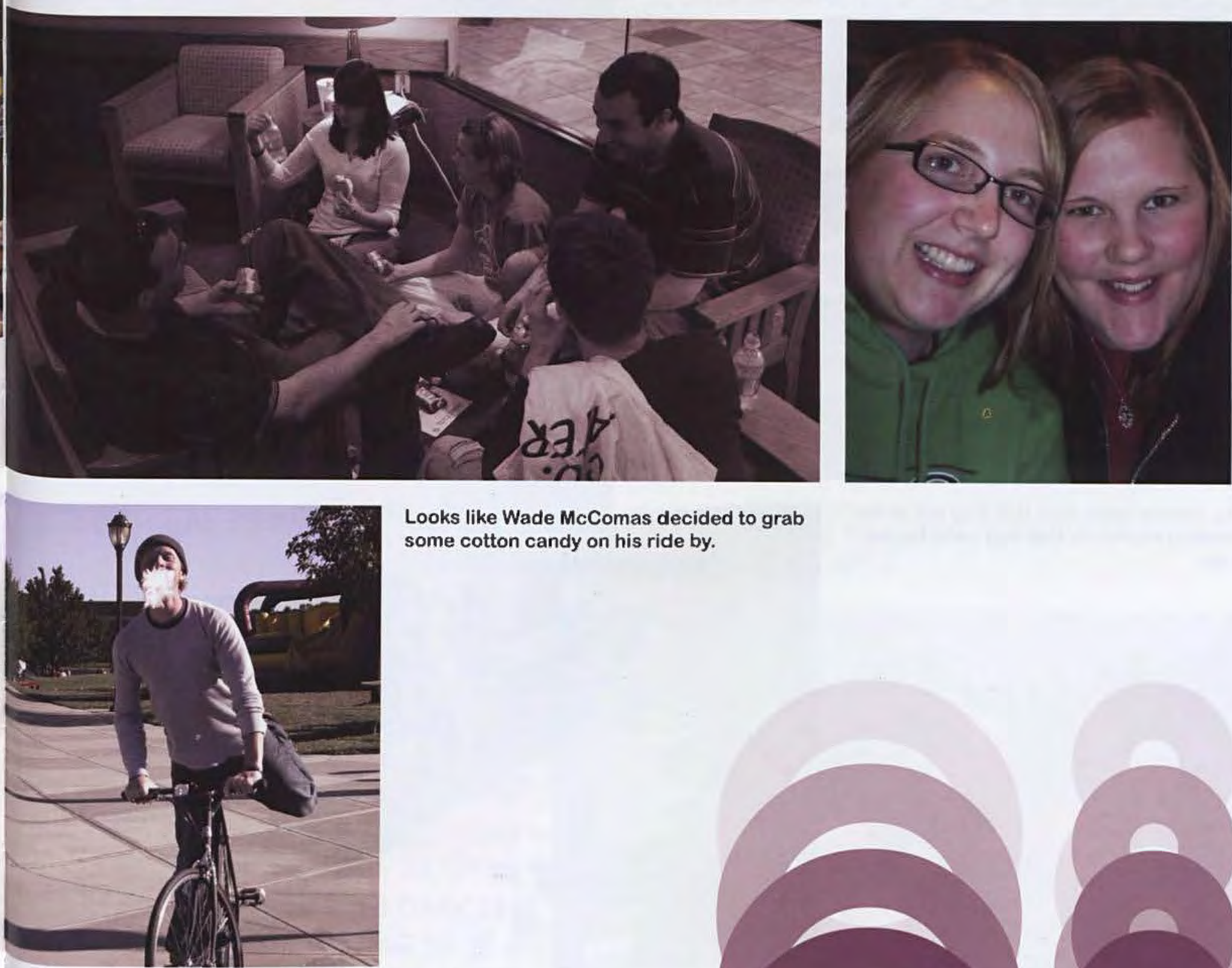

Looks like Wade McComas decided to grab some cotton candy on his ride by.

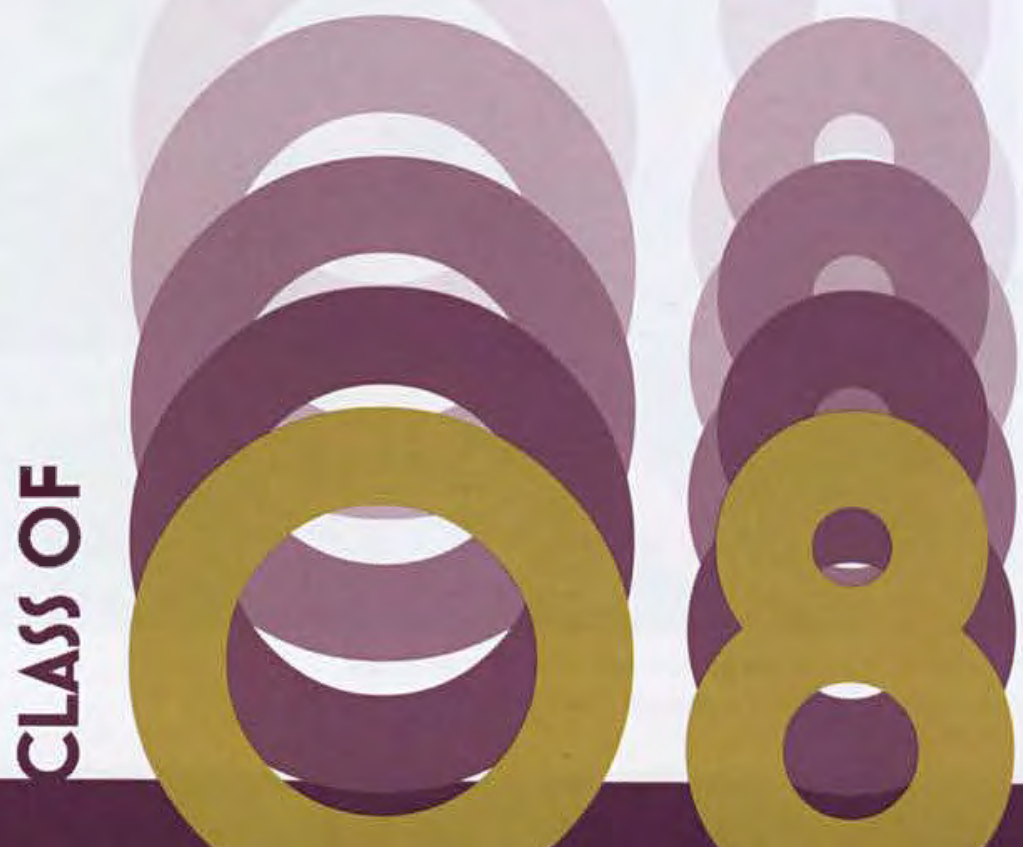




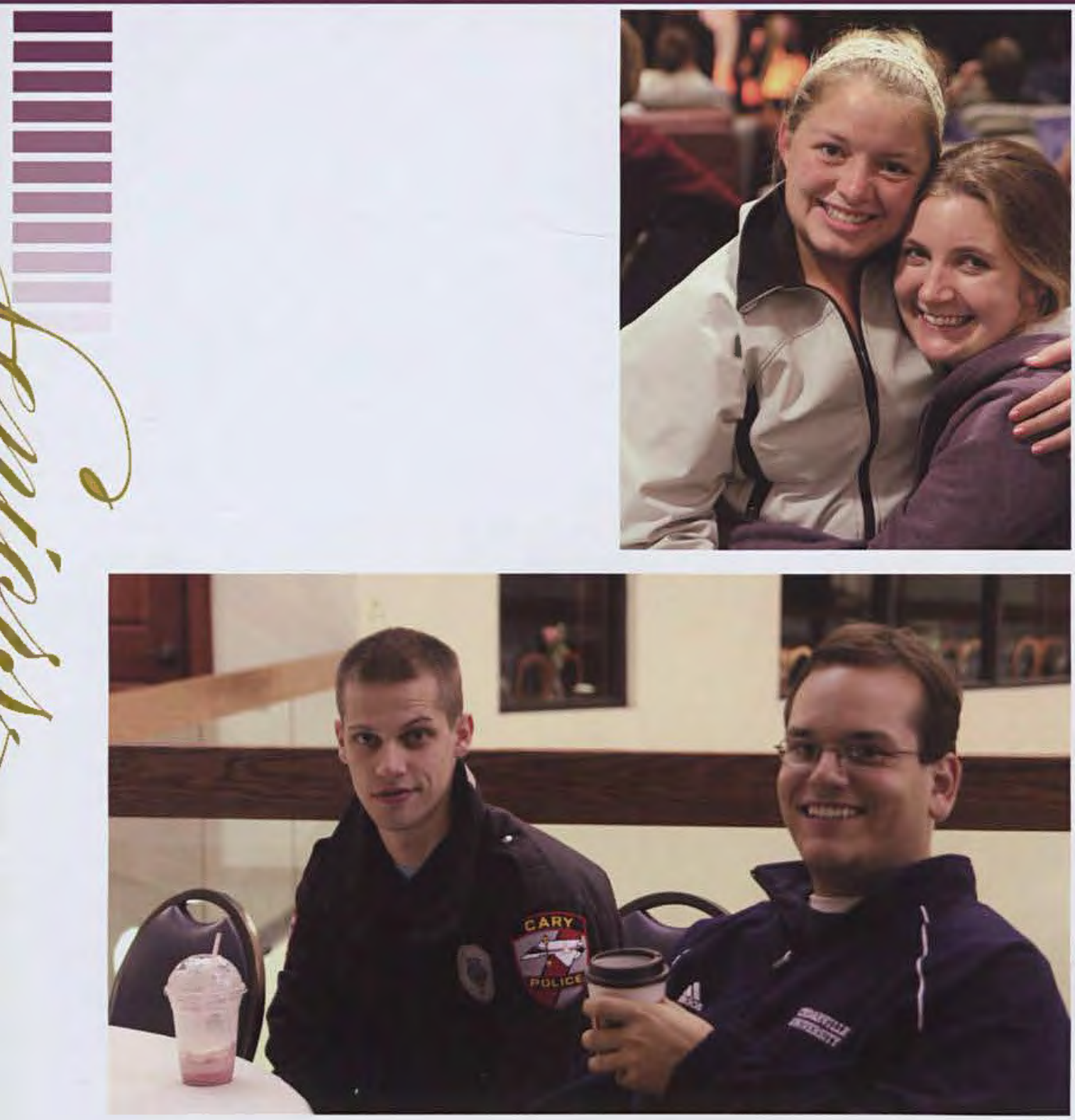

Elizabeth Hays and her friend stick close together for their final year.

Tom Borck and friend stop for a drink from Vecino's.

Zach Brochu looking every bit the suave senior that he is.

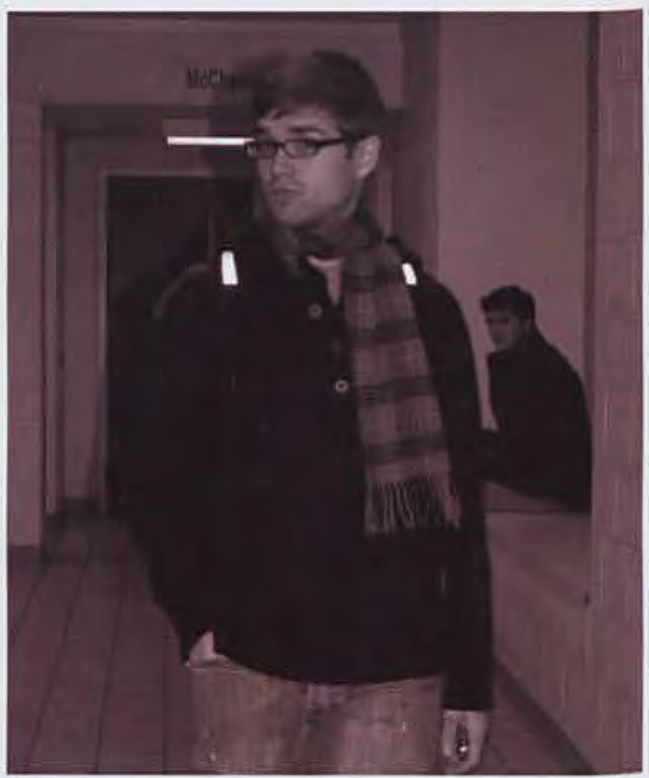

All the seniors make sure that they get all the graduation essentials that they need for the big day.

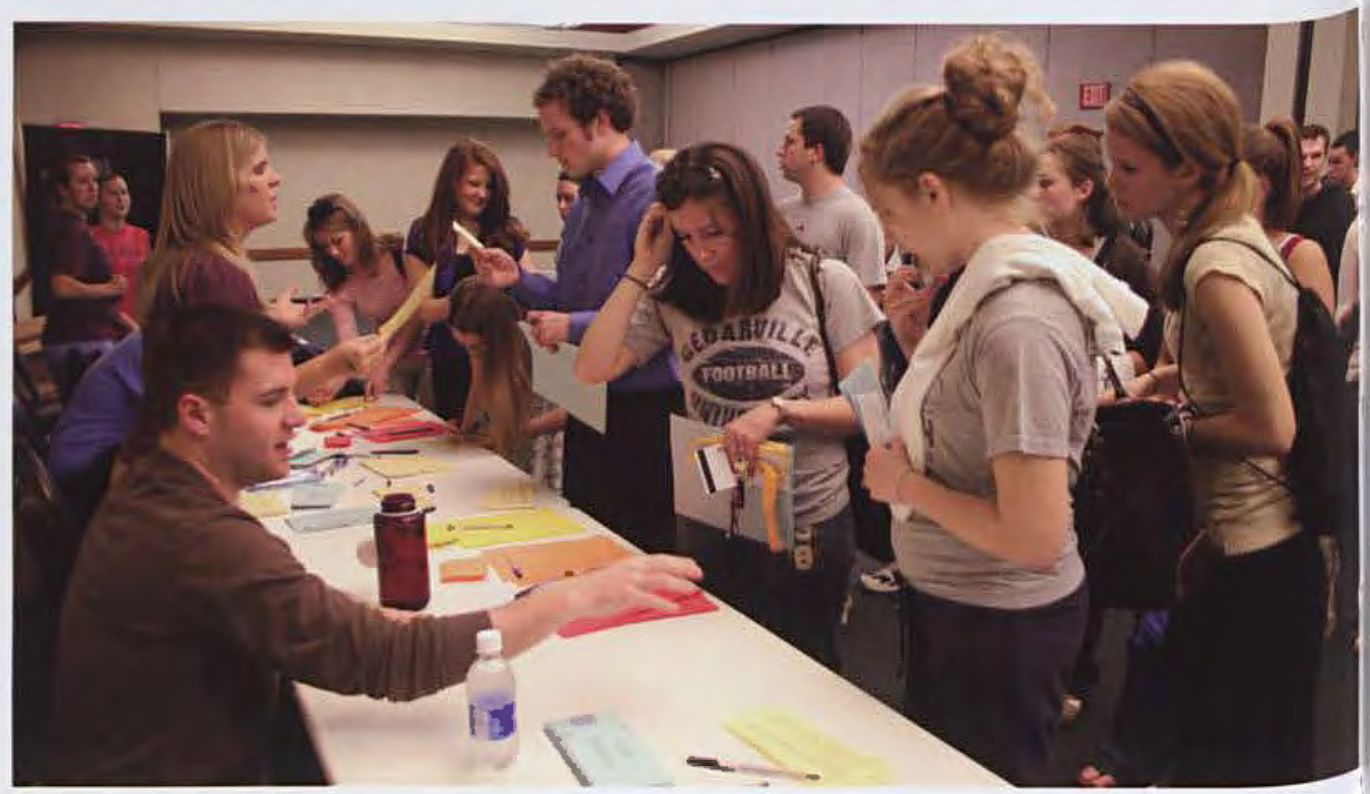



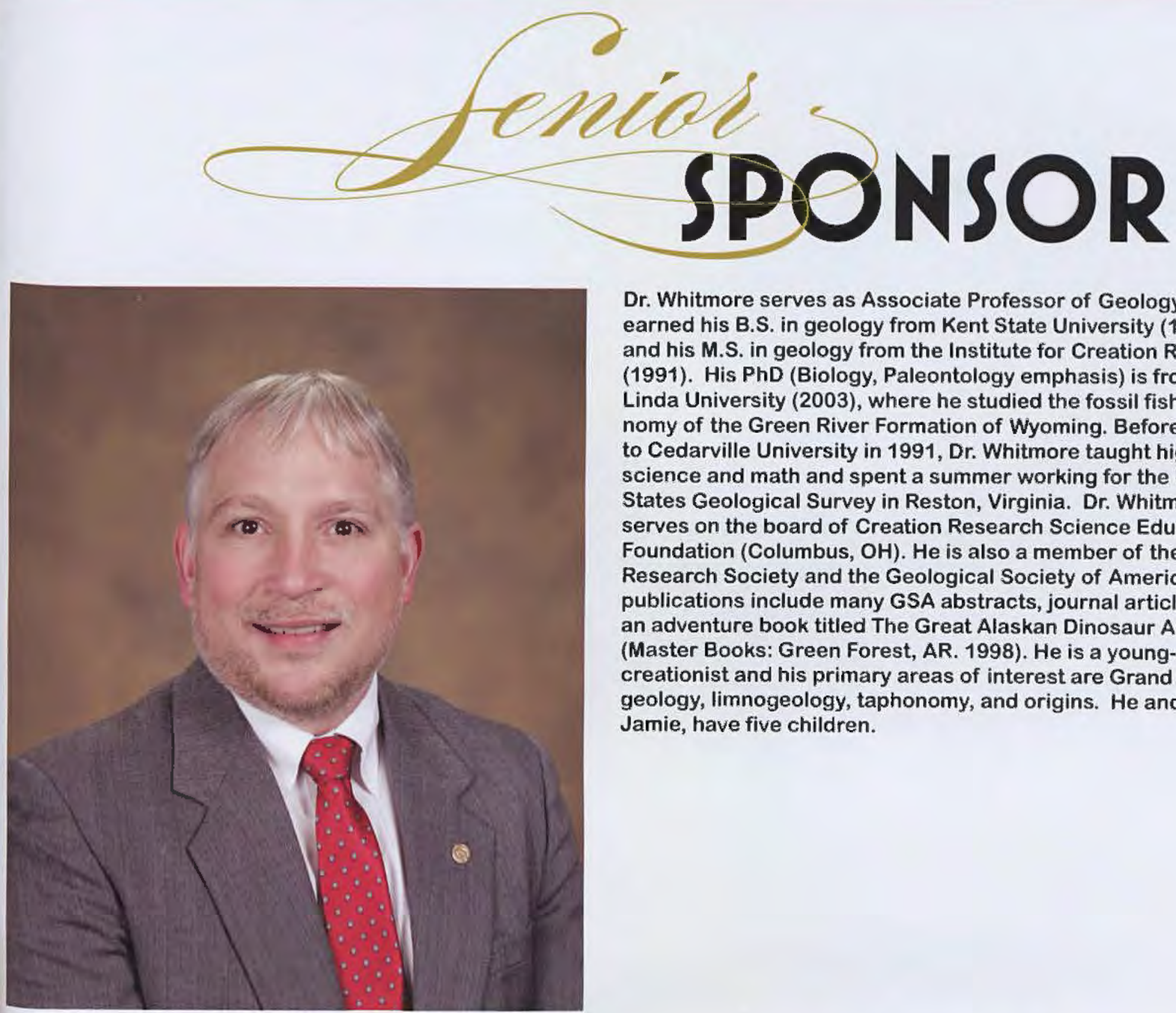

Dr. Whitmore serves as Associate Professor of Geology. He earned his B.S. in geology from Kent State University (1985) and his M.S. in geology from the Institute for Creation Research (1991). His PhD (Biology, Paleontology emphasis) is from Loma Linda University (2003), where he studied the fossil fish taphonomy of the Green River Formation of Wyoming. Before coming to Cedarville University in 1991, Dr. Whitmore taught high school science and math and spent a summer working for the United States Geological Survey in Reston, Virginia. Dr. Whitmore serves on the board of Creation Research Science Education Foundation (Columbus, $\mathrm{OH}$ ). $\mathrm{He}$ is also a member of the Creation Research Society and the Geological Society of America. His publications include many GSA abstracts, journal articles and an adventure book titled The Great Alaskan Dinosaur Adventure (Master Books: Green Forest, AR. 1998). He is a young-earth creationist and his primary areas of interest are Grand Canyon geology, limnogeology, taphonomy, and origins. He and his wife, Jamie, have five children.

"WORKING WITH THE INTERCLASS COUNCIL HAS BEEN A GREAT JOY THIS PAST YEAR. I HAVE THOROUGHLY ENJOYED WORKING THE THE CLASS OFFICERS AND GETTING TO BE A PART OF THEIR LIVES." _BRITTANY DONALD, PRESIDENT

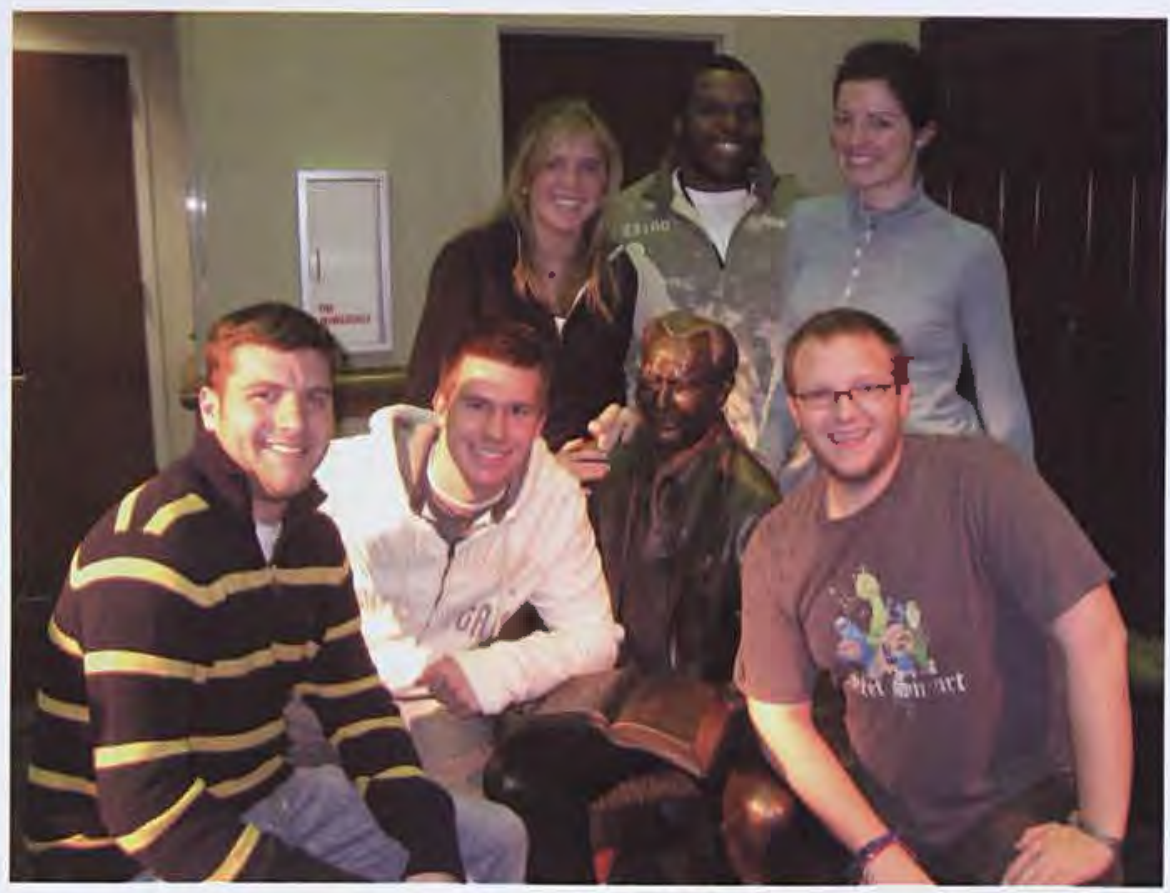

Members of the Senior class student council pose with the infamous Dr. Dixon statue. 
17

IS NATURE'S

W/A

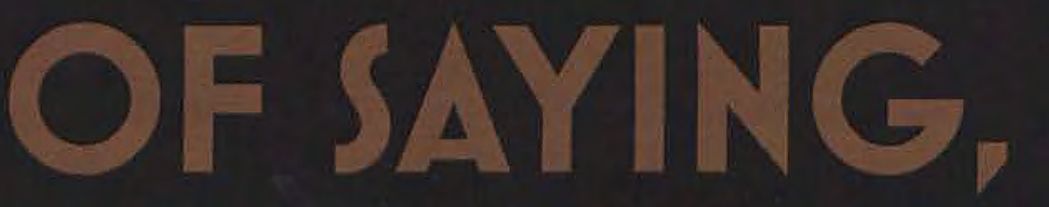

'LET'S

PARTY!" "

- ROBIN WILLIAMS 


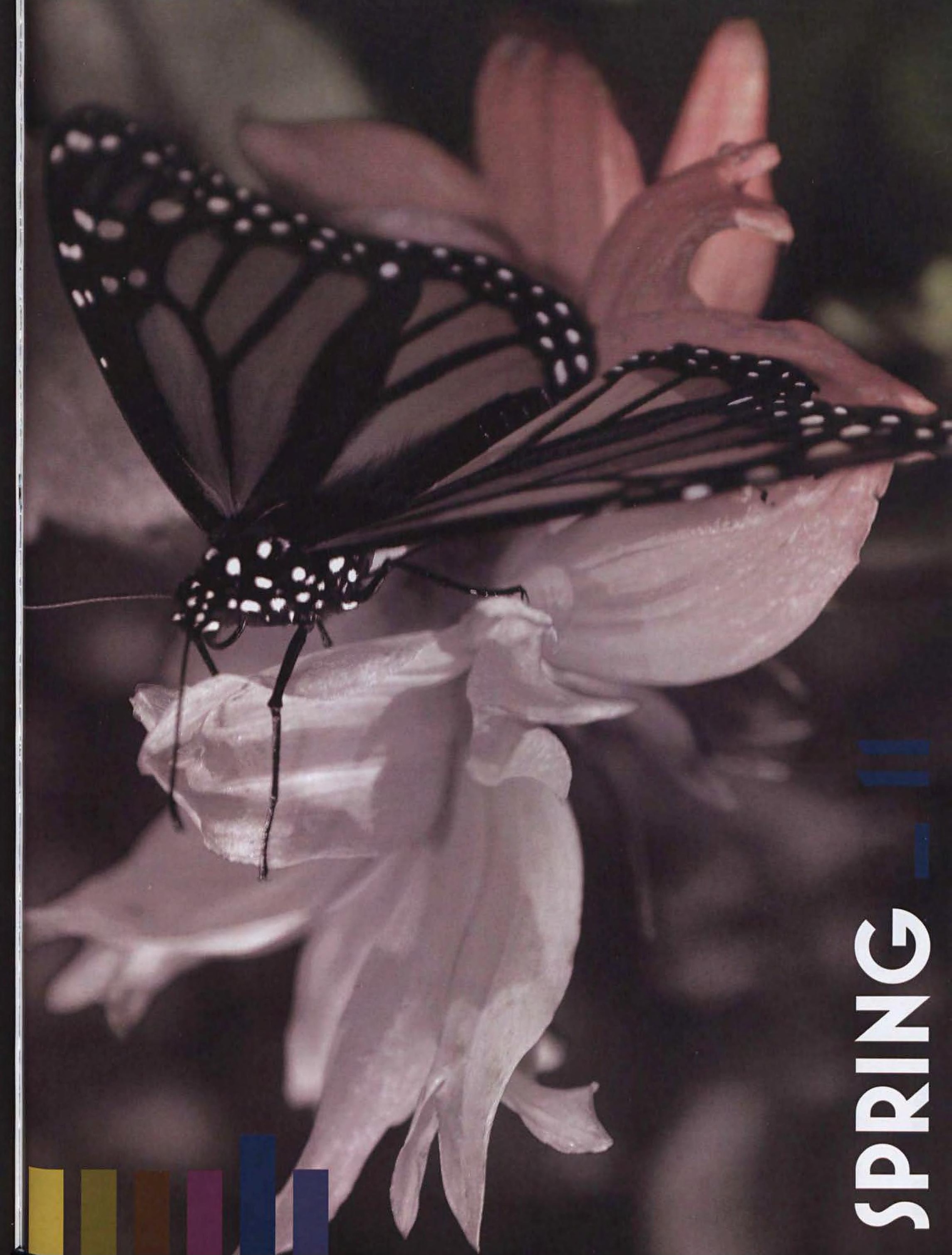


When missionaries like Pioneers-USA President Steve Richardson and founder of Laszlo Mission League Marilyn Laszlo get together for a mission conference, you can be sure to hear some memorable stories, filled with drama and danger (and leeches and rats). This year's mission conference, "Unreachable?!" filled the Jeremiah chapel with missionary accounts of God's work among the various unreached people groups of the world. "I appreciate the university's effort to turn the focus of its students away from the communities we know, and toward the broader picture. God can use anyone to do anything anywhere in the world; all $\mathrm{He}$ asks is that we be willing and ready for the life He's planned for us." (Debbie Strutton, senior)

Their testimonies of how the gospel is impacting people around the world proved to be both encouraging and challenging. "There were speakers who talked about the fact that to be a missionary doesn't just mean that you have to only plant churches or only preach. It's important for us to remember that God has given us each different passions that are all for us to use for His glory and service in whatever capacity He places us." (Amanda Einselen, senior)

"This semester's missions conference meant a lot to me. It's always refreshing to see the world from the perspective of our missionaries, while getting a wakeup call about my responsibility as a Christian." (Ben Roscup, junior) Whether it means ministering to an unreached tribe in Papua New Guinea or to a tribe of sixth graders in Ohio, this year's conference reminded students to leave the duty of planning out our life courses to the Lord, instead of dictating to Him our own lofty ideas for the future.
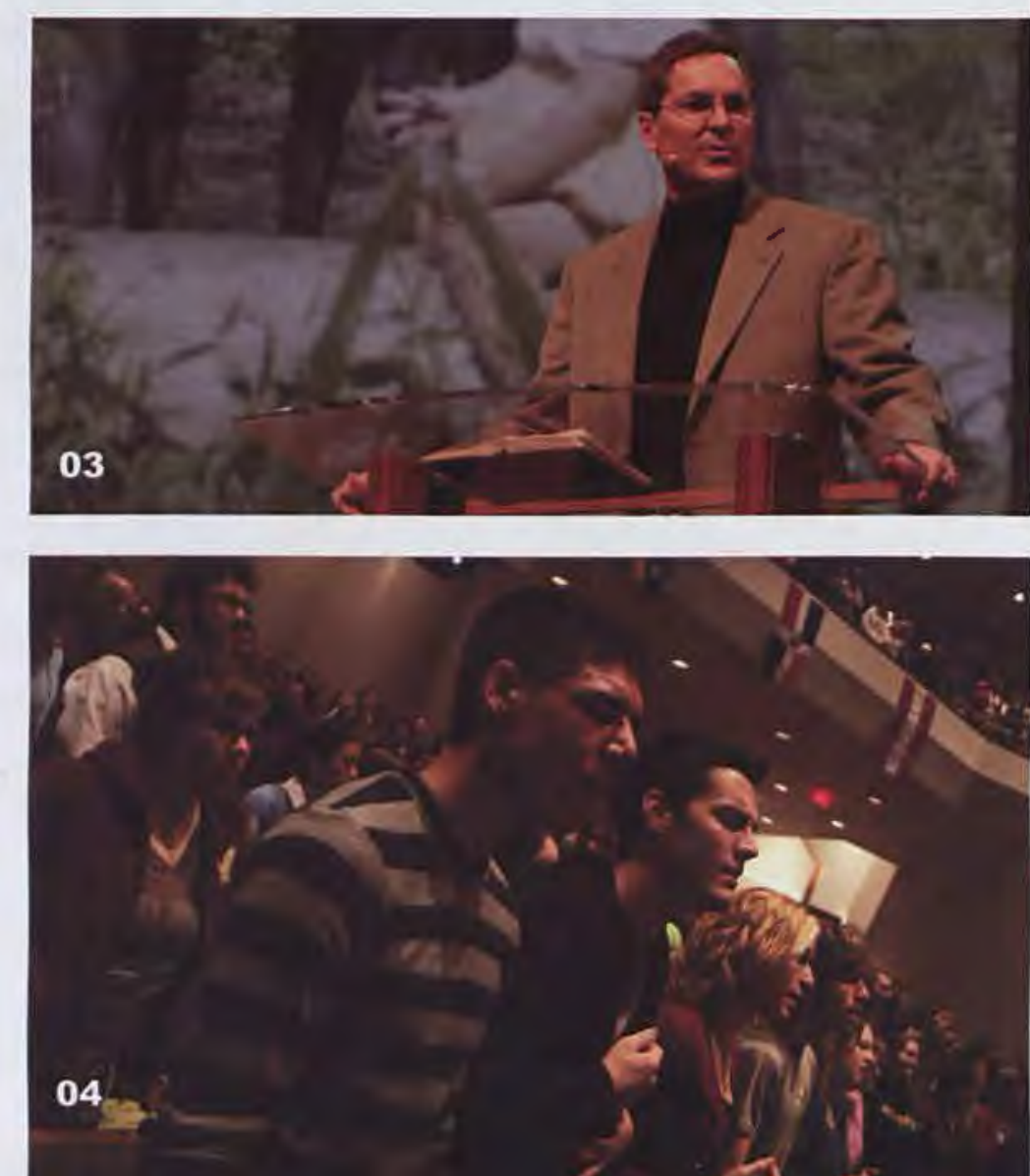
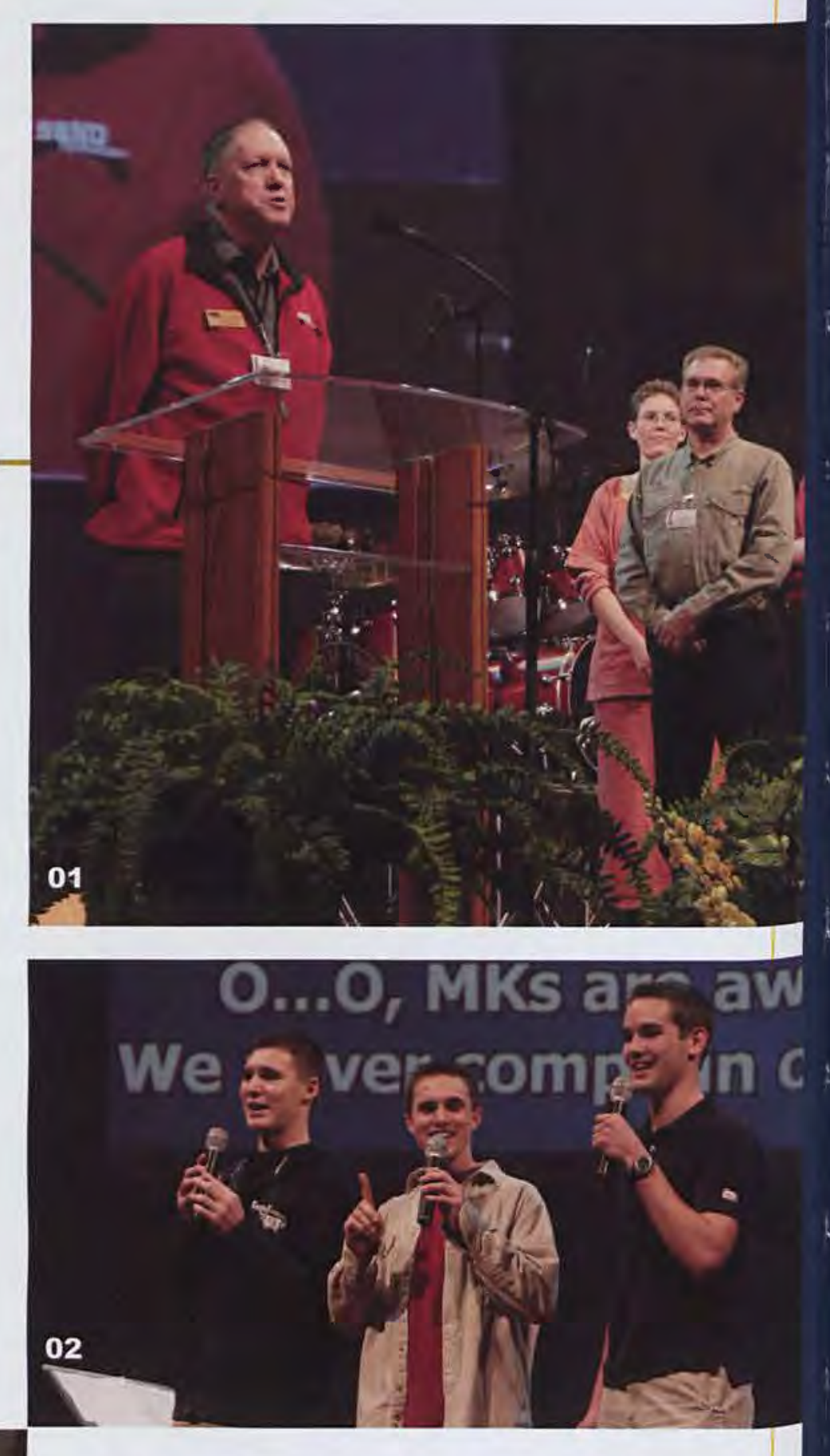

01 Each missionary has only a couple seconds to give his or her name and some other biographical information.

02 Three missionary kid cousins treat the student body to their own version of "We Three Kings" with an MK twist.

Steve Richardson, one of the main speakers at the conference, tantilizes the students with tales of eating termites and living among the cannibals.

CU students take advantage of the opportunity to spend time in worship to God as the new semester starts. 


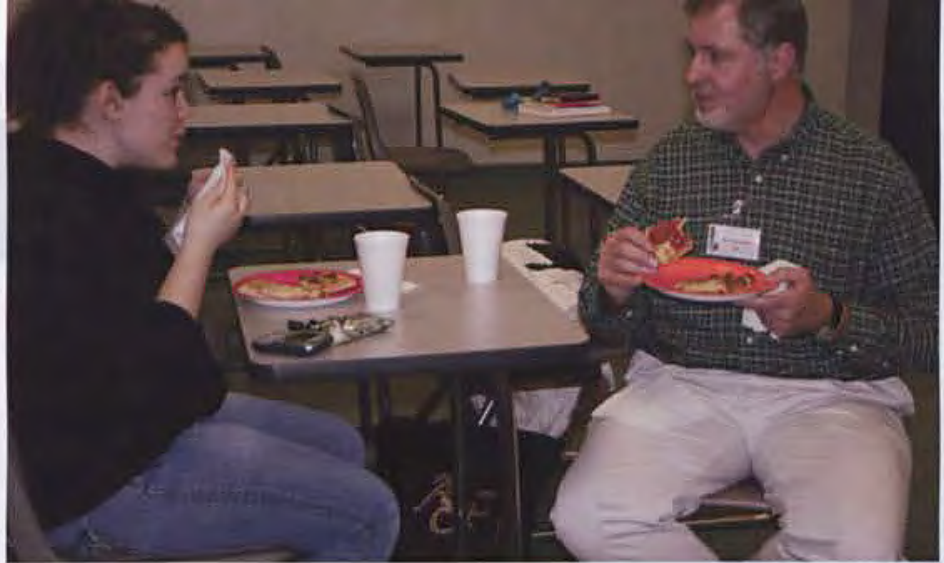

Some of the missionaries meet with some of the students after the conference meetings.

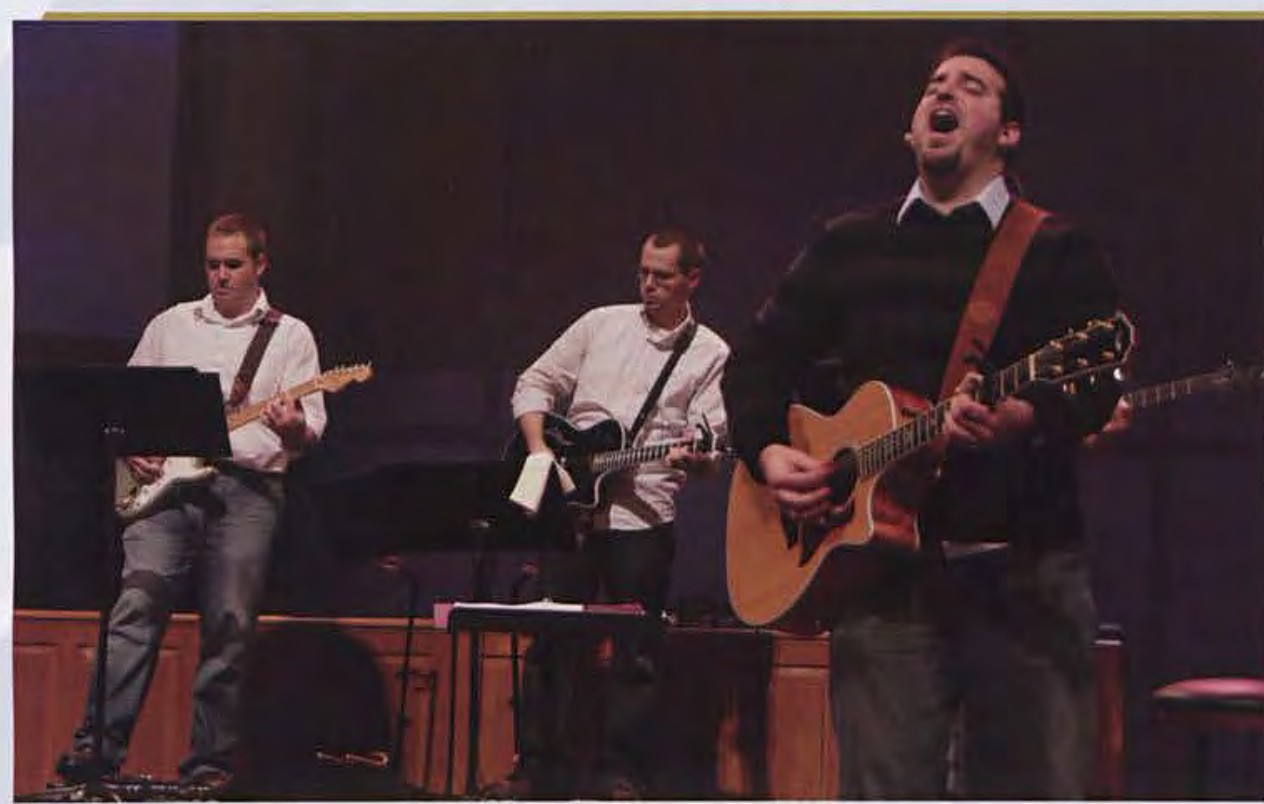

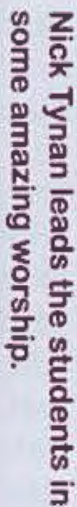
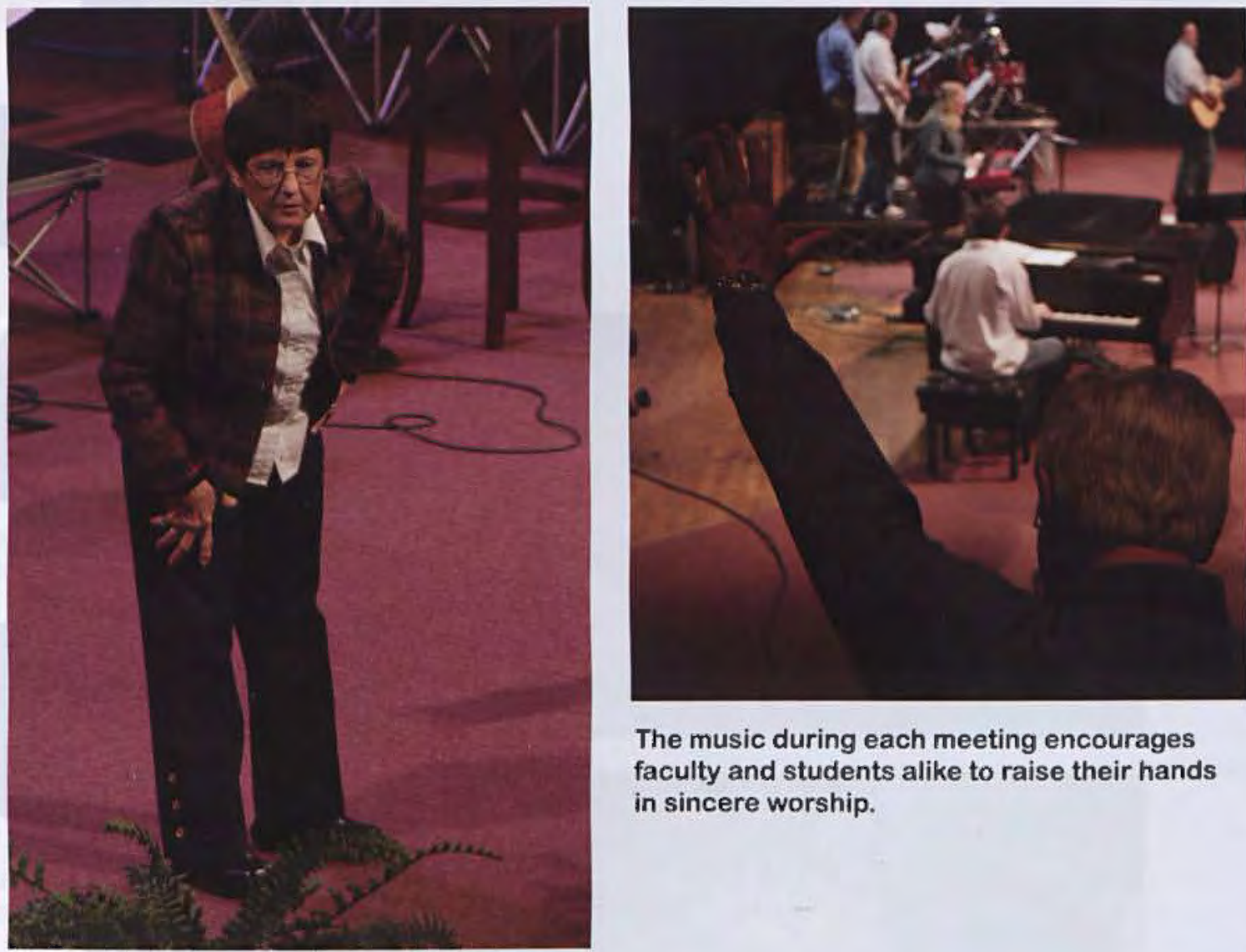

The music during each meeting encourages faculty and students alike to raise their hands in sincere worship.

Marilyn Laszlo captivates her audience with her stories of taking the Scripture to the natives of Papua New Guinea. 
Alice in Wonderland "appealed to audiences of all ages." (Michael Domeny, Junior) Audiences, cast, and, crew treasured this theatrical experience. The play was "very fun and satisfying to work on." (Charlie Hoffman, freshman) The classic tale of the young girl who stepped through the looking glass came alive with a rotating set, detailed costumes, and superb acting. The story is known for its eccentric characters, and Cedarville's cast portrayed them skillfully. "Each actor brought a little something extra to their character that only they could." (Laura Besaw, junior) The cast was led by Annalise Hickok, who turned in a stunning performance as the adventurous Alice.

Audiences were enraptured as Alice listened to the Mock Turtle's song, accompanied by Gryphon's occasional squawks. Humpty Dumpty quipped from his wall as it rotated around the stage to Alice. The Mad Hatter and March Hare presided over their perpetual tea party, interrupted only by occasional squeaks from the Dormouse. The Cheshire Cat grinned over the play with the familiar face of Lewis Carroll. The Queen of Hearts boomed "Off with her head!" causing Alice to disappear through the rabbit hole in terror. Finally, Alice awoke to find that her adventures in Wonderland were merely a dream; however, her experiences were not forgotten.

Alice in Wonderland was whimsical and truly a "childfriendly theatre experience." (Christa Funke, junior) The play was "a beautiful theatrical excursion" (Kelsey Nelson, senior) that captivated audiences and will be cherished in the memories of all those who played a part in it.

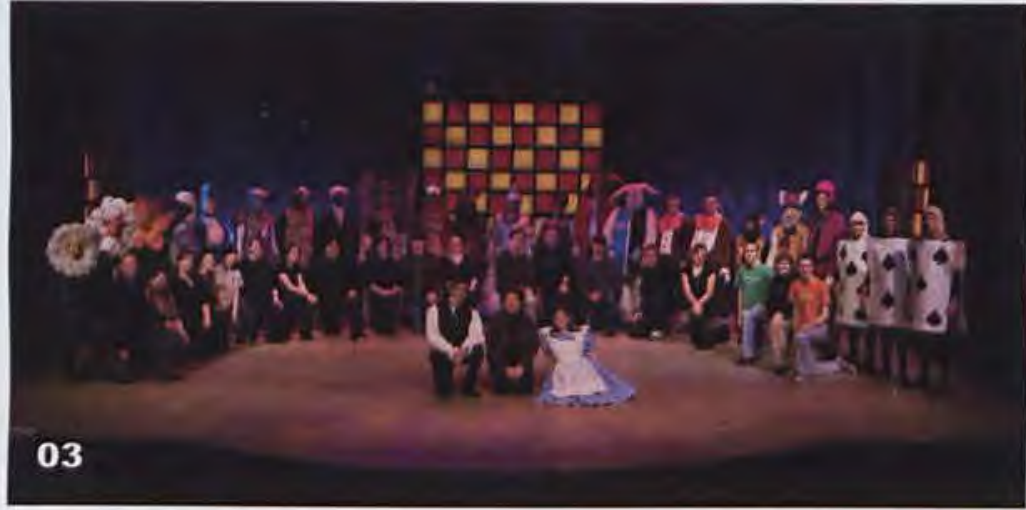

The entire cast and crew come together with director

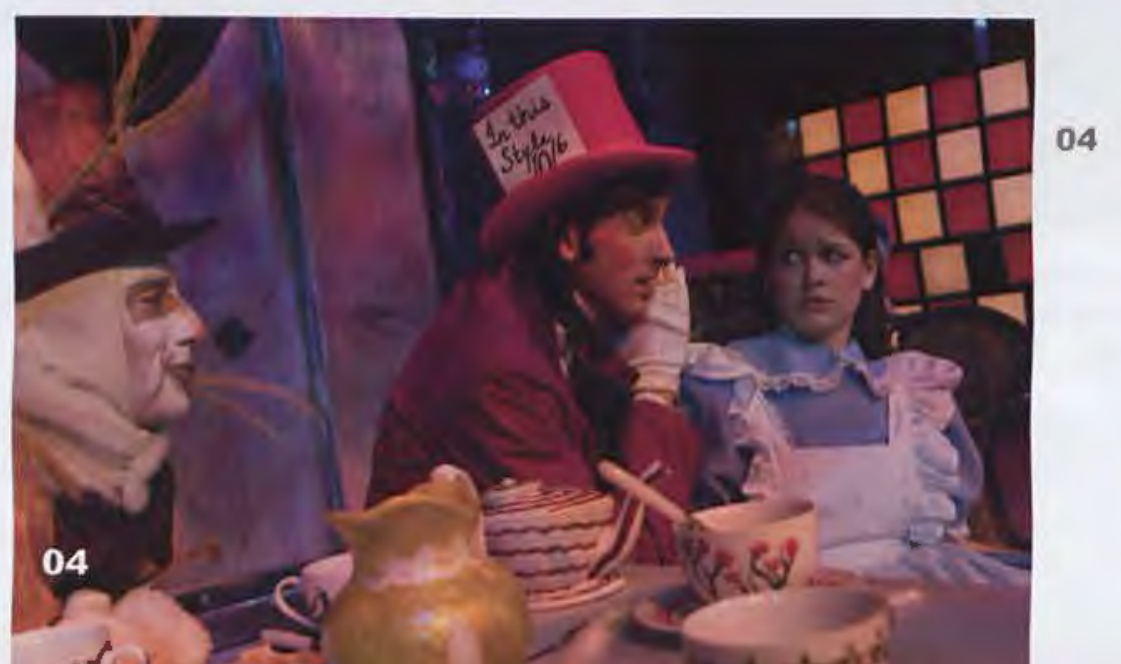
Dr. Diane Merchant for a group shot.

Annalise Hickok, as Alice, samples one of the tarts offered by Jordan Hickling, the Knave of Hearts.

Alice makes a quick escape through the rabbit hole, much to the surprise of those around her.

The Mad Hatter, Justin Hobbs, whispers secrets to Alice at his perpetual tea party with the March Hare, played by Paul Mitchell Smith. 


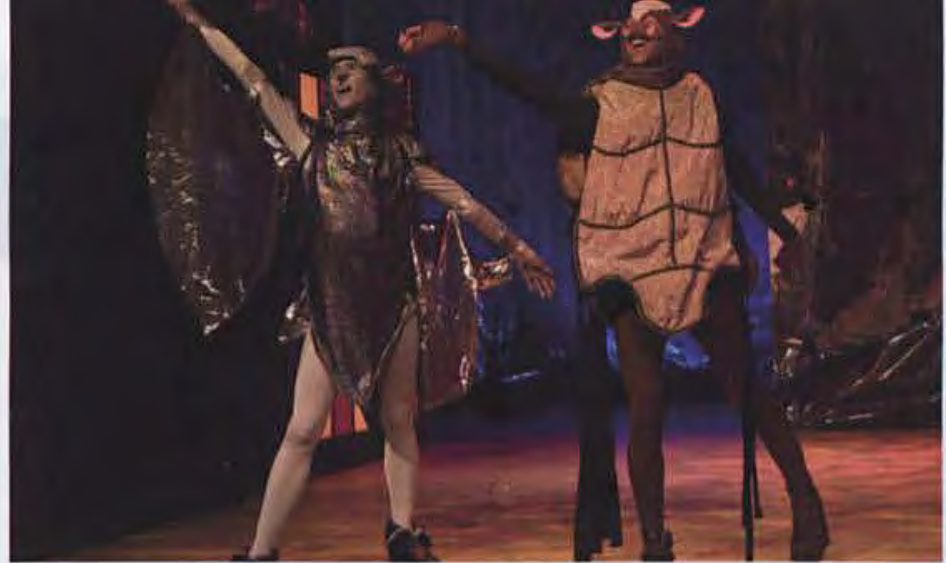

JP Adams as the Gryphon and Erik Strebig as the Mock Turtle make the audience laugh with their comedic song and dance.
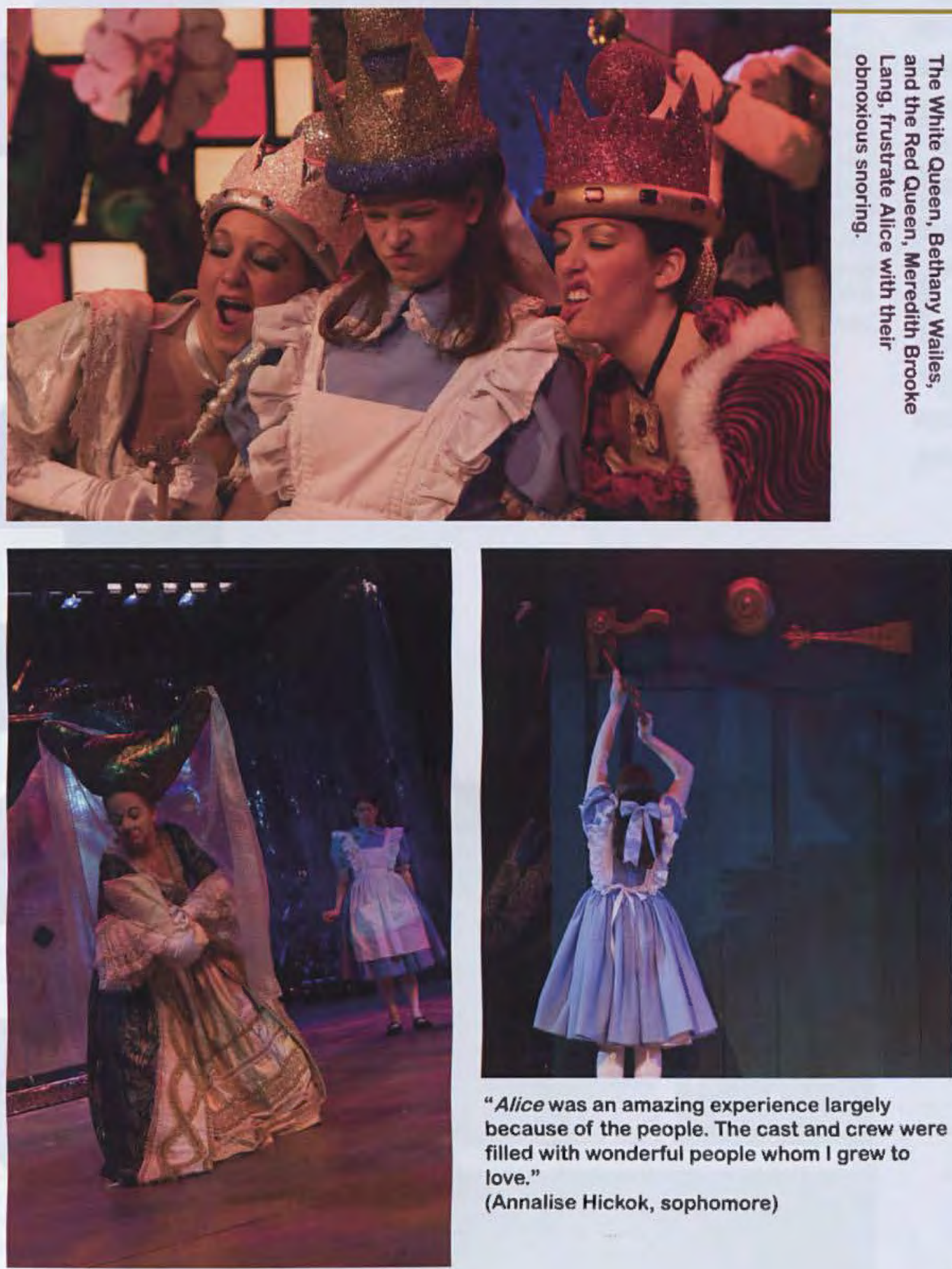

"Alice was an amazing experience largely because of the people. The cast and crew were filled with wonderful people whom I grew to love."

(Annalise Hickok, sophomore)

"I loved being the Duchess! She is exactly what I wanted to play! She was loud, hideous, frightening, and just all around unpleasant.. such a fun character to portray." (Katy Russell, sophomore) 
"Sometimes schoolwork needs a little interruption, a time one can put the books down and pick the guitar up and just sing instead of read." (Gabriel Coyle, senior) SCAB agreed and put on numerous musical Interruptions in the Hive, providing that muchneeded break for the musicians as well as talented performances for the audience's listening pleasure. This year's artists included everyone from the wellknown Demerits to first-time freshmen. "Everyone's Interruption is different; some are funny, others focus on worship...but no matter the style, it's just another cool part of the 'Cedarville experience." (Alle Pennell, sophomore) Always an inviting hang-out, the Hive would turn into an experience with each Interruption as audience and performers alike enjoyed the musical breaks. "I felt that playing at Interruptions this year and attending them as well were great ways to engage the Cedarville community and were an excellent way for Cedarville students to creatively celebrate the artistic talents that God has blessed us with."

(Sean Ewing, sophomore)

"Playing at interruption is the highlight of each semester for me. It is awesome to have all my friends come and get to play music for them and just have a great time. I am definitely going to miss it after I graduate."

(Adam Hundley, senior)

01

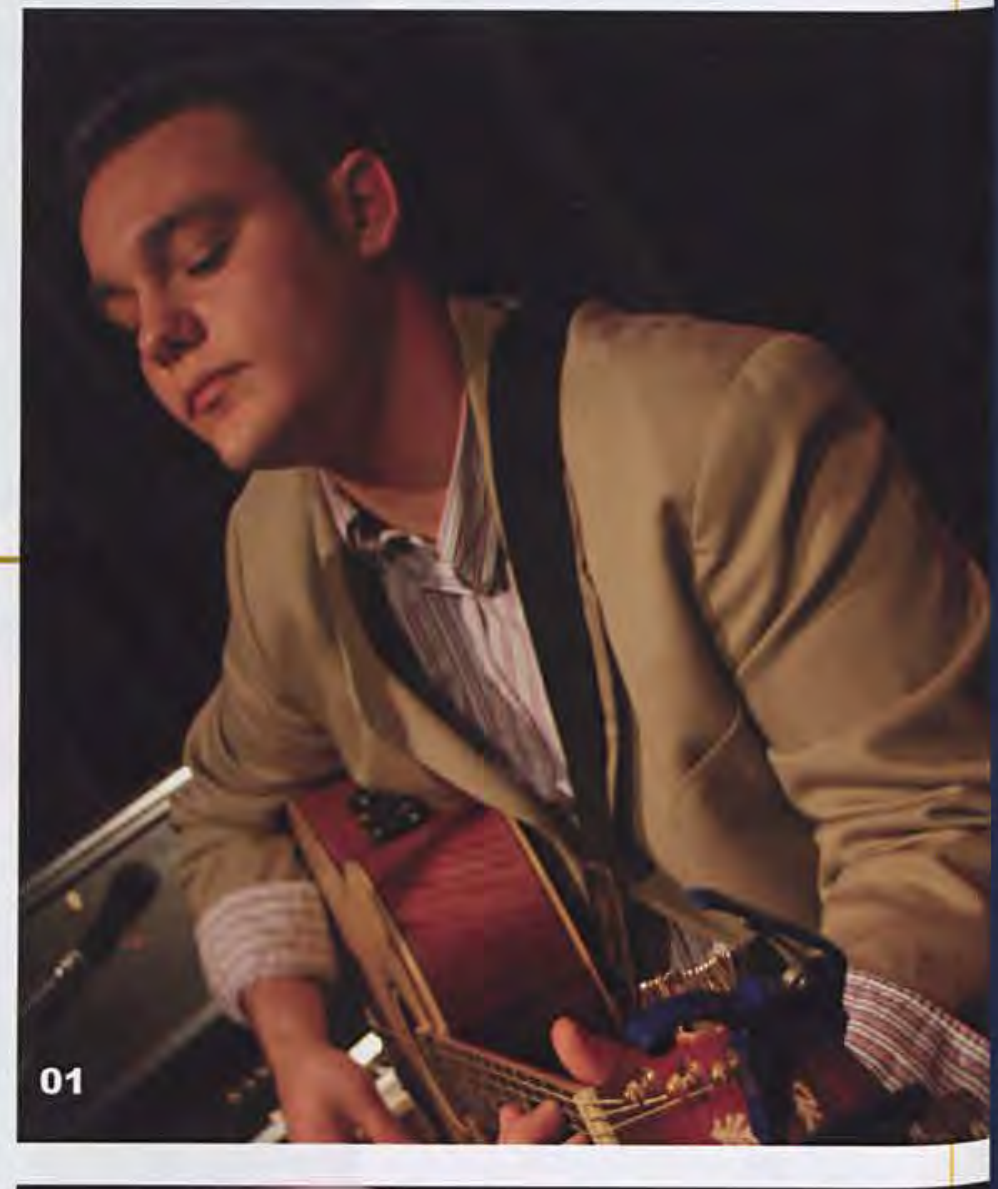

02

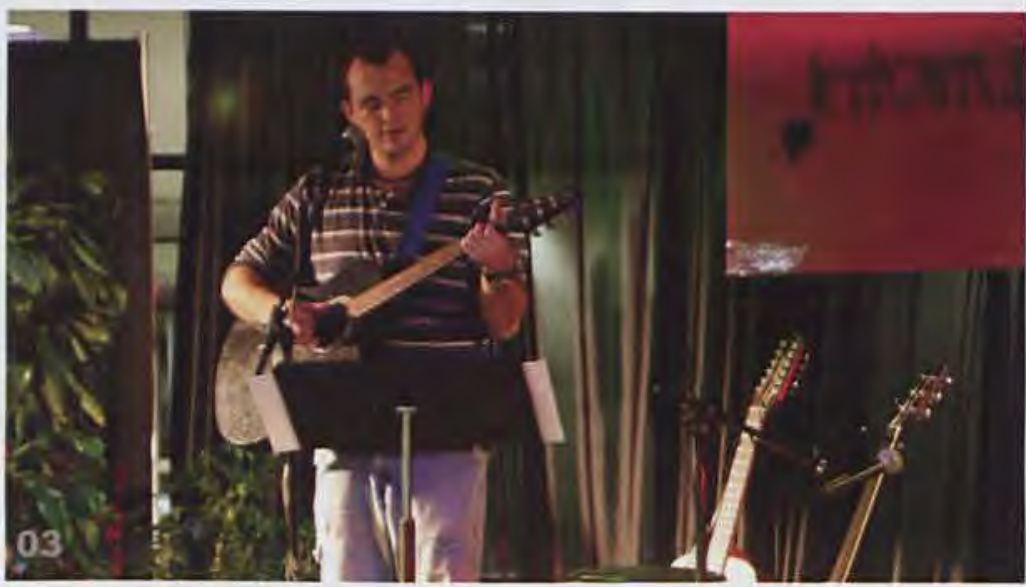

01 Tim Doenges, junior, creates quite an enjoyable and entertaining evening by sharing his talent.

02 Sometimes Interruptions are performed by groups of musicians, but this night, Erin Gollihue, sophomore, needs no one else as she accompanies herself on the

piano.

03 Andrew Costersian, junior, has many guitars to choose from as he performs in the upper SSC.

"Interruptions are an incredible way to have fun, connect with your friends, and hang out, " (Alle Pennell, sophomore), and Nate Keller and Zach Seelye, sophomores, are making connections with their music.

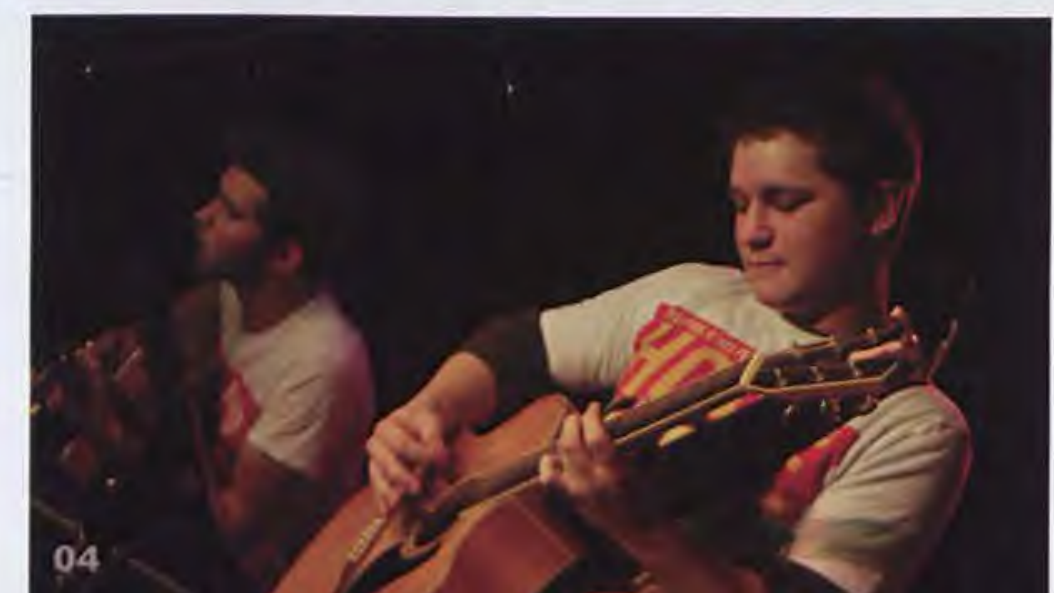


February 15-16 marked a weekend of fun with younger siblings, parents, and cousins. This time with family was a well-loved tradition by all of the students and especially appreciated at that point of the semester when it feels that spring will never come. Whether as you, a freshman or a senior, it was exciting to see faces from home and get to share some experience with dining at Chucks, class lecturing, and dorm room living.

The attractions of the weekend included the play Alice in Wonderland, late night bowling and ice skating, Men's and Women's Basketball games, the film Bee Movie, and the Alpha Chi Talent Show. Saturday even offered some inflatable fun time in the Doden Field House. No matter the little siblings' interest or age, there was something for them to enjoy.

Sophomore Valerie Gingrich really enjoyed the weekend because "it gave me a chance to show my two youngest sisters what college life is really like." Also appreciating the time with her "little" sib (a junior in high school), Junior Heather Wuobio reflected that "it was really nice to see my sister and my parents here at Cedarville since they don't live close enough to visit often." Although Sophomore Elyse Looyengoed did not have a sibling come for the weekend, she enjoyed watching all of the loving interaction that she saw between Cedarville students and their brothers and sisters: "I loved watching how older Cedarville brothers compassionately guided their younger siblings along while they were ice skating; it made me wish my lil' sib was here!" It was a fun time had by all and continued to be a favorite time with Cedarville students and their families

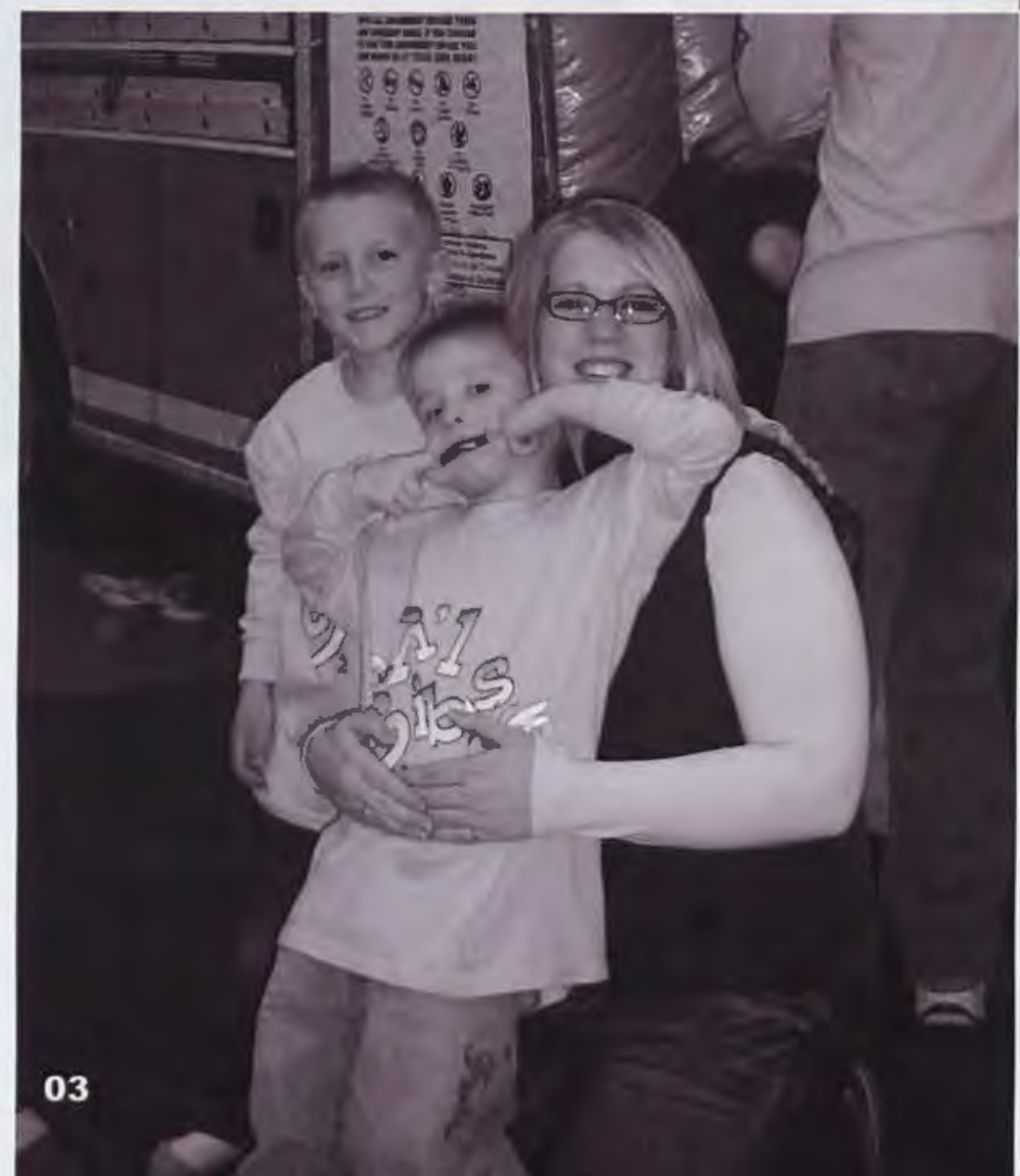

We at Cedarville are really one big family; Lil' Sibs Weekend allows students to enjoy a bit of sisterly bonding, whether it is with their own sister or someone else's.

02 Little sibs enjoy all the pleasures of being a Cedarville student, including going to classes, even if listening to a lecture seems less than exciting.

03

"My little brother had a blast coming down to visit my sister Alisha and me! He made a little group of friends that afternoon, and you could tell that he didn't want to leave." (Megan Brown, sophomore) 
On February 15, many people joined together in the Jeremiah Chapel to witness the amazing talent of our student body at the 41st Alpha Chi Talent Show. There was a wide variety of talent evident in the thirteen acts presented, ranging from a show of El Diablo "Chinese Yo-yo" presented by Josh Gelser with Ethan and Joel to sign language accompanying the song "Redeemer" by Lindsey Leppke. All of the acts were very impressive and received great approval from the student body. "Dan Zimmerman's parody and "Rindercella" by Eric Mishne and Jessica Hickling were my favorite! I couldn't stop laughing!" (Tiffany Lethbridge, sophomore)

At the end of the evening, audience members were able to vote for the "Best Act" and the "Most Original Act." Although this was a hard decision, the winners were soon announced. Best Act went to Karl Eiker and his amazing talent doing Tae Kwon Do. "I thought that the tae kwon do act was very impressive, especially the part where he crushed the glass with his feet." (Emily Shanahan, freshman)

The award for Most Original went to Eric Mishne and Jessica Hickling with their dramatic rendition of "Rindercella," which Mishne adapted for drama from Archie Campbell's story. Once again, the tremendous talent of the student body was evident by everyone's performance. The vision for this talent show which was brought about forty-one years ago by Dr. Murdoch, has been carried on and continues to grow, thanks to the men of Alpha Chi and the fabulous talent of the student body.

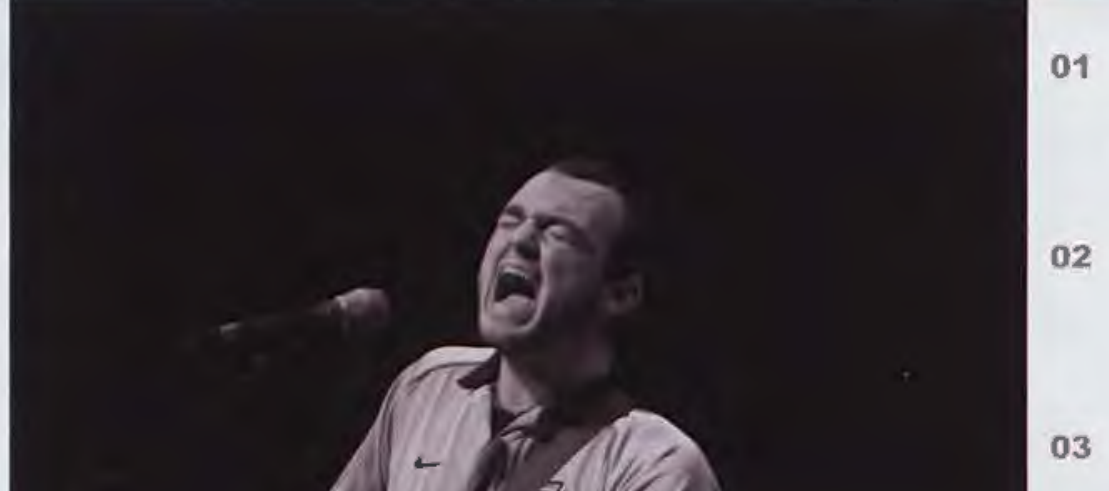

02

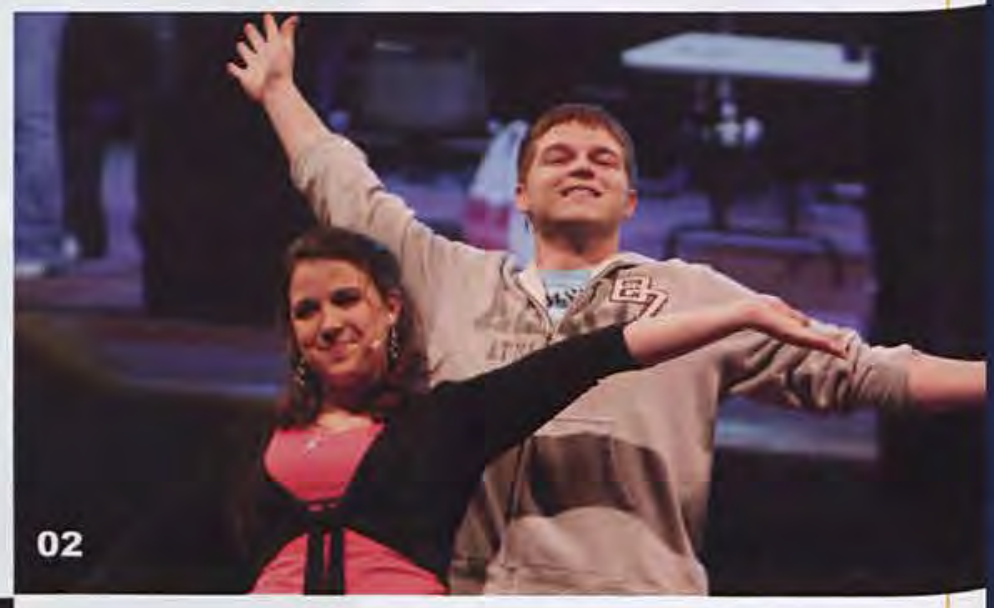

Lindsey Leppke impresses the audience with her ability to make song come alive through the beauty of sign language.

Laura Thayer, sophomore, and Zach Roberts, freshman, try to outdo one another as they sing "Anything You Can Do, I Can Do Better."

Andrew Costersian, junior, provides the encore in thanks to Alpha Chi for giving him \$1 from every ticket sold to support a summer missions trip. 
Elliv 2008 differed from previous years in several ways. This year, SGA avoided spending large sums on special effects and focused instead on the quality of the performances and videos. The event had a city theme, and SGA felt that Cedarville should minister to an inner-city area to reflect our theme. They decided to donate one dollar from each ticket sale to Urban Light Ministries in Springfield. Another difference this year was that everyone was invited to attend a preshow party in front of the DMC, instead of the usual red carpet event. The pre-show party included free ice cream, popcorn, street performers, and music.

As always, students went all out with their costumes. "I absolutely love the creativity Cedarville students possess in designing and making costumes! Everywhere I turned there was a crayon, Wii, domino, princess, villain, or even a Chinese dragon." (Elyse Looyengoed, sophomore) The shows this year included Step Up break dancing, a performance based on Stomp, and a song from the Broadway musical Wicked. Hosts Grant Hansen and Tori Duff kept the audience entertained in between performances with a range of jokes including the "Radec" awards and a look-alike contest. "The banter between the hosts was great, and I loved experiencing the Cedarville version of The Office." (Brietta Allen, junior) After the last act, students attended a post-show party in the DMC with a live performance by the "Mood Swingers" and an art exhibit. Others headed off campus to enjoy their discounts at Chik-fil-A or Red Robin. "From the first act to the last, I am glad that I went! Elliv 2008 is one that will be remembered for a while." (Joshua Witry, sophomore)
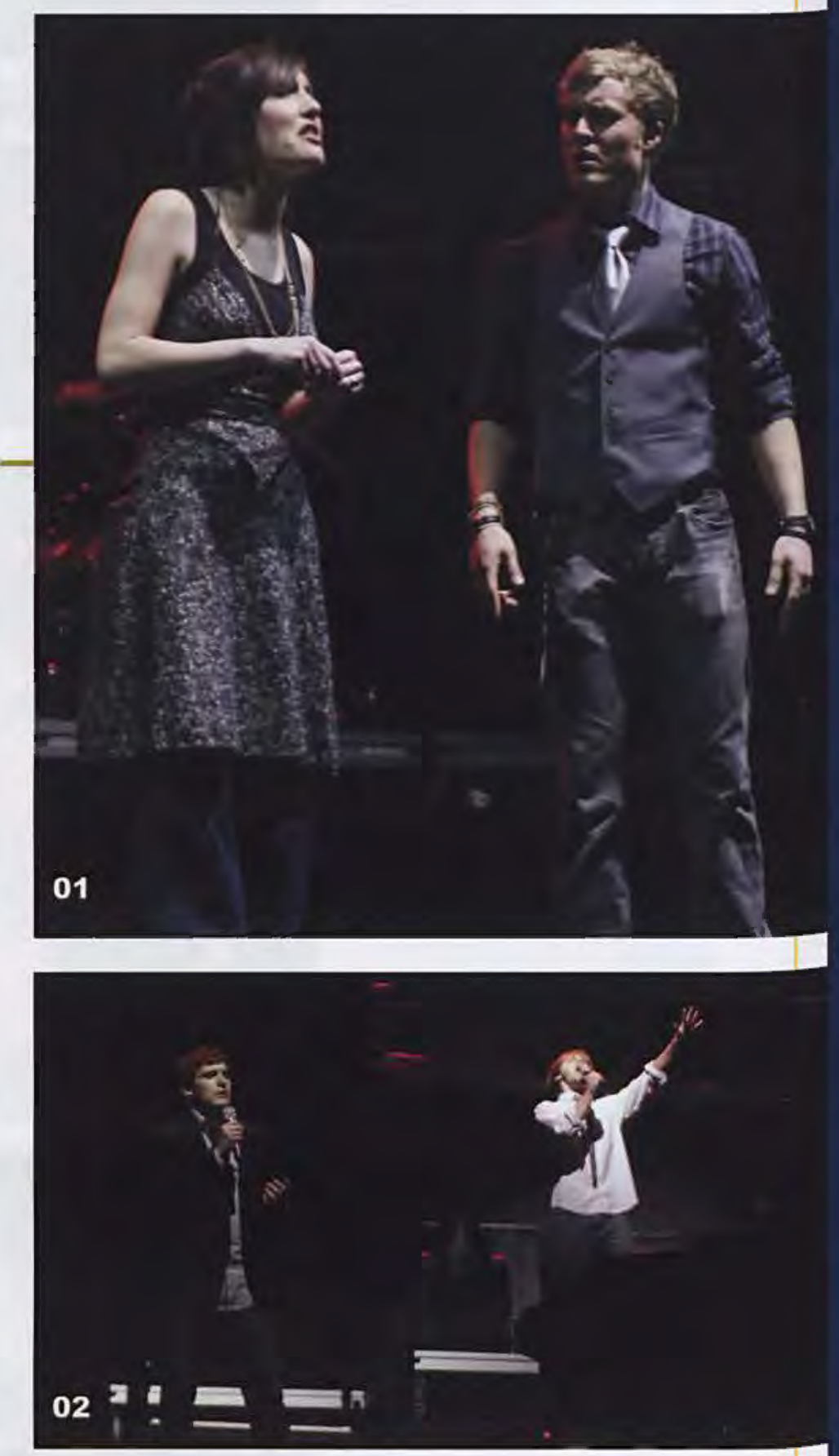

01 "I was amazed at the professionalism of Elliv this year. The script was amazing and the comedy fresh and clever. I'd award a Radec to all the people who put on the show this year!" (Christa Funke, junior)

02 "Elliv this year was fantastic! The quality of the musical acts was superb, and they were coupled with hilarious hosts who had the audience rolling in the aisles. All in all, it was extremely entertaining." (Justin Duff, sophomore)

Ahna Buckwalter and friends dress up as members of the medical field, scary syringes and all.

Chris Williams, Chris Gehman, Tommy Carey, Becky

Gregg, Becky Hamilton, Allie Babbitt, and Hannah Olmstead show off their costumes. "At Elliv we can be whoever we want to be or not be." (Becky Gregg, sophomore) 


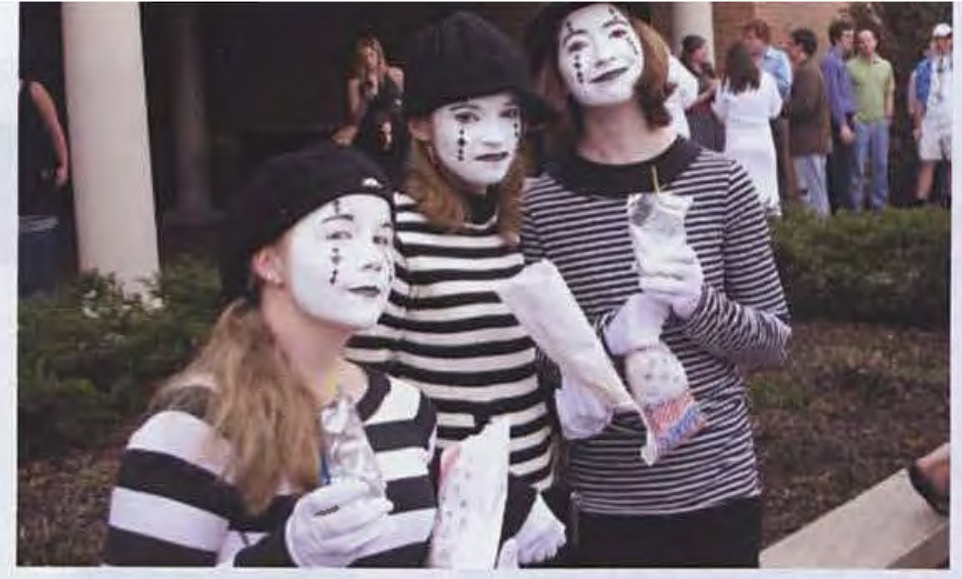

Jannae Turley, Keriann Arnott, and Kaitlyn Arnott leave the crowd speechless with their mime costumes.
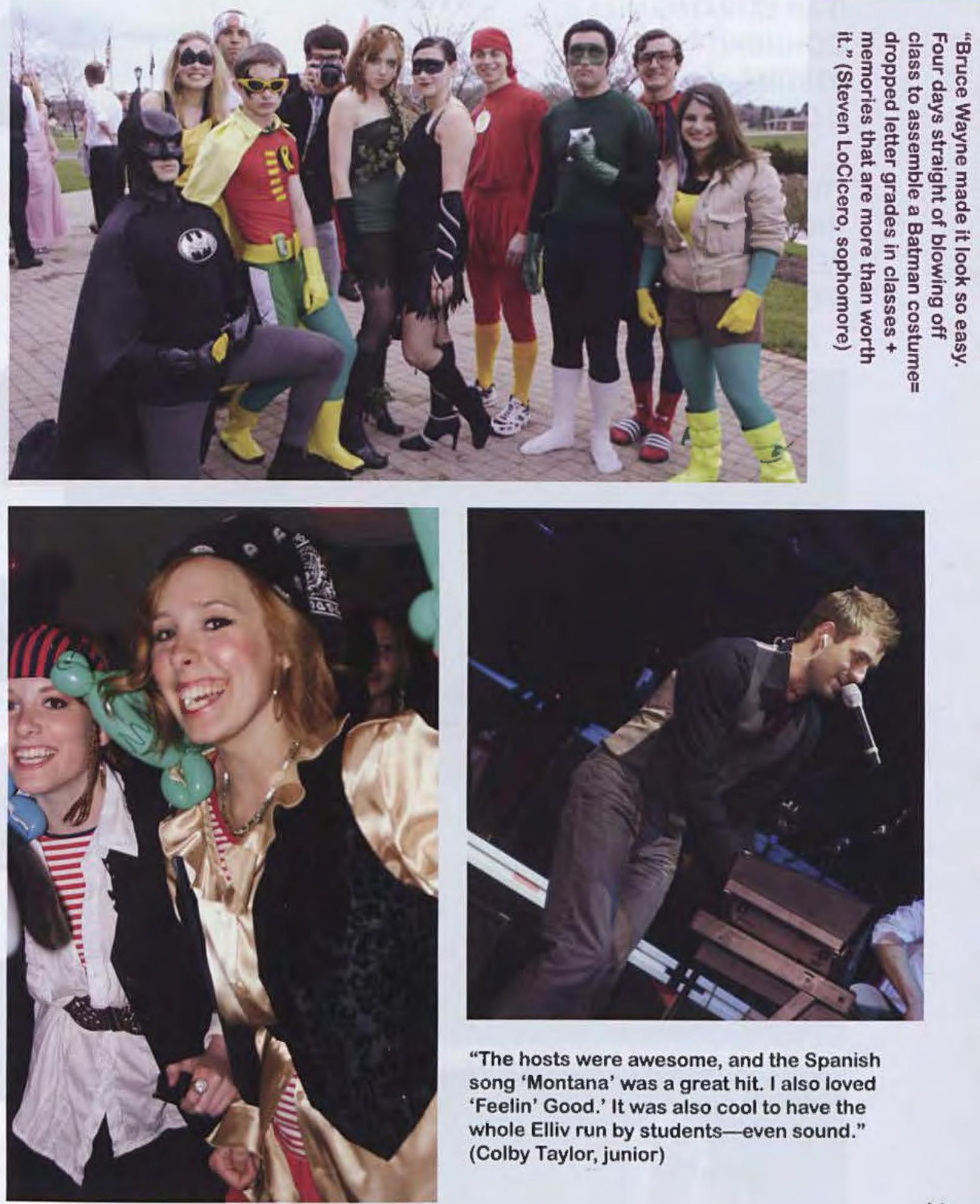

"The hosts were awesome, and the Spanish song 'Montana' was a great hit. I also loved 'Feelin' Good.' It was also cool to have the whole Elliv run by students-even sound." (Colby Taylor, junior)

Elliv this year saw a series of creative costumes, from caddies, to dominoes, to pirates; Cedarvillians are always innovative with costume ideas. 
"ELLIV WAS ONE OF THE HIGHLIGHTS OF MY YEAR- THE COSTUME SCHEMING, THE LATE NIGHT TRIPS TO WALMART AND GOODWILL, THE SHOW AND THE AFTERPARTY WAS ALL A FANTASTIC WAY FOR US AS A GROUP TO BOND AND HAVE AN AMAZING TIME WHILE DOING IT."

- CLAIRE WILLIAMSON, SOPHOMORE

"ELLIV MAY JUST BE VILLE BACKWARDS, BUT IT IS AN EXTRAVAGANZA THAT PUSHES OUR COMMUNITY FORWARDS TO GREATER DEPTHS."

- CHUCKY KLINT, SOPHOMORE

"THE VARIETY OF ACTS AND THE AMOUNT OF TIME EACH GROUP PUT INTO

PERFECTING THEIR ACT MADE ELLIV TOTALLY WORTH ATTENDING."

- JOHN BERTSCHE, SOPHOMORE

01
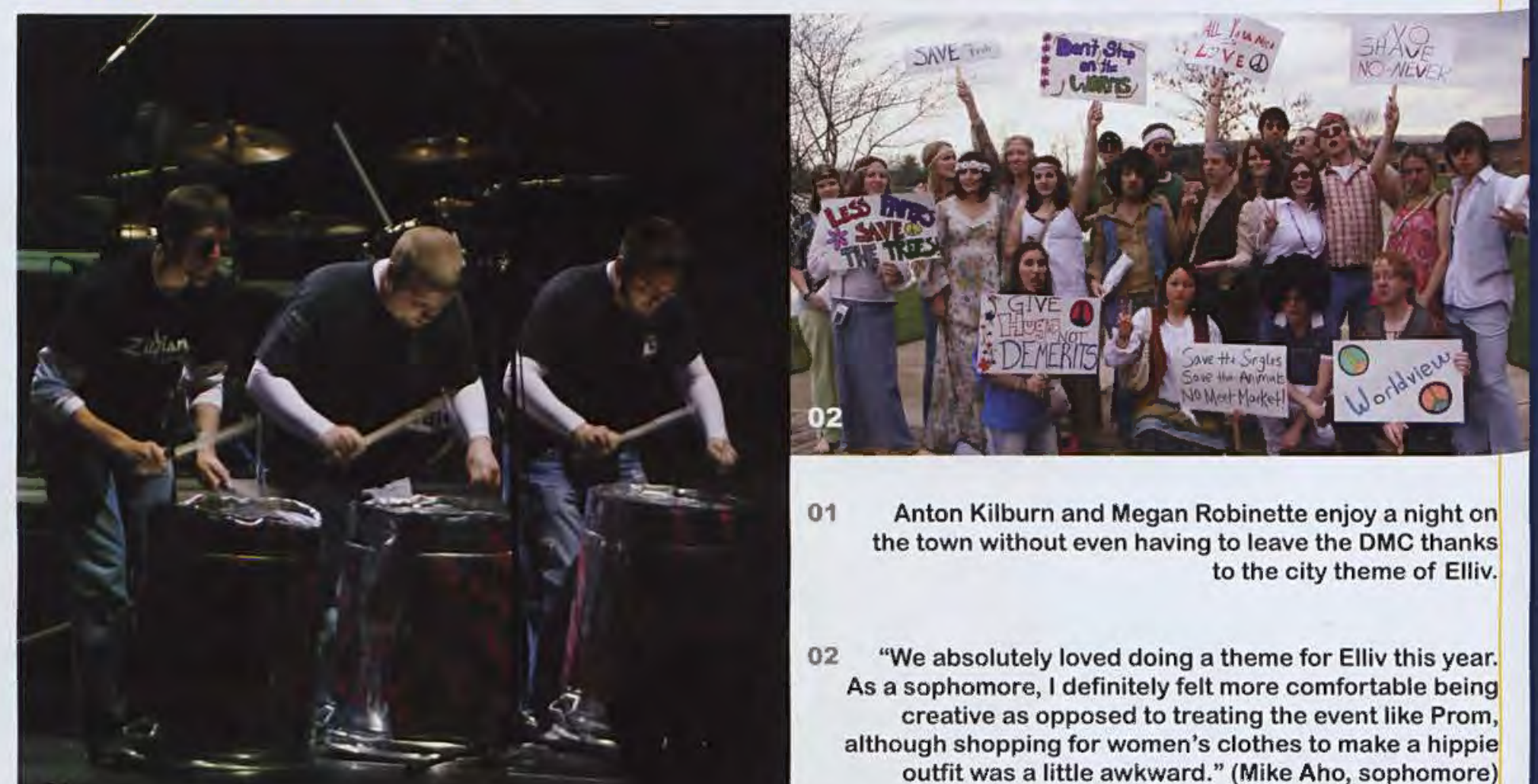

01 Anton Kilburn and Megan Robinette enjoy a night on the town without even having to leave the DMC thanks to the city theme of Elliv.

02 "We absolutely loved doing a theme for Elliv this year. As a sophomore, I definitely felt more comfortable being creative as opposed to treating the event like Prom, although shopping for women's clothes to make a hippie outfit was a little awkward." (Mike Aho, sophomore)

03

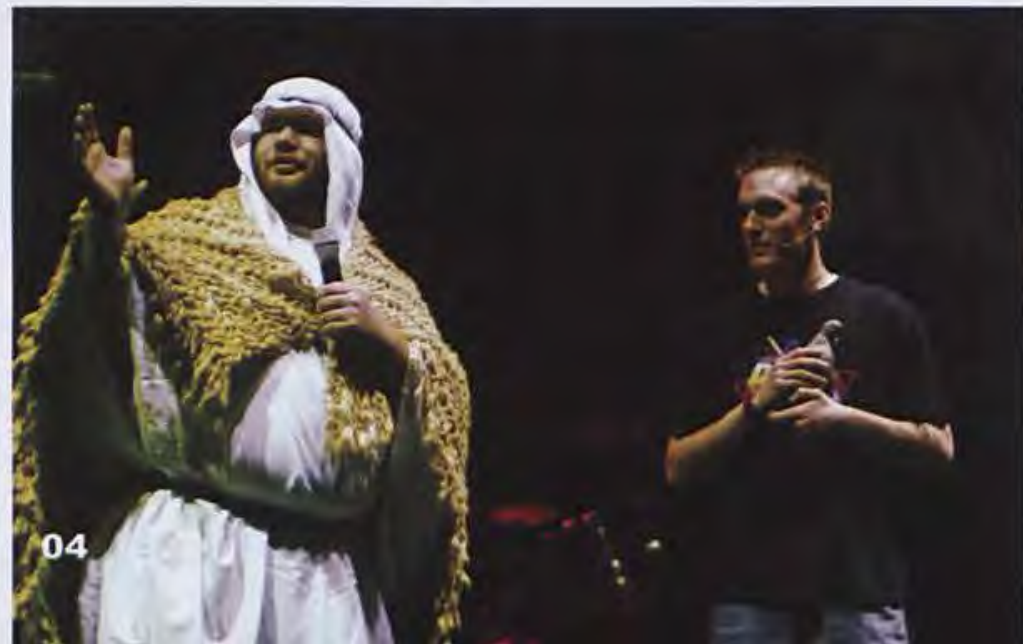

03 “As a senior, this year's Elliv was a great one to end on. What I enjoyed most about this year was how diverse the acts were. From Stomp to Montana to Mute Math, there was something for everyone." (Rich Davies, senior)

"Doing a skit with Craig was real easy, and it was fun! Working together in chapel this year gave us the chemistry to be able to goof around on stage at Elliv." (Mike Angle, junior) 


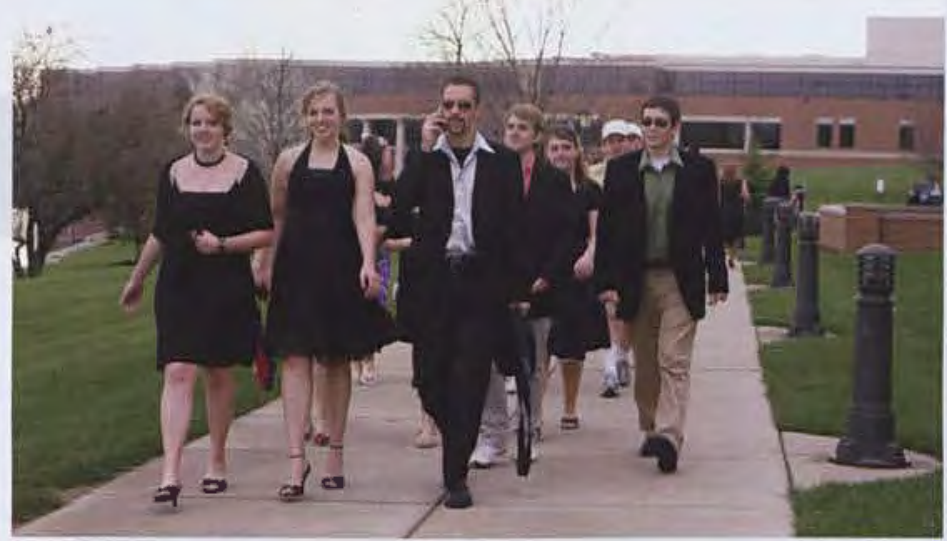

Students were very relieved that it did not rain before or after Elliv this year, unlike the previous two years.
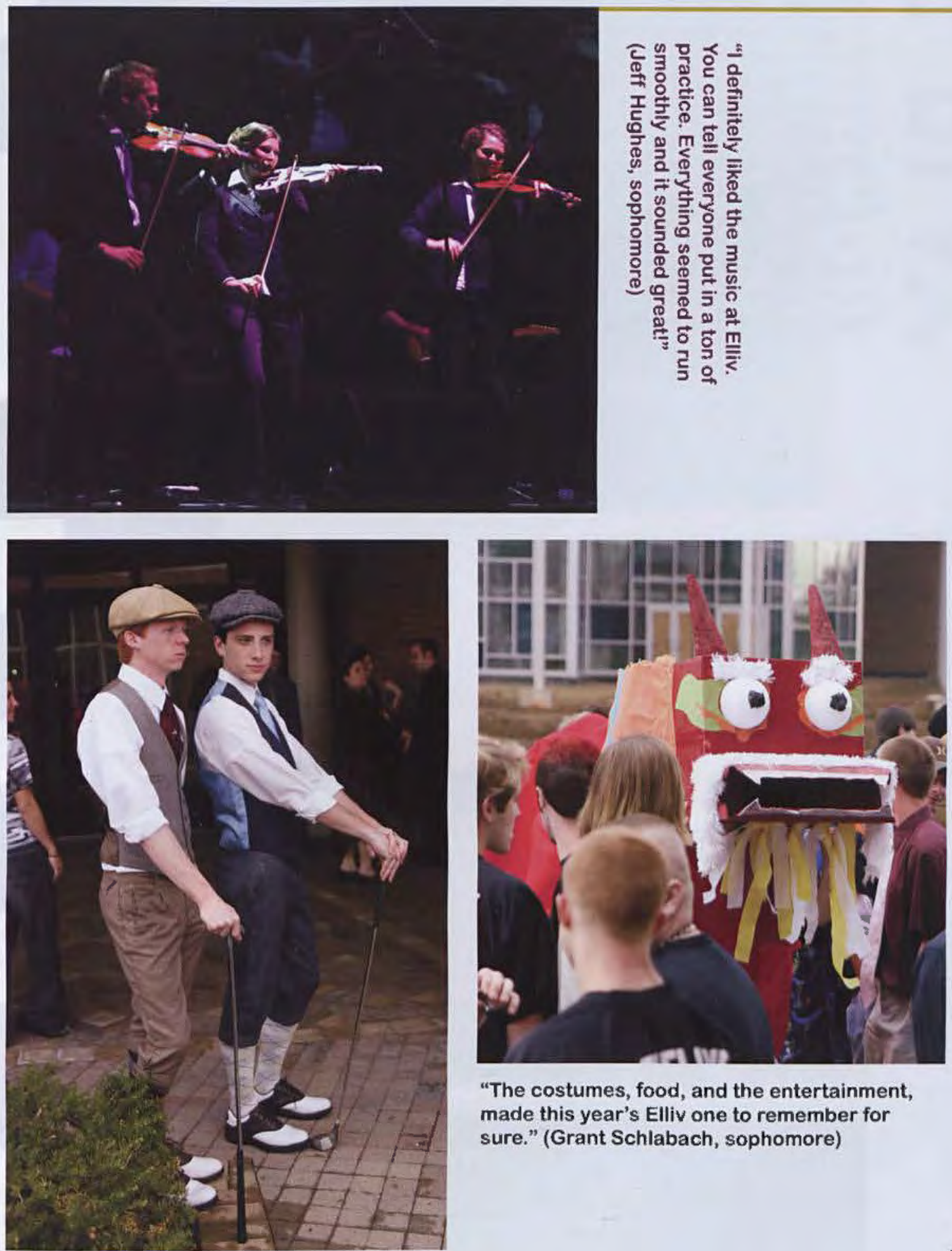

"The costumes, food, and the entertainment, made this year's Elliv one to remember for sure." (Grant Schlabach, sophomore)

"Elliv was a BLAST last year. The theme was all industrial and edgy, yet the acts were still very well done and interesting. I had a great time (though I may be partly biased since I was a presenter of an award with Kelsey Neison)." (Paul Smith, sophomore) 
Crossing Delancey, a romantic comedy, takes place in 1985. It is the story of a Jewish grandmother, Bubbie, who hires a matchmaker, Hannah, to find a husband for her granddaughter, Izzy. "Playing Izzy in [Crossing Delancey] was like going for a ride on a rollercoaster... as Izzy faced the ups and downs of romance... it was such a thrill to feel the audience hanging to her every word waiting to see what happened next. The greatest thrill was the roaring cheer when Tyler Moss was put in his place and the 'oo and aah' of the crowd when the unexpected stole their hearts." (Kasey Rising, junior) The story centers around the clash between cultures-the Orthodox Jewish community on the lower east side and "Uptown New York City". "It was interesting reasearching and incorporating Jewish culture among the pop culture of the 80 's. One of my favorite parts was researching Jewish cooking and providing the cast with delactable Jewish cuisine every evening." (Emily Bush, freshman) Izzy learns some valuable lessons about the role of tradition in her modern life and about where to find "true love." "Crossing Delancey was definitely the best MainStage Cedarville production for the '07' 08 season. I was definitely impressed by the complete believability of the cast, and the set was absolutely phenomenal. It was very well-done, and absolutely hilarious." (Paul Smith, sophomore)
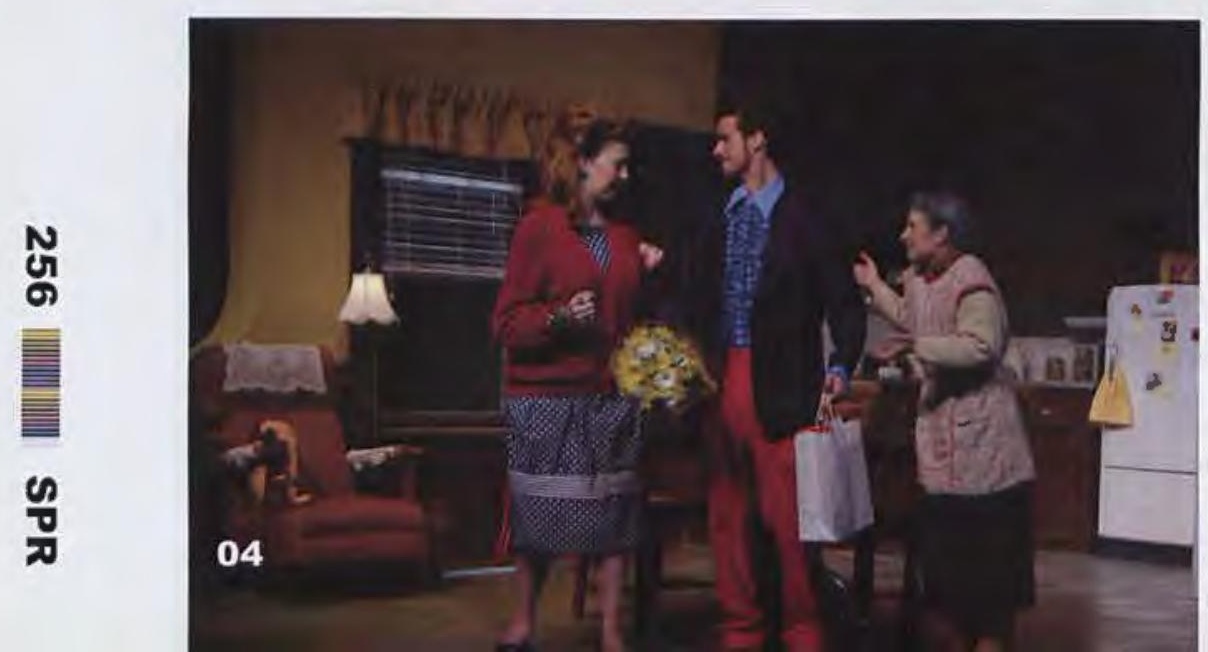

"I've absolutely loved being a part of Crossing Delancey. It's such a warm, fun play with so much spunk to it." (Laura Anfang, sophomore)

02 Isabelle finds herself having to deal with her pushy, but loving grandmother who is always trying to find her a good husband.

03 "I really enjoy my character because it has given me a chance to wear an 80 's argyle sweater. I have really enjoyed this show; I really enjoy putting smiles on people's face and hearing people laugh."

(Jordan Hickling, freshman)

04 "I've really enjoyed making Sam someone the audience can love. I wanted to show them that even though Sam may only look like your average Joe off the street, he still has a lot to offer." (Nathan Terra, sophomore) 


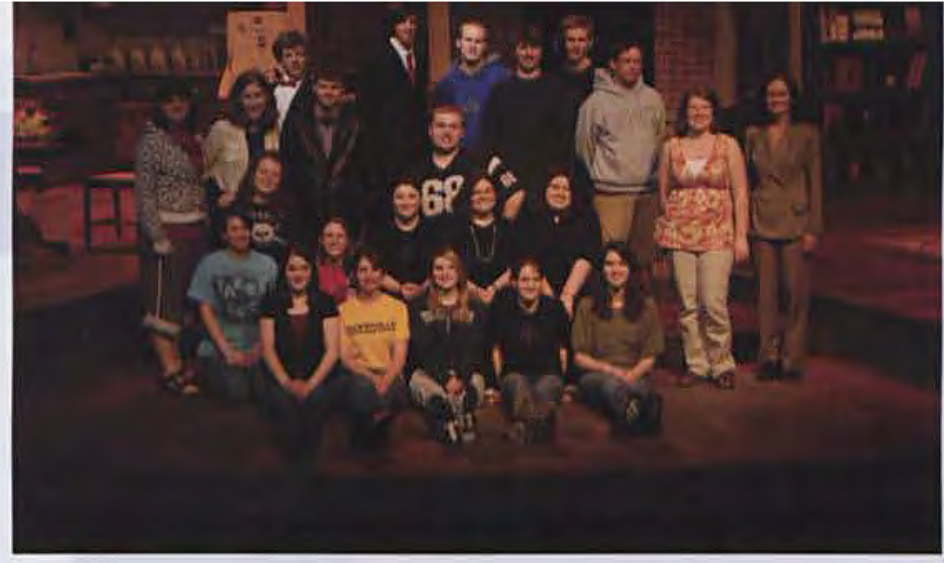

"I have a wonderful cast and crew. We have bonded and put together a fantastic production!"

(Mischelle McIntosh, Director)
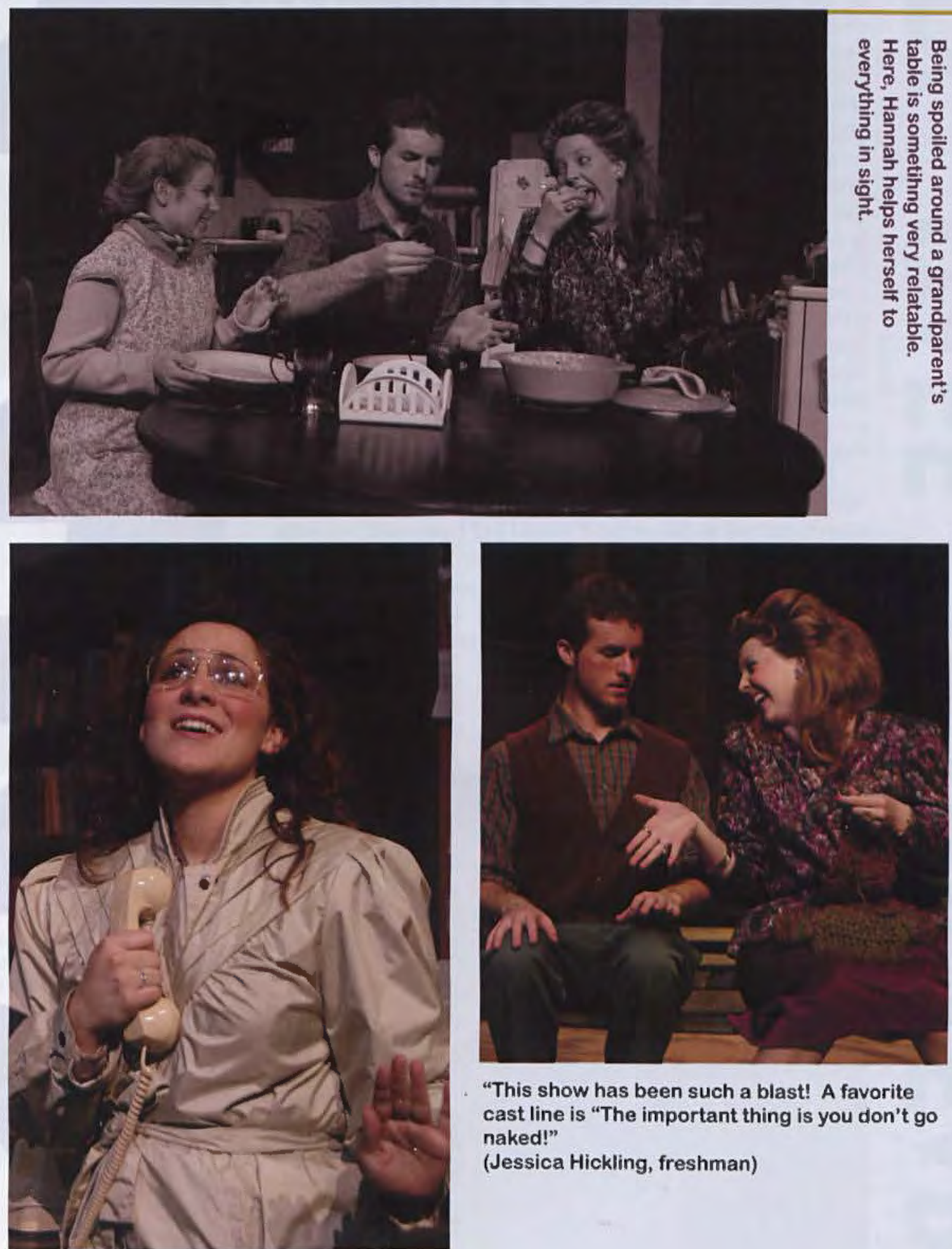

"This show has been such a blast! A favorite cast line is "The important thing is you don't go naked!"

(Jessica Hickling, freshman)

"I have to admit creating Izzy was a little frustrating because she seems so shallow at times, but once the show came together it was totally worth it. I think by far this show has been my favorite on-stage experience as the audiences have loved it."

(Kasey Rising, senior) 
In his eleven years at Cedarville University, Dr. Jeff Cook has been an active member of the Cedarville family, serving on committees, devoting several weekends a semester to poverty and refugee experiences for his students, and acting as Faculty Advisor for the organization Amplified. Dr. Cook's passion for students, urban ministry, and missions is evident in all that he does: the "Introduction to Urban Ministries" and "Contemporary World Missions" courses continually receive rave reviews.

Outside of the Cedarville campus, Dr. Cook is a former elder at Apex Community Church and still serves on the worship team and is highly involved with the leadership of the church. Additionally, he is the co-pastor of a church in Kansas City, Missouri, an inner-city church he helped to plant when he taught at a seminary in Kansas City.

"I have never had a professor who cares more about his students than Dr. Cook. He is truly passionate about both urban ministry and the students he teaches. No one has challenged my thinking and invested in me more than Dr. Cook has over the past three years. God is clearly working through him." (Tim Voltz, junior) Other students echo these sentiments. "Through his classes, Dr. Cook introduced me to a Jesus of the Bible I had overlooked before. God used his classes to challenge my thinking, transform my heart, and develop passion for life and ministry." (Kelsey Nelson, senior) Dr. Cook's contribution to the university is immeasurable, and it is clear that he is extremely deserving of the Faculty of the Year award.

"Students are a profound gift of God to me in my life. Words fail me to describe the joy I get from walking with them for a while during these strategic and formative years of their lives. My constant prayer is that God will mold them into men and women of God whose lives count for something that is bigger than they are." (Papa C.)

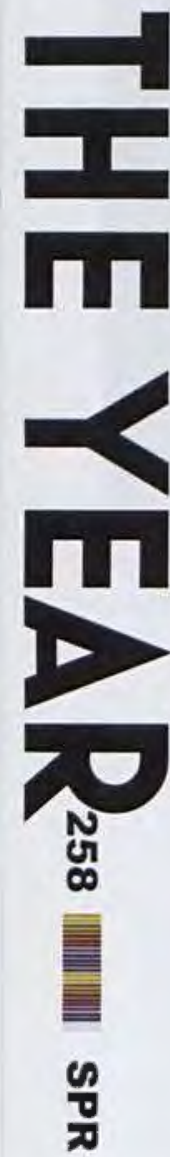

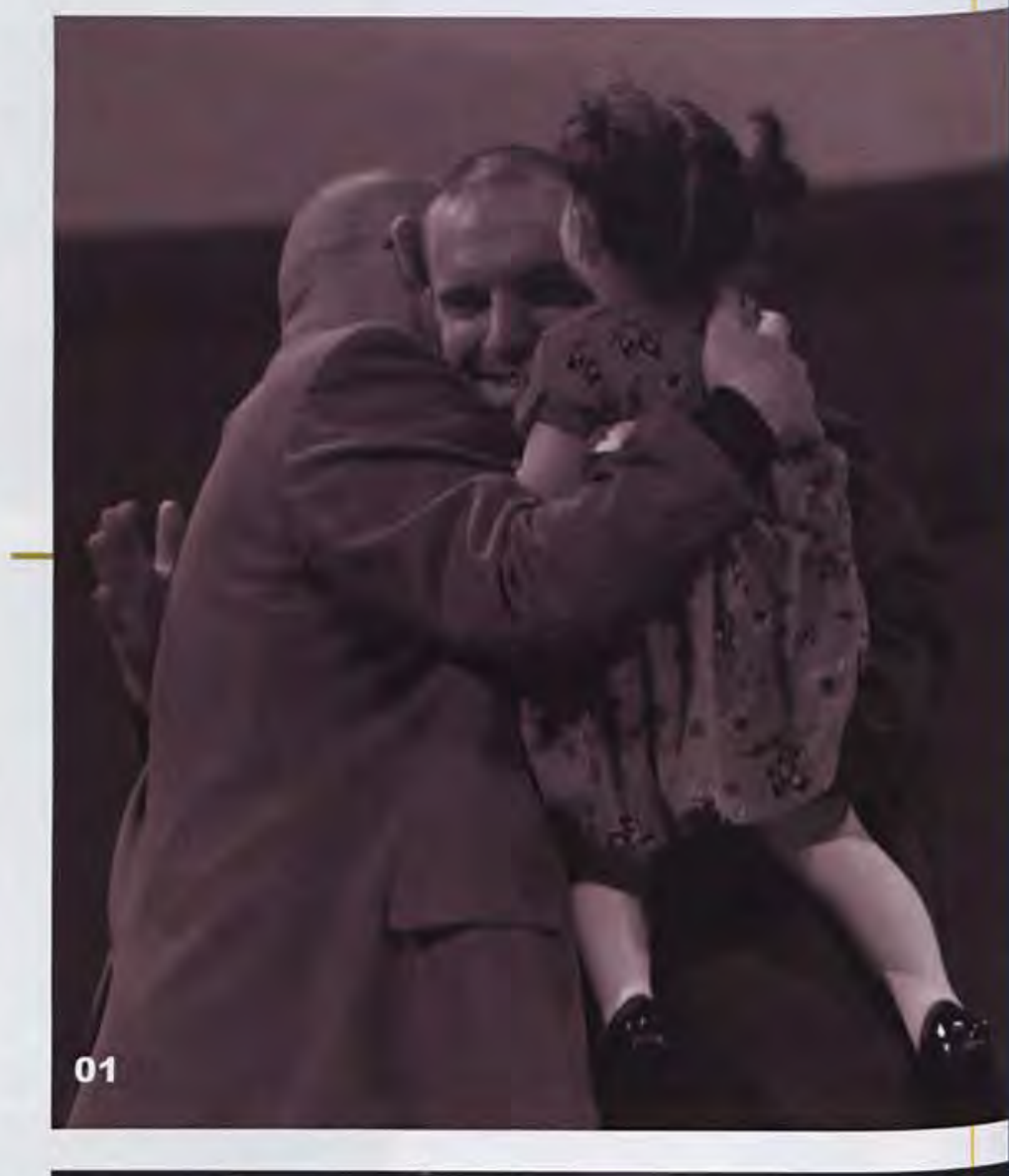

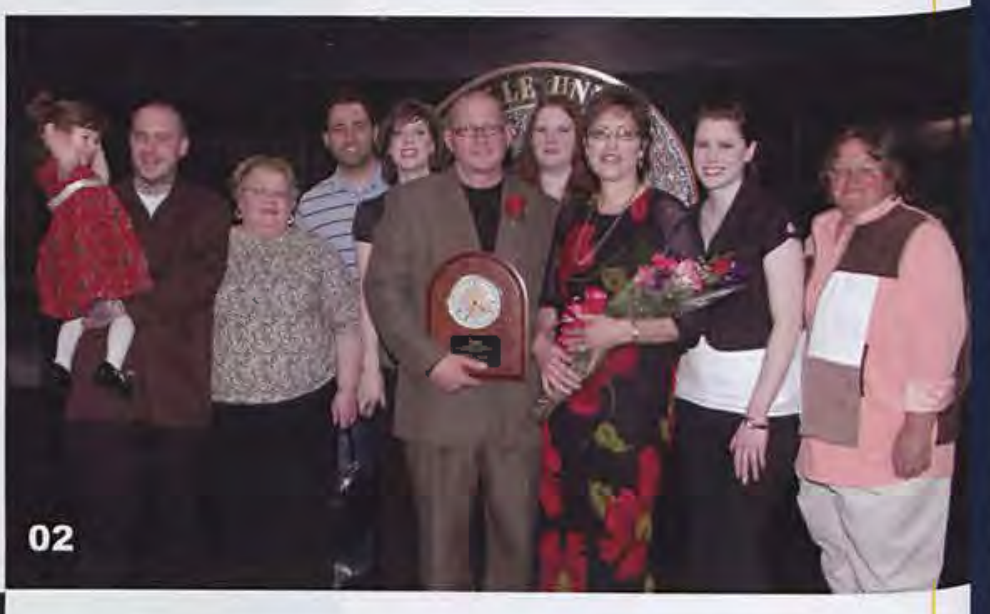

01 Dr. Cook enjoys having his son and granddaughter with him as he receives his award.

02 Dr. Cook shares his award day with his wife, Inge, son Joshua and granddaughter Audrey, daughters Emily, $\mathrm{Abi}$, and Natalie, and sisters Denise and Casey.

03 "I love Dr. Cook! He challenges us to learn by showing us the things that break the heart of God. He is man who lives out what he believes and is dedicated to pursing Christ and bringing others alone in that journey." (Becky Gregg, sophomore student) 


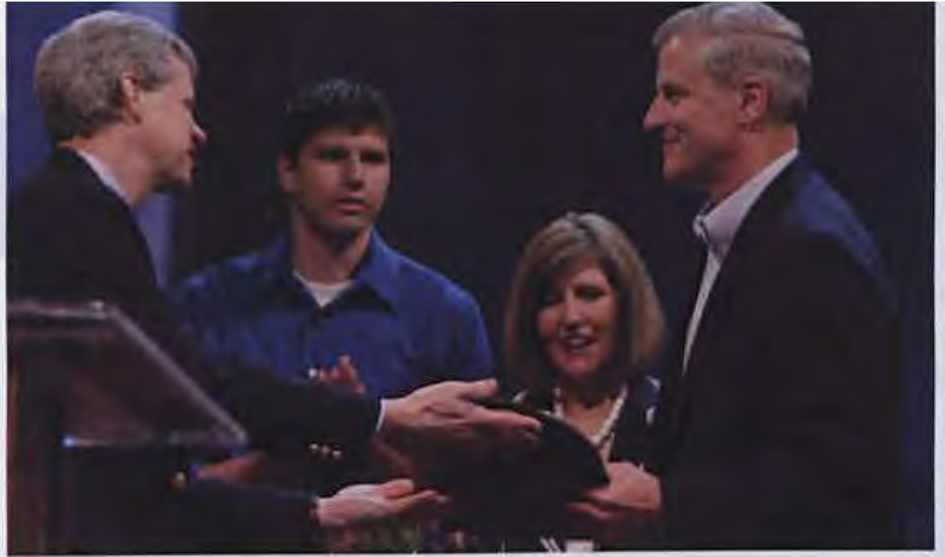

"My uncle is one of the most disciplined and hard-working people I know. He has always helped me without hesitation when I have a question about classes or anything. He also is a great teacher." (Ken Reep, sophomore student and nephew)

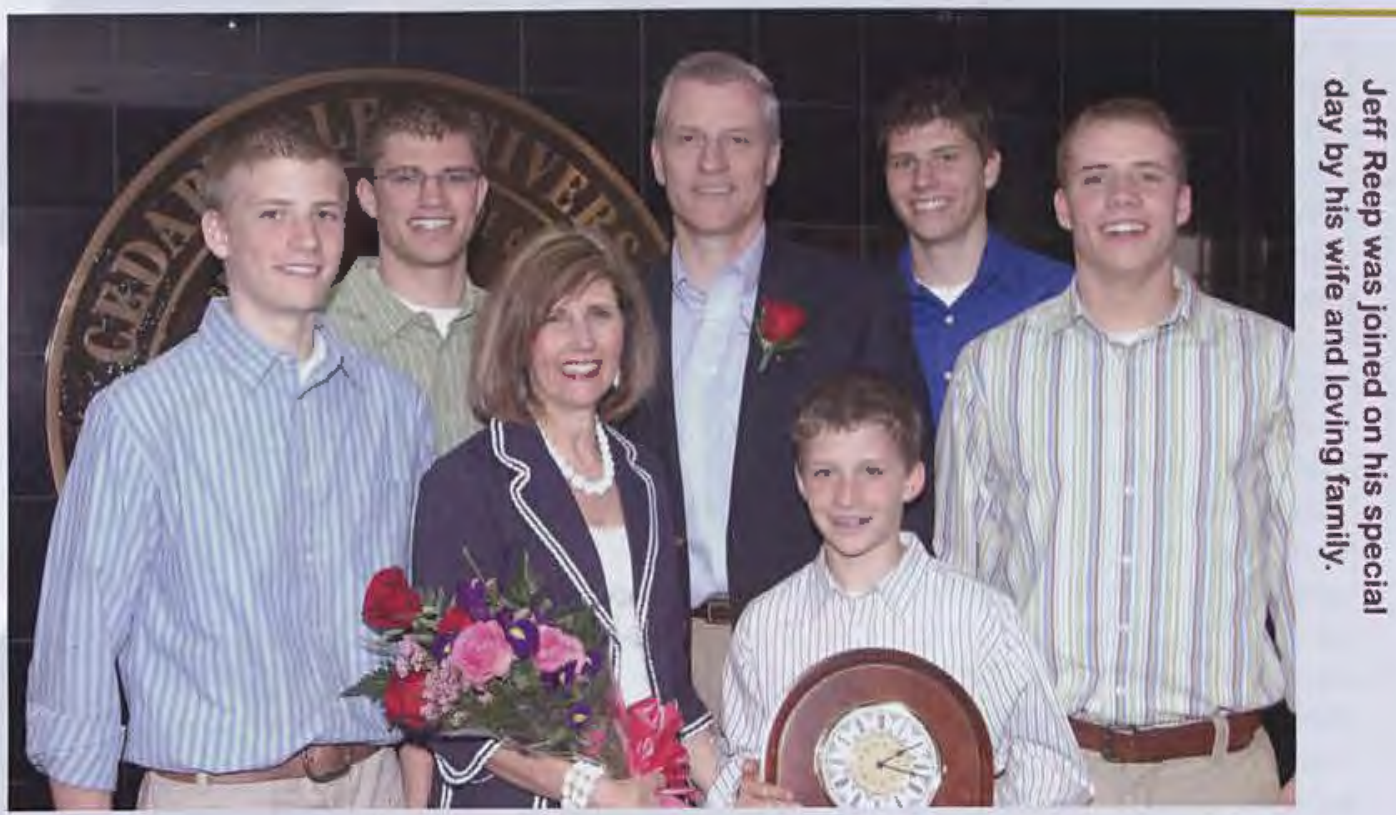

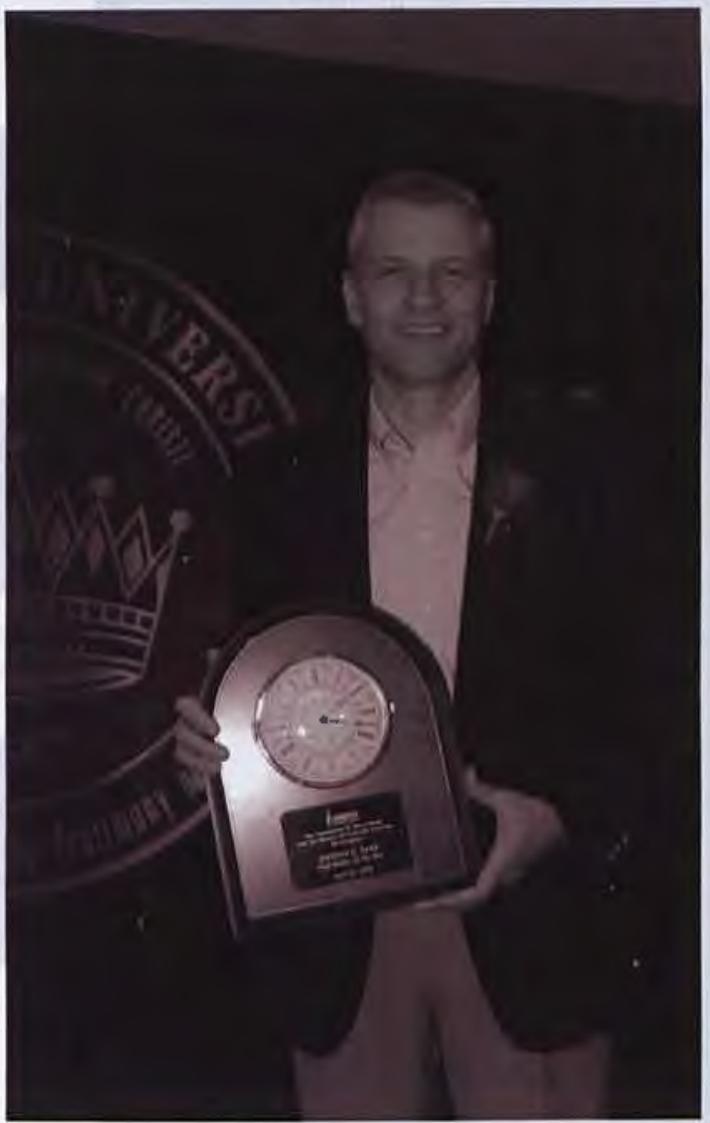

"I'm extremely thankful for the privilege of getting up every morning to work with people I admire and respect, and for the opportunity to have an influence for the Lord in the lives of some of the best young people in our country." (Jeff Reep)
This year's Staff of the Year award was given to Jeffery Reep. Mr. Reep currently works in Career Services as Associate Director where he networks with alumni and helps current students with a variety of issues - from selecting a major to crafting a resume. Jeff is known on campus for his mass e-mails making students aware of various internship and job opportunities. Mr. Reep's peers comment that he is willing to participate in extras and take on responsibility.

As well as working in Career Services, Jeff Reep teaches a number of first aid and physical education classes. Students say that he is willing to do anything for them.

Previously Mr. Reep coached the men's basketball team and continues to be an avid Yellow Jacket supporter. Students and peers alike describe him as easy to get along with and easy to relate and talk with.

"It is a great honor to be selected for this award in light of the many other deserving staff who serve the Lord faithfully day after day. It is especially rewarding to be recognized by our students with whom I strive to effectively serve throughout the year." (Jeff Reep) 
An allusion to last year's SGA chapel began this year's Senior Chapel, with seniors Wade McComas and Michael Strawser giving highlights from the last few years, such as the incredible "Black Savvy" event and the Walden cabin that was, according to both, unfortunately torn down. The seniors' class verse was Micah 5:2, and senior class chaplain Nathan Lane explained the decision for the verse, saying, "When we have experienced both tragedy and joy, I believe our only response should be humility towards God."

James McClenahan and Kristie Febo brought up highlights such as the ERAP program, now affectionately acronymed Everyone Receives A Proposal. James Mcclenahan was also light-hearted, saying, "Thanks to things like the Walden Cabin, Dr. Spencer, chucks weekend plea, and Marilyn Ware's poetry, Cedarville will always be Cedarville."

"Overall, I loved the focus on the class of 2008 , and I think my favorite part was how the music progressed with where our class has been. When Gabe started playing 'There is No One Like You,' it took us all back to freshman year class chapels, and I loved being able to finish on the same note." (Jacinda Gillette, senior)

The senior band included Gabe Coyle, Ben Summers, Adam Hundley on guitar, Stephen Sylvester on bass, Lukas Seelye on the keyboard, female vocalist Liz Korkosz, Micah Martin on auxillary, Kate Talbott on violin, and Nate Lane on drums.

Dr. Brown sent a special message via a video broadcast, commenting that the class of 2008 will be the "last class ever not to set foot in the Center for Biblical and Theological Studies." Dr. Brown exhorted the class to be accountable to others to maintain a close walk with God, to give back to Cedarville, and to let Cedarville know how it can improve in the years to come.
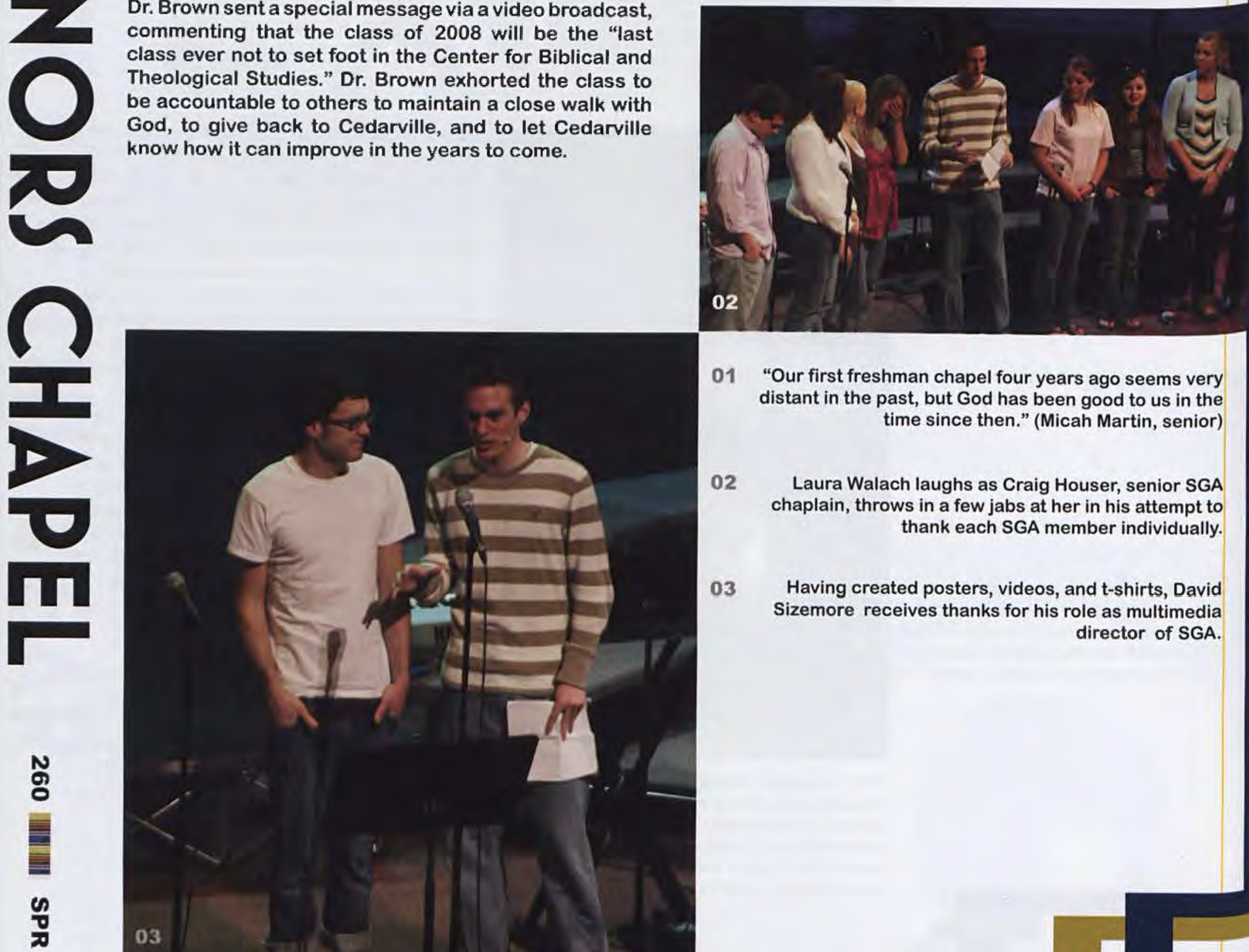

01 "Our first freshman chapel four years ago seems very distant in the past, but God has been good to us in the time since then." (Micah Martin, senior)

Laura Walach laughs as Craig Houser, senior SGA chaplain, throws in a few jabs at her in his attempt to thank each SGA member individually.

Having created posters, videos, and t-shirts, David Sizemore receives thanks for his role as multimedia director of SGA. 
Bert Wheeler, interim chair of the Business Administration Department, shakes hands with one of the recipients of an Honors' Day award.
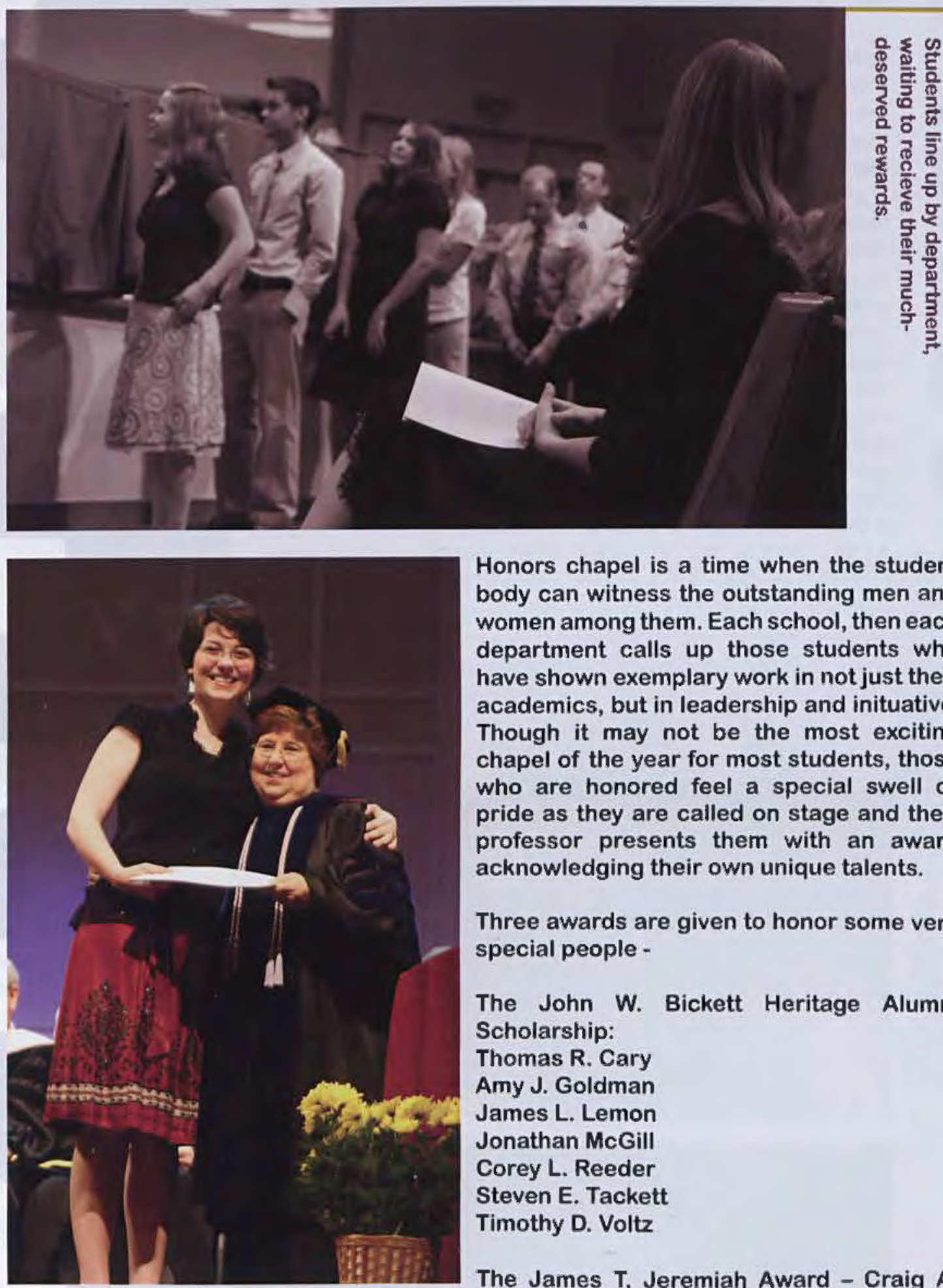

Honors chapel is a time when the student body can witness the outstanding men and women among them. Each school, then each department calls up those students who have shown exemplary work in not just their academics, but in leadership and inituative. Though it may not be the most exciting chapel of the year for most students, those who are honored feel a special swell of pride as they are called on stage and their professor presents them with an award acknowledging their own unique talents.

Three awards are given to honor some very special people -

The John W. Bickett Heritage Alumni Scholarship:

Thomas R. Cary

Amy J. Goldman

James L. Lemon

Jonathan McGill

Corey L. Reeder

Steven E. Tackett

Timothy D. Voltz

The James T. Jeremiah Award - Craig A.

Nursing majors love Jan Conway, chair of the department, which is why Jen Davis gives her a huge hug while receiving an award.

Houser

Anderson Brown 
The candles shimmered, the jazz orchestra played, and the Manor House opened its doors to welcome students to the Junior Senior banquet of 2008. Dripping in elegance, the Manor House in Mason, Ohio provided one of the classiest environments JS goers have seen. Between the verdant gardens, the sparkling chandeliers, the delicious food, and the rich desserts, JS provided a spectacular evening for seniors.

First, guests arrived and strolled through the immaculate gardens snapping pictures of friends and admiring the spring atmosphere. Visitors were then led into the Georgian Ballroom where dinner was served, and Mike Domeny entertained with a comical, yet sobering, after dinner speech. Following dinner, the doors glided open to present an extravagant array of dessert and coffee. Attendees sat around umbrella tables in the Manor Ballroom, lounged in the Atrium, and soaked up the southern feel of the Manor House. "JS was so fun this year," said senior Dan Parrott, "I went without any expectations and was blown away by the Manor House. It was the perfect setting for a laid back evening to just hang out, eat great food, and take lots of pictures." Others shared Dan's sentiments. "JS facilitated a beautiful evening to relax with friends before we part ways after graduation." (Stacey Reeder, senior).

This year, the JS Committee focused on making the night special for soon-to-be graduates. "From the beginning of the planning process, our goal was to plan an event that honored the seniors," explains Sarah Matney, chair of the JS Committee. "I'm confident that we accomplished our goal. The Manor House is the most gorgeous venue I have ever seen. It has an air of Southern affluence about it that transports me back to Gone with the Wind."

At the end of the evening, attendees lingered in the gardens to take a few last pictures and headed home with a centerpiece in hand. The theme of the night resounded in everyone's mind. As said by C.S. Lewis, "Friendship is born at that moment when one person says to another, 'What? You too? I thought I was the only one."

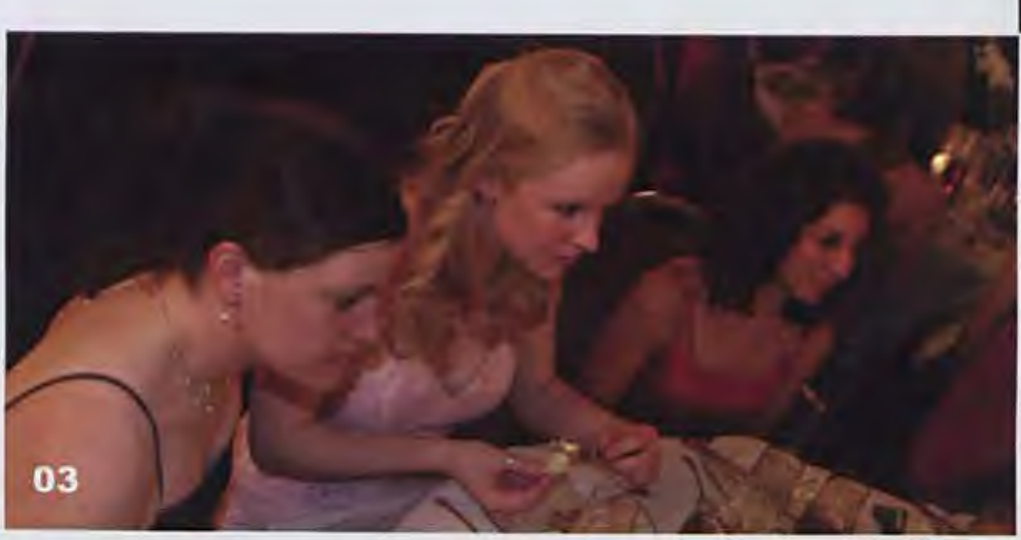

02

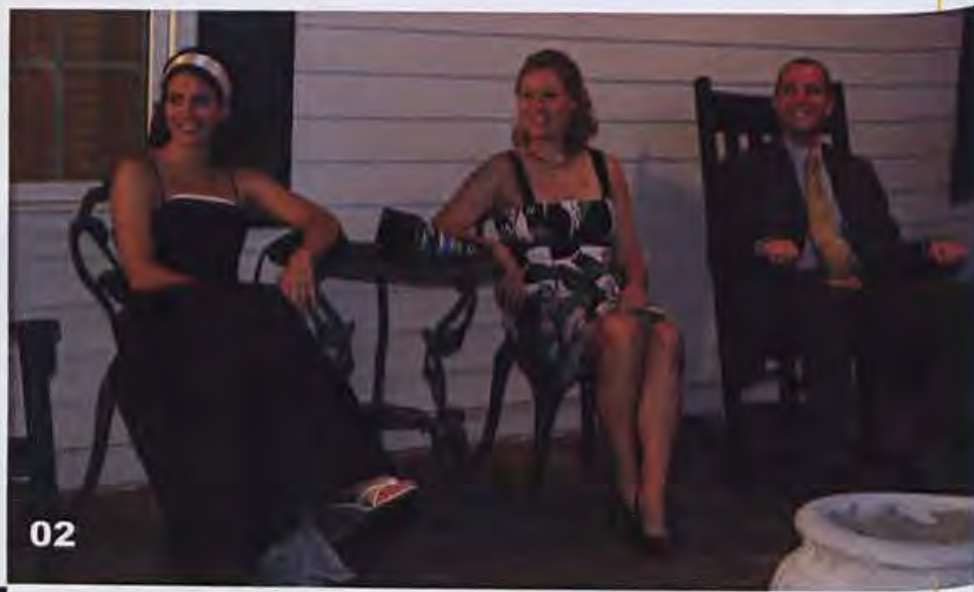

Two girls peruse their pictures from the night as they sit on the butterfly chair in the garden.

Mark Becknell, in his rocking chair, and his lady friends spend some time on the veranda.

All the attendees enjoyed the luscious food that was served, including chicken and potatoes.

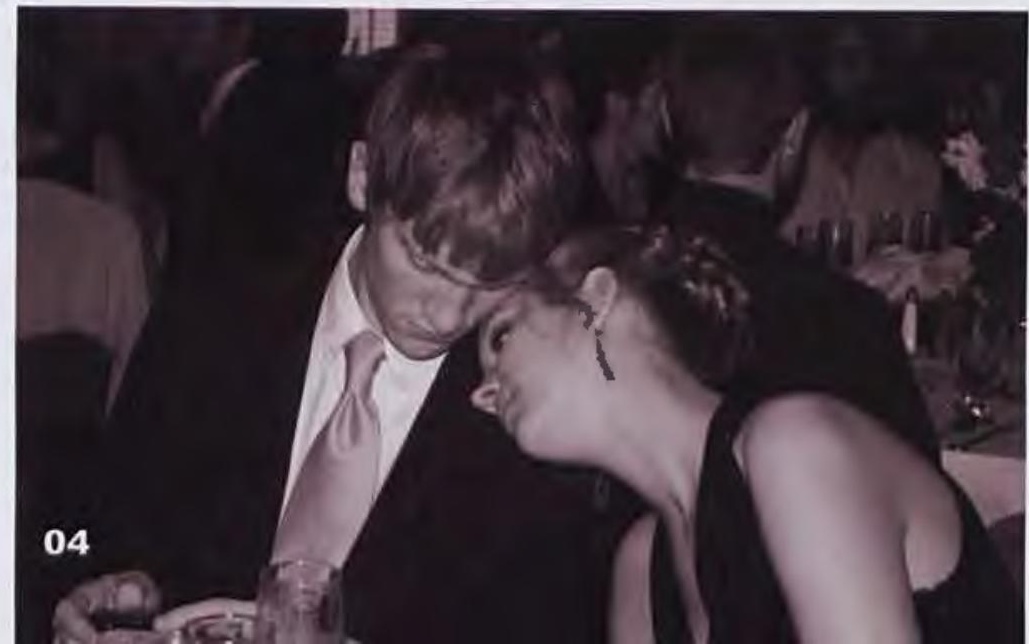




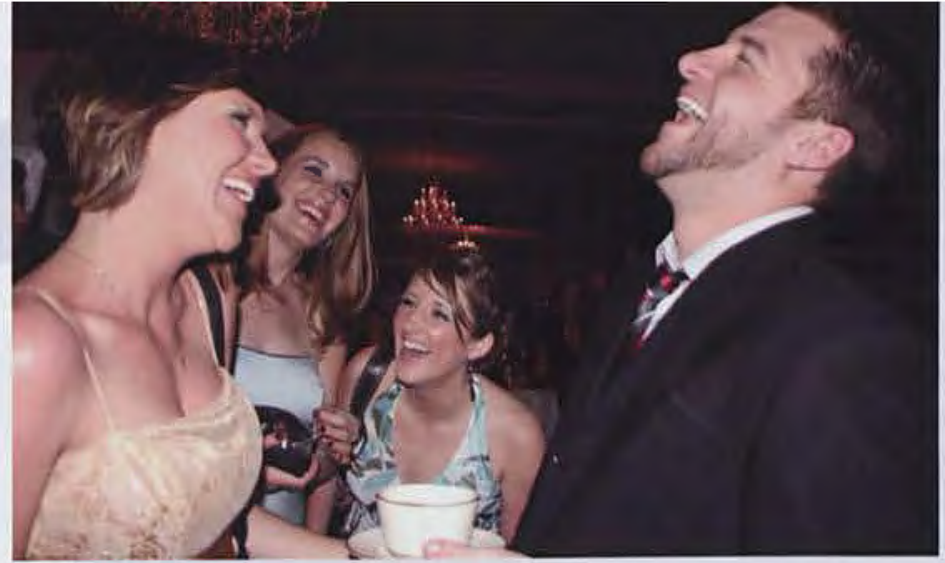

Michael Strawser laughs boisterously at the hilarious joke Nicole Rose just told.
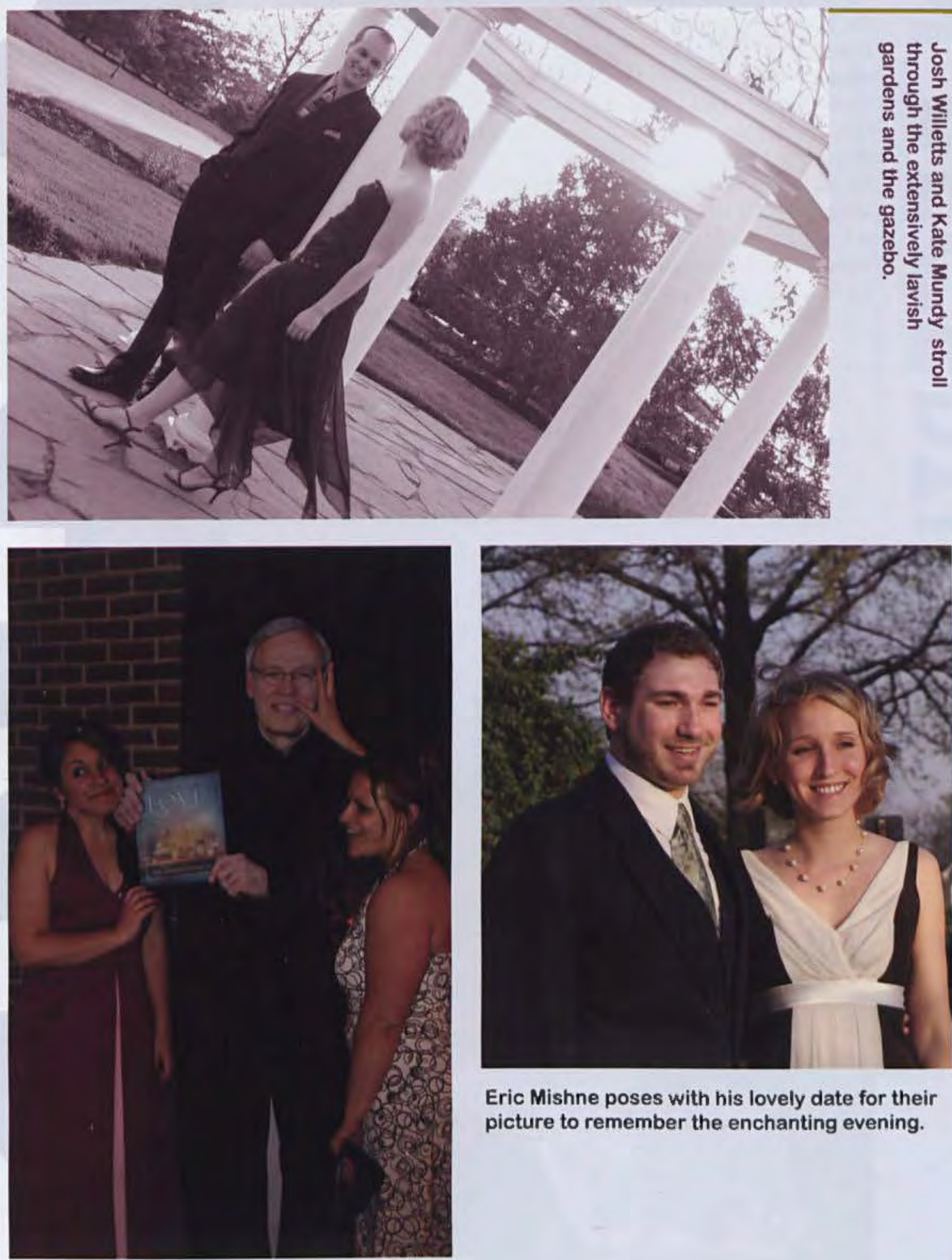

Eric Mishne poses with his lovely date for their picture to remember the enchanting evening.

Large cutouts of Pastor Rohm and other Cedar celebs stood waiting to have their picture taken. 
On April 23, Dr. Bill and Mrs. Lynne Brown hosted the graduating class of 2008 in their home for a time of food, fun, and fellowship. Over three hundred students attended the fifth reception hosted by the Browns.

The reception gave the seniors an opportunity to have Brown's undivided attention, as well as a chance to see his home, take pictures with the man himself, and enjoy the company of other graduating seniors.

The seniors enjoyed having free reign of Dr. Brown's house: "My favorite part was snooping around - I got to see what magazines the great Dr. Brown reads." (Brandon Doyle, senior) Some of them were able to see Dr. Brown in a new light. "I think I was most surprised by the Dave Barry calendar in Dr. Brown's office--I always enjoy finding a fellow fan."(Anna Cummings, senior) "My favorite part was finding out that Dr. Brown is a Beatles fan. That was also what most surprised me about Dr. Brown's house - stumbling across his collection of Beatles memorabilia." (Whitney Miller, senior)

When asked by Katherine Tuttle why he does not have a hot tub or swimming pool in his back yard, Dr. Brown was quick to assure her that Cedarville University will be investing in a pool in the coming years.
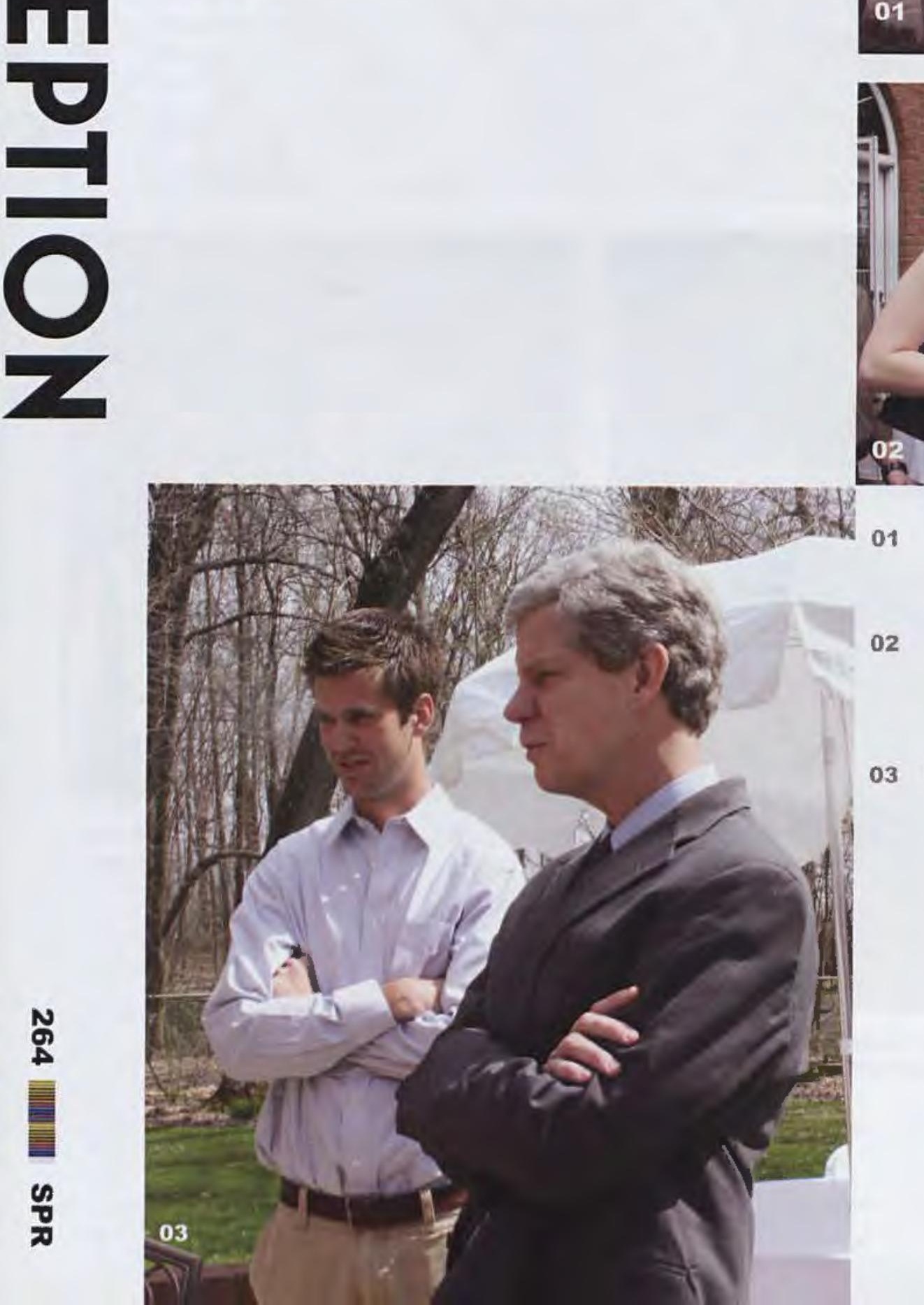

\section{Eva Stark, Kyle Jackson, and Caleb Rettig socialize} together on the Browns' grounds.

Three senior girls are quite excited to be at the reception.

Dr. Brown carries on a deep, intellectual conversation with a senior student... or maybe they're just talking about the backyard. 


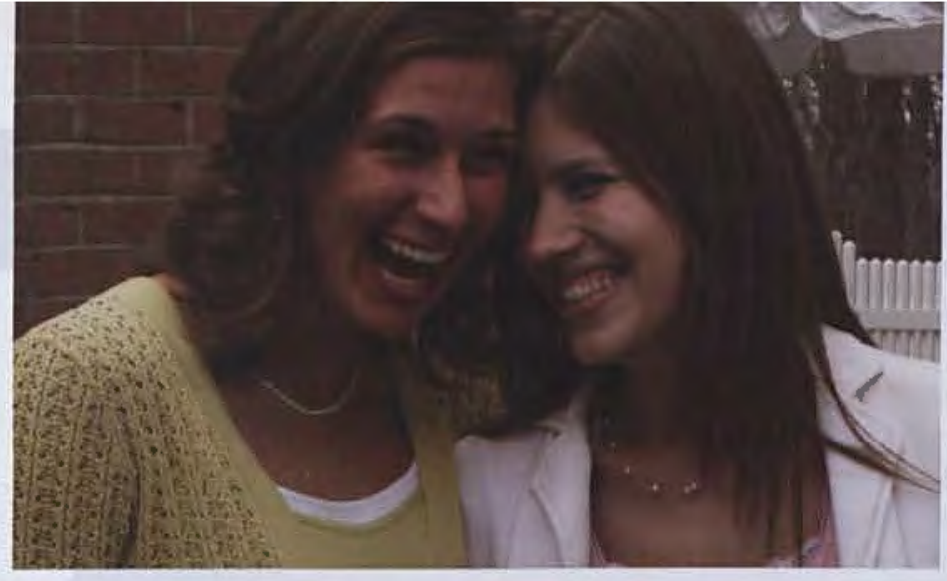

Can life get much better than spending time with friends at the Browns'?
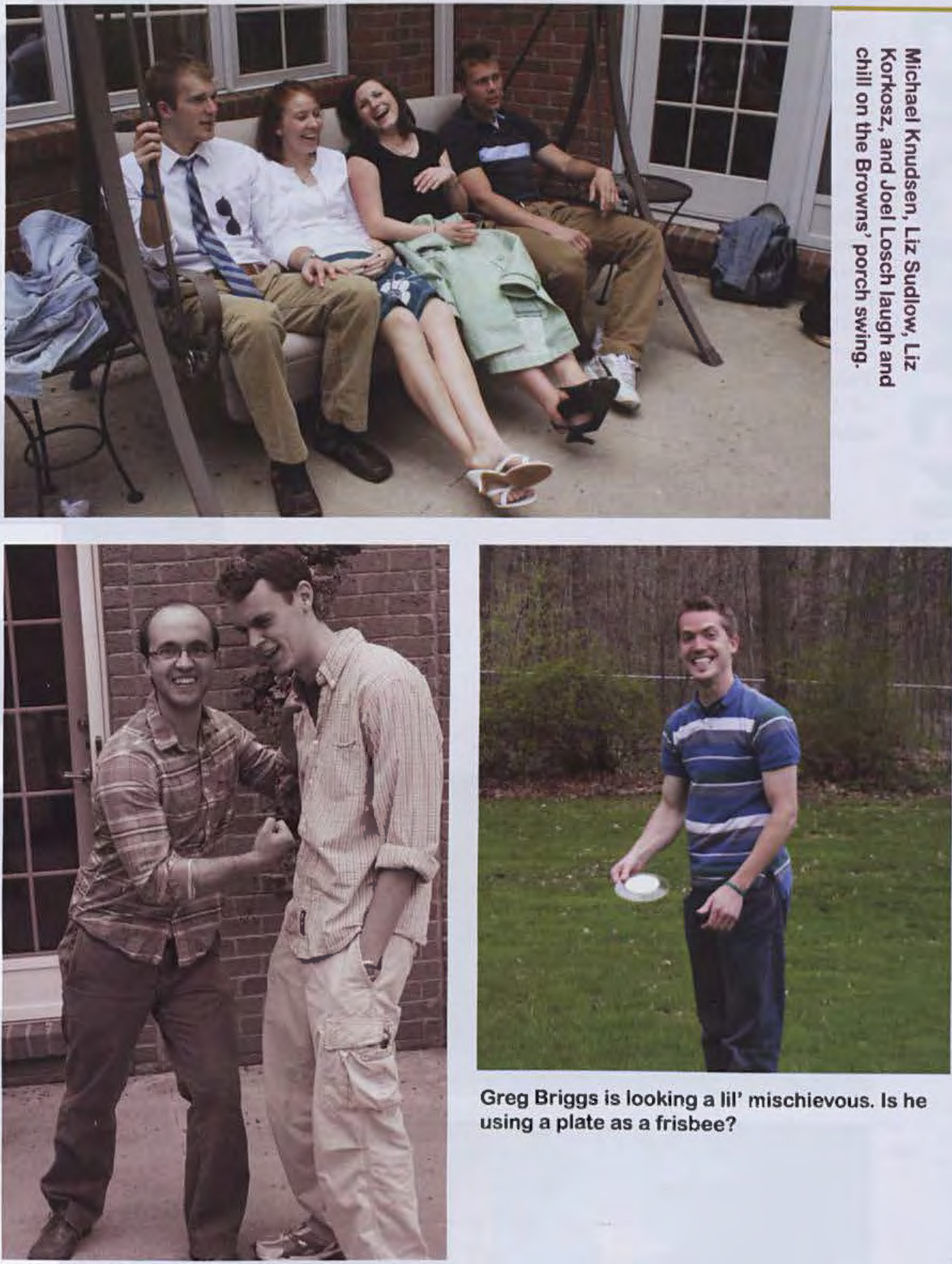

Greg Briggs is looking a lil' mischievous. Is he using a plate as a frisbee?

Dave Elgena takes a sucker punch at Ryan Schiller, all in good fun of course. 
All students enter college knowing that one day the time will come for his or her graduation. Every student works hard to eventually meet this ultimate goal. May 3, 2008 was the long awaited day for 651 students and marked the completion of their graduation requirements. All of these students were able to walk up and receive their diploma, signifying their graduation from Cedarville University.

This year the Commencement speaker was Kay Coles James. She is the former Director of the U.S. Office of Personnel Management and founder of The Gloucester Foundation, which is an organization dedicated to identifying, training, and nurturing African American leaders. James encouraged the University's graduating class, "When you take your robes off today, be prepared to put on your game face." She challenged the class to become students of culture, able to defend positions based on biblical principles. Referencing Ephesians 6:10, James concluded, "Be strong in the Lord and in His mighty power. Put on the full armor of God."

In honor of their fellow classmate Dan Knudsen, the class of 2008 presented the University with a financial donation. This will be used to help remodel a men's residence hall for the benefit of male students with disabilities.

As the ceremony ended, family and friends gathered to congratulate their graduate on his or her achievement. These men and women have ended one time period of their life and are now going on to new and great adventures.

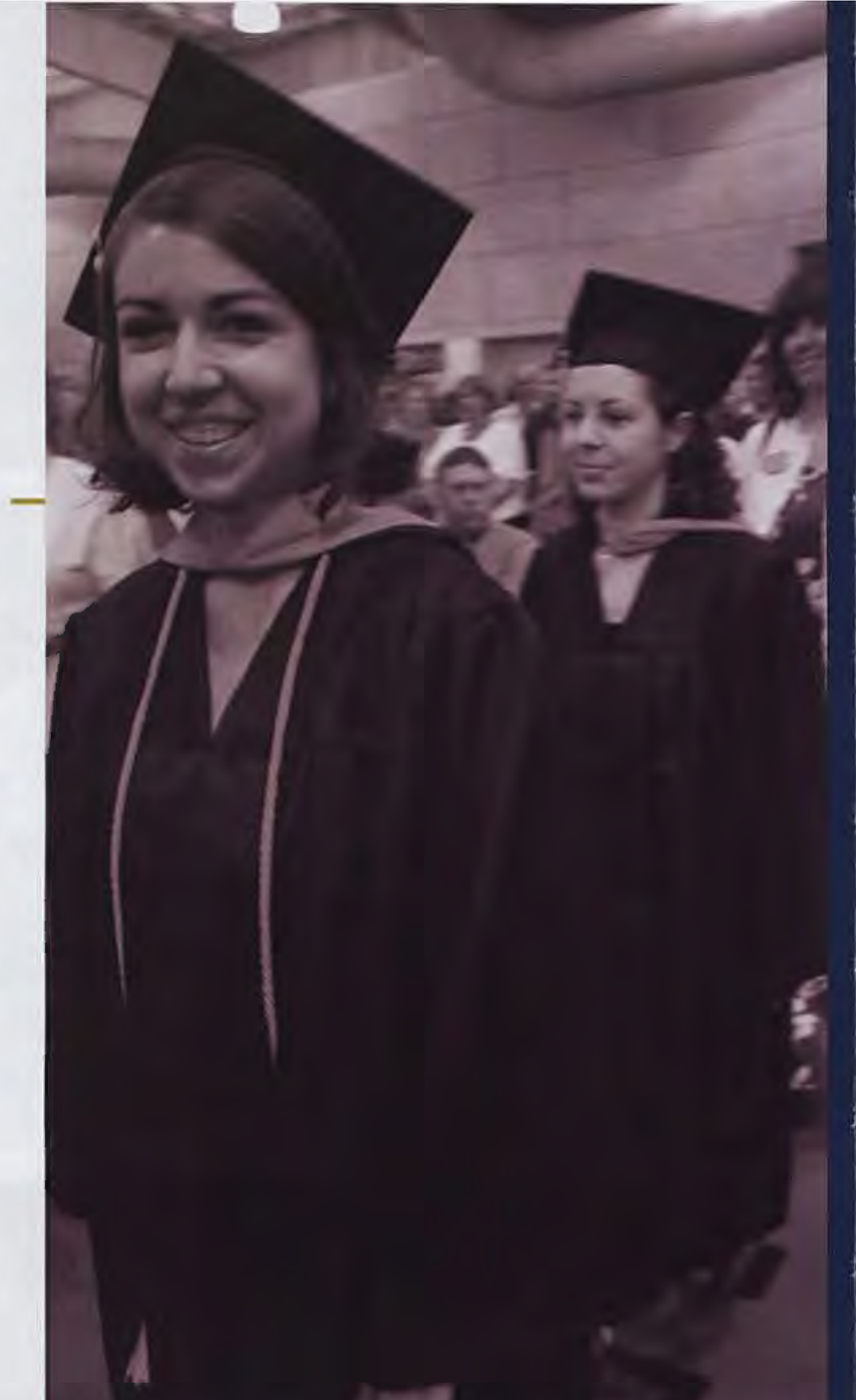

01

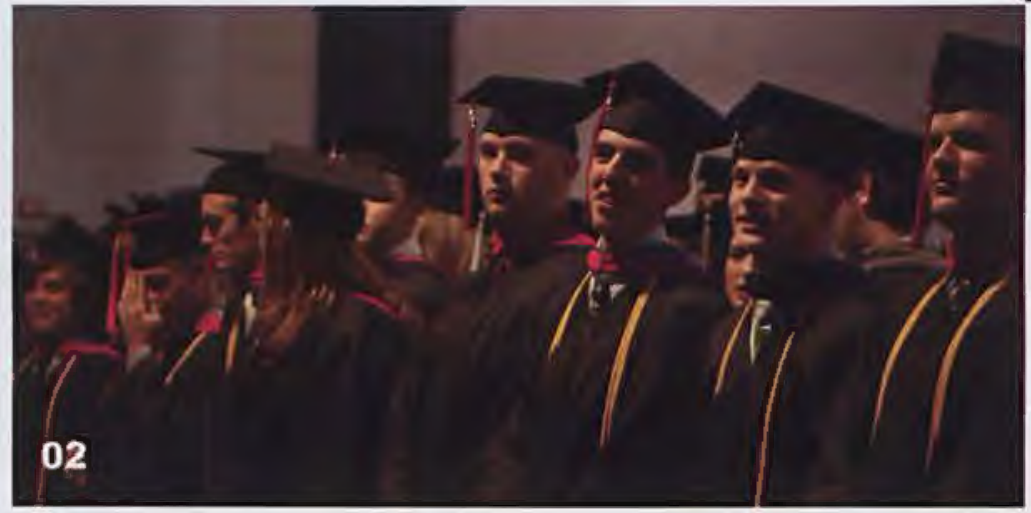

Tarah Wolf shows her excitement as she faces graduation and an upcoming summer wedding.

These graduates from the Bible department are full of excitement and anticipation as they prepare to walk.

Erin Rodgers expresses joy and a feeling of accomplishment after receiving her diploma.

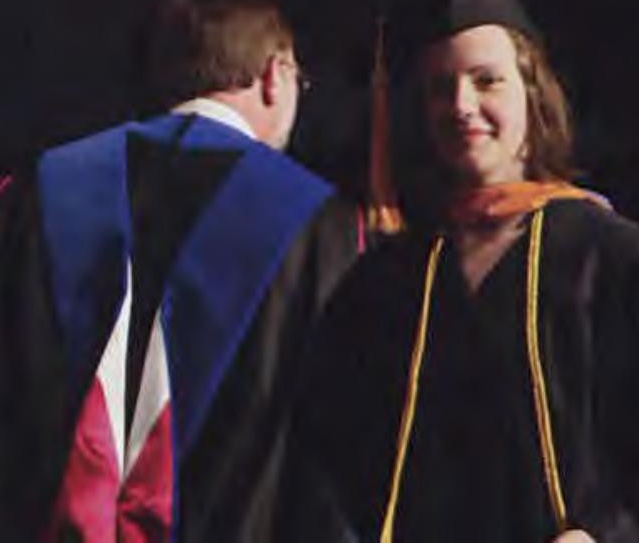




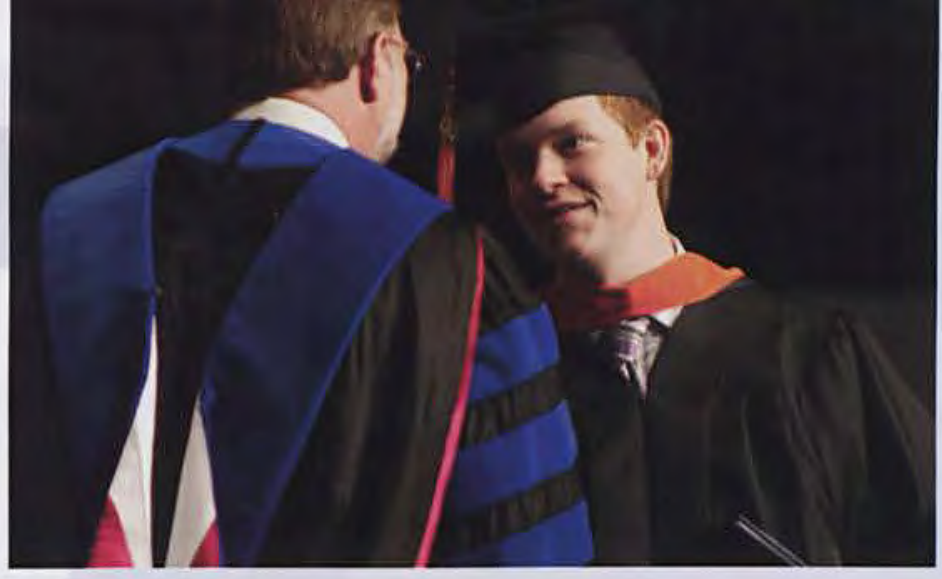

Garrett Williams shakes the hand of his professor, Stan Baczek, on his final day as a student.
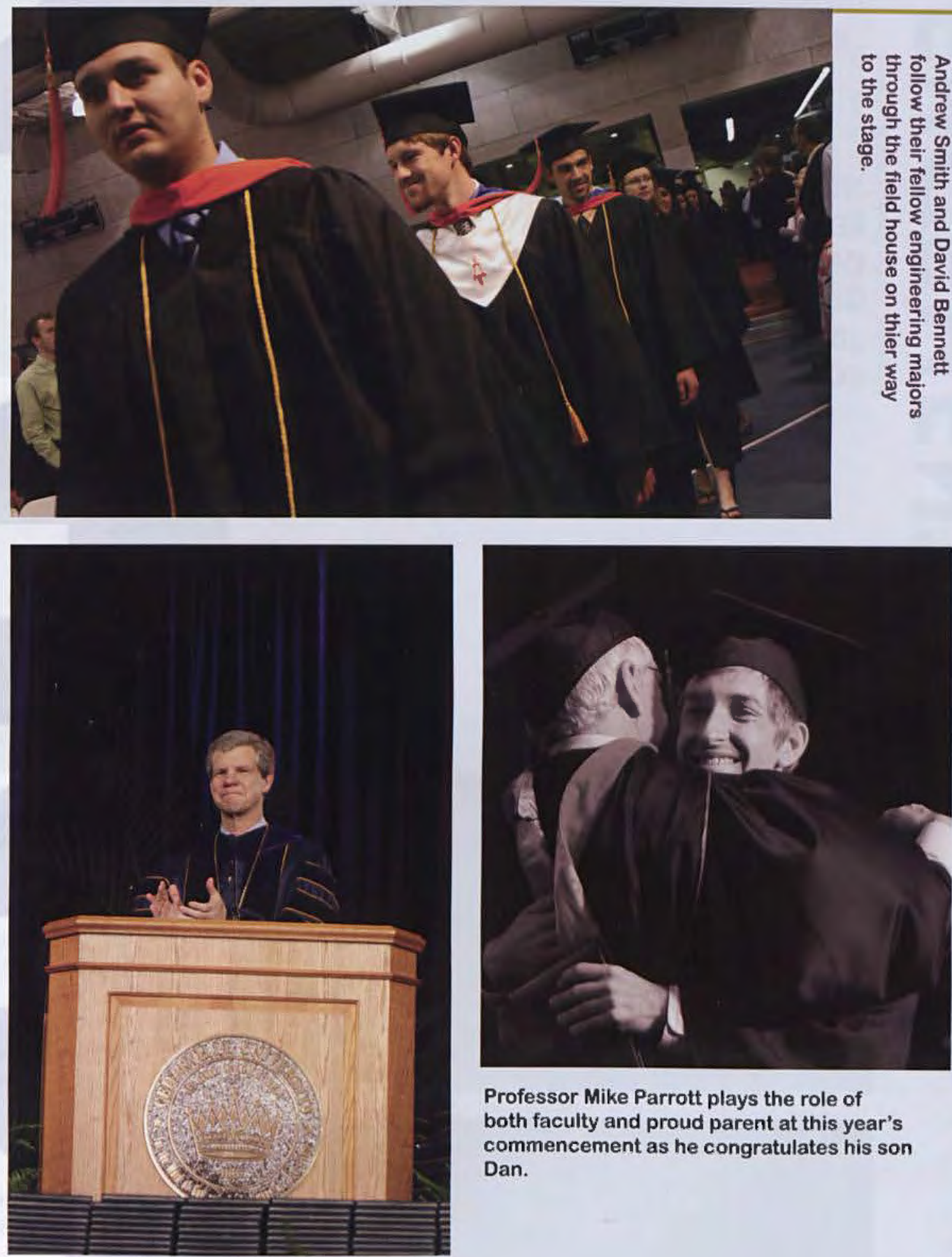

Professor Mike Parrott plays the role of both faculty and proud parent at this year's commencement as he congratulates his son Dan.

Dr. Brown applauds the graduates one final time. 


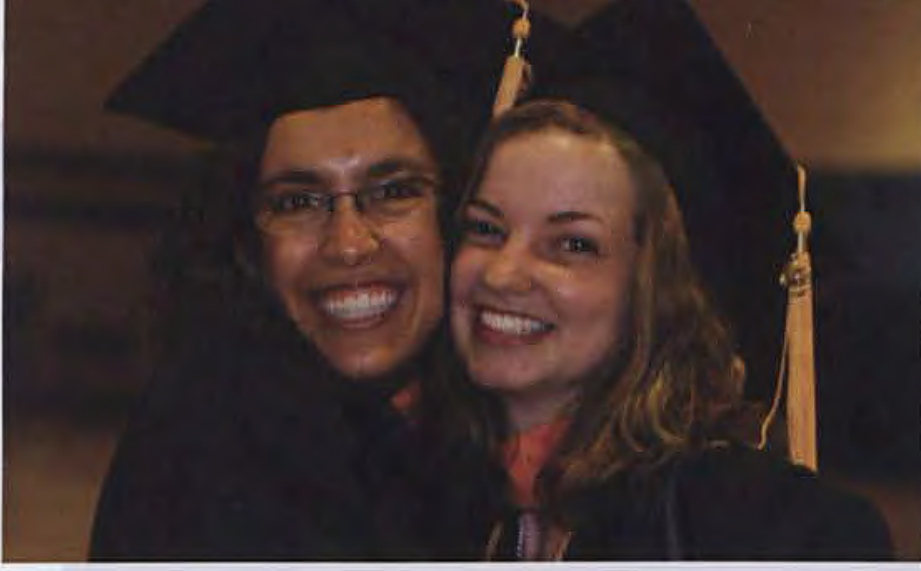

Loren Montes and Alissa Clutcher embrace on their final day as $\mathrm{CU}$ sudents.

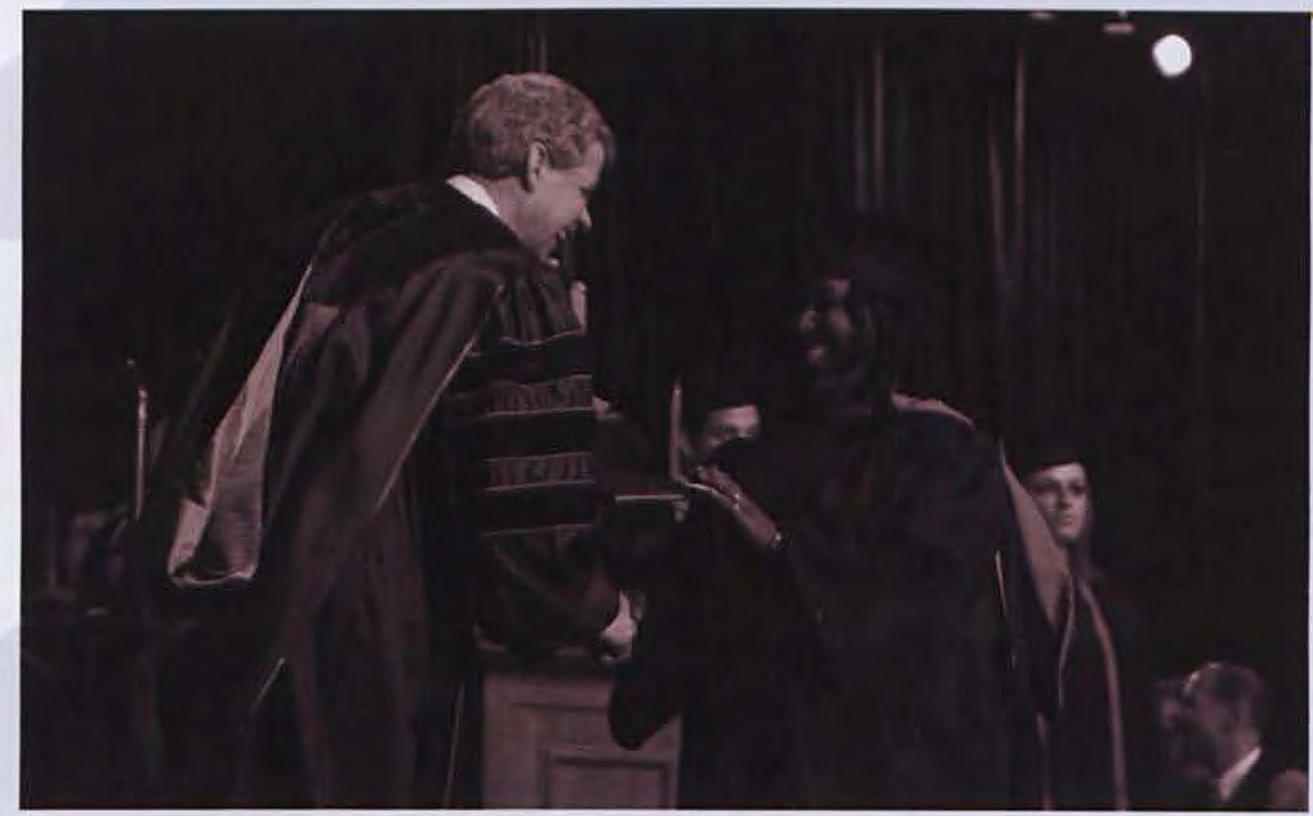

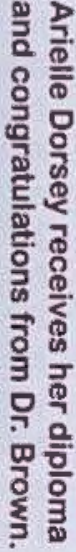
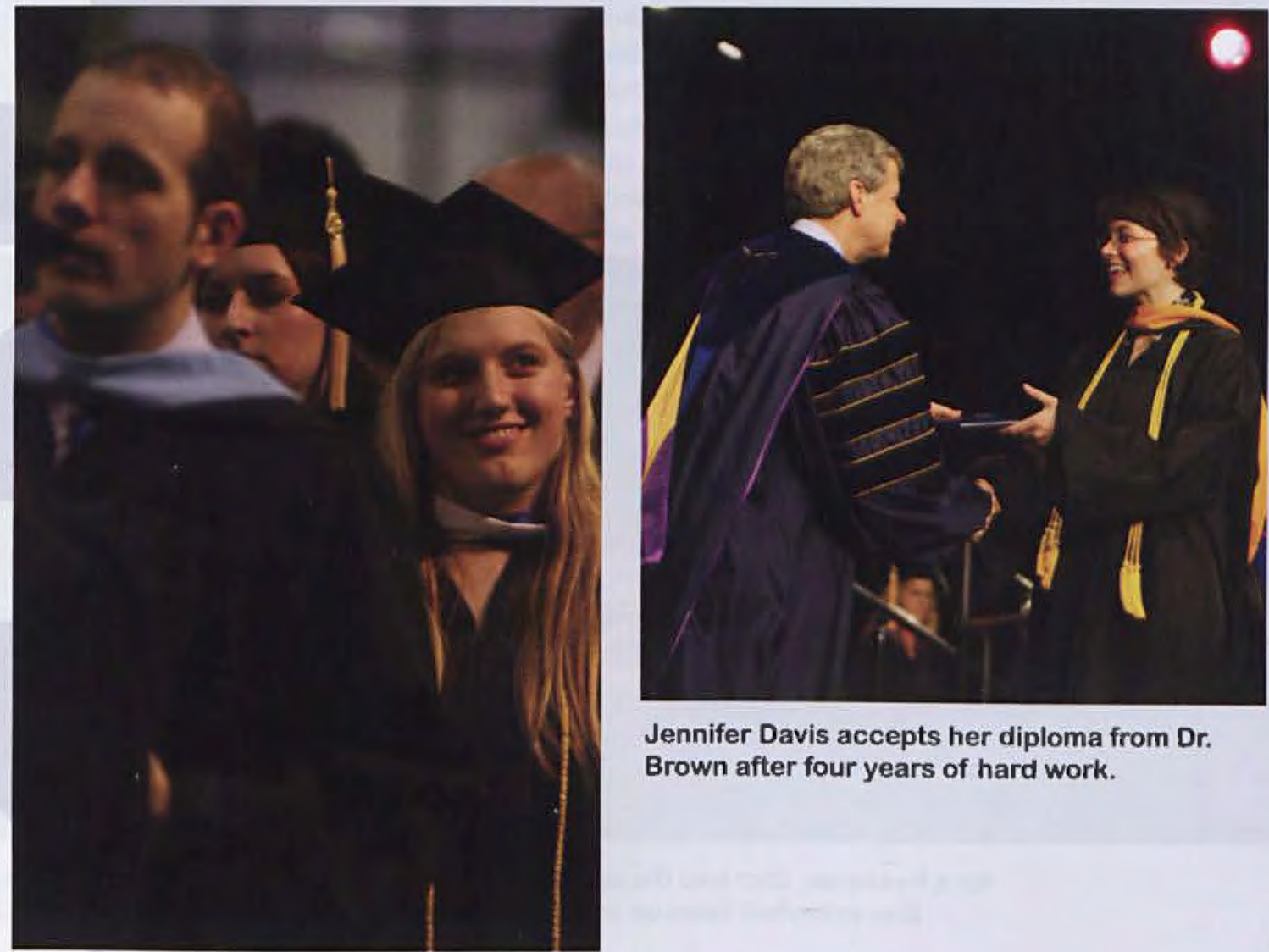

Jennifer Davis accepts her diploma from Dr. Brown after four years of hard work.

Dezirae Kolmertenis is elated to finally be making that walk across CU's stage and into the next stage of life. 
I was sailing through my first year at Cedarville as an Early Childhood Education major and a starter on the NCCAA National Champion volleyball team when I was diagnosed with Acute Lymphoblastic Leukemia (ALL) on March 22, 2006 at the Cleveland Clinic. I had not felt well for several weeks, and it was deduced that I had mono. However, after a trip to Greene Memorial Hospital in Xenia, a blood test showed that my white blood cells had risen very rapidly and that I had to be immediately transported to the Cleveland Clinic.

After several weeks of aggressive chemotherapy, I was in remission. However, in June the leukemia manifested itself again in my spinal fluid. A decision was made by the doctors, my family, and me to prepare for a bone marrow transplant and go through full body chemo and radiation. After a donor search found no matches in the United States, a donor was found that matched in Europe. The transplant took place on Sept. 5, 2006. After nearly two months in the hospital, I was able to be released home.

From the time of my diagnoses to after the transplant, I was hospitalized about half of the year. I battled some of the effects of graft vs. host disease after the transplant, but my body slowly but surely began to accept the donor's stem cells.

I returned to Cedarville in the fall of 2007 and not only completed my freshman year, but finished my sophomore year, as well. I re-joined the volleyball team as a red shirt player. I am truly a miracle of God and a testimony of the faithfulness of God's people through the prayers of the body of Christ from Cedarville and throughout the world. Although I have faced and will face more challenges, my family and I praise Him for bringing me through this one step at a time. A running diary of my story can be found at www.carepages.com under 'praying4cari'.

\section{-CARI GREETHAM}

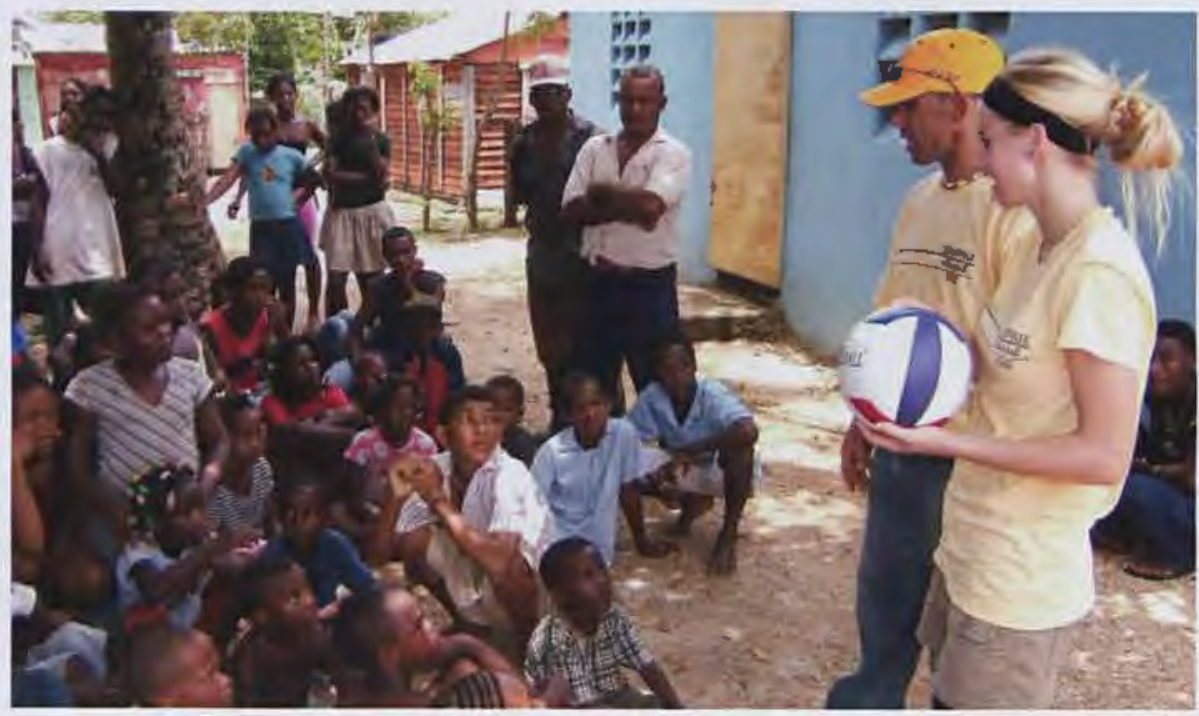

As a freshman, Cari had the opportunity to travel with ther volleyball team on an overseas mission trip.
Cari is an example to all with her smile even after numerous treatments.
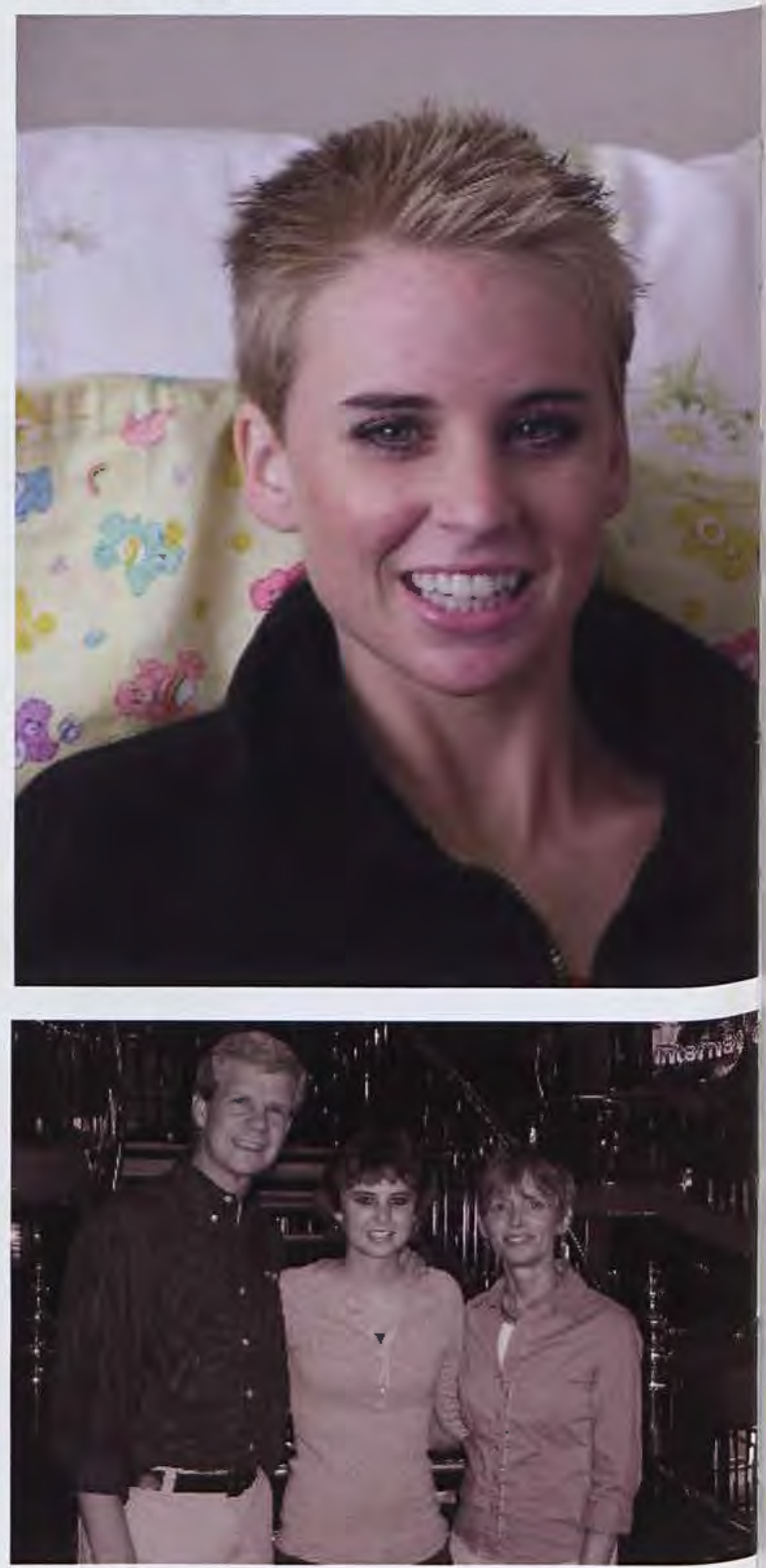

Dr. and Mrs. Brown take some time to visit Cari. 
Believe it or not, the SGA officers make house calls. Here they are shown visiting Dan and witnessing his amazing progress.

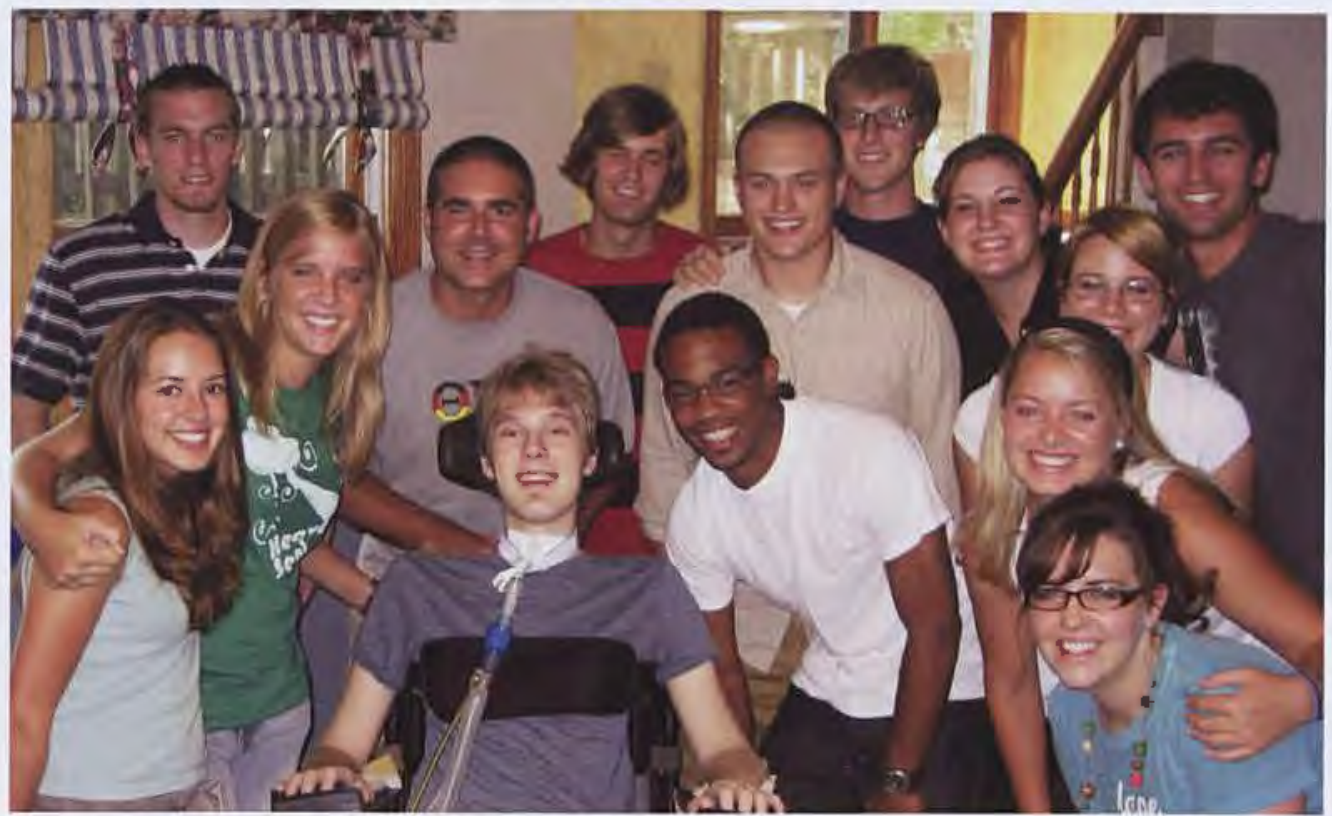

\title{
_DAN KNUDSEN
}

While on a MIS trip to Mexico, Cedarville University student Dan Knudsen suffered a spinal cord injury on March 9th, 2007. This injury has left Dan wheelchair-bound, but regular updates from the family (and even Dan himself) assure us that Dan is doing well and finding ways to adjust to a new lifestyle. Dan continues to encourage his family and friends as well as Cedarville University students, faculty, and staff. Dan's love for the people of Mexico has not changed: Mexico's flag still hangs in his room.

Dan continues to suffer from muscle spasms and soreness. He has been seeing specialists in the field of spinal cord injuries to pursue other avenues of treatment. The Knudsen family is in the process of building a home to best accommodate Dan's needs.

Dan is making plans to return to Cedarville in the fall of 2008. In order to help make this possible, the graduating class of 2008 chose to remodel a men's dorm room to make it handicap accessible. Dan inspired this project, and the room, once finished, will be available to him when he returns. "We wanted to give the university a gift that would change the lives of Dan and the many other male students that will benefit from the room. I love Dan and am looking forward to having him back at Cedarville! I am honored to be a part of getting him back here." (Brittany Donald, senior class president)

\author{
"I'M THRILLED TO HEAR THAT DAN \\ IS ON CAMPUS AND DOING \\ WELL." \\ _BRITTANY DONALD, SENIOR
}


With hundreds of young men housed under the dormitory named in his honor, Hugh B. Carr passed away on November 2,2007 . Carr led the construction work for building the dormitory, but that construction is only one of the numerous acts Carr accomplished while alive.

Hugh graduated from Falconer High School in Falconer, New York, 1930, with an interest in math and science. After graduating and getting married shortly thereafter, Carr grouped several young men together in the community of Gerry, New York to form the first fire department ever to exist in the community. He also was instrumental in starting the Gerry Rodeo, a wild-west show that came to Gerry every summer. The Rodeo is still being shown, with last summer being the 64th annual event.

In the early 1960 s, Hugh accepted the opportunity to lead men in the congregation to rebuild Sinclairville Baptist Church in Sinclairville, New York, after it had caught fire and burned to the ground, sacrificing many weekend and evening hours. In 1968 he and his wife came to Cedarville, Ohio to work at then known as Cedarville College. This lasted eight years, during which he supervised the construction for both Carr and Marshall dorms.

After several years of serving in the Philippine Islands supervising the construction of a mission hospital, Carr and his wife moved to Costa Mesa, California to construct the Christian high school's gymnasium, eventually becoming a member of the maintenance staff. Carr was very generous with his money regarding the kingdom of God, and his grandson David Carr commented during his eulogy that, "It was not uncommon for him to approach a missionary or other servant for the cause of Christ and shake hands with them, slipping a ten or twenty dollar bill into their hands as a love gift." Carr even volunteered his services to install all of the electrical work, plumbing, and heating in the first three-story addition to Grace Baptist Church in Cedarville. Carr dedicated his life to the service of Christ, and he is greatly missed by Cedarville University.

Hugh B. Carr poses with some of his loving family. 01,02

Posing here with an antique wagon, Hugh enjoys 03 some of his favorite hobbies.
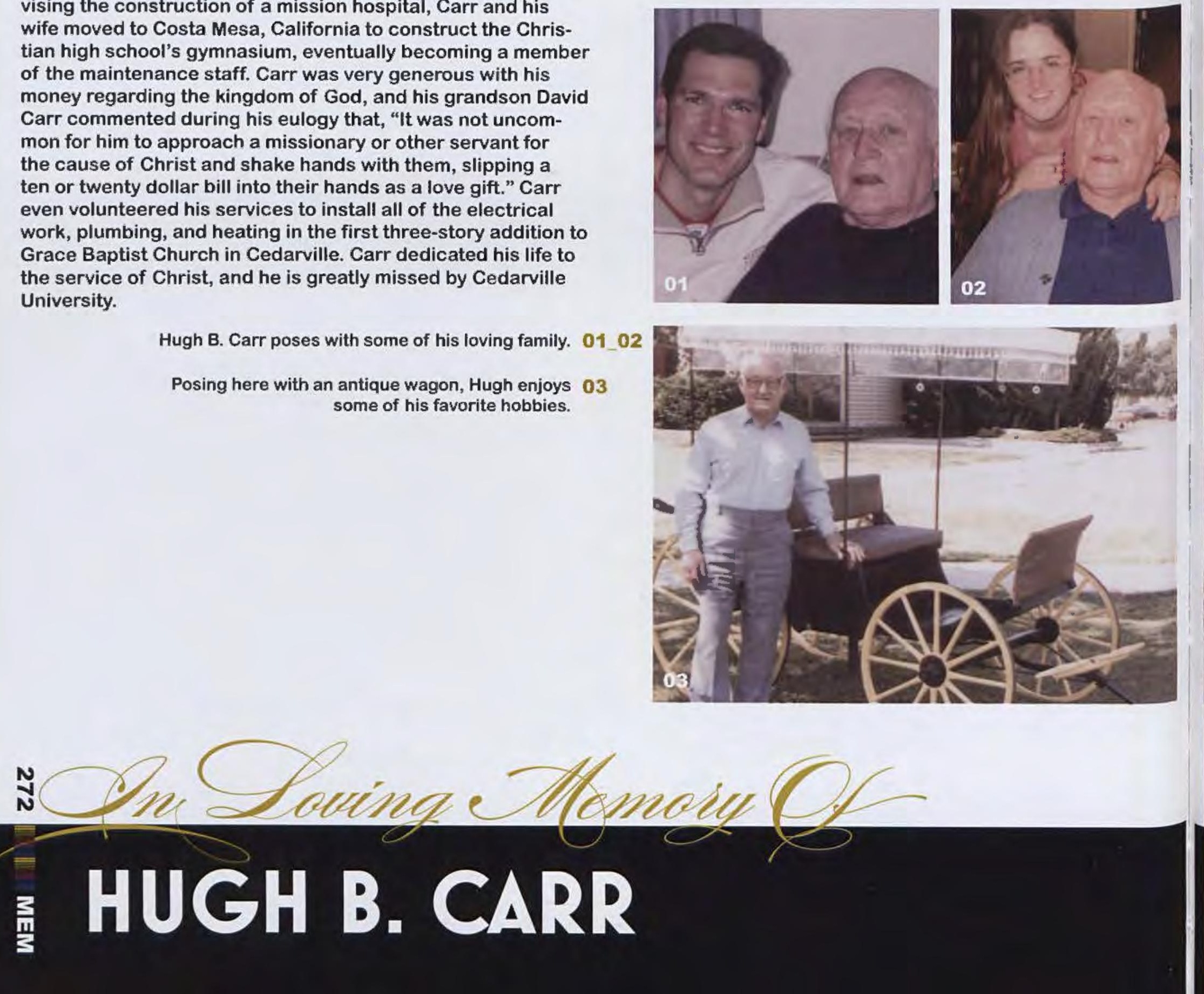
"RON COY WAS A DEAR CHRISTIAN BROTHER WITH A

STEADFAST LOYALTY TO HIS WORK AT THE PATH. HE WAS A MAN WHO COULD ALWAYS BE COUNTED UPON TO JOIN ANY TASK IN SERVICE TO CHRIST. HE GAVE HIS ALL. HE WAS A DEAR FRIEND. HE WILL BE GREATLY MISSED BY ALL OF US WHO CONTINUE AT CEDARVILLE UNIVERSITY."

- MARVIN SPARKS, CDR RADIO NETWORK GENERAL MANAGER

Ronald Coy, Computer Network Supervisor for CDR radio network, passed away on February 8, 2008. Coy was married to his wife, Janice, for 47 years and lovingly raised four children with Christian values and morals. Coy was committed to God, his family, and his church and enjoyed hunting, collecting antique guns, and attending auctions.

One of Coy's visions for The PATH was to see the radio network technologically prepared for the future. Under his leadership, the CDR Radio Network began planning a major upgrade of the control systems at the network to enable a blending of all electronic media on the air and over the internet.

Ron was a dear friend to all and would often brighten those around with his wry sense of humor. He loved his Lord and Savior, his wife Jan, his family, his church, and everyone he knew through Cedarville University.

01 Ron Coy with his loving wife, Jan.

02 Ron was an avid hunter and loved spending time out in nature.
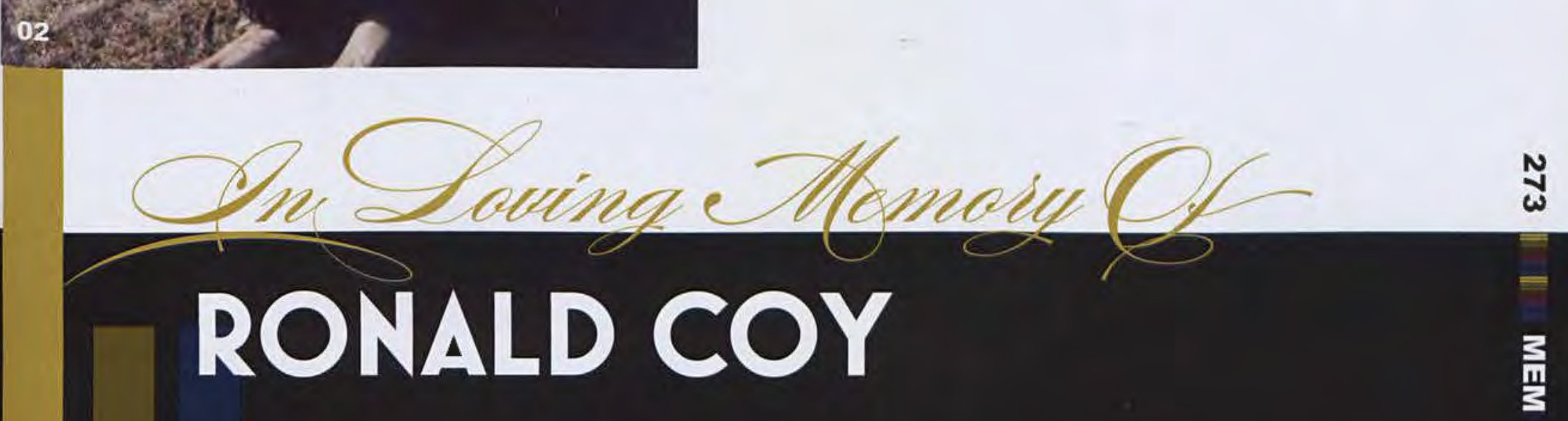


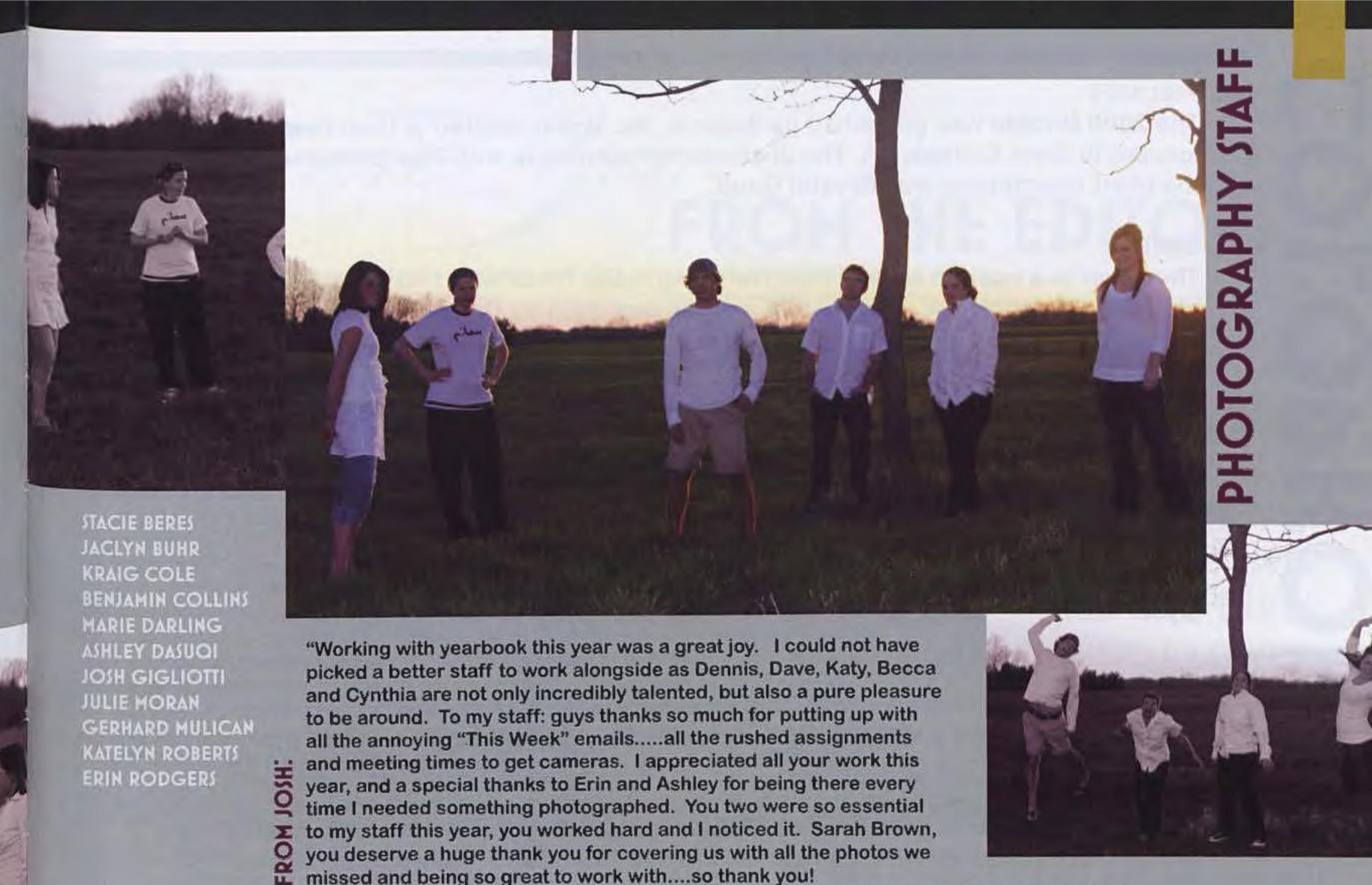

STACIE BERES

JACLYA BUHR

KRAIG COLE

BENIAMIN COLLINS

MARIE DARLING

ISHLEY DASUOI

IOSH GIGLIOTI

JULIE MORAN

C:RHRD MULICAN

KATELYN ROBERTS

突

and meeting times to get cameras. I appreciated all your work this

and a special thanks to Erin and Ashley for being there every

I to my staff this year, you worked hard and I noticed it. Sarah Brown,

O you deserve a huge thank you for covering us with all the photos we

판 missed and being so great to work with....so thank you!

I'll miss Dennis and his humor and David with his amazing talent, but

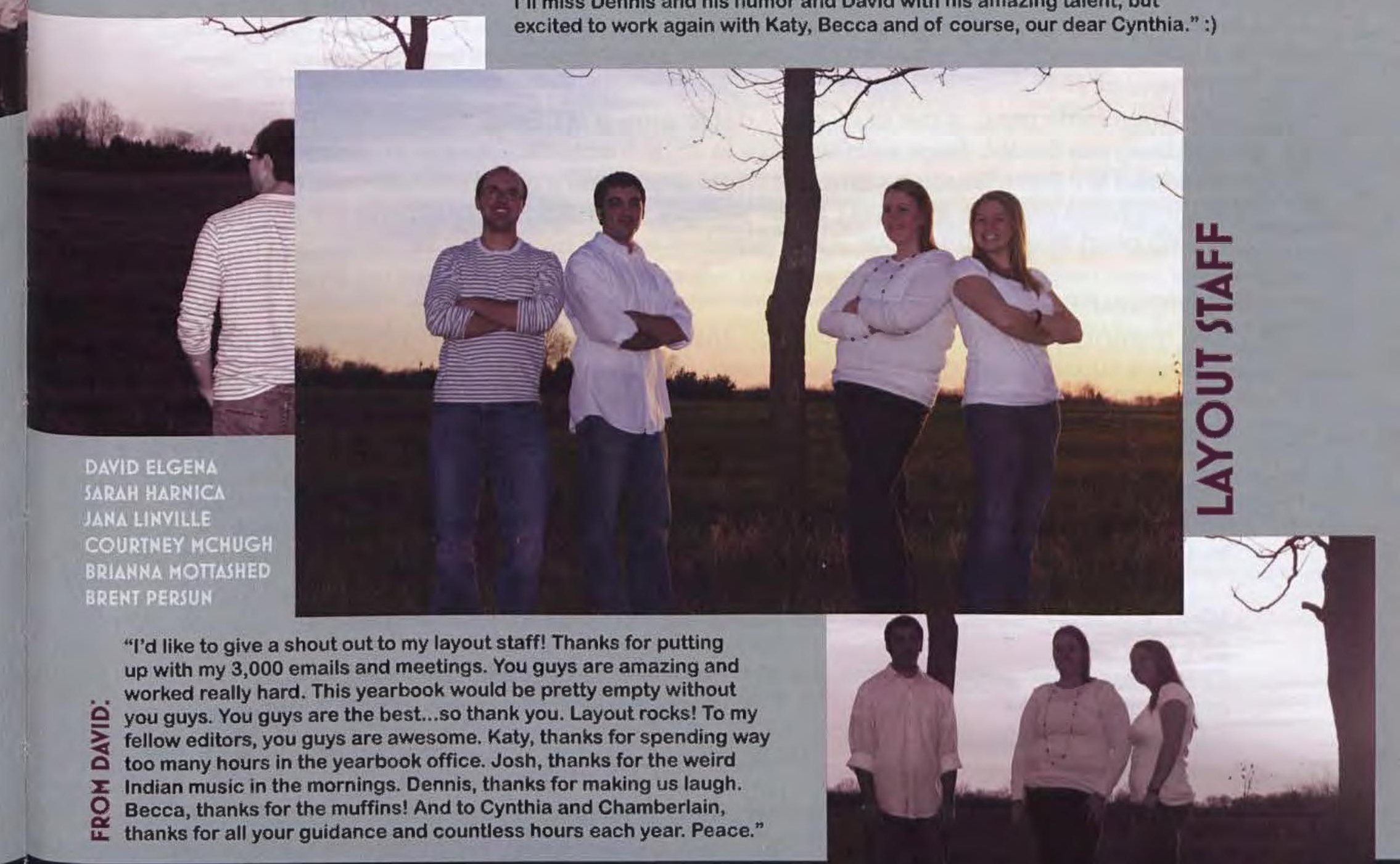




\section{PUBLISHER}

The 2008 Miracle was published by Jostens, Inc. It was printed at their plant located in State College, PA. The Jostens representative was Tille Billheimer, and the plant coordinator was Crystal Gault.

\section{COVER}

The cover is a custom screen material using matte black with two applications of black and rich gold ink. The custom art was designed by David Elgena.

\section{PAPER STOCK}

The paper for this book is $80 \#$ gloss finish. 292 all color pages were used.

\section{COLOR}

The 2008 Miracle was printed with four color process ink.

\section{DESIGN}

The 2008 Miracle yearbook was designed by David Elgena with help from the layout staff.

\section{THEME}

The 2008 Miracle theme evolved from an original idea by Katy Russell, in which all on the editorial staff had great impact on creating the idea and design of the book.

\section{PRODUCTION}

The 2008 Miracle was produced on IBM computers. Layouts were created using Adobe InDesign CS2. Photos were cropped, resized, edited using Adobe Photoshop CS3. Copy was typed in Microsoft Word and then imported into InDesign.

\section{TYPOGRAPHY}

The main fonts used in the book are Arial Rounded MT Bold, Mostra One Bold, and Burgues Script. Page numbers are in Arial Black. Stories are 10 point Arial Rounded MT Bold. Captions and freshman,sophomore and junior portrait names are in 9 point Arial Rounded MT Bold. Seniors are 8.3 point. Titles and divider text are 60 point Mostra One Bold. Page numbers are 12 point Arial Black.

\section{PHOTOGRAPHY}

The majority of pictures were taken by Josh Gigliotti and his photography staff. Student submissions were also accepted. Several photos were also taken by Nathan Chester, Sarah Brown and Scott Huck, photographer for Cedarville University, Public Relations. Jim Rainey acted as the DaVor representative for portraits.

\section{INOUIRIES}

The Miracle Yearbook office may be contacted for additional information about this book's production at:

Miracle, Cedarville University

251 N. Main St.

Cedarville, Ohio 45314

(937) 766-4995

miracle@cedarville.edu 
Arnott, Kaitlyn 76, 253

Arthur, Peter 76

Arthur, Rachel

118,199

Abbate, Erin 76

Abbey, Rebekah 154

Abraham, Mary 118

Abraham, Matthew

208

Achenbach, Kelly 76

Acheson, Christo-

pher 76

Ackerman, Joseph

154

Adams, Alyssa 144, 208

Adams, John Paul

245

Adams, Rebekah

154

Adams, Theodore

208

Adkins, Kristin 118

Affleck, Alexis 118

Agler, Jonathan 208

Ahn, Ae Un 76

Aho, Michael 118

Ahrens, Emily 76

Ajamian, Alexandra

76

Albarano, Jenna154

Albert, Dannielle

208

Alexander, Emily

208, 262

Alfieri, Jennifer 118 , 276

Allen, Brietta

154, 252, 276

Allen, Caitlin 154

Allen, Jennifer 208

Allen, Molly 76

Alliman, Ricardo

$103,136,184,185$

Allison, Sarah 118

Amarante, Holly 154

Amburgy, Carline 76

Andersen, Eric 154

Andersen, Sarah

198

Anderson, Benjamin

154

Anderson, Bradley

76

Anderson, Frederick

76

Anderson, Haddon

128, 184, 185

Anderson, Melissa

208, 261

Anfang, Laura 23 ,

118, 256

Anfang, Robert 83, 86

Angle, Mike 111, 254

Annanie, Christo-

pher 208

Antioho, Jeffrey 118

Arch, Nicholas 69,

154

Arndt, Joshua 208
Ashinghurst, Amy

208

Atkeson, Daniel

118,191

Augenstein, Emily 76

Augustine, Bradley

$70,71,76,91$

Austin, Wendy 208

Auyer, Jeremy 62,

154

Ayers, Nannette 76

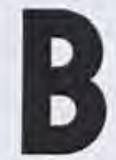

Babbitt, Allison 118, 252

Babbitt, Amy 208

Babcock, Devin 115

Bachman, Becky

208

Bacon, Angela 22

Bacon, Grant 17, 76 , 193

Baden, John 76

Bailey, Benjamin

118

Bailey, Julita 118

Bainbridge, Chad 208

Baker, Elizabeth 118

Baker, Katharine

208

Baker, Stephanie 76

Balch, Maria 180 ,

181, 195, 209

Baldwin, Chase 118

Balint, Jennifer 76

Ballard, Daniel

196, 197, 209

Banks, Jonathan

209

Banz, Jared 118

Baranowski, Brit-

tany 154

Baranski, Jacob 154

Barber, Andrew 209

Bardakjy, Scott

118, 125

Barham, Nathanael 154

Barkas, Elizabeth

118

Barnard, Rachel 154

Barnes, Brianne 175

Barrett, Collin 76

Basford, Diana 118

Basford, Julia 209

Bash, Steven 76

Battista, Kim 156,

209

Bauernschmitt,

Janet 109, 209

Baumer, Leanna 68 ,

71,118
Beall, Benjamin 154 Blocher, Brian 119 Brown, Andrew 77

Beals, Christian 128, Bochman, Heidi 154 Brown, Brandon 125

184, 185

Beatty, Angela 76

Bogan, Robert 119

Brown, Danielle 77

Beauchemin, Faith

Boles, Stephen 209 Brown, Erin 77

76

Bollenbacher,

Karissa 154

Beck, Geoffrey 76 Boliman, Stephanie

Becknell, Mark 262209

Beesley, Amanda Bonardi, Jordana

154

209, 236

Behn, Sarah 209 Bone, Kendra 77

Brown, Gracia 108, 155

Brown, Joshua 77

Brown, Megan 248

Brown, Nathaniel

26, 77

Beight, Michael

Boren, Angela 119

118, 193

Belden, Anastacia

118,189

Bell, Eric 118

Bell, Katie 154

Bell, Nathan 76

Belleman, Chelsea

118,279

Belote, Rebecca 76

Bender, Jason 173

Bender, Kevin 173

Benjamin, Marcus

86, 193

Bennett, David

209, 267

Boucek, Corbin 155

Boudreau, Michelle

209

Boward, Gabrielle

119

Brown, Rebekah155

Brown Jr., Andrew

77

Brumbaugh,

Amanda 210

Brunelle, Jessica 77

Bowers, Melanie209 Bryan, Clayton 77

Bowers, Rachel 119 Bubacz, Christin

Bowersox, Amanda 155

209

Bowersox, Roland

Bu

155

Bowes, Hanna 77

Buchheit, Andrew

Bowman, Trevor

155

190,191

Benson, David 154 Brady, Bonnie 58

Bentley, Robert 154 65, 69, 155

Buck, Hali 155

Buckwalter, Ahna

210,252

Buenning, Caitlin 77

Buenz, Bridget 119

Beres, Stacie 12, 76, Brady, Hannah 77 Buhr, Jaclyn 210,

$277 \quad$ Brady, Patrick 21, 77277

Berger, Emily 177 Brammer, David 210 Buhr, Jeffrey 210

Bernard, Stacey 118 Brammer, Tacie 77 Buhr, Kristin 77

Berry, Lauren 209 Brammer, Teresa

Bertsche, Benjamin 155

118

Bertsche, Eva 154

Bertsche, John

$118,189,254$

Berwager, Sarah

76

Besaw, Laura 154,

244

Betzold, Haeli 76

Bidwell, Jennifer

154

Biehl, Kathryn 209

Biga, Jordan 209

Bigg, Jenne 118

Brand, Amy 155

Brandt, Julie 155

Brandt, Katie 77,

78,91

Brandt, Sarah 145

Braswell, Cathryn

210

Burbury, Dina 210

Burch, Whitney 119

Burchfield, Suzanne

77

Burgman, Lisa $175 \quad 7$

Burk, Elyse 210, 236

Burks, Naomi 210

Burley, Jade 210

Busenitz, Justin 119

Brazalovich, Jessica Bush, Christopher 119

Brenneman, Carla Bush, Emily 77, 256

210

Brenneman, Kyle

77

Bresson, Sarah 11977

Bigler, Brett 94, 154, Brewer, Elizabeth

190, 191

210

Bigler, Nicholas 76, Brewin, Nicole 155

191

Bigney, Lauren 77,

Briggs, Greg

97

141,210, 265

118

Bird, Bethany 77 ,

182

Black, Dillon 72

Black, Dylan 77

Black, John 154

Brinks, Emile 210

Blackburn, Erin 77

Briscoe, Corwin 77

Brittin, David 119

Brochu, Zachary

210, 238

Brock, Peter 155 ,

201

Blackburn, Kelly 154 114, 210

Blackburn, Melody Brooker, Judson

154

179,193

Bushre, Stephen

210

Butterfield, Karen

Blacklidge, Sara 118 Brooks, Nevin 77

Blackstone, Valerie Broscious, Jonathan

119,144

Blake, John 154

Blatherwick, DJ

111,173

Bliss, Katie 119

14,210

Brown, Alexis 149,

155

Brown, Alisha 155

Brown, Amy 210 
Clements, Alexandra 155

Clouse, Adam 119

Clouse, Michael 78

Clutcher, Alissa 139,

211, 269

Clymer, Kaydrie 155

Coakley, Rachel 211

Coale, Ashley 104,

188, 189, 211

Cobb, Laurielle 78

Cobucci, Stephen

155,173

Cochran Jr., Timothy

119

Cody, Andrew 119

Coffelt, Joanna 211

Coffill, Samantha

119

Coffindaffer, Kari

175

Coffman, Jennifer

155

Cohoon, Michelle

211

Colas, Bethany 211

Colas, Bradley 119

Cole, Amanda 212

Cole, Esther 212

Cole, Kraig 277

Coleman, Laura 212

Coleman, Sarah 155

Coleman, Stephanie

212

Collins, Allen 155

Collins, Benjamin

107, 212, 277

Colman, Kristin 120

Comers, Luke

120, 148

Comers, Trisha 120

Compitello, Everett

155

Compton, Bethany

212

Compton, Matthew

78

Condit, Katherine

212

Condon, Lacie 186,

187

Conkling, Elizabeth

212

Conner, Amy 78, 86

Contreras, Rafael 78

Conway, Jillanne 78

Cook, Felicia 120

Cook, Jazmine 120

Cook, Kaitlyn 65 ,

120

Cook, Lauren 212

Cook, Matthew 212

Cook, Robert 212

Cooper, April 58 .

212

Cooper, John 120

Copeland, Daniel

212

Cordial, Mara 120

Cornell, Laura 155
Correia, Stephanie 79

Costerisan, Andrew 156

Cottings, Bethany 156

Coudriet, Jessica

212

Coulter, Jonathan 120

Cover, Laura 156

Cowell, Benjamin 108

Cox, Amanda 212

Cox, Chad 120

Cox, Heather 79

Cox, Michael 120

Cox, Rachel 189

Coyle, Gabriel 212,

236, 246, 247, 260

Cozad, Hannah 212

Crabtree, Deborah

212

Craft, Gregory 121

Craig, Audrey 79

Craig, Jennifer 79

Craig, Sara 156

Crawford, Erin 27, 86

Crawford, Scott 173

Craycraft, Abigail

212

Crichlow, Sarah 60, 67, 156

Croft, Jennifer 79

Crommett, April 63

Cronin, Jennifer 79

Crowder, Lisa 156

Crowe, Kaitlyn 79, 189

Crunelle, Leanne

$180,181,212$

Cruz, Philip 201

Cuenin, Renee 156

Cuffman, Timothy 79

Culver, Jenna 156

Cummings, Anna

22, 213, 264

Cummings, Eliza-

beth 79

Cummings, Katie

213

Cummings, Lisbeth

121

Cummings, Sara 79

Cunliffe, Christy 61

Cunliffe, Evelyn 121

Cunningham, Pat-

rick 213

Curby, Erin 79

Curtis, Andrew 213

Curtis, Benjamin

156

Cyrus, Amanda 156

Czaplicki, Daniel

213

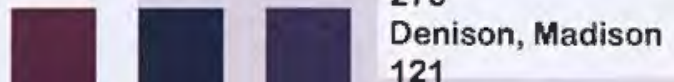

121

Dammer, Matthew

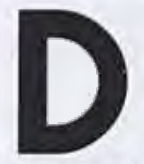

D'Anna, Matthew

79

Dallas, Natalie 213 Develbiss, Jenna

213

Dammer, Nathan

213

Dammer, Timothy

121

Dankert, Andrea213

Darling, Marie 277

Dasuqi, Ashley

103, 121, 277

Daugherty, Jessica

213

David, Priscilla 157

Davidson, Elizabeth 79

Davidson, Robert

157

Davies, Bethany

$157,181,195$

Davies, Jordan 79 ,

179, 193

Davies, Richard 213

Davis, Adam 213

Davis, Bryan 79

Davis, Courtney 121

Davis, Jennifer

$137,213,261,269$

Davis, Jewell 121

Davis, Kenneth 172 , 173

Davis, Matthew 213

Davis, Michelle 213

Davison, Danny 157

De Waal Malefyt,

Matthew 213

DeBoer, Kyle 197

DeGroft, Jennifer

121

DeKorne, Tricia 121

DeRusha, Emily 79 ,

181, 195

DeRusha, Shannon

$157,180,181$

Devalve, Daniel 79

DeVault, Katherine

121

DeVinney, Thomas

121

DeVries, Merissa

213

Deakin, Diana 121

Dearden, Matthew

157

Decker, Jonathan

86, 157

Deemer, Carolyn

121

Deeter, Sarah 79

Dellicarpini, Leah 79

Demers, Jonathan

79

Denen, Alyssa 79 ,

276
Denningham, Brittany 79, 102

Dennis, Amy 157

Depew, Amber 79,

91

Deseno, Kimberly

121

121, 189

Devereaux, Stephen 79

Devine, Stephanie

71,79

Dewhurst, Gwendo-

lyn 105

Di Donato, Lindsay

213

Dickhoner, Barbara

121

Didik, Yekaterina 96,

$121,125,279$

Dixon, Jennifer 213

Dobrinoff, Ashley

213

Dodson, Justin 98 , 214

Doenges, Timothy

121, 246

Doleys, Daniel 214

Dolph, Olivia 198

199, 214

Domeny, Michael

22, 70, 71, 244, 262

Donald, Brittany

214, 239, 271

Donaldson, Benja-

$\min 95$

Donaldson, Ericka

157

Donaldson, Gregory

20

Donohue, Kelly 99 ,

121

Doot, Emily 214

Dorbritz, Kristina 79

Dorsey, Arielle

214, 236, 269

Douglas, Abby 157

Douglas, Allison 79

Doyle, Brandon

102, 214, 264

Dreher, Joshua 79

Dreyer, Meredith 79

Driscoll, Emily 121

Drum, Rebekah 157

DuPree, Briana 64 ,

183,249

Duarte, Rachel 121

Duerrwaechter,

David 189, 214

Duff, Justin 121.

147, 252

Duffell, Monica

121, 195

Duncan, Bethany

98,157

Duncan, Nicholas

157

Dunnevant, Kaitlin

104

Dunning, John
Dix, Nathan 79

Duell, Lani 214

Dunton, Matthew

185

Durr, Angela

214

Everett, Abby 215

Everitt, Joshua 157

80

Everswick, Shannon

68, 215, 268

Ewers, Lacy 157 
Fox, Jenna 12, 122 , 202, 203

Fox, Matthew 95,

156, 158

Francis, Josh 215

Francis, Justin 158

Franke, Annamarie

158

Fraser, Heidi 215

Fraser, Jeremiah 80

Frasier, Kristie 158,

189

Frederick, Betty 80

Frederick, Tanya

122

Freed, Richard 158

Freeman, Adam 86

French, Kaitlyn 158

Frey, Austin 216

Frichtl, Johanna 158

Fridenmaker, Nicho-

las 216

Fugate, Brent 122

Funke, Christa 158 ,

244, 252

Furst, Kevin 196

Futoran, Anna 122

Fye, Elyse 24, 158

Fye, Vincent 20, 80

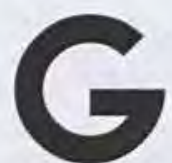

Gabbard, Amanda

158

Galloway, Cali 158

Galloway, Sarah 216

Gardner, Keith 216

Garling, Joshua 216

Garlow II, Arthur

Brian 122

Garner, Amy 122,

176,177

Garrett, Ross 122

Garrison, Jacob 158

Gass, Lynn 80

Gaston, Tiffani 80

Gebert, Clara 122

Geddes, Amelia 80

Gehman, Christo-

pher 252

Gelser, Joshua

$172,173,216,250$

Gelwicks, Patricia

80

Gensler, Amy 80 ,

182

George, Matthew

173

George, Stefanie

216

George, Tricia 122

Gerard, Elizabeth

216

Geringer, Amber

158

Gerton, Matthew

80,193

Gibson, Leah 122

Gier, Megan 216
Gifford, Rebekahm

122

Giglio, Benjamin 158

Gigliotti, Jillian 80

Gigliotti, Joshua

$138,156,158,274$,

277, 278

Gilbert, Steven 80

Gilin, Rachel 97 ,

$122,125,268,279$

Gillette, Jacinda

216, 260

Gingell, Elizabeth

$70,71,80$

Gingerich, Katrina

80

Gingrich, Valerie

122, 248

Glass, Lynn 60

Gleichauf, Ashley

158

Glorioso, Callie 80

Godwin, Bethany

122

Goecke, Erica 122

Gohdes, Peter 216

Golden, Adam 216

Goldman, Amy 122,

261

Gole, Robert 216

Gollihue, Erin 120 ,

147, 246

Good, Emilie 216

Goodew, Audree

$180,181,195,216$

Goodman, Steven

80

Goodman, Terri 142,

158,182

Goodrow, Erika 158

Goodwin, Rebekah

80,96

Gorrell, Jonathan

122

Gouch, Emilie 158

Graeff, Michelle 158

Grant, Jennifer 158

Grant, Stephanie 80 175

Graves, Amanda

122, 276

Graves, Elizabeth

216

Gray, John 216

Gray, Lisa 122

Gredy, Amy 158

Green, Stephen 216

Green, Stuart 81

Green, Timothy $\mathbf{8 1}$,

172, 173

Greenberg, Leah-

Ruth 216

Greenberg, Sarah

158

Greenfield, Amy 158

Greer, Kimberly 216

Greetham, Carissa

177,270

Gregg, Becky 258

Gregg, Rebecca 122

Greve, Gabriel 158

Grewe, Jessica 217
Griest, Jared 201,

217

Griffith, Joshua 158

Griffith, Luke 173

Griggs, Aaron 217

Grigsby, Megan 81

Grist, Stephen 203

Griswold, Kelsey

158

Groce, Ashley 122,

137

Groff, Adam 158

Grollimund, Julie

217

Groman, Kurt 66 ,

$122,192,193$

Grooms, Heather

187,217

Groves, Crystal 81

Grudda, David 217

Gruenberg, Stephen Hartman, Sarah 81, 193, 217

Guenther, Kathleen

158

Gulley, Kevin 217

Guth, Jennifer 217

Gvora, Lyndsey 122

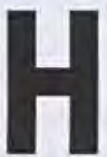

Haas, Kaylyn 81

Hackney, Drew 217

Haegele, Lauren

158,175

Haetinger, Amy 217

Hagen, John 122

Hager, Regina 122

Hagman, Michael

81

Haines, Stephanie

81

Hale, Paul 217

Hales, Ryan 122

Hall, Andrew 158

Halladay, Laura

158,203

Halvorsen, Jason 81

Halvorson, Chris-

tiana 83

Halwes, Stephen

123

Hamann, Maria 159

Hamilton, Elizabeth

81

Hamilton, Sarah 123

Hamminga, Kristin 159

Hammond, Kelly 81

Hampton, Maija 159

177

Hanby, Caleb 159 ,

173

Hancock, Charity

140, 159, 184

Hand, Jacob 123

Haney, Emily 123

Hanna, John 81

Hanna, Zachary 159

Hannay, Sarah 81 ,

195

217

Hansen, Grant 23 , 159,252

Hansen, Ryan 217

Harenda, Timothy

159

Haring, Kyle 70, 71,

123

Harmon, Chris 182

Harnica, Sarah 81,

203, 277

Harpest, Kaci 217

Harpole, Bethany

123

Harris, Sonya 159,

161

Harrison, Autumn

159

177

Hasselbach, Kortni

105, 123

Hatch, Alison 159

Hatch, Cristina 159

Hatch, Joseph 123

Hattenfield,

Rebecca 123

Hauser, Chelsey 97 , 123,148

Hawkins, John 217 Hawkins, Katy 71, 811

Hawkins, Rebecca 123

217

Hayes, Jordan 123

Hayes, Ruth 217

Hayes, Sara 217

236

Haynes, Sarah 81

Hays, Elizabeth

159,238

Hazen, Alicia 159

Heading, Christo-

pher 24

Hearle, Abigail $\mathbf{8 1} \mathbf{8 1}$

Hearle, John 123

Heckendorn, Kath-

ryn 25,81

Heckman, Chloe 81 ,

83

Heerschap, Juliana 159

Hefner, Craig 81

Hegarty, Beth 159

Hegarty, John 83

Hegna, Julianne 81

Heiss, Leslie 218

Hejl, Anna 159

Hellwig, Ashley 81

Hemphill, Joseph

159

Hen

159

Hayes, Bethany 175 Hilderbrand, Jaclyn Hayes, Erin 175, 276159

Hayes, Heather 182, Hilerio, Stephanie

218

Hill, Zachary 123, 173

Haynes, Hannah 217 Hindle, Hannah 159

Haynes, Rachel 218 Hinkle, Jessica

Heady, Julianne 8171,159

Heagy, Heather 218 Hiteshew, Mark 21,

Hlad, Lindsey 218

Hobbs, Justin 22,

123,244

Hobbs, Rachel 218

Hodges, Megan 123

Hoeflinger, Erin 81 ,

91

Hofert, Suzanne 159

Hoff, Erica 82

Hoffman, Chelsie 
J

Jackson, Brent 160 Jackson, Brittany 219

Jackson, Clarissa 160

Jackson, Jennifer 219

Jackson, Kyle 219, 264

Jackson, Lillian 82 Jackson, Tonisia $156,160,164$

Jacobs, Amy 65, 69, 160

Jacobs, CeCeLia

219

Jacobson, Ashley

219

Jacobson, Sarah

114,123

Jano, Jessica 82

Janssen, Amber 219

Jantzen, Andrew

82

Jaquery, Rachel 82

Jarvis, Emily 82

Jasper, Natalie 160

Jenkins, Benjamin

160

Jenne, Aaron 160

Jeska, Rebecca 82

Jewett, Daniel 82

Jillich, Nicole 160

Johnson, Alicia 219

Johnson, Alissa 82

Johnson, Alyssa

$123,125,133,279$

Johnson, Courtney

219

Johnson, Evan 123

Johnson, Ian 160

Johnson, Jessica

82, 123

Johnson, Julie 60 ,

123

Johnson, Matthew

123

Johnson, Steven

219

Jones, Allison 24,

160

Jones, Amber 160

Jones, Grace 160

Jones, Hannah 82

Jones, Jesse 12 ,

72,82

Jones, Sarah 124

Jordan, Jesse 219

Jordan, Lindsay 124

Judd, Rachel 188 ,

189

Juhant, Hannah 82
Knudsen, Michael 220,265

Knupp, Tiffany 220

Kobinah, Sharon

83

Koch, Kathryn 160

174,175

Kochanowski, Ben-

jamin 124, 169

Kochersperger,

Ryan 160

Koepke, Sara 202,

203

Kohl, Caleb 83

Keller, Amy 220

Keller, Lauren 220

Keller, Nathan 246

Keller, Stacey 160

181, 195

Keller, Teresa 17 ,

62,220

Kellogg, Joy 198 ,

199

Kelly, John 82

Kelly, Lindsay 82 , 189

Kelton, Griffin 82

Kempf, Jacob 82

Kempton, Eric 179,

193

Kennedy, Zachary

124

Kern, Jacob 220

Kidd, David 124

Kilburn, Leigh 160

Kilian, Benjamin 82

Kilmer, Kameron

82

Kindt, Laura 124

King, Shannen 124

Kingma, Alexandra

220

Kinnaman, Sarah

124

Kinnick, Bethany 82

Kirby, Kyle 197

Kiser, Andrea 160

Kjellman, Andrew

124

Klein, Andrew 22

Klein, Katherine 27,

160

Klimek, Emily 27

Klimek, Kathryn 160

Kline, Courtney 160

Kline, Lisa 220

Klint, Charles 124,

254

\section{Rebecca}

160

Kloosterman, Daniel

220,276

Knesnik, Andrew

82

Knesnik, Drew 21,

82

Knight, Jonathan

124,146

Knilans, Joshua 220

Knorr, Elizabeth 160

Knott, Christine 160

220

Kolody, Jessica 83

Komarek, Lauren

124

106,276

Korkosz, Liz 260,

265

Korthals, Jessica

$61,124,133$

Kraft, Emily 18, 160

Kragel, Samantha

220

Kraker, Justin 220

Kramer, Devin 124

Kranenburg, Julia

160

Kraus, Charles 221

Kreeger, Carol 58 .

221

Kremer, Katherine

83

Krogstad, Matthew

$124,191,204$

161

Krupka, Devin 63 ,

221

Kuhn, Kevin 178

179,193

Kurtz, Isaac 83 Kusky, Sarah 83
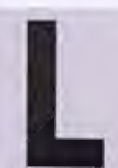

Laake, Lauren 66

Lagan, Daniel 161

Lagar, Natalie 161

Laing, Amber 161 ,

175 hicholas 220 Larsen, Brooke 124

Kolmerten, Dezirae

Koranek, Daniel 220 Latario, Brian 20, 84 Liu, Annette 162

Kordic, Scott 16, Latario, Rachel 124 Liu, Daniel 222

Kramer, Laura 83

Krieger, Eliott 160 Lee, Alisha 187

Kriss, Lauren $124 \quad$ Lee, Laura 221

Krizo, Kathryn 124 Lee, Michael 221

Kroll, Michelle 161 Lehmann, Gail 84

Kroninger, Krista 83 Lehmann, Lindsay

Kropf, Michelle 99, 221

Kushnir, Michelle 83 Leman, Richard 17

Lagan, Joel 221, 268

Lambright, Rhoda

161
Leffel, Erin 84

Leffel, Jordan 162

Lehr, Sharon 124

Leightenheimer,

Johannah 221, 276

Leitch, Hannah 124

Leman, Jordan 18 , 162

Lethbridge, Tiffany

124,250

Lewallen, William 84

Lewis, Mary 84

Lewis, Melissa 221

Lightner, Joel 21

incoln, Kimberly

Lincoln, Michael 221

en, Bethanne

84,91

inden, Kyle 162

Linder, Nathan 162

inebaugh, Patricia

Linville, Jana 277

, Katherine

221,268

itchfield, Natalie 84

LoCicero, Steven

$104,125,188,189$,

253

Locke, Paul 125

188,189

Lockridge, Andrew

200, 201

Lockridge, Heidi 84

London, Racquel

162,177

Long, Andrew 125

Looyengoed, Elyse

$125,248,252$

Loper, Katherine

222

Losch, Jessica 162

Losch, Joel 106,

222, 265

Louie, Aaron 150,

222

Lounds, Courtney

125

Lowe, Garrett 222

Lowe, Jeremy 84

Lowry, Ryan 222

Lowry, Sarah 84

Lucas, Courtney 125

Lucas, Sharayah

222

Ludlow, Clayton 222

Lukasiewicz, Timo-

thy 83

Lupka, Ashley 162

Lemon, Alison 186 ,

187

Lemon, James 261

Lempa, Dale 112.

124

Lengefeld, Philip

162

Lentz, Jason 124

Leonard, Christina

140,162

Leppke, Lindsay

124,250

Lester, Jen 14

Lester, Jennifer 66 ,

124
Luster, Marilyn 84

Lustig, Ryan 172,

173

Lutz, Kathryn 162

Lyman, Daniel 84

Lyon, Justin 222

Lyons, Whitney 125 ,

189

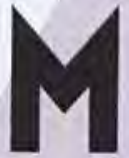

Maat, Christian

162,193

Mable, Kourtney 162

MacKenzie, Kather-

ine 84,177

Mackenzie, Matthew

162

Macaluso, Rebekah

162

Mace, Laura 84

Mage, Peter 125 
McCay, Carrianna

162

McClenahan, James

$146,223,260$

McCloskey, Nate

14

McClure, Georgiann

104, 126, 198, 199

McClure, John 162

McCollim, Amanda 223

McCollim, Caleb 223

McComas, Wade 16, 237, 260

McCool, Logan 126

McCoskey, Karen

84

McCowen, Amber

164

McCoy, Justin 223

McCoy, Michael 162

McCue, Jamin 162

McCullough, Alicia

68

McDonald, Jennifer

162

McFarland, Bryan

83, 84

McGee, Heather 162

McGee, Miles 126

McGill, Jonathan

162, 169, 261

McGuire, Erin 84

McGunnigal, Kris-

tine 162

McHugh, Courtney

277

Mclntosh, Lauren

12, 13, 84

Mclnturf, Callie 126

McKee, Kate 223

McKenna, Robert

223

McKinley, Amanda

223

McKinley, Darcy 162

McLeese, Nathan

162

McLeod, Phil 108

McLeod, Philip 223

McMaster, Alicia 27,

78, 91

McQuarry, David

84

McQueen, Julie 223

Meadors, Ronald

84

Mehra, Anjuli 223

Meier, Allyson 163

Meitzler, Faith 163

Melendez, Angeline

163

Mellum, Gregory

84

Mellum, Lynn 163

Melvin, Megan 59

Mena, Kena 163 ,

169

Merkel, Kristin

$174,175,223$

Merkh, Daniel 126

Merrin, Alise 18,

108,126
Merritt, Stephanie 84

Mertus, Megan 163 Meyers, Sterling 67, 163, 276

Michael, Daniel 126

Michaud, Benjamin

193

Miedema, William 84

Mikolon, Marguerite 223

Miles, Brittany 163

Millar, Becky 163

Millay, Emily 163

Miller, Bethany 163

Miller, Bobbi 223

Miller, Christine 84

Miller, Corey $\mathbf{8 5}$

Miller, Emily 85

Miller, Hannah 85

Miller, Janel 224,

236

Miller, Jeremy 224

Miller, Joshua 224

Miller, Katherine 126

Miller, Kelly 163

Miller, Lydia 187

Miller, Mark 63, 104,

163

Miller, Melissa 126

Miller, Melody 126

Miller, Peter 26

Miller, Sarah 59 ,

126, 224

Miller, Scott 224

Miller, Sharon 85

Miller, Whitney

224, 264

Milliman, John 163

Millington, Karisa

109, 224

Mills, Andrea 85

Mills, Stephanie 85

Mishne, Eric 23,

$108,224,250,263$

Mitchell, Peter 126

Mitchener, Scott 224

Moffitt, Trevor $\mathbf{8 5}$

Moger, Richard 85

Mohler, Emily 224

Mohler, Joshua 163

Mol, Alexander 126

Molby, Lena 85

Molby, Nathan 149

Molstre, Jordan 85 ,

193

Monroe, Jennifer 85

Montes, Loren

224, 269

Montie, Scott 224

Montzka, Amanda

85

Moon, Katie

176,177

Moore, Alexander

$85,178,179,193$

Moore, Andrea 163

Moore, Jennifer 163

Moore, Katelyn 126

Moore, Kenneth 224

Moore, Nicole 224

Moore, Stephanie 85
Moore, Timothy 126, Nelson, Katherine 224

Moore II, Timothy

126

Moran, Julia 277

Moran, Stan 109,

$143,150,163$

Morgan, Danielle

224

Morgan, Jonathan 224

Morgan, Sarah 189

Moriarty, Jennifer 224

Morrison, Matthew

78,85

Isen, Erin 17, 115, 127

Nelson, Kelsey 22,

$109,225,244,255$,

258

Nelson, Megan 163

Nemec, Elyse 85

Nesbitt, Rebecca

126

Neuhart, Micaela

163

Newfield, Allison

225

Newfield, Matthew

126

126

Newman, Christo-

Morrison, Phillip 126 pher 83, 126

Morrow, James 224 Newman, Justin 127

Morse, Camille 224 Ney, Sara $63 \quad$ Overly, Nicole 127

Olsen, Rebekah 163

Olson, Toryn 149 ,

164

Omdal, Tom 127

Oosterhouse, Whit-

ney 225

Organ, Paul 148,

225

Ormsby, Daniel 12,

85, 196, 197

Ortiz, Deborah 24,

164

Ortiz, Joshua 226

Osborn, Jared 149, $150,226,251$

Moser, John 85 Nichelson, Craig 85 Owens, Matthew

Moses, Andrew 85 Nichols, Daniel 127 200, 201, 226

Mosher, Ryan 185 Niday, Hannah 127,

Moss, Joseph 225140

Moss, Susan 19, Niedermayer, Sarah

225

Mostaed, Michelle

225

126

Niemi, Katie 163

Niemiec, Matthew

Mottashed, Brianna 173

$17,126,277$

Mounce, Colten 20

Mounts, Caleb 225,

262

Nikerle, Jordan 127

Niknam, Jonathan

225

Noble, Emily 187

Muhlenkamp, Whit- Noble, Garrett 163

ney 133,163

Norman, Bryan 225

Mukes, Jennifer 126 Norman, Dustin 72

Mullen, Catherine 85 Normandeau, Nicole

Mullican, Gerhard 163

27

Norris, Linnea 225

Mulligan, David 163 North, Brittany 163

Mumme, Courtney Norton, John 172, 85

Mundy, Katharine

163,263

173,225

Mundy, Rachel 146 Nosal, Bayley 186

Munson, Aubree 203187

Murphy, Sarah 126, Nowak, Lauryn 85

139

Murray, Erin 85

Nowels, Kelly 163 ,

126

Muschott, Bradley

163

Musselman, Brittany

126

Myers, Janelle 126

Myers, Justin 225

Myers, Leslie 225

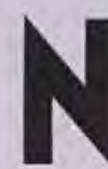

Nangle, Dennis 225, 274, 276

Nanney, Philip 225

Neal, Kristen 225

Neal, Lindsay 120 ,

126

Nelson, Annalise

163

Nelson, Brian 225

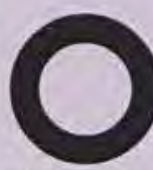

O'Connor, Thomas

85

O'Neal, Christine

163

O'Neal, Erica 85

O'Neal, Renee 127

O'Prandy, Justin 85

Oakiey, Jeffrey 85

Oana, Asheritah 127

Oddis, Matthew 85

Ohlin, Bethany 127

Ohms, Joshua 225

Ojala, Brendan

190,191

Okoro, Stephen 127

Oller, Ryne 185

Olmstead, Hannah

Nelson, Elizabeth 85 Olney, Lucy 163

Pheasant, Paula 226

Phillips, Andrea 164

Phillips, Rebecca

226

Philpott, Katherine 226

Philyaw, Erin 86

Picazo, Kaitlyn 226

Piette, Timothy 226

Pinkham, Daniel 226

Plasterer, Anna 86

Plasterer, Ruth 127

Platt, Andrew 226

Plumley, Trevor 127

Pollock, Lisa 86 


\section{$\mathbf{R}$}

Rabb, Brandon 87

Ragle, Zachary 87

Raimer, Randi 127

Ralph, Taylor 87

Rambikur, Amy 165

Rambikur, Elizabeth 227, 268

Ramsey, Aaron 127

Ramsey, Kelly 227

Randolph, Brittaney

165

Randolph, Danielle

73,227

Ranney, Amber 87

Rarick, Jessica 87, 175

Rasnick, Robert 193

Ratliff, Mark 165

Ray, Krista 125, 128, 143

Ray, Meagan 22, 73 ,

87,97

Raybuck, Lindsay

175

Rayder, Kelley 87

Rector, Aaron 128

Rector, Ethan 87

Recupero, Kristen

128, 276

Reed, Nathan 128

Reeder, Blake 87

Reeder, Corey 165 ,

169,261

Reeder, Stacey 227,

262

Reep, Ken 259

Reep, Kenneth 185

Reep, Ryan 165 ,

184, 185

Reese, Morgan 87

Reid, Courtney 194 ,

195, 227

Reilmann, Krista 165

Reinacher, Ina 165

Reiner, Timon 227

Reiskytl, Anna 227

Reke, David 128

Renke, Andrew 165

Rettig, Caleb 227 ,

264

Reuther, Katelyn

128

Reyes, Christina 227

Reyes, Jessica 203

Rhoads, Heather

227

Riber, Chase 173

Riber, Logan 173

Rice, Heather 128

Rice, John 16

Rice, Keith 227

Rice, Marla 165, 195

Rice, Melissa 227

Rice, Stephanie 128
Richard, Meredith

128

Richardson, Lindsey

128

Richardson, Noah

128

Richter, Lachelle 59 ,

$62,141,227$

Rieches, Veselin 87

Riehle, Adam 24,

185

Riethmiller, Scot 228

Rigg, Elizabeth $\mathbf{8 7}$

Riggs, Bethany 175

Rill, Amanda 103 ,

228

Rill, Angela 165

Riney, Stephanie

228

Rising, Kasey 228 ,

256, 257

Rizzo, Matthew 87

Roach, Katelyn $\mathbf{8 7}$

Roach, Trent 87, 191

Robb, Jessica 86 ,

87, 97

Robbins, Laura 228

Roberto, Samuel

129

Roberts, Amanda

129

Roberts, Katelyn 25 .

129,277

Roberts, Rachel 228

Roberts, Zachary

250

Robertson, Joy 87

Robinette, Keith 129

Robinette, Megan

228, 254

Robison, Laura 228

Roby, Chelsae 228,

276

Rodgers, Erin 228,

266, 277

Rodgers, Karolyn

129

Rodgers, Stefanie

187

Roebuck, Amanda

165

Roelli, Matt 228

Roller, Amanda 165

Ronan, Kristina 165

Roney, Frank 129

Rosario, Eber 189

Rose, Daniel 185

Rose, Nicole 16 ,

228, 263

Rosner, Nevin 129

Ross, Courtney 228

Ross, Kieralyn 87

Ross, Rachel 165 ,

203

Rost, Tyler 87,200 ,

201

Rost, Zachary 197

Rothacker, Lisa 129

Rothhaar, Jenna 87

Rowe, Charissa 203
Rowlands, Kimberly Schiller, Ryan

228

Roy, Nathan 228

Ruck, Carolyn 87

229,265

Sherry, Mychaela

125, 129

Rucker, Kristine 187 Schindehette,

Ruckman II, Michael Joshua 87

129

Ruffner, Emily $65, \quad 129,255$

129

Ruhlman, Kevin 87, 165

179,193

Russell, Katy 109

Schlindwein, Ann

129, 245, 274, Schlueter, Tiffany

278,279

165

Russell, Stacey 87 Schmidt, Frances

Rustine, Steven 228229

Rutt, Alisa 198, 199, Schmidt, Matthew 228

Ryninger, Caitlin 129 Schmidt, Stacie 87

Schmitt, Sarah 129

Schneider, Tanja 87

Schnepp, Rachael

68,229

Schoen, David 165

Scholes, Melissa 87201

Salaverria, Abigail

87

Schoonover, Michael Shumaker, Timothy

129

Schulert, Allison

Salsbury, Brandon 108,129

129,133

Sammons, Emily 165

Samuelsen, Ryan

145,165

SanGregory, Angela

65,129

SanGregory, Erin

165

Sandberg, Janaye

129

Sandberg, Julianne

228

Sandefur, Karyn 129

Sanders, Angela165

Sanders, Stephanie

229

Sanderson, Zach-

ary 24

Sanford, Timothy

165

Santos, Nicole 165 ,

181,195

Sartori, Jessica 229

Sattler, Kaitlin 165

Saunders, Joshua

$59,165,178,179$,

193

Saxe, Sarah 129

Scarpuzzi, Joanna

229

Schaszberger,

Sarah 129

Schedlbauer,

Genelle 128,129

Scheerschmidt,

Benjamin

Scott, Cayla 129

Scott, Jessica 165

Scott, Kathryn 129

Scott, Michael 166

Scott, Tyler 172, 17323

Sides, Justin 130 ,

151

Siebert, Zachary

130

Siefkes, Jordan 201

Scott, Zachary 229 Siemon, Aubrey 186

Scouten, Andrew 187

87

Scull, Peter 129

Seawell, Bethany

229

Seelye, Lukas 147 ,

229,260

Seelye, Zachary

120,246

Segebart, Kyle 173

Seifert, Samantha

129

Self, Tara 229

Sergent, Andrea

129,147

Serna, Denise 70, 71 Sims, Sarah 230

Servi, Daniel 191, 229

Shackelford, Kelly

129

Shaffer, Daniel $\mathbf{8 7}$

Shanahan, Emily

$88,250,251$

Shanks, Catherine

58,166

Shaw, Kelly 88

Sheers, Sarah 166

177

87

Scheerschmidt,

Sean 95, 148

Schellin, Bradley

165

Schenk, Terri 229

Scherner, Rachel

129

Scheunemann, Kari

229

166

229

Shetler, Ami 129

Katherine

Shinabarger, Rachel

Shinabarger,

ebekah 88

70,276

166

horey, Benjamin

hort, Ryan 184,

orts, Mikal 166

Sigmon, Danielle

183

Silveira, Matthew

179,193

Simon, Ashley 230

Simon, Hollice 88

Simpson, Adam 276

Simpson, Brittany

$166,180,181,195$

Simpson, Jared 130

Simpson, Sherri 88

Simpson, Stacy 88

Sims, Grace 166 ,

175, 203

Sipe, Jessica 130 ,

195

Sizemore, David 16, 230,260

Sjoquist, Megan 
Stahl, Stephanie

142,166

Stambach, Sarah

130

Stampfli, Catherine 88

Stapleton, Baxter 18

Stark, Eva 230, 264

Starr, Samuel 130,

192, 193

Start, Kaitlin 88

States, Crystal Rae

202, 203

Staudt, Daniel 88

Stauffer, Aaron 166

Steckel, Jennifer

130

Steckel, Jeremy 95 , 161,166

Steckel, Joshua 88 91

Steele, Meghan 166 Steele, Michael 166 Stefan, Johnathan 230

Steinbach, Elisabeth 231

Steinbach, Mary 130 Steiner, Heather 130 Steiner, Michael 231 Steingass, Kelly 231 Steinmetz, Jarrod $72,73,166$

Steinmetz, Jessica 166

Stephens, Amanda 231

Stern, Jennifer 65

Sterner, Shelly 231

Stevens, Daniel 88

Stevens, Jennifer

231

Stevens, Katharina

$63,182,231$

Stevenson, John

130

Stevenson, Reese

12,88

Stewart, Ashleigh

166

Stewart, Caroline

231

Stewart, Christine 130

Stock, Amanda 166

Stockdale, Mary

186, 187, 231

Stockwell, Brandon

231

Stockwell, Derek

110

Stoltzfus, Colby 201

Stone, Lindsay

195, 231

Stout, Heather 130

Stout, Jacob 231

Straton, Macy 166

Strawser, Michael

$231,260,263$

Strayhorn, Anna

167, 177, 198

Strebig, Erik 109

245
Streitmatter, Amy

130

Stringfellow,

Michelle 131

Strode, Elizabeth 131

Stroud-Lusk, Sari

131, 175

Strowd, Elizabeth

231

Strutton, Debbie 242

Strutton, Deborah

231

Studebaker, Eliza-

beth 167

Studebaker, Nathan-

iel $\quad 131$

Sudlow, Elisabeth

231

Sudlow, Liz 265

Sugg, Amanda 131

Summers, Benjamin

$231,247,260$

Surant, Zachary

131, 236

Sutton, Amanda 167

Svendsen, Caleb

167

Swayze, Jessica 167

Swett, Alanna 88

Swoveland, Jona-

than 88

Sylvester, Brittany

167

Sylvester, Stephen

231,260

Syme, Steven 231

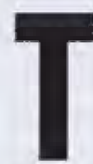

Tackett, Steven

167, 261

Taft, Ashley 231

Talbott, Katelyn 232, 260

Talbott, Valerie 131

Talone, Andrew 232

Tasker, Catherine

182,232

Taylor, Colby 253

Taylor, Elizabeth 58 , 232

Taylor, Joanna 88 , 200, 201

Taylor, Thomas 88

Temple, Kathryn 167

Ternes, Shayla 131

Terra, Nathan 256

Terrall, Julie 89 ,

91

TerreBlanche,

Johann 131

Thacker, Benjamin

131

Thalman, Heidi 131

Thalman, Robert

232

Thayer, Laura 131 ,

250

Thomas, Daniel 131
Thomas, Holly 232 Van Schepen, David Ward, Jerica 146,

Thomas, Ian 232167

Thomas, James 89 Van Schepen,

$147,164,167$

Ward, Jernelle 89 , Willetts, Justin 140 ,

Thomas, Katie 131 Megan 131

Thomas, Seth 89 Van Zandt, Noah

Thompson, Allison 131

89 Van der Hoeven,

204

Ward, Rebecca 233

Waring, Amanda

Thompson, Michaela Luke 142

232 Van der Wal, John

Thompson, William 167

Warmelink, Erica 89

Warwick, Stephen

131

131 Van vliet, Anna 167 Wasem, Rachael

Thompson II, Rill 89 VanDette, Emily 16789

Tilli, Katelyn 89 VanDette, Ethan 167 Wasem, Robert 201

Tilton, Emily $167 \quad$ VanDyke, Scott 62 Washatka, Nathan

Tofilon, David 89 VanDyke, William

Tormey, Stephen 233

$167 \quad$ VandenBerg,

Torres, David 232 Michelle 232

67

Washatka, Nathaniel

233

Waters, Benjamin 89

Torres, Rachel 131 Vasser, Donald 233 Waters, Megan 71,

Totten, Matthew 201 Vaughan, Alexander 233

Townsend, Joshua 67,167

232

Townsend, Lauren

Vaughn, Christo-

Watkins, Jaimie 175

Watkins, Sarah 89

89

Traeger, Brittany

pher 179, 192, 193 Watson, Katherine

Vawser, Tyler $23389,188,189$

Veldt, Mordecai 62, Waugh, Dakotah 131 167

Weaver, Marcus 233

232

Vella, Mitchell

89 , Webster, Jennifer 89

Weed, Karli 89

167

201

Travis, Mallory

108,167

Veres, Joseph 89 Weeks, Matthew 131

Verlander, Lynn 167 Wegman, Tricia 233

Trego, Justine 167 Villanyi, Sara 233 Weideman, Cassie

Trennepohl, Robert Vincent, Timothy 233

$178,179,193 \quad 167$

Tress, Brandon

131, 192, 193

Vinciguerra, Chris-

Weidman, Amanda

131

Weilein, Janna 89

roiano, Kristin 232

Troike, Daniel 89

Troxel, Hollis

179,193

Vinson, Philip 167 Weix, Elizabeth 131

Tryon, Cherie 232, Voris, Angel 233

237

Tucker, Joshua $\mathrm{H}$.

20,89

Tucker, Joshua W.

20,89

Tucker, Katie 232

Tucker, Lauren 232

Turley, Jannae 89 , 253

Turner, Joseph 167 Wagner, Jonathan

Turner, Kimberly 89233

Tutino, Kathryn 131 Wagner, Micah 167

Tuttle, Katherine

232, 264

Wagner, Nicole 131

Wailes, Bethany 89 ,

175,245

Wailes, Hannah

$167,174,175$

Walach, Laura

233, 260

Walburg, Jonathan 131

Unis, Alexander 232 Walker, Andrea

Unis III, Robert 232 203, 233

Utz, Julie 205

Walker, Christopher $136,184,185$

Walker, Grant 185

Wallace, Nathan 201

Walter, Rachelle 89

Walters-Carlson,

Cameron 89

Walther, Joshua 233

Valji, Emily 89

Van Matre, Emily

167

Walton, Joel 111

Waltz, Sharon 151 ,

167

Willetts, Joshua 234 263

147

Williams, Christo-

pher 131, 252

Williams, Garrett 15

$148,234,247,267$

Williams, Karen 71 , 234

Williams, Mark 131, 193

Williams, Michelle 234

Williams, Richard 90

Williams, Valerie 168

Williamson, Claire

132,254

Wilson, Ashley 90

Wilson, Lindsay

185, 187

Wilson, Micah 95

168,201

Wilson, Nathan 201

Wilson, Paul 201

Wilson, Suzanne

108,234

Winchester, Jesse

168

Winget, Andrew 132

Winkle, Melissa 90

Winter, Edward 168

Winter, Kenneth 173

Wirt, Lisa 168

Wise, Kelly 132,174 ,

175

Welborn, Megan 89 Wiseman, Joshua

Welker, Kendall $23390,179,193$

Wesolek, Mary 131 Witry, Joshua 252

West, Brittany 167 Woiwood, Adam 132 
Wuenstel, Leslie 168 Wuobio, Heather $168,195,248$

Wurz, Darren 115

Wynalda, Jessica 90 Wynalda III, Robert 132

Wysong, Melissa 180,181

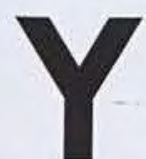

Yahara, Katie 168 Yanega, Elisa 234 Yarbrough, Micah 168

Yecke, Alex 132

Yeiter, Matthew 190, 191, 204

Yetter, Alisa 234

Yoder, Caitlin 90

Yoder, Janelle 90

Yoder, Jo Lyn 168

Yoder, Lance 90

Yoder, Lauren 234

York, Caitlyn 234,

276

York, Rachel 96, 132

Young, Bethany 96 , 168

Young, Brandon

132, 201

Young, Hilary 234

Young, Linnea 132

Young, Richard 234

Young, Shannon 19,

168

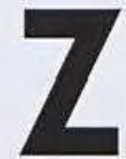

Zastrow, Jason 234

Zboran, Jessica 90

Zehring, Jessicah

234

Zeiset, Ryan 132

Zeliner, Matthew 168

Zeltman, Sarah

$176,177,235$

Zerminski, Michelle

168

Zeron, Joshua 132

Ziegenfus, Laura 98,

235

Ziemblicki, Bethany 168

Zimmerman, Crystal 90

Zimmerman, Daniel 73,132

Zimmerman, Kris-

tiana 90
Zion, Nathan 90, 91

Zorn, Christina 203

Zumbo, Kristina 235

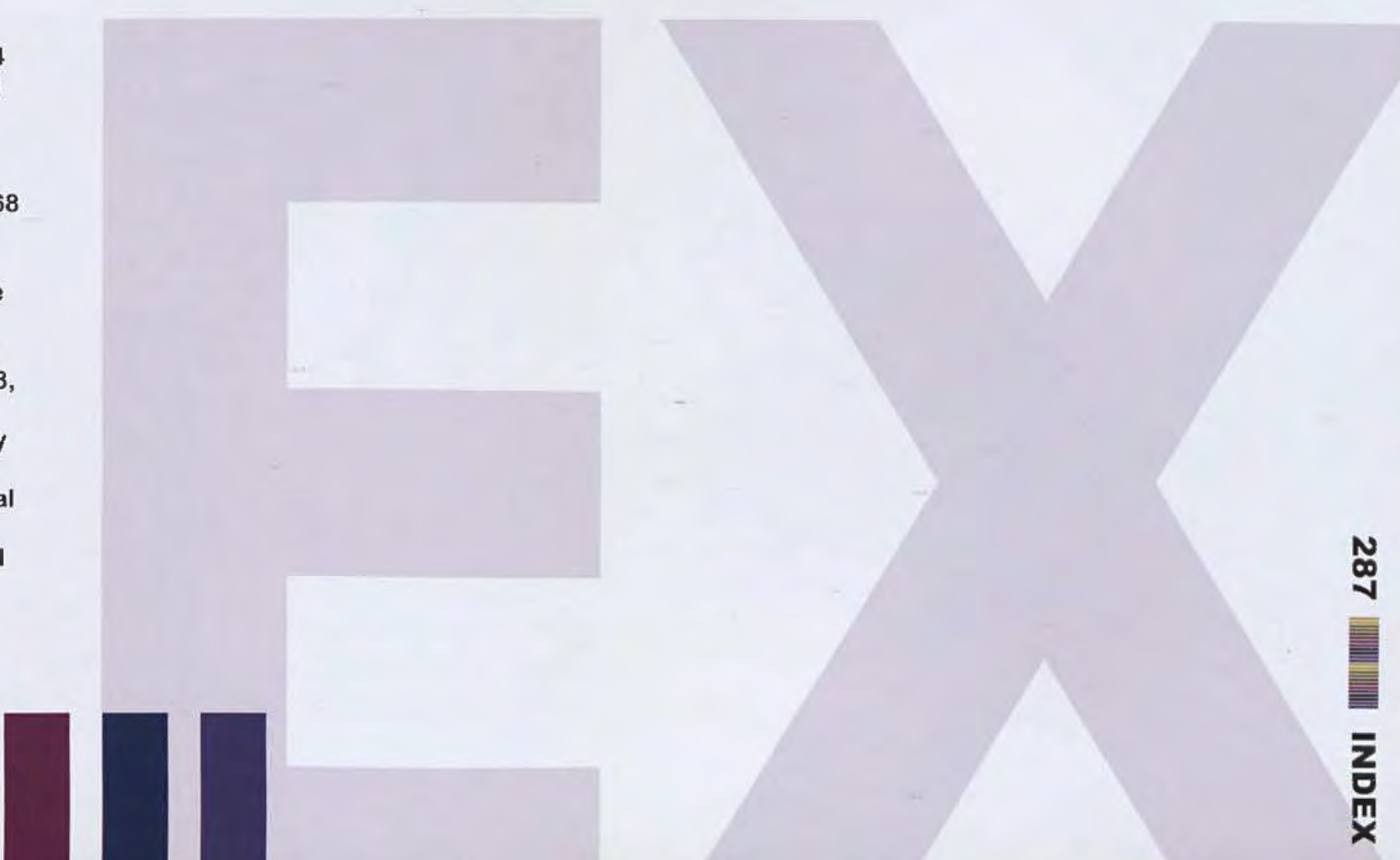




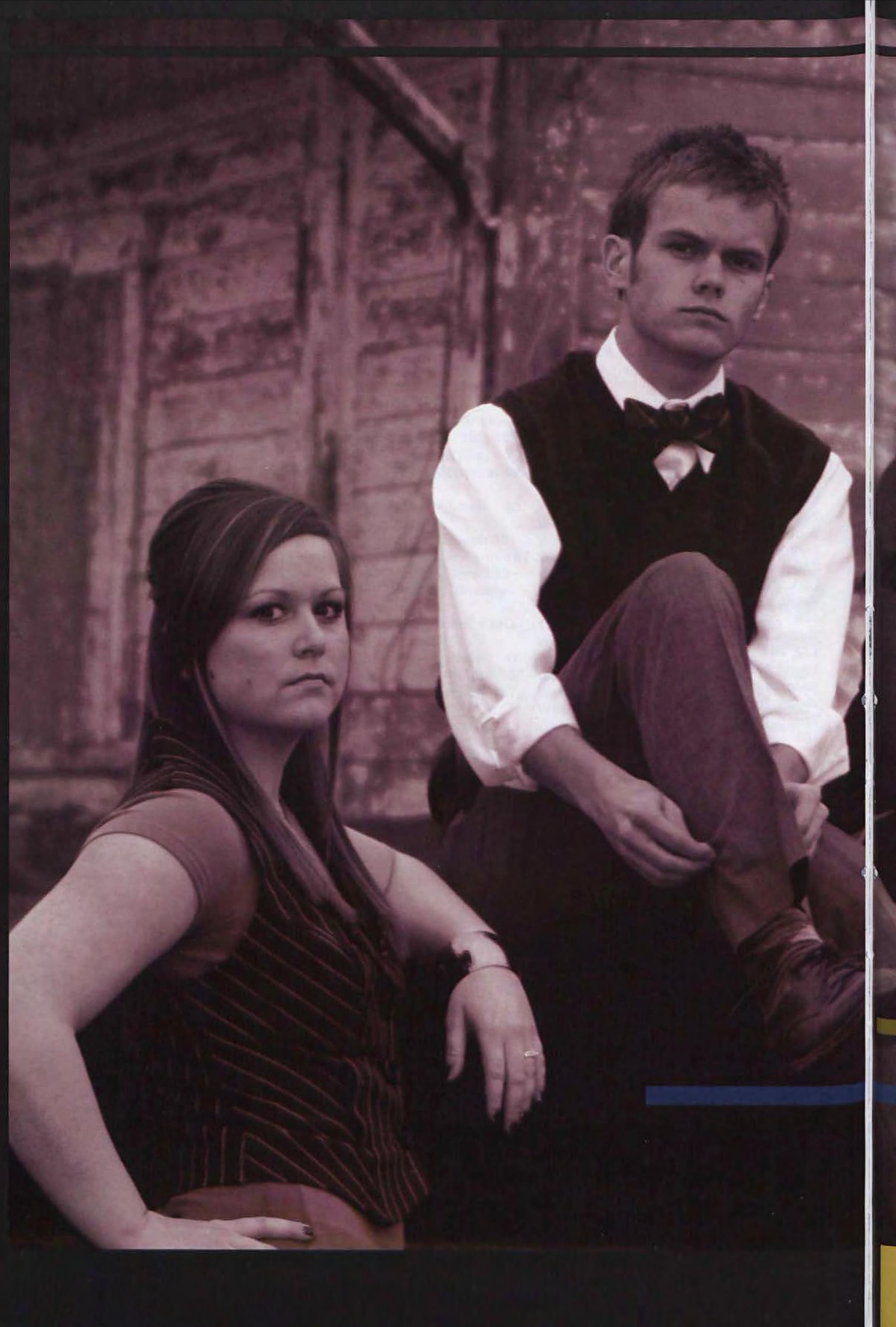




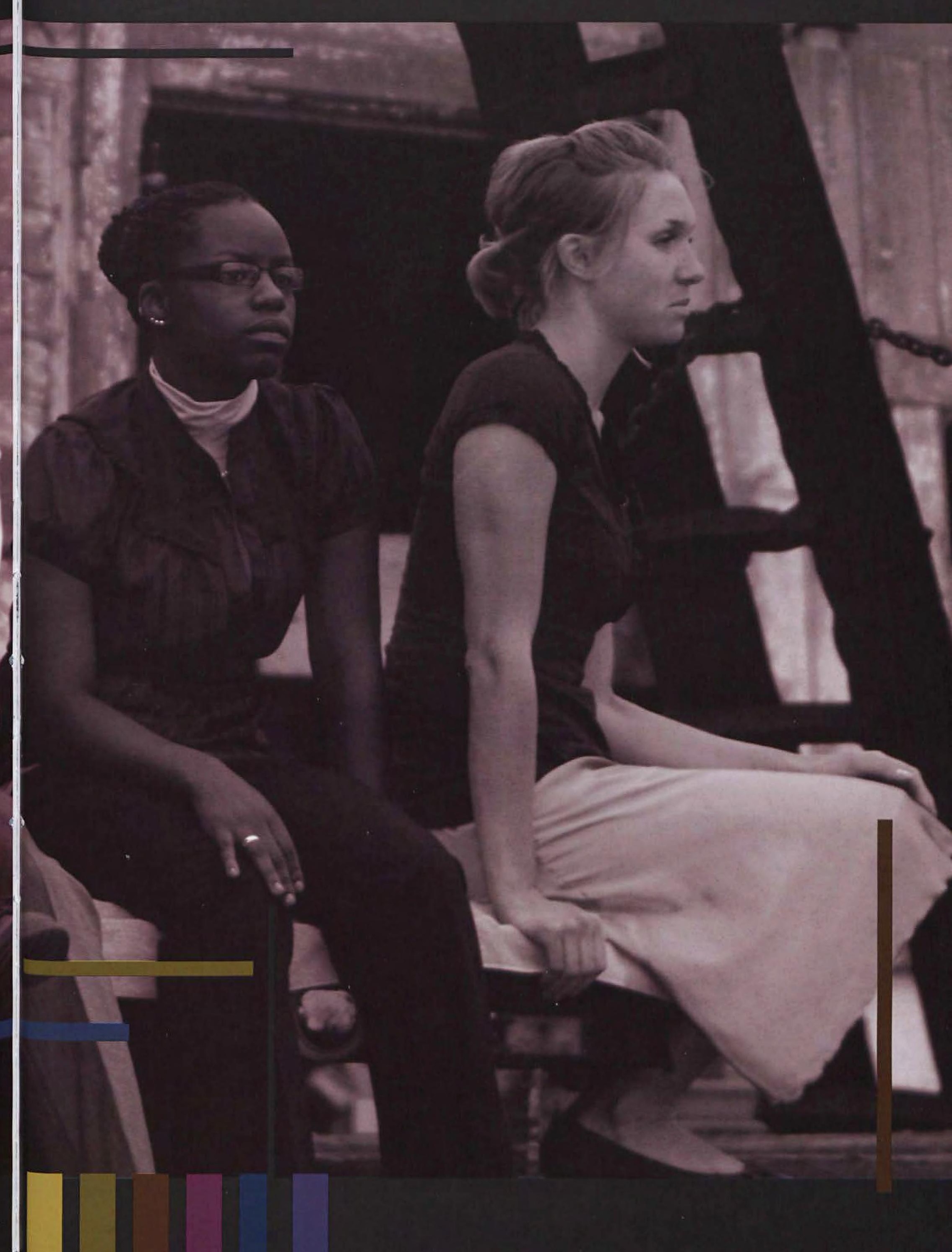




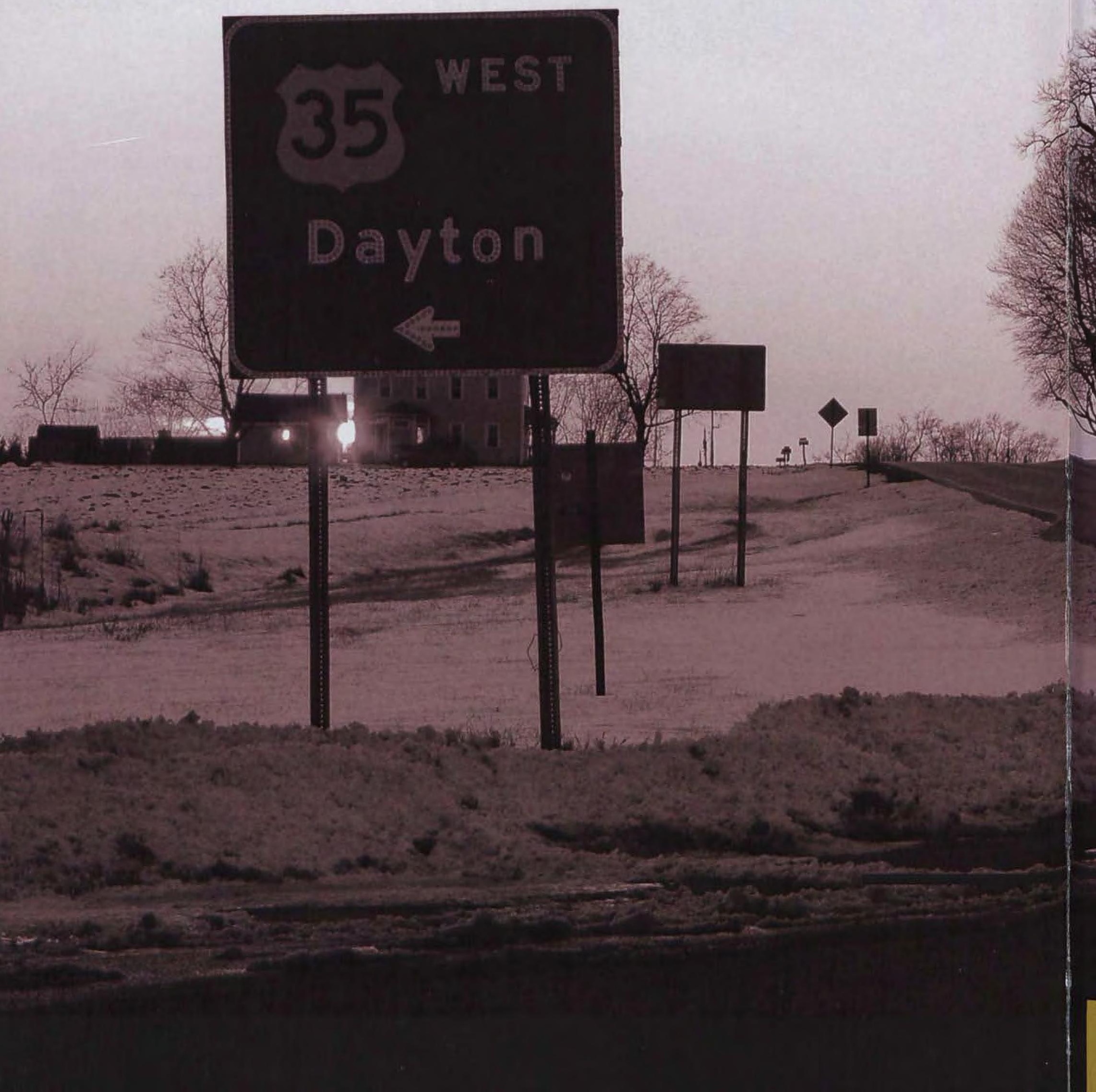




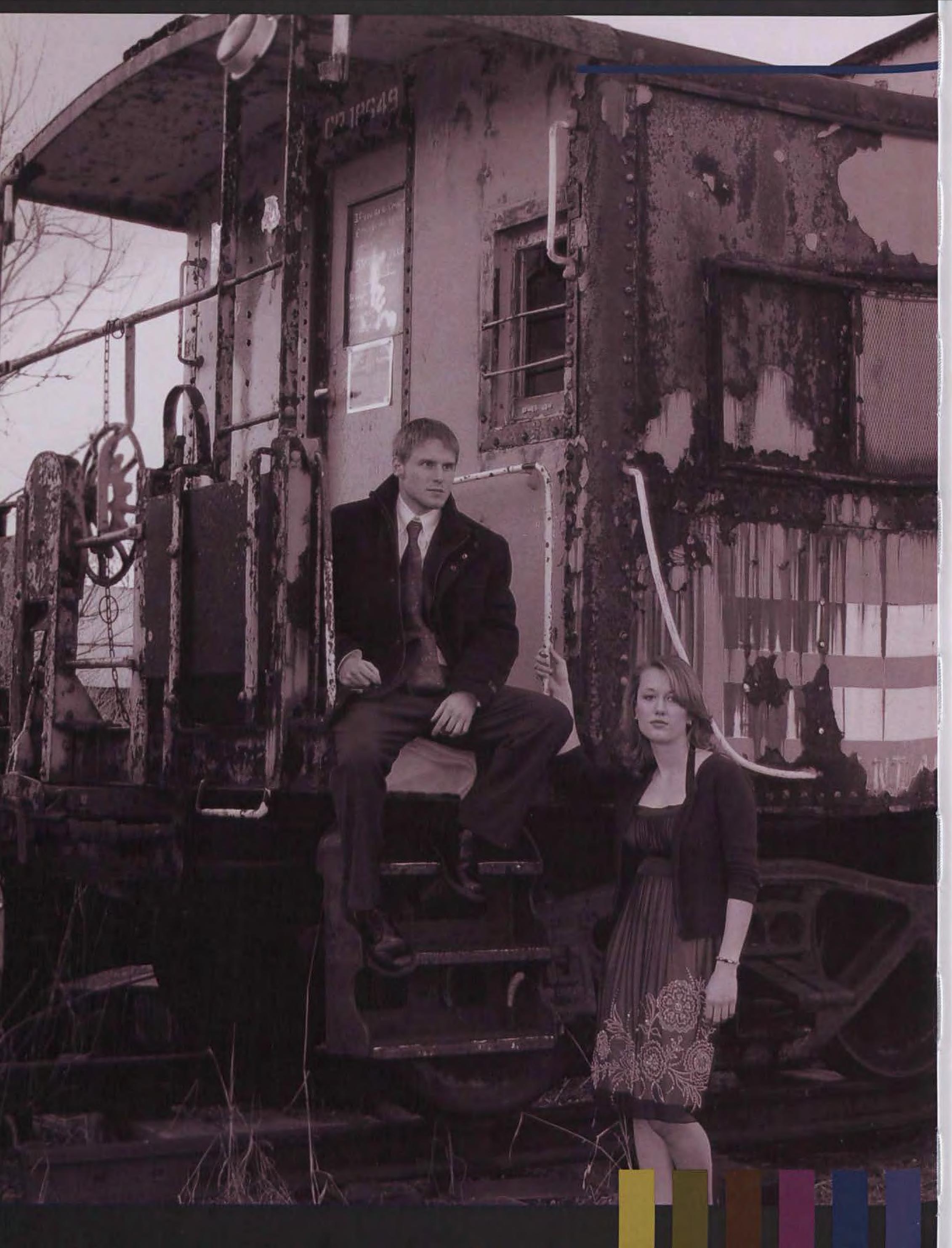




6 


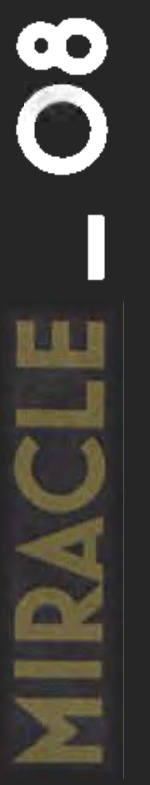


